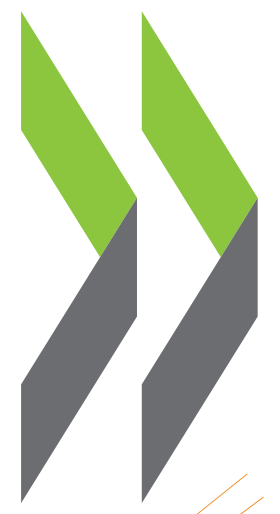

\title{
Perspectivas económicas de América Latina 2021
}

\section{AVANZANDO JUNTOS HACIA UNA MEJOR RECUPERACIÓN}

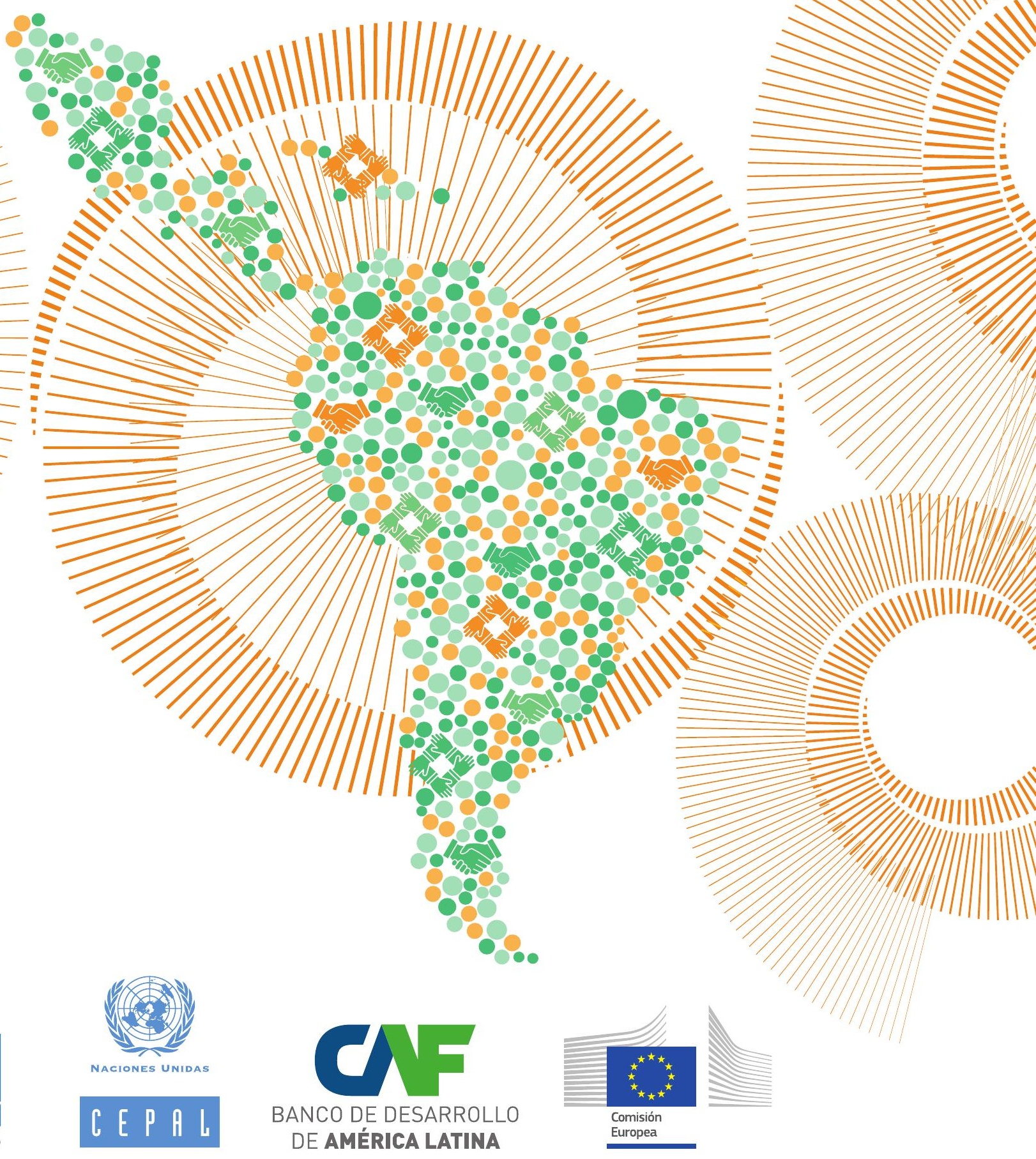





\title{
Perspectivas económicas de América Latina 2021
}

\author{
AVANZANDO JUNTOS HACIA UNA MEJOR \\ RECUPERACIÓN
}


El presente trabajo se publica bajo la responsabilidad del Secretario General de la OCDE, del Presidente del Banco de Desarrollo de América Latina (CAF) y del Presidente de la Comisión Europea. Las opiniones expresadas y los argumentos utilizados en el mismo no reflejan necesariamente el punto de vista oficial de los Miembros de la OCDE, ni del Centro de Desarrollo de la OCDE, ni de las Naciones Unidas, ni del Banco de Desarrollo de América Latina (CAF) o de la Unión Europea.

Tanto este documento, así como cualquier dato y cualquier mapa que se incluya en él, se entenderán sin perjuicio respecto al estatus o la soberanía de cualquier territorio, a la delimitación de fronteras y límites internacionales, ni al nombre de cualquier territorio, ciudad o área.

Los nombres de los países y territorios y los mapas utilizados en esta publicación conjunta siguen la práctica de la OCDE.

Por favor, cite esta publicación de la siguiente manera:

OECD et al. (2021), Perspectivas económicas de América Latina 2021: Avanzando juntos hacia una mejor recuperación, OECD

Publishing, Paris, https://doi.org/10.1787/2958a75d-es.

ISBN 978-92-64-82289-4 (impresa)

ISBN 978-92-64-47036-1 (pdf)

Perspectivas Económicas de América Latina

ISSN 2072-5191 (impresa)

ISSN 2072-5183 (en línea)

Número de referencia del CAF: CAF-513-2021

Número de referencia de la CEPAL: LC/PUB.2021/12

Unión Europea

ISBN 978-92-76-42388-1 (impresa)

ISBN 978-92-76-36200-5 (pdf)

Número de catálogo: MN-03-21-331-ES-C (impresa); MN-03-21-331-ES-N (pdf)

Imágenes: Diseño de la portada realizado por Aida Buendía (Centro de Desarrollo de la OCDE).

Las erratas de las publicaciones se encuentran en línea en: www.oecd.org/about/publishing/corrigenda.htm.

C OCDE/CAF/UNIÓN EUROPEA 2021

El uso del contenido del presente trabajo, tanto en formato digital como impreso, se rige por los términos y condiciones que se encuentran disponibles en: $h t t p: / / w w w . o e c d . o r g /$ termsandconditions. 


\section{Prefacio}

El informe Perspectivas económicas de América Latina 2021 (LEO) analiza cuestiones críticas relativas al desarrollo sostenible e inclusivo en América Latina y el Caribe (ALC). Desde su primera edición en noviembre de 2007, este informe anual compara el desempeño de ALC con el de otras regiones, analiza los principales retos en materia de desarrollo y plantea recomendaciones, experiencias y buenas prácticas para la elaboración de políticas públicas.

El LEO se beneficia de los conocimientos especializados y las contribuciones de sus coautores. Desde 2011, este informe se publica de forma conjunta con la Comisión Económica para América Latina y el Caribe de las Naciones Unidas. En 2013, se incorporó al equipo de autores el Banco de Desarrollo de América Latina (CAF). Y desde 2018, la Comisión Europea pasó a ser uno de sus principales socios.

Esta decimocuarta edición de las Perspectivas económicas de América Latina: Avanzando juntos hacia una mejor recuperación analiza y ofrece recomendaciones de política para una recuperación fuerte, inclusiva y sostenible en la región. El informe explora las políticas necesarias para mejorar los mecanismos de protección social y promover la inclusión fomentando la integración regional, fortaleciendo las estrategias industriales, y repensando el contrato social para restaurar la confianza y empoderar a los ciudadanos en todas las etapas del proceso de elaboración de políticas públicas. Además, resalta la necesidad de promover marcos macroeconómicos sostenibles y adaptables para financiar la recuperación, y la importancia de renovar la cooperación internacional para apoyar estos esfuerzos. Por último, la publicación incluye tres temas transversales clave: el cambio climático y la recuperación verde, la transformación digital y la dimensión de género. 



\section{Agradecimientos}

Los socios de este informe son la Comisión Económica para América Latina y el Caribe (CEPAL), el Banco de Desarrollo de América Latina (CAF), la Unión Europea (UE) y el Centro de Desarrollo de la Organización para la Cooperación y el Desarrollo Económicos (OCDE). El LEO 2021 constituye el Pilar 1 del Fondo Regional para el Desarrollo en Transición para América Latina y el Caribe de la Unión Europea, una iniciativa liderada por la Unión Europea e implementada conjuntamente con la OCDE, el Centro de Desarrollo de la OCDE y la CEPAL. Asimismo, es una actividad central del Programa Regional de la OCDE para América Latina y el Caribe.

La contribución del Centro de Desarrollo de la OCDE a este informe ha sido liderada y dirigida por Sebastián Nieto-Parra, jefe de la Unidad para América Latina y el Caribe del Centro de Desarrollo de la OCDE, con el apoyo y la coordinación de Luis Cecchi, analista de políticas de esta Unidad, bajo la dirección de Ragnheidur Arnadottir, directora del Centro de Desarrollo de la OCDE, Federico Bonaglia, director adjunto del Centro de Desarrollo de la OCDE, y Mario Pezzini, antiguo director del Centro de Desarrollo de la OCDE. La contribución de la CEPAL ha estado liderada por Sebastián Rovira, oficial de Asuntos Económicos de la Unidad de Innovación y Nuevas Tecnologías, con el apoyo de Andrés Boeninger y Nunzia Saporito, asistentes de investigación de la Unidad de Innovación y Nuevas Tecnologías, bajo la dirección de Mario Cimoli, secretario ejecutivo adjunto de la CEPAL. La contribución de la CAF ha estado liderada por Adriana Arreaza, directora de Estudios Macroeconómicos. La contribución de la Comisión Europea (CE) ha estado liderada por Sergio Martín Moreno, mánager de programas en la Dirección de América Latina y el Caribe de la Dirección General de Cooperación Internacional y Desarrollo de la Comisión Europea (INTPA), y Pelayo Roces Fernández, ex mánager de programas en la Dirección de ALC de la INTPA, bajo la dirección de Jorge de la Caballería, jefe de Unidad.

El informe se ha beneficiado de la investigación, la redacción y la fructífera colaboración establecida entre varios autores de estas organizaciones, entre los que se incluyen: Adriana Arreaza (CAF), Andrés Boeninger (CEPAL), Nathalie Basto-Aguirre (OCDE), Adriana Caicedo (OCDE), Cristina Cabutto (OCDE), Luis Cecchi (OCDE), Simone Cecchini (CEPAL), Mathilde Closset (CEPAL), Rita Da Costa (OCDE), Laura Gutiérrez Cadena (OCDE), Martina Lejtreger (OCDE), Thomas Manfredi (OCDE), Alejandra Martínez (OCDE), Nathalia Montoya González (OCDE), Sofía Mora Restrepo (OCDE), Sebastián Nieto-Parra (OCDE), René Orozco (OCDE), Juan Ortegón Ocampo (OCDE), Sara Piñero Mosquera (OCDE), Sebastián Rovira (CEPAL), Andrés Rugeles (CAF), Nunzia Saporito (CEPAL), Daniel Titelman (CEPAL), Juan Vázquez Zamora (OCDE) y Juan Nicolás Velandia (OCDE). Agustina Vierheller (OCDE), Olivia Cuq (OCDE), Julia Peppino (OCDE) e Isabel Sirven-Villaros (OCDE) han prestado un apoyo administrativo inestimable durante la elaboración del informe.

Un grupo de expertos y colegas han participado de forma especialmente activa y generosa a lo largo del proceso de producción, proporcionando opiniones, aportaciones o gráficos, comentarios y orientación estratégica al informe. Nos gustaría destacar el apoyo de Felipe Bosch (Le Grand Continent), Gabriela Casanova Rangel (Universidad del Rosario), Anthony Caubin (AFD), Angie Contreras Sanabria (DNP), Jason Gagnon (OCDE), Juan Miguel Gallego (Universidad del Rosario), Daniel Gómez Gaviria (DNP), Lianne Guerra (Le Grand Continent), Bruno Leclerc (AFD), Marc Litvine (CE), Natali Maldonado Pineda (Universidad del Rosario), Natalia Moreno Rigollot (Telefónica), Lorenzo Pavone (OCDE), Alexander Pick (OCDE), Laure Rogès (CE), Marta Salafranca (Telefónica), Juan Manuel Santomé Calleja (EUROsocial), Melanie Vilarasau Slade (OCDE) y Felix Zimmermann (OCDE). 
El contenido del informe se ha enriquecido gracias a las constructivas observaciones proporcionadas durante la Reunión en línea de Intercambio de Ideas LEO 2021 que tuvo lugar el 28 de enero de 2021; la consulta informal con los países de ALC, miembros del Comité Directivo del Centro de Desarrollo de la OCDE, del 5 de febrero de 2021; las Reuniones virtuales de Expertos que se celebraron los días 29 y 30 de marzo de 2021, y el evento virtual de prelanzamiento del LEO 2021 que tuvo lugar el 15 de julio de 2021 en el marco del Foro Político de Alto Nivel de las Naciones Unidas y como parte de los "Diálogos de Desarrollo en Transición para trazar nuevos caminos para América Latina y el Caribe". Además de los delegados de ALC al Comité Directivo del Centro de Desarrollo de la OCDE, estamos especialmente agradecidos con los expertos, académicos, representantes del sector privado y funcionarios públicos que nos han aportado su apoyo durante las reuniones de expertos: Gloria Alonso (Colombia), Fernando Álvarez (CAF), Alberto Arenas de Mesa (CEPAL), Eric Beaume (CE), Mariano Berro (Agencia Uruguaya de Cooperación Internacional, AUCI), Eduardo Bitrán (Chile), Romina Boarini (OCDE), Adrián Bonilla (Fundación UE-ALC), Francisco Bustillo (Uruguay), Rodrigo A. Carazo (Costa Rica), Claire Charbit (OCDE), Paul Chet Greene (Antigua y Barbuda), Andrea Costafreda (OXFAM), Guillermo Cruces (CEDLAS), Silvia Da Rin Pagnetto (OCDE), Luiz de Mello (OCDE), Martha Delgado Peralta (México), Koen Doens (EC), Karina Dzialowska (CE), Mayumi Endoh (OCDE), Manuel Escudero (OCDE/España), João Carlos Ferraz (Universidad Federal de Río de Janeiro), Juan Flores (Universidad de Ginebra), Andrés García (Universidad del Rosario), Claudia Gintersdorfer (Servicio Europeo de Acción Exterior, SEAE), Ana Güezmes (CEPAL), Sebastián Herreros (CEPAL), Alejandro Izquierdo (BID), Galina Karamalakova (SEAE), Guillermo Larraín (Universidad de Chile), Carlos Malamud (Real Instituto Elcano, España), Francisco Monge (Costa Rica), Juan Carlos Moreno-Brid (Universidad Nacional Autónoma, México), Ana Patricia Muñoz (Grupo FARO), Hugo Ñopo (GRADE, Perú), José Antonio Ocampo (Universidad de Columbia), Juan Daniel Oviedo (DANE), Luciana Peres (Brasil), Wilson Peres (CEPAL), Ramón Pineda (CEPAL), Monika Queisser (OCDE), Darío Rodríguez (Universidad de la Sorbona), Juan Ruiz (BBVA), José Antonio Sanahuja (Fundación Carolina, España) y Rubén Silié (República Dominicana).

Asimismo, un grupo de compañeros de la OCDE ha aportado sus observaciones y análisis, mejorando de forma considerable el informe: Aimee Aguilar Jaber, José Antonio Ardavín, Jens Arnold, Janos Bertok, Sofia Blamey Andrusco, Frederic Boehm, Monica Brezzi, Emanuele Ciani, Juan de Laiglesia, Charlotte Dubald, Mayumi Endoh, Manuela Fitzpatrick, Michael Förster, Mills Gary, Fabio Gehrke, Santiago González, Felipe GonzálezZapata, Håvard Halland, Jean-Jacques Hible, Michael Jelenic, Fatos Koc, Alexandre Kolev, Kamil Kouhen, Iris Mantovani, Alejandra Maria Meneses, Neil Martin, Ana Novik, Masayuki Omote, Nestor Pelecha Aigues, Nicolás Penagos, y Jan Rielaender, Jacob Arturo Rivera Pérez, Camila Saffirio, Katherine Scrivens, Kimiaki Shinozaki, Ana Stringhini, Enes Sunel, Juan Yermo, Gabriela Villa Aguayo y Martin Wermelinger.

Las notas-país se han beneficiado de las aportaciones constructivas, los análisis y las comprobaciones realizadas por las delegaciones de Chile, Colombia, Costa Rica y México ante la OCDE, así como por las embajadas en Francia de Argentina, Brasil, Ecuador, El Salvador, Guatemala, Panamá, Paraguay, Perú, República Dominicana y Uruguay.

El Centro de Desarrollo de la OCDE también desea expresar su sincero agradecimiento a la Agencia Francesa de Desarrollo (AFD), el Departamento Nacional de Planeación (DNP) de Colombia, el Ministerio de Asuntos Exteriores, Unión Europea y Cooperación de España, la Agencia Suiza para el Desarrollo y la Cooperación, Telefónica y la Universidad del Rosario (Colombia) por su apoyo a las Perspectivas Económicas de América Latina. 
Por último, nos gustaría dar las gracias a la División de Publicaciones y Comunicaciones del Centro de Desarrollo de la OCDE, en particular a Aída Buendía, Delphine Grandrieux, Elizabeth Nash, Irit Perry, Henri-Bernard Solignac-Lecomte y Anne Thomas, por su gran paciencia y su oportuna labor en la producción de este informe y los materiales relacionados. Los autores también agradecen sinceramente las actividades de edición realizadas por Elizabeth Holbourne, del Centro de Desarrollo de la OCDE, Jessica Hutchings y Jane Marshall; y los servicios de traducción y edición en español prestados por Alejandro Barranco, Julia Gregory, Alexander Summerfield y Liliana Tafur. 



\section{Índice}

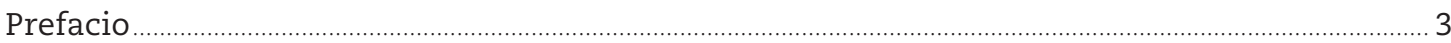

Agradecimientos

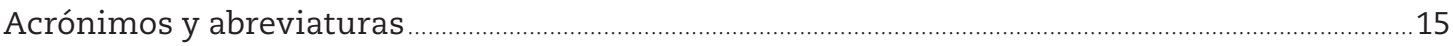

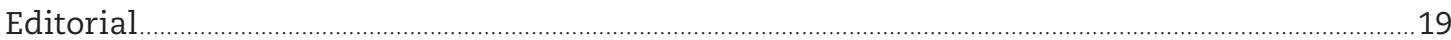

Resumen ejecutivo

Resumen: Avanzando juntos hacia una recuperación fuerte, sostenible e inclusiva

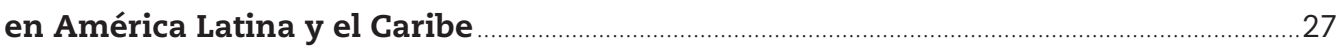

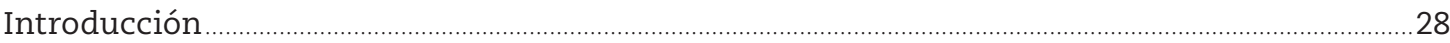

Una política fiscal integral y consensuada será fundamental para impulsar una

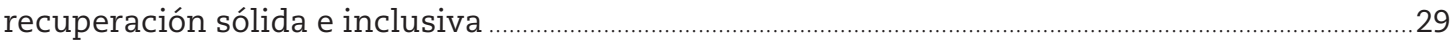

Fortalecer los sistemas de protección social, aprovechando las innovaciones adoptadas

durante la pandemia, para una recuperación inclusiva y sostenible ................................................. 31

Promover una mayor integración regional y estrategias de transformación productiva para impulsar nuevas oportunidades de desarrollo ..................................................................34

Se necesitan grandes consensos - un nuevo contrato social- para promover una

nueva agenda de reformas que impulse la recuperación y ayude a superar los desafíos estructurales

Cooperación internacional para la recuperación: facilitando un nuevo contrato social

en ALC

Referencias

Capítulo 1. Perspectiva macro-estructural y el camino hacia la recuperación ……………………….....47

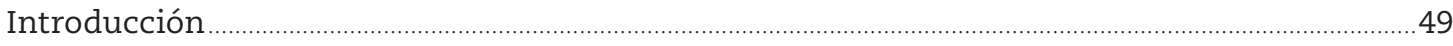

Un contexto internacional desafiante

Movilización de recursos para mitigar la crisis e impulsar la recuperación ................................59

Efectos sociales de la crisis del COVID-19

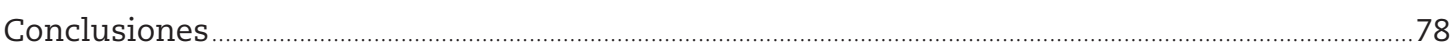

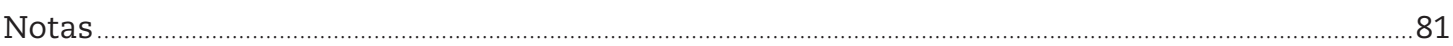

Referencias

Capítulo 2. Desafíos y lecciones para una recuperación inclusiva …………………................................. 85

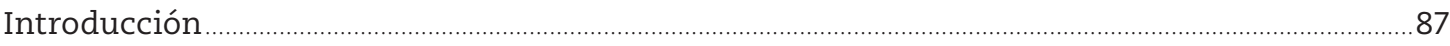

Una protección social más amplia para sociedades más inclusivas y resilientes …………….........88

Una recuperación inclusiva y sostenible, requiere proteger y sostener a los grupos

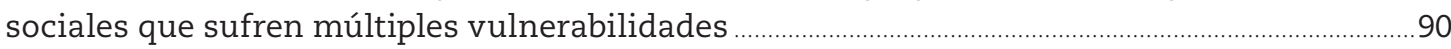

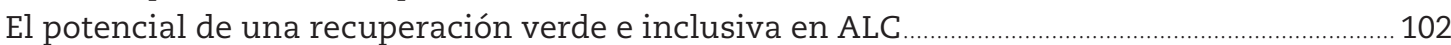

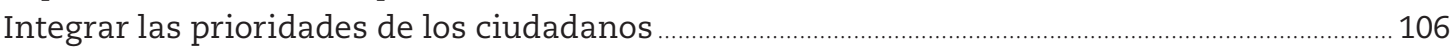

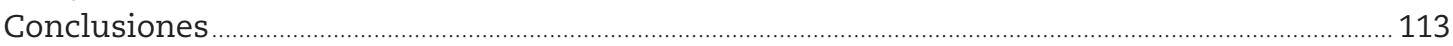

Notas

Referencias

Capítulo 3. Integración regional y transformación productiva para una recuperación

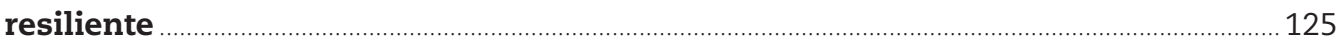

Promover las cadenas de valor regionales y aumentar la participación de ALC

en el comercio internacional como medio para la recuperación …………………………………... 127

Las cadenas de valor globales en un nuevo contexto económico ........................................................... 128 


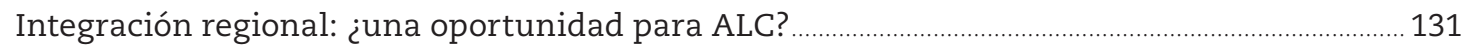

La recuperación como oportunidad para promover una transformación sostenible..................139

Del enfoque nacional al regional: las experiencias sectoriales como oportunidad de integración productiva y transformación sostenible ........................................................................... 142

Conclusión $\ldots$

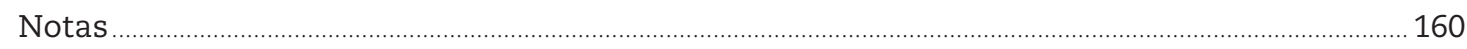

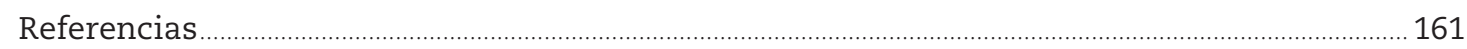

Capítulo 4. Repensar el contrato social en América Latina y el Caribe ……........................................ 165

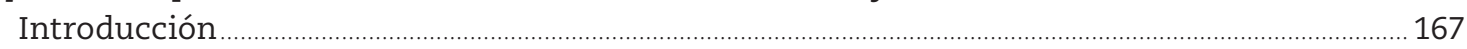

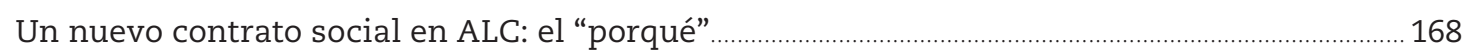

Definir el nuevo contrato social en ALC: el "qué" ........................................................................................ 179

Diseñar el nuevo contrato social en ALC: el "cómo" .................................................................................... 183

Conclusiones

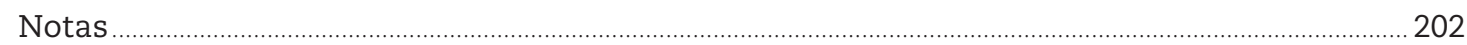

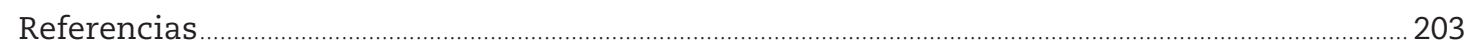

Capítulo 5. La cooperación internacional en tiempos de COVID-19: facilitando un nuevo contrato social en América Latina y el Caribe (ALC) …............................................. 213

Introducción.

Lo que la crisis del COVID-19 ha revelado: dinámicas globales arraigadas y el surgimiento

de nuevos retos que requieren la adaptación de la cooperación internacional .............................216

¿Qué tipo de alianzas internacionales podrían facilitar los esfuerzos hacia un nuevo

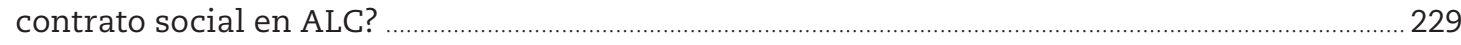

Conclusiones .

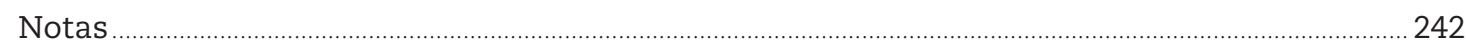

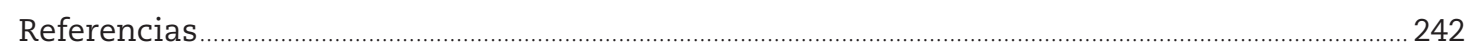

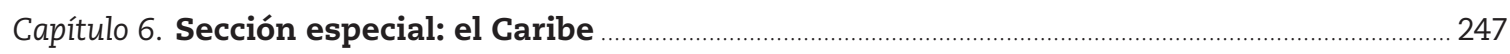

Los desafíos estructurales del Caribe se han visto agravados por el impacto

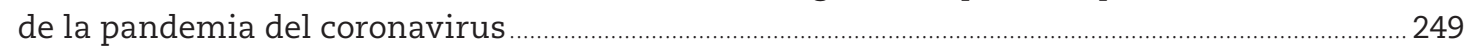

Políticas públicas implementadas como respuesta a la crisis del COVID-19 y principales

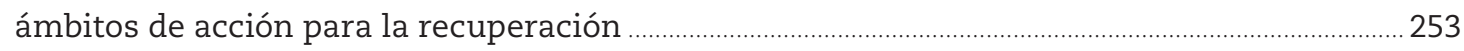

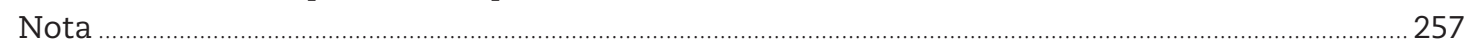

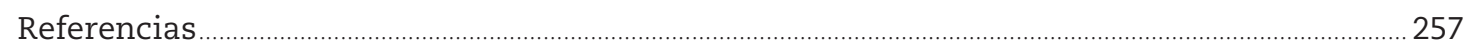

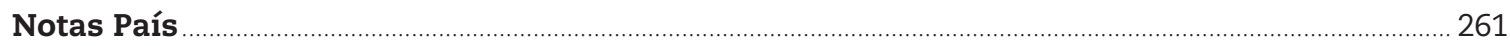

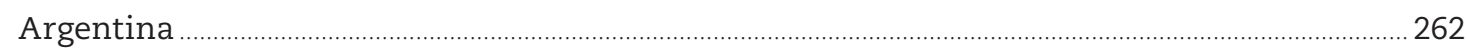

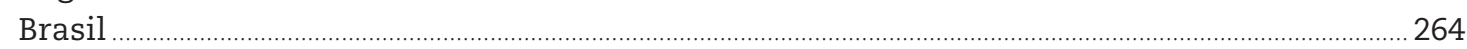

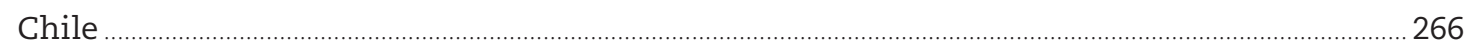

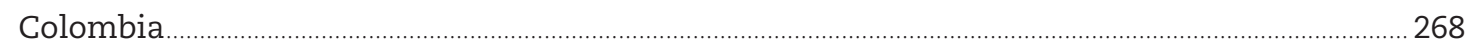

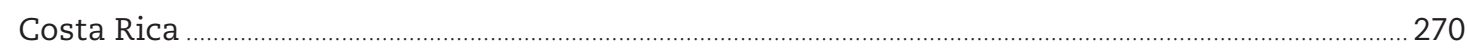

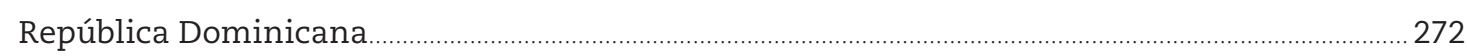

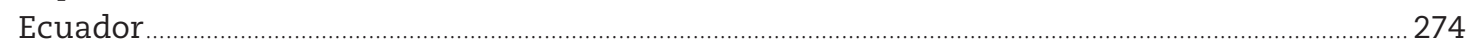

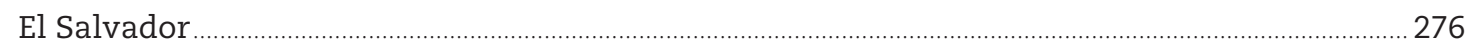

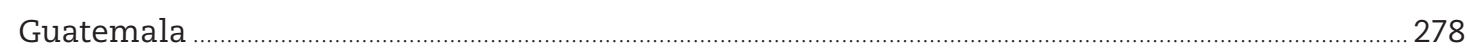

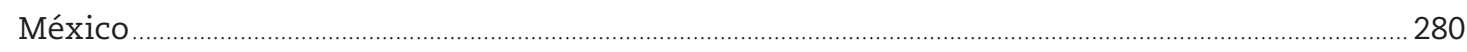

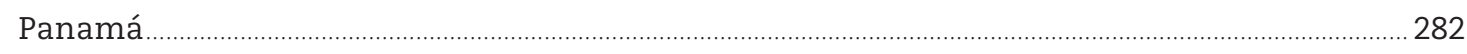

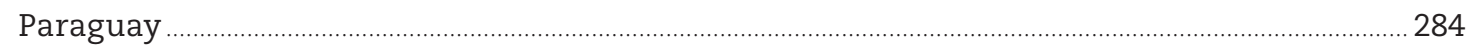


Perú

\section{Gráficos}

1. Evolución del PIB per cápita a precios constantes

2. Impacto de la crisis del COVID-19: casi el $70 \%$ de los latinoamericanos viven en hogares informales o mixtos, hay más personas con ingresos bajos y la clase media se redujo

3. Los cierres escolares han sido más largos en ALC que en la OCDE, y pueden agravar las desigualdades educativas

4. Porcentaje de trabajadores que dudan que vayan a cobrar una pensión, desglosado por características sociodemográficas, en países seleccionados de ALC _..................................33

5. América Latina y el Caribe: exportación intrarregional, 1960-2020 ……………………….........35

6. América Latina y el Caribe (principales mecanismos de integración): estructura

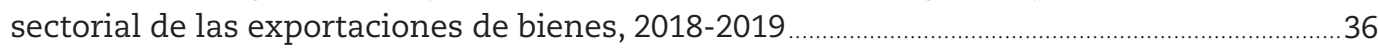

7. La insatisfacción con los servicios públicos ha aumentado de forma constante en los últimos años y continuó creciendo durante la crisis del COVID-19 ….........................38

8. El círculo vicioso entre las dinámicas de desarrollo global y nacional en ALC ..........................41

1.1. Comercio mundial de mercancías (\% de variación anual, promedio móvil trimestral), 2015-2021

1.2. Precios de los productos básicos (precios internacionales de productos básicos;

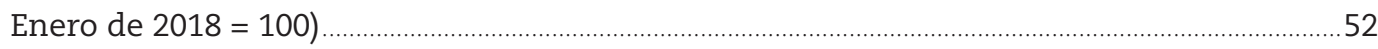

1.3. Condiciones financieras en los mercados emergentes y ALC …………………............................54

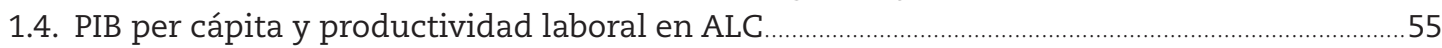

1.5. Indicadores de la calidad de la IED de la OCDE para países de América Latina

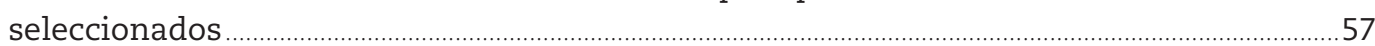

1.6. Relación entre la deuda pública e impuestos en países seleccionados de América

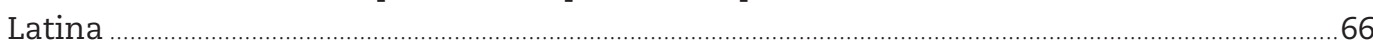

1.7. Emisión anual de deuda pública en países de ALC seleccionados por divisa y país de emisión..

1.8. Más de la mitad de los latinoamericanos viven en hogares mixtos o que dependen por completo de la economía informal

1.9. El COVID-19 ha provocado pérdidas de empleo considerables en toda la región de ALC, algo que ha afectado más a las mujeres que a los hombres.......................................74

1.10. La crisis del COVID-19 ha multiplicado el número de personas que viven con bajos ingresos y ha reducido las clases media y alta.

1.11. Debido a la falta de protección social, los trabajadores informales tienen un riesgo mucho mayor de caer en la pobreza ante situaciones adversas que los del sector formal.

1.12. Efecto de las transferencias monetarias para contrarrestar COVID-19 en indicadores sociales seleccionados

2.1. Los cierres escolares han sido más largos en ALC que en los países de la OCDE, lo que amenaza con agravar las desigualdades educativas. 
2.2. Búsquedas en Google sobre el tema "ayudas gubernamentales", selección de países de ALC, 2018-20

2.3. Porcentaje de trabajadores que dudan que vayan a recibir una pensión, por características sociodemográficas, selección de países de ALC.

2.4. Efecto, expresado en puntos porcentuales, sobre la disposición a aceptar una reforma que eleve la edad de jubilación uno o dos años.

2.5. Preferencias por una reforma de las pensiones tendiente al equilibrio de las cuentas públicas, por características sociodemográficas

2.6. Búsquedas en Google sobre el tema "salud", selección de países de ALC (2020-21) ............ 112

2.7. Percepciones sobre la calidad del sistema de salud en ALC, 2019 ….............................. 112

2.8. Porcentaje de la población que destina más del $10 \%$ de sus ingresos o el $25 \%$ del consumo familiar a gasto sanitario de bolsillo

3.1. Exportaciones de bienes, por tipo de producto en región y países seleccionados, 1995-2018

3.2. Consecuencias inmediatas del COVID-19 para el comercio y la producción y oportunidades para reforzar la integración regional en América Latina y el Caribe ...... 128

3.3. América Latina y el Caribe: Exportaciones intrarregionales, 1960-2020.

3.4. ALC: Estructura del contenido importado en las exportaciones totales por origen, países seleccionados, 2017

3.5. América Latina y el Caribe (principales mecanismos de integración): estructura sectorial de las exportaciones de bienes, 2018-19

3.6. Número de vendedores comercio electrónico en ALC, países seleccionados, 2019-20 ….. 138

3.7. Valor del mercado de la industria farmacéutica, países seleccionados de ALC, 2019 ….... 144

3.8. Producción de vehículos, regiones y países seleccionados, 1950-2020 .................................. 146

3.9. Argentina, Brasil y México: producción de automóviles, 2000-2020 …................................ 147

3.10. Brasil: exportación e importación de productos del sectore automotriz con Argentina, 1990-2020

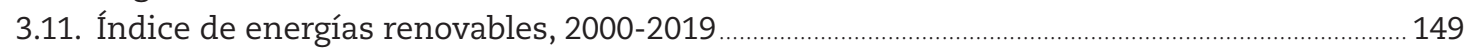

3.12. Inversión anunciada en proyectos de energías renovables en ALC, 2020-2021 ……............ 150

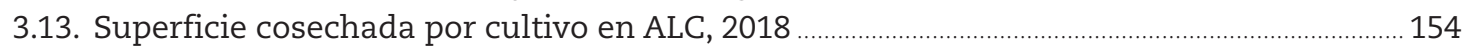

4.1. La confianza en el gobierno nacional ha disminuido en los últimos años y se recuperó en 2020, aunque la aprobación de la gestión de los gobiernos de la crisis del COVID-19 se mantuvo altamente volátil..

4.2. La insatisfacción con los servicios públicos ha aumentado de forma constante en los últimos años y continuó creciendo durante la crisis del COVID-19

4.3. Protestas en la calle y percepción de que los ingresos no están distribuidos equitativamente

4.4. La cohesión social es débil en los países latinoamericanos seleccionados.

4.5. La falta de confianza interpersonal y de confianza en las instituciones públicas ha

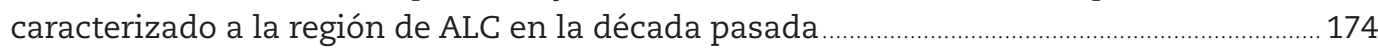

4.6. ALC sigue siendo la región más violenta del mundo ….................................................... 175

4.7. En promedio, la identificación con una ideología política ha aumentado en ALC en los últimos años, mientras que la confianza en los partidos políticos ha disminuido.

4.8. Unas mayores restricciones a la libertad de prensa van acompañadas de mayores niveles de corrupción en el sector público

4.9. Crisis de legitimidad y representación de los partidos políticos en América Latina ........... 190

4.10. Volatilidad electoral en América Latina 
4.11. El nivel de impunidad en ALC sigue siendo entre medio y alto

5.1. Percepción de los ciudadanos de América Latina y el Caribe acerca de la cooperación internacional

5.2. Un círculo vicioso entre las dinámicas de desarrollo global y nacional en ALC .................... 222

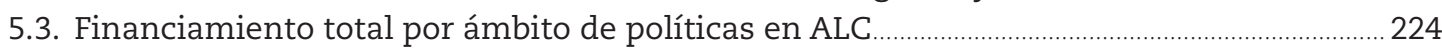

5.4. Percepciones sobre la integración política en América Latina (a favor o en contra) ........... 228

6.1. El Caribe: tasa de crecimiento del PIB en 2020 y proyecciones para 2021 y $2022 \ldots \ldots \ldots \ldots \ldots \ldots . . .249$

6.2. Deuda pública bruta del gobierno central en economías seleccionadas del Caribe y promedio de América Latina (\% del PIB) ………….................................................................... 251

6.3. Estructura tributaria de economías seleccionadas del Caribe y promedios de ALC

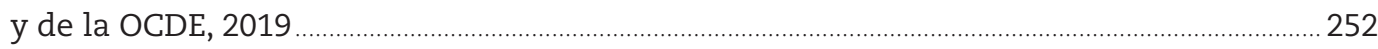

6.4. Cierres totales de centros escolares en las economías del Caribe en comparación con ALC y la OCDE.

Tablas

1. Los elementos básicos del nuevo contrato social

2. Enfoques integrados para que la cooperación internacional facilite un nuevo contrato social en ALC.

3.1. Países productores de soja en la región de América: superficie cosechada, producción, rendimiento y número de productores, 2019.

3.2. Países productores de café en América Central: superficie cosechada, producción, rendimiento y número de productores, 2020.

4.1. Los elementos básicos del nuevo contrato social.

5.1. Dimensiones fundamentales para repensar la cooperación internacional como facilitadora del desarrollo sostenible de ALC

5.2. Enfoques integrados para que la cooperación internacional facilite un nuevo contrato social en ALC.

\section{Recuadros}

1.1.IED y desarrollo sostenible ..................................................................................................................... 56

1.2. Olas de crisis de la deuda: una perspectiva histórica .....................................................................69

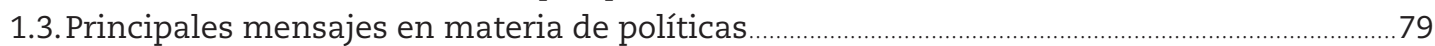

2.1.El programa nacional de regularización de Colombia para responder ante la crisis venezolana

2.2. Mensajes clave en materia de políticas ................................................................................ 115

3.1.El papel del sector exterior en el fomento de la actividad económica y el empleo:

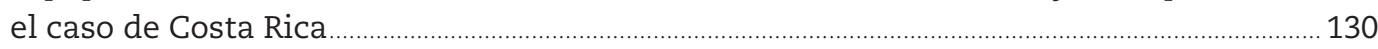

3.2. Cómo satisfacer la creciente demanda de energía con electricidad limpia y sostenible. 151

3.3. Soja certificada para la sostenibilidad, la experiencia de Argentina ........................................ 155

3.4.Experiencias latinoamericanas de las nuevas tendencias - Juan Valdez y Britt .................... 156

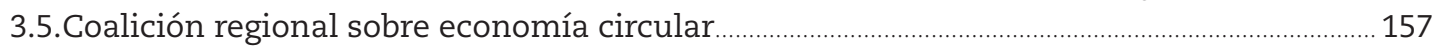

3.6.Principales mensajes en materia de políticas ............................................................................. 160

4.1.La violencia como obstáculo para el logro del contrato social en ALC …….............................. 174

4.2. Los pactos sociales dentro del contrato social ............................................................................ 180

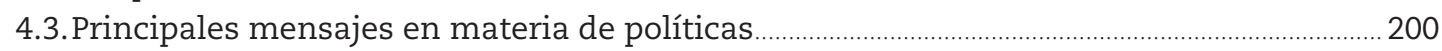


5.1.Fondo para Aliviar la Economía COVID-19

5.2. Plan 3R: Plan para la Recuperación, Reconstrucción Social y Resiliencia de Centroamérica y República Dominicana

5.3. Equipo Europa: una iniciativa orientada a las metas creada en el contexto del COVID-19

5.4.La experiencia participativa del Acuerdo de Escazú .

234

5.5.Inversión Pública Global.

238

5.6.Mensajes clave 


\section{Acrónimos y abreviaturas}

ACNUDH Oficina del Alto Comisionado de las Naciones Unidas para los Derechos Humanos

ACRF Marco Integral de Recuperación de la ASEAN

ADPIC Acuerdo sobre los Aspectos de los Derechos de Propiedad Intelectual relacionados con el Comercio

AEWG Grupos de Trabajo de Educación Acelerada

AFC Acuerdo sobre Facilitación del Comercio

AFD Agencia Francesa de Desarrollo

ALADI Asociación Latinoamericana de Integración

ALALC Área de Libre Comercio de América Latina

ALC América Latina y el Caribe

AOD Ayuda oficial al desarrollo

AP Alianza del Pacífico

ASEAN Asociación de Naciones de Asia Sudoriental

Bancoldex Banco de Desarrollo Empresarial de Colombia

BEPS Erosión de la base imponible y traslado de beneficios

BID Banco Interamericano de Desarrollo

BNDES Banco Nacional de Desarrollo Económico y Social de Brasil

CAD Comité de Asistencia para el Desarrollo

CAF Banco de Desarrollo de América Latina

CAN Comunidad Andina

CARICOM Comunidad del Caribe

CARIFORUM Foro del Caribe del Grupo de Estados de África, del Caribe y del Pacífico

CCT Transferencias en efectivo condicionadas

CdG Centro de Gobierno

CE Comisión Europea

CEPAL Comisión Económica para América Latina y el Caribe

CER Conducta Empresarial Responsable

CGV Cadenas Globales de Valor

CIAT Centro Interamericano de Administraciones Tributarias

CIS Consejo de Ministros de la Integración Social Centroamericana

COP Peso colombiano

COVAX Acceso Mundial a las Vacunas contra el COVID-19

COVID-19 Coronavirus

CPD Coherencia de las Políticas en favor del Desarrollo

C-TAP Acceso Mancomunado a la Tecnología contra el COVID-19

CTCN Centro y Red de Tecnología del Clima

DAES Departamento de Asuntos Económicos y Sociales de las Naciones Unidas

DEG Derechos especiales de giro

DiT Development in Transition (Desarrollo en Transición)

ECAF Encuesta CAF

ECR Estándar Común de Reporte

EPTV Estatuto Temporal de Protección para Migrantes Venezolanos

FACE Fondo para Aliviar la Economía COVID-19

FAO Organización para la Alimentación y la Agricultura 
FEM Foro Económico Mundial

FFI Flujos financieros ilícitos

FMI Fondo Monetario Internacional

FOGAPE Fondo de Garantía para Pequeños Empresarios

G20 Grupo de los 20

GAD Grupo Agenda Digital del MERCOSUR

GEI Gases de Efecto Invernadero

GPI Inversión Pública Global

I+D Investigación y desarrollo

IED Inversión extranjera directa

IFI Instituciones financieras internacionales

IIF Institute of International Finance (Instituto de Finanzas Internacionales)

IRENA Agencia Internacional de Energías Renovables

IRPF Impuesto sobre la Renta de las Personas Físicas

IRS Impuesto sobre la Renta de las Sociedades

ISSD Iniciativa de Suspensión del Servicio de la Deuda

ITC Centro de Comercio Internacional

IVA Impuesto sobre el Valor Agregado

KAS Fundación Konrad Adenauer

LEO Perspectivas Económicas de América Latina

Mercosur Mercado Común del Sur

Mipymes Microempresas y pequeñas y medianas empresas

NDC Contribuciones determinadas a nivel nacional

OCDE Organización para la Cooperación y el Desarrollo Económico

ODS Objetivos de Desarrollo Sostenible

OGP Alianza para el Gobierno Abierto

OIT Organización Internacional del Trabajo

OLADE Organización Latinoamericana de Energía

OMS Organización Mundial de la Salud

ONU-Hábitat Programa de las Naciones Unidas para los Asentamientos Humanos

ONU-Mujeres Entidad de las Naciones Unidas para la Igualdad de Género y el Empoderamiento de las Mujeres

OOP Out of Pocket (Gastos por cuenta propia)

ONUDI Organización de las Naciones Unidas para el Desarrollo Industrial

OPS Organización Panamericana de la Salud

PACE Plataforma para Acelerar la Economía Circular

PAYG Pay as You Go (Sistema de reparto)

PEDN Plan Estratégico de Desarrollo Nacional

PEP Permiso Especial de Permanencia

PIB Producto Interno Bruto

PIM Países de ingresos medios

PND Planes nacionales de desarrollo

PNUD Programa de las Naciones Unidas para el Desarrollo

PNUMA Programa de las Naciones Unidas para el Medio Ambiente

PRGT Poverty Reduction and Growth Trust (Fondo para el Crecimiento y la Reducción de la Pobreza)

Pymes Pequeñas y medianas empresas

SEAE Servicio Europeo de Acción Exterior 
SEGIB Secretaría General Iberoamericana

SICA Sistema de la Integración Centroamericana

SISCA Secretaría de la Integración Social Centroamericana

TIC Tecnología de la información y las comunicaciones

T-MEC Tratado entre México, Estados Unidos y Canadá

UA Unión Africana

UCI Unidad de Cuidados Intensivos

UE Unión Europea

UNCTAD Conferencia de las Naciones Unidas sobre Comercio y Desarrollo

USD Dólar de Estados Unidos

ZEE Zona Económica Especial 



\section{Editorial}

América Latina y el Caribe (ALC) ha sido la región más afectada por la pandemia y apenas está saliendo de la que es la recesión más profunda de su historia reciente. Aunque las respuestas de política pública fueron rápidas y proactivas desde el comienzo del coronavirus (COVID-19) y se evitaron escenarios más pesimistas, la pandemia ha dejado grandes cicatrices, especialmente en los grupos más vulnerables, en particular, mujeres y jóvenes. Sigue siendo necesario actuar de manera urgente y decidida para superar la pandemia, mitigar sus consecuencias socioeconómicas a largo plazo y sentar las bases de un futuro mejor.

El informe Perspectivas Económicas de América Latina 2021 (LEO por sus siglas en inglés) concibe la recuperación de la crisis del coronavirus (COVID-19) como una oportunidad para implementar reformas estructurales y analiza qué tipo de políticas y enfoques de cooperación internacional pueden ayudar a los gobiernos a construir un futuro mejor. La respuesta a la crisis puede proporcionar el impulso necesario para diseñar y aplicar una estrategia renovada de desarrollo que promueva la inclusión, la resiliencia y la sostenibilidad, respondiendo a las expectativas de los ciudadanos y acelerando el progreso hacia la Agenda 2030 de las Naciones Unidas para el Desarrollo Sostenible. El informe LEO 2021 propone el enfoque de Desarrollo en Transición (DiT) como marco general para la acción nacional e internacional, orientada en particular a fomentar la integración regional y a reforzar el contrato social - dos objetivos cruciales para superar las vulnerabilidades y las trampas de desarrollo que limitan el progreso de la región.

ALC es altamente heterogénea en cuanto al impacto de la pandemia y la capacidad de reacción ante los desafíos que esta plantea. Sin embargo, los países latinoamericanos se enfrentan a un desafío común excepcional. En el corto plazo, aplicar estrategias de vacunación eficaces y equitativas como elemento clave para la recuperación. A mediano plazo, luchar contra los efectos de la pandemia y transformar las trampas del desarrollo de la región - la baja productividad, la vulnerabilidad social, la debilidad institucional y la insostenibilidad medioambiental - en círculos virtuosos que sitúen a ALC en una senda de mayor bienestar para todos los ciudadanos.

Asimismo, la recuperación ofrece la oportunidad de seguir renovando el papel y el potencial de la cooperación internacional, en consonancia con el enfoque de DiT desarrollado en el informe LEO 2019. La cooperación y el diálogo de políticas seguirán siendo esenciales para reunir la experiencia de múltiples actores y emprender una mejor trayectoria para alcanzar los Objetivos de Desarrollo Sostenible. Los factores clave para un mejor diálogo de políticas dentro de ALC y entre regiones incluyen el fortalecimiento de las instituciones, la cohesión social, el apoyo a una transición verde y la transformación digital en un modelo de producción renovado. En este contexto, el LEO 2021 hace especial hincapié en el potencial de ALC para reforzar las alianzas, entre otros con la Unión Europea y sus Estados miembros.

La crisis del COVID-19 evidenció la naturaleza global y la interdependencia de los retos del desarrollo y reforzó la necesidad de coordinar mejor las acciones de recuperación a nivel nacional, regional e internacional.

A nivel nacional, los gobiernos de ALC deben utilizar las políticas fiscales, sociales y de transformación productiva para construir un nuevo contrato social. En particular, deben considerarse debidamente los elementos de movilidad y equidad intra e intergeneracionales, así como los desafíos asociados al cambio climático y a la transición hacia un modelo de desarrollo bajo en carbono. 
La pandemia ha puesto de relieve la apremiante necesidad de redefinir las políticas nacionales creando consenso entre los ciudadanos. Reforzar la rendición de cuentas y la confianza en las instituciones es clave para emprender un ciclo virtuoso de reformas pendientes a nivel nacional, necesarias para la recuperación, que puedan enmarcarse en un nuevo contrato social. Los objetivos fundamentales de un nuevo contrato social incluyen una mayor cobertura de la protección social, servicios públicos más accesibles y de mejor calidad, una estrategia de transformación productiva, marcos fiscales más justos y la promoción de la participación ciudadana en el diseño e implementación de políticas públicas.

Una mayor financiación para el desarrollo será clave para las políticas de recuperación y financiación de un nuevo contrato social. La mayoría de los países de ALC entraron a la crisis con un espacio fiscal limitado. Si bien la situación es, en parte, resultado del débil crecimiento en los últimos años, también tiene que ver con los desafíos pendientes relacionados con las estructuras económicas y con la política y administración tributaria. Una recuperación fuerte, sostenible e inclusiva exige una respuesta fiscal holística urgente y debe aplicarse mediante una secuencia bien definida de reformas, respaldada por un amplio consenso construido a través del diálogo a nivel nacional y de estrategias de comunicación claras. También será necesaria una mejor coordinación en la gestión de la deuda pública con todos los acreedores y agentes del mercado. En este sentido, el diseño del tratamiento de la deuda deberá prestar especial atención a las características de cada país, particularmente a los desafíos que enfrentan los Pequeños Estados Insulares en Desarrollo del Caribe y los países de América Central.

La crisis del COVID-19 ha ocasionado daños a un tejido social extremadamente vulnerable, resultando en un significativo aumento de la pobreza y la desigualdad. Cuando estalló la crisis en la región, la informalidad laboral afectaba a más del 50\% de los trabajadores. Los países de ALC deben promover opciones innovadoras de formalización laboral y reducir las brechas de cobertura social para proteger a las poblaciones más vulnerables - en particular, las mujeres, los jóvenes, migrantes y las poblaciones vulnerables a cambios climáticos -, mejorando al mismo tiempo la calidad y la cobertura de los servicios básicos, especialmente en salud y educación.

El principal reto al que se enfrenta la región para lograr una recuperación fuerte e inclusiva es la generación de empleos de calidad. Se necesitan urgentemente acciones de política ambiciosas por parte de los países de ALC para estimular la innovación y el desarrollo de capacidades, diversificar y mejorar la estructura económica y atraer inversiones de calidad.

A nivel regional, una respuesta eficaz a la crisis sanitaria también podría ser el "gran impulso" necesario para que ALC avance hacia una mayor cooperación regional. Las estrategias nacionales deben converger para promover la diversificación productiva y favorecer la integración regional y global.

ALC está rezagada en materia de integración. Apenas el 14\% de sus exportaciones permanecieron dentro de la región en 2019, y la proporción ha ido disminuyendo a un ritmo constante desde 2014. El fomento del comercio intrarregional, la creación de cadenas regionales de valor y la mejora de la participación de la región en las cadenas mundiales de valor, a través de la conexión de las microempresas y las pequeñas y medianas empresas con el comercio internacional son objetivos clave de política pública en el contexto post-COVID-19. Las políticas comerciales, industriales y de inversión pueden desempeñar un papel importante a la hora de abordar las vulnerabilidades de las estructuras de producción que la pandemia ha puesto de manifiesto. Si se diseñan adecuadamente, pueden ayudar a obtener un triple dividendo de mayor competitividad y creación de empleo, mejor preparación para afrontar futuras crisis y mayor capacidad 
para embarcarse en las transiciones verde y digital. Algunos sectores económicos que podrían beneficiarse específicamente de una mayor integración regional y contribuir a reducir las vulnerabilidades son los sectores de la industria automotriz, el farmacéutico, las energías renovables, la economía circular y la agricultura sostenible.

A nivel mundial, la cooperación internacional debería facilitar un nuevo modelo de desarrollo y un nuevo contrato social en ALC. El impacto de la pandemia del COVID-19 ha puesto de relieve la importancia de avanzar hacia un multilateralismo renovado y eficaz. Teniendo esto en cuenta, será importante que los países consoliden la concepción del DiT, basándose en nuevos enfoques con respecto a la formulación de políticas nacionales y la cooperación internacional que sitúen la sostenibilidad, la resiliencia y el bienestar en su centro, y proporcionen respuestas de política multidimensionales que incluyan esfuerzos para medir el desarrollo más allá de los ingresos. Esto implica seguir explorando alianzas enfocadas en las metas que se basen en valores compartidos y garanticen una mayor coherencia, coordinación y sinergia entre las iniciativas de desarrollo nacionales e internacionales. La mejora del diálogo sobre políticas en igualdad de condiciones, el aumento de la cooperación regional y la renovación de los mecanismos de participación de los ciudadanos podrían ser elementos esenciales para apuntalar estas alianzas reforzadas y aprovechar al máximo su potencial. Por último, una combinación equilibrada de financiación sostenible innovadora, estándares y reglas globales, cooperación técnica y diálogo político serán la clave para mejorar las alianzas con ALC.

El LEO pretende estimular el debate nacional e internacional sobre la transición hacia mejores modelos de desarrollo y alianzas. Tres aspectos dan especial relevancia a su edición de 2021: el momento, debido a que el análisis y los mensajes políticos del informe llegan en una instancia crucial para abordar el impacto transversal de la crisis en ALC; la preparación, ya que cada institución que respalda el LEO está trabajando para crear nuevos instrumentos financieros y/o enfoques políticos para apoyar a la región; y la unión, ya que, más que nunca en estos tiempos extraordinarios, es necesario unir fuerzas para avanzar en una recuperación fuerte, sostenible e inclusiva mediante la creación de diálogos participativos que permitan el surgimiento de un gran consenso que sustente una acción coordinada a nivel nacional, regional e internacional.

$\begin{array}{cccc}\text { Alicia Bárcena } & \text { Sergio Díaz-Granados } & \text { Mathias Cormann } & \text { Jutta Urpilainen } \\ \text { Secretaria Ejecutiva } & \text { Presidente Ejecutivo } & \text { Secretario General } & \text { Comisaria } \\ \text { CEPAL } & \text { CAF - Banco de } & \text { OCDE } & \text { de Asociaciones } \\ & \text { Desarrollo de América } & & \text { Internacionales } \\ & \text { Latina } & & \text { Comisión Europea }\end{array}$





\section{Resumen ejecutivo}

El informe Perspectivas económicas de América Latina 2021 (LEO) identifica y analiza los pilares fundamentales para que en América Latina y el Caribe (ALC) la recuperación de la pandemia del coronavirus (COVID-19) sea sólida, sostenible e inclusiva. En este sentido, el LEO plantea mensajes en materia de políticas públicas para avanzar juntos hacia una mejor recuperación.

La pandemia impactó a la región agravando sus principales desafíos estructurales, las cuatro trampas del desarrollo identificadas en el informe Perspectivas económicas de América Latina 2019: i) baja productividad; ii) desigualdades y vulnerabilidad social; iii) debilidades institucionales; y iv) sostenibilidad medioambiental en riesgo. El contexto posterior al COVID-19 debe aprovecharse como una oportunidad única para adoptar una estrategia de desarrollo multidimensional y para redefinir las políticas nacionales creando consenso entre los ciudadanos e implementando las reformas pendientes necesarias para impulsar la recuperación. Avanzar hacia una mayor integración regional y hacia una cooperación internacional que incluya a los países de ALC en igualdad de condiciones, independientemente de su nivel de desarrollo, debería contribuir a la recuperación de la región.

\section{Las consecuencias socioeconómicas del COVID-19 y el camino hacia la recuperación}

A pesar de que ALC adoptó rápidamente políticas bien orientadas para responder a la pandemia, ha sido la región más afectada del mundo en términos socioeconómicos. Aunque en 2021 se espera un crecimiento positivo, no se prevé alcanzar los niveles de producto interno bruto per cápita anteriores a la pandemia hasta 2023-2024. El impacto de la crisis ha sido asimétrico, ya que ha afectado especialmente a los grupos más vulnerables. La pobreza y la pobreza extrema han alcanzado niveles no observados en los últimos 12 y 20 años, respectivamente. Las políticas de demanda, principalmente a través de transferencias no condicionadas y otras medidas innovadoras, actuaron rápidamente para apoyar a los sistemas de salud pública, los hogares y las empresas. Sin esta reacción, las pérdidas de vidas y los aumentos de la pobreza y la desigualdad habrían sido aún mayores. Sin las transferencias gubernamentales para mitigar la pérdida de ingresos laborales, el Índice de Gini habría aumentado un 5.6\% respecto a 2019, en lugar del 2.9\% registrado.

No existe un único enfoque o solución que garantice una recuperación sólida, sostenible e inclusiva. Las características socioeconómicas de cada país y el impacto diferenciado que ha tenido la crisis, exigen la adopción de un enfoque adaptado al contexto específico. Sin embargo, una característica común para la recuperación es la necesidad de adoptar una secuencia claramente definida de medidas de política fiscal en materia de gasto, tributación y gestión de la deuda pública. La movilización de recursos para la recuperación requerirá esfuerzos a nivel nacional y una mejor cooperación y coordinación a nivel internacional, especialmente en lo que respecta a la deuda pública.

\section{Fortalecimiento de las políticas sociales y servicios públicos de calidad para una recuperación inclusiva}

La crisis del COVID-19 reveló que los mecanismos de protección social en la región son insuficientes debido a la alta incidencia del trabajo informal, que afecta a más del $50 \%$ de los trabajadores. Además, las brechas de género en el mercado laboral y la mayor presencia de mujeres en los hogares más pobres siguen siendo retos estructurales. La crisis también ha puesto de relieve la necesidad de mejorar la calidad y el acceso a los servicios públicos básicos, especialmente la salud y la educación. ALC es la región en la 
que más días lectivos se han perdido en promedio a nivel mundial (un 70\% más que en los países de la OCDE y un 13\% más que el promedio mundial) a causa de la pandemia, lo que representa un importante riesgo para el desarrollo del capital humano.

Los programas de protección social en ALC deben avanzar hacia sistemas que garanticen la cobertura universal. Es fundamental mejorar los regímenes de protección social, tanto en lo que se refiere a la cobertura sanitaria como de las pensiones, en apoyo de las personas mayores. Para mejorar las condiciones socioeconómicas de las mujeres, es esencial diseñar políticas para la recuperación con perspectiva de género y asegurar una redistribución más equitativa del trabajo de cuidados. Es importante poner en marcha políticas que reduzcan las brechas en educación y promuevan la adquisición de competencias en una etapa temprana de la vida para reducir la desigualdad de resultados y de oportunidades.

\section{Una mayor integración regional que ayude a impulsar el empleo formal y la resiliencia medioambiental}

El principal reto al que se enfrentará la región durante la recuperación será el de generar puestos de trabajo formales de calidad y garantizar, al mismo tiempo, la sostenibilidad a largo plazo. La actual estructura productiva dificulta las posibilidades de desarrollo de la región.

Los países de ALC deben adoptar políticas más ambiciosas para mejorar las competencias de los trabajadores, lograr la transformación productiva y atraer inversiones sostenibles. Las políticas productivas deben promover la innovación, la modernización tecnológica y la diversificación de la estructura productiva hacia sectores con un uso menos intensivo de los recursos naturales, fomentando inversiones más ecológicas, la economía circular y la adopción de nuevas tecnologías. Se debe fomentar el comercio intrarregional, favorecer la creación de cadenas regionales de valor y aumentar la participación de ALC en las cadenas mundiales de valor y sus flujos de inversión, y facilitar la conexión de las microempresas y las pequeñas y medianas empresas con el comercio internacional. Una mayor integración regional podría reforzar la competitividad y la creación de empleo en sectores con alto potencial, como los de la automoción, el farmacéutico, las energías renovables, la economía circular y la agricultura sostenible.

\section{Un nuevo contrato social en el mundo pospandémico}

La creación de grandes consensos entre los ciudadanos será crucial para avanzar en la ambiciosa agenda de reformas necesaria para impulsar la recuperación. Sin embargo, los altos niveles de descontento social en ALC, demostrados por la ola de protestas en varios países de la región desde 2019, suponen un reto importante. Los factores determinantes de la insatisfacción social son multidimensionales y, en gran parte, se explican porque no se han visto satisfechas las aspiraciones de la ciudadanía, que demanda mejores puestos de trabajo, servicios públicos de calidad y una mayor representación política. El descontento social pone de relieve la necesidad de que los países de ALC renueven su contrato social para garantizar el bienestar de las personas y la participación ciudadana.

Un nuevo contrato social puede alcanzarse a través de pactos concretos en ámbitos específicos (p. ej., un pacto fiscal) en los que se consigue un amplio apoyo de los diferentes actores sociales involucrados (p. ej., el gobierno, la sociedad civil, los sindicatos y el sector privado). Un contrato social pospandémico debe articularse en torno a dos dimensiones principales, que están interconectadas. En primer lugar, debe ser un acuerdo transversal entre: i) grupos socioeconómicos; a través de un enfoque que tenga en cuenta las diferencias de ingresos, de género, étnicas y raciales, entre otras; ii) territorios, teniendo en cuenta las diferentes necesidades y oportunidades locales y cerrando las brechas 
territoriales; y iii) generaciones, garantizando que las políticas tengan en cuenta los intereses de las generaciones actuales y futuras, ofreciendo oportunidades a los jóvenes y fomentando la noción de solidaridad intergeneracional. En segundo lugar, un nuevo contrato social debe fomentar: i) estrategias productivas resilientes y sostenibles que den prioridad a la creación de empleos de calidad y promuevan una transformación verde y digital; ii) sistemas de protección social más amplios y eficaces; y iii) un modelo más sostenible de financiamiento para el desarrollo.

Un proceso de elaboración de políticas abierto e inclusivo, que incorpore y empodere a los ciudadanos y a las autoridades locales, puede ayudar a promover una mayor responsabilidad en las reformas pendientes necesarias para la recuperación y a incorporar a los actores relevantes al debate para lograr consensos, al tiempo que se garantiza su implementación. La economía política de la reforma es crucial para alcanzar acuerdos estables y duraderos o para revisarlos con éxito cuando sea necesario. Es esencial evaluar el contexto sociopolítico, garantizar estrategias claras de comunicación, y disponer de sistemas de compensación para mitigar los aspectos distributivos negativos de las reformas y garantizar que sean justas.

\section{Cooperación internacional para la recuperación: Facilitando un nuevo contrato social en ALC}

El alcance mundial de la pandemia ha mostrado que las respuestas nacionales a las consecuencias sanitarias y socioeconómicas de esta crisis no son suficientes. Dado el aumento del descontento social y de la interconexión entre la dinámica del desarrollo nacional y las megatendencias mundiales, la cooperación internacional se ha convertido en una esfera de actuación esencial en este proceso.

El enfoque de Desarrollo en Transición plantea que la cooperación internacional debe desempeñar una nueva función para facilitar la transformación de los retos estructurales de ALC en oportunidades de desarrollo. La transformación continua de la cooperación internacional y regional resulta fundamental para apoyar a la región en su avance hacia un nuevo contrato social.

Es necesario reforzar las alianzas basadas en valores compartidos para apoyar a los países de ALC en la construcción de nuevos modelos de desarrollo que sitúen la sostenibilidad, la resiliencia y el bienestar en su centro. Estos nuevos modelos deben proporcionar respuestas de política multidimensionales, incluyendo esfuerzos para medir el desarrollo más allá de los ingresos. Para aprovechar todo su potencial, la cooperación internacional y el multilateralismo deben seguir adaptándose y evolucionando, aprovechando las lecciones aprendidas y las innovaciones durante la crisis. Las alianzas enfocadas en las metas, una mayor cooperación e integración regional y el uso equilibrado de las herramientas de cooperación - como la financiación sostenible, las reglas y estándares globales, la cooperación técnica y el desarrollo de capacidades- podrían ser catalizadores para superar las trampas del desarrollo y facilitar un nuevo contrato social en la región.

De cara al futuro, la multidimensionalidad y la complejidad del desarrollo exigen que estas nuevas alianzas incorporen a los ciudadanos al proceso de elaboración de políticas internacionales, y que impulsen un enfoque global de los esfuerzos, herramientas y actores de la cooperación internacional, que promueva la coherencia de las políticas para articular objetivos nacionales, regionales y globales sostenibles e inclusivos para el mundo pos-COVID-19. 


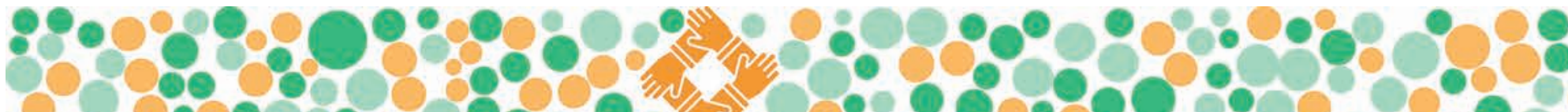
:00 O.

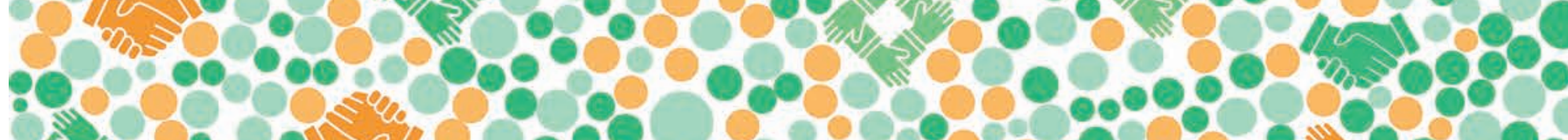

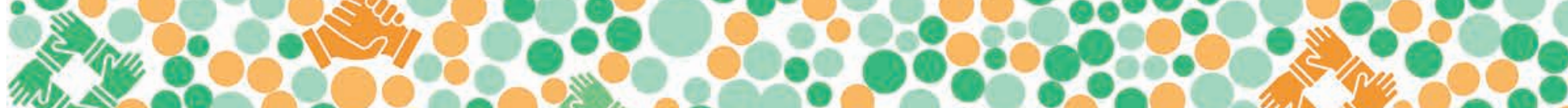

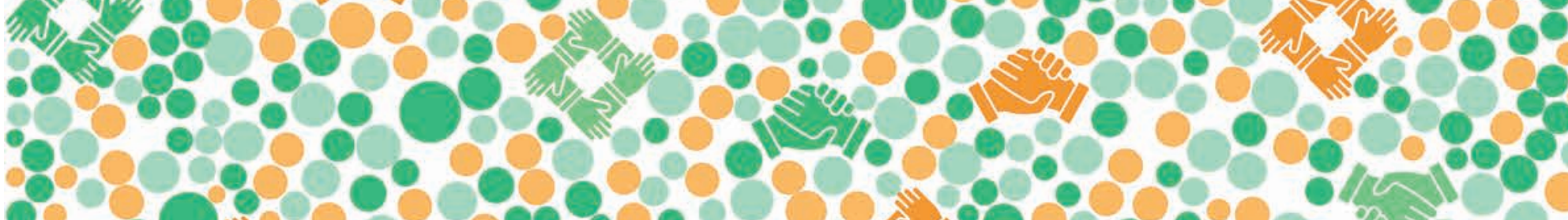

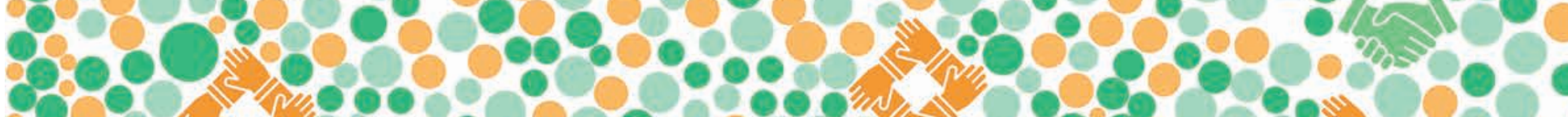

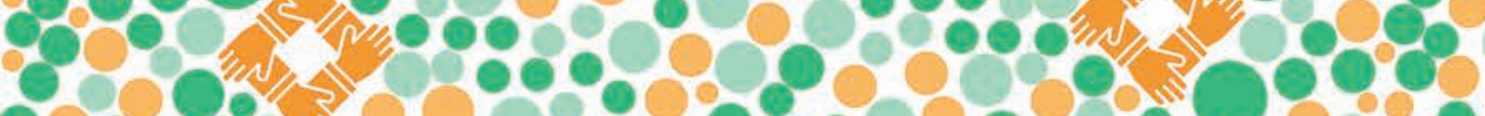

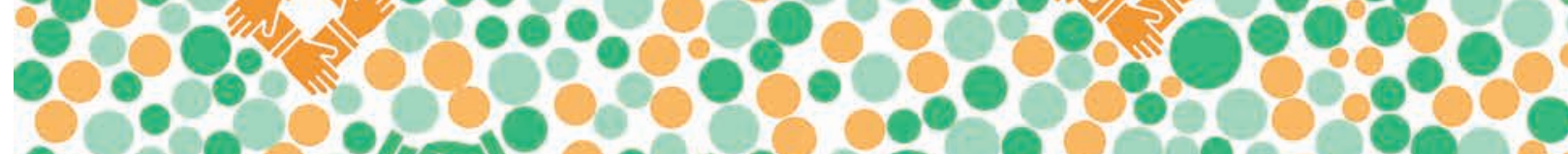
:36\%

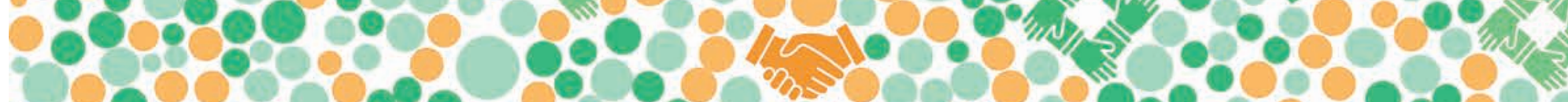
00000000000000000 :0\%

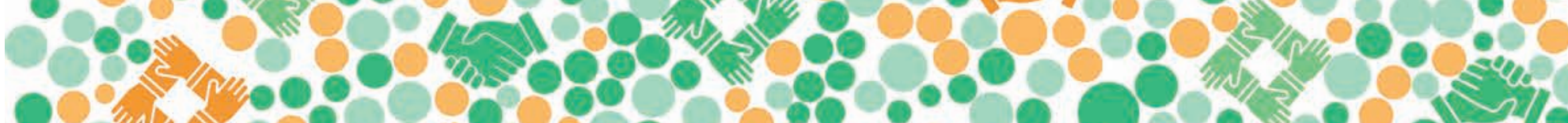

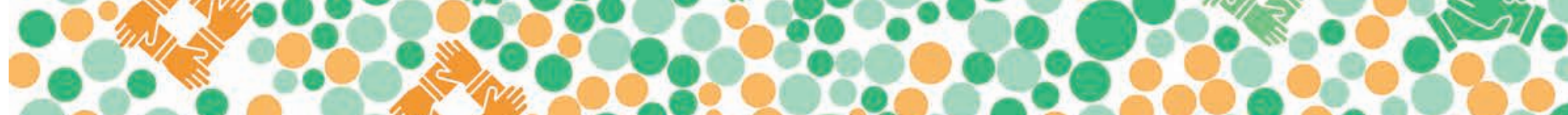

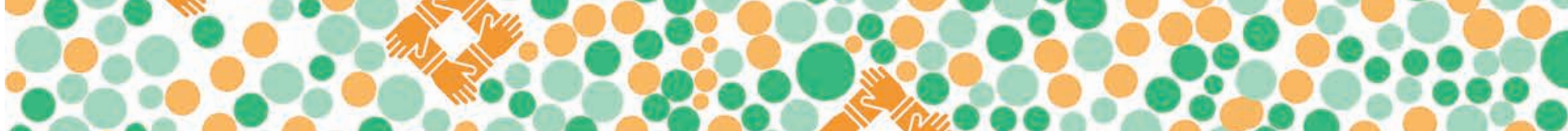

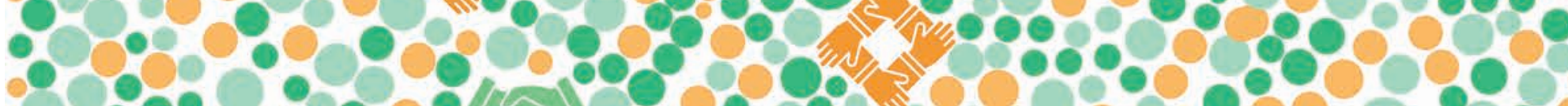

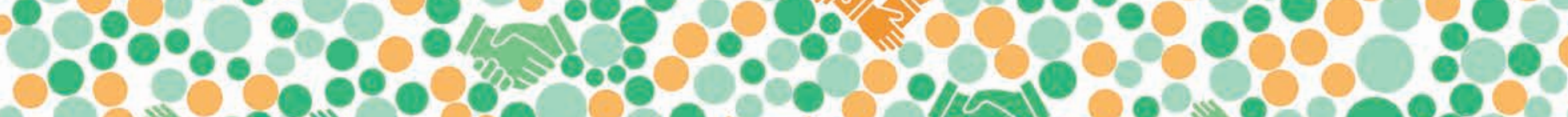
200 30003

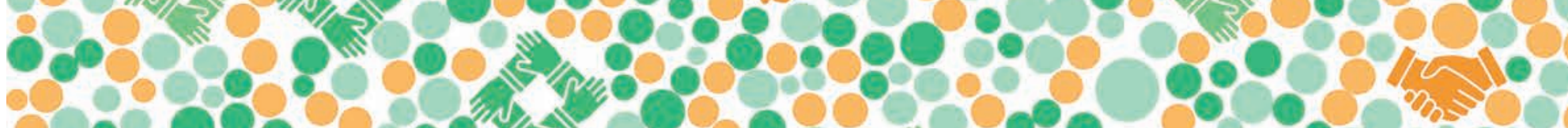
:080 0.000. 8.

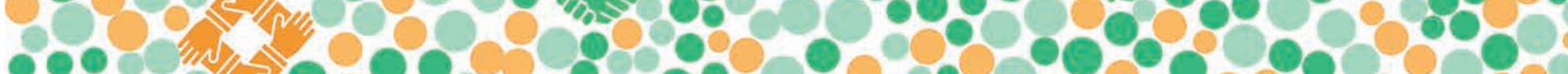

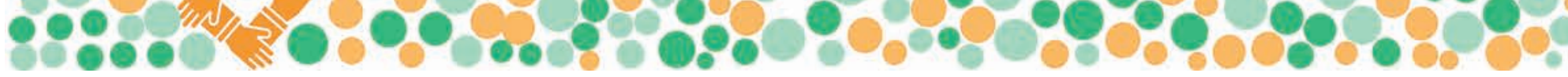




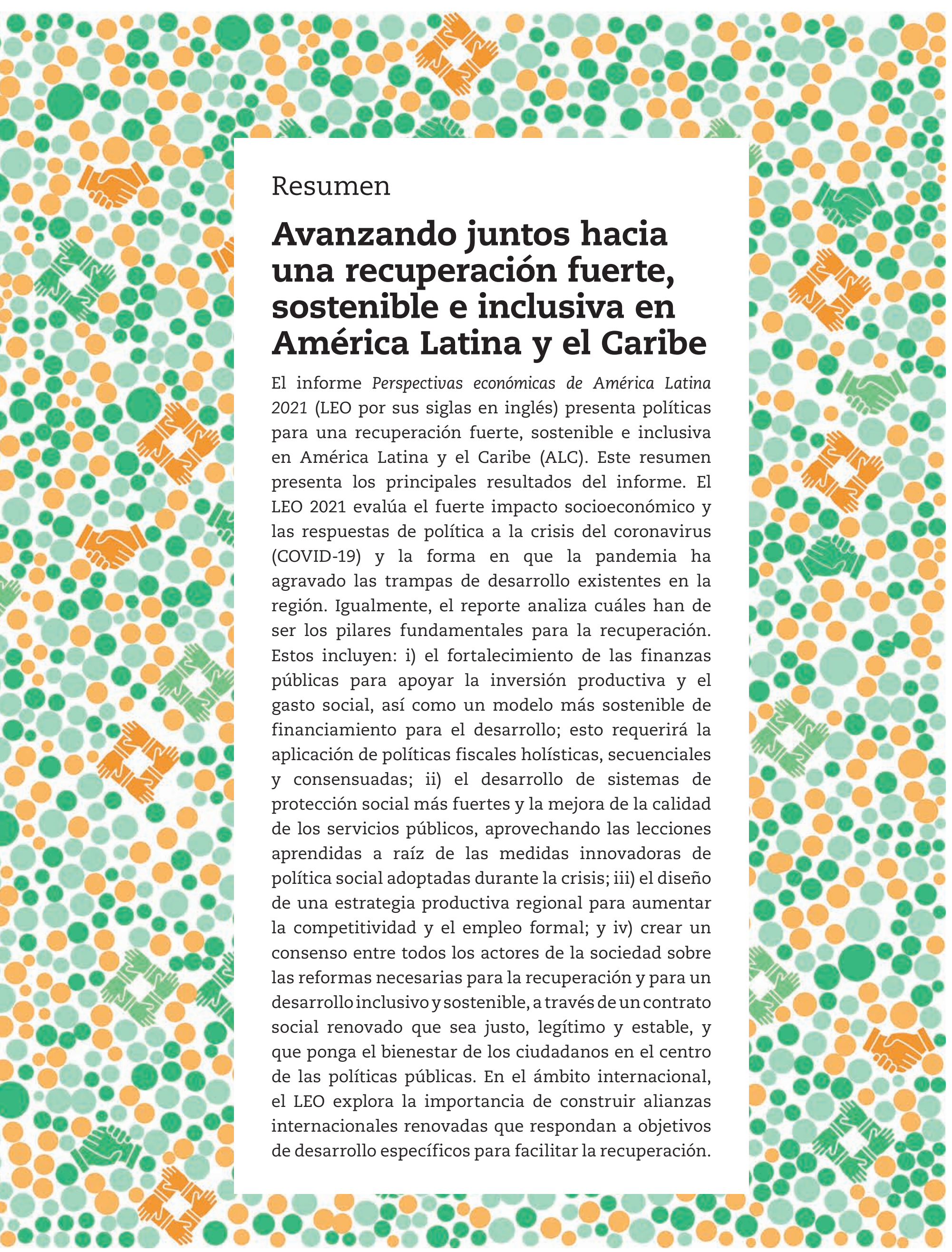




\section{Introducción}

El informe Perspectivas económicas de América Latina 2021: Avanzando juntos hacia una mejor recuperación (LEO 2021) analiza y plantea mensajes de políticas públicas para apoyar una recuperación sólida, inclusiva y sostenible de la crisis del coronavirus (COVID-19) en América Latina y el Caribe (ALC). La crisis está transformando de manera profunda las economías y sociedades de la región. El COVID-19 ha acentuado las trampas del desarrollo multidimensionales y persistentes, en particular la baja productividad, los altos niveles de desigualdad e informalidad, las debilidades institucionales y de los servicios públicos, y los desafíos medioambientales. La pandemia impactó la región en un momento de gran descontento social, como se observó en la reciente ola de protestas en varios países de la región. Esto destaca la necesidad de reconstruir la confianza de la sociedad en las instituciones públicas y de renovar los consensos entre los ciudadanos en torno a una nueva senda de desarrollo para la región.

La recuperación de la crisis del COVID-19 plantea desafíos excepcionales a los países de ALC, pero también debe interpretarse como una oportunidad para llevar a cabo una agenda de reformas pendientes. Esta agenda debe impulsar una estrategia renovada de desarrollo que promueva la inclusión, la resiliencia y la sostenibilidad, respondiendo asía las aspiraciones de los ciudadanos al tiempo que se promueve la Agenda 2030 de las Naciones Unidas. El fomento de una mayor integración regional y de una cooperación internacional que incluya a los países de ALC en igualdad de condiciones, independientemente de su nivel de desarrollo, debería contribuir a la recuperación de la región.

La estrategia de recuperación debe tomar en cuenta las características socioeconómicas de cada país y el impacto específico que haya tenido la crisis. Sin embargo, existen elementos comunes para una recuperación exitosa y que no deje a nadie de lado: i) prestar atención a la economía política de las reformas; ii) establecer una secuencia de políticas claramente definida; y iii) evaluar el contexto sociopolítico, garantizando una estrategia de comunicación clara y estableciendo sistemas de compensación para mitigar el impacto distributivo negativo de las reformas, especialmente en los más vulnerables. La recuperación debería poner en marcha un proceso de formulación de políticas abierto e inclusivo que garantice una mayor rendición de cuentas e incluya a todos los agentes pertinentes en el debate para lograr consensos. Esto exigirá esfuerzos a nivel nacional y una mejor cooperación y coordinación a nivel regional e internacional.

El informe LEO 2021 ofrece mensajes de política pública para avanzar juntos hacia una mejor recuperación. En primer lugar, examina el impacto socioeconómico de la crisis del COVID-19 y las políticas adoptadas para hacerle frente. Asimismo, analiza los principales fundamentos macro para la recuperación en la región. En particular, insiste en la necesidad de implementar políticas fiscales holísticas, secuenciales y consensuadas para lograr una recuperación fuerte e inclusiva (Capítulo 1). En segundo lugar, destaca la necesidad de reforzar los sistemas de protección social y mejorar la calidad y accesibilidad de los servicios públicos, aprovechando los aprendizajes de la pandemia e incorporando algunas de las innovaciones de política social adoptadas durante la crisis (Capítulo 2). Además, el LEO 2021 destaca la importancia de diseñar una estrategia productiva regional, buscando impulsar la integración regional, incrementar la productividad y promover la creación de empleo formal (Capítulo 3). Estos esfuerzos de política requieren de amplios consensos entre todos los actores de la sociedad. Por ello, será necesario avanzar hacia un nuevo contrato social que sea justo, legítimo y estable, y que ponga el bienestar de los ciudadanos en el centro de las políticas públicas (Capítulo 4). El informe explora la importancia de avanzar hacia alianzas internacionales renovadas y enfocadas en objetivos de desarrollo específicos para impulsar la recuperación. Estas alianzas deben promover la participación de los países de ALC en igualdad de condiciones, una 
mayor coherencia de políticas en todos los niveles de gobierno, enfoques integrados y herramientas para abordar la naturaleza multidimensional del desarrollo, incluyendo los esfuerzos para medir el desarrollo más allá de los ingresos, tanto a escala nacional como internacional (Capítulo 5). La publicación resalta que tener en cuenta la economía política de las reformas y las características propias de cada país será fundamental para alcanzar los acuerdos estables y duraderos necesarios para que la recuperación beneficie a todos. Asimismo, incluye tres temas transversales clave: i) el cambio climático y la recuperación verde; ii) la transformación digital; y iii) la dimensión de género.

\section{Una política fiscal integral y consensuada será fundamental para impulsar una recuperación sólida e inclusiva}

En 2020, ALC sufrió una recesión económica histórica, siendo la región más afectada por la pandemia. El producto interno bruto (PIB) de la región se contrajo alrededor de $7.0 \%$ en ese año y no se prevé alcanzar los niveles de PIB per cápita anteriores a la crisis hasta 2023-2024 (Gráfico 1). Se espera que la crisis tenga también un impacto sobre la productividad y el crecimiento potencial de la región. El ritmo de la recuperación, depende de la eficacia de la distribución de las vacunas, de la evolución del contexto internacional y del curso del ciclo político en la región.

\section{Gráfico 1. Evolución del PIB per cápita a precios constantes}

Dólares en paridad de poder adquisitivo de 2017

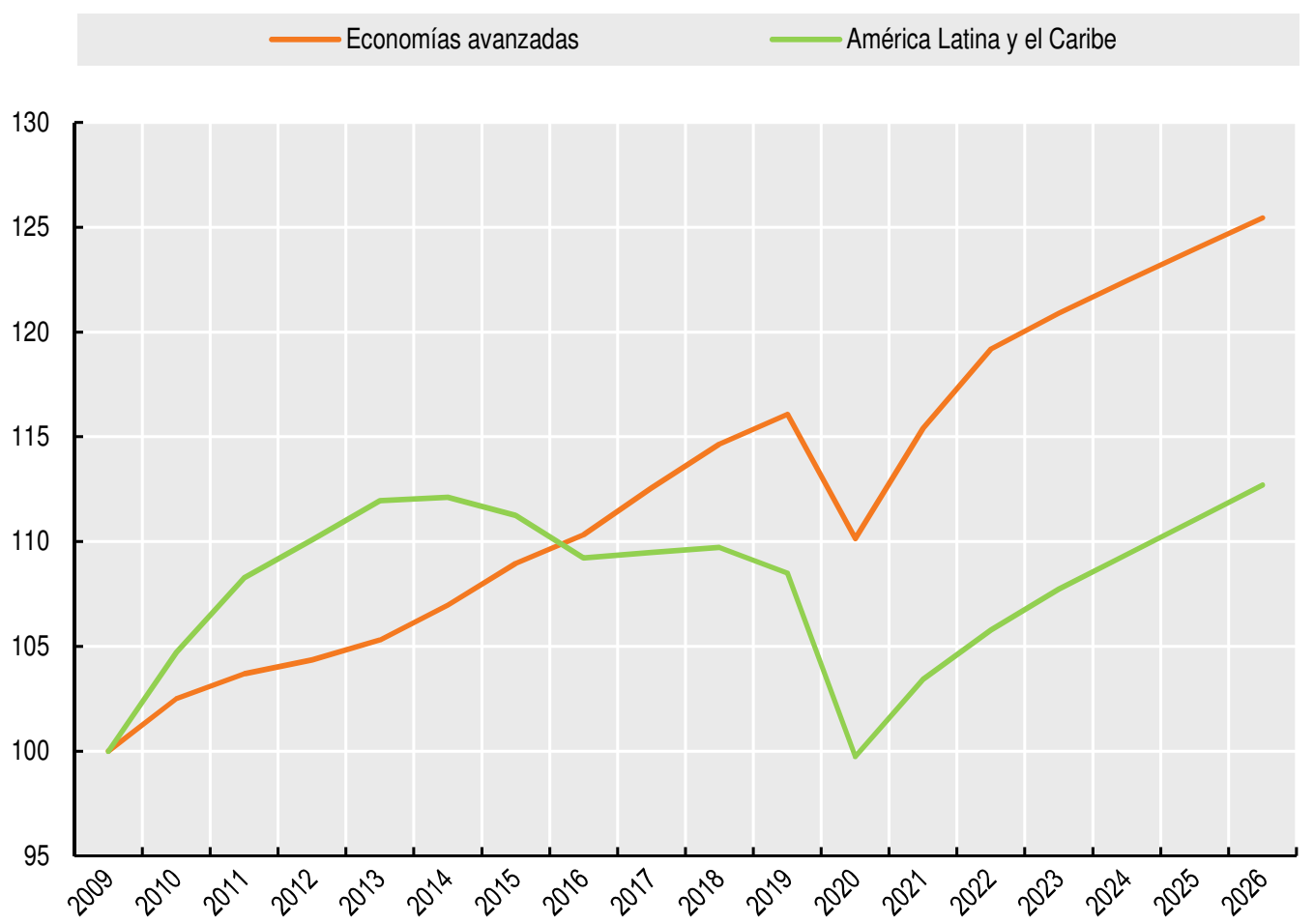

Fuente: Cálculos del Centro de Desarrollo de la OCDE a partir de FMI (2021 1 ) Perspectivas de la economía mundial, abril de 2021, https://www.imf.org/es/Publications/WEO/Issues/2021/03/23/world-economic-outlook-april-2021.

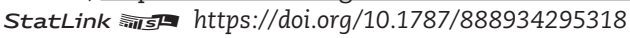

Elimpacto de la crisis del COVID-19 ha sido asimétrico, ya que ha afectado especialmente a los grupos más vulnerables y ha revertido algunos de los progresos socioeconómicos experimentados en la región en las últimas décadas. Como consecuencia de la crisis, se estima que en 2020 la tasa de pobreza extrema subió más de un punto porcentual, hasta 
alcanzar el 12.5\% de la población, y que la tasa de pobreza subió tres puntos porcentuales, hasta alcanzar el $33.7 \%$. No se habían observado estos niveles de pobreza en los últimos 20 y 12 años, respectivamente. Del mismo modo, se estima que la desigualdad, medida por el coeficiente de Gini, se ha incrementado un $2.9 \%$ en la que ya era la región más desigual del mundo, dado que las personas más afectadas por la pérdida de empleo pertenecían al primer quintil.

Tradicionalmente los mercados laborales de ALC han sido informales, frágiles y excluyentes. Más de la mitad de los trabajadores de ALC ocupan puestos de trabajo informales (OCDE, 2020 ${ }_{[2]}$ ). Los hogares informales - es decir, aquellos cuyos ingresos dependen íntegramente de la economía informal - son los más afectados por la crisis del COVID-19, pues han perdido sus empleos y los ingresos que obtenían con ellos. En promedio, el $45 \%$ de la población de ALC vive en hogares que dependen exclusivamente del empleo informal, el $22 \%$ vive en hogares mixtos y el $33 \%$ vive en hogares que solo dependen de la economía formal (OCDE, Próximo a publicarse ${ }_{[3]}$ ). Sin embargo, según la base de datos Key Indicators of Informality Based on Individuals and their Households (Indicadores clave de la informalidad en función de los individuos y sus hogares) del Centro de Desarrollo de la Organización para la Cooperación y el Desarrollo Económicos (OCDE), existen grandes disparidades en los niveles de informalidad que se registran en los distintos países de ALC, desde un nivel de menos del 20\% en Chile y Uruguay hasta más del $60 \%$ en Bolivia, Honduras y Nicaragua (Gráfico 2, Panel A).

\section{Gráfico 2. Impacto de la crisis del COVID-19: casi el 70\% de los latinoamericanos viven en hogares informales o mixtos, hay más personas con ingresos bajos y la clase media se redujo}

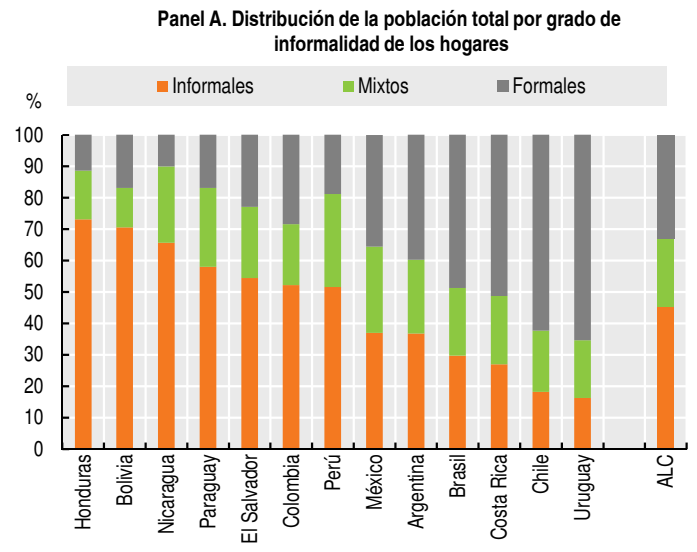

Panel B. Cambios por grupo socioeconomico, 2019-20, millones de personas

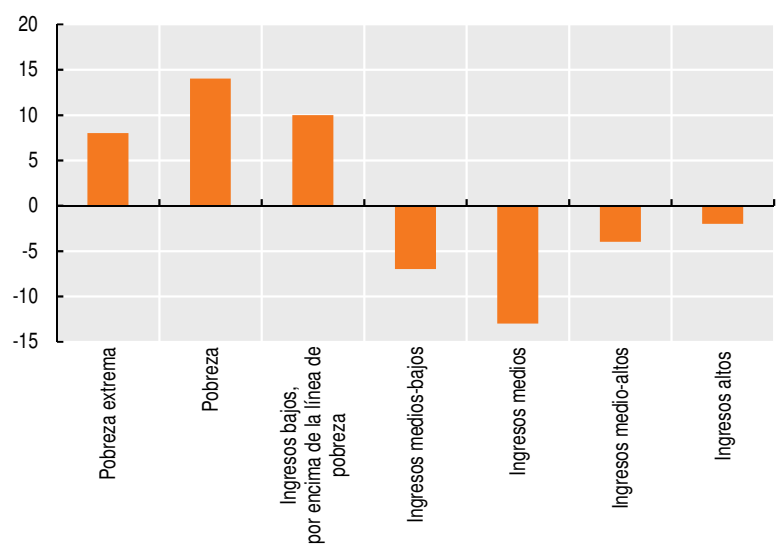

Notas: Panel A: a partir de la clasificación de la OCDE/OIT (2019 $\left.{ }_{[4]}\right)$ y la OIT (2018 $\left.{ }_{[5]}\right)$, se asigna a las personas a una de las tres categorías en función del grado de informalidad de sus hogares. Hogares formales: todos los miembros del hogar trabajan en el sector formal. Hogares informales: todos los miembros del hogar trabajan en el sector informal. Hogares mixtos: algunos miembros del hogar trabajan en el sector formal y otros, en el informal. El Panel B incluye a Argentina, Bolivia, Brasil, Chile, Colombia, Costa Rica, Ecuador, El Salvador, Guatemala, Honduras, México, Nicaragua, Panamá, Paraguay, Perú, República Dominicana, Uruguay y Venezuela.

Fuente: OCDE (Próximo a publicarse ${ }_{[3]}$ ), Labour informality and households' vulnerabilities in Latin America; CEPAL, a partir del Banco de Datos de Encuestas de Hogares. Cifras adaptadas a las proyecciones demográficas de las Naciones Unidas: UN (2019), World Population Prospects 2019, https://population.un.org/wpp/.

StatLink ints] https://doi.org/10.1787/888934295147

La evolución negativa del empleo y los ingresos durante la crisis ha tenido un impacto sobre la clase media, que se vio reducida, y amenaza con agravar las brechas sociales y económicas existentes en una región que ya presentaba grandes desigualdades. El número 
de personas que viven con bajos ingresos (vulnerables, pobres y extremadamente pobres) ha aumentado significativamente, en concreto 32 millones más que antes de la crisis. Por otro lado, el número de personas con ingresos medios-bajos disminuyó en 7 millones, el número de personas con ingresos medios disminuyó en 13 millones (13.1\%), el número de personas con ingresos medios-altos disminuyó en 4 millones (14.2\%), y el número de personas con ingresos altos disminuyó en 2 millones (10.5\%) (Gráfico 2, Panel B).

Las medidas de política fiscal y monetaria han sido un elemento central de la respuesta a la actual crisis, y determinarán en gran medida el grado de inclusión y de solidez de la recuperación. La política fiscal, a través de una combinación de medidas de alivio tributario, reasignaciones presupuestarias, gastos adicionales y acceso a crédito en condiciones favorables, ha sido esencial para mitigar el impacto de la crisis del COVID-19 en los hogares y las empresas, en particular sobre los más vulnerables, y para fortalecer los sistemas de salud pública (CEPAL, 2021 ${ }_{[6]}$ ).

El margen de maniobra es más limitado en los países con altos niveles de endeudamiento o donde la inflación no está controlada. Por este motivo, las medidas de gasto, tributación y gestión de la deuda deben adaptarse al contexto de cada país. Algunas de estas medidas requieren una mayor cooperación y coordinación a nivel internacional (Capítulo 5).

En primer lugar, las medidas en materia tributaria deben encontrar un equilibrio para aumentar la recaudación sin poner en peligro la recuperación económica ni el bienestar de los ciudadanos. En tal sentido, la secuencia de implementación de estas políticas y el hecho de que estén consensuadas a nivel nacional serán factores determinantes de su éxito (Mora, Nieto-Parra y Orozco, 2021 $1_{[7]}$ ). Entre las posibles medidas se incluyen aquellas orientadas a reducir la evasión y elusión fiscal, que representan en ALC una pérdida de recaudación de un importe equivalente a aproximadamente el 6.1\% de su PIB en impuestos sobre la renta de las personas físicas, impuestos sobre la renta de las sociedades e impuestos sobre el valor añadido no percibidos (CEPAL, 2021 ${ }_{[6]}$ ). En segundo lugar, mientras la pandemia siga poniendo vidas en peligro, el gasto público anticíclico debería seguir destinándose a proteger a las personas, apoyar a los hogares más vulnerables, y apoyar a las empresas y el empleo. La vacunación es esencial para ofrecer una salida a la pandemia y reducir la incertidumbre. Una vez que la pandemia esté bajo control, el gasto público debería ir destinándose gradualmente a gastos de capital de largo plazo con el fin de lograr una transformación productiva que genere empleo formal, aproveche al máximo la transformación digital y priorice el medioambiente. En tercer lugar, además de reforzar la confianza de los ciudadanos en el gobierno, garantizar la sostenibilidad fiscal será fundamental para el éxito de estos esfuerzos. Dadas las implicaciones globales de la pandemia, y a medida que aumentan los recursos financieros necesarios para hacer frente a sus consecuencias, la coordinación mundial de la gestión de la deuda pública debería ser una prioridad para abordar o evitar posibles problemas de sostenibilidad de la deuda (OCDE, 2020 ${ }_{[2]}$ ).

\section{Fortalecer los sistemas de protección social, aprovechando las innovaciones adoptadas durante la pandemia, para una recuperación inclusiva y sostenible}

La crisis ha evidenciado que los actuales mecanismos de protección social en la región son insuficientes. Los países de ALC entraron en la crisis con cerca del $40 \%$ de los trabajadores sin cobertura de protección social. Esto se debe en gran medida a la prevalencia de la informalidad laboral en la región, que afecta a casi el $60 \%$ de los trabajadores, aunque la situación es muy variada entre los países.

Las mujeres, los jóvenes, los mayores, los pueblos indígenas, los afrodescendientes y los migrantes se han visto afectados desproporcionadamente por la crisis. La tendencia al 
envejecimiento ya está ocasionando graves problemas sociales en ALC. Antes de la crisis, alrededor del 75\% de la población mayor de 65 años recibía una pensión, aunque el importe percibido era insuficiente para sustituir el nivel de ingresos de una persona durante su vida productiva. Además, mientras que casi un tercio de las pensiones procedían de un régimen no contributivo, el $42 \%$ de las personas mayores de 65 años estaban cubiertas por el sistema de salud público no contributivo, lo que limitaba recibir una cobertura adecuada y el acceso a una atención de calidad mientras añadía presión financiera a los sistemas sociales. Las disparidades en el acceso a la atención sanitaria y en su calidad están relacionadas con los ingresos, el género y la ubicación geográfica (urbana o rural). Los elevados gastos de bolsillo en salud y los bajos ratios de recursos humanos, como, por ejemplo, médicos y enfermeras especializados y otros recursos físicos, han puesto límites a la lucha contra la pandemia. El descontento con los servicios sanitarios, el cual ya era bastante alto en comparación con los países de la OCDE, ha aumentado durante la crisis del COVID-19.

La pandemia y los cierres de los centros educativos aumentaron las desigualdades existentes en ALC en el acceso a la educación y su calidad. Muchos centros educativos de la región se vieron obligados a cerrar para contener la propagación del virus (Gráfico 3). Desde marzo de 2020 hasta mayo de 2021, en todo el mundo los centros educativos han estado totalmente cerrados un promedio de 19 semanas. En ALC, esta cifra fue de 26 semanas, lo que la convierte en la región que más días lectivos ha perdido en promedio (UNICEF, $\left.2021_{[8]}\right)$, un 70\% más de tiempo que en la OCDE. La mayor parte de los alumnos de ALC no cuenta con los recursos disponibles para conectar o utilizar un dispositivo electrónico, existiendo una clara diferencia entre centros educativos en entornos favorecidos y desfavorecidos, lo que da lugar a mayores desigualdades educativas entre estudiantes de distintos contextos socioeconómicos. Las interrupciones prolongadas de los estudios plantean problemas relacionados con la pérdida de capital humano y también afectan a la recuperación del empleo perdido por las mujeres, que asumen principalmente la responsabilidad del cuidado de los niños.

\section{Gráfico 3. Los cierres escolares han sido más largos en ALC que en la OCDE, y pueden agravar las desigualdades educativas}

Número de semanas de cierres totales de centros educativos debido al COVID-19, marzo de 2020 a mayo de 2021

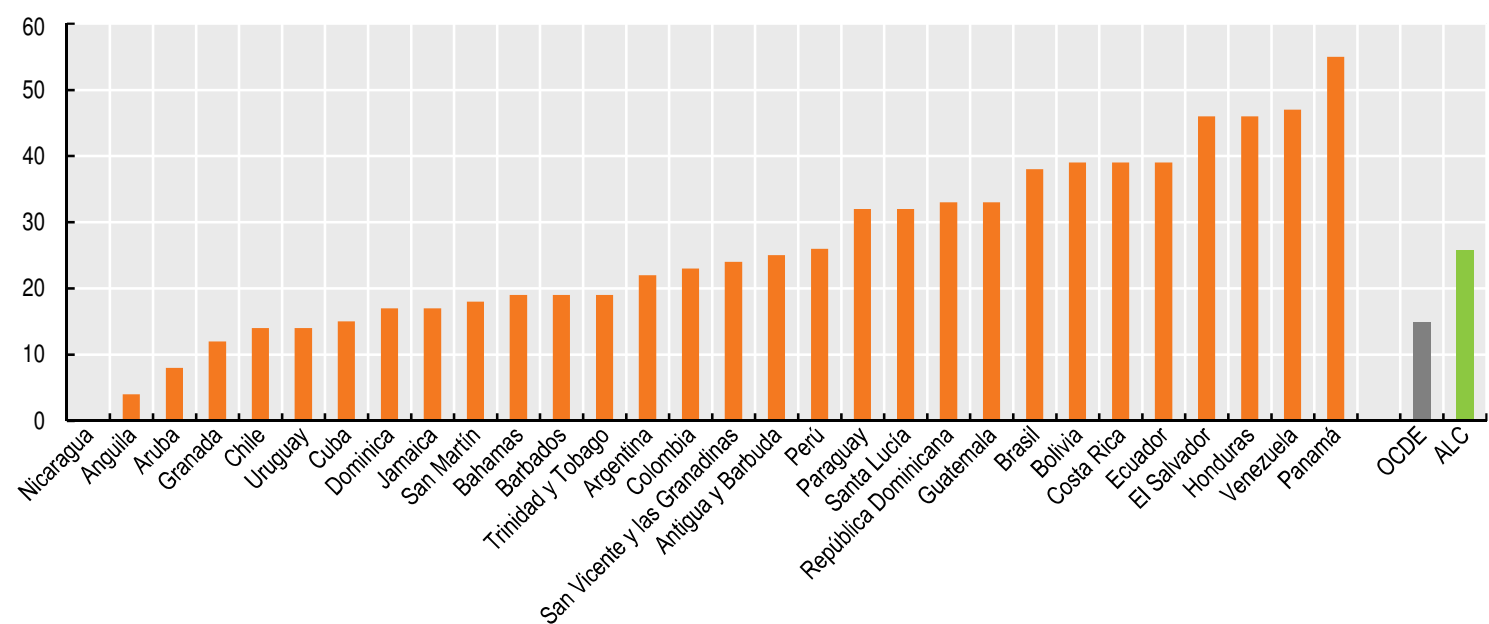

Nota: El promedio de la OCDE engloba a los entonces 37 Estados miembros. El promedio de ALC está formado por Brasil, Chile, Colombia, Costa Rica, Cuba, Ecuador, El Salvador, Guatemala, Haití, Honduras, México, Nicaragua, Panamá, Perú, República Dominicana, Uruguay y Venezuela. Actualizado al 1 de mayo de 2021.

Fuente: UNESCO $\left(2020_{[9]}\right)$, Seguimiento mundial de los cierres de escuelas causados por el COVID-19, https://es.unesco.org/covid19/ educationresponse\#schoolclosures.

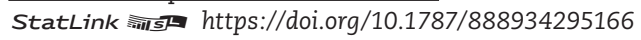


El nivel de desconfianza en el sistema de protección social es mayor entre los grupos más pobres y los trabajadores informales (Gráfico 4). La crisis presenta una oportunidad para reformar los sistemas de protección social para hacerlos más inclusivos y más sostenibles. Los actuales mecanismos de protección podrían adaptarse mejor a la dinámica de los mercados laborales de la región y a la heterogeneidad de las habilidades de los trabajadores. Las medidas adoptadas en materia de política social como respuesta a la crisis del COVID-19 representan una base sólida para avanzar hacia sistemas de protección social universales, integrales y sostenibles.

\section{Gráfico 4. Porcentaje de trabajadores que dudan que vayan a cobrar una pensión, desglosado por características sociodemográficas, en países seleccionados de ALC}

$\%$ de personas empleadas

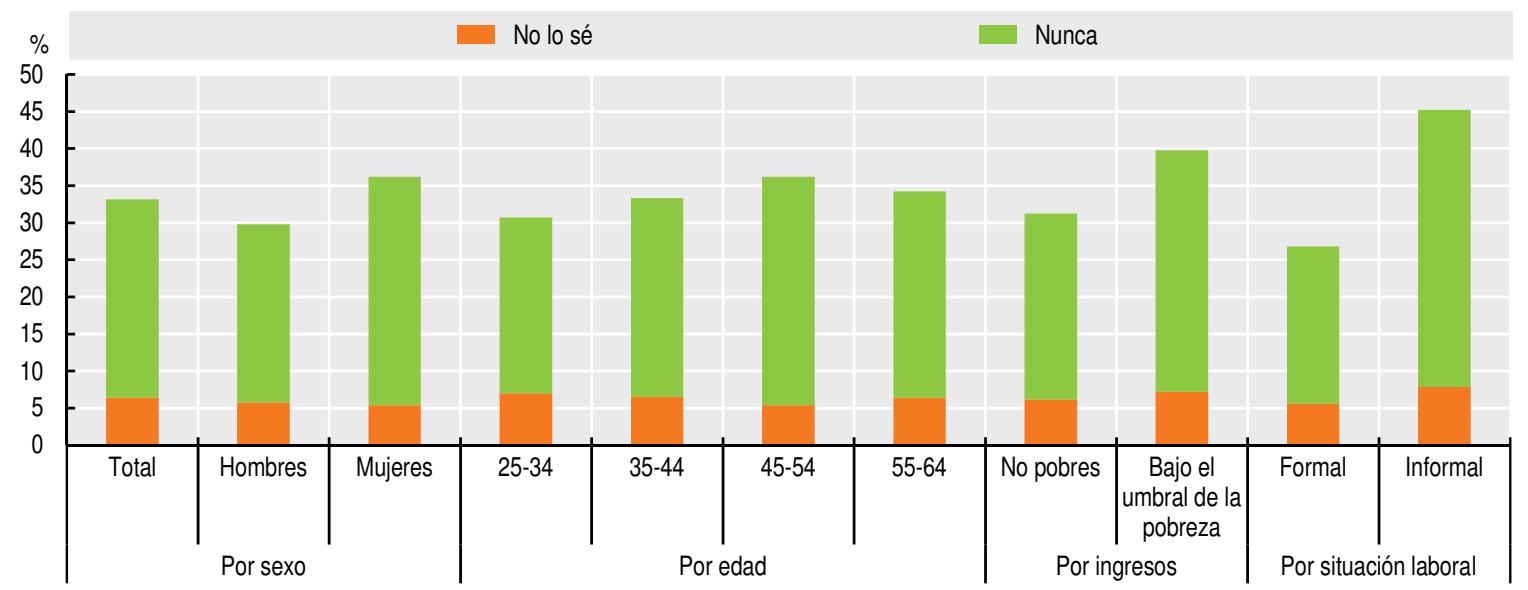

Notas: Los datos se refieren a un promedio ponderado de las siguientes ciudades: Asunción, Buenos Aires, Bogotá, Ciudad de México, Ciudad de Panamá, El Alto, La Paz, Lima, Montevideo, Quito, Santiago y São Paulo. Dado que los datos se refieren a áreas metropolitanas (normalmente, capitales) y no engloban las zonas rurales, el análisis debe realizarse con cierta cautela. Sin embargo, los indicadores se consideran representativos de cada país de ALC.

Fuente: Cálculos de la OCDE basados en CAF $\left(2020_{[10]}\right)$, ECAF 2019. Percepciones de los latinoamericanos sobre los sistemas de pensiones, salud y cuidados y el avance tecnológico en el mercado laboral, http://scioteca.caf.com/handle/123456789/1646.

StatLink तiा st https://doi.org/10.1787/888934295185

Los gobiernos respondieron rápidamente a la crisis del COVID-19 aprobando ayudas sociales específicas para poblaciones vulnerables no cubiertas por los programas sociales o los mecanismos de protección social tradicionales. Esta respuesta innovadora podría sentar las bases de sistemas de protección social más sólidos en el futuro. La asistencia social durante la pandemia se dirigió a las poblaciones vulnerables no cubiertas por los programas sociales o los mecanismos de protección social existentes. Como estas poblaciones suelen ser difíciles de identificar, ya que muchas no están registradas, o no es sencillo transferirles recursos, ya que no siempre tienen una cuenta bancaria, los gobiernos invirtieron en mejorar los registros, cotejando los existentes, y en encontrar formas alternativas de entregar las transferencias de dinero, principalmente a través de tecnologías digitales y teléfonos móviles (Basto-Aguirre, Nieto-Parra y Vázquez-Zamora, $\left.2020_{[11]}\right)$. La focalización permanente y la provisión de protección social a las poblaciones vulnerables son condiciones clave de un estado de bienestar funcional e inclusivo. La protección social en la región de ALC necesita mecanismos de financiación más fuertes, flexibilizando las cotizaciones sociales con una mezcla de aportes no contributivos, contributivos y voluntarios. La mejora de los regímenes de protección social para apoyar a las personas mayores, tanto en términos de cobertura de pensiones como de asistencia sanitaria, es clave en sociedades cada vez más envejecidas. 
Es importante poner en marcha políticas que reduzcan las desigualdades en educación y promuevan la adquisición de competencias en una etapa temprana de la vida, lo que posteriormente se traducirá en una mayor probabilidad de conseguir un empleo de calidad. Este reto se ha agravado durante la pandemia: la reapertura segura de las escuelas y la formación y el apoyo extraescolar a los alumnos más desfavorecidos son, por tanto, prioridades para facilitar una recuperación equitativa en la región. La planificación de la oferta y la demanda de profesores, la mejora de la formación y el acceso a Internet y a las tecnologías para los que no pueden volver a la escuela son pasos intermedios que deben aplicarse rápidamente para proteger el acceso y la calidad de la educación. Asimismo, el impacto diferenciado de la crisis para las mujeres ha sido especialmente evidente como consecuencia del cierre de escuelas. El diseño de políticas de género para la recuperación y la garantía de una redistribución más equitativa del trabajo de cuidados son claves para mejorar las condiciones socioeconómicas de las mujeres.

La pandemia ha hecho más necesario afrontar conjuntamente los retos de la desigualdad, el cambio climático y la degradación ambiental. La crisis ha incrementado el número de personas que viven por debajo del umbral de pobreza en ALC, y se prevé que los efectos del cambio climático sumen otros 5 millones de pobres en la región para 2030. Las consecuencias de estos fenómenos suelen concentrarse entre los grupos y los hogares vulnerables debido a sus bajos ingresos y su mayor dependencia de los recursos naturales. Sin embargo, el crecimiento verde y el progreso socioeconómico pueden ir de la mano en ALC. Si se aplican las políticas adecuadas, una recuperación verde podría crear 15 millones de empleos netos en la región para 2030 (OIT/BID, 2020 ${ }_{[31]}$ ).

Los sistemas de protección social deberían incorporar consideraciones relativas al cambio climático como temática transversal en la formulación de políticas. Los enfoques integrados permitirían tener en cuenta las cuestiones de desarrollo social y humano en la transición ecológica, con el objetivo de conseguir la neutralidad en emisiones de carbono a nivel global y reducir las desigualdades multidimensionales. La economía política de la reforma de los sistemas de protección social supone un reto, pero esta crisis puede crear el contexto adecuado para promover reformas estructurales postergadas. La ciudadanía es muy consciente de la necesidad de cambiar las políticas. La evidencia apunta a que están a favor de la reforma de las pensiones en general, pero discrepan en cuanto a las opciones para implementarla, especialmente si se tiene en cuenta la sostenibilidad fiscal. Los ciudadanos bien informados son más proclives a apoyar reformas más amplias, pero la información por sí sola no es suficiente, sobre todo si la confianza en las instituciones es limitada. A la hora de reformar la protección social y de mejorar los servicios públicos, será esencial gestionar los equilibrios y tener en cuenta la sostenibilidad fiscal, aunque no resultará sencillo. Dirigir las medidas adoptadas hacia aquellos que están más expuestos a la crisis actual podría ser un buen punto de partida.

\section{Promover una mayor integración regional y estrategias de transformación productiva para impulsar nuevas oportunidades de desarrollo}

La dependencia de ALC de la producción internacional y su débil integración regional quedaron en evidencia como consecuencia de las disrupciones sin precedentes causadas por la pandemia del COVID-19 en los sistemas comerciales y productivos mundiales. La magnitud de la crisis y la capacidad de reacción de los países dependen en gran medida de la estructura productiva de sus economías y de la participación de las empresas en las cadenas de valor regionales y globales. En este contexto, el desarrollo de políticas industriales y productivas más fuertes a nivel intrarregional es esencial para que la región pueda fortalecer las capacidades existentes y generar otras nuevas en sectores estratégicos. 
La integración regional debe desempeñar un papel clave en las estrategias de recuperación de la crisis en ALC. En un contexto mundial de creciente regionalización de la producción, serán necesarios importantes esfuerzos de política industrial para que se desarrollen cadenas de valor regionales más fuertes y ALC pueda competir en las ya muy diversificadas cadenas de suministro mundiales. La convergencia entre los mecanismos de integración y las instituciones existentes podría ofrecer una oportunidad para impulsar las inversiones en conocimiento y tecnología, desarrollar la capacidad productiva y superar la fragmentación del mercado regional.

Aunque la integración regional sigue siendo débil en la región, podría ser un motor para la transformación productiva. La mayoría de las iniciativas de integración de ALC se han centrado en la integración comercial y de mercados, prestando poca atención a la integración productiva. A pesar de sus numerosos acuerdos comerciales intrarregionales, ALC tiene uno de los niveles más bajos de comercio intrarregional del mundo. Apenas el 13\% de sus exportaciones se quedaron dentro de la región en 2020, y esa proporción ha ido disminuyendo constantemente desde 2014 (Gráfico 5). La escasa integración productiva entre los países de ALC se evidencia en el menos de $6 \%$ de contenido importado intrarregional en las exportaciones totales, en promedio. Asimismo, la integración de ALC en las cadenas globales de valor es baja y ha estado asociada principalmente a la extracción y procesamiento de materias primas.

\section{Gráfico 5. América Latina y el Caribe: exportación intrarregional, 1960-2020}

Miles de millones USD y porcentaje de las exportaciones totales de bienes

Exportaciones intrarregionales _ _ Proporción de las exportaciones intrarregionales (escala derecha)

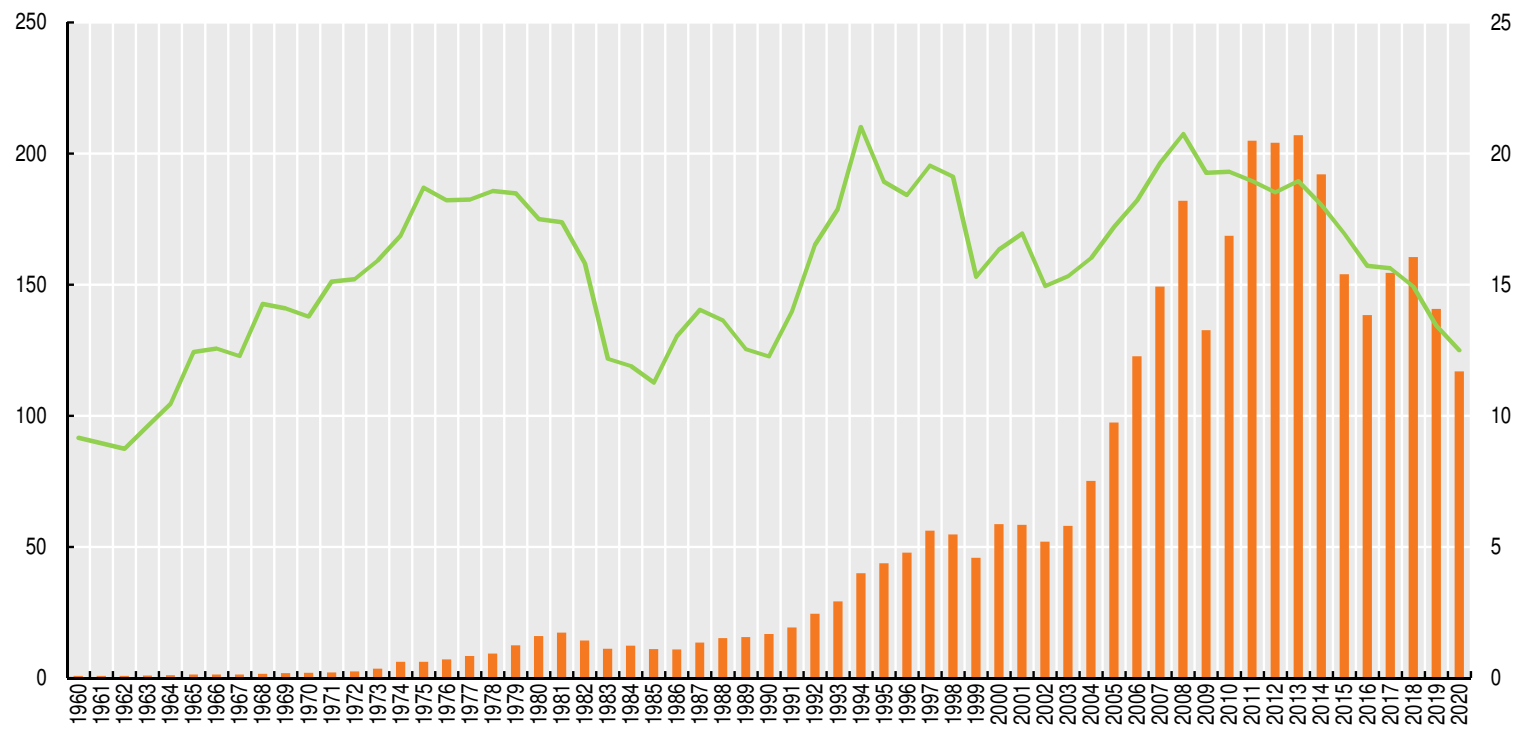

Fuente: CEPAL $\left(2021_{[12]}\right)$ Perspectivas del comercio internacional de América Latina y el Caribe, 2020 (LC/PUB.2020/21-P). StatLink 슈내 https://doi.org/10.1787/888934295204

La especialización sectorial y las estructuras productiva y empresarial de ALC no contribuyen a la integración regional. ALC no ha sido capaz de lograr ganancias de productividad a largo plazo que le permitan sostener un mayor crecimiento (Capítulo 1). ALC tiene una estructura productiva poco diversificada, concentrada en sectores de bajo valor añadido, y las exportaciones se concentran en bienes de bajo contenido tecnológico. En las dos últimas décadas, el $76 \%$ del crecimiento medio del PIB alcanzado en ALC se generó a través de la acumulación de empleo y solo el $24 \%$ a través del aumento de la 
productividad laboral. Este patrón contrasta con países como China, donde la contribución de la productividad es del 96\%, e India, donde es de casi el $80 \%$.

Las características de la estructura productiva de la región limitan las oportunidades y los incentivos para la innovación técnica y la diversificación. La integración internacional de la región se limita principalmente a un pequeño número de grandes empresas en sectores intensivos en recursos naturales, que ofrecen pocas oportunidades de participación en actividades de mayor valor añadido. Al mismo tiempo, abundan las micro, pequeñas y medianas empresas (mipymes) de baja productividad y desconectadas de los mercados internacionales. Con escasos incentivos para que esas mipymes inviertan en capacidades productivas o tecnológicas, la región sigue inmersa en una trampa de baja productividad y bajo valor añadido.

El contenido tecnológico de las exportaciones de ALC es generalmente bajo. Sin embargo, la proporción del contenido manufacturero en comparación con los productos primarios en el comercio intrarregional de ALC, es mayor que en el caso de las exportaciones al resto del mundo. En promedio, los productos industrializados representaron el 73\% de los flujos intrarregionales en 2018-20, pero solo el 63\% en el caso de las exportaciones extrarregionales (Gráfico 6). Estas cifras muestran el papel crucial que podría desempeñar el comercio intrarregional en la diversificación económica, el desarrollo de las capacidades manufactureras y la internacionalización de las pequeñas y medianas empresas (pymes).

\section{Gráfico 6. América Latina y el Caribe (principales mecanismos de integración): estructura sectorial de las exportaciones de bienes, 2018-2019}

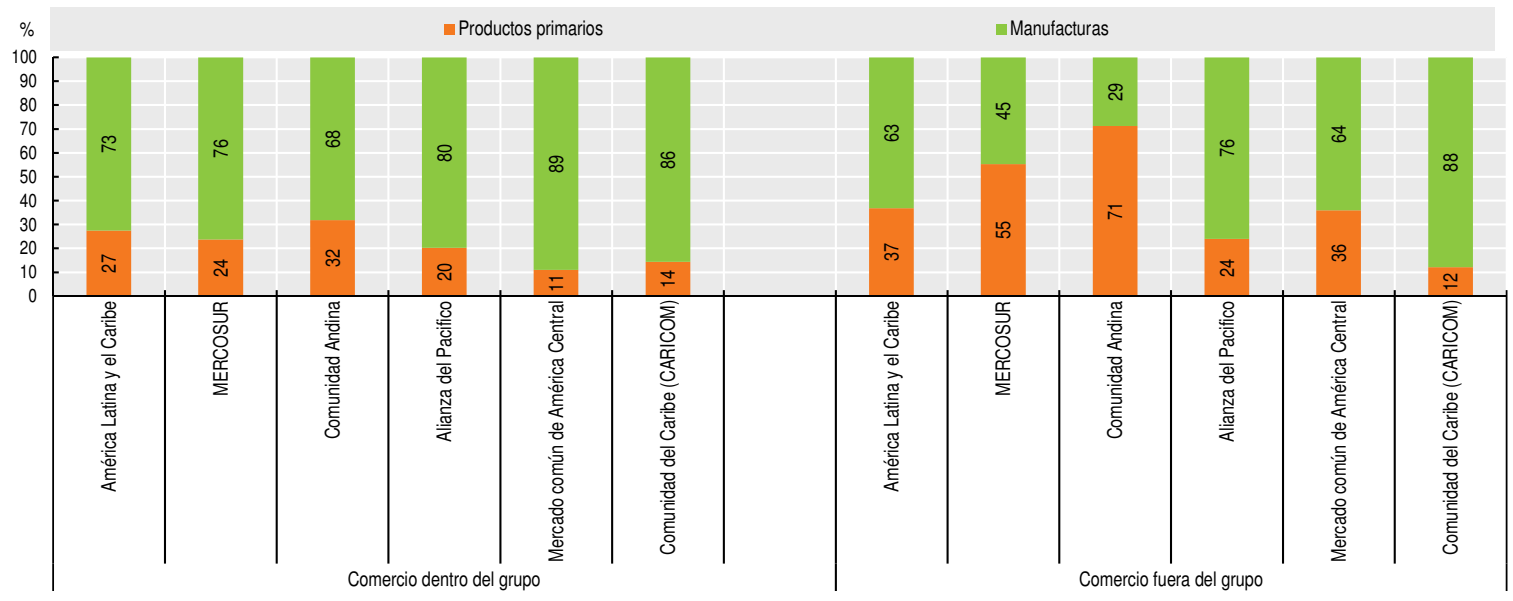

Fuente: Comisión Económica para América Latina y el Caribe (CEPAL) Base de datos de estadísticas de comercio de productos básicos de las Naciones Unidas (COMTRADE, siglas en inglés).

StatLink तillst https://doi.org/10.1787/888934295223

Un mercado único podría ser una forma de fomentar el desarrollo tecnológico en ALC. La transformación digital está generando cambios importantes para las empresas y la dinámica del mercado. Si bien la transformación digital presenta una oportunidad para abordar el persistente desafío de la baja productividad, también existe el riesgo de que se acentúen las disparidades de productividad según el tamaño de la empresa, que ya son considerables (OCDE, 2020 ${ }_{[13]}$ ).

La integración regional y las estrategias de políticas coordinadas serán fundamentales para garantizar la creación de oportunidades digitales que aumenten la productividad. A pesar de los avances en términos de conectividad, el ritmo de la transformación digital ha sido moderado. En promedio en ALC, la adopción digital en las empresas fue del 4.5\% 
entre 2014 y 2016, muy por debajo de los países altamente dinámicos del sudeste asiático (13.1\%) o China (16.4\%). Un mercado integrado sería económicamente beneficioso para la región. Por ejemplo, desde la creación de la estrategia de mercado único digital en la Unión Europea, su grado de digitalización creció más que el de otros países de la OCDE que no forman parte de este espacio.

En general, la región necesita un cambio estructural para superar las limitaciones impuestas por su actual modelo de desarrollo y aumentar el crecimiento de la productividad (CEPAL, 2020 ${ }_{[14]}$ ). La estructura productiva debe avanzar hacia sectores más intensivos en tecnología con mayores niveles de demanda y empleo cualificado. Esto debe lograrse preservando los recursos naturales, la biodiversidad y el medioambiente. Dado que los mercados no pueden impulsar por sí solos una transformación estructural sostenible, estos cambios exigen un conjunto coordinado de políticas tecnológicas, industriales, fiscales, financieras, medioambientales, sociales y regulatorias para promover la sostenibilidad. Cada país, dadas su estructura productiva y sus prioridades sociales, debe determinar las actividades y políticas para impulsar el cambio estructural progresivo y el gran impulso a la sostenibilidad (CEPAL, 2020 ${ }_{[14]}$ ).

Muchas estrategias de recuperación de la pandemia en la región asignaron recursos a sectores específicos para abordar las necesidades de desarrollo nacional o regional. La transformación de la estructura productiva y la combinación de inversiones con visión de futuro para sentar las bases de un gran impulso a la sostenibilidad en la región podrían centrarse en sectores con gran potencial, entre ellos el de la industria automotriz, el farmacéutico, las energías renovables, la economía circular y la agricultura sostenible.

\section{Se necesitan grandes consensos -un nuevo contrato social- para promover una nueva agenda de reformas que impulse la recuperación y ayude a superar los desafíos estructurales}

La desconfianza en los gobiernos y las exigencias de la ciudadanía por mayores niveles de democracia ya evidenciadas en la ola de protestas que ha sacudido a la región en los últimos años, continuan aumentando en un momento en el que la crisis del COVID-19 está poniendo a prueba la capacidad de resistencia de los países de ALC.

En 2020, solo el 38\% de la población de la región confiaba en su gobierno (Gallup, $2021_{[18]}$ ), más de la mitad de los ciudadanos creían que su gobierno no estaba luchando eficientemente contra la corrupción (Transparency International, 2019 ${ }_{[16]}$ ), y la mayoría de los países de ALC presentaban unos niveles de impunidad medios y altos en el Índice Global de Impunidad (CESIJ, 2020 ${ }_{[17]}$ ). La confianza en el gobierno siguió siendo muy inestable a medida que evolucionaba la crisis del COVID-19 y la satisfacción con los servicios públicos, incluidas la educación y la salud, disminuyó notablemente durante la pandemia. En 2020, en promedio, casi el 50\% de la población de ALC estaba insatisfecha con la educación pública y el 53\% con la atención sanitaria, en parte debido a los desafíos para garantizar la continuidad de los programas escolares durante los cierres, el aumento de la carga del cuidado de los niños durante el cierre de las escuelas y la falta de recursos para responder a la crisis sanitaria (Gráfico 7).

La concentración de poder ha sido otra fuente de insatisfacción, ya que el 73\% de los ciudadanos latinoamericanos cree que su país está gobernado en función de los intereses de unos pocos grupos de poder. La baja confianza interpersonal ha caracterizado a la región históricamente, con una notable tendencia decreciente desde 2011, alcanzando niveles especialmente bajos en 2020 (12\%) (Latinobarometro, $2021_{[15]}$ ). Por último, la identificación con una ideología política ha aumentado en los últimos años en ALC, mientras que la confianza en los partidos políticos ha disminuido. Los mecanismos tradicionales de 
representación no han logrado canalizar las crecientes y cambiantes demandas políticas, aumentando la frustración popular.

\section{Gráfico 7. La insatisfacción con los servicios públicos ha aumentado de forma constante en los últimos años y continuó creciendo durante la crisis del COVID-19}

Porcentaje de personas satisfechas con la calidad de la atención sanitaria y con el sistema educativo, promedio de ALC, 2006-2020

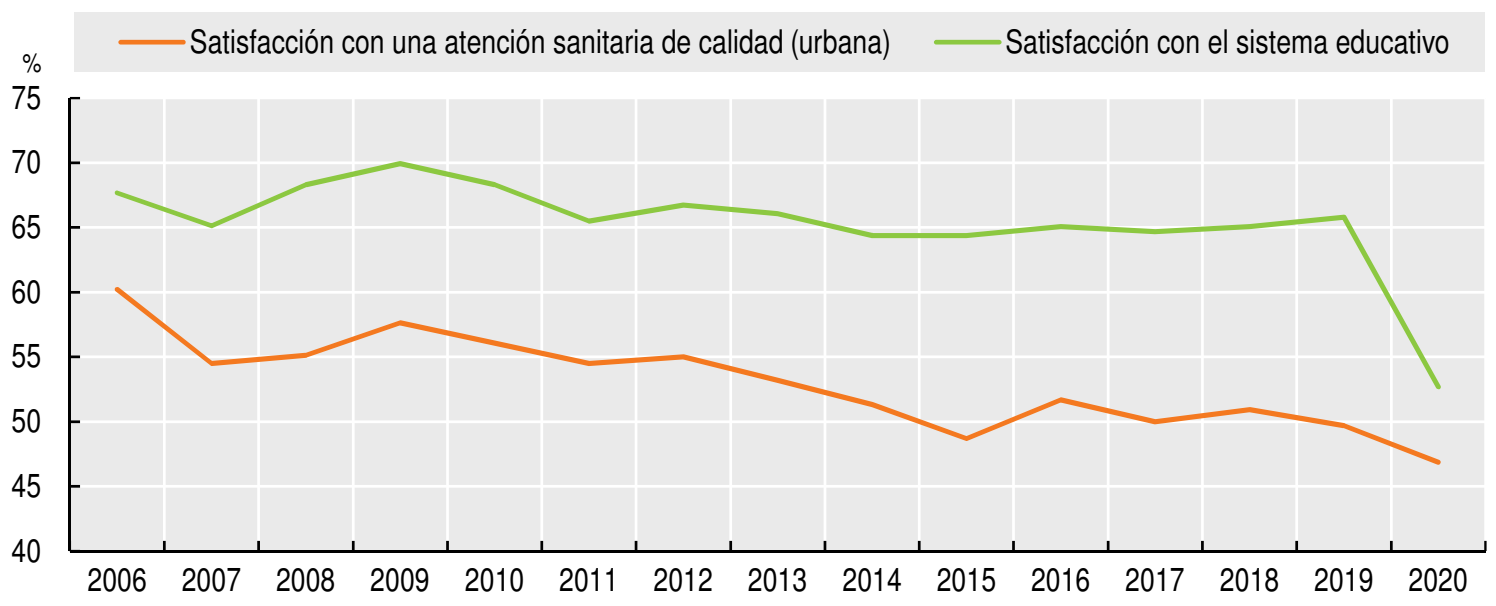

Notas: Promedio no ponderado de ALC que incluye 16 países. Faltan los datos de 2020 de Honduras y Panamá sobre la satisfacción con la atención sanitaria. Faltan los datos de 2020 de Guatemala, Honduras y Panamá sobre la satisfacción con el sistema educativo.

Fuente: Gallup (2021 $\left.{ }_{[18]}\right)$, Gallup World Poll (base de datos), https://ga.gallup.com.

StatLink :

Esta dinámica sugiere una profunda erosión del contrato social en la región. La pandemia del COVID-19 ha acentuado estas tendencias, al tiempo que ha llevado a la región a un punto de inflexión; sin un sólido consenso entre todos los actores de la sociedad, las reformas necesarias para impulsar la recuperación y superar las debilidades estructurales pendientes no llegarán a buen puerto. Por eso es necesario un nuevo contrato social. LEO 2021 adopta una definición amplia del contrato social, que se entiende como el acuerdo integral, intangible e implícito que une a la sociedad y que se enmarca dentro de un determinado conjunto de normas y prácticas formales e informales.

Los elementos básicos de un contrato social pospandémico deben girar en torno a dos dimensiones interconectadas. En primer lugar, debe ser un acuerdo transversal entre: i) grupos socioeconómicos; ii) territorios; y iii) generaciones. En segundo lugar, debe fomentar: i) sistemas de protección social más amplios y eficaces (Capítulo 2); ii) estrategias productivas resilientes y sostenibles que prioricen la creación de empleos verdes y de calidad e incluyan la transformación digital (Capítulo 3); y iii) un modelo más sostenible de financiamiento para un desarrollo con bajas emisiones de carbono (Capítulo 1). La intersección de estas dimensiones muestra áreas específicas donde alcanzar pactos sociales concretos que, en suma, conformarían un nuevo contrato social en su sentido más amplio (Tabla 1).

Avanzar hacia un nuevo contrato social puede conllevar un profundo replanteamiento de sus pilares fundacionales (p. ej., el actual proceso constituyente en Chile) o intentos más específicos de alcanzar un pacto inclusivo en áreas concretas de la recuperación (p. ej., fiscalidad, ecología y empleo). Cualquiera que sea la naturaleza del esfuerzo, una lección clave aprendida de las experiencias pasadas es que la atención al proceso en sí mismo es de suma importancia para construir un consenso que sea justo, legítimo y 
duradero, especialmente en un contexto de alto descontento y espacio fiscal reducido (Cabutto, Nieto-Parra y Vázquez-Zamora, 2021 $[19]$ ).

Tabla 1. Los elementos básicos del nuevo contrato social

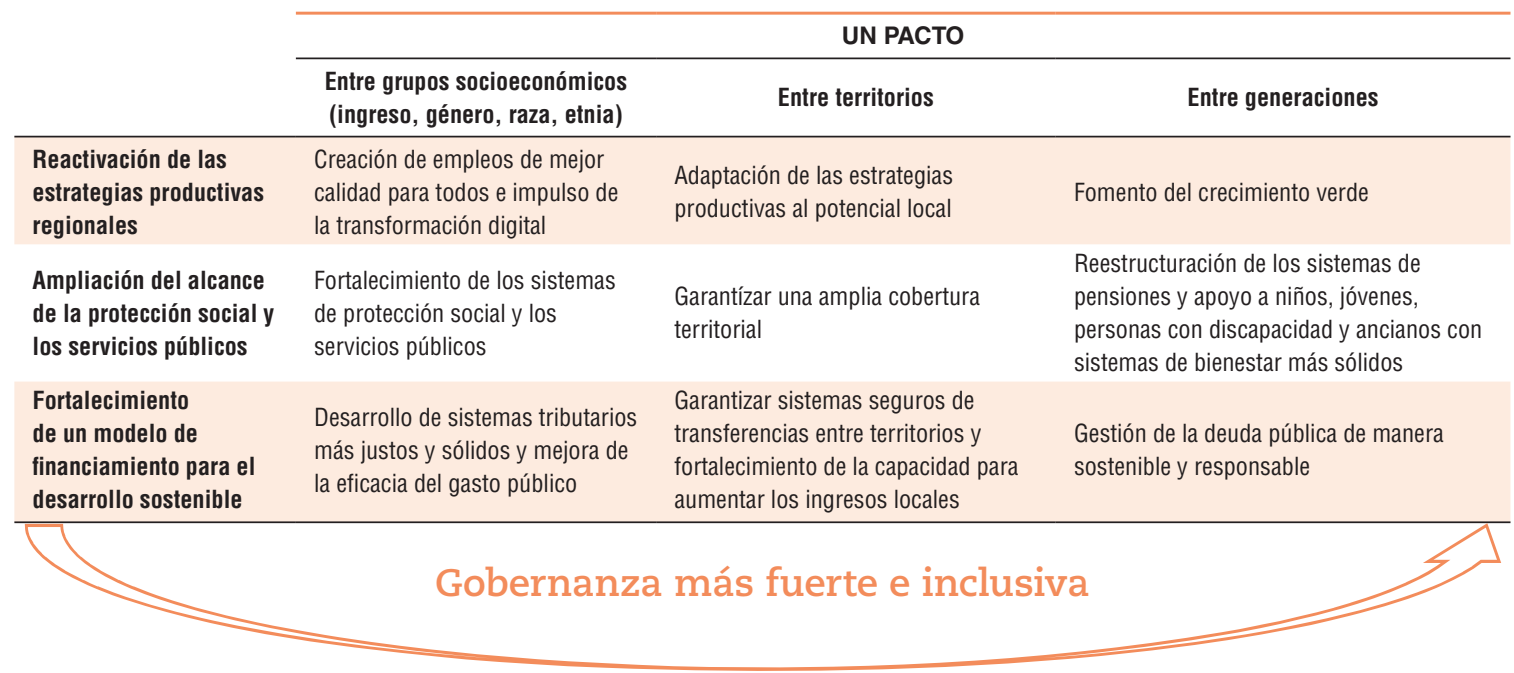

Nota: Elaboración propia.

Cuatro principios fundamentales deben contribuir a orientar el proceso de creación de consensos. Estos principios pueden resumirse en cuatro ces: conciliar, contextualizar, compensar y comunicar (pero no necesariamente en ese orden) (Cabutto, Nieto-Parra y Vázquez-Zamora, $\left.2021_{[19]}\right)$. En primer lugar, el proceso debe ser inclusivo. Esto significa conciliar diversos intereses y conseguir que todas las partes interesadas participen en el debate desde el principio. Un proceso inclusivo de formulación de políticas que aproveche las ideas y los recursos de las diversas partes puede aumentar la rendición de cuentas y la confianza, reducir las dudas sobre la influencia indebida, incrementar el compromiso político de todas las partes interesadas a lo largo del tiempo, generar reformas más sostenibles y aportar soluciones innovadoras a cuestiones complejas. En segundo lugar, el contexto es importante. Los procesos participativos también pueden malograrse si no están bien diseñados. Es importante evaluar aspectos del contexto sociopolítico que puedan generar riesgos u oportunidades para la estrategia (Naser, Williner y Sandoval, $\left.2021_{[20]}\right)$. En tercer lugar, es vital compensar a los posibles "perdedores". Las reformas pueden empeorar la situación antes de mejorarla y dejar a ciertos grupos vulnerables en peores condiciones. Es importante prever mecanismos de compensación claros para mitigar el posible impacto distributivo negativo de las reformas (Rodrik, 1996 ${ }_{[21]}$; OCDE, $\left.2010_{[22]}\right)$. En cuarto lugar, es esencial la comunicación relativa a la justificación y el posible impacto de las reformas. En un contexto de polarización de los discursos políticos y de aumento de la desinformación, el análisis con base empírica y la comunicación eficaz son aspectos clave para arrojar luz sobre los beneficios de las reformas. Las evaluaciones independientes ex ante y ex post son un factor importante para justificar las razones de las medidas adoptadas (Worley, Bryan Pasquier y Canpolat, $2018_{[23]}$ ).

La secuencia y el ritmo de estas medidas son factores esenciales para que las reformas sean un éxito, aunque ambas dimensiones dependen en gran medida de contextos específicos. Por ejemplo, en el caso de la política fiscal, la secuencia de las políticas en materia de gasto, tributación y gestión de la deuda pública es crucial para equilibrar las necesidades presupuestarias, así como para financiar las políticas de ayuda a los más vulnerables y garantizar un amplio apoyo a las reformas (Mora, Nieto-Parra y Orozco, 
$\left.2021_{[7]}\right)$. En general, el éxito de las reformas puede ayudar a que se aumente el apoyo a otras posteriores. Los responsables de la formulación de políticas pueden preferir agrupar las reformas en un paquete integral para compensar las pérdidas derivadas de una reforma con los efectos positivos de otras (Dayton-Johnson, Londoño y Nieto-Parra, $2011_{[24]}$ ), o, si esto no es posible, pueden preferir lograr acuerdos específicos en ámbitos en los que exista posibilidad de consenso.

Por último, para lograr el consenso y mantenerlo en el tiempo, es fundamental contar con instituciones intermedias eficaces para garantizar la sostenibilidad a largo plazo de un nuevo contrato social. Al actuar como interlocutores entre los ciudadanos y el Estado, esas instituciones intermedias, como los partidos políticos, los sindicatos y las asociaciones, favorecen una mayor rendición de cuentas de las instituciones públicas y ofrecen a los ciudadanos la oportunidad de expresar sus quejas (OCDE, 2021 ${ }_{[25]}$ ). Este diálogo bidireccional puede promover la cohesión social y proporcionar observaciones útiles durante la fase de implementación y posible ajuste de las reformas. El fortalecimiento de la colaboración de las instituciones públicas con estos organismos intermedios es un ámbito de relevancia para fortalecer la legitimidad y la inclusividad en los procesos de formulación de políticas (Cabutto, Nieto-Parra y Vázquez-Zamora, 2021 ${ }_{[19]}$ ).

\section{Cooperación internacional para la recuperación: facilitando un nuevo contrato social en ALC}

La oportunidad de un nuevo contrato social en ALC para superar la crisis implica pasar del actual statu quo fragmentado a un nuevo equilibrio basado en la igualdad de oportunidades a largo plazo. Dado el aumento del descontento social y de la interconexión entre la dinámica del desarrollo nacional y las megatendencias mundiales, la cooperación internacional se ha convertido en una herramienta esencial de apoyo a la región, al contribuir a construir nuevos modelos de desarrollo. El actual círculo vicioso entre las dinámicas de desarrollo global y nacional en ALC exige una mayor consolidación del marco de Desarrollo en Transición (DiT) - propuesto en el LEO 2019 - y que la cooperación internacional asuma un papel facilitador para apoyar a los países de ALC a superar las trampas de desarrollo - institucionales, de productividad, sociales y ambientales - y fortalecer el desarrollo inclusivo y sostenible de la región.

Aunque durante la crisis surgieron prácticas innovadoras en materia de cooperación internacional, las deficiencias estructurales en el apoyo a la región se mantuvieron. A pesar de los esfuerzos - la ayuda oficial al desarrollo alcanzó su máximo histórico en 2020 -, los actuales mecanismos financieros internacionales han resultado insuficientes, especialmente para los países de ingresos medios, que constituyen la mayoría de los de ALC. La cooperación con la región y dentro de ella ofrece ejemplos innovadores de cooperación técnica, Sur-Sur, triangular e incluso Sur-Norte que tuvieron lugar en la región a lo largo de la crisis. Se hicieron propuestas transformadoras concretas, avanzando en un enfoque DiT, por ejemplo, el Fondo para Aliviar la Economía COVID-19 (FACE) propuesto por Costa Rica y el nuevo esquema "Equipo Europa" (Team Europe) coordinado por la Unión Europea.

De cara al futuro, una cooperación internacional que facilite un nuevo contrato social en ALC y permita un círculo virtuoso entre las dinámicas de desarrollo nacionales e internacionales, requiere: i) alianzas basadas en propósitos claros que den prioridad a una cooperación entre iguales, con estrategias participativas y coherencia de politicas; ii) una cooperación regional que refuerce la voz de la región en el mundo; y iii) un uso equilibrado de herramientas, incluyendo la financiación sostenible, normas y estándares globales, y la cooperación técnica para el desarrollo de capacidades; todo lo cual debe respaldarse en diálogos de políticas internacionales más sólidos. 
Estas alianzas internacionales implican ir más allá de áreas e instituciones tradicionales para abarcar todos los recursos, herramientas y actores relevantes. Con un plazo y un objetivo predeterminado, las alianzas enfocadas en las metas podrían ofrecer mejores incentivos para lograr resultados de desarrollo cuantificables. Asimismo, podrían impulsar la experimentación de nuevas formas de incorporar a los ciudadanos a la conceptualización y ejecución de la cooperación internacional. La participación activa de grupos representativos de la sociedad civil, el sector privado, los gobiernos sub-nacionales y el mundo académico en el proceso de establecimiento de la agenda politizaría positivamente y aumentaría la legitimidad de su objetivo, convirtiéndola en una oportunidad para conectar más estrechamente la gobernanza mundial con las preocupaciones cotidianas de los ciudadanos. Por último, estas nuevas alianzas internacionales harían especial énfasis en abordar la incoherencia de las políticas, ya sea entre los objetivos nacionales e internacionales, o entre los objetivos políticos.

\section{Gráfico 8. El círculo vicioso entre las dinámicas de desarrollo global y nacional en ALC}

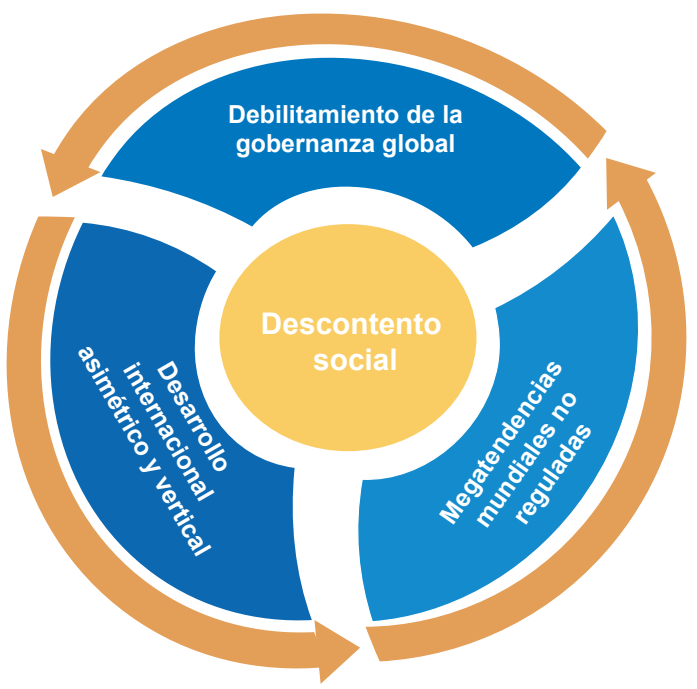

Fuente: Elaboración propia.

La cooperación y la integración regionales serán elementos claves en este proceso. Las iniciativas regionales pueden desempeñar un papel fundamental apoyando los esfuerzos nacionales para avanzar hacia nuevos modelos de desarrollo para la recuperación, adoptar mega-tendencias (p. ej., la transformación digital) como herramientas para la recuperación y crear resiliencia frente a futuras crisis. La región es un espacio único en el que los Estados que se enfrentan a retos similares pueden compartir las mejores prácticas y orientaciones sobre cómo diseñar políticas, y comparar los resultados. La colaboración en toda la región también puede ayudar a formar una visión regional de las acciones a implementar para hacer frente a los desafíos regionales y globales. ALC podría hacer un balance de otras iniciativas regionales, como el presupuesto a largo plazo de la Unión Europea, la Agenda 2063 de la Unión Africana y el Marco Integral de Recuperación de la Asociación de Naciones del Sudeste Asiático, para amplificar una voz común en el sistema multilateral e impulsar acciones políticas más transformadoras en toda la región a largo plazo mediante agendas de desarrollo compartidas. ALC tiene mucho que aprender de su propia experiencia regional, desde el Sistema de Integración Centroamericana hasta la más reciente experiencia participativa, apoyada por la Comisión Económica de las Naciones Unidas para América Latina y el Caribe, que condujo a la firma del Acuerdo de Escazú. 
Un uso equilibrado de los instrumentos de cooperación internacional, respaldado por el fortalecimiento de los diálogos de políticas internacionales, también es crucial para la recuperación de ALC. En primer lugar, debería ser prioritaria una solución coordinada para gestionar el reto de la deuda, especialmente teniendo en cuenta las inversiones que deben realizarse a medio y largo plazo para recuperarse y alcanzar los ODS. También deberían ser prioritarios los mecanismos de financiación innovadores, incluida la mejora de la participación del sector privado. En segundo lugar, el carácter transfronterizo de los grandes desafíos del desarrollo no solo exige mejores capacidades nacionales, sino que requiere igualmente, o incluso más, acuerdos multilaterales sobre reglas y estándares compartidos que reduzcan la desigualdad global y promuevan la coherencia de políticas. Por último, los esfuerzos de cooperación internacional deberían hacer especial énfasis en la transferencia de capacidades y el intercambio de opciones de políticas innovadoras para revitalizar las estrategias productivas regionales, ampliar el alcance de la protección social o garantizar la sostenibilidad del medioambiente.

Tabla 2. Enfoques integrados para que la cooperación internacional facilite un nuevo contrato social en ALC

\begin{tabular}{|c|c|c|c|}
\hline & $\begin{array}{l}\text { Integración de la sostenibilidad } \\
\text { medioambiental }\end{array}$ & $\begin{array}{l}\text { Ampliar el alcance de la protección social } \\
\qquad y \text { los servicios públicos }\end{array}$ & $\begin{array}{l}\text { Reforzar las estrategias } \\
\text { productivas regionales }\end{array}$ \\
\hline $\begin{array}{l}\text { Financiación } \\
\text { sostenible }\end{array}$ & $\begin{array}{l}\text { Integrar la sostenibilidad } \\
\text { medioambiental en todos los } \\
\text { instrumentos de financiación. }\end{array}$ & $\begin{array}{l}\text { Garantizar que los planes de reembolso de la deuda no } \\
\text { comprometan la ampliación del alcance de la protección } \\
\text { social y la prestación de servicios públicos }\end{array}$ & $\begin{array}{l}\text { Garantizar una financiación } \\
\text { pública y privada suficiente para } \\
\text { la producción estratégica. }\end{array}$ \\
\hline $\begin{array}{l}\text { Reglas y } \\
\text { estándares } \\
\text { globales }\end{array}$ & $\begin{array}{l}\text { Adoptar reglamentos y estándares } \\
\text { ambientales, siguiendo el principio de } \\
\text { responsabilidades compartidas, pero } \\
\text { diferenciadas. }\end{array}$ & $\begin{array}{l}\text { Adoptar una normativa internacional para la } \\
\text { transferencia transfronteriza de las cotizaciones a la } \\
\text { seguridad social y un tipo impositivo global para las } \\
\text { empresas. Acordar estándares internacionales de } \\
\text { protección social, trabajo justo, fiscalidad, migración } \\
\text { internacional, etc. }\end{array}$ & $\begin{array}{l}\text { Acordar y aplicar estándares } \\
\text { que favorezcan la diversificación } \\
\text { productiva de ALC. }\end{array}$ \\
\hline $\begin{array}{l}\text { Cooperación } \\
\text { técnica } \\
\text { para el } \\
\text { desarrollo de } \\
\text { capacidades }\end{array}$ & $\begin{array}{l}\text { Proporcionar cooperación técnica } \\
\text { sobre prácticas de sostenibilidad, } \\
\text { investigación y conocimientos; } \\
\text { promover diálogos de políticas } \\
\text { centrados en la sostenibilidad } \\
\text { ambiental. }\end{array}$ & $\begin{array}{l}\text { Intercambiar experiencias de políticas en materia de } \\
\text { protección social y prestación de servicios públicos; } \\
\text { fomentar el desarrollo de capacidades en las } \\
\text { instituciones públicas, entre otras cosas, mejorando la } \\
\text { comprensión de las interconexiones entre las estrategias } \\
\text { nacionales de desarrollo y la dinámica mundial. }\end{array}$ & $\begin{array}{l}\text { Transferir conocimientos y } \\
\text { tecnología para aumentar la } \\
\text { productividad; impulsar el } \\
\text { diálogo político a nivel regional } \\
\text { y global para fomentar las } \\
\text { cadenas de valor regionales. }\end{array}$ \\
\hline
\end{tabular}

Fuente: Elaboración propia.

La transformación continua de la cooperación internacional es esencial para alcanzar todo el potencial de un nuevo contrato social en la región, alinearlo con los acuerdos globales e involucrar a ALC en la gobernanza de las tendencias globales a través de una cooperación multilateral efectiva. ALC es un terreno fértil para fortalecer y experimentar nuevas formas de multilateralismo impulsando el diálogo de políticas dentro y fuera de la región, a través de alianzas políticas internacionales en igualdad de condiciones que den prioridad a las personas y a las políticas. La apremiante necesidad de adaptar la cooperación internacional para que contribuya de forma significativa a la recuperación mediante la construcción de nuevos modelos de desarrollo en la región debería traducirse en un urgente llamado global a la acción. 


\section{Referencias}

Basto-Aguirre, Nieto-Parra y Vázquez-Zamora (2020), "Informality in Latin America in the post COVID-19 era: towards a more formal "new normal"?", http://vox.lacea.org/?q=blog/ informality latam_postcovid19.

Bianchi y Lara (2021), "Gobernanza regional 3M : hacia una convergencia del multilateralismo en América", https://opendocs.ids.ac.uk/opendocs/bitstream/handle/20.500.12413/16775/ Colabora.Lat_Working_Paper_1.pdf? sequence $=2$.

Cabutto, C., S. Nieto-Parra y J. Vázquez-Zamora (2021), "A post-pandemic social contract for Latin America: the why, the what, the how", Vox Lacea (blog), http://vox.lacea.org/?q=blog/social contract latam.

CAF (2020), ECAF 2019. Percepciones de los Latinoamericanos sobre los Sistemas de Pensiones, Salud y Cuidados y el Avance Tecnológico en el Mercado Laboral, http://scioteca.caf.com/handle/123456789/1646. [10]

CEPAL (2021), Panorama Fiscal de América Latina y el Caribe 2021: los desafíos de la política fiscal en la recuperación transformadora pos-COVID-19, Publicación de las Naciones Unidas, Santiago, https://www.cepal.org/es/publicaciones/46808-panorama-fiscal-america-latina-caribe-2021desafios-la-politica-fiscal-la.

CEPAL (2021), Perspectivas del Comercio Internacional de América Latina y el Caribe, Publicación de las Naciones Unidas, Santiago, https://www.cepal.org/es/publicaciones/pci.

CEPAL (2020), Construir un nuevo futuro: una recuperación transformadora con igualdad y sostenibilidad, Publicación de las Naciones Unidas, Santiago, https://www.cepal.org/es/publicaciones/46225construir-un-nuevo-futuro-recuperacion-transformadora-igualdad-sostenibilidad.

CESIJ (2020), Global Impunity Index 2020 (GII-2020), Center of Studies on Impunity and Justice, UDLAP Jenkins Graduate School, Universidad de las Américas Puebla, Puebla, México, http://www. udlap.mx/cesij.

Dayton-Johnson, J., J. Londoño y S. Nieto-Parra (2011), “The Process of Reform in Latin America: A Review Essay", OECD Development Centre Working Papers 304, pp. 1-60, https://dx.doi.org/10.1787/ 5kg3mkvfcjxv-en.

FMI (2021), World Economic Outlook, Base de datos de abril, https://www.imf.org/en/Publications/ WEO/weo-database/2021/April.

Gallup (2021), Gallup World Poll (base de datos), Gallup Inc., Washington, DC, https://ga.gallup.com. [18]

Latinobarometro (2021), Encuesta Latinobarómetro 2020 (base de datos), Latinobarómetro, Santiago, http://www.latinobarometro.org/latOnline.jsp.

Mora, S., S. Nieto-Parra y R. Orozco (2021), Fiscal policy to drive the recovery in Latin America: the "when" and "how" are key, http://lacea.org/vox/?q=blog/fiscal_policy_latam.

Naser, A., A. Williner y C. Sandoval (2021), Participación ciudadana en los asuntos públicos: Un elemento estratégico para la Agenda 2030 y el gobierno abierto, Publicación de las Naciones Unidas, CEPAL, https://repositorio.cepal.org/bitstream/handle/11362/46645/1/S2000907_es.pdf.

OCDE (2021), Perspectives on Global Development 2021: From Protest to Progress?, Publicaciones de la OCDE, París, https://doi.org/10.1787/405e4c32-en.

OCDE (2020), COVID-19 in Latin America and the Caribbean: Regional Socio-Economic Implications and Policy Priorities, Publicaciones de la OCDE, París, https://www.oecd.org/coronavirus/policy-responses/ covid-19-in-latin-america-and-the-caribbean-regional-socio-economic-implications-andpolicy-priorities-93a64fde/.

OCDE et al. (2020), Perspectivas económicas de América Latina 2020: Transformación digital para una mejor reconstrucción, Publicaciones de la OCDE, París, https://dx.doi.org/10.1787/e6e864fb-en.

OCDE (2010), Making Reform Happen: Lessons from OECD Countries, Publicacioes de la OCDE, París, https://doi.org/10.1787/9789264086296-en.

OCDE (Próximo a publicarse), Labour informality and households' vulnerabilities in Latin America [Título provisional], Publicaciones de la OCDE, París.

OCDE/OIT (2019), Tackling Vulnerability in the Informal Economy, Development Centre Studies, Publicaciones de la OCDE, París, https://doi.org/10.1787/939b7bcd-en.

OCDE (2020), OECD’s COVID-19 Country Policy Tracker, Publicaciones de la OCDE, París, https://www. oecd.org/coronavirus/country-policy-tracker/.

OCDE et al. (2019), Perspectivas económicas de América Latina 2019: Desarrollo en transición, Publicaciones de la OCDE, París, https://doi.org/10.1787/g2g9ff1a-es. 
OIT (2018), Mujeres y hombres en la economía informal: Un panorama estadístico. Tercera edición, Organización Internacional del Trabajo, Ginebra, https://www.ilo.org/global/publications/ books/WCMS 635149/lang--es/index.htm.

OIT/BID (2020), Jobs in a net zero emissions future in Latin America and the Caribbean, Organización Internacional del Trabajo, Ginebra, Suiza/Banco Interamericano de Desarrollo, Nueva York, http://www.ilo.org/americas/publicaciones/WCMS 752069/lang--en/index.htm.

Rodrik, D. (1996), "Understanding Economic Policy Reform”, Journal of Economic Literature, Vol. 34/1, pp. 9-41, https://www.jstor.org/stable/2729408.

Transparency International (2019), Global Corruption Barometer Latin America and the Caribbean 2019: Citizen's views and experiences of corruption, Transparency International, Berlín, https://images.transparencycdn.org/images/2019_GCB_LatinAmerica_Caribbean_Full Report_200409_091428.pdf.

UNESCO (2020), Seguimiento mundial de los cierres de escuelas causados por el COVID-19, https://es.unesco.org/covid19/educationresponse\#schoolclosures.

UNICEF (2021), COVID-19 and school closures: One year of education disruption, UNICEF, Nueva York, https://data.unicef.org/wp-content/uploads/2021/03/COVID19-and-school-closures.pdf. [8]

Worley, H., S. Bryan Pasquier y E. Canpolat (2018), Designing Communication Campaigns for Energy Subsidy Reform, ESRAF Good Practice Note 10, Documento ESMAP, Banco Mundial, Washington, DC. 



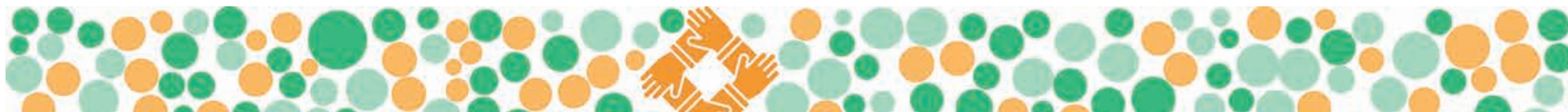
:00 O.

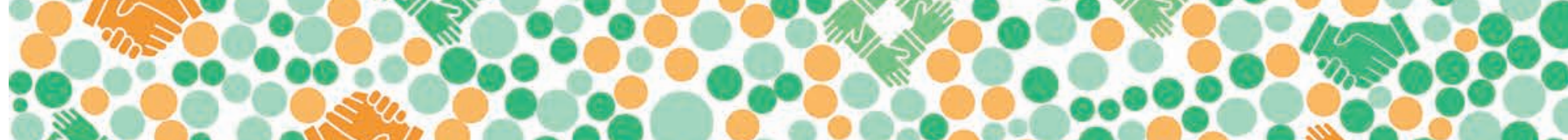

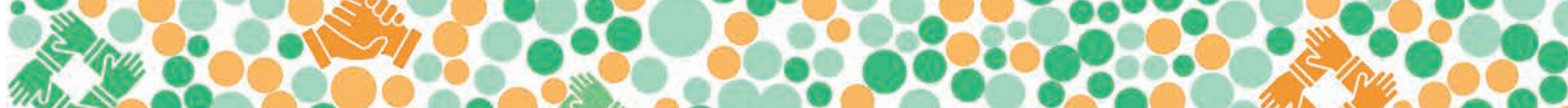

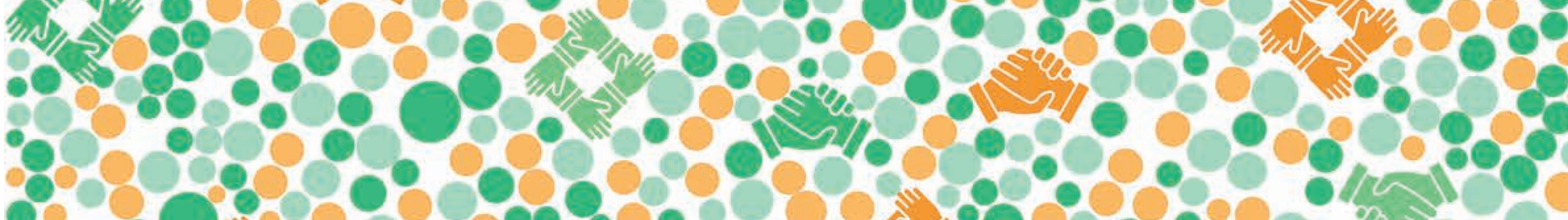

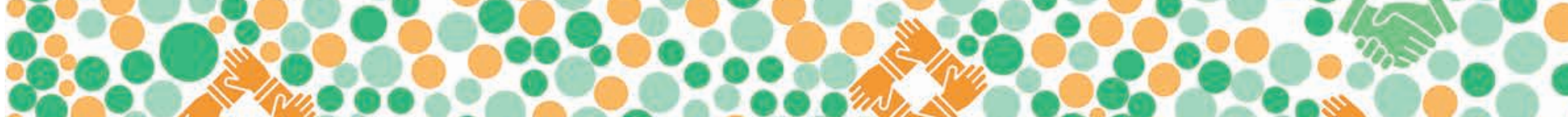

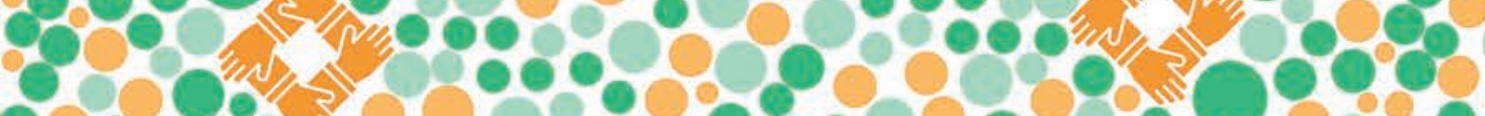

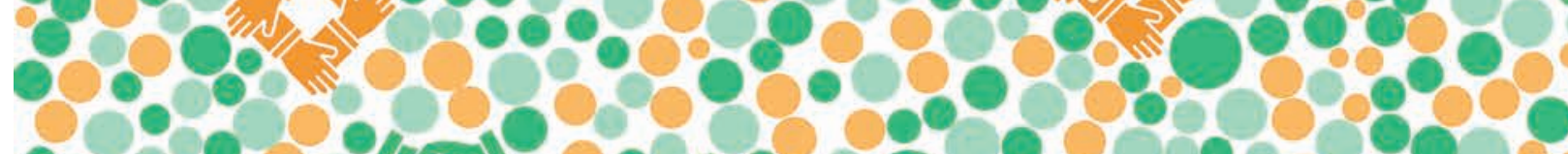
:36\%

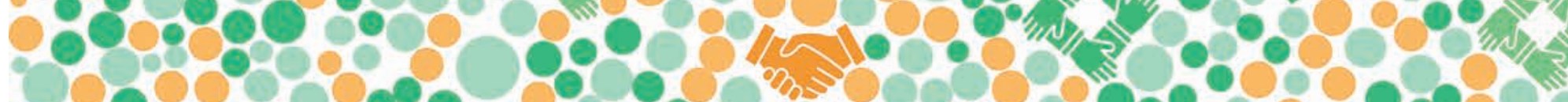
00000000000000000 :0\%

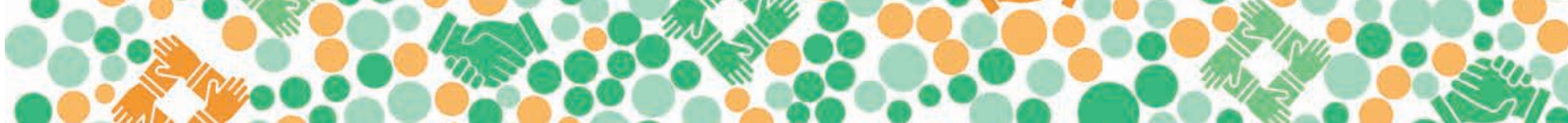

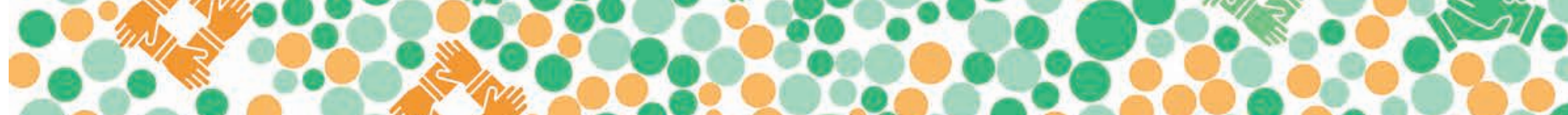

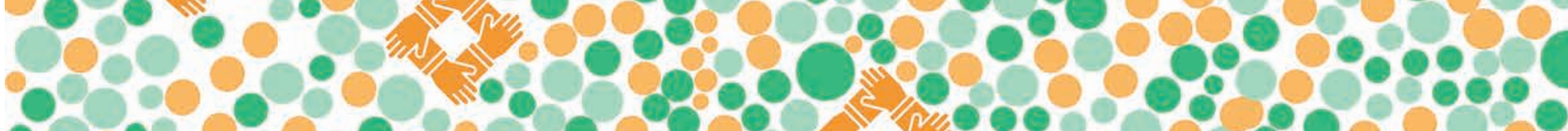

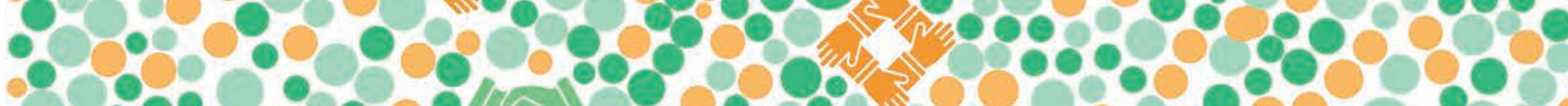

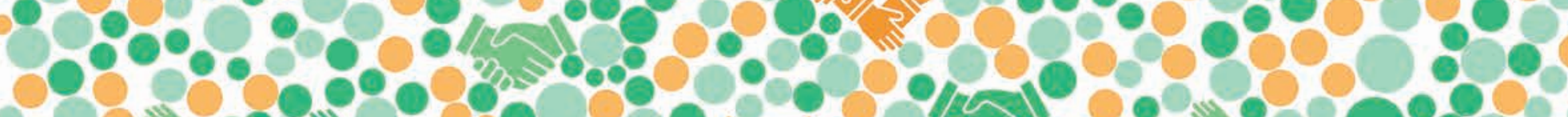
200 30003

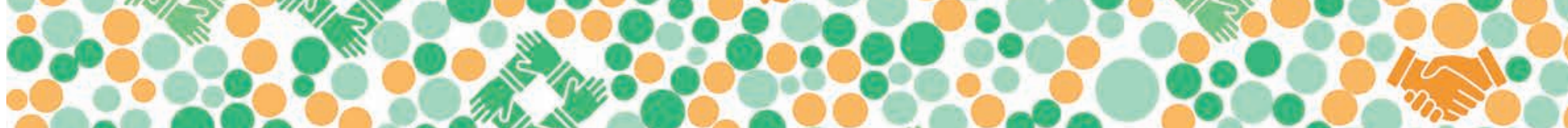
:080 0.000. 8.

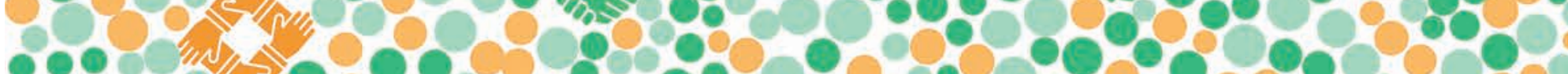

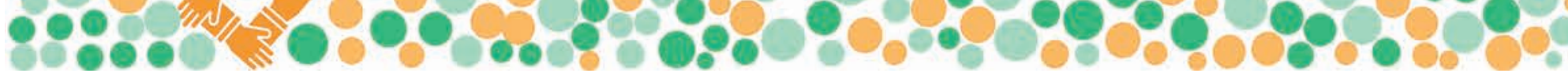




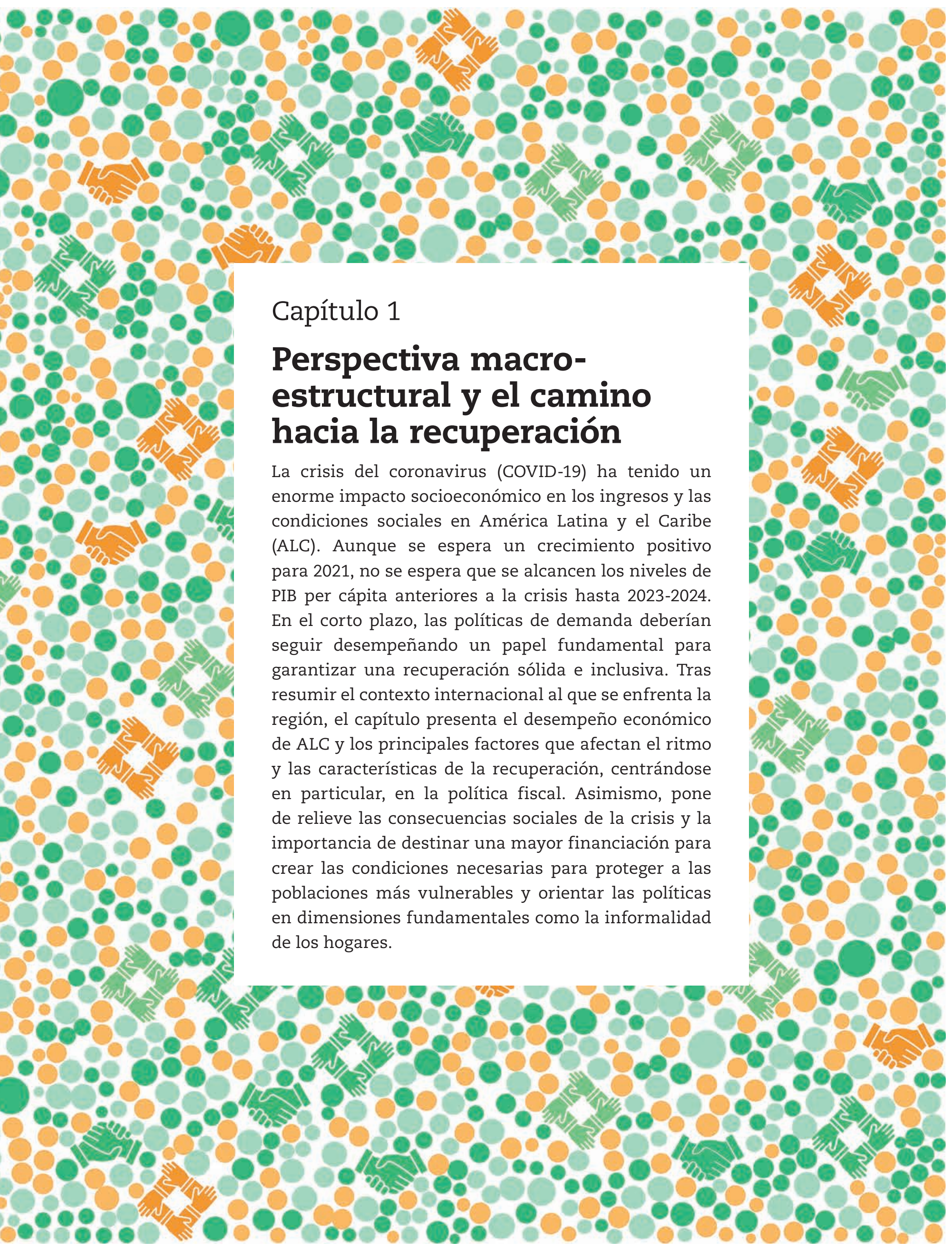




\section{Los efectos de la crisis del COVID-19 en América Latina y el Caribe}

En la región de ALC, el año 2020 terminó con la mayor recesión económica de los últimos dos siglos debido a la crisis del COVID-19...

... ubicando a las tasas de crecimiento anual del PIB

alrededor del -7.0\%.

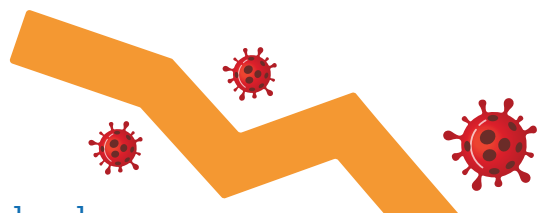

La crisis ha afectado algunos los progresos de la última década en erradicación de la pobreza $\mathrm{y}$ desigualdad

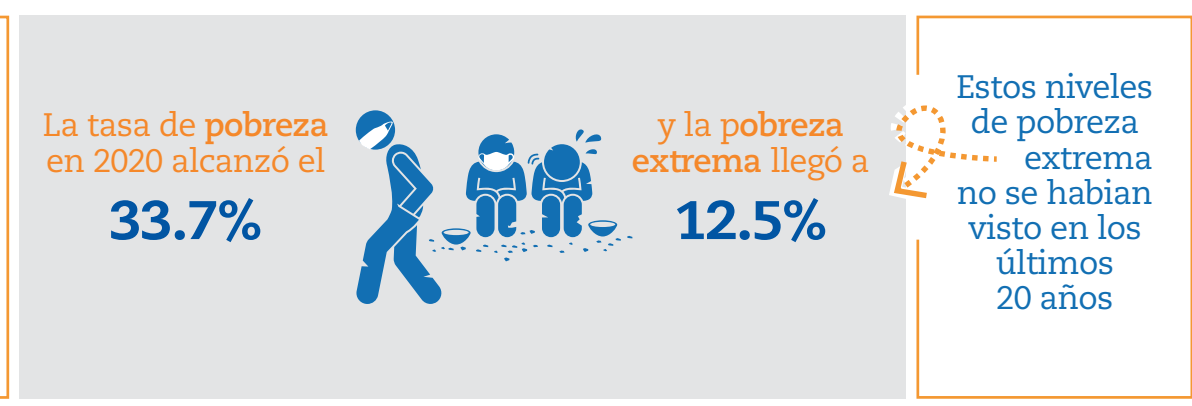

Los hogares informales son los más afectados por la crisis del COVID-19, enfrentando pérdidas de empleo y de ingresos laborales

La región no alcanzará los niveles de PIB per cápita anteriores a la pandemia hasta 2023-24

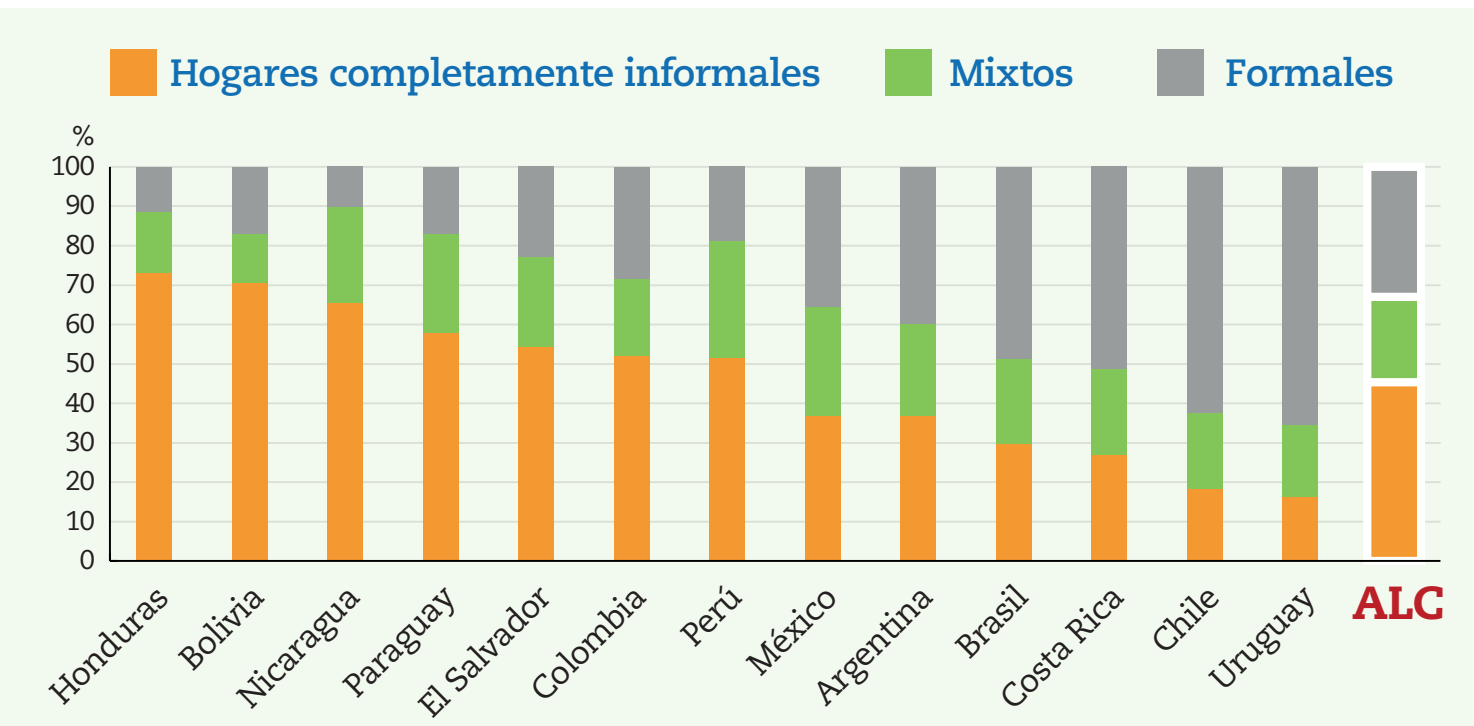




\section{Introducción}

Como consecuencia de la pandemia de coronavirus (COVID-19), América Latina y el Caribe (ALC) cerró el año 2020 con la mayor desaceleración económica de los últimos dos siglos, situando el crecimiento anualizado del producto interno bruto (PIB) en tasas alrededor del $-7.0 \%$ (CEPAL, 2021 $1_{[1]}$ ) (CAF, 2021 $1_{[2]}$ ), con daños inmediatos en el tejido económico y social y posibles cicatrices a largo plazo. Los costos sociales son drásticos en términos de desigualdades y pobreza, ya que el impacto de la crisis del COVID-19 ha afectado especialmente a los grupos más vulnerables.

Las economías de ALC deberían recuperar algo de terreno en 2021, pero sigue existiendo incertidumbre respecto a la fuerza de la recuperación. Esta será probablemente prolongada y se explica principalmente por un efecto de arrastre estadístico que se moderará en 2022, asimismo se espera que sea heterogénea tanto entre países como dentro de ellos.

Las principales amenazas para la recuperación son el aumento de los contagios y la lentitud en la vacunación, que retrasa la normalización de la actividad económica. Entre los posibles aspectos positivos cabe destacar un incremento de la demanda mundial mayor del esperado gracias a la recuperación más sólida de socios esenciales de la región, como la República Popular China (en lo sucesivo, "China") y los Estados Unidos. Del mismo modo, aunque los motores impulsores del crecimiento tendrán efectos distintos en cada país, se prevé que, en promedio, el PIB volverá a los niveles anteriores a la crisis en 2023-2024.

En el plano internacional, el aumento del precio de algunos productos básicos, la recuperación del comercio mundial y la producción industrial deberían ser favorables para las exportaciones de ALC. No obstante, la disminución del comercio exterior en la región durante 2020 tuvo graves repercusiones para la economía y puso de relieve las fragmentaciones comerciales existentes, sobre todo en lo que respecta al comercio intrarregional. Para favorecer una recuperación sólida y más inclusiva, y, al mismo tiempo, mejorar la competitividad y garantizar la protección frente a futuras perturbaciones exógenas, será crucial apoyar una mayor integración, dentro y fuera de ALC (Capítulo 3) (CEPAL, 2021 $1_{[3]}$ ). Las políticas comerciales orientadas al desarrollo, unidas a políticas relativas a la competencia y los consumidores, también serán fundamentales en la recuperación y deberían contribuir al logro de la Agenda 2030 de las Naciones Unidas para el Desarrollo Sostenible, así como a una constante resiliencia económica (UNCTAD, $\left.2020_{[4]}\right)$.

Si bien en 2020 los gobiernos de ALC, al igual que los de otras economías emergentes y en desarrollo, pudieron acceder a mercados de capitales con condiciones de financiación favorables (OCDE, 2021 ${ }_{[5]}$ ), sigue habiendo incertidumbre en cuanto a las condiciones de liquidez internacional. Además, algunos países no han tenido acceso a los mercados de capitales globales, por lo que dependen en gran medida de los bancos multilaterales y de los acreedores públicos para financiar su recuperación.

A escala regional, los responsables de política en ALC se enfrentan a dificultades para apoyar la demanda interna. Los países de la región deben superar la crisis sanitaria en una carrera entre los nuevos contagios y el suministro de la vacuna. Cuanto más se tarde en alcanzar la inmunidad colectiva mediante la vacunación, más probable será que la economía sufra daños permanentes.

La política fiscal será esencial para garantizar una recuperación fuerte e inclusiva, pero debe hacerse efectiva de manera integral y escalonada. El uso de políticas tributarias y de gastos y el diseño de reformas fiscales, que incluyan medidas como el fortalecimiento de la administración tributaria, deben coordinarse y escalonarse para contrarrestar el 
impacto de la pandemia en los hogares y las empresas y apoyar los sistemas de salud pública. Por otro lado, cada vez es más necesario adoptar un enfoque holístico en términos de política fiscal que tenga en cuenta la economía política de la reforma, la moral tributaria y las complejas condiciones socioeconómicas resultantes de la crisis. El uso adecuado de los recursos fiscales podría aumentar el nivel de satisfacción con los servicios públicos, incrementar la moral tributaria, reforzar la confianza y ayudar a salir de la "trampa institucional" en la que está inmersa la región (OCDE et al., 2019 ${ }_{[6]}$ ).

Asimismo, los gobiernos deben maniobrar entre mantener un estímulo fiscal para cimentar la recuperación y evitar posiciones fiscales insostenibles. La retirada temprana del estímulo fiscal podría descarrilar la recuperación y mermar el crecimiento a largo plazo. La política fiscal, por lo tanto, es crucial para mitigar las consecuencias inmediatas de la crisis, pero también para evitar que la economía quede marcada de forma permanente. También es fundamental para diseñar y financiar medidas dirigidas a los hogares y empresas más vulnerables. La estabilidad macroeconómica sigue siendo altamente heterogénea entre los distintos países de ALC; ello implica que el margen de maniobra es más limitado para los países muy endeudados o en los que el anclaje de la inflación es cada vez más difícil. Por este motivo, es necesario adaptar las políticas macroeconómicas a la realidad de cada país en las fases de gasto, tributación y gestión de la deuda. Algunas de estas medidas requieren una mayor cooperación y coordinación a escala internacional (Capítulo 5).

Este capítulo examina, en primer lugar, el contexto global, con especial atención a los principales socios de la región y a los mercados financieros y de productos básicos. En segundo lugar, presenta el desempeño económico de ALC, poniendo enfasis en la heterogeneidad de la región, sus cuentas externas y la necesidad de sustentar la recuperación en políticas de apoyo a la demanda. En tercer lugar, centra la atención en el papel esencial que desempeña la política fiscal de cara a la recuperación y en la necesidad de generar consensos y escalonar las medidas fiscales de un modo favorable. En cuarto lugar, hace hincapié en las consecuencias sociales de la crisis, en las condiciones subyacentes de la informalidad y en la necesidad de financiar los sistemas de protección. El capítulo concluye con los principales mensajes en materia de políticas públicas.

\section{Un contexto internacional desafiante}

\section{La recuperación mundial es gradual y desigual}

La recuperación económica global está en marcha, pero sigue dependiendo de la vacunación. En 2020, la actividad económica se contrajo drásticamente en todo el mundo, y el PIB global cayó un 3.4\% (OCDE, 2021 $1_{[7]}$ ). En 2021, gracias al suministro gradual de vacunas efectivas, la prestación de apoyo fiscal adicional y la adopción de medidas acertadas en la mayoría de los países para hacer frente al virus, las perspectivas económicas han mejorado notablemente y se prevé que el PIB mundial crecerá un 5.7\% en 2021 y un $4.5 \%$ en 2022. La producción mundial ha superado el nivel anterior a la pandemia, pero en muchos países siguen existiendo diferencias en la producción y el empleo, especialmente en las economías con bajas tasas de vacunación (OCDE, 2021 $\left[1_{[7]}\right.$ ).

Si bien la recuperación global mejoró el comercio internacional, este no volverá a los niveles anteriores a la crisis en todos los bienes y servicios en 2021. Está previsto que el comercio mundial se refuerce en 2021 , y se estima que el volumen de las operaciones aumentará un 8.2\%, tras caer un 8.5\% en 2020 (OCDE, 2021 ${ }_{[8]}$ ). En 2021, la recuperación paulatina de la economía mundial, combinada con los cambios en los patrones de consumo (por ejemplo, con el aumento de la demanda de productos médicos y de tecnología para teletrabajar), ha permitido que el comercio de mercancías se recupere a paso constante. 
Sin embargo, el comercio de servicios, especialmente el de turismo, seguirá siendo reducido mientras la pandemia obligue a imponer restricciones sanitarias y socave la confianza de los viajeros (OCDE, 2021 ${ }_{[8]}$ ) (Gráfico 1.1).

Existen notables divergencias en el modo en que cada país ha lidiado con la crisis sanitaria y la recuperación. Los Estados Unidos encabezan el crecimiento entre las economías avanzadas, impulsado por el rápido avance en el proceso de vacunación y el importante paquete de estímulo de la Administración Biden (OCDE, 2021 ${ }_{[7]}$ ). Esto tendrá efectos indirectos positivos para sus principales socios comerciales, entre los que figuran economías de ALC. En Europa, las constantes medidas de confinamiento impuestas en el primer semestre de 2021, el menor apoyo fiscal y la todavía complicada situación epidemiológica están retrasando la normalización de la actividad. Se espera que la zona Euro crezca gracias, en particular, al consumo privado (OCDE, 2021 ${ }_{[7]}$ ). Entre las economías emergentes, China ha recuperado su trayectoria previa de crecimiento y se espera que la mantenga en 2021 y 2022. Es posible que otras economías emergentes sigan sufriendo importantes caídas en su PIB frente a las expectativas previas a la pandemia, y solo se espera que vuelvan a crecer a buen ritmo cuando las consecuencias del virus se atenúen (OCDE, 2021 $\left.{ }_{[8]}\right)$.

\section{Gráfico 1.1. Comercio mundial de mercancías (\% de variación anual, promedio móvil trimestral), 2015-2021}

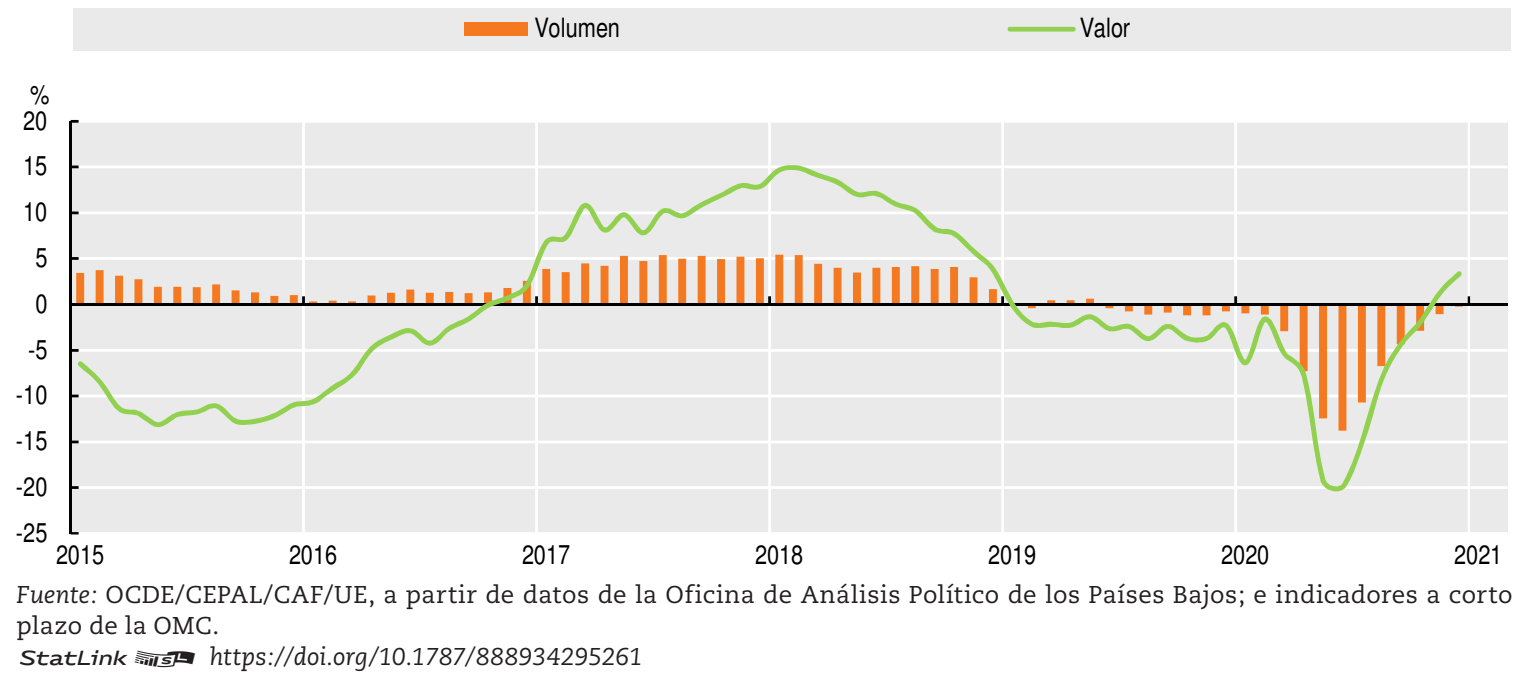

\section{Los precios de los productos básicos están al alza}

La mayoría de los precios de los productos básicos han aumentado por encima de los niveles previos a la pandemia (Gráfico 1.2). La crisis del COVID-19 hizo desplomarse los precios de los productos básicos, tendencia que se revirtió en mayo de 2020. En 2021, la recuperación de la economía mundial, los problemas de producción y los cambios en los patrones de consumo han seguido aumentando los precios de estos productos. Los precios de la energía, cuya recuperación se retrasó en comparación con los de otros productos básicos, se han disparado desde finales de 2020. Estos cambios apuntan a una recuperación tras el desplome histórico del año pasado, pero no señalan necesariamente el inicio de un nuevo superciclo de los productos básicos. Los precios de estos productos deberían estabilizarse cuando el marcado repunte de la demanda, especialmente en China y, en menor medida, en los Estados Unidos, se suavice y el crecimiento converja con el potencial. Asimismo, en el futuro el proceso de descarbonización podría limitar 
los precios del petróleo y ser positivo para algunos metales. La adopción de un modelo de consumo más sostenible desde el punto de vista ambiental, sobre todo en los países desarrollados, incrementará la demanda de algunos metales de base necesarios para la fabricación de componentes y baterías (p. ej., el cobre y el litio), como se observó con el auge de los vehículos eléctricos.

Algunos de los motores que impulsaron el último superciclo de los productos básicos —la rápida industrialización de China y el consolidado comercio mundial - tienen hoy menor fuerza. Es más, la globalización se estaba estancando incluso antes de la pandemia, lo que podría aumentar la reubicación y fragmentación de algunas cadenas de valor, con lo que se debilitaría el impulso del comercio mundial. Por lo tanto, mientras la economía mundial recupera las anteriores tendencias de crecimiento, el comercio mundial, y en particular el comercio de productos básicos, difícilmente contribuirá de manera sustancial a impulsar el crecimiento de las economías de ALC en comparación con antes de la crisis financiera de 2008.

\section{Gráfico 1.2. Precios de los productos básicos (precios internacionales de productos básicos; Enero de $2018=100$ )}

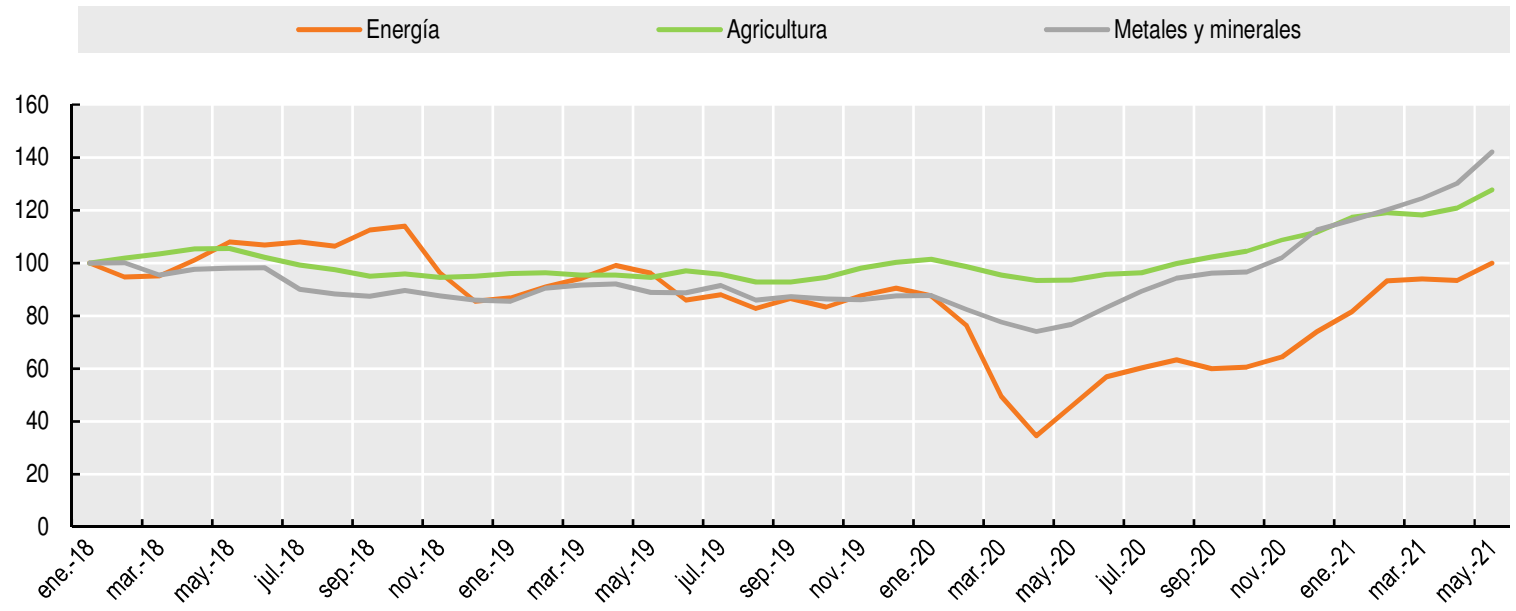

Fuente: OCDE/CEPAL/CAF/UE, a partir de datos del Banco Mundial sobre los mercados de productos básicos. StatLink (i⿱亠⿻⿰丿亅八-1 https://doi.org/10.1787/888934295280

\section{Relajación de las condiciones financieras, pero con volatilidad e incertidumbre}

Las condiciones financieras han seguido suavizándose desde la repentina interrupción de los flujos de capital en marzo de 2020. El apetito de riesgo se despertó de nuevo y el capital volvió a fluir a los mercados emergentes. En contraste con anteriores crisis internacionales, la del COVID-19 tuvo la ventaja de ir acompañada de un elevado nivel de liquidez internacional. Aunque es probable que las tasas de interés sigan siendo relativamente bajas en las economías avanzadas, el extremo largo de la curva de rendimiento se mantiene sometido. En el caso de los Estados Unidos, y tras el denominado taper tantrum, el aumento de la rentabilidad de los bonos estadounidenses y la fuerte recuperación del país podrían desencadenar un cambio en los flujos de capital y una mayor volatilidad de la divisa (OCDE, 2021 $1_{[8]}$ ). El aumento de la rentabilidad desde principios de 2021 indica que los mercados esperan un incremento de la inflación a medio plazo, en consonancia con la recuperación económica. Todavía no se han endurecido las condiciones financieras, pues las tasas de interés reales siguen siendo de casi cero o negativas. 
El aumento de la inflación debería empujar a los bancos centrales con regímenes de objetivos de inflación a adoptar una política menos expansiva. En muchas economías, la inflación general ha subido a medida que se ha recuperado la demanda debido al aumento de los precios de la energía, la devaluación de la moneda y el incremento del precio de algunos alimentos. Es poco probable que estas presiones provoquen un aumento sostenido de los salarios y otros costos, por lo que los bancos centrales se verán obligados a adoptar una política menos expansiva. Mientras las brechas de producto sigan siendo negativas, los mercados laborales continúen inactivos y las expectativas sigan afianzadas, las presiones inflacionistas deberían ser transitorias. En aquellas economías emergentes donde las expectativas no están tan afianzadas, los bancos centrales podrían adoptar políticas más neutrales. No obstante, el traspaso de la depreciación del tipo de cambio, el aumento del costo de la energía y la subida de los precios de los alimentos podrían elevar las expectativas respecto de la inflación y subir las tasas de interés, sobre todo en países donde la sostenibilidad fiscal pende de un hilo.

El acceso a financiación externa no ha sido una limitación vinculante para la mayoría de los países de ALC a corto plazo, si bien el acceso a crédito sigue siendo desigual. El atractivo de los títulos de deuda en divisa extranjera se ha mantenido desde el segundo semestre de 2020 y ha sido mayor que el de las acciones (Gráfico 1.3, Panel A), lo que ha permitido que mercados emergentes emitan una cantidad considerable de bonos a tasas relativamente bajas. En América Latina, desde abril de 2020 los países que poseen la calificación de grado de inversión no se toparon con grandes obstáculos para emitir deuda en los mercados a unas tasas de interés bajas (p. ej., Chile, Colombia ${ }^{1}$, México, Panamá, Paraguay, Perú y Uruguay). Otros países estaban en proceso de reestructurar su deuda sin acceder a los mercados (Argentina y Ecuador), mientras que para otros el costo del crédito ha subido rápidamente (p. ej., Bolivia, Costa Rica y Trinidad y Tobago). Tras la reestructuración de la deuda en Argentina, ha seguido habiendo una gran diferencia, de cerca de 400 puntos básicos, entre los diferenciales de los bonos soberanos de los países que poseen la calificación de grado de inversión y los que no (Gráfico 1.3, Panel B) (véase la sección relativa a la gestión de la deuda). La reciente subida del rendimiento de los bonos estadounidenses provocó un aumento del costo de contraer préstamos en moneda local en los mercados internos (IIF, 2021 $1_{[9]}$; FMI, 2021 $1_{[10]}$ ). 
Gráfico 1.3. Condiciones financieras en los mercados emergentes y ALC
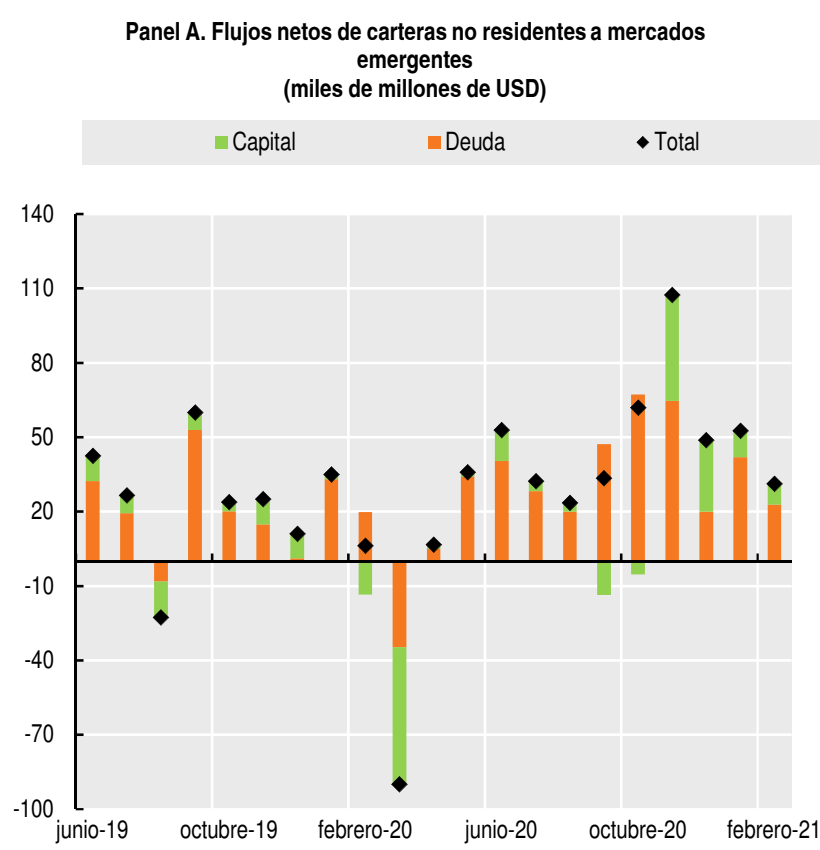

Panel B. Diferencial del riesgo soberano en

América Latina

(JP Morgan EMBI+, EMBIG)

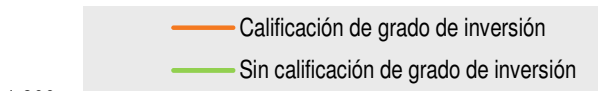

Fuente: OCDE/CEPAL/CAF/UE, a partir de Bloomberg y (IIF, 2021 $1_{[9]}$ ); Débiles resultados económicos en la región.

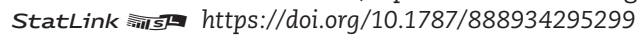

\section{Crecimiento insuficiente en la región en 2021, con un alto grado de incertidumbre}

América Latina y el Caribe fue la región emergente y en desarrollo más perjudicada por la pandemia, dado que registró una de las mayores contracciones del mundo (Gráfico 1.4, Panel A). Es probable que la recuperación sea más larga que en otras regiones debido a los grandes estragos de la segunda ola y la lenta vuelta a la normalidad.

Conviene señalar que la crisis del COVID-19 es la segunda perturbación que ha sufrido la región en la última década, tras el desplome de los precios de los productos básicos en 2014. Desde ese año, la región ha experimentado un crecimiento reducido o nulo, lo que supone una amenaza adicional, y algunas previsiones sugieren que ALC no recuperará los niveles de PIB per cápita anteriores a la pandemia hasta 2023-2024. Cuando se avance hacia la recuperación de la crisis, hay que tener muy presente el peligro de perder otra década; resulta crucial adoptar una visión a largo plazo a la hora de plantear las reformas estructurales necesarias en la región para lograr un crecimiento sostenible y a largo plazo. Por ejemplo, el crecimiento de la productividad es el motor central del progreso económico sostenido, pero en ALC la productividad laboral agregada muestra un crecimiento reducido y persistentemente bajo, con descensos desde los años 60 en relación con los países de la OCDE (Gráfico 1.4, Panel B).

Hasta que pase la crisis sanitaria, las economías de ALC tendrán grandes dificultades para volver a experimentar un crecimiento sostenido. En 2020, la crisis económica inducida por la pandemia ha afectado fuertemente a las economías de la región, ya que, anualmente, el PIB cayó en promedio alrededor de 7\% en la región (CEPAL, 2021 ; CAF, $2021_{[2]}$ ). La pandemia azotó la región en el primer trimestre de 2021, obligándola a imponer restricciones adicionales a la movilidad que han afectado su actividad. Las restricciones de la segunda ola no tuvieron repercusiones tan graves para las economías de ALC como las registradas en el segundo trimestre de 2020. No obstante, los procesos de vacunación avanzaron lentamente salvo en ciertos países, entre los que destacan 
Chile y Uruguay. Las campañas de vacunación se aceleraron durante el segundo semestre en varios países, como Ecuador, Paraguay, Argentina, Colombia, Panamá, la República Dominicana y Brasil, a medida que se aliviaban los cuellos de botella en el suministro y la disponibilidad de vacunas aumentaba. Además de los obstáculos existentes para adquirir las vacunas (cuellos de botella en la producción mundial, escasa coordinación internacional o restricciones financieras, en algunos casos), la mayoría de los países de ALC se enfrentan a dificultades relacionadas con la deficiente logística interna y las limitadas capacidades locales para llevar a cabo campañas de inmunización. Ambos aspectos (el acceso a las vacunas y la implementación de las estrategias de vacunación) pueden retrasar la vuelta a la normalidad de las actividades en la mayoría de los países y, en consecuencia, entorpecerá el crecimiento. Cuanto más se demore la recuperación, más extendidas estarán las repercusiones de la crisis y más permanente será el daño para el crecimiento potencial, que ya se ha visto afectado.

\section{Gráfico 1.4. PIB per cápita y productividad laboral en ALC}

Panel A. Evolución del PIB per cápita (índice = 2009)

Economías avanzadas _—América Latina y el Caribe

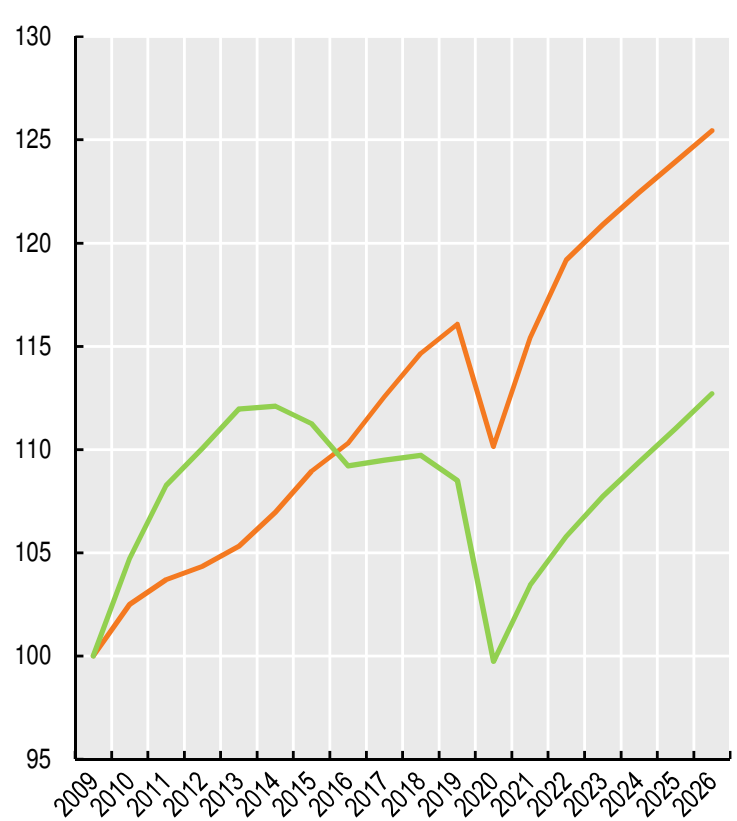

Panel B. Productividad laboral en ALC (como \% de la OCDE)

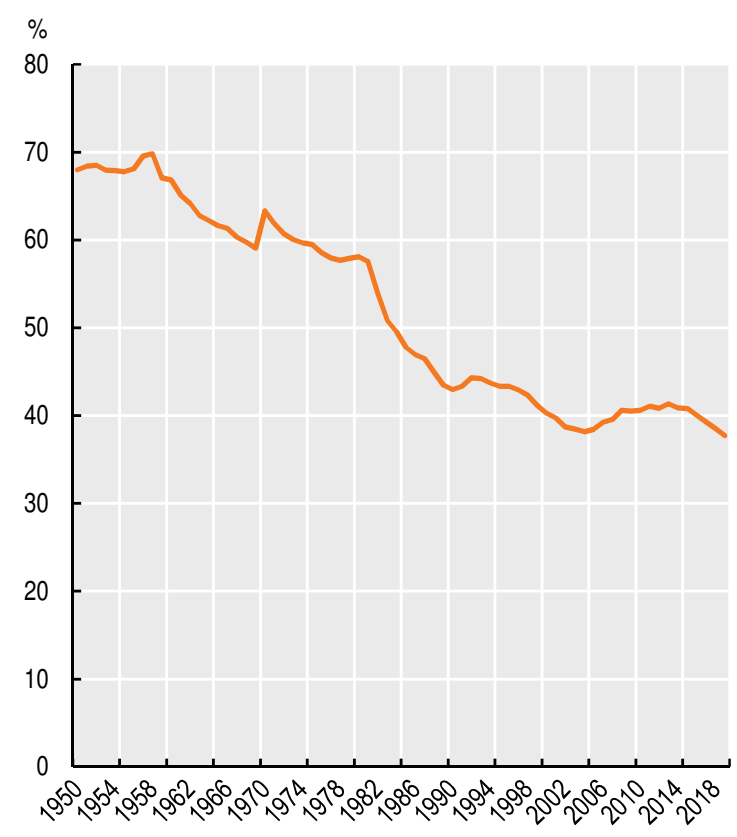

Fuente: OCDE/CEPAL/CAF/UE, a partir de datos del (FMI, $2021_{[10]}$ ), Perspectivas de la economía mundial, https://www.imf.org/es/ Publications/WEO/Issues/2021/03/23/world-economic-outlook-april-2021.

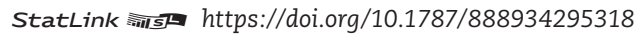

Se espera un crecimiento promedio alrededor del 6\% para 2021 en la región, seguido de una desaceleración en 2022 (CEPAL, 2021 ${ }_{[1]}$; CAF, 2021 ${ }_{[2]}$; FMI, 2021 $1_{[11]}$ ). El crecimiento en 2021 se atribuye principalmente a la baja base de comparación -después de la fuerte caída de 2020 - junto con los efectos positivos derivados de la demanda externa y la subida del precio de las materias primas que exporta la región, así como al aumento de la demanda agregada (CEPAL, 2021 $1_{[1]}$; CEPAL, 2021 ${ }_{[3]}$ ). El escenario para lo que queda de 2021 y para el 2022 está sujeto a la evolución de la pandemia, el aumento de la variante Delta, la vacunación y el descontento social, que ha desembocado en protestas en algunos países. La demanda interna, y en particular el consumo, será el principal motor del crecimiento a corto plazo a medida que se levanten las restricciones a la movilidad y los servicios 
puedan reanudarse. Además, el ajetreado ciclo político de la región, donde entre el segundo semestre de 2021 y 2022 se celebrarán elecciones presidenciales o legislativas en Argentina, Brasil, Chile, Colombia, Costa Rica, Ecuador, El Salvador, México y Perú, influirá en las expectativas y podría frenar las inversiones. Por último, el malestar social sigue siendo uno de los principales factores que afectan la estabilidad económica. Las recientes protestas sociales ponen de relieve la necesidad de lograr un crecimiento más inclusivo y mejorar el bienestar de los ciudadanos (véanse las siguientes secciones y el Capítulo 2), así como de conseguir el consenso de la ciudadanía respecto de un pacto social renovado (Capítulo 4).

La recuperación será desigual en la región. Dependerá de la exposición de los países a sectores de servicios gravemente afectados, su acceso a financiación, los efectos de arrastre y el margen normativo que tengan para satisfacer la demanda. Por ejemplo, los países muy dependientes del turismo, como las economías caribeñas, mostrarán una expansión más comedida, pues es probable que este sector tarde en recuperarse. Panamá y Perú, que sufrieron una caída de dos dígitos en 2020, se encontrarán entre las economías que más rápido crecerán este año. En Chile y Perú (y, en menor medida, Colombia), la inversión pública en infraestructura sustentará la demanda

\section{Los déficits de cuenta corriente habituales en ALC están de vuelta}

Los saldos por cuenta corriente de la mayoría de los países de ALC deberían volver en 2021 a los déficits habituales, lo que refleja las dificultades estructurales existentes en la región. En comparación con años anteriores, en 2020 el promedio de ALC registró un ligero superávit por cuenta corriente debido a la notable disminución de las importaciones (CEPAL, 2021 $1_{[1]}$ ). Los saldos por cuenta corriente deberían irse deteriorando a medida que remonte la demanda interna en la región. No obstante, en 2021 los déficits no deberían ser excesivos, pues el aumento de las importaciones no será suficiente para eclipsar la mejora de las exportaciones, y el incremento de la inversión extranjera directa (IED) es clave para financiar dichos déficits. La instauración de un mercado más interconectado en ALC brindaría una protección sustancial frente a futuras perturbaciones exógenas y mejoraría la competitividad (Capítulo 3) (CEPAL, 2021 ${ }_{[12]}$ ).

La IED neta cayó un 35\% en 2020, alcanzando el 2.5\% del PIB, el valor más bajo de la última década (CEPAL, 2021 ${ }_{[13]}$ ). A pesar de las mejoras, la región debe diversificar las fuentes de IED a fin de impulsar la competitividad y la diversificación económica, dimensiones clave para superar la "trampa de la productividad" (OCDE et al., 2019 ${ }_{[6]}$ ) (Capítulo 3). La diversificación también significa atraer IED de calidad, que puede contribuir a aumentar la productividad y ofrecer una recuperación más rica en empleo y sostenible (Recuadro 1.1).

\section{Recuadro 1.1. IED y desarrollo sostenible}

La inversión extranjera directa (IED) puede hacer importantes contribuciones al desarrollo sostenible que vayan mucho más allá del capital invertido por las empresas vinculadas a multinacionales extranjeras. Se suele pensar que los inversores extranjeros tienen acceso a mejores tecnologías y conocimientos especializados que sus homólogos nacionales gracias al nexo que tienen con sus matrices multinacionales. Estas ventajas tecnológicas pueden transferirse a las economías receptoras estableciendo vínculos en la cadena de suministro e interacciones comerciales con empresas nacionales. En consecuencia, la IED puede impulsar el crecimiento y la innovación, crear empleos de calidad, desarrollar el capital humano y mejorar los niveles de vida y la sostenibilidad ambiental. Los indicadores de la calidad de la IED de la 


\section{Recuadro 1.1. IED y desarrollo sostenible (cont.)}

Organización para la Cooperación y el Desarrollo Económicos (OCDE) tratan de dilucidar en qué medida la IED contribuye al desarrollo sostenible, prestando especial atención a la productividad y la innovación, la calidad de los empleos y las competencias, la igualdad de género y la transición a una economía con bajas emisiones de carbono (OCDE, 2019 ${ }_{[14]}$ ). El próximo "Conjunto de herramientas sobre la calidad de la IED" de la OCDE ayudará en mayor medida a los gobiernos a definir políticas y acuerdos institucionales destinados a mejorar el impacto de la IED en el desarrollo sostenible (OCDE, 2021 $1_{[57]}$ ).

En el caso de América Latina, los indicadores de la calidad de la IED de la OCDE muestran que, en la mayoría de los países para los que se disponen datos, los inversionistas extranjeros son más productivos y más propensos a introducir innovaciones en los productos o a invertir en investigación y desarrollo (I+D) que las empresas nacionales (Gráfico 1.5, Paneles A a C). Estas diferencias en términos de productividad e innovación sugieren que existe la posibilidad de que las empresas extranjeras transfieran sus conocimientos y tecnologías a las empresas nacionales. Las empresas extranjeras también suelen ofrecer unos salarios medios más elevados, lo que indica que su mayor productividad redunda, al menos en parte, en beneficio de los empleados (Gráfico 1.5, Panel D). Al mismo tiempo, en la mayoría de los países latinoamericanos examinados, las empresas extranjeras tienden a contratar a una mayor proporción de trabajadores no cualificados que las empresas nacionales, pero también son mucho más proclives a ofrecer oportunidades de capacitación (Gráfico 1.5, Paneles E y F). La información de que se dispone sugiere que los inversionistas extranjeros son una importante fuente de empleo para los trabajadores no cualificados de América Latina y pueden contribuir de manera considerable a mejorar sus competencias y a aumentar sus posibilidades de encontrar un empleo en el futuro. Para potenciar aún más la contribución de la IED al desarrollo inclusivo y sostenible, los esfuerzos de promoción de la inversión en la región deberían estar alineados con estrategias productivas bien definidas que promuevan la diversificación económica.

\section{Gráfico 1.5. Indicadores de la calidad de la IED de la OCDE para países de América Latina seleccionados}

Las empresas extranjeras obtienen mejores resultados que las nacionales si el valor es $>0$
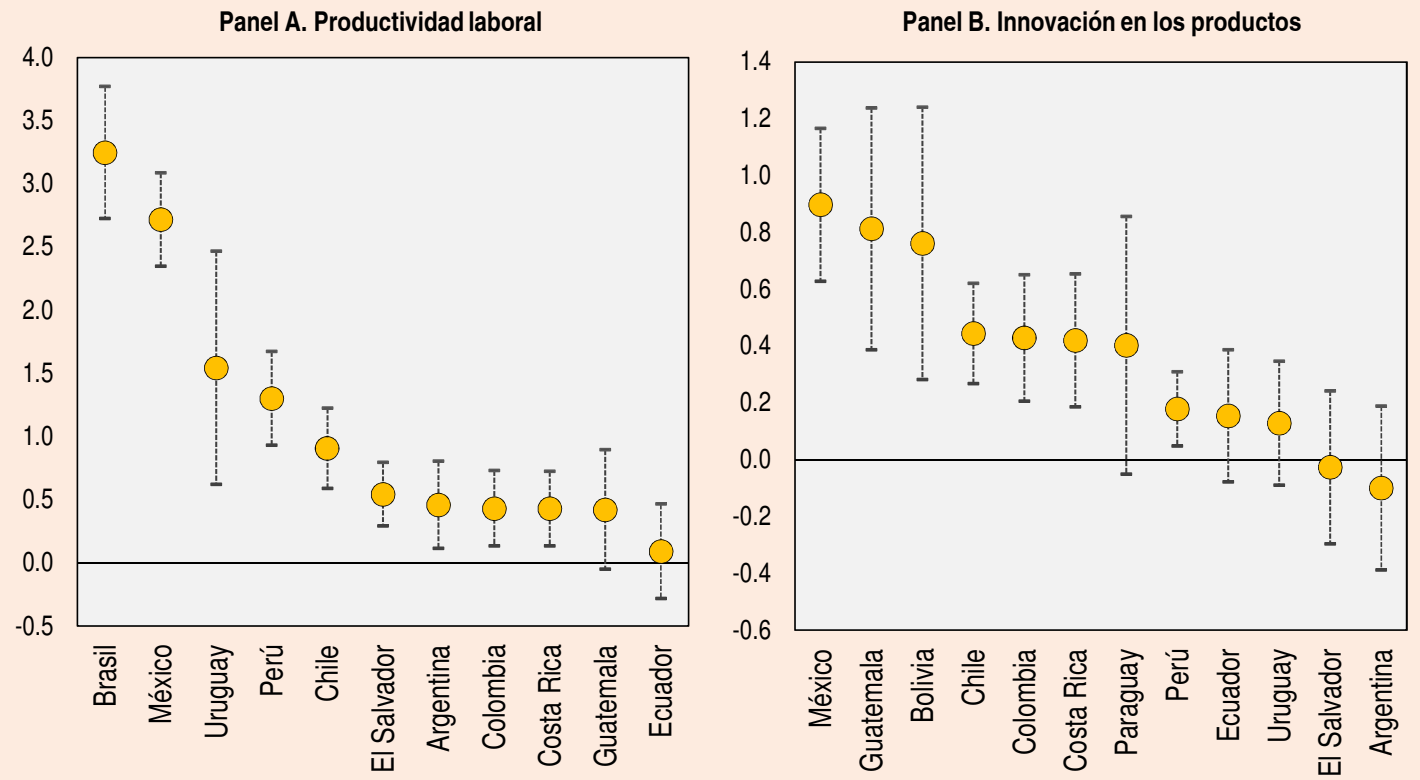


\section{Recuadro 1.1. IED y Desarrollo Sostenible (cont.)}

\section{Gráfico 1.5. Indicadores de la calidad de la IED de la OCDE para países de América Latina seleccionados (cont.)}

Las empresas extranjeras obtienen mejores resultados que las nacionales si el valor es $>0$

Panel C. I+D

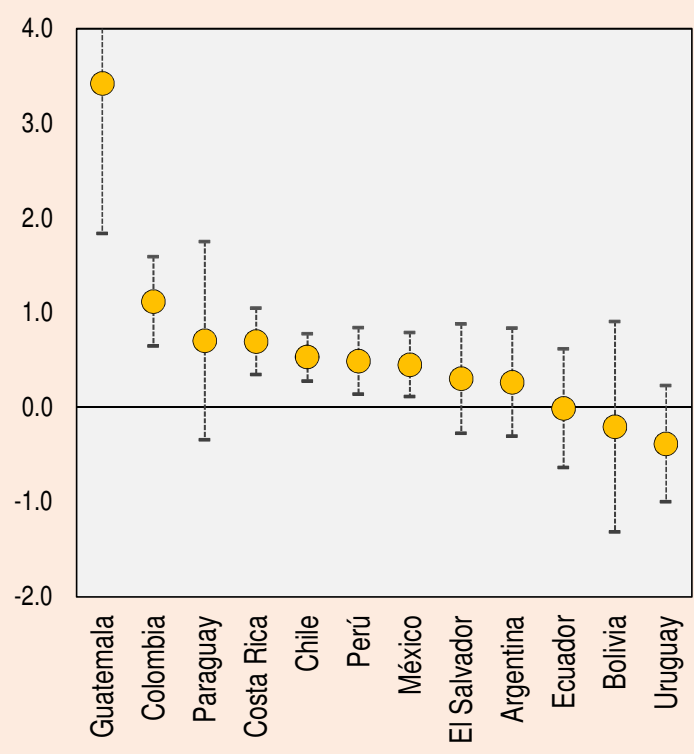

Panel E. Porcentaje de trabajadores cualificados

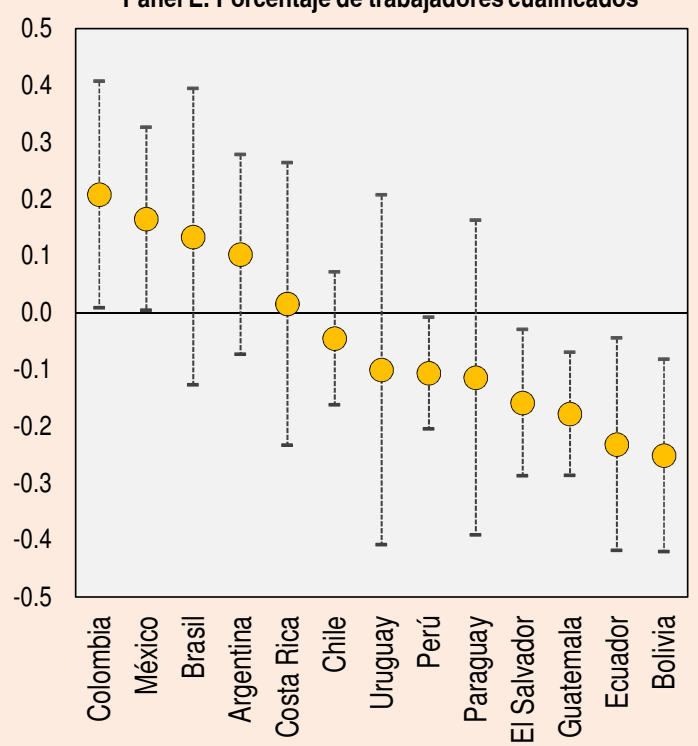

Panel D. Salarios medios
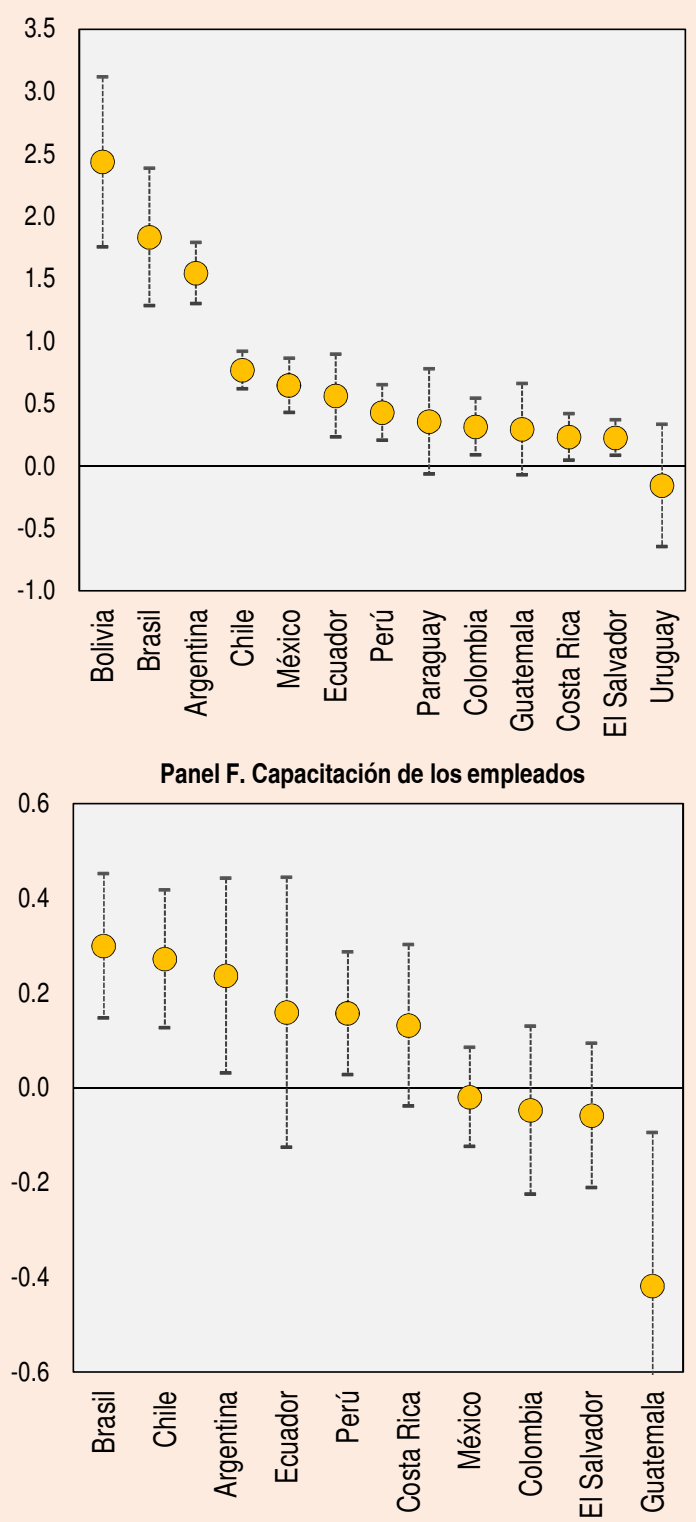

Nota: Datos alrededor de 2017, excepto para Brasil, México, Chile y Costa Rica (alrededor de 2010).

Fuente: Basado en (OCDE, 2019 ${ }_{[14]}$ ), para los detalles metodológicos, www.oecd.org/fr/investissement/fdi-qualitiesindicators.htm.

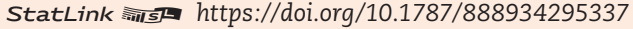




\section{Capacidad monetaria reducida en la mayoría de los países: hacia una política más agresiva}

El margen para estimular la actividad durante la transición a la normalidad dependerá del margen normativo que hubiera antes de la crisis y de cuánto de ese margen hayan gastado los países. Las respuestas de la política monetaria fueron desiguales en ALC durante 2020. Los bancos centrales de países con regímenes monetarios creíbles (p. ej., bancos centrales independientes con regímenes de objetivos de inflación) y expectativas bien afianzadas desplegaron políticas anticíclicas que redujeron las tasas de interés nominal a mínimos históricos y recurrieron a la expansión cuantitativa. Estas medidas fueron efectivas para evitar la interrupción de los sistemas de pago e impedir el colapso del crédito interno. Obviamente, el desplome de la demanda disminuyó los precios en la mayoría de los países, lo que permitió adoptar esas medidas extraordinarias y, al mismo tiempo, mantener la inflación bajo control.

El reciente repunte de la inflación relacionado con la devaluación de la divisa y los precios de la energía debería afectar a la política monetaria, que aun así debería seguir sirviendo de estímulo. Los bancos centrales con regímenes de objetivos de inflación vigilarán de cerca los efectos secundarios que podrían alejar las expectativas de tales objetivos. La mayoría de los bancos centrales deberían ser capaces de favorecer la recuperación manteniendo unas tasas de interés bajas, pues la inflación continúa bajo control y persisten condiciones financieras favorables. No obstante, los bancos centrales dispondrán de menos margen, dado que las expectativas de inflación ya se sitúan ligeramente por encima del objetivo y tienen balances más grandes (Cavallo y Powell, $\left.2021_{[15]}\right)$. De hecho, varios países empezaron a adoptar una postura más neutral, como Brasil, México, Chile y Perú.

\section{Movilización de recursos para mitigar la crisis e impulsar la recuperación}

La política fiscal ha sido un instrumento esencial para contrarrestar el impacto de la crisis del COVID-19 en las familias y las empresas, y para dar apoyo a los sistemas de salud pública (CEPAL, 2021 $1_{[3]}$; CEPAL, 2021 $1_{[16]}$; CEPAL, 2021 $1_{[17]}$ ). En toda la región se han adoptado medidas que combinan alivios fiscales, reasignaciones presupuestarias, el aumento del gasto y préstamos con condiciones favorables para responder a las dificultades sanitarias y socioeconómicas generadas por la pandemia, que han afectado en especial a los más vulnerables. Como resultado, la región movilizó una cantidad de recursos sin precedentes. El tamanio varió de unos países a otros, en función del impacto de la pandemia, su posición fiscal inicial y sus oportunidades de financiación. Esta movilización de recursos fiscales, unida al declive de la actividad económica, ha añadido tensión a la situación fiscal de la región.

La política fiscal seguirá siendo un elemento central de la respuesta a la crisis y esencial para garantizar una recuperación fuerte e inclusiva. En especial, la respuesta fiscal para mitigar la crisis tendrá que ser focalizada, centrándose en los sectores (p. ej., el turismo), las empresas (p. ej., las pymes) y grupos de población vulnerables que continúan enfrentándose a los mayores desafíos, incluyendo el impacto debido al cierre de las escuelas en 2020-2021. Asimismo, la política fiscal tendrá que abordar las vulnerabilidades estructurales que la pandemia ha puesto en evidencia, con el fin de reforzar las bases de la recuperación y construir un futuro mejor.

La política fiscal puede ser crucial para orientar la necesaria transformación productiva generar empleo formal de calidad, aprovechar al máximo la transformación digital y priorizar el cuidado del medioambiente. Esto implica aumentar la inversión en capital humano y físico (lo que incluye las infraestructuras), dirigir el gasto a las 
poblaciones más vulnerables, mejorar la eficacia del gasto público y la calidad de los servicios públicos y abordar coherentemente los objetivos de desarrollo y del clima. Para financiar estas inversiones, es preciso redoblar la movilización de recursos a escala nacional e internacional, lo que a su vez supone aumentar la progresividad del sistema tributario y mejorar la administración tributaria y la gestión de la deuda. Del mismo modo, es necesario hacer esfuerzos adicionales encaminados a eliminar la posibilidad de que se produzcan los sesgos de género que siempre han estado presentes en los actuales regímenes. Los sistemas tributarios vigentes imponen una carga adicional a las fuentes secundarias de ingresos de los hogares (tradicionalmente, las mujeres) y desalientan su participación en el mercado laboral (CEPAL, 2021 ${ }_{[16]}$ ). Para que estos esfuerzos den sus frutos, será esencial garantizar la sostenibilidad fiscal y reforzar la confianza de los ciudadanos en el gobierno a fin de superar la trampa institucional a la que muchos países ya se estaban enfrentando antes de la pandemia (OCDE et al., 2019 ${ }_{[6]}$ ).

En el futuro, para que las políticas fiscales sean efectivas deben tener en cuenta la complejidad del contexto actual mediante una secuencia de acciones claramente definida. También deben sustentarse en un amplio consenso logrado gracias al diálogo nacional y a una comunicación clara (Capítulo 4). La economía política de la política fiscal es más importante que nunca. Además, no existe un enfoque o una solución única que garantice que una política fiscal se traduzca en una recuperación sólida, inclusiva y sostenible. Las características socioeconómicas propias del contexto de cada país, unidas a las repercusiones heterogéneas de la crisis, exigen la adopción de un enfoque adaptado. No obstante, algunas consideraciones generales pueden ayudar a los países de ALC a elaborar un buen "menú de políticas" y lograr un equilibrio adecuado entre el gasto público, la política fiscal y la gestión de la deuda pública.

\section{Recaudación fiscal en tiempos de crisis}

La recaudación fiscal de la región contribuye poco a reducir las desigualdades y sigue siendo insuficiente para financiar la agenda de desarrollo de la región. Los ingresos tributarios se mantienen bajos, pues la recaudación como porcentaje del PIB fue del 22.9\%, un porcentaje considerablemente inferior al promedio de la OCDE del $33.8 \%$, y se redujo en promedio alrededor del 3\% en 2020. Existe una gran heterogeneidad entre los países de ALC en términos de recaudación tributaria como proporción del PIB, la cual va desde el $42.0 \%$ de Cuba y el 33.1\% de Barbados y Brasil hasta el 13.9\% de Paraguay, el 13.5\% de la República Dominicana y el $13.1 \%$ de Guatemala. Asimismo, a diferencia de la mayoría de las economías de la OCDE, las estructuras tributarias de ALC siguen dependiendo más de los impuestos indirectos que de los directos. Los impuestos aplicables a bienes y servicios (fundamentalmente el impuesto sobre el valor agregado [IVA] y los impuestos sobre las ventas) representaron en torno al $49.8 \%$ del total de ingresos tributarios, frente al $32.7 \%$ de la OCDE. Además, mientras que en 2018 los impuestos sobre la renta de las sociedades constituyeron el $15.5 \%$ de los ingresos tributarios de ALC, el impuesto sobre la renta de las personas físicas únicamente representó el 9.1\%. A diferencia de ALC, este último constituye una proporción mayor de la recaudación fiscal en las economías de la OCDE (el $23.5 \%$ del total), en comparación con los impuestos sobre la renta de las sociedades $(10.0 \%$ de la recaudación fiscal total) (OCDE et al., 2021 ${ }_{[18]}$ ).

La combinación de los alivios fiscales concedidos en respuesta a la pandemia y la marcada disminución de la actividad económica provocaron una reducción significativa de los ingresos públicos en ALC. La recaudación del IVA, La recaudación del impuesto sobre el valor añadido (IVA), principal fuente de ingresos fiscales para ALC, cayó con especial fuerza en muchos países, con descensos interanuales en términos reales del $40 \%$ en mayo de 2020. Esta cifra fue mayor en Antigua y Barbuda, Chile, Costa Rica, Ecuador, Granada, Honduras y Jamaica. La recaudación del impuesto sobre la renta también disminuyó 
considerablemente en el primer semestre de 2020, principalmente debido a la prórroga de las medidas de alivio fiscal con las que se aplazó la liquidación de las obligaciones fiscales correspondientes a 2019 y se suspendió el pago anticipado de impuestos. En algunos casos, los ingresos no percibidos superaron el 1\% del PIB. En Chile, se estima que la disminución de la recaudación equivalió al 1.4\% del PIB (DIPRES, $2020_{[19]}$ ), un porcentaje similar al de Perú (1.5\% del PIB) (MEF, 2020 ${ }_{[20]}$ ). Sin embargo, el gran tamaño del sector informal en la región y la escasa participación de las personas y las pequeñas y medianas empresas (pymes) en el sistema tributario y el sistema de seguridad social limitaron la eficacia de la desgravación fiscal (OCDE et al., 2021 ${ }_{[18]}$ ).

El objetivo principal de las medidas fiscales era fortalecer los sistemas de salud con miras a apoyar a los hogares, los trabajadores por cuenta propia y las empresas. La pandemia pronto saturó los sistemas sanitarios de la región, poco desarrollados, (OCDE/ Banco Mundial, $2020_{[21]}$ ) y los gobiernos promulgaron medidas destinadas a apoyarlos con las que trataron, fundamentalmente, de reducir el costo que suponía importar productos médicos esenciales. Dado que la región depende de proveedores externos, muchos países aplicaron temporalmente exenciones o tipos cero a los productos médicos para subsanar la escasez de recursos (p. ej., de alcohol, artículos de laboratorio, guantes, desinfectante, equipo y otros suministros sanitarios). En algunos casos, estas medidas fueron acompañadas de la exención del IVA para los productos médicos, como en Colombia, o de deducciones temporales en el impuesto sobre la renta de las personas físicas destinadas a incentivar que la población hiciese donaciones directas a los sistemas de salud.

Los gobiernos aplicaron alivios fiscales para compensar la disminución de los ingresos de los hogares y de los trabajadores por cuenta propia. Las medidas fiscales más comunes fueron el aplazamiento del pago de impuestos, la suspensión de las liquidaciones por adelantado y la creación de sistemas de liquidación favorables del IVA y el impuesto sobre la renta de las personas naturales, como planes de cuotas sin intereses ni sanciones. Varios países, entre ellos Chile, Colombia, Perú y Trinidad y Tobago, también implementaron el reembolso acelerado del impuesto sobre la renta de las personas naturales para prestar más apoyo. En algunos países, como Argentina, Colombia, Costa Rica, Dominica, Guyana, Honduras y San Vicente y las Granadinas, también se ayudó a los hogares con exenciones en el pago del IVA de productos médicos esenciales, productos de la canasta básica de alimentos y servicios, como la electricidad. En Colombia se puso en práctica un plan de reembolso del IVA dirigido a 1 millón de personas que viven en la pobreza, con el cual se realizaron cinco pagos de 75000 COP (pesos colombianos) a lo largo del año (OCDE et al., $\left.2021_{[18]}\right)$.

Al igual que en el caso de los hogares, los alivios fiscales dirigidos a las empresas también consistieron principalmente en medidas temporales para estimular el flujo de efectivo, sobre todo en los primeros meses de la crisis, por medio de aplazamientos y la suspensión de la liquidación por adelantado del IVA y el impuesto sobre la renta de las sociedades. En concreto, la reducción del IVA tuvo una incidencia considerable en la región, especialmente para las micro, pequeñas y medianas empresas (mipymes). En varios casos, los alivios fiscales se dirigían a mipymes o a sectores particularmente afectados por la crisis, como la construcción, el turismo y los servicios personales. Además, los países hicieron la desgravación extensiva a las empresas modificando los planes de cotización a la seguridad social. Tal fue el caso del Programa de Asistencia de Emergencia al Trabajo y la Producción de Argentina, que introdujo una reducción de hasta el 95\% en las contribuciones que los empleadores debían abonar al Sistema Integrado Previsional Argentino. En Brasil se suspendieron los pagos al Fondo de Seguro de Desempleo y se redujeron un $50 \%$ las cotizaciones al Sistema S, que financia la formación técnica y profesional (OCDE et al., 2021 $1_{[18]}$ ). 
De cara al futuro, un conjunto de opciones de política fiscal podría aumentar los ingresos sin comprometer la recuperación económica ni el bienestar de los ciudadanos, pero el escalonamiento de estas políticas, respaldada por un consenso nacional, definirá su éxito (Mora, Nieto-Parra y Orozco, 2021 $[22]$ ). Entre ellas se encuentran las medidas orientadas a reducir la evasión y elusión de impuestos, que cuestan a América Latina un importe equivalente a aproximadamente el $6.1 \%$ de su PIB en IVA, impuestos sobre la renta de las personas físicas e impuestos sobre la renta de las sociedades no percibidos $($ CEPAL, 2021 $[16]$ ). Otras opciones son políticas destinadas a aumentar el cumplimiento de las obligaciones fiscales, fortalecer la administración tributaria y suprimir el gasto tributario que genera pocos beneficios en términos de capital o creación de empleo (el promedio del total de los gastos tributarios en América Latina entre 2015 y 2019 fue del $3.7 \%$ del PIB) (OCDE et al., 2021 $1_{[18]}$ ). Unidas a las medidas internacionales orientadas a evitar que se erosione la base imponible y que las empresas multinacionales trasladen sus beneficios (p. ej., mediante la ejecución del proyecto de la OCDE y del G20 sobre la erosión de la base imponible y el traslado de beneficios, BEPS por sus cifras en ingles), estas medidas tienen un beneficio adicional: mejoran la moral fiscal y, en consecuencia, la credibilidad de las instituciones. La economía digital, y los desafíos que conlleva, es otro de los grandes retos fiscales internacionales a los que se enfrenta la región (OCDE et al., 2020 [23]; Mora, Nieto-Parra y Orozco, 2021 ${ }_{[22]}$ ).

Los países tal vez tengan que plantearse otras formas de incrementar su recaudación para subsanar las deficiencias estructurales (OCDE et al., 2021 ${ }_{[18]}$; Mora, Nieto-Parra y Orozco, $2021_{[22]}$ ). Los plazos, la rapidez y la forma de estas políticas deberían adaptarse a la realidad de cada país y estar estrechamente vinculadas al consenso de los ciudadanos. Mientras que en las economías de la OCDE los impuestos y las transferencias reducen el coeficiente de Gini en aproximadamente 16 puntos porcentuales, en ALC la reducción comparable es inferior a 3 puntos porcentuales en promedio (OCDE, 2020 ${ }_{[24]}$ ) (OCDE et al., 2019 $\left.{ }_{[6]}\right)$. Sin embargo, en la mayoría de los países deberían valorarse medidas encaminadas a aumentar el impuesto de la renta sobre las personas naturales a los deciles superiores. Este impuesto es el principal factor que explica la brecha fiscal entre ALC y la OCDE, pues no solo limita la posible recaudación del sistema tributario, sino también su capacidad de redistribución (OCDE et al., 2021 ${ }_{[18]}$ ). Las medidas adicionales centradas en impuestos concretos, como la tributación de los bienes inmuebles (Izquierdo y Pessino, 2021 $[25]$ y de las plusvalías de los particulares, deberían contribuir a aumentar la recaudación destinada a financiar la recuperación y mejorar la progresividad del sistema tributario. Otras medidas incluyen la introducción de impuestos sobre la riqueza y sobre las sucesiones (OCDE, 2021 $1_{[26]}$ ), cuya aplicación efectiva requiere mejorar la capacidad de las administraciones tributarias y estadísticas (Mora, Nieto-Parra y Orozco, 2021 ${ }_{[22]}$ ). La reforma fiscal internacional, que cuenta con el respaldo de 130 países (23 de ALC), proporcionará ingresos necesarios. La reforma garantizará una distribución más justa de los beneficios y los derechos de imposición entre los países en lo que respecta a las empresas multinacionales de mayor tamaño, incluidas las empresas digitales, y limitará la competencia en términos de impuesto sobre la renta de las sociedades mediante la introducción de un tipo mínimo (de al menos el 15\%) para el impuesto de sociedades a nivel mundial, que los países pueden aplicar para proteger sus bases imponibles (OCDE, $\left.2021_{[27]}\right)$.

A medida que avanza la recuperación, hay políticas fiscales que la región no ha explorado del todo. Entre ellas se encuentran impuestos correctivos, como los impuestos ambientales. En ALC, los ingresos procedentes de los impuestos ambientales equivalieron en promedio al 1.2\% del PIB en 2019 (fundamentalmente impuestos sobre la energía, aplicados en su mayoría al diésel y la gasolina), un porcentaje inferior al promedio de la OCDE, que se sitúa en el $2.1 \%$ del PIB (OCDE et al., 2021 ${ }_{[18]}$ ). Los impuestos asociados 
a la salud pública, como los que gravan el consumo de tabaco, alcohol, azúcar y ciertas bebidas, pueden resultar esenciales para crear incentivos encaminados a que los agentes económicos promuevan dietas más saludables, lo que en última instancia generará mejores resultados de salud y reducirá los costos ligados a la sanidad. Se podrían contemplar medidas destinadas a mejorar la eficiencia del IVA que reduzcan el número y el alcance de las exenciones y compensen a las poblaciones más vulnerables (OCDE et al., $\left.2021_{[18]}\right)$. La crisis del COVID-19 brinda la oportunidad de replantearse la política tributaria tradicional de ALC, prestando especial atención a temas de genero arraigado en los actuales regímenes fiscales. Por ejemplo, los sistemas fiscales por lo general no tienen en cuenta que las mujeres realizan en mayor medida trabajos no remunerados, por lo que la carga tributaria de los hogares resulta desproporcionada. Otro ejemplo de los sesgos de género presentes en la política fiscal son las desgravaciones fiscales para sectores económicos eminentemente masculinos (CEPAL, 2021 ${ }_{[16]}$ ).

\section{El gasto público debería ser anticíclico y tener visión a largo plazo gracias al gasto de capital}

Antes de la pandemia, el gasto público en la región de ALC registró un crecimiento modesto, y el gasto social y los servicios de la deuda estaban en alza. El gasto público aumentó del 20.1\% del PIB en 2010 al 21.5\% del PIB en 2019. En términos generales, el aumento del gasto público ha sido escaso, ya que muchos países han adoptado políticas de consolidación fiscal para controlar el aumento de la deuda pública y hay poca flexibilidad $\left(\mathrm{OCDE}, 2020_{[28]}\right)$. Los principales cambios se produjeron en la composición del gasto y se debieron, en su mayoría, al incremento de los pagos del servicio de la deuda tras el aumento de la deuda pública y los gastos corrientes, que refleja el incremento del gasto social. El gasto de capital disminuyó para compensar el aumento de los pagos del servicio de la deuda y los gastos corrientes, lo que agrandó la brecha de inversión entre ALC y otras economías (CEPAL, 2021 ${ }_{[16]}$ ) y obstaculizó el crecimiento de la productividad.

En respuesta a la pandemia, en 2020 el gasto público corriente aumentó considerablemente en todo el mundo con el fin de prestar apoyo a los sistemas de salud, las familias y las empresas. En 2020, el gasto total de los gobiernos centrales de América Latina ascendió al 24.7\% del PIB, su nivel más alto desde la década de 1980, en plena crisis de la deuda. Sin embargo, las distintas regiones siguen presentando considerables diferencias en cuanto a su capacidad para reaccionar a la crisis, pues ALC ha adoptado, en promedio, medidas a menor escala que países emergentes de Asia o economías avanzadas (FMI, 2020 ${ }_{[29]}$ ).Y ello a pesar de la debilidad de los estabilizadores automáticos y del mayor tamaño de la población vulnerable que no disponía de redes de seguridad o sistemas de protección social en los que apoyarse cuando azotó la crisis. Sigue existiendo una gran heterogeneidad entre los países de ALC: en Argentina, Brasil, El Salvador y la República Dominicana, el gasto primario del gobierno central creció más de un $20 \%$ en los primeros nueve meses de 2020, mientras que Costa Rica, Ecuador, Honduras y México prosiguieron con sus políticas de consolidación fiscal y redujeron el gasto público. La variedad de respuestas ante la crisis se debe a las decisiones políticas de los países, las distintas repercusiones que la pandemia ha tenido para ellos, su situación fiscal previa, su capacidad para acceder a los mercados financieros nacionales y mundiales, la diversidad de instituciones multilaterales de préstamo y la capacidad de sus bancos centrales. La mayor parte del incremento del gasto público (el 70\%) se destinó a la realización de transferencias corrientes como medidas de alivio y prestaciones sociales.

Las medidas de gasto tuvieron especial importancia y se centraron en los sistemas de salud, los hogares y las pequeñas empresas. Con el objetivo de prestar apoyo a los sistemas de salud, muchos países redistribuyeron o aumentaron el gasto para adquirir suministros médicos, contratar personal adicional o ampliar sus infraestructuras. Entre 
las medidas destinadas a apoyar los ingresos de los hogares cabe mencionar el diseño de nuevos programas de transferencias dirigidas a trabajadores informales sin empleo y grupos sociales vulnerables, o el fortalecimiento de los programas ya existentes (OCDE, $\left.2020_{[30]}\right)$. Algunas de las transferencias creadas son el Ingreso Familiar de Emergencia en Argentina, el Auxílio Emergencial en Brasil, el Ingreso Familiar de Emergencia en Chile, el Ingreso Solidario en Colombia el Bono Proteger en Costa Rica (OCDE, 2020 ${ }_{[28]}$ ), el Subsidio Pytyvõ en Paraguay y el Bono Familiar Universal y el Bono Independiente en Perú (OCDE, $\left.2020_{[24]}\right)$. También se destinaron transferencias a los trabajadores del sector formal, por ejemplo, mediante el Programa de Asistencia de Emergencia al Trabajo y la Producción en Argentina (Capítulo 2). Asimismo, los países expandieron o complementaron sus sistemas de protección social ampliando el seguro de desempleo (p. ej., en Brasil, Chile, Ecuador, México y Uruguay) y las prestaciones de la seguridad social, tales como las pensiones (p. ej., en Argentina, Colombia, Guatemala, México y Paraguay). Con el fin de prestar asistencia directa a los hogares con bajos ingresos, se incluyó apoyo en especie en forma de paquetes de alimentos y subsidios para cubrir el costo de los suministros domésticos básicos (electricidad, gas y agua).

En ALC, el gasto público también se destinó a preservar la capacidad productiva, haciendo especial hincapié en las mipymes. Las medidas, los subsidios y la financiación tenían el objetivo principal de preservar el empleo y velar por que las empresas dispusieran de suficiente liquidez, dada la frecuencia de la demanda y de choques ligados a la oferta. Economías como Chile, Colombia, Perú y Uruguay adoptaron programas de subsidio salarial para proteger el empleo. Colombia, por ejemplo, estableció el Programa de Apoyo al Empleo Formal para proporcionar un subsidio mensual, equivalente al $40 \%$ del salario mínimo, con el que ayudar a cubrir el costo de los salarios a las empresas que pudiesen demostrar que sus ingresos habían disminuido un $20 \%$ entre febrero y marzo de 2020. En Guatemala, México y Panamá se establecieron subsidios para empresas con el fin de compensar los gastos de funcionamiento vinculados a la adquisición de los suministros necesarios en el sector agrícola. Las economías de ALC recurrieron a medidas extraordinarias, como la concesión de líneas especiales de crédito y la capitalización de las instituciones financieras estatales, para garantizar que las empresas pudieran acceder a la liquidez necesaria. Por ejemplo, Brasil amplió los programas de financiación del Banco Nacional de Desarrollo (BNDES). Chile hizo una cuantiosa inyección de capital en el Fondo de Garantía de Pequeños Empresarios. En Colombia, Bancoldex lanzó nuevas líneas de crédito. El programa Reactívate Ecuador proporcionó crédito a un tipo preferencial a mipymes. Perú estableció un nuevo programa en el marco del Programa de Garantías "Reactiva Perú", con el cual los créditos garantizados por el Tesoro Público estaban respaldados por una contribución del banco central. Algunos países, como Argentina y Perú, hicieron efectivos programas para el estímulo de la productividad financiando proyectos de I+D, promoviendo la digitalización y fomentando el emprendimiento.

Para evitar poner vidas en peligro y asegurar una recuperación fuerte e inclusiva, el gasto público debe realizarse de manera efectiva mediante una secuencia de acciones claramente definida (Mora, Nieto-Parra y Orozco, 2021 ${ }_{[22]}$ ). Puesto que los recursos son escasos, la región debe tratar de redistribuir el gasto de usos ineficientes a otros eficientes y, por ejemplo, resolver las fugas de las transferencias sociales o el fraude, la corrupción y el despilfarro en las adquisiciones públicas (Cavallo y Powell, 2021 ${ }_{[15]}$; OCDE, 2020 ${ }_{[31]}$ ) o aumentar el porcentaje del gasto público sujeto a la contratación pública (OCDE, 2020 ${ }_{[28]}$ ). En el corto plazo, y mientras la pandemia siga poniendo vidas en peligro, la prioridad debería seguir siendo proteger a las personas, apoyar a las familias más vulnerables, y salvar a las empresas y el empleo. La vacunación es esencial para ofrecer una salida a la pandemia y reducir la incertidumbre que generan las medidas de confinamiento que tan pronto se levantan como se vuelven a imponer. Por otro lado, los países deben continuar 
defendiendo la asistencia social, con miras a diseñar mecanismos que promuevan efectos económicos a largo plazo. Se ha comprobado, por ejemplo, que las transferencias monetarias dirigidas a beneficiarios específicos pueden estimular la inversión en la escolarización de los niños, sobre todo si están sujetas a condiciones (OCDE, 2019 ${ }_{[14]}$ ). Del mismo modo, el gasto público debe seguir respaldando la capacidad productiva y, en especial, protegiendo a las mipymes. Sigue siendo crucial no perder de vista que la crisis tiene repercusiones distintas para los hombres y las mujeres y que la política fiscal tradicional no es neutra en cuanto al género. Detectar y eliminar los sesgos existentes para promover la no discriminación puede favorecer una recuperación inclusiva (CEPAL, $2021_{[16]}$ ).

Una vez que la pandemia empiece a estar bajo control, el gasto público debería empezar a destinarse gradualmente a otros asuntos, como, por ejemplo, a prestar un apoyo específico en vez de general, con especial atención a los sectores que más lo necesitan, y dejar de ser un gasto corriente para ser un gasto de capital (Mora, Nieto-Parra y Orozco, 2021 ${ }_{[22]}$ ). Tradicionalmente, el $80 \%$ del gasto público en ALC se concentra en el gasto corriente, y solo el 20\% corresponde a gasto de capital (OCDE et al., 2019 ${ }_{[6]}$ ). En consecuencia, la región está rezagada en lo que respecta a la formación bruta de capital. Antes de que comenzara la crisis del COVID-19, existía una brecha equivalente a 4 puntos porcentuales del PIB entre las economías avanzadas y a más de 21 puntos porcentuales del PIB entre las economías emergentes y en desarrollo de Asia (FMI, 2021 ${ }_{[10]}$ ). Resulta fundamental aumentar y mejorar el gasto de capital para lograr una recuperación robusta e impulsar la inversión en infraestructura (también en tecnologías digitales y verdes) necesaria para promover empleos de calidad y una transformación de la producción que dé prioridad al medioambiente. Es más, en especial en lo que respecta a la infraestructura, el gasto de capital tiene un gran efecto multiplicador (de hasta dos veces) tanto en la actividad económica como en el empleo (Izquierdo y Pessino, 2021 ${ }_{[25]}$ ). Por último, ALC debe retornar gradualmente a los marcos fiscales, incluidas las normas fiscales destinadas a proteger la inversión; garantizar la claridad, eficiencia y equidad del gasto; así como añadir cláusulas de escape apropiadas para circunstancias excepcionales (Mora, Nieto-Parra y Orozco, $\left.2021_{[22]}\right)$.

\section{Gestionar la deuda y aumentar los recursos disponibles sin poner en peligro el futuro: el papel de la cooperación internacional}

La crisis del COVID-19 ha afectado la situación fiscal de los países de ALC, que ya era delicada; en 2020, el déficit general promedio en América Latina equivalía al 6.9\% del PIB (CEPAL, 2021 $1_{[16]}$ ). Se trata de un porcentaje considerablemente superior al déficit promedio de 2019 (del - 4\% del PIB), o la del 2009 (del -3.6\% del PIB) provocado por la crisis financiera internacional. Los déficits fiscales históricamente elevados de la región están relacionados principalmente con el descenso de la recaudación fiscal debido a la baja actividad económica y a las medidas fiscales aplicadas para contrarrestrar los efectos de la pandemia, combinado con la introducción de planes de gasto como las transferencias corrientes en apoyo de las familias y las empresas, dio lugar a mayores déficits fiscales en la región, que, en algunos casos, alcanzaron máximos históricos. La presión fiscal comenzó en un momento en que las economías de ALC se encontraban efectuando ajustes, y el crecimiento era anémico en el mejor de los casos (OCDE, 2020 ${ }_{[24]}$; FMI, 2020 ${ }_{[29]}$ ).

Los grandes déficits fiscales han provocado el marcado aumento de la deuda pública y el servicio de la deuda, acentuando así una tendencia que ya existía. En 2020, la deuda pública bruta promedio de los gobiernos centrales ascendió al $56.3 \%$ del PIB, un incremento de 10.7 puntos porcentuales con respecto a 2019 (CEPAL, 2021 $1_{[16]}$ ). Los coeficientes entre la deuda pública y los impuestos, un indicador aproximado de la capacidad financiera de los países para pagar la deuda pública, también aumentó en la mayoría de los países, dejándolos en una posición más débil para enfrentar la crisis del COVID-19 que en la 
que estaban en 2007, antes de la crisis financiera de 2008 (Gráfico 1.6). Se espera que el coeficiente entre la deuda pública y los impuestos aumente considerablemente en 2021, en vista de la caída de los ingresos fiscales y el crecimiento de la deuda pública, que han dejado a la región debilitada para hacer frente a futuras crisis (CEPAL, 2021 $1_{[16]}$ ).

\section{Gráfico 1.6. Relación entre la deuda pública e impuestos en países seleccionados de América Latina}

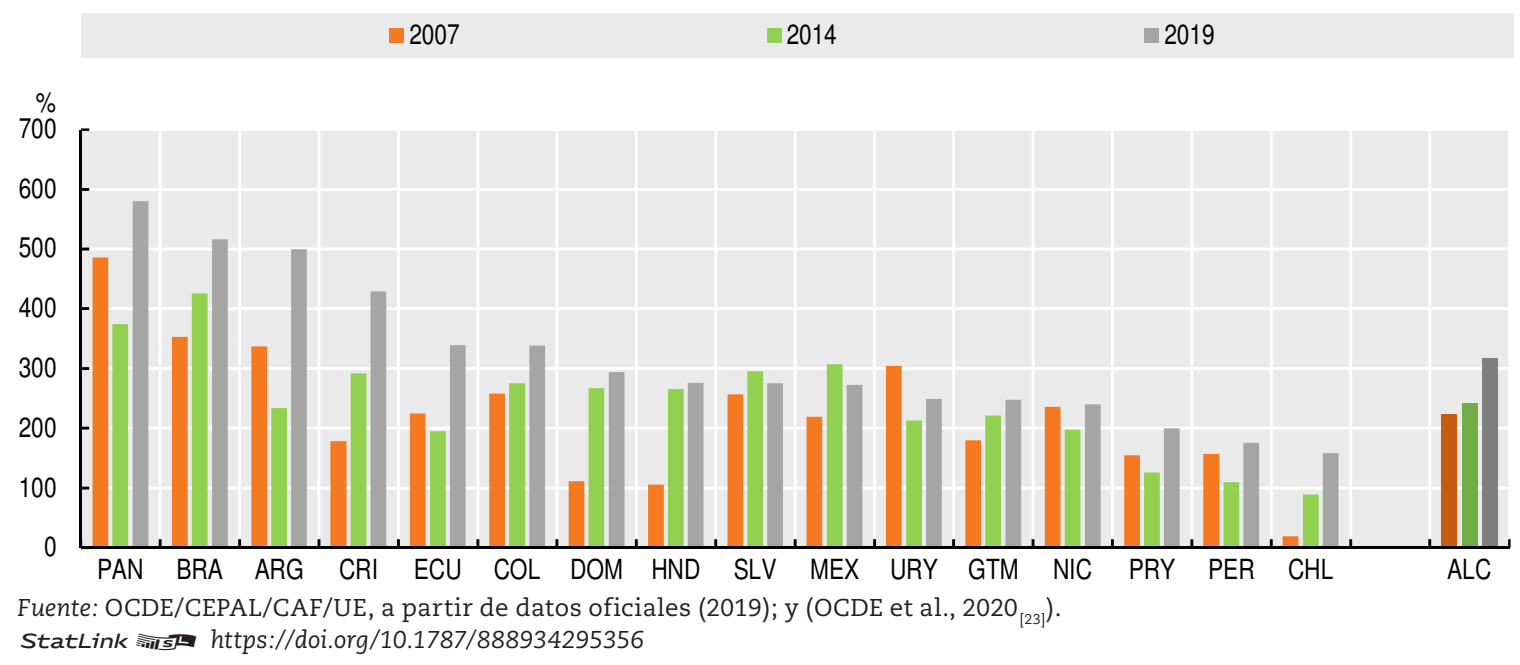

El marcado aumento de la deuda demuestra que la región ha seguido teniendo oportunidades de financiación a pesar de la crisis mundial. La emisión de deuda soberana aumentó considerablemente en los mercados internacionales (el $45 \%$ en los primeros diez meses de 2020), ya que algunos países pudieron acceder a ellos, a menudo con condiciones favorables, para cubrir sus crecientes necesidades de financiación para 2020 y, en algunos casos, prefinanciar sus presupuestos para 2021. La mayoría de la deuda emitida procedía del sector público (CEPAL, 2021 $1_{[16]}$ ). Esto ha sido posible porque los mercados emergentes se han beneficiado de las políticas monetarias adoptadas en respuesta a la crisis y la posterior inyección de liquidez realizada por los principales bancos centrales de los países desarrollados. En particular, tanto en Colombia como en México los costos de financiación han disminuido notablemente, y el rendimiento de los bonos de referencia a diez años cayó 1.55 y 1.16 puntos porcentuales, respectivamente, entre diciembre de 2019 y diciembre de 2020, lo que en ambos casos supone una disminución mucho mayor que las registradas en los países de la OCDE (OCDE, 2021 $1_{[5]}$ ). En este contexto de gran liquidez y tasas de interés bajas en todo el mundo, los bancos centrales de ALC han podido reducir las tasas de interés de sus políticas monetarias como respuesta alternativa a la política fiscal, a fin de mantener la demanda agregada. Además, gracias a la expansión de la liquidez mundial, los costos de financiación se mantuvieron bajos en muchos países de ALC. La financiación de emergencia procedente de instituciones financieras internacionales también tuvo un papel importante, en especial para apoyar a los países con un acceso reducido o nulo a los mercados financieros internacionales. Estos últimos emitieron 47800 millones de dólares estadounidenses (USD) en crédito nuevo y redirigieron las líneas de crédito existentes (CEPAL, 2021 $1_{[1]}$ ).

Aunque el aumento de la emisión de deuda en 2020 es común a la mayoría de los países de ALC que pueden financiar su gasto mediante la emisión de bonos, continúan las diferencias en su capacidad y condiciones relativas para conseguir financiación. Curiosamente, dada la persistente liquidez de los mercados financieros mundiales y el mayor apetito de los inversores por el riesgo, los países de ALC también han podido 
hacer un mayor uso de sus propias monedas y mercados para emitir bonos. En concreto, los países de la región que emiten bonos fundamentalmente en su moneda nacional han podido servirse de los mercados locales para emitir su deuda (p. ej., Brasil, Chile, Colombia, Costa Rica, México y Uruguay). Esto reduce enormemente el riesgo de sufrir crisis ligadas a la sostenibilidad de la deuda y brinda la posibilidad de reunir más recursos. Otros países emiten deuda principalmente en moneda extranjera y en mercados externos (p. ej., Panamá, Paraguay y Perú) (Gráfico 1.7). Esta pluralidad de mecanismos de emisión de deuda resultará importante para determinar los posibles riesgos de las futuras crisis de la deuda, sobre todo a medida que los países vayan necesitando más recursos para financiar la recuperación.

A medio plazo, los coeficientes de endeudamiento en ALC deberían estabilizarse, pero a niveles más altos que antes de la crisis. Debido a la abundante liquidez existente, los mercados de capital internacionales parecen más dispuestos a admitir coeficientes de endeudamiento superiores y, por lo tanto, se mantiene el acceso a flujos de capital. Sin embargo, las condiciones podrían cambiar rápidamente a medio plazo si, tras los grandes paquetes de estímulo, se normaliza la política monetaria de las economías avanzadas. Además, en este contexto incierto, sigue existiendo el riesgo de que se produzca una interrupción súbita, esto es, una reducción abrupta de las entradas netas de capital. La dolarización de la deuda nacional, los déficits fiscales y los déficits de cuenta corriente son factores determinantes de las interrupciones súbitas sistémicas. Los dos primeros han empeorado considerablemente debido a la pandemia, y se espera que el tercero aumente con la recuperación. De ser así, la sostenibilidad de la deuda podría verse afectada, se generaría una crisis de deuda en caso de inacción de emisores o acreedores, lo que complicaría aún más el panorama mundial y pondría de relieve la importancia de coordinar la gestión de la deuda a escala global (OCDE, 2020 ${ }_{[24]}$; Nieto-Parra y Orozco, $\left.2020_{[32]}\right)$.

La coordinación mundial de la gestión de la deuda pública debería convertirse en una prioridad a medida que aumentan los recursos financieros globales necesarios para hacer frente a la pandemia, a fin de evitar o resolver posibles problemas asociados a la sostenibilidad de la deuda (OCDE, 2020 ${ }_{[24]}$ ). La naturaleza compleja de la crisis del COVID-19 puede aumentar el riesgo de que se produzcan crisis monetarias y de deuda pública, lo que pone en peligro los planes orientados a responder a la crisis y reconstruir para mejorar. Puesto que la recuperación dependerá del constante apoyo político, este podría ser el momento idóneo para que la comunidad internacional innove en lo que respecta a los instrumentos de deuda extranjeros (Breuer y Cohen, $2020_{[33]}$ ), sobre todo teniendo en cuenta las inversiones que se necesitan para tratar de hacer realidad los Objetivos de Desarrollo Sostenible (ODS) y la Agenda 2030 (UNCTAD, 2020 ${ }_{[34]}$ ). 


\section{Gráfico 1.7. Emisión anual de deuda pública en países de ALC seleccionados por divisa y país de emisión}

Panel A. Emisión de deuda pública anual por divisa, economías seleccionadas

Nacional Extranjera

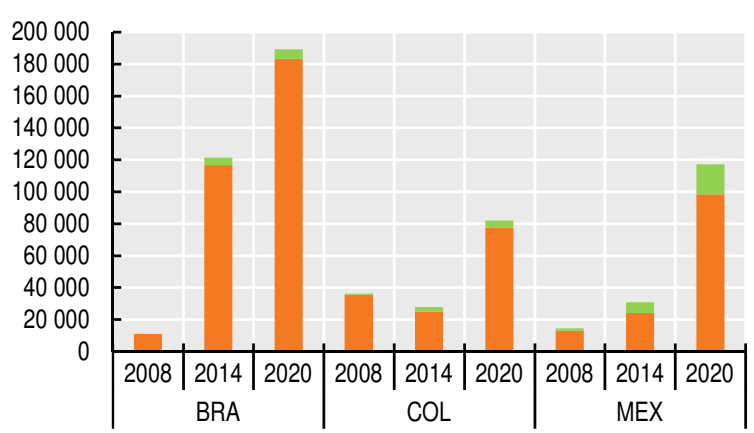

Panel C. Emisión de deuda pública anual por divisa, economías seleccionadas

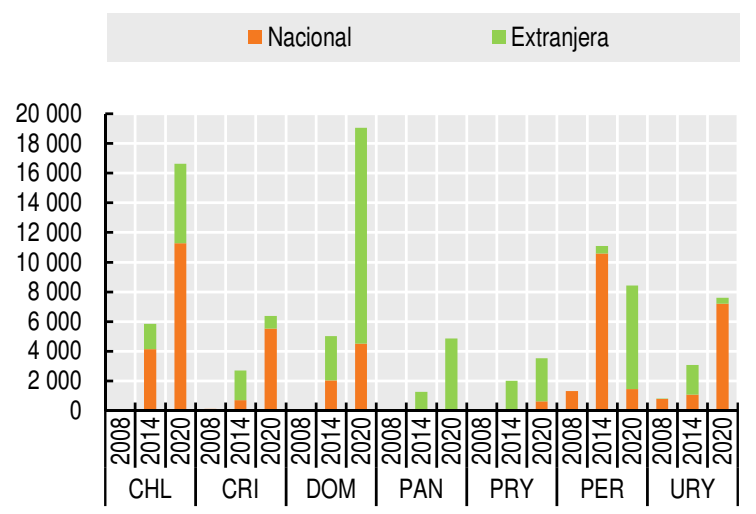

Panel B. Emisión de deuda pública anual por país de emisión, países seleccionados

- Local Extranjera

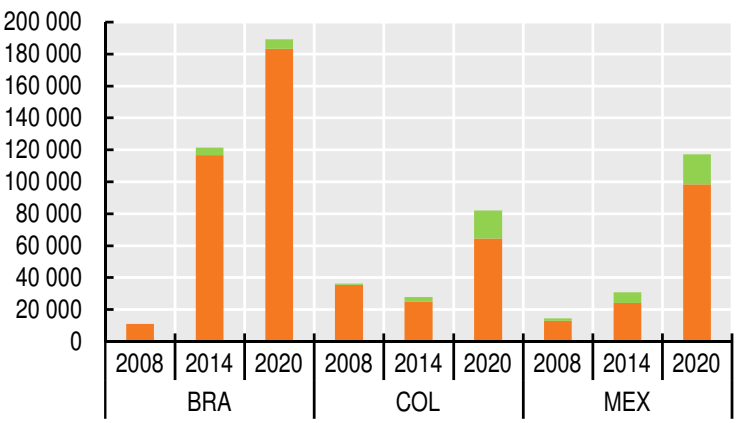

Panel D. Emisión de deuda pública anual por país de emisión, países seleccionados

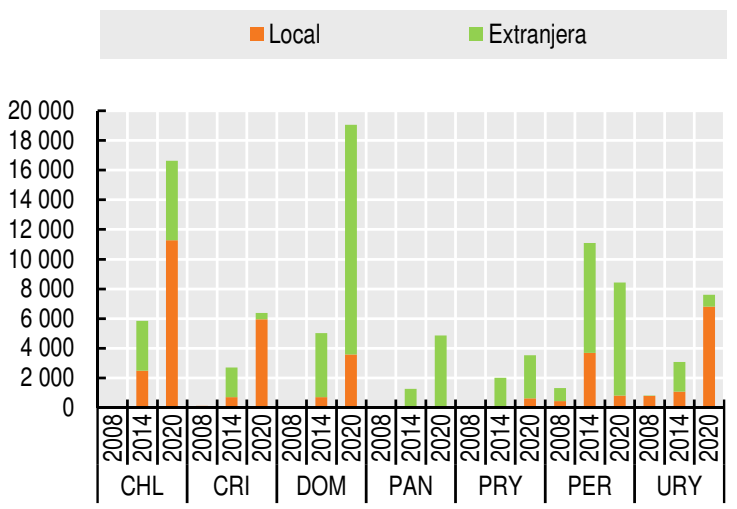

Nota: Millones de dólares USD. La emisión anual de deuda pública se refiere al total de emisiones de bonos públicos activas incluidas las reaperturas.

Fuente: OCDE/CEPAL/CAF/UE, a partir de datos de Refinitiv.

StatLink 젶ㄴ https://doi.org/10.1787/888934295375

Aunque no existe una única solución para conseguir los fondos necesarios que permitan impulsar la recuperación ni para protegerse frente a posibles problemas relacionados con la sostenibilidad de la deuda en ALC, en muchos casos la recuperación económica tendrá que apoyarse en una coordinación internacional que permita a los países deudores seguir llevando a cabo políticas macroeconómicas anticíclicas para responder a la crisis (UNCTAD, 2020 ${ }_{[4]}$ ). Si bien las posibles soluciones a los problemas de financiación dependerán de las características iniciales del país y de su acceso a los mercados, estas deben centrarse en devolver a la región su capacidad para cubrir la deuda mediante un aumento de la inversión, la producción y las exportaciones, y no mediante una disminución del gasto, la recaudación y la contracción de las importaciones (UNCTAD, $\left.2020_{[4]}\right)$. Contamos con ejemplos históricos que nos muestran cómo debemos enfrentarnos a los actuales retos de financiación pública. Tal es el caso del resultado del largo proceso de resolución de la crisis de la deuda del decenio de 1980 en la región (Recuadro 1.2). 


\section{Recuadro 1.2. Olas de crisis de la deuda: una perspectiva histórica}

La historia de las crisis económicas mundiales confirma que la recuperación nunca es uniforme. Lo ocurrido en la década de 1980 constituye un ejemplo histórico de recuperación desigual de una recesión económica. En América Latina, esa década se caracterizó por un lento crecimiento económico, el aumento de las desigualdades y el incremento de la pobreza (Szekely y Montes, $2006_{[35]}$ ), tras un período de fuerte crecimiento económico que había durado al menos un par de décadas. A finales de los años 70, los gobiernos de países pobres habían incrementado su nivel de endeudamiento público. Esta deuda procedía fundamentalmente de los préstamos concedidos por bancos comerciales occidentales, con unas tasas de interés que variaban en función de las tasas de interés interbancario que hubiera en los países de los acreedores principales. En 1979, la Reserva Federal aumentó su tasa de interés para hacer frente a la creciente inflación en los Estados Unidos. Al descenso de la tasa de crecimiento económico en los países desarrollados a principios de los años 80 se unió después la caída de los precios del petróleo y otros productos básicos, lo cual desencadenó la disminución de los ingresos de las exportaciones en los países en desarrollo y el incremento general del costo del servicio de la deuda de los gobiernos.

Algunos académicos consideran que las graves consecuencias económicas y sociales que se produjeron podrían haberse evitado si la crisis se hubiera gestionado de otra manera (Diaz-Alejandro, Krugman y Sachs, $1984_{[36]}$ ). Varios gobiernos de países en desarrollo reestructuraron sus deudas y se adhirieron a programas de ajuste, mientras que los bancos concedieron nuevos préstamos adicionales, pero involuntarios, para respaldar las medidas de ajuste (Devlin, $1989_{[37]}$ ). Tras la adopción de estas soluciones a corto plazo, pensadas para afrontar una crisis de liquidez más que una crisis de solvencia, se produjeron sucesivas rondas de reestructuración entre 1984 y 1986 (Vasquez, 1996 ${ }_{[38]}$ ). Después de 1985, cuando el crecimiento económico se seguía resistiendo debido al deterioro de las condiciones comerciales y la reducción del gasto público, el reajuste de los plazos de la financiación y la renovación de esta empezaron a vincularse oficialmente al crecimiento económico de los países prestatarios, en el marco del conocido como Plan Baker. En consecuencia, el acceso a un nuevo paquete de préstamos de bancos y prestamistas multilaterales y bilaterales se supeditó a la evolución del precio del petróleo (en el caso de México) y a la consecución de una tasa objetivo de crecimiento económico previamente establecida, la cual debía alcanzarse mediante reformas económicas de liberalización.

La evolución de los coeficientes entre los intereses totales abonados y las exportaciones, que siguieron siendo relativamente elevadas durante los primeros años de la crisis, ilustra el resultado de las largas negociaciones mantenidas y de la falta de alivio de la deuda. El promedio en América Latina fue del 41\% en 1982 y solo disminuyó ligeramente en 1985, hasta el 35\%. No se concedió cierto alivio de la deuda hasta 1989, con la aplicación del Plan Brady.

El Plan Brady pretendía reducir la deuda de los bancos comerciales y, al mismo tiempo, brindarles la posibilidad de aumentar o reducir su exposición a cada deudor. Este enfoque "a la carta" incluía el intercambio de préstamos por nuevos bonos, modificando su valor nominal, en función de la nueva provisión de capital y de los riesgos asumidos. Una opción consistía en convertir los préstamos en bonos emitidos por la Tesoro de Estados Unidos y financiados con cargo a las propias reservas de México y mediante préstamos de organizaciones financieras internacionales. Los posteriores pactos Brady establecieron distintas disposiciones para la reducción de la deuda y la emisión de nueva moneda, y fueron aprobados por 18 países. Según (Cline, $1995_{[39]}$ )el pacto habitual consistía en la condonación de entre el 30\% y el 35\% de la deuda de un país. 
Recuadro 1.2. Olas de crisis de la deuda: una perspectiva histórica (cont.)

Existe un gran desacuerdo entre los expertos en lo que respecta a los beneficios del Plan Brady y a si el alivio de la deuda concedido fue suficiente para garantizar un proceso de crecimiento saludable y mejorar la capacidad crediticia de cada país. Para (Rogoff, $1993_{[40]}$ ) considera que estos planes fueron más provechosos para los bancos, que incrementaron el valor de la deuda restante en sus carteras. Si bien el Plan Brady logró reducir el coeficiente de endeudamiento de todos los países, este aumentó posteriormente. De acuerdo con (Cline, $1995_{[39]}$ ), en los años posteriores al Plan Brady los países mostraron un mejor desempeño económico en términos de estabilidad de los precios, crecimiento económico y menores tasas de interés. De hecho, gracias al plan las empresas y los gobiernos pudieron volver al mercado, en su mayoría en condiciones favorables (Buckley, $\left.1998_{[41]}\right)$.

Sigue siendo importante proporcionar ayuda oficial a los países con un acceso escaso o nulo a los mercados de capital. Hasta la fecha, y con el fin de aliviar las presiones financieras, el G20 ha ayudado a los países de bajos ingresos suspendiendo hasta diciembre de 2021 el pago del servicio de las deudas asociadas a préstamos públicos bilaterales. En este sentido, el Fondo Monetario Internacional (FMI) ha brindado asistencia financiera a numerosos países y ha aliviado su servicio de la deuda mediante, por ejemplo, el incremento de los servicios de crédito rápido, instrumentos de financiación rápida y líneas de crédito flexibles para distintos niveles de ingresos. Estas medidas han sido bien recibidas y han dado un respiro temporal a más de 100 países durante la pandemia.

Sin embargo, el apoyo que tanto necesitan los países de ingresos medios, muchos de los cuales se encuentran en ALC, sigue prácticamente sin figurar en la agenda internacional. Aunque los países de ingresos medios se beneficiarán del reciente acuerdo de emisión de derechos especiales de giro (DEG), así una asignación histórica de DEG equivalente a 650000 millones de dólares (unos 456000 millones de DEG), de los cuales unos 275000 millones de dólares (unos 193000 millones de DEG) de la nueva asignación se destinarán a los mercados emergentes. Para estos países es importante acceder a financiación multilateral, pues sigue existiendo el riesgo de que disminuya la financiación privada internacional (Ocampo, 2021 ${ }_{[42]}$ ). Una de las ideas propuestas en este marco consiste en ofrecer una liquidez extraordinaria a los países en desarrollo mediante la creación de fondos de liquidez. Un ejemplo es el Fondo para Aliviar la Economía COVID-19 propuesto, al que los países desarrollados aportarían fondos a través de instituciones multilaterales (CEPAL, 2021 ${ }_{[16]}$ ).

Los países que podrían tener acceso a los mercados de capital, pero seguir incurriendo en un elevado costo de la deuda por la posible rebaja de su calificación crediticia o por las bajas previsiones sobre crecimiento futuro, cuentan con diversas opciones en materia de políticas, como moratorias o interrupciones del pago de la deuda, distintas modalidades de alivio de la deuda (OECD, 2021 $\left.1_{[5]}\right)$, la creación de un instrumento especial para financiar la crisis o pagar la deuda y un mayor uso de los DEG. En particular, la emisión de nuevos DEG o la redistribución de los ya existentes podría ser un medio eficiente para incrementar la liquidez, tanto en ALC como en las economías en desarrollo, sin por ello aumentar la deuda (CEPAL, 2021 $1_{[16]}$ ). Sin embargo, es importante adoptar una visión a largo plazo, más allá de la crisis del COVID-19. Se sigue sin aprovechar lo suficiente los DEG como instrumentos de la comunidad internacional, lo que hace necesario examinar sus marcos fundamentales y su asignación tradicional (Ocampo, 2021 $1_{[42]}$ ). Para ello se requiere una 
cooperación internacional que implique a bancos multilaterales, países desarrollados o acreedores privados (OCDE et al., 2020 ${ }_{[23]}$ ); (Nieto-Parra y Orozco, 2020 ${ }_{[32]}$ ); (Bolton, $2020_{[43]}$ ). Hasta la fecha, los acreedores privados se han mantenido al margen y algunos países han decidido no participar en los programas internacionales para evitar la posibilidad de que sus calificaciones crediticias bajen (OCDE, 2021 ${ }_{[8]}$ ).

Por último, los países que ya disfrutaban de una amplia sostenibilidad fiscal deben seguir teniendo acceso a los mercados de capital con unas primas de bajo riesgo que les permitan obtener los fondos necesarios para plantar cara a la crisis. A nivel internacional, también conviene tratar de lograr una transparencia adecuada de la deuda y brindar asistencia técnica, de modo que los países de la región puedan reforzar sus capacidades de gestión de la deuda (OCDE, 2021 $\left.{ }_{[8]}\right)\left(\right.$ Subacchi, 2020 $\left.{ }_{[44]}\right)$.

En cuanto a los mecanismos de reestructuración de la deuda, resulta esencial establecer una estrecha coordinación con los titulares de bonos y las partes interesadas en el mercado de capitales para reducir al mínimo el riesgo reputacional (es decir, el futuro acceso a los mercados de capital). Las recientes experiencias vividas con la reestructuración de la deuda en Argentina y Ecuador demuestran la importancia de incluir cláusulas de acción colectiva en los contratos de bonos soberanos (OCDE et al., 2020 ${ }_{[23]}$ ). Aunque el uso de los mecanismos existentes es bienvenido, de ahora en adelante es importante replantearse los procedimientos internacionales de reestructuración de la deuda soberana para que no se limiten a las cláusulas de acción colectiva (Ocampo, 2021 $1_{[42]}$ ).

Con el fin de facilitar una recuperación sólida e inclusiva, las economías de ALC pueden recurrir a opciones de política innovadoras con alcance social o ambiental para satisfacer sus necesidades de financiación. Por ejemplo, podrían ponerse en práctica canjes de deuda por medidas de protección frente al COVID-19, por medidas para la consecución de los ODS, por medidas de adaptación al cambio climático o por medidas de conservación de la naturaleza. Los gobiernos deudores y prestamistas, así como los acreedores privados, se beneficiarían a medida que los países deudores canalizan los pagos del servicio de la deuda previstos a través de políticas nacionales de mitigación del COVID-19 o inversiones relacionadas con los ODS, el cambio climático o la naturaleza (ONU/DAES, 2020 [45]; Steele y Patel, $\left.2020_{[46]}\right)$. Del mismo modo, la introducción de bonos "verdes" ligados a la sostenibilidad social y ambiental vincularía la financiación extranjera sostenible a los compromisos relacionados con los ODS. Esto permitiría a los países reunir los recursos financieros que tanto necesitan para lidiar con la crisis del COVID-19 y, al mismo tiempo, comprometerse a alcanzar los ODS (Caputo Silva y Stewart, $2021_{[47]}$ ). Hace poco, México se convirtió en el primer país de ALC en emitir un bono vinculado a la consecución de los ODS: 750 millones de EUR (euros) con una tasa de interés del 1.35\% (CEPAL, 2021 ${ }_{[16]}$ ).

Los países vulnerables al cambio climático (como es el caso de la mayoría de los de ALC) tienen unas calificaciones crediticias desfavorables y los prestamistas consideran que tienen una mayor probabilidad de impago de la deuda que los que los paises más resilientes al cambio climático. En un momento en que la región debe buscar soluciones sostenibles para recuperarse de la crisis por la pandemia, los países de ALC con poco margen fiscal podrían beneficiarse de instrumentos de política alternativos que les proporcionen recursos para luchar contra el cambio climático y, simultáneamente, reducir la carga de la deuda, su costo y la presión sobre los balances fiscales (Cevik y Tovar Jalles, $2021_{[48]}$ ). Por último, los futuros instrumentos de deuda que incluyan cláusulas "similares a un seguro" y supediten los pagos a los acreedores al desempeño económico del país del deudor ofrecerán algo de alivio cuando la situación económica no sea favorable y compensarán a los acreedores cuando mejoren las previsiones del país en cuestión (Breuer y Cohen, $2020_{[33]}$; OCDE et al., 2020 ${ }_{[23]}$ ). Por ejemplo, en el Caribe, donde los países están muy expuestos a riesgos de desastres naturales, debería ser habitual incluir cláusulas de 
salvaguardia en caso de huracán para mejorar la capacidad de amortización de la deuda. En Granada, la introducción de dichas cláusulas ha reducido los niveles de deuda (CEPAL, $\left.2021_{[16]}\right)$.

En el caso de economías como las del Caribe, la exposición recurrente a peligros naturales y sus devastadores efectos sociales y económicos pueden empeorar la situación financiera y conducir al sobreendeudamiento. Las cláusulas de salvaguardia en caso de huracán permiten aplazar el pago de capital y los intereses del servicio de la deuda, o contemplan la posibilidad de acelerar la reestructuración de la deuda en caso de huracán (u otro desastre natural cubierto por dichas cláusulas).

Las economías de ALC deben recuperar gradualmente sus marcos fiscales y emprender las medidas necesarias para garantizar la claridad y eficiencia del gasto. Las normas fiscales, un elemento clave de los marcos fiscales, son esenciales para reducir o revertir la conducta procíclica propia de la política fiscal de ALC (Vegh y Vuletin, $2014_{[49]}$; Alberola et al., 2016 ${ }_{[50]}$ y proteger la inversión pública. Como medida extraordinaria, muchos países de la región decidieron no aplicar sus normas en la materia para emprender grandes expansiones fiscales. A medida que la pandemia remita y los países reduzcan su gasto público, y a fin de evitar repercusiones a largo plazo para las futuras consolidaciones fiscales, la recuperación de sus marcos fiscales o la aplicación de normas fiscales puede ser una herramienta útil para proteger la inversión pública y añadir una dimensión que impulse el crecimiento (Ardanaz et al., 2021 ${ }_{[51]}$ ). Estas reglas deben ser claras y transparentes, y garantizar cláusulas de escape para medidas excepcionales.

\section{Efectos sociales de la crisis del COVID-19}

La pérdida de ingresos se tradujo en peores condiciones de vida, así como en un incremento notable del desempleo, la pobreza y la desigualdad (CEPAL, 2021 $1_{[17]}$ ). El desplome de los ingresos en ALC se concentra en los sectores más vulnerables. El sector informal, por ejemplo, es en el que más empleos se han perdido en todas las economías regionales. Los hogares cuyos ingresos dependen de la economía informal o de sectores peor remunerados estuvieron desprotegidos frente a la pérdida durante los confinamientos. La caída de la demanda exterior de ciertos productos que suelen exportarse también fue un factor decisivo que desencadenó una crisis más profunda en ALC.

\section{La crisis provocó el cierre de miles de negocios y, en consecuencia, destruyó millones de empleos, sobre todo en el sector informal}

Tradicionalmente, losmercadoslaboralesdeAméricaLatinahansidoinformales, frágiles y excluyentes. Más de la mitad de los trabajadores ocupan puestos de trabajo informales (OCDE, 2020 ${ }_{[24]}$ ). Los hogares dependientes de la economía informal son los más afectados por la crisis del COVID-19, pues han perdido sus empleos y los ingresos que obtenían con ellos. En promedio, casila mitad (el 45\%) de la población de ALC vive en hogares que dependen exclusivamente del empleo informal; el $22 \%$ vive en hogares mixtos, y el $33 \%$ vive en hogares que solo dependen de la economía formal (OCDE, Próximo a publicarse $\left.{ }_{[52]}\right)$. De acuerdo con con los Indicadores de Informalidad basados en los Individuos y sus Hogares (KIIBIH), los niveles de informalidad en los países de ALC presentan una gran heterogeneidad, desde menos del $20 \%$ en Chile y Uruguay hasta más del $60 \%$ en Bolivia, Honduras y Nicaragua (Gráfico 1.8). 


\section{Gráfico 1.8. Más de la mitad de los latinoamericanos viven en hogares mixtos o que dependen por completo de la economía informal}

Distribución de la población total por grado de informalidad de los hogares (\%) 2018 o último año disponible

Informales

Mixtos

Formales

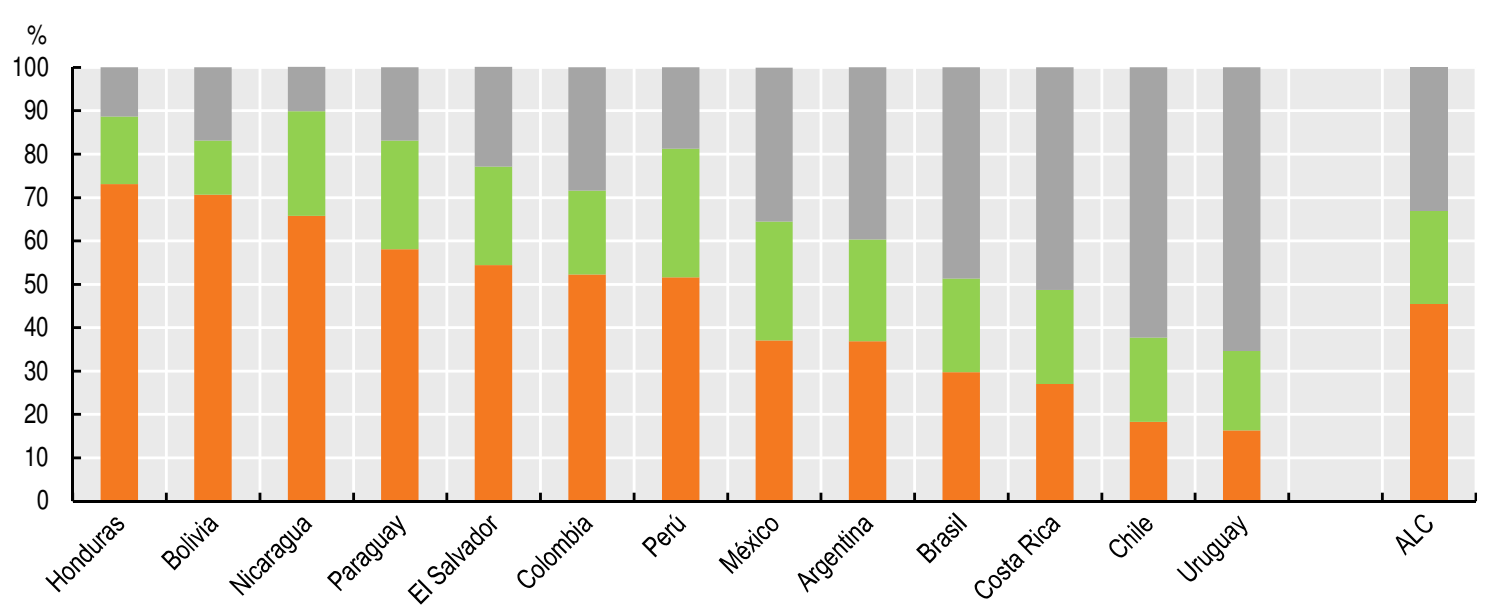

Nota: A partir de la clasificación de la OCDE/OIT $\left(2019_{[53]}\right)$ se asigna a las personas a una de las tres categorías en función del grado de informalidad de sus hogares. Hogares formales: todos los miembros del hogar trabajan en el sector formal. Hogares informales: todos los miembros del hogar trabajan en el sector informal. Hogares mixtos: algunos miembros del hogar trabajan en el sector formal y otros, en el informal.

Fuente: (OCDE, Próximo a publicarse ${ }_{[52]}$ ), Informalidad laboral y vulnerabilidad de los hogares en América Latina (título provisional).

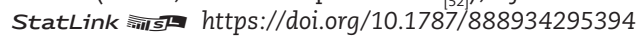

Los programas dirigidos a la población más afectada deben tener en cuenta la dimensión del hogar. El bienestar de los hogares que están del todo en la economía informal difiere, a veces de manera significativa, del de aquellos en "estatus mixto" o en su totalidad de aquellos en la economía formal. Existe una segmentación a nivel de los hogares que pone de relieve la importancia de hacer una distinción entre los hogares mixtos y aquellos que dependen en exclusiva de la economía informal cuando se diseñan las intervenciones de políticas públicas. Ambos tipos de hogares representan a un porcentaje importante de la población.

Es necesario examinar la informalidad desde el punto de vista de los hogares para así registrar el nivel de pobreza económica e inseguridad en términos de ingresos de los trabajadores informales, medir la capacidad para pagar la protección social, detectar la posibilidad de acceder a ella a través de los miembros del hogar que trabajan en la economía formal, y evaluar hasta qué punto la vulnerabilidad de los trabajadores informales se transmite a las personas a su cargo (OCDE, Próximo a publicarse ${ }_{[52]}$ ).

Debido a la falta de protección social o de mejores condiciones laborales, los trabajadores informales están atrapados en un círculo vicioso que les impide escapar de su vulnerabilidad. En algunos países, como Bolivia, Ecuador, Paraguay y Perú, existen importantes diferencias entre los trabajadores informales y los formales que viven en la pobreza o en situación de vulnerabilidad. No es solo que los trabajadores informales tengan un acceso más limitado o insuficiente a protección social, es que la inestabilidad de sus ingresos les impide invertir en capital humano y conseguir trabajos más productivos (OCDE et al., 2019 ${ }_{[6]}$ ).

Los efectos de la pandemia provocaron importantes retrocesos en varios indicadores laborales, tales como la contracción del empleo (CEPAL, 2021 ${ }_{[3]}$ ). Los más perjudicados fueron los jóvenes y las mujeres, que, además de verse muy afectados por la pérdida 
de trabajo, tuvieron que dedicar una enorme cantidad de tiempo a los cuidados no remunerados debido al funcionamiento limitado de los centros educativos y los servicios asistenciales para personas dependientes (Gráfico 1.9). Además, las poblaciones más vulnerables de la región, como los afrodescendientes, los pueblos indígenas, los migrantes y las personas con menor nivel educativo, suelen trabajar en el sector informal, que prácticamente se detuvo por completo durante los confinamientos.

Los problemas estructurales preexistentes, como la brecha digital y el acceso desigual a recursos financieros, también repercuten en los niveles de informalidad e incrementan la desigualdad. La brecha digital ha agravado la desigualdad en la región y ha afectado de manera desproporcionada a los trabajadores informales. La desigualdad generada por la pandemia queda en evidencia, principalmente, en la capacidad de teletrabajar, que guarda relación con el nivel de ingresos. La falta de competencias e infraestructuras digitales impiden que los trabajadores informales se desempeñen desde casa y los priva de los beneficios generales de la transformación digital (OCDE et al., 2021 ${ }_{[18]}$ ). En ese sentido, es posible que los hogares dependientes del sector informal no tengan acceso al sistema financiero, de modo que no pueden obtener un préstamo para invertir o consumir. De hecho, la falta de acceso a los servicios del sistema financiero (préstamo, cuenta bancaria) puede frenar el crecimiento de las empresas informales y podría obstaculizar la formalización (OCDE/OIT, 2019 ${ }_{[53]}$ ).

\section{Gráfico 1.9. El COVID-19 ha provocado pérdidas de empleo considerables en toda la región de ALC, algo que ha afectado más a las mujeres que a los hombres}

Variación de la población ocupada total, por sexo, segundo trimestre de 2019 a segundo trimestre de 2020 (\%)

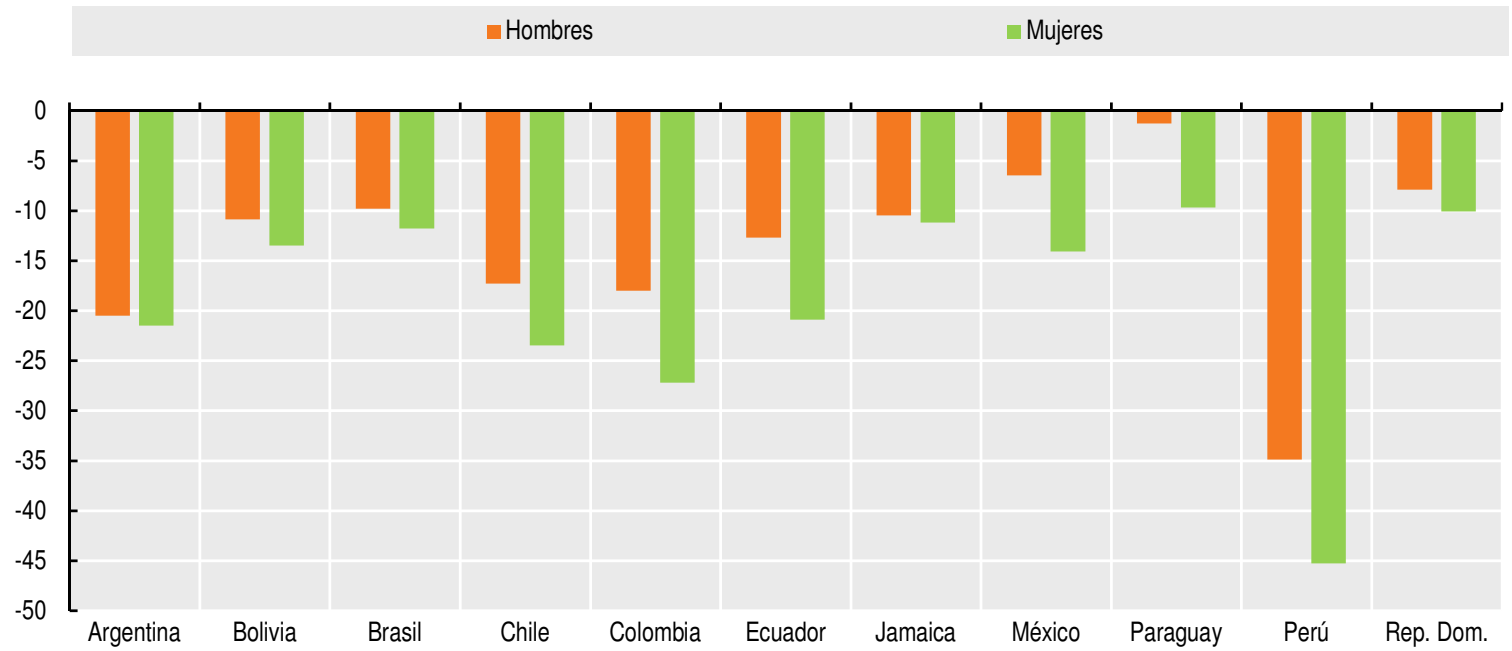

Notas: Los datos relativos a Argentina solo se refieren a 31 núcleos urbanos. Los datos de Bolivia solo se refieren a las zonas urbanas. Los de Ecuador abarcan de junio de 2019 a mayo/junio de 2020. Los datos de Jamaica corresponden a julio de 2020 y los de México corresponden a mayo de 2020.

Fuente: (CEPAL, 2021 ${ }_{[17]}$ ), Panorama Social de América Latina 2020 www.cepal.org/es/publicaciones/46687-panorama-socialamerica-latina-2020.

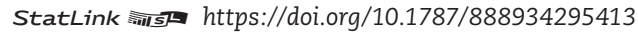

Millones de latinoamericanos vulnerables han caído en la pobreza y la pobreza extrema, mientras que las brechas de desigualdad siguen aumentando en la región

La crisis del COVID-19 ha revertido algunos de los avances en la erradicación de la pobreza y la desigualdad logrados durante la década pasada. En los últimos decenios, los gobiernos de ALC han reducido considerablemente la pobreza, pues sacaron en torno a 
42 millones de personas de esta situación entre 2004 y 2019. Antes de la crisis, alrededor del 30.5\% de la población total de ALC vivía en la pobreza (187 millones de personas), y el $11.3 \%$ vivía en la pobreza extrema (70 millones de personas). Como resultado de la pandemia, se estima que la tasa de pobreza extrema en 2020 fue del $12.5 \%$ y que la tasa de pobreza alcanzó el 33.7\%, unos niveles nunca vistos en los últimos 12 años —o 20, en el caso de la pobreza extrema- (CEPAL, 2021 ${ }_{[17]}$ ).

La crisis afectó a los grupos vulnerables al reducir las oportunidades laborales y los ingresos. La pérdida de empleo y la consiguiente pérdida de ingresos provocadas por la pandemia han incrementado la pobreza, reducido la clase media y aumentado la desigualdad. Las personas más afectadas por la pérdida de empleo pertenecían al primer quintil, ya que la proporción de trabajadores de ese quintil que dejaron de percibir ingresos por su trabajo (respecto de los ingresos de 2019) aumentó 5.7 puntos porcentuales, un valor considerablemente superior al de quintiles posteriores. En el quintil más rico el aumento fue de 0.7 puntos porcentuales. Del mismo modo, para quienes conservaron su trabajo, se estima que la pérdida de ingresos equivale a una disminución del $15 \%$ del promedio de ingresos laborales. Se calcula que en 2019 los ingresos de los trabajadores del primer quintil se redujeron un $42 \%$, mientras que los de los trabajadores del quinto quintil disminuyeron en torno a un 7\% (CEPAL, 2021 $[17]$ ).

Las dinámicas negativas del empleo y los ingresos han reducido a la clase media y amenazan con agravar las brechas sociales y económicas existentes en una región que ya presenta grandes desigualdades. El número de personas que viven con bajos ingresos (vulnerables, pobres y extremadamente pobres) se ha disparado, y ya son 32 millones más que antes de la crisis. En contraste, el número de personas que perciben ingresos medio-bajos disminuyó en 7 millones, el número de personas con unos ingresos medios disminuyó en 13 millones (13.1\%), el número de personas con unos ingresos medio-altos disminuyó en 4 millones (14.2\%), y el número de personas con ingresos altos disminuyó en 2 millones (10.5\%) (Gráfico 1.10).

En resumen, los hogares dependientes del sector informal son los más perjudicados por la crisis del COVID-19, pues se enfrentan a la pérdida de empleo y el descenso de sus ingresos procedentes del trabajo. Los efectos de la pandemia provocaron importantes retrocesos en varios indicadores laborales, tales como la contracción del empleo. Los grupos más afectados son las mujeres y las poblaciones más vulnerables de la región, como los afrodescendientes, los pueblos indígenas, los migrantes y las personas con menor nivel educativo. Los problemas estructurales, como la brecha digital y el acceso desigual al mercado del trabajo, también repercuten en la inclusión en los mercados laborales. 


\section{Gráfico 1.10. La crisis del COVID-19 ha multiplicado el número de personas que viven con bajos ingresos y ha reducido las clases media y alta}

$\square$ Pobreza Extrema $\quad \square$ Pobreza $\quad \square$ Bajos ingresos, por encima de linea de pobreza $\quad \square$ Clase media baja $\quad \square$ Clase media $\square$ Clase media alta $\square$ Clase alta

Panel A. Cambios, 2019-20, millones de personas

Panel B. Millones de personas, 2020

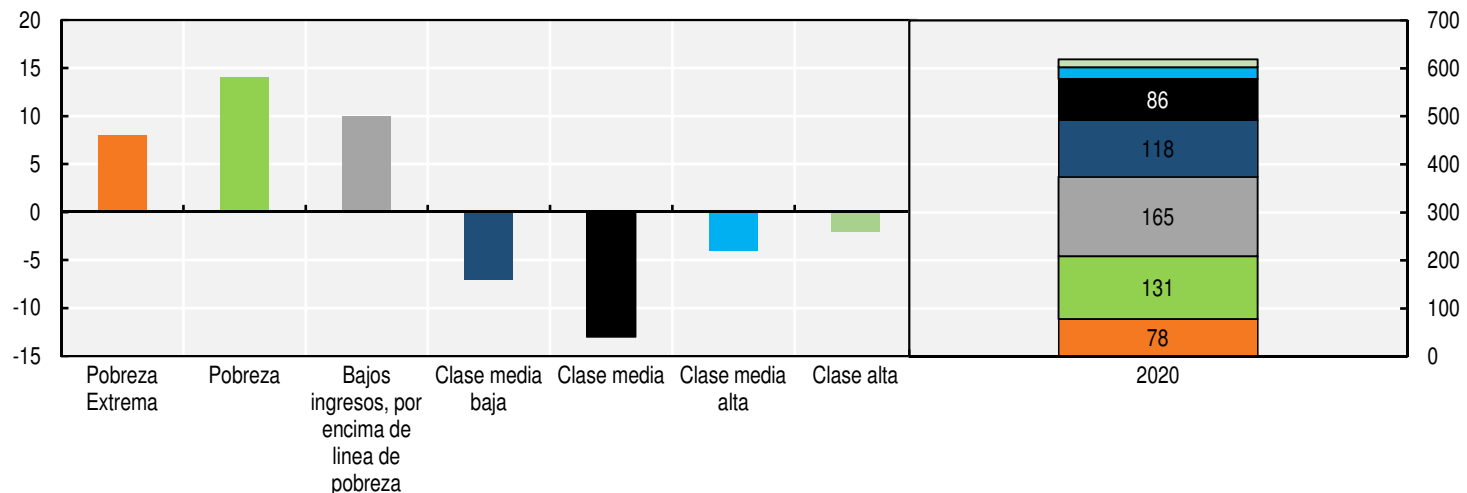

Nota: Incluye a Argentina, Bolivia, Brasil, Chile, Colombia, Costa Rica, Ecuador, El Salvador, Guatemala, Honduras, México, Nicaragua, Panamá, Paraguay, Perú, República Dominicana, Uruguay y Venezuela. Los datos se refieren a la definición de los estratos de ingreso, según lo especificado por la Comisión Económica para América Latina y el Caribe de las Naciones Unidas (CEPAL, 2021), Panorama Social de América Latina 2020 y (CEPAL, 2019), Panorama Social de América Latina 2019. La línea de pobreza extrema representa el nivel de ingresos que permite a cada hogar satisfacer las necesidades básicas de todos sus miembros. La canasta básica para medir la pobreza se forma a partir de una selección de alimentos, que incluye los bienes requeridos para satisfacer las necesidades nutricionales, tomando en cuenta los precios de los alimentos en cada país y área geográfica. A continuación, se añade la cantidad requerida por los hogares para satisfacer las necesidades básicas no alimentarias para definir el umbral de pobreza. Los no pobres de renta baja son aquellos hogares con una renta per cápita de hasta 1.8 veces el umbral de pobreza; el estrato medio-bajo, el estrato medio-alto se definen por tener, respectivamente, una renta per cápita de hasta 3, 6 y 10 veces el umbral de pobreza. El estrato de ingresos altos es el que supera hasta 10 veces el umbral de pobreza.

Fuente: Comisión Económica para América Latina y el Caribe, a partir del Banco de Datos de Encuestas de Hogares (BADEHOG). Cifras adaptadas a las proyecciones demográficas de las Naciones Unidas, "World Population Prospects 2019", Nueva York, 2019 [en línea], https://population.un.org/wpp/, y estimaciones de las tendencias de la pobreza para aquellos países sobre los que no se dispone de datos correspondientes a los años indicados.

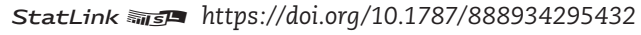

\section{Los débiles mecanismos de protección social de la región no lograron impedir la grave crisis social provocada por la pandemia}

Debido a la inexistencia de mecanismos de protección social robustos en ALC, millones de familias que trabajan en la economía informal sufrieron una caída drástica de sus ingresos durante los confinamientos. A raíz de la estrategia para contener los contagios que se adoptó en todo el mundo, los países de ALC paralizaron sus economías (OCDE, $\left.2020_{[30]}\right)$. Sin embargo, mientras que los países de la OCDE, donde predomina el sector formal, proporcionaron seguros de desempleo a sus ciudadanos y prestaron asistencia a las empresas para evitar la pérdida de empleos, cuando la pandemia llegó a ALC, millones de familias y empresas no estaban protegidas por los mecanismos de seguridad social. En promedio, en la región, más del $60 \%$ de los trabajadores económicamente vulnerables y del sector informal no reciben protección social de carácter laboral ni están amparados por un programa de asistencia social (como las transferencias monetarias condicionadas; Gráfico 1.11, Panel A).

ALC tiene una larga historia de programas de asistencia social, y cuenta con casos ejemplares como la Bolsa Família de Brasil o el programa de transferencias monetarias condicionadas de México, llamado "Oportunidades", y, antes de que se interrumpiera, "Prospera". No obstante, aunque los programas de asistencia social están generalizados y han sido de gran ayuda para muchas familias, en torno al $50 \%$ de los trabajadores 
informales pobres no reciben asistencia (Gráfico 1.11, Panel B). Además, el porcentaje de familias que no están cubiertas por estos programas varía mucho de unos países a otros, pues se sitúa entre el $97 \%$ de los trabajadores pobres en El Salvador y el $26 \%$ en Argentina.

La protección social en ALC debe empezar a fortalecer los mecanismos de financiación, y así flexibilizar las cotizaciones sociales con una combinación de programas no contributivos, contributivos y voluntarios. Las contribuciones a la seguridad social como porcentaje de los costos laborales son relativamente elevadas en ALC. Los promedios de los países de la región son similares a los de los países de la OCDE y excepcionalmente altos para los deciles inferiores (OCDE/CIAT/BID, 2016 ${ }_{[55]}$ ). La reducción de los costos laborales no salariales podría fomentar la creación de empleos formales, especialmente en las pymes, y, de ese modo, promover el emprendimiento. Del mismo modo, trasladar parte de la carga fiscal de las cotizaciones a la seguridad social a los impuestos sobre la propiedad también podría resultar útil para reducir la informalidad (OCDE, 2020 ${ }_{[28}$ ). Sin embargo, una estrategia productiva clara es clave para apoyar esas políticas (Capítulo 3). También podría mejorar la percepción de los ciudadanos sobre la protección social del Estado, reforzando así los incentivos para la formalización y el pago de impuestos (OCDE et al., $\left.2019_{[6]}\right)$. Una manera de alcanzar este objetivo es creando una red de seguridad social que no esté ligada al empleo formal y se financie con cargo a impuestos generales.

\section{Gráfico 1.11. Debido a la falta de protección social, los trabajadores informales tienen un riesgo mucho mayor de caer en la pobreza ante situaciones adversas que los del sector formal}
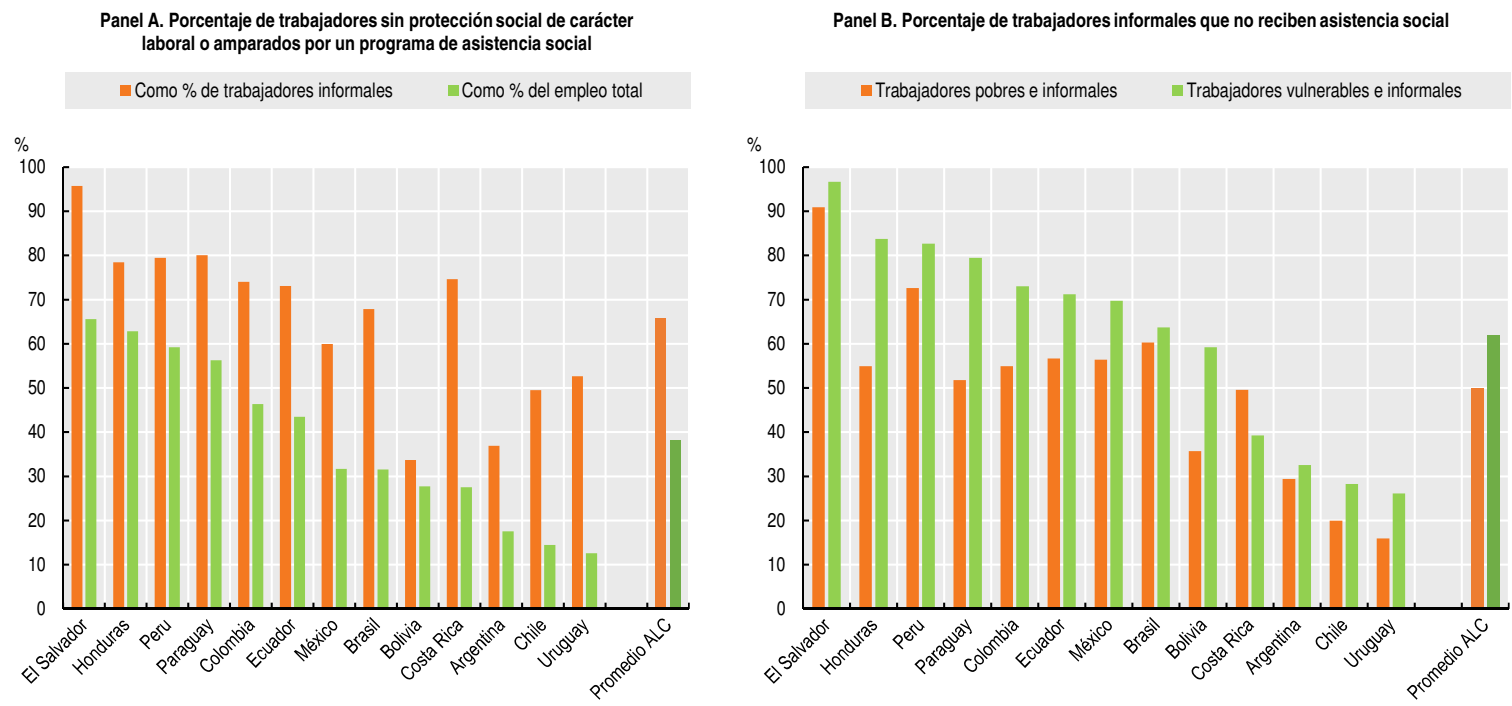

Notas: El promedio regional no está ponderado. La definición de “informalidad” se basa en la de la OIT (OCDE/OIT, 2019 ${ }_{[53]}$ ). Los principales programas de asistencia social se refieren únicamente a los principales programas de transferencias monetarias condicionadas y las pensiones sociales no contributivas. No obstante, la disponibilidad de datos sobre los beneficiarios obtenidos a partir de las encuestas de hogares varía de unos países a otros, lo cual puede dar lugar a datos no comparables que el proceso de armonización no resuelva por completo. En el caso de Argentina y Brasil, estos porcentajes se han calculado en función de las condiciones de focalización de los programas sociales. Debido al enfoque sistemático para generar datos comparables a nivel internacional y al uso de encuestas de hogares distintas de las encuestas de población activa, las estimaciones relativas a la informalidad pueden diferir de las presentadas en otras fuentes, incluidas las estadísticas nacionales. Estas cifras podrían actualizarse. "Vulnerabilidad económica" se refiere a una renta per cápita de 5.5 a 13 USD al día. "Pobreza" se refiere a una renta per cápita de menos de 5.5 USD diarios.

Fuente: Cálculos propios basados en las encuestas de hogares: Argentina: EPH 2018. Bolivia: Encuesta de hogares 2018. Brasil: PNAD 2015. Chile: CASEN 2017. Colombia: ENCV 2017. Costa Rica: ENH 2018. El Salvador: EHPM 2017. Ecuador: ENEMDU 2018. Honduras: EPHPM 2014. México: ENH 2018. Paraguay: EPH 2018. Perú: ENH 2018. Uruguay: ECH 2018.

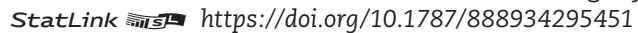




\section{Si no se hubiesen adoptado políticas rápidas y eficientes, las consecuencias de la} crisis podrían haber sido aún más profundas

Las políticas de apoyo a los trabajadores, los hogares y las empresas ayudaron a mitigar los efectos negativos de la crisis del COVID-19 sobre la pobreza y la desigualdad. Los países de América Latina implementaron políticas rápidas, efectivas y bien orientadas para los grupos más vulnerables (véase la sección sobre política fiscal y el capítulo 2). Por ejemplo, las transferencias monetarias ayudaron a reducir los efectos de la pobreza; sin ellas, se estima que el número de personas que viven en la pobreza habría sido de 21 millones más (hasta 230 millones de personas) y 20 millones más en la pobreza extrema (hasta 98 millones) (Gráfico 1.12). Del mismo modo, sin las transferencias gubernamentales para mitigar la pérdida de ingresos laborales, el Índice de Gini habría aumentado un 5.6\% más alto que el registrado en 2019-, en lugar del 2.9\%.

\section{Gráfico 1.12. Efecto de las transferencias monetarias para contrarrestar COVID-19 en indicadores sociales seleccionados}

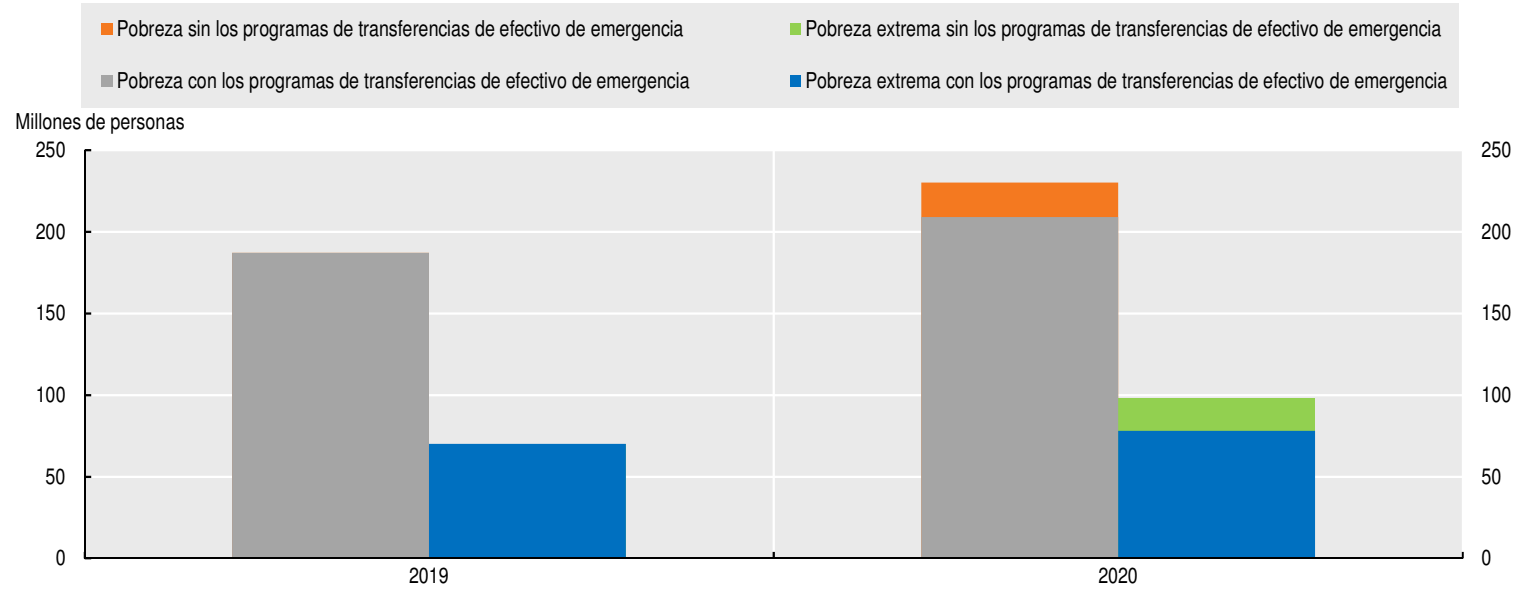

Fuente: Cálculos propios basados en (CEPAL, 2021 $\left.{ }_{[17]}\right)$.

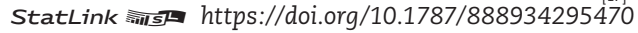

Las iniciativas políticas emprendidas para hacer frente a la crisis del COVID-19 sientan los cimientos para avanzar hacia unos sistemas de protección social universales, integrales y sostenibles. Para responder a la crisis, los gobiernos reaccionaron rápidamente adoptando medidas de asistencia social dirigidas a las poblaciones vulnerables que no estaban cubiertas por los programas sociales o los mecanismos de protección social tradicionales. Continuar prestando una atención prioritaria a las poblaciones vulnerables tras la crisis y brindarles protección social son condiciones esenciales para un estado de bienestar (Capítulo 2).

\section{Conclusiones}

La crisis del COVID-19 ha agravado la situación ya de por sí complicada de ALC. Cuando comenzó la pandemia, la región presentaba problemas estructurales persistentes (p. ej., un bajo crecimiento de la productividad, una clase media vulnerable, la informalidad laboral, la debilidad de las instituciones) y tenía poco margen para adoptar políticas expansionistas a nivel monetario y fiscal. Sin embargo, y a pesar de las complicaciones y los desafíos ocasionados por la pandemia, la crisis y su recuperación han ofrecido un impulso y una oportunidad que podrían ser propicios para emprender los cambios estructurales que garantizarán una vía de desarrollo sostenible e inclusivo para la región.

La recesión económica ha empeorado las condiciones de vida y ha aumentado considerablemente el desempleo, la pobreza y la desigualdad, lo que ha afectado profundamente a los más vulnerables. Los trabajadores del sector informal han sido los más perjudicados, 
pues la falta de protección social o las peores condiciones laborales que tienen los dejan desprotegidos. La crisis puso de relieve la necesidad y la oportunidad de aumentar la cobertura y la calidad de los sistemas de protección social.

Hasta la fecha, la respuesta a la crisis ha girado en torno a las políticas relativas a la demanda que apoyan a los sistemas de salud pública, los hogares y las empresas, y la política fiscal debería desempeñar un papel fundamental en la recuperación. Algunos países deberían continuar apoyándose en la política monetaria, a pesar de la subida de los precios. No obstante, su capacidad sigue siendo limitada, y la política fiscal debería cobrar un mayor protagonismo para lograr una recuperación sólida, inclusiva y sostenible.

Para lograrlo, la clave es llevar a cabo acciones coordinadas a nivel fiscal. En particular, las medidas de gestión del gasto público, la tributación y la deuda pública deberían coordinarse en el marco de una serie de políticas bien escalonadas que puedan adaptarse a las distintas fases de la recuperación. El gasto público debería dirigirse a la población más vulnerable y dejar gradualmente de ser un gasto corriente para ser un gasto de capital, para lo cual se deberán tener en cuenta los beneficios de la transformación digital y habrá que invertir en la transición a una economía con bajas emisiones de carbono. Para movilizar los recursos necesarios se requerirá una estrategia fiscal que combine la mejora de la estructura del sistema tributario, la reducción de la evasión y elusión de impuestos, y políticas encaminadas a redoblar el cumplimiento de las obligaciones fiscales y fortalecer la administración tributaria. Por otro lado, para garantizar la sostenibilidad fiscal a largo plazo, se deberían instaurar marcos fiscales nuevos e innovadores que contengan reglas fiscales. Estos marcos deberían ser claros y transparentes y proteger la inversión, además de incluir cláusulas de escape apropiadas. Por último, las respuestas nacionales no son suficientes; la naturaleza de esta crisis y las interrelaciones entre países exigen una mayor coordinación y cooperación a escala internacional. Esto es especialmente evidente en lo que respecta a la gestión de la deuda pública.

En términos generales, es preciso que existan un consenso y un diálogo nacional en torno a los plazos y las dimensiones de las medidas públicas necesarias. Si se quiere lograr un cambio estructural, la economía política es más importante que nunca. Cualquier reforma estructural debe acometerse sin perder de vista el contexto actual y escalonando adecuadamente las actuaciones. También deben sustentarse en un amplio consenso logrado gracias al diálogo nacional y una comunicación clara (Capítulo 4). Sin embargo, es posible adoptar algunas medidas a corto plazo que pueden ser sumamente efectivas, como aquellas orientadas a reducir la evasión y elusión de impuestos.

\section{Recuadro 1.3. Principales mensajes en materia de políticas}

No existe un enfoque o una solución única que garantice que las políticas se traduzcan en una recuperación sólida e inclusiva de la crisis del coronavirus (COVID-19) para América Latina y el Caribe (ALC). Las características socioeconómicas propias del contexto de cada país, unidas a las diversas repercusiones de la crisis, exigen la adopción de un enfoque adaptado. No obstante, algunas consideraciones generales pueden ayudar a los países a elaborar un buen "menú de políticas" y lograr un equilibrio adecuado entre todas ellas.

1. Aplicar estrategias de vacunación eficaces y equitativas como elemento clave para la recuperación a a corto plazo.

- Garantizar un despliegue rápido y eficaz de las vacunas para permitir la normalización de la actividad económica a nivel nacional.

- Promover la integración regional y la cooperación internacional para fomentar la investigación, el desarrollo y la producción de vacunas y medicamentos en ALC 


\section{Recuadro 1.3. Principales mensajes en materia de políticas (cont.)}

2. La política fiscal es un elemento central de la respuesta a la actual crisis, y determinará en gran medida el grado de inclusividad y la solidez de la recuperación. A pesar de que los contextos nacionales son muy variados, los países deben tener en cuenta ciertos factores y medidas fiscales comunes en su camino a la recuperación.

- Una respuesta fiscal integral debería aprovechar todas las herramientas que ofrece la política fiscal. Existen argumentos para "agrupar" las reformas en un paquete integral a fin de crear legitimidad fiscal en la región. Este agrupamiento, propicia el apoyo político para reformas fundamentales y soluciona los problemas de distribución.

- Las medidas fiscales deberían coordinarse en el marco de una sucesión bien definida de políticas que puedan adaptarse a las distintas fases de la recuperación.

- Es preciso que haya un consenso y un diálogo nacional en torno a los plazos y las dimensiones del gasto público y los impuestos necesarios. El consenso puede ayudar a renovar el contrato social.

- Acciones bien enfocadas, tanto en términos de gastos como de ingresos, deberían promover una mayor progresividad y una creación de empleo formal sostenible.

- Para garantizar la sostenibilidad fiscal a largo plazo, se deberían instaurar marcos fiscales nuevos e innovadores que contengan reglas fiscales. Estos marcos deberían ser claros y transparentes y proteger la inversión, además de incluir cláusulas de escape apropiadas.

- La adopción de medidas a nivel nacional no es suficiente. La naturaleza de esta crisis y los vínculos existentes entre los países hacen necesaria una mayor coordinación y cooperación a escala internacional.

3. Si es posible, conviene mantener una política monetaria expansiva que respalde la recuperación.

- La política monetaria debe seguir teniendo fines de estímulo. Si la inflación se mantiene bajo control y las condiciones financieras siguen siendo favorables, la mayoría de los bancos centrales deberían ser capaces de facilitar la recuperación manteniendo unas tasas de interés bajas, aunque con menos margen.

- Los bancos centrales con regímenes de objetivos de inflación deben vigilar de cerca los efectos secundarios que podrían alejar las expectativas de tales objetivos.

- Hay que seguir apoyando, controlando y supervisando el sistema financiero.

4. Hay que atraer una inversión extranjera directa (IED) de calidad, ya que puede estimular un crecimiento inclusivo y sostenible.

- Una IED de calidad puede realizar importantes contribuciones al desarrollo sostenible al incrementar la productividad y la innovación, crear empleos de calidad, desarrollar el capital humano y mejorar los niveles de vida y la sostenibilidad ambiental. La mejora y el aumento de la IED deberían formar parte de una estrategia productiva más amplia.

5. Para proteger a las poblaciones más vulnerables, y en especial a los hogares que dependen del sector informal, es preciso adoptar políticas bien diseñadas.

- Los programas dirigidos a los más perjudicados por la crisis deben tener en cuenta la dimensión del hogar. La segmentación a nivel de los hogares pone de relieve la importancia de hacer una distinción entre los hogares mixtos y aquellos que dependen en exclusiva de la economía informal cuando se diseñan las intervenciones políticas.

- Es necesario examinar la informalidad desde el punto de vista de los hogares para así registrar el nivel de pobreza económica e inseguridad en términos de ingresos de los 


\section{Recuadro 1.3. Principales mensajes en materia de políticas (cont.)}

trabajadores informales, medir la capacidad para pagar la protección social, detectar la posibilidad de acceder a protección social a través de los miembros del hogar que trabajan en la economía formal, y evaluar hasta qué punto la vulnerabilidad de los trabajadores informales se transmite a las personas a su cargo.

- Es preciso adoptar políticas que vayan más allá de la dimensión social y favorezcan la formalización del empleo. Estas políticas deben estar encaminadas a: i) promover un mayor nivel de inclusión financiera, en particular para los trabajadores del sector informal que carecen de cuenta bancaria o no pueden obtener un préstamo; ii) reducir la brecha digital y aumentar las competencias digitales para aprovechar al máximo las nuevas tecnologías; iii) mejorar los servicios públicos; y iv) ampliar el margen fiscal para proporcionar un mayor apoyo específico a los trabajadores del sector informal.

6. Hay que dotar de financiación a los mecanismos de protección social al tiempo que se promueve la formalización del empleo.

- Es preciso reducir los costos laborales no salariales para promover la formalización, especialmente en los trabajadores de ingresos bajos. Las contribuciones a los programas de seguridad social son demasiado costosas en relación con los ingresos de los trabajadores informales, especialmente para los que se encuentran en el extremo inferior de la distribución de ingresos.

- Es preciso utilizar el sistema tributario general para financiar la ampliación de los mecanismos de protección social.

\section{Notas}

1. S\&P redujo la calificación de las emisiones a largo plazo de Chile en marzo de 2021, pero mantuvo su grado de inversión y recortó la calificación soberana de Colombia por debajo del grado de inversión en mayo de 2021 (OCDE, $\left.2021_{[57]}\right)$.

\section{Referencias}

Alberola, E. et al. (2016), "Fiscal policy and the cycle in Latin America: the role of financing conditions and fiscal rules", BIS Working Papers, Vol. No 543, https://www.bis.org/publ// work543.pdf.

Ardanaz, M. et al. (2021), Research Insights: Can the Design of Fiscal Rules Help to Protect Productive Public Investment from Budget Cuts? https://publications.iadb.org/en/research-insights-can-designfiscal-rules-help-protect-productive-public-investment-budget-cuts.

Bolton (2020), Born Out of Necessity: A Debt Standstill for COVID-19, Center for Economic Policy Research. [43]

Breuer y Cohen (2020), Time is Ripe for Innovation in the World of Sovereign Debt Restructuring.

Buckley (1998), The facilitation of the Brady Plan emerging markets debt trading from 1989 to 1993.(Capital Markets and International Finance).

CAF (2021), Perspectivas Económicas, Informe Trimestral. Manuscrito interno.

Caputo Silva y Stewart (2021), "My word is my bond: Linking sovereign debt with national sustainability commitments", World Bank Blogs, https://blogs.worldbank.org/climatechange/ my-word-my-bond-linking-sovereign-debt-national-sustainability-commitments.

Cavallo y Powell (2021), Oportunidades para un mayor crecimiento sostenible tras la pandemia, Informe macroeconómico de América Latina y el Caribe 2021, Banco Interamericano de Desarrollo, https://publications.iadb.org/publications/spanish/document/Informe-macroeconomico-deAmerica-Latina-y-el-Caribe-2021-Oportunidades-para-un-mayor-crecimiento-sostenible-trasla-pandemia.pdf.

CEPAL (2021), Estudio Económico de América Latina y el Caribe 2021: dinámica laboral y políticas de empleo para una recuperación sostenible e inclusiva más allá de la crisis del COVID-19, Publicación de las Naciones Unidas, Santiago, https://www.cepal.org/es/publicaciones/47192-estudio-economicoamerica-latina-caribe-2021-dinamica-laboral-politicas-empleo. 
CEPAL (2021), La paradoja de la recuperación en América Latina y el Caribe. Crecimiento con persistentes problemas estructurales: desigualdad, pobreza, poca inversión y baja productividad, Publicación de las Naciones Unidas, Santiago, https://www.cepal.org/en/publications/47059-recovery-paradoxlatin-america-and-caribbean-growth-amid-persisting-structural.

CEPAL (2021), La Inversión Extranjera Directa en América Latina y el Caribe 2021, Publicación de las Naciones Unidas, Santiago, https://www.cepal.org/es/publicaciones/47147-la-inversionextranjera-directa-america-latina-caribe-2021.

[13]

CEPAL (2021), Panorama Fiscal de América Latina y el Caribe 2021: los desafíos de la política fiscal en la recuperación transformadora pos-COVID-19, Publicación de las Naciones Unidas, Santiago, https://www.cepal.org/en/publications/46809-fiscal-panorama-latin-america-and-caribbean2021-fiscal-policy-challenges.

CEPAL (2021), Panorama social de América Latina 2020, Publicación de las Naciones Unidas, Santiago, https://www.cepal.org/en/publications/46688-social-panorama-latin-america-2020.

CEPAL (2021), Perspectivas del Comercio Internacional de América Latina y el Caribe 2020: la integración regional es clave para la recuperación tras la crisis, Publicación de las Naciones Unidas, Santiago, https://repositorio.cepal.org/bitstream/handle/11362/46613/1/S2000805 es.pdf.

CEPAL (2020), Panorama Fiscal de América Latina y el Caribe, 2020: la política fiscal ante la crisis derivada de la pandemia de la enfermedad por coronavirus (COVID-19), Publicación de las Naciones Unidas, CEPAL, Santiago, https://www.cepal.org/es/publicaciones/45730-panorama-fiscal-america-latinacaribe-2020-la-politica-fiscal-la-crisis-derivada.

Cevik y Tovar Jalles (2021), La vulnerabilidad al cambio climático perjudica las calificaciones crediticias de la deuda soberana.

Cline, W. (1995), International Debt Reexamined.

Devlin (1989), Debt and Crisis in Latin America : The Supply Side of the Story.

Diaz-Alejandro, Krugman y Sachs (1984), Latin American Debt: I Don't Think We are in Kansas Anymore.

DIPRES (2020), Informe de Ejecución del Gobierno Central Tercer Trimestre 2020, http://www.dipres.gob. cl/598/articles-212454 doc pdf reporte mensual.pdf.

FMI (2021), Perspectivas de la economía mundial: Manejar recuperaciones divergentes, Fondo Monetario Internacional, Washington, DC. https://www.imf.org/en/Publications/WEO/Issues/2021/03/23/ world-economic-outlook-april-2021.

FMI (2021), Perspectivas Económicas, Las Américas: Un largo y sinuoso camino hacia la recuperación, Fondo Monetario Internacional, Servicios de publicación, Washington, DC. https://www.imf.org/es/ Publications/REO/WH/Issues/2021/10/21/Regional-Economic-Outlook-October-2021-WesternHemisphere

FMI (2020), La Política Fiscal en Tiempos de Pandemia: ¿Cómo les ha Ido a América Latina y al Caribe?, Fondo Monetario Internacional, Washington, DC., https://www.imf.org/en/Publications/REO/ WH/Issues/2020/10/13/regional-economic-outlook-western-hemisphere.

IIF (2021), Base de datos del Instituto de Finanzas Internacionales, https://www.iif.com/Research/ Data.

Izquierdo y Pessino (2021), A Post COVID-19 Fiscal Strategy for Latin America and the Caribbean. [25]

MEF (2020), Reporte Fiscal Trimestral: Seguimiento de las Reglas Macrofiscales: Segundo Trimestre 2020, https://www.mef.gob.pe/es/?option=com content\&language=es-ES\&Itemid=102387\&lang=esES\&view=article\&id=3926.

Mora, S., S. Nieto-Parra y R. Orozco (2021), La política fiscal para impulsar la recuperación en América Latina: el "cuándo" y el "cómo" son claves, http://lacea.org/vox/?q=blog/fiscal_policy_latam. [22]

Nieto-Parra y Orozco (2020), Public debt and COVID-19. Paying for the crisis in Latin America and the Caribbean, Groupe d'études géopolitiques, Latin America, Policy Paper 4. https://legrandcontinent. eu/fr/2020/07/22/public-debt-and-covid-19-paying-for-the-crisis-in-latin-america-and-thecaribbean/.

Ocampo, J. (2021), Significant but insufficient progress in financial support for developing countries, https://oecd-development-matters.org/2021/04/13/significant-but-insufficient-progress-infinancial-support-for-developing-countries/.

OCDE (2021), 130 países y jurisdicciones se integran en un nuevo y ambicioso marco para la reforma fiscal internacional.

OCDE (2021), OECD Tax Policy Studies: Inheritance Taxation in OECD Countries, Publicaciones de la OCDE, París, https://doi.org/10.1787/e2879a7d-en.

OCDE (2021), Perspectivas económicas de la OCDE, informe provisional de septiembre de 2021, Keeping the Recovery on Track, Publicaciones de la OCDE, París, https://doi.org/10.1787/490d4832-en. 
OCDE (2021), Perspectivas Económicas de la OCDE, Volumen 2021 Edición 1, Publicaciones de la OCDE, París, https://doi.org/10.1787/edfbca02-en.

OCDE (2021), "Polices for improving the sustainable development impacts of investment", Artículo de consulta marzo 2021, https://www.oecd.org/daf/inv/investment-policy/FDI-Qualities-PolicyToolkit-Consultation-Paper-2021.pdf.

OCDE (2021), Sovereign Borrowing Outlook for OECD Countries 2021, Publicaciones de la OCDE, París, https://www.oecd.org/daf/fin/public-debt/Sovereign-Borrowing-Outlook-in-OECD-Countries2021.pdf.

OCDE (2020), COVID-19 en América Latina y el Caribe: Implicaciones socioeconómicas regionales y prioridades políticas, https://www.oecd.org/coronavirus/policy-responses/covid-19-in-latin-america-andthe-caribbean-regional-socio-economic-implications-and-policy-priorities-93a64fde/. [24]

OCDE (2020), Estudios económicos de la OCDE: Costa Rica 2020, Publicaciones de la OCDE, París, https://doi.org/10.1787/2e0fea6c-en.

OCDE (2020), Government at a Glance: Latin America and the Caribbean 2020, Publicaciones de la OCDE, París, https://doi.org/10.1787/13130fbb-en.

OCDE (2020), OECD’s COVID-19 Country Policy Tracker, Publicaciones de la OCDE, París, https://www. oecd.org/coronavirus/country-policy-tracker/.

OCDE (2019), Can Social Protection Be an Engine for Inclusive Growth?, Publicaciones de la OCDE, París, https://doi.org/10.1787/9d95b5d0-en.

OCDE (Próximo a publicarse), Labour informality and households' vulnerabilities in Latin America [Título provisional].

OCDE et al. (2021), Estadísticas tributarias en América Latina y el Caribe, Publicaciones de la OCDE, París, https://www.oecd.org/tax/tax-policy/folleto-estadisticas-tributarias-en-america-latinay-el-caribe.pdf.

OCDE et al. (2020), Perspectivas Económicas de América Latina 2020: Transformación digital para una mejor reconstrucción, Publicaciones de la OCDE, París, https://doi.org/10.1787/f2fdced2-es.

OCDE et al. (2019), Perspectivas Económicas para América Latina: Desarrollo en transición, Publicaciones de la OCDE, París, https://doi.org/10.1787/f2fdced2-es.

OCDE/Banco Mundial (2020), Panorama de la Salud: Latinoamérica y el Caribe 2020, https://doi.org/ 10.1787/6089164f-en.

OCDE/CIAT/BID (2016), Taxing Wages in Latin America and the Caribbean, Publicaciones de la OCDE, París, https://dx.doi.org/10.1787/9789264262607-en.

OCDE/OIT (2019), Tackling Vulnerability in the Informal Economy, Estudios del Centro de Desarrollo, Publicaciones de la OCDE, París, https://doi.org/10.1787/939b7bcd-en.

OIT (2018), Mujeres y hombres en la economía informal: Un panorama estadístico. Tercera edición, Organización Internacional del Trabajo, Ginebra, https:/www.ilo.org/global/publications/ books/WCMS 635149/lang--es/index.htm.

ONU/DAES (2020), COVID-19 and sovereign debt, ONU DAES, https://www.un.org/development/desa/ dpad/publication/un-desa-policy-brief-72-covid-19-and-sovereign-debt/.

Rogoff, K. (1993), Third World Debt.

Steele y Patel (2020), Tackling the triple crisis. Using debt swaps to address debt, climate and nature loss post COVID-19. Documento temático del IIED, 48 páginas, https://pubs.iied.org/16674iied.

Subacchi (2020), A Good but Incomplete Start to Debt Relief, https://www.project-syndicate.org/ commentary/g20-common-framework-debt-restructuring-by-paola-subacchi-2020-11?barrier= accesspaylog.

Szekely y Montes (2006), Poverty and Inequality, Cambridge University Press, enero, https://doi.org/ 10.1017/CHOL9780521812900.016.

UNCTAD (2020), Developing Country Debt in the Time of COVID-19: From the Great Lockdown to the Great Meltdown, Publicación de las Naciones Unidas, UNCTAD, https://unctad.org/fr/node/27494. [34]

UNCTAD (2020), El Impacto de la Pandemia COVID-19 sobre el Comercio y Desarrollo: Transición a una Nueva Normalidad, Publicación de las Naciones Unidas, UNCTAD, https://unctad.org/system/ files/official-document/osg2020d1 en.pdf.

Vasquez (1996), “The Brady Plan and Market-Based Solutions to Debt Crises”, Cato Journal 16 (2): 233-43.

Vegh, C. y G. Vuletin (2014), "The Road to Redemption: Policy Response to Crises in Latin America”, Documento de trabajo del NBER, Vol. 20675, https://www.nber.org/papers/w20675. 


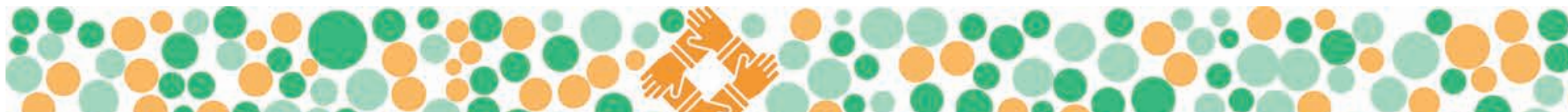
:00 O.

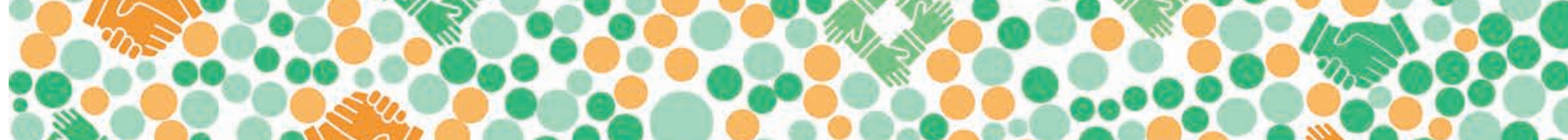

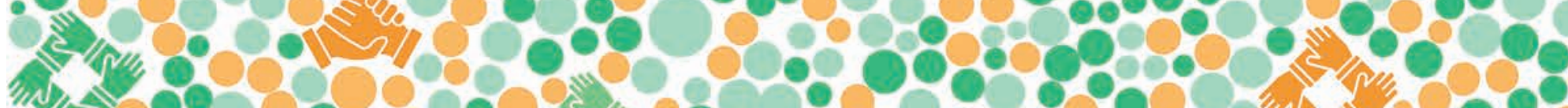

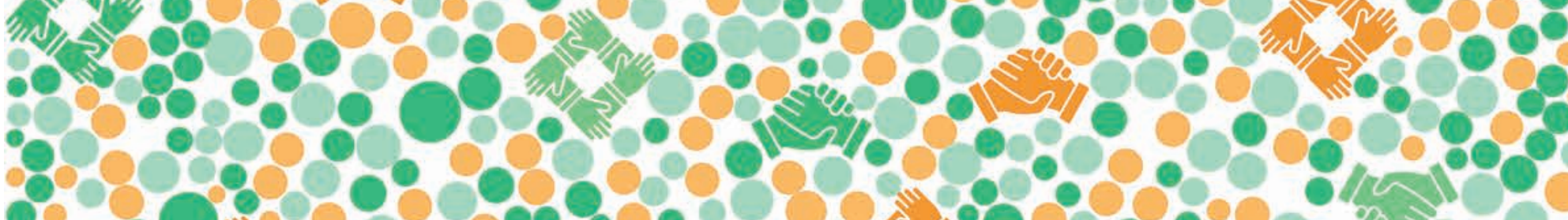

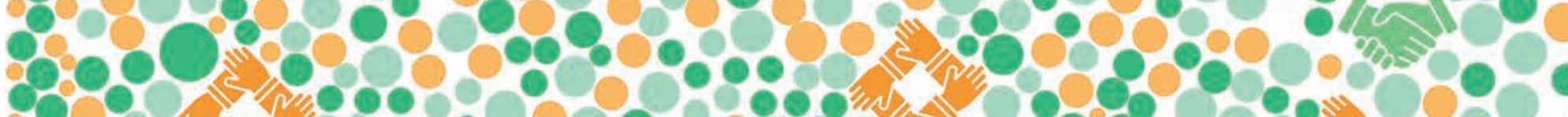

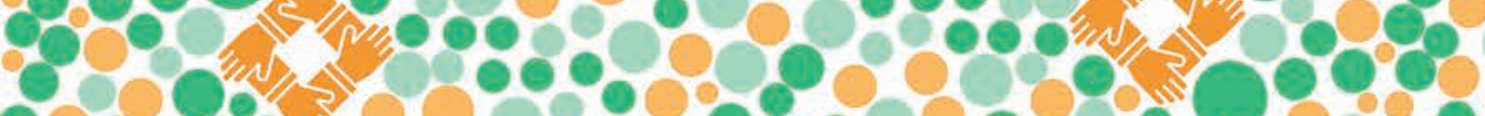

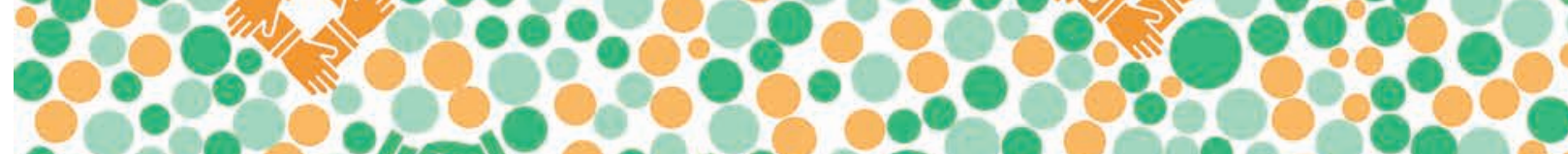
:36\%

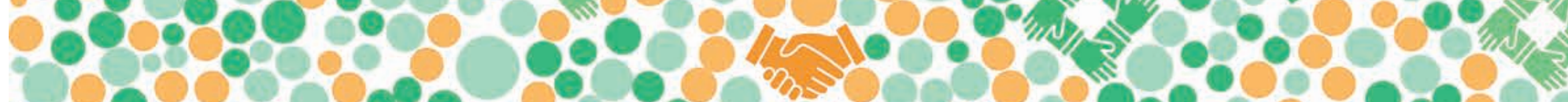
00000000000000000 :0\%

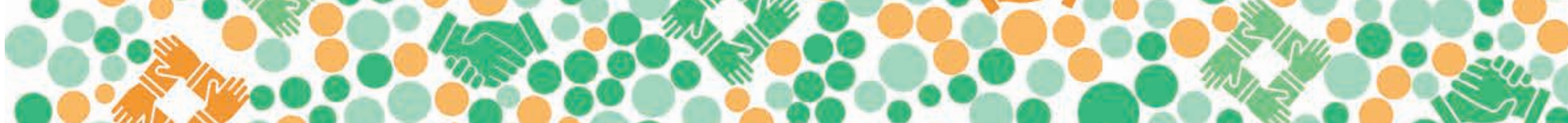

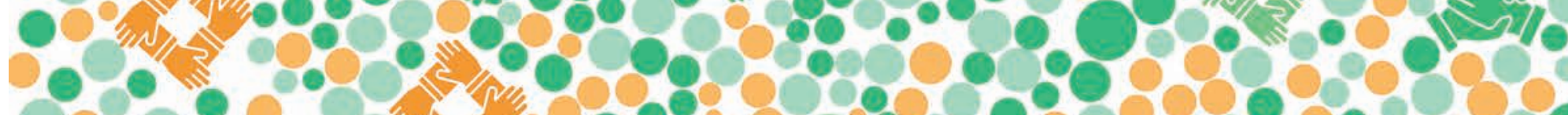

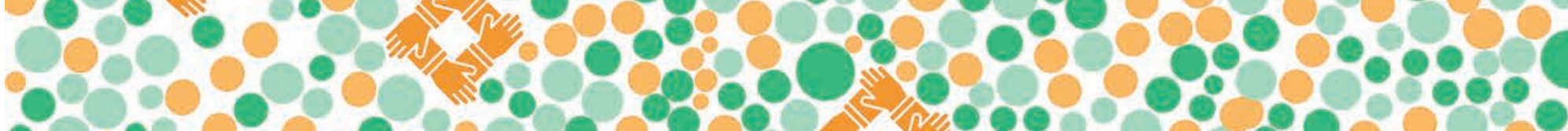

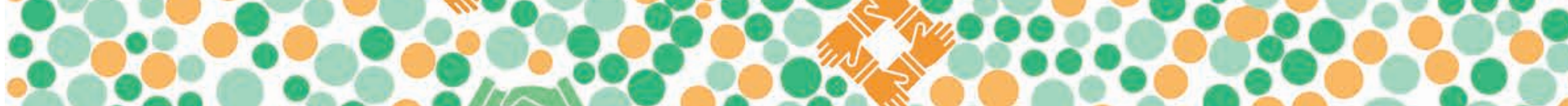

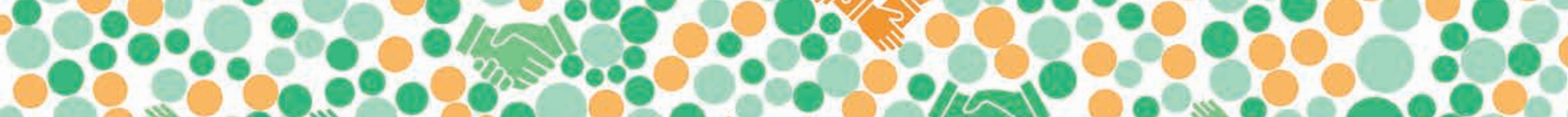
200 30003

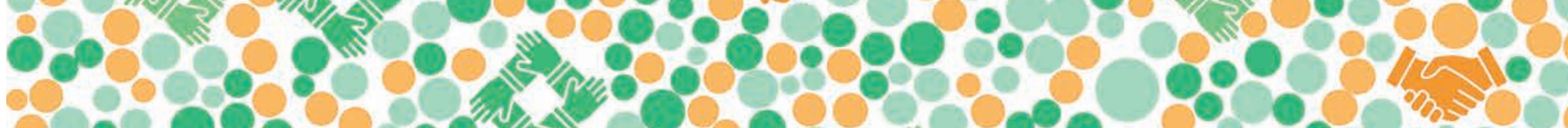
:080 0.000. 8.

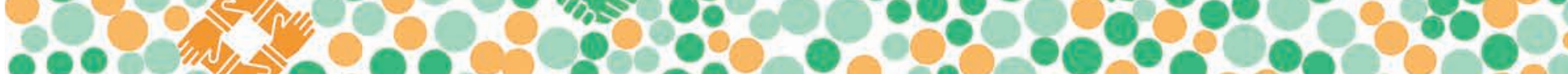

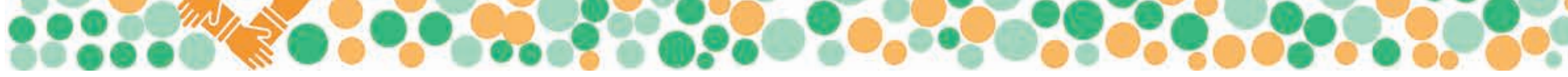




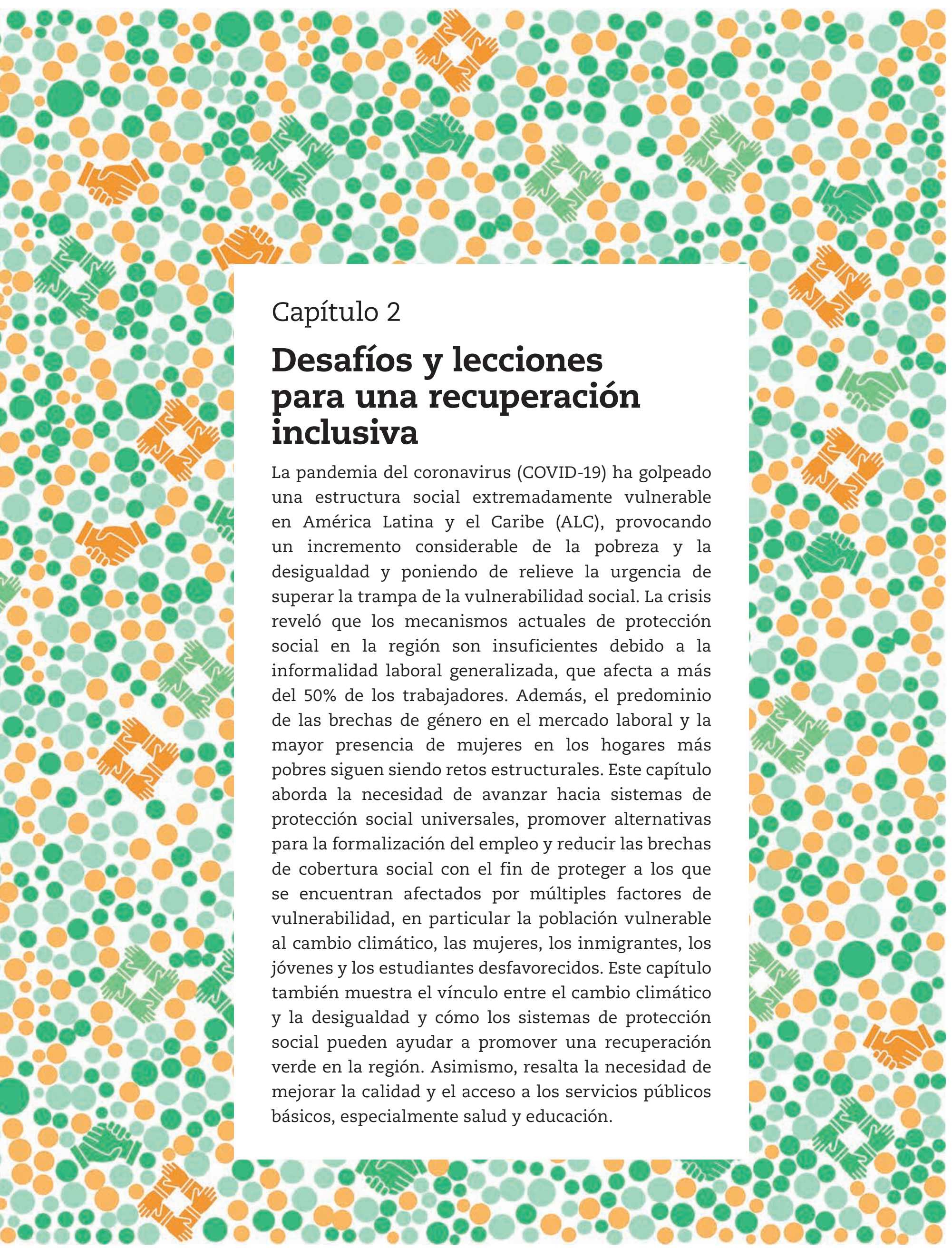




\section{Mejorar la protección social y los servicios públicos es clave para una mejor recuperación}

Las políticas de empleo con enfoque de género, la vuelta de los niños y niñas a la escuela y la promoción de una transición verde deben estar en el centro de la recuperación

La tasa de pobreza de las mujeres en edad laboral eran

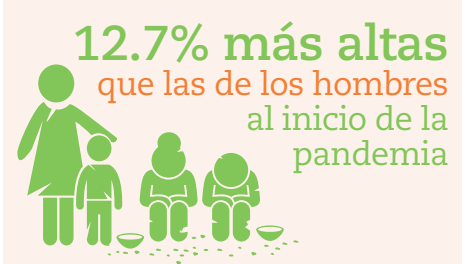

La tasa de participación laboral de las mujeres en ALC es de $51.4 \%$

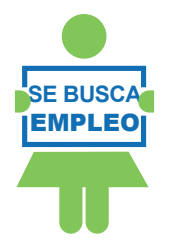

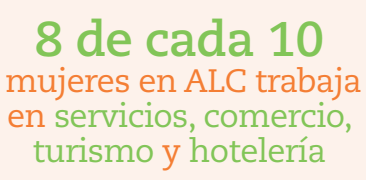

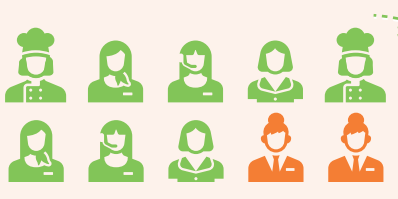

Estas industrias fueron las más vulnerables a la pérdida de puestos de trabajo causada por la crisis

Una recuperación medioambientalmente justa es una oportunidad para crear empleos de calidad y promover la inclusión social

Porcentaje de cambio neto en puestos de trabajo, ALC, 2014-2030

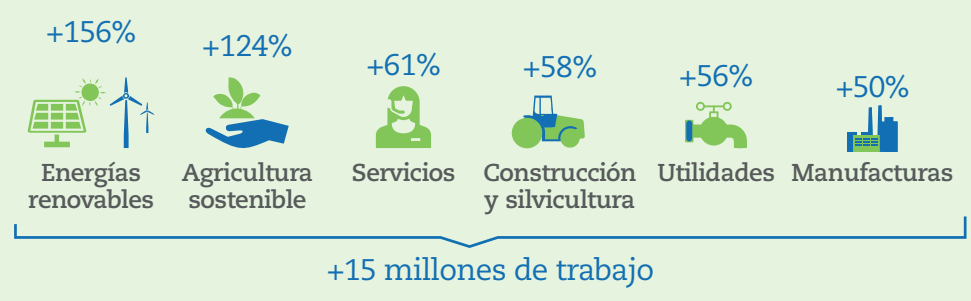

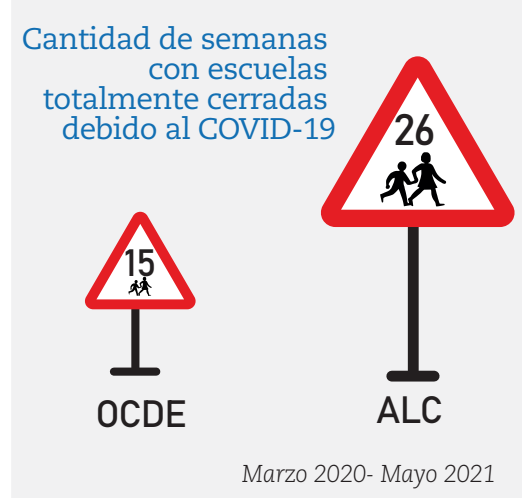

Los sistemas de protección social deben reformarse para responder a las preocupaciones de los ciudadanos y abordar las deficiencias estructurales

Promedio de búsquedas en Google sobre el tema:

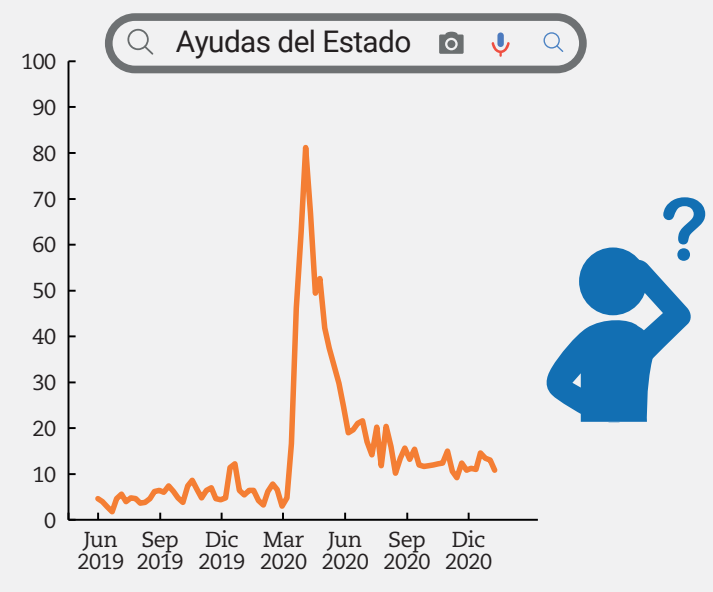

Proporción de trabajadores dudando si alguna vez recibirán una pensión en países seleccionados de ALC

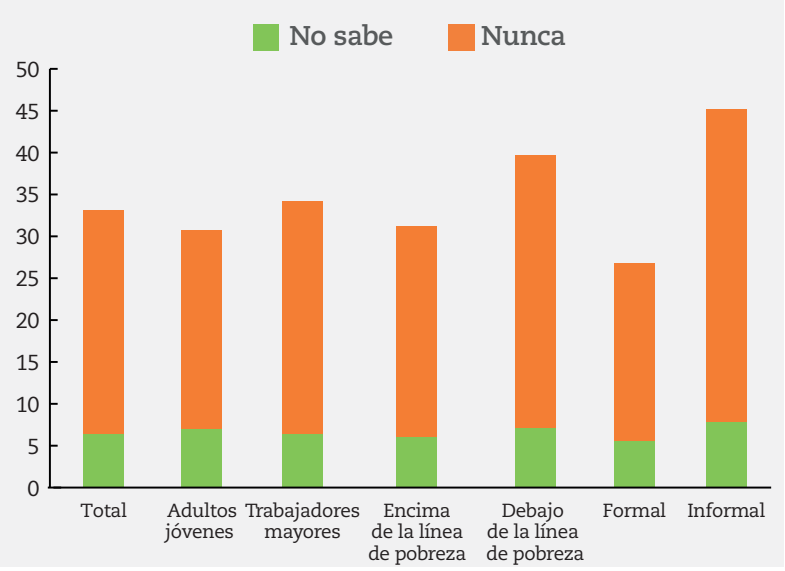




\section{Introducción}

Para luchar contra la crisis generada por el coronavirus (COVID-19), los gobiernos de América Latina y el Caribe (ALC) han reaccionado rápidamente adoptando políticas para reforzar las medidas de protección social y proteger a las poblaciones más vulnerables. Las medidas de protección social han estado dirigidas a las personas más afectadas por la pandemia, como los trabajadores pobres, informales e independientes. En este sentido, los programas de protección social han evolucionado para proveer cobertura a una proporción más amplia de ciudadanos.

A pesar de la respuesta rápida y eficaz de muchos países de la región ALC, la crisis del COVID-19 ha sumido a ALC en su recesión social y económica más grave desde el siglo XX. A pesar del carácter mundial de la crisis, ha afectado de forma más profunda a los países de la región debido a la elevada vulnerabilidad de algunos grupos sociales ante las conmociones provocadas por la pandemia. El COVID-19 está teniendo un impacto considerable en la pobreza y la desigualdad de ingresos. A pesar de las medidas de protección social adoptadas durante la pandemia, el número de personas que viven en la pobreza aumentó en 2020 comparado a 2019 alrededor de 3 puntos porcentuales y la desigualdad de ingresos, medida por el índice Gini, se prevé que aumente alrededor de un 2.9\% en 2020 (Capítulo 1) (CEPAL, 2021 ${ }_{[1]}$ ).

La pandemia ha agravado las debilidades estructurales de ALC. Las vulnerabilidades sociales han hecho que los gobiernos tengan más dificultades para resistir los efectos socioeconómicos adversos generados por el COVID-19. Entre los principales retos para el desarrollo futuro, se encuentran los siguientes: i) el envejecimiento de la población; ii) el hacinamiento en las ciudades y la falta de acceso a servicios sociales; iii) el alto porcentaje de informalidad; iv) los débiles sistemas de protección social, incluidos la cobertura inadecuada y la deficiente calidad en salud, así como la falta de sistemas de atención integrados; y v) las desigualdades elevadas y persistentes en múltiples dimensiones. En particular, la crisis atrapó a los trabajadores de la economía informal en una situación de gran vulnerabilidad debido a la falta de empleos estables de calidad y a la escasa protección social (OCDE et al., 2020 ${ }_{[2]}$; CEPAL, 2021 ${ }_{[1]}$; OIT, 2021 ${ }_{[3]}$ ). El alto grado de informalidad limita el rol que desempeñan los sistemas de protección social en la sociedad, así como su eficacia y su viabilidad económica (Álvarez, $2020_{[4]}$ ). La informalidad también redujo la efectividad de la implementación de medidas para contener el virus (como confinamientos) y agravó su impacto sobre la población.

Más allá de los trabajadores, las personas que se encuentran en la confluencia de múltiples factores de vulnerabilidad se han visto afectadas desproporcionadamente por la crisis. Los grupos más vulnerables que más han sufrido los efectos negativos de la pandemia son los mayores, los jóvenes, los inmigrantes, los pueblos indígenas y los afrodescendientes, que usualmente se enfrentan a condiciones precarias (CEPAL/UNICEF, $\left.2020_{[5]}\right)$. La incertidumbre sobre la evolución y consecuencias de la pandemia aún persiste en ALC dificultando que las políticas de respuesta para contrarrestar los efectos adversos de la pandemia y dar impulso a la recuperación sea más complejo.

A corto plazo, los gobiernos de la región deberían enfocarse en la inmunización de la población y continuar con la asistencia a los más vulnerables. En ausencia de medidas de las autoridades para reducir las crecientes brechas socioeconómicas de estos grupos, los efectos de la crisis del COVID-19 serán duraderos y podrían contrarrestar las mejoras socioeconómicas conseguidas durante las últimas décadas (OIT, 2021 [3] ).

Volver al statu quo social anterior a la crisis no debería ser la meta de la recuperación. La crisis debería ser una oportunidad para abordar los retos estructurales y las desigualdades, mejorando al mismo tiempo la capacidad de recuperación. La pandemia 
requiere acciones coordinadas a diferentes niveles, conjuntamente con el incremento de las tasas de vacunación, el impulso a la recuperación económica y la creación de empleo. Expandir el sistema de protección social es vital para proteger los medios de vida de los grupos vulnerables y reducir los efectos negativos para su bienestar, reduciendo al mismo tiempo los impactos duraderos. A largo plazo, las medidas de protección social podrían contribuir a afianzar la clase media. Las políticas de protección social deberían amortiguar el impacto en el empleo y la renta de las personas afectadas en el marco del proceso de recuperación y más allá. Crear un sistema sólido, donde la economía, los hogares y las personas estén protegidos de futuros shocks macro y microeconómicos, es crucial para abordar los retos de la región en el futuro e impedir un retroceso sustancial de los progresos en materia de desarrollo.

Esta crisis ofrece una oportunidad única para promover reformas urgentes y postergadas y redefinir el contrato social de la región (Capítulo 4). Dentro de este nuevo contrato social, algunos de los ingredientes clave son nuevos modelos sociales basados en sistemas de protección social más sólidos y sostenibles y servicios públicos más inclusivos y ecológicos.

Este capítulo aborda en primer lugar la necesidad de avanzar hacia sistemas de protección social universales y tener en cuenta varias consideraciones para su puesta en marcha. En segundo lugar, insiste en la necesidad de ayudar a las poblaciones en situación vulnerable que se han visto afectadas considerablemente por la pandemia, en especial los mayores, las mujeres, los inmigrantes, los jóvenes y los estudiantes desfavorecidos. En tercer lugar, explora el vínculo entre la transición de modelos de desarrollo con baja intensidad en uso de carbón (“Transición ecológica”) y la inclusión social. En particular resalta como la transición ecológica se relaciona con los objetivos de creación de empleos de calidad, reducción de desigualdades y el rediseño de los sistemas de protección social. En cuarto lugar, presenta las percepciones de los ciudadanos en las principales dimensiones socioeconómicas, como el empleo, las pensiones y la calidad de los sistemas de salud, y muestra la importancia de tomar en cuenta las preferencias de los ciudadanos a la hora de adoptar reformas en la región. El capítulo concluye con varios mensajes clave en materia de políticas.

\section{Una protección social más amplia para sociedades más inclusivas y resilientes}

La falta de protección social y la vulnerabilidad económica de los hogares siguen siendo retos en ALC (Capítulo 1). El sistema de protección social es esencial en toda sociedad. Debido a que este ofrece seguridad a los ciudadanos y a los hogares ante vulnerabilidades y contingencias, garantizando el acceso a servicios de cuidado, incluido el servicio de salud y la protección de ingresos a lo largo del ciclo de vida de las personas. Los mecanismos débiles de protección social dejan a los hogares expuestos al efecto directo de las crisis y los choques externos. En ALC, los elevados niveles de informalidad en los mercados laborales han sido un factor determinante para la baja cobertura de seguridad social. Antes de la pandemia, el trabajo informal suponía en promedio un 56\% del empleo en la región $\left(\mathrm{OCDE}, 2020_{[6]}\right)$. Adicionalmente, la organización del sistema de cuidados en la sociedad sigue siendo injusta y desbalanceada y se concentra en los hogares, especialmente en las mujeres que desempeñan trabajos no remunerados. La división desigual del trabajo de prestación de cuidados es una de las principales barreras para la plena participación de la mujer en el mercado laboral. Antes incluso de la pandemia, la tasa de participación de la mujer en la región era del 51.4\%, frente a alrededor del $75.0 \%$ entre los hombres (CEPAL, 2019 ${ }_{[7]}$ ). 
A pesar de los importantes esfuerzos realizados para ampliar los programas de ayuda de emergencia, la falta de sistemas de protección social sólidos dejó a sectores vulnerables sin protección frente a los efectos de la crisis del COVID-19. La fuerte caída de los ingresos en ALC se concentra entre los menos protegidos. Por ejemplo, los hogares que dependían de los ingresos del trabajo informal estaban desprotegidos frente a la pérdida de ingresos debido a los confinamientos. El descenso de la demanda externa de algunas exportaciones también tuvo un rol a la hora de generar una crisis más profunda en ALC.

Varios países promulgaron políticas audaces para responder a la crisis y proteger a los más vulnerables. La asistencia en ingresos a población focalizada con el fin de estimular el consumo y los esfuerzos de inversión para promover las actividades productivas seguirán siendo determinantes para superar la crisis y fomentar un desarrollo sostenible (Capítulos 1 y 3). Sin embargo, para consolidar la recuperación y aumentar la resiliencia serán necesarias nuevas y más ambiciosas estrategias junto a las reformas políticas necesarias.

\section{La protección social universal es imprescindible para propiciar un crecimiento inclusivo y elevar la capacidad de recuperación en el periodo posterior a la crisis}

La crisis actual pone de relieve la necesidad de disponer de mecanismos de protección social que mitiguen sus repercusiones e impidan que los hogares caigan en la pobreza. La crisis demostró que poner en marcha medidas de emergencia es mucho menos complicado en países con mecanismos de protección social robustos, como seguro de desempleo, pensiones y un acceso más amplio a servicios de cuidado y salud. Como aspecto positivo, la crisis aceleró la ampliación de los programas de ayudas sociales en la región.

Un sistema de protección social universal sólido puede aunar políticas para reducir la pobreza, la exclusión social y la vulnerabilidad a lo largo de su ciclo de vida. Los sistemas de seguridad social generalmente articulan diversos mecanismos que ayudan a garantizar la renta de las personas a lo largo de sus vidas. También garantizan el acceso a los servicios de salud buscando proteger a los más vulnerables de acuerdo a su edad, sexo y clase social, entre otras dimensiones (OCDE, 2019 ${ }_{[8]}$ ). Los sistemas de protección social también fomentan la igualdad de oportunidades a través de programas de ayudas sociales.

Más allá de la protección a los hogares, las sociedades también se benefician de contar con un sistema de protección social a través de efectos que se observan a nivel agregado. A nivel de sociedad (macro), la protección social puede contribuir a estimular la demanda agregada y, por lo tanto, aumentar el empleo. Asimismo, puede aumentar el consumo y los ingresos fiscales. Estimular la demanda agregada a través de la protección social es clave durante los periodos de crisis como mecanismo anti cíclico de gasto (OCDE, $2019_{[8]}$ ). Durante las crisis, la suma de las ayudas a escala micro puede evitar una recesión económica más profunda.

Como mecanismo fundamental de protección social, los programas de asistencia social correctamente focalizados pueden contribuir considerablemente a nivelar el efecto positivo del crecimiento en dos formas. En primer lugar, garantizan un nivel mínimo de bienestar social y económico. Las ayudas sociales aseguran y mitigan el riesgo de que los hogares de ingresos bajos caigan en la pobreza y fomenta la movilidad social, contribuyendo a reducir las brechas de desigualdad. En segundo lugar, la asistencia social permite un acceso más equitativo a las oportunidades. De este modo, se superan las limitaciones en materia de ahorro y crédito que sufren los hogares de ingresos bajos y que limitan las inversiones en capital humano y perpetúan la pobreza intergeneracional. Si se diseñan adecuadamente, las ayudas sociales también pueden fomentar la participación en el mercado laboral, la innovación y el emprendimiento (OCDE, $2019_{[8]}$ ). 
Los gobiernos han realizado importantes esfuerzos para llegar a los individuos y hogares en situación de vulnerabilidad durante la crisis ampliando los programas de transferencias monetarias. Los gobiernos han incrementado las ayudas sociales: i) ampliando el conjunto de beneficiarios atendidos para incluir a más individuos y hogares en los programas tradicionales y creando nuevos programas para atender a las franjas desprotegidas de la población; y ii) Incrementando la transferencia y la frecuencia de los beneficios para sustituir un mayor porcentaje de los ingresos (OCDE, próximo a publicarse $\left.{ }_{[9]}\right)$. Por ejemplo, en Argentina el Ingreso Familiar de Emergencia es un nuevo programa dirigido a personas desempleadas y a hogares que dependen totalmente del empleo informal e independiente. El país también ha incrementado la cuantía de los pagos del programa Asignación Universal y las pensiones no contributivas, los programas de ayudas sociales más tradicionales. La aparición de estos nuevos programas, como Auxílio emergencial en Brasil, Ingreso Familiar de Emergencia en Chile, Ingreso Solidario en Colombia, Subsidio Pytyuõ en Paraguay y Bono Familiar Universal, Independiente y Yo me quedo en casa en Perú, ofrecen nueva redes de seguridad a los hogares vulnerables y los trabajadores informales que antes no estaban cubiertos (OCDE, próximo a publicarse ${ }_{[9]}$ ).

Estas medidas temporales pueden sentar las bases para replantear la protección social en la región y promover un sistema de protección social más universal, resiliente y sólido que incluya a aquellos que tradicionalmente han quedado excluidos, haciendo que la economía y los hogares estén mejor preparados para enfrentar futuros choques negativos.

La crisis ofrece una oportunidad para crear un sistema de protección social universal más amplio e inclusivo en muchos países. Ha demostrado lo vulnerables que eran la mayoría de las economías de ALC debido a sus elevados niveles de informalidad y la importancia de impulsar el empleo formal como pilar del proceso de recuperación. A la hora de replantear las políticas sociales en ALC hay que tener en cuenta varios elementos, como la necesidad de un sistema de seguridad social más amplio que cubra a los trabajadores vulnerables, la adaptabilidad y robustez de los sistemas de seguro de desempleo, una estrategia de desarrollo que fomente el empleo formal y la sostenibilidad fiscal de estas medidas (OIT, $\left.2021_{[10]}\right)$. Los registros de políticas sociales pueden facilitar la identificación de trabajadores en situación de vulnerabilidad, mejorando así el diseño y focalización de las mismas. Los gobiernos se han enfrentado a numerosas dificultades a la hora de identificar nuevos beneficiarios debido a que muchos de ellos no se encuentran registrados en las bases de datos públicas o no siempre cuentan con una cuenta bancaria. Por lo tanto, los gobiernos han cotejado los registros existentes para encontrar formas alternativas de ampliar las bases de datos y realizar transferencias monetarias, principalmente mediante el uso de tecnologías digitales y teléfonos móviles. La coordinación y cooperación con el sector privado, principalmente con los intermediarios financieros, surgió como una prioridad para llegar a la población sin cobertura y a aquellos que sufren las consecuencias de la brecha digital (en lo que respecta al acceso a la tecnología y la falta de competencias). Esta cooperación público-privada es clave para desarrollar mecanismos más eficaces dirigidos a estos grupos de población, como la banca móvil y los corresponsables financieros.

\section{Una recuperación inclusiva y sostenible, requiere proteger y sostener a los grupos sociales que sufren múltiples vulnerabilidades}

Las medidas adoptadas para ayudar a los grupos vulnerables no cubiertos por los mecanismos tradicionales de seguridad social y ayudas sociales pueden constituir la base para replantear y promover sistemas de protección social más resilientes en la región. Estas medidas han incluido la introducción de nuevos programas de ayudas sociales, aumentando la cobertura de transferencias monetarias o aumentando el número de 
beneficiarios, y la realización de pagos en especie, como alimentos y acceso a Internet o dispositivos digitales (CEPAL, 2021 $1_{[1]}$; OCDE, 2020 ${ }_{[6]}$ ).

Determinados grupos sociales tienen características preexistentes que los hacen estar muy expuestos a los choques de la crisis. Estos grupos requieren estar en el centro de las estrategias de la política social. Las condiciones socioeconómicas previas a la pandemia que determinan la capacidad de recuperación de las personas y los hogares estaban distribuidas de forma desigual. Más allá de los trabajadores informales por cuenta propia, y los hogares pobres y vulnerables, otros grupos que se vieron afectados desproporcionadamente por la crisis fueron las mujeres, los jóvenes, los mayores, los pueblos indígenas, los afrodescendientes y los inmigrantes (PNUD, 2020 ${ }_{[11]}$; OIT, 2021 $1_{[3]}$ ). Los gobiernos necesitan implementar políticas que sean sensibles a las necesidades de estos grupos, diseñándolas con participación inclusiva de representantes de los mismos y enfocándolas hacia la protección de sus vidas, sus medios de vida y su bienestar. Los grupos afectados deben ser consultados sistemáticamente sobre las iniciativas pertinentes, con programas de retroalimentación transparentes que respondan a sus necesidades particulares y que no afiancen las condiciones de discriminación y marginación preexistentes. Las políticas públicas deben aplicar un enfoque intersectorial con perspectiva de género para tener en cuenta las múltiples formas de discriminación y barreras estructurales que enfrentan los diversos grupos poblacionales.

Aunque los esfuerzos por aumentar el gasto social a través de la protección social no contributiva evidenciaron una rápida respuesta por parte de los gobiernos, la capacidad de protección social previa a la crisis ha determinado las posibilidades de los países a la hora de contener los efectos negativos de la crisis. El aumento de los recursos adicionales para financiar los programas de protección social en América Latina representó el 1.25\% del producto Interior Bruto (PIB) en 2019. Los programas de ayudas sociales tradicionales han sido vitales para garantizar la protección social de los hogares pobres y vulnerables. Por ejemplo, en México las pensiones no contributivas se universalizaron en 2019 para así proteger a los mayores, que tradicionalmente experimentan una mayor vulnerabilidad en sus ingresos y su salud (CEPAL, 2021 $1_{[1]}$ ). En Paraguay, la Tarjeta Universal Social cubre a alrededor del 12\% de la población. En Uruguay, las transferencias de Asignaciones Familiares cubren alrededor del 11\% de la población.

Concentrar los esfuerzos adicionales en apoyar a las personas que experimentan múltiples vulnerabilidades es clave para mitigar la pérdida de bienestar y los efectos potenciales sobre las trayectorias de desarrollo. Aunque la crisis afecta a toda la población económicamente activa, los efectos son desproporcionadamente negativos sobre los trabajadores informales, y en especial las mujeres, los jóvenes, los pueblos indígenas, los afrodescendientes y los inmigrantes, son consecuencia de la conjunción de rasgos y condiciones sociodemográficas que tienden a acentuar las vulnerabilidades (PNUD, $2020_{[11]}$; CEPAL, 2020 $\left.{ }_{[12]}\right]$. Las próximas secciones presenta los retos y las recomendaciones de política para afrontar las vulnerabilidades de los grupos que sufren formas particulares de discriminación en ALC.

\section{Mejorar los sistemas de protección social para atender las necesidades de la tercera edad es clave para mejorar la capacidad de recuperación}

Los países de ALC se enfrentan a un doble reto: por un lado, la cobertura de la protección social es desigual y se expande a un ritmo insuficiente, por el otro, debido al envejecimiento sus ratios de dependencia y de población en edad de trabajar están empeorando. Si bien, el envejecimiento poblacional es el resultado de la mejora de las condiciones de vida y de las políticas sanitarias y de desarrollo, también plantea retos en lo que respecta a la protección social y la salud que deben ser abordados por los 
hacedores de política (Álvarez, $\left.2020_{[4]}\right)$. Aunque América Latina sigue siendo una región relativamente joven, el proceso de envejecimiento demográfico está avanzando a un ritmo acelerado: el porcentaje de población de más de 65 años se prevé que llegue al $18 \%$ en 2050, más del doble del $9 \%$ actual (OCDE/The World Bank, $2020_{[13]}$ ). Las tasas de envejecimiento varían significativamente entre los países, siendo Uruguay (15\%), Chile $(12 \%)$ y Argentina (11\%) los que tienen una mayor proporción de población mayor de 65 años (DAES, 2019 ${ }_{[14]}$ ). El envejecimiento poblacional implica una disminución de la proporción de población en edad de trabajar. La relación entre la población en edad de trabajar y los mayores de 65 años pasará de 8.6 en 2015 a 3.4 en 2050, sin embargo, la situación difiere entre países, en particular Chile, Costa Rica, Uruguay y países del Caribe experimentarán las disminuciones más significativas (DAES, 2019 ${ }_{[14]}$ ). Estos cambios demográficos probablemente aumenten la presión económica sobre los sistemas de salud, el riesgo de sostenibilidad de algunos sistemas de pensiones y los retos para los procesos de producción y el conjunto de la economía. El envejecimiento poblacional también supone que las familias tendrán que cuidar a los miembros de mayor edad durante más tiempo en ausencia de sistemas asistenciales universales. Las mujeres serán las más afectadas, porque son las que tradicionalmente soportan la mayor carga de cuidado. En promedio, las mujeres dedican dos tercios de su tiempo a trabajos no remunerados y un tercio a trabajos remunerados, mientras que las proporciones se invierten en el caso de los hombres (CEPAL, 2021 $1_{[15]}$ ).

En ALC, el 42\% de las personas de más de 65 años están cubiertas por el sistema de salud público no contributivo, lo que indica una cobertura y un acceso limitados a cuidados de calidad y añade presiones económicas a los sistemas sociales. En promedio, solo una de cada cuatro personas mayores tiene acceso a la asistencia sanitaria a través del sistema público. Los países de ALC presentan la mayor heterogeneidad en lo que respecta a la cobertura de seguridad social que ofrecen los sistemas de salud a los mayores, que va del 94\% de Argentina al 24\% de Bolivia (Álvarez, 2020 ${ }_{[4]}$ ). Esta situación de protección social en salud está vinculada a la elevada inseguridad económica asociada con el gasto privado en salud. La pandemia actual puede ser un punto de partida para reforzar los sistemas de salud y cuidados, dado que ha elevado la presión para que los gobiernos aumenten el grado de preparación de estos sistemas ante crisis sanitarias futuras y ante el reto que plantea el envejecimiento de la población.

La crisis del COVID-19 ha puesto en evidencia algunas deficiencias de los sistemas de salud en América Latina. A este respecto, cabe mencionar las disparidades en el acceso efectivo y en la calidad asociada con los de más altos ingresos y los emplazamientos urbanos. El elevado gasto de bolsillo en salud, las desigualdades en las tasas de inmunización y los bajos ratios de recursos humanos, médicos y enfermeras especializados y otros recursos físicos, como camas y unidades de cuidados intensivos, han limitado la capacidad de los sistemas de salud de ALC a la hora de lidiar con el aumento de la demanda a causa de la pandemia. Es necesario reforzar la prestación de servicios de salud tanto a corto como a largo plazo, ya que el porcentaje de población de edad avanzada aumentará en los países de ALC. Entre las acciones a medio plazo, los gobiernos de la región deberían aumentar la dotación económica, reducir el gasto de bolsillo en salud y reforzar el personal asistencial a largo plazo (Muir, 2017 ${ }_{[16]}$ ).

Conseguir sistemas de pensiones más sostenibles y sólidos es importante para proteger el bienestar de la tercera edad. Las elevadas tasas de informalidad en América Latina (alrededor del 56\% antes de la pandemia) suponen que un alto porcentaje de los futuros ancianos tienen menos probabilidades de recibir una pensión de un sistema contributivo (OCDE, próximo a publicarse ${ }_{[9]}$ ). En promedio, en 2017 antes de la crisis, el $75 \%$ de la población de más de 65 años recibía algún tipo de pensión en América Latina; sin embargo, un $28 \%$ de los receptores de pensiones son beneficiarios de pensiones no 
contributivas (Arenas De Mesa, 2019 ${ }_{[17]}$ ). Además, el monto de las pensiones contributivas son insuficientes para reemplazar los ingresos de una persona durante su vida productiva. Solo países como Argentina y Ecuador presentan una tasa de reposición de alrededor del $60 \%$, mientras que muchos otros se sitúan por debajo del nivel estándar fijado por la OIT (45\%), entre ellos Chile, México y Perú (Álvarez, 2020 ${ }_{[4]}$ ). Si bien, las pensiones solidarias han mejorado el acceso a las pensiones para los mayores en ALC, la capacidad de estas transferencias para sustituir los ingresos es deficiente en comparación con las pensiones contributivas, especialmente para las mujeres. En muchos países, como Bolivia, Colombia, Ecuador y Perú, el monto de estas transferencias se sitúa por debajo de la línea de pobreza, lo que hace difícil que estos programas reduzcan las tasas de pobreza y la desigualdad de ingresos para las personas mayores de 65 años.

Las políticas de protección social deben afrontar el envejecimiento demográfico aumentando la cobertura, el número de transferencias y servicios que ofrecen para garantizar un determinado nivel de ingresos y la calidad de esos servicios, al mismo tiempo, que promueven la sostenibilidad económica y la inclusividad de los sistemas de protección social. Para alcanzar estas metas, es preciso abordar con urgencia, como se expone en la sección anterior, el fomento del trabajo formal, la búsqueda de formas alternativas de financiar la protección social desligándola de la situación laboral y el diseño de programas de incentivos de seguridad social que tengan en cuenta la heterogeneidad de los mercados laborales y las economías de los países de ALC.

La mayoría de los países necesitarán ejecutar un conjunto de reformas para mejorar la protección social, como una transformación profunda de los sistemas contributivos, los sistemas públicos y la legislación laboral, y reformas fiscales o del gasto para atender las demandas de atención de los ciudadanos. Replantear el sistema social para proteger a la tercera edad obliga a tener en cuenta problemas estructurales, como la informalidad, las desigualdades de género, la baja recaudación tributaria y un margen presupuestario muy limitado (Capítulo 1). Todos estos problemas se agravaron con la pandemia y las posibles políticas de recuperación variarán en función del contexto de cada país. No existe una solución única y cada país necesita encontrar una combinación particular de políticas. Por ejemplo, en Chile, donde el sistema está basado principalmente en cuentas de capitalización individuales obligatorias y los tipos de cotización son bajos $(10 \%$ del salario), las tasas netas de reposición de menos del $40 \%$ (frente a un promedio que roza el 60\% en los países de la Organización para la Cooperación y el Desarrollo Económicos [OCDE]) son relativamente bajas (OCDE, 2019 ${ }_{[18]}$ ). En Colombia, el sistema de pensiones se caracteriza por su complejidad. Su estructura es inusual, ya que está formado por dos sistemas obligatorios paralelos; un sistema público de prestación definida basado en el reparto y un sistema privado de aportación definida. Los trabajadores pueden cambiar de un sistema a otro cada cinco años y hasta diez años antes de la jubilación. Comparado con el promedio de la OCDE y únicamente para los trabajadores de la economía formal, aunque las tasas de reposición son relativamente elevadas en el sistema público de reparto, siguen siendo relativamente bajas en el sistema privado. Las reformas recientes han tendido a reducir los riesgos de pobreza en la tercera edad para los trabajadores informales, pero siguen siendo insuficientes. El programa de ayudas a la tercera edad se reforzó en 2010 a través de la creación de Colombia Mayor (OCDE, 2015 ${ }_{[19]}$ ). En Costa Rica, en contraste con los países de la OCDE, el gobierno paga, junto con las empresas y los trabajadores, un porcentaje de las cotizaciones a la seguridad social de los empleados y los autónomos tanto en el sector público como en el privado. Estas elevadas aportaciones públicas explican, en parte, los relativamente bajos niveles de informalidad entre los trabajadores autónomos de Costa Rica (los más bajos de América Latina (OCDE, 2017 ${ }_{[20]}$ ). Sin embargo, los años mínimos de cotización (15 años para una pensión reducida) desincentivan el empleo formal entre los trabajadores con vidas 
laborales discontinuas. En México, donde las tasas previstas de reposición son bajas (28.6\% en los hombres y $26.7 \%$ en las mujeres), el gobierno se vio obligado a instaurar una nueva red de seguridad para personas de 68 años o más (Programa Pensión para el Bienestar de Adultos Mayores) para sostener los ingresos de los jubilados y evitar que los trabajadores de mayor edad, especialmente si son informales, caigan en la pobreza $\left(\right.$ OCDE, $\left.2020_{[21]}\right)$. En Perú, los componentes de las pensiones con financiación pública y privada funcionan actualmente en paralelo y compiten entre ellos, en lugar de garantizar la complementariedad. Los estrictos requisitos de aptitud del sistema público hacen que los particulares incapaces de reunir 20 años de cotizaciones no reciban ninguna prestación del sistema público. Este umbral desincentiva a los trabajadores informales a entrar en la economía formal y los particulares que cambien al sistema privado perderán acceso a las prestaciones mínimas de jubilación (OCDE, 2019 [22] ). En la región de ALC, en general las políticas que se plantean son elevar la edad de jubilación, permitir cotizaciones por trabajo a tiempo parcial, reducir las obligaciones de cotización en el sector formal, financiar la protección social a través de impuestos generales que unifiquen los programas de ayudas sociales y aumenten el importe de las aportaciones. Por último, la economía política que interviene en estas reformas tendrá un impacto enorme a la hora de que las economías de América Latina estén preparadas para proteger a los mayores en el futuro.

\section{Las políticas laborales con enfoque de género y la redistribución del trabajo de prestación de cuidados deberían conformar la base de la recuperación}

Las dificultades materiales asociadas al COVID-19 han afectado a las mujeres de forma desproporcionada (OIT, 2021 $1_{[3]}$ ). La pérdida de ingresos a causa de la crisis y las perturbaciones económicas de menor intensidad tienen más probabilidades de repercutir en la situación socioeconómica de las mujeres (OCDE et al., 2020 ${ }_{[2]}$ ). La brecha de género en la posesión de activos, la generación de ingresos, la participación en el mercado laboral y el trabajo de prestación de cuidados hace que las mujeres sean más vulnerables a la crisis. Los ingresos y la riqueza de las mujeres son, en promedio, inferiores a los de los hombres, y tienen más probabilidades de ser pobres. Antes de la pandemia, las tasas de pobreza entre las mujeres en edad de trabajar eran un $12.7 \%$ más altas que entre los hombres del mismo grupo de edad (CEPAL, 2021 ${ }_{[1]}$ ). Además, el salario por hora era más alto en los hombres, con 6.0 USD (dólares estadounidenses) en PPP, frente a los 5.7 USD de las mujeres (FMI, 2020 ${ }_{[23]}$ ).

Las mujeres de la región de ALC estaban especialmente expuestas a los efectos del virus, ya que representan la mayor parte del personal de la salud. Aunque las mujeres están escasamente representadas entre los médicos y farmacéuticos, están sobrerrepresentadas entre el personal de enfermería y preparación para el parto, que debe estar en contacto directo con los pacientes infectados. En América Latina, las mujeres son el $46 \%$ de los médicos y el $86 \%$ del personal de enfermería.

Otras variables asociadas con las condiciones anteriores a la pandemia contribuyeron a las vulnerabilidades de las mujeres a la hora de afrontar la crisis. Las mujeres estaban sobrerrepresentadas en los sectores más afectados, lo que les hizo más vulnerables a la destrucción de empleo (OIT, 2020 ${ }_{[24]}$ ). En América Latina, ocho de cada diez mujeres trabajan en servicios, comercio, turismo y hostelería (Gutiérrez, 2021 ${ }_{[25]}$ ). Además, el $54 \%$ de las mujeres trabaja en la economía informal, frente el $52 \%$ de los hombres. Las características del mercado laboral agravaron las vulnerabilidades de las mujeres en ALC. En promedio, las tasas de reducción del empleo (18.1\% frente al $15.1 \%$ de los hombres) y salida del mercado laboral (15.4\% frente al $11.8 \%$ de los hombres) fueron sensiblemente más elevadas entre las mujeres (CEPAL, 2021 $1_{[1]}$ ). 
Los jóvenes, en especial las mujeres jóvenes, perdieron su empleo y sufriendo penurias durante 2020. Alrededor del 34\% de los hombres jóvenes perdió su empleo, frente al 39\% de las mujeres jóvenes; en este sentido, la heterogeneidad de las brechas de género asociadas a la destrucción de empleo entre los países de ALC osciló entre el 20\% de Colombia y el $65 \%$ de Honduras (Gutiérrez, 2021 ${ }_{[25]}$ ). El proceso de recuperación puede ser más lento para las mujeres en edad fértil, cuya trayectoria laboral puede verse afectada por la carga de cuidar de los hijos y la discriminación en el mercado laboral (Tribin, Vargas y Ramírez, 2019 $\left.{ }_{[26]}\right)$.

El confinamiento y el cierre de múltiples servicios, como los centros educativos y otros servicios sociales, impusieron graves limitaciones al trabajo de las mujeres y aumentaron su carga de trabajo no remunerado, ya que asumieron responsabilidades de prestación de cuidados adicionales para apoyar el aprendizaje de los hijos y se ocuparon de familiares enfermos y vulnerables (OCDE, 2020 ${ }_{[27]}$; CEPAL, 2021 $1_{[1]}$ ). Las mujeres tuvieron un acceso limitado al teletrabajo como mecanismo para seguir trabajando, a la vista de la distribución del personal femenino en sectores y áreas que requieren interacción personal. A las mujeres también puede resultarles más difícil mantener su empleo e ingresos después de un despido- debido a sus mayores obligaciones de prestación de cuidados. En la región, los hombres pasaron la mayor parte de su tiempo en trabajos remunerados, mientras que las mujeres pasaron la mayor parte de él en trabajos no remunerados dentro de sus hogares (OIT, 2019 ${ }_{[28]}$ ). Antes de la crisis, el 11.1\% de las mujeres desempeñaba trabajos domésticos remunerados y sólo el $24 \%$ de ellas estaba afiliada o contribuía a sistemas de seguridad social (CEPAL, 2021 ${ }_{[29]}$ ). El desigual reparto del trabajo doméstico y de cuidados, junto con las tendencias de envejecimiento que aumentarán la demanda de cuidados, suponen amenazas para la inclusión económica y laboral de las mujeres en ausencia de un estado y un mercado que se ocupe de prestar esto servicios.

Las medidas de confinamiento, junto con las consecuencias psicológicas de la pandemia y las dificultades económicas, podrían haber agravado la violencia contra las mujeres (OCDE, 2020 ${ }_{[30]}$; CEPAL, 2020 ${ }_{[31]}$ ), lo que tiene un enorme impacto negativo en su bienestar. Aunque no existen suficientes datos del periodo de la pandemia para cuantificar el incremento de la violencia contra las mujeres, durante los primeros meses de la crisis las denuncias por violencia revelaron un aumento que refuerza la necesidad de que las políticas públicas ofrezcan servicios relacionados con la atención y el apoyo a las víctimas en contextos de violencia de género contra las mujeres (CEPAL, 2020 ${ }_{[31]}$ ). En Argentina, el número de consultas sobre violencia de género aumentó un 39\%. En Brasil, se registró un incremento del 50\% en el número de denuncias en Río de Janeiro. En Colombia, las denuncias aumentaron un $51 \%$ en los primeros días de la cuarentena. En el estado mexicano de Nuevo León, se produjo un aumento del 30\% en los casos denunciados de violencia en el ámbito familiar (ONU Mujeres, $2020_{[32]}$; Gutiérrez, 2021 $1_{[25]}$ ). Además, el cierre de las escuelas y el aumento de las dificultades en el hogar dieron lugar a un gran número de niñas que abandonaron definitivamente la escuela, sobre todo en las comunidades desfavorecidas, lo que provocó a su vez un riesgo mucho mayor de embarazos no deseados y matrimonios precoces (Szabo y Edwards, 2020 [33] . Se necesitan acciones urgentes para proteger las vidas y el bienestar de las mujeres.

La transformación digital puede ofrecer oportunidades a las mujeres para que recuperen espacio en el mercado laboral. Las nuevas tecnologías y la aceleración de la digitalización durante la pandemia pueden ayudar a las mujeres a seguir trabajando desde casa, ofrecer trabajo a tiempo parcial, conciliar la vida familiar y laboral de forma más eficaz y reducir los costos y el tiempo invertido en transporte. Sin embargo, la brecha digital de género puede dificultar la inclusión de la mujer en el futuro del trabajo, por ejemplo debido a diferencias en la edad del primer acceso a dispositivos digitales y en la percepción de las competencias necesarias para desenvolverse en el mundo digital (OCDE 
et al., $\left.2020_{[2]}\right)$. Conseguir una transformación digital inclusiva que englobe el acceso de la mujer a las tecnologías digitales y medidas para impartir las competencias necesarias para usarlas y derribar barreras socioeconómicas y, por tanto, mejorar las oportunidades económicas son factores necesarios para promover la autonomía de las mujeres en el contexto posterior a la pandemia (CEPAL, 2021 ${ }_{[29]}$ ). Eso facilitará también el aprendizaje a distancia, reducirá el trabajo no remunerado y mejorará las posibilidades de que las mujeres se incorporen al mercado laboral a través de nuevas formas de trabajo, por ejemplo a través de la economía de las plataformas.

Los gobiernos de ALC deberían promover una mayor participación laboral e ingresos laborales para las mujeres, generando una sinergia en las intervenciones de política. En primer lugar, la redistribución del trabajo de cuidados mediante la oferta de servicios de cuidados públicos y privados de calidad puede incentivar a las mujeres a entrar en el mercado laboral, o a aumentar las horas de trabajo, en caso de que tengan empleos informales a tiempo parcial. Así mismo, las políticas con enfoque de género que permitan a las mujeres balancear la familia y el trabajo para aumentar la productividad laboral (OIT, 2019 $\left.{ }_{[28}\right)$. Subsidiar la educación preescolar puede dar alternativas a los cuidados parentales (OCDE, 2020 ${ }_{[30]}$ ), lo que permitiría a las mujeres regresar al mercado laboral, después del embarazo. Por lo tanto, es esencial diseñar sistemas asistenciales amplios para los mayores, los niños, los estudiantes jóvenes y los enfermos que combinen políticas relacionadas con la distribución del tiempo, los recursos, las prestaciones y los servicios y que conecten con las políticas sanitarias y educativas sin someter a las mujeres a una carga excesiva de trabajo no remunerado (CEPAL, 2021 ${ }_{[29]}$ ). Estas acciones revisten una importancia aún mayor en el contexto de la recuperación, ya que será necesario poner al mismo nivel de aprendizaje a la mayoría de alumnos de la región, dado el elevado número de días en los que los centros educativos estuvieron cerrados, comparado con los países de la OCDE (véase la próxima sección).

Es vital ampliar la cobertura de protección social para abarcar la diversidad de situaciones de las mujeres. Los gobiernos de ALC han usado profusamente los programas de ayudas económicas directas para mitigar los efectos de la pandemia en los hogares. Sin embargo, podría ser necesario suspender algunas de las condiciones de estos programas para que las mujeres, jóvenes y los niños sigan recibiendo prestaciones mientras se recobra la normalidad y para evitar el trabajo adicional no remunerado para las mujeres. A corto plazo, es esencial asegurarse de que las mujeres más afectadas por la crisis están cubiertas como beneficiarias, es decir, convirtiéndolas en receptoras directas de ayudas económicas dentro de los miembros de los hogares o priorizando a las mujeres cabeza de familia.

La transformación de las normas sociales asociadas a una distribución desigual del trabajo de cuidados podría llevar un tiempo considerable. Sin embargo, la pandemia ofrece la oportunidad de concienciar sobre el valor del trabajo de cuidados y doméstico y aumentar la comunicación y la educación efectiva sobre estas cuestiones para corregir el desequilibrio en el trabajo no remunerado en el hogar. A medio plazo, los hombres y los niños deben tomar parte en los esfuerzos por promover metas esenciales del desarrollo social y económico de las mujeres, especialmente mediante la redistribución de los cuidados no retribuidos, cuestionan así la idea de que es responsabilidad exclusiva de las mujeres. Para conseguirlo, la inclusión de nuevas masculinidades más equitativas en un nuevo contrato social en la región puede promover el empoderamiento de las mujeres e impulsar la igualdad entre los sexos. Las políticas de recuperación con enfoque de género deben fijarse como meta la promoción de esta transformación de las masculinidades (OCDE, 2021 $\left.{ }_{[34]}\right)$. 
Por último, elevar la participación de los representantes de las mujeres en el proceso de diseño de programas de protección social con perspectiva de género y tener en cuenta la dimensión de género en las políticas públicas deben ser prioridades en la elaboración de un nuevo contrato social (Capítulo 4).

\section{Las acciones rápidas para abordar las desigualdades en educación y adquisición de competencias son claves para la recuperación}

La pandemia de COVID-19 amplió las desigualdades existentes en el acceso y la calidad de la educación en América Latina. Los países de ALC no estaban preparados para digitalizar la educación, lo que afectó a 154 millones de alumnos en la región (UNICEF, 2020 $\left.{ }_{[35}\right)$. La mayor parte de los alumnos de ALC no cuenta con los recursos para conectarse o utilizar un dispositivo electrónico, existiendo una clara diferencia entre los alumnos que asistían a centros educativos en entornos favorecidos y desfavorecidos. Mientras que el $51 \%$ de los alumnos de 15 años que asistían a centros educativos en entornos favorecidos tiene acceso a plataformas de enseñanza en línea, únicamente el 21\% de los alumnos en entornos desfavorecidos lo tiene (OCDE, 2020 ${ }_{[6]}$ ). El papel de los docentes puede agravar las brechas en el aprendizaje de los alumnos durante la pandemia. En promedio en los países de ALC, únicamente el 58\% de los alumnos de 15 años está matriculado en un centro educativo donde el director cree que pueden adaptar sus competencias técnicas y pedagógicas para incorporar los dispositivos digitales (OCDE et al., 2020 ${ }_{[2]}$ ).

Los resultados educativos durante la pandemia dependieron del entorno familiar y antecedentes familiares. Alrededor del $73.6 \%$ de los estudiantes de ALC en el quintil más pobre dispone de un espacio de estudio (Jaramillo, $2020_{[36]}$ ). Las competencias de los padres, el capital social, la disponibilidad de tiempo y la capacidad para ayudar a los niños a utilizar la tecnología para el aprendizaje contribuyen a ampliar las brechas $\left(O C D E, 2020_{[37]}\right.$ ). Los alumnos en entornos favorecidos tienen más probabilidades de que los padres posean más competencias cognitivas y digitales que pueden apoyar el aprendizaje a distancia (OCDE, 2020 ${ }_{[38]}$ ). Los progenitores más pobres no han terminado la educación secundaria y rara vez utilizan las tecnologías de la información y la comunicación (TIC) más allá de los teléfonos móviles. En ALC, los niveles de implicación escolar de los padres, medidos como el porcentaje de padres que hablaron con un profesor por iniciativa propia sobre los progresos de sus hijos, son inferiores al promedio de la OCDE (37\%, frente al 41\%) (OCDE, 2020 $\left.{ }_{[39]}\right)$. Además, el índice de implicación parental en el aprendizaje en casa muestra una importante variación entre niveles socioeconómicos: entre 10.4 y 22.6 veces más bajo en el quintil más pobre, comparado con el más alto (Jaramillo, $\left.2020_{[36]}\right){ }^{1}$

Un elevado número de centros educativos se vieron obligados a cerrar en ALC para contener la propagación del virus. En el momento de redactar este documento, en todo el mundo los centros educativos han estado totalmente cerrados un promedio de 19 semanas. En ALC, esta cifra de cierres totales de centros educativos es de 26 semanas en promedio, lo que convierte a la región en la que más días lectivos ha perdido en promedio (UNICEF, $\left.2021_{[40]}\right)$. Entre marzo de 2020 y mayo de 2021 los cierres de centros educativos en ALC eran, en promedio, un 70\% más altos que en la OCDE (Gráfico 2.1). En los países de la región de ALC, existe una considerable variación en las semanas lectivas perdidas; por ejemplo, Chile y Uruguay han perdido un promedio de 14 semanas debido al COVID-19. La mayor parte de las veces, los centros educativos de estos países han permanecido abiertos o parcialmente abiertos, pero países como Brasil y Panamá han perdido $38 \mathrm{y}$ 55 semanas, respectivamente. 


\section{Gráfico 2.1. Los cierres escolares han sido más largos en ALC que en los países de la OCDE, lo que amenaza con agravar las desigualdades educativas}

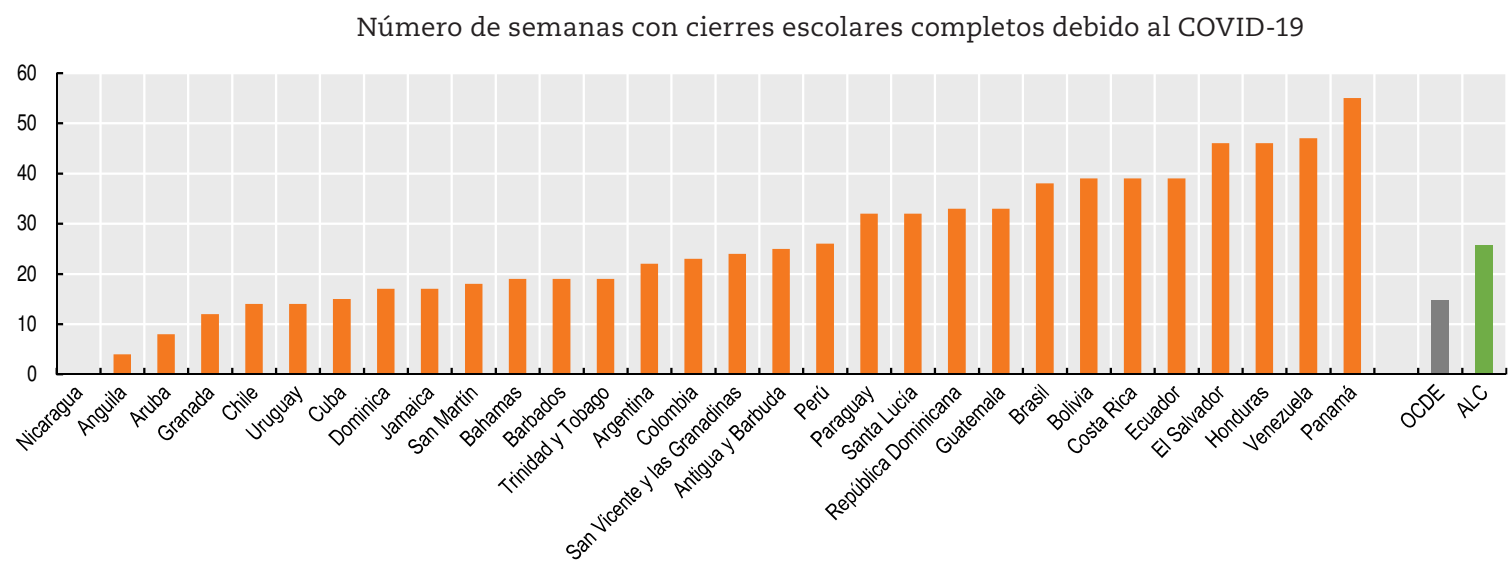

Notas: El promedio de la OCDE engloba a los entonces 37 estados miembros. El promedio de ALC está formado por Brasil, Chile, Colombia, Costa Rica, Cuba, República Dominicana, Ecuador, El Salvador, Guatemala, Haití, Honduras, México, Nicaragua, Panamá, Perú, Uruguay y Venezuela. Actualizado a 1 de mayo de 2021.

Fuente: UNESCO (2020). Seguimiento global de los cierres de centros educativos provocados por el COVID-19 https://en.unesco.org/covid19/educationresponse\#schoolclosures

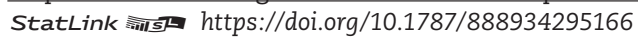

El impacto directo de los cierres escolares es una posible pérdida de aprendizaje. Las interrupciones prolongadas de los estudios (por ejemplo, debido a vacaciones o huelgas) se asocian a una reducción del nivel de aprendizaje, especialmente entre los alumnos en situación de vulnerabilidad (Azevedo et al., 2020 ${ }_{[41]}$; Busso, 2021 ${ }_{[42]}$ ). Además, este impacto puede diferir de un grupo socioeconómico a otro y puede aumentar la desigualdad. Muchos centros educativos de ALC permanecen cerrados en el momento de redactar este documento y no existen suficientes datos para evaluar minuciosamente el impacto de la pandemia de COVID-19 sobre el aprendizaje de los estudiantes. Sin embargo, los datos preliminares que ofrece EE.UU. muestran que entre marzo y mayo de 2020 los alumnos pertenecientes a hogares de ingresos altos que utilizaron la plataforma de matemáticas Zearn aprendieron menos temporalmente, pero pronto recuperaron los niveles de referencia de enero, mientras que los alumnos de hogares de ingresos bajos terminaron el año escolar casi un 50\% por debajo de los niveles de referencia (Jaramillo, 2020 ${ }_{[36]}$; Chetty, $2020_{[43]}$. Esta diferencia puede explicarse en parte por el hecho de que los estudiantes de hogares de ingresos altos, que ya han desarrollado competencias cognitivas digitales, tienen acceso a las TIC y tienen progenitores que pueden orientarles en el uso de los recursos en línea, pueden beneficiarse de las herramientas que ofrecen las tecnologías digitales (Basto-Aguirre, Cerutti y Nieto-Parra, 2020 $\left.{ }_{[44]}\right)$.

El cierre prolongado de los centros educativos también está afectando a la recuperación de la destrucción de empleo sufrida por las mujeres. La presencia de niños en edad escolar se asocia a una mayor probabilidad de desempleo durante la pandemia debido a las mayores necesidades de cuidados infantiles en el hogar, dado que las normas sociales empujan a las mujeres a convertirse en la fuente primaria de cuidados familiares (Cucagna y Romero, $\left.2021_{[45]}\right)$. La carga del trabajo doméstico y de cuidado no retribuido entre las niñas y las adolescentes también podría aumentar. Además, la pandemia podría obligar a los niños de familias más pobres a ponerse a trabajar, aumentando así las tasas de trabajo infantil hasta el 7.3\% de los niños entre 5 y 17 años, lo que supone alrededor de 10.5 millones de niños (OIT/CEPAL, 2020 ${ }_{[46]}$ ). Por lo tanto, la reapertura segura de los centros educativos y el apoyo formativo y extracurricular para los alumnos más desfavorecidos son elementos prioritarios para facilitar una recuperación equitativa en la región. 
Cada vez existen más pruebas de que la asistencia a los centros educativos no es un vector importante de contagios y que el impacto de la pandemia en los niños podría ser peor si no regresan a las aulas (UNICEF, 2021 $1_{[40]}$ ). Se necesita con urgencia invertir en mejorar el estado de las infraestructuras escolares para garantizar unas condiciones básicas de saneamiento e higiene, sobre todo en la región de ALC, donde la mayoría de los países optó por mantener cerrados los centros educativos. La reapertura debería seguir las directrices fijadas por la Organización Mundial de la Salud y entidades como UNICEF (OMS, 2020 ${ }_{[47]}$; UNICEF, 2020 ${ }_{[48]}$ ). Planificar la oferta y la demanda de docentes y mejorar la formación y el acceso a Internet y las tecnologías para los que no pueden regresar a los centros educativos constituyen pasos intermedios que deberían ponerse en marcha rápidamente para proteger el acceso y la calidad de la educación en ALC.

Es preciso que exista una continuidad en las medidas de los países para abordar la pandemia, especialmente aquellas que pueden reducir las desigualdades en el acceso a las infraestructuras de comunicación, las instalaciones, los equipos y los contenidos (Basto-Aguirre, Cerutti y Nieto-Parra, 2020 ${ }_{[44]}$ ). En ALC, se han adaptado alrededor de 100 medidas de política educativa desde el comienzo de la pandemia, pero la mayoría de ellas aludía a la suspensión de las clases: 62 medidas tomadas en relación con las herramientas de aprendizaje a distancia (CEPAL, 2020 ${ }_{[49]}$ ). Los programas de protección social también constituyen un mecanismo importante para reducir la presión a la que se enfrentan algunos hogares debido a los problemas de convivencia o económicos que podrían afectar al bienestar de los niños (Jaramillo, 2020 ${ }_{[36]}$ ).

El COVID-19 agravó las brechas educativas y creó otras nuevas. Es esencial apoyar a los centros educativos poniendo en marcha iniciativas que ayuden a los alumnos a recuperar el aprendizaje perdido (OCDE, $2020_{[50]}$ ). En Europa y Norteamérica, se diseñaron cursos de verano, programas educativos acelerados y otras prácticas identificables para ayudar a los alumnos desfavorecidos a ponerse al día. Los cursos de verano se pusieron en marcha en Canadá, Alemania y el Reino Unido. A la hora de planificar cómo abordar las desigualdades, será necesario incorporar la ejecución de estos tipos de iniciativas para motivar y mejorar el aprendizaje de forma sustancial en un breve periodo para las poblaciones desfavorecidas de ALC. Por ejemplo, en 2020 Colombia proporcionó un incentivo especial de transferencia monetaria a los beneficiarios del "Programa Jóvenes en Acción" con la única condición de que estuvieran matriculados en la educación desde marzo de 2021. El programa tiene como objetivo garantizar el acceso a una educación de calidad a los jóvenes en desventaja económica o en situación de vulnerabilidad desde 2012.

Los países pueden escoger entre implantar programas acelerados centrados en materias clave, haciéndolos flexibles y adaptándolos por edades (OCDE, 2020 ${ }_{[50]}$ ) social and emotional needs - is crucial, especially in times of crisis. School closures related to the coronavirus (COVID-19. Noruega es uno de los países que los está poniendo en marcha y organizaciones como UNICEF y los Grupos de Trabajo sobre Educación Acelerada (AEWG) aconsejan utilizarlos para abordar la brecha educativa. Francia costeó 1.5 millones de horas lectivas adicionales después del horario escolar para apoyar a los estudiantes. Diseñar y aplicar planes de estudios universales, apoyar las actividades de aprendizaje no formal en casa y fomentar la orientación extraescolar son medidas que podrían tomar las autoridades para cerrar las crecientes brechas educativas. Por último, es importante para la recuperación centrarse en el bienestar y las competencias socioemocionales de los alumnos y el personal docente, ya que estas les permiten abordar situaciones traumáticas con calma y estabilidad emocional (CEPAL/UNESCO, 2020 ${ }_{[51]}$ ).

Las políticas deben garantizar los derechos básicos y la atención a los inmigrantes, que se enfrentan a múltiples vulnerabilidades en la región

La migración está aumentando en ALC, especialmente a causa de la crisis venezolana, entre otros importantes corredores. Más de 11.6 millones de inmigrantes residían en 
países de ALC en 2019 (UNDESA, 2019 ${ }_{[52]}$ ). Las crecientes desigualdades en la región han cambiado la forma y las rutas de las migraciones. Las cifras de inmigración han aumentado espectacularmente desde 2015 y la crisis humanitaria y económica de Venezuela ha empujado a alrededor de 4.7 millones de personas a abandonar el país entre 2015 y 2020, cerca de 4 millones de las cuales se han establecido en países de ALC (OCDE, 2020 ${ }_{[6]}$ ). Colombia ha soportado la mayor parte de estos flujos, pero la crisis migratoria también se ha extendido a Chile, Ecuador y Perú. La situación también se ha caracterizado por una mayor emigración a lo largo de una nueva ruta migratoria desde Haití hasta Sudamérica y la ruta que cruza Centroamérica, México y Estados Unidos (OCDE/ILO, 2018 ${ }_{[53]}$ ).

Los inmigrantes y sus familias se ven afectados desproporcionadamente por la crisis, lo que justifica una mayor atención por parte de los gobiernos (ACNUDH, 2020 ${ }_{[54]}$ ). Las crisis económicas anteriores han hecho posible determinar la vulnerabilidad de los inmigrantes en indicadores como la salud, el empleo, la educación y otros (OCDE, 2020 $\left.{ }_{[55]}\right)$, lo que permite dimensionar los problemas a los que se enfrentan durante la pandemia. Los migrantes en ALC están sobrerrepresentados entre los segmentos más pobres de la población y el aumento de la inmigración, sumado a la crisis del COVID-19, ha generado percepciones negativas sobre los inmigrantes entre la población ${ }^{2}$. Por último, las familias inmigrantes tienen más probabilidades de ser desahuciadas por impago (muchas no disponen de un contrato de alquiler formal) y de vivir hacinadas en barrios marginales, con un menor acceso a servicios públicos esenciales y medios para cumplir con las recomendaciones de saneamiento (CEPAL, 2020 ${ }_{[56]}$ ).

Los trabajadores inmigrantes se concentran en sectores informales de baja productividad, lo queles hace estar más expuestos al coronavirusy tener más probabilidades de perder su empleo. La falta de reconocimiento de su formación y cualificaciones limita su acceso al mercado laboral formal y su capacidad para recuperarse en el periodo posterior a la pandemia. Entre los inmigrantes, las mujeres sufren diversas carencias y vulnerabilidades. Más de las mitad de los inmigrantes son mujeres (51.6\%) y más de una tercera parte de ellas realiza trabajos domésticos remunerados (35.3\%) (OIT, 2016 ${ }_{[57]}$ ). El importante efecto de la crisis en el personal de servicio doméstico ha hecho que muchas mujeres inmigrantes perdieran su fuente de ingresos sin la posibilidad de regresar a su país de origen. Para los inmigrantes, el racismo y la xenofobia también suponen importantes retos para una protección adecuada y la reincorporación al mercado laboral después de la crisis (CEPAL, 2020 ${ }_{[56]}$ ). La situación jurídica de los inmigrantes influye también en su integración en el mercado laboral del país de destino. Los diferentes requisitos legales suelen ser un obstáculo para la empleabilidad. Por ejemplo, los refugiados pueden no tener derecho a ocupar puestos de trabajo en el sector formal, o no tienen derecho a acceder a la educación pública, a la sanidad o a beneficiarse de los servicios públicos de empleo y asistencia social. Lo mismo puede aplicarse a los inmigrantes irregulares. La regulación suele ser más flexibles en el caso de las reagrupaciones familiares, y los migrantes que se reúnen con las familias tienen más posibilidades de una transición fluida en el mercado laboral del país de acogida (OCDE/OIT, $2018_{[53]}$ ).

Facilitar el acceso de los inmigrantes a medidas de protección social deber ser una prioridad. Reemplazar parte de los ingresos perdidos ayudará a estas familias a cumplir con las medidas de distanciamiento social. Dar acceso a servicios de salud y vacunas reducirá la propagación del virus, dado que la mayor parte de los inmigrantes desempeñan empleos que requieren interacciones personales. Este factor externo es uno de los principales argumentos a favor de priorizar a los grupos vulnerables en el contexto de una pandemia; la protección social universal se convierte en condición previa para el éxito a la hora de combatir la propagación de la enfermedad (Lusting y Tommasi, $2020_{[58]}$ ). Es esencial garantizar el acceso de los inmigrantes a los servicios de salud (ACNUDH, $\left.2020_{[54]}\right)$, especialmente en los países de ALC que no tienen trayectoria en la implantación 
de este tipo de programas. Hasta hora, Colombia ha sido uno de los pocos países que ha puesto en marcha una política para ayudar a los inmigrantes durante la pandemia, principalmente mediante la detección y la prevención (CEPAL, 2020 ${ }_{[56]}$ ) (Recuadro 2.1).

Ampliar la cobertura de las ayudas modificando su acceso y duración para beneficiar a la población inmigrante forma parte de las políticas de recuperación inclusiva que pueden acelerar la recuperación socioeconómica de la región. Algunos países de la OCDE han cambiado sus políticas o marcos normativos para ampliar la cobertura y las ayudas. Bélgica y España redujeron la duración mínima de empleo necesaria para acceder a prestaciones por desempleo, lo que ayuda a atender a los inmigrantes a través de medidas de protección social (OCDE, $\left.2020_{[55]}\right)$. En ALC, Brasil puso en marcha un fondo de emergencia para ayudar a los inmigrantes con empleos informales o desempleados (PNUD, 2020 ${ }_{[59]}$ ), mientras que Colombia y Perú lanzaron programas de ayudas económicas directas (Ingreso Solidario, Apoyo económico para migrantes venezolanos). Se han puesto en marcha políticas similares en Chile (Ingreso Familiar por Emergencia), Panamá (Plan Solidario) y Trinidad y Tobago (Asistencia COVID-19). A escala mundial, los países donantes de la OCDE han trabajado en favor de ampliar el acceso de los inmigrantes y refugiados a los bienes y servicios públicos (como los centros educativos públicos), la participación en el mercado laboral formal, el emprendimiento y el trabajo cualificado en las energías renovables (Gagnon y Rodrigues, $2020_{[60]}$ ).

Ayudar a los inmigrantes que viven o viajan en condiciones inapropiadas, sin acceso a agua, saneamiento o una buena higiene, es clave para luchar contra la pandemia (ACNUDH, $\left.2020_{[54]}\right)$. En ALC, los países como Colombia han ayudado a los inmigrantes venezolanos en zonas fronterizas construyendo refugios temporales y distribuyendo alimentos (PNUD, $\left.2020_{[59]}\right)$. Las acciones para mitigar los problemas que sufren los inmigrantes deberían englobar: i) el acceso a pruebas y a cuidados médicos para prevenir el COVID-19; ii) la reubicación de asentamiento densamente poblados; iii) un marco para suspender los desahucios, y iv) estrategias para abordar la violencia de género.

$\mathrm{El}$ hecho de que los trabajadores inmigrantes son esenciales para muchos sectores de la economía, incluidos aquellos que prestan servicios básicos durante la pandemia (CCI, 2020 $[61]$ ), puede concienciar sobre la importancia de ampliar sus derechos laborales. Eso implica regularizar la situación laboral de los inmigrantes para que puedan acceder a las mismas prestaciones laborales que los nacionales. Colombia, por ejemplo, amplió el Permiso Especial de Permanencia (PEP) para permitir a los inmigrantes venezolanos acceder a los servicios públicos en las áreas de salud, servicios de nutrición, educación y trabajo (PNUD, 2020 ${ }_{[59]}$ ) (Recuadro 2.1).

\section{Recuadro 2.1. El programa nacional de regularización de Colombia para responder ante la crisis venezolana}

De acuerdo con el Departamento de Asuntos Económicos y Sociales de Naciones Unidas, más de 5 millones de venezolanos han abandonado el país debido a la crisis política y económica. Colombia ha sido el destino principal de los inmigrantes y refugiados venezolanos, ya que acogía a alrededor de 1.8 millones de venezolanos a diciembre de 2020, seguido de Brasil, Chile, Ecuador y Perú. Alrededor del 56\% de los inmigrantes en Colombia se encuentra en situación irregular. Según las Naciones Unidas, la inmigración venezolana no ha disminuido durante la pandemia. A finales de 2021, podría haber 6.2 millones de inmigrantes y refugiados venezolanos, de los cuales un porcentaje considerable se espera que opte por Colombia como nuevo país de residencia. 


\section{Recuadro 2.1. El programa nacional de regularización de Colombia para responder ante la crisis venezolana (cont.)}

El gobierno colombiano ha implantado medidas para proteger a su población frente a los riesgos planteados por el COVID-19 y las ha ampliado para incluir a los refugiados e inmigrantes venezolanos entre los beneficiarios. Entre las medidas adoptadas, está el acceso gratuito a servicios sanitarios de urgencia y por COVID-19 para inmigrantes irregulares. Incluso antes de la pandemia, el país daba pleno acceso a los programas del sistema nacional de salud a los poseedores del Permiso Especial de Permanencia (Ministerio de Salud y Protección Social, $2018_{[62]}$ ), un documento de identificación creado en 2017 que permite a los inmigrantes registrados acceder a los mismos servicios públicos que los nacionales durante dos años.

Prestar ayuda humanitaria en los corredores fronterizos, ofrecer acceso a algunos de los programas de protección social y promover la coordinación de acciones a través de la cooperación internacional y con las administraciones locales han resultado ser elementos clave en los esfuerzos de apoyo a los inmigrantes. Las ayudas sociales directas a través del Ingreso Solidario y las transferencias en especie por medio de los comedores escolares adoptadas en 2020 benefician a los hogares vulnerables sin diferenciar por nacionalidad (Ministerio de Salud y Protección Social, 2020 ${ }_{[63]}$ ). Promover la coordinación y compartir información con las administraciones locales en áreas de alto impacto y con actores humanitarios internacionales ha brindado soluciones eficaces para responder a las necesidades de los inmigrantes.

En febrero de 2021, Colombia amplió las medidas de integración para inmigrantes creando el Estatuto de Protección Temporal para Venezolanos (EPTV), lo que convirtió el país en pionero en la región a la hora de adoptar medidas universales para proteger a esta población. El EPTV consiste en un mecanismo complementario al régimen de protección internacional para refugiados que permite cerrar las brechas existentes basándose en la realidad migratoria y la capacidad de respuesta institucional, social y económica del país (Migración Ministerio de Relaciones Exteriores, 2021 ${ }_{[64]}$ ). Al ofrecer permisos de residencia de diez años a todos los inmigrantes venezolanos (regulares e irregulares), con la posibilidad de obtener la residencia a largo plazo, la nueva estrategia de Colombia protege los derechos humanos de una parte de la población que actualmente se encuentra en una situación de mayor vulnerabilidad. Este nuevo conjunto de medidas dará estatus legal a más de 1 millón de inmigrantes irregulares en Colombia.

El EPTV protege a los venezolanos de quedar excluidos de los servicios públicos y frente a los retornos involuntarios. Además, reduce el riesgo de explotación en los mercados laborales y protege a los hogares venezolanos de las consecuencias de la pandemia. Este nuevo estatus mejora el acceso de los inmigrantes a los servicios públicos y la protección social y podría mejorar su acceso a empleos de calidad y condiciones de vida dignas. Para poner en marcha dicha iniciativa a gran escala, se necesita una importante inversión de tiempo, logística y recursos. Sin embargo, la medida ha recibido apoyo de la comunidad internacional y ha reforzado la necesidad de poner en marcha acciones generosas y audaces para ofrecer soluciones a largo plazo a los retos de la inmigración.

\section{El potencial de una recuperación verde e inclusiva en ALC}

Los riesgos medioambientales y socioeconómicos están estrechamente relacionados. Después de la pandemia, los riesgos que anteriormente se consideraban una amenaza lejana se perfilan como una oportunidad concreta para crear un desarrollo inclusivo y sostenible. 
Avanzar hacia un modelo de desarrollo bajo en carbono, o hacia una transición ecológica, no sólo es necesario para reducir el aumento de las temperaturas y salvaguardar el planeta, sino que también puede ser una forma de reducir las desigualdades, crear empleos de calidad y rediseñar los sistemas de protección social. Al mismo tiempo, abordar las desigualdades y avanzar hacia sistemas de protección social más universales, como se ha sugerido anteriormente, será determinante para afrontar los impactos del cambio climático, que afectan desproporcionadamente a los grupos más vulnerables. También ayudará a reducir los posibles impactos negativos sobre los trabajadores en actividades económicas afectadas por la transición ecológica y a que puedan acceder a nuevas oportunidades laborales.

El crecimiento ecológico y la prosperidad socioeconómica pueden ir de la mano en ALC. Los países de ALC podrían aprovechar la oportunidad creada por la pandemia para poner en marcha reformas estructurales para avanzar hacia un modelo de desarrollo más sostenible, más inclusivo y resiliente. Los paquetes de estímulos deberían facilitar esa "transición justa", centrarse en conseguir beneficios directos para las personas y abordar las brechas en las infraestructuras para alcanzar Objetivos de Desarrollo Sostenible de la ONU como son movilizar inversiones verdes y crear empleo.

El mundo posterior al COVID-19 demanda una visión integrada del desarrollo social y medioambiental aplicada a todos los niveles de gobierno. Es necesario integrar los ámbitos sociales en el diseño de políticas de transición ecológica y es clave generalizar las consideraciones sobre el medio ambiente y la mitigación del cambio climático como cuestiones transversales en todas las áreas de gobierno, especialmente en lo que respecta a los sistemas de protección social. No hacerlo conlleva el riesgo de socavar la aceptación social de políticas ambiciosas en el futuro que se centren en el medio ambiente. Los enfoques integrados permitirían que las cuestiones relativas al desarrollo humano y social se tomen plenamente en cuenta en la transición ecológica, con el fin de conseguir la neutralidad en emisiones de carbono y reducir drásticamente las desigualdades multidimensionales (AFD, 2019 ${ }_{[65]}$ ). Además, la adopción de una perspectiva de bienestar para abordar la transición verde podría ayudar a diseñar estrategias climáticas con el potencial de acelerar la mitigación del cambio climático al tiempo que se mejoran los resultados de bienestar en general (OCDE, 2019 ${ }_{[66]}$ ).

Vincular una transición ecológica con los retos sociales de la región podría posibilitar una recuperación exitosa del COVID-19 en al menos tres ámbitos: i) reducir el desigual impacto del cambio climático en grupos vulnerables; ii) crear empleos de calidad; y iii) promover la inclusión social a través de sistemas de protección social más amplios.

\section{Abordar el cambio climático para reducir la desigualdad: Dos retos interconectados}

La pandemia puso en evidencia la estrecha interacción entre la salud humana y animal y el medio ambiente, ampliando la necesidad de abordar conjuntamente los retos de la desigualdad y la degradación medioambiental (OCDE, 2021 ${ }_{[67]}$ ). El cambio climático agrava las desigualdades existentes y las tensiones sociales dentro de las fronteras nacionales y entre países, ya que los impactos de la degradación medioambiental suelen concentrarse en los grupos vulnerables. Existe una especie de "doble castigo": los que más sufren y sufrirán las consecuencias del cambio climático son los que menos contribuyen al problema (AFD, 2019 ${ }_{[65]}$; AFD, 2018 ${ }_{[68]}$ ). Aunque la pandemia incrementó el número de personas que viven por debajo de la línea de pobreza en ALC (Capítulo 1), se prevé que el cambio climático sume otros 5 millones de personas en 2030 (BID, 2021 ${ }_{[69]}$ ). El cambio climático amenaza con revertir las mejoras de la salud mundial conseguidas durante los últimos 50 años (The Lancet Commissions, $2015_{[70]}$ ). 
La desigualdad representa un obstáculo importante en la lucha contra el cambio climático y las alteraciones de los ecosistemas. De hecho, las ambiciosas políticas de transición necesarias para responder ante los retos climáticos y ecológicos podrían afectar a los grupos más vulnerables por la vía de la reestructuración laboral, la destrucción temporal de empleo y la pérdida de ingresos (OCDE, 2021 ${ }_{[67]}$ ). Estos efectos indeseables probablemente sean difíciles de aceptar para las poblaciones más frágiles y los grupos sociales que ya se encuentran en situación de estrés debido a las pronunciadas desigualdades. Las políticas públicas deben tener en cuenta esta situación en sus fases de diseño e implementación (AFD, 2019 ${ }_{[65]}$; AFD, 2018 ${ }_{[68]}$ ).

En las ciudades de América Latina, los grupos vulnerables que viven en barrios precarios son más susceptibles a sufrir los efectos del cambio climático y otros fenómenos, como la contaminación atmosférica, debido a los elevados niveles de segregación residencial por motivos socioeconómicos. Las elevadas tasas de urbanización y la expansión no planificada de las zonas urbanas llevaron a esos grupos a situarse en zonas de alto riesgo, como llanuras aluviales y laderas propensas a sufrir corrimientos de tierras, con infraestructuras deficientes o inexistentes, lo que incrementa los riesgos de salud de los residentes y su vulnerabilidad ante sucesos meteorológicos extremos debido a su situación socioeconómica $\left(\mathrm{CAF}, 2014_{[71]}\right)$. Las ciudades tienen un enorme potencial para contribuir a los esfuerzos de mitigación y adaptación y a la consecución de los objetivos climáticos de cada país. Cada vez se reconoce más la urgencia de desarrollar estrategias territoriales eficaces y convertir las ciudades en mejores lugares para vivir, en armonía con la naturaleza, incluso mediante el uso adecuado de soluciones basadas en la naturaleza y enfoques basados en los ecosistemas (OCDE, 2019 ${ }_{[72]}$ ).

Abordar los déficits de infraestructuras y servicios básicos en asentamientos informales e involucrar a los ciudadanos en las decisiones políticas son formas de propiciar una mayor capacidad de recuperación ante los fenómenos climáticos. Invertir en infraestructuras y servicios que contribuyen a mitigar riesgos (p. ej., suministro de agua y electricidad asequible y de calidad, saneamiento, centros de salud y carreteras asfaltadas), así como en adaptación y mitigación del cambio climático, podría mejorar el bienestar de los asentamientos informales y mejorar su capacidad de afrontar los riesgos climáticos (OCDE, 2021 $\left.{ }_{[67]}\right)$. Involucrar a los ciudadanos en el diseño y ejecución de estas políticas es esencial (Capítulo 4).

La contaminación atmosférica también tiene impactos desiguales en los grupos socioeconómicos. La contaminación atmosférica es causada en su mayor parte por el crecimiento del transporte privado, que tiene efectos notables en la mortalidad, la morbilidad, la productividad y el bienestar (CEPAL, 2021 ${ }_{[73]}$ ). Se calcula que los efectos de la contaminación del aire para la salud les cuestan a los ciudadanos el equivalente al 15\% de sus ingresos (Hidalgo y Huizenga, 2013 ${ }_{[74]}$ ). Sin embargo, la contaminación del aire exterior no es la única fuente de problemas de salud y económicos para las personas. La contaminación interior también tiene efectos negativos considerables. La quema de biomasa para cocinar y calefaccionar genera la mayor parte de las emisiones en los hogares. Aunque están disminuyendo, las tasas de mortalidad en ALC por la contaminación del aire en interiores se acercan a 15 por 100000 en 2017 (OCDE, 2019 ${ }_{[72]}$ ).

En una región altamente vulnerable al cambio climático y a la pérdida de biodiversidad, los países del Caribe serán los más afectados (Capítulo 6). Las desigualdades en materia de impactos potenciales del cambio climático varían entre los países de ALC. Más de la mitad de los países caribeños se enfrenta a riesgos de exposición "extremos" (CAF, $2014_{[71]}$ ). Entre los principales riesgos a los que se enfrenta el Caribe, cabe destacar la exposición a meteorología extrema, como huracanes y tormentas graves, una mayor intensidad y frecuencia de sequías, aumento del nivel del mar y acidificación de los océanos. Los 
grupos vulnerables serán los menos preparados y los más afectados por estos sucesos. La falta de información para identificar las áreas más propensas al cambio climático y la ausencia de herramientas de mitigación de riesgos para integrar el cambio climático en la elaboración de políticas son las barreras más importantes para la adaptación climática de la región (CAF, $\left.2014_{[71]}\right)$.

\section{Una recuperación ecológica justa es una oportunidad para crear empleo y promover la inclusión social}

Se prevé que una recuperación verde para América Latina puede crear 15 millones de empleos netos para 2030 (OIT/BID, 2020 ${ }_{[75]}$ ) en los siguientes sectores: electricidad renovable (156\% más empleos que en 2014$)$, agricultura sostenible (124\%), servicios (61\%), construcción y silvicultura (58\%), suministros públicos (56\%) e industria (50\%) (OIT/ BID, $\left.2020_{[75]}\right)$. El número de empleos agrícolas se duplicará en 2030 gracias a los enfoques agrícolas de bajas emisiones y orientados hacia la recuperación ante los fenómenos climáticos. En 2030, la transición hacia una economía con bajas emisiones se prevé que aumente el empleo en ALC en 4.0\% frente a 2014. Brasil y Centroamérica se beneficiarán especialmente, con un incremento del 5.5\% (BID, 2021 ${ }_{[69]}$ ).

La descarbonización de ALC se prevé que cree sobre todo empleos de media y baja cualificación. Esto podría promover la inclusión social si se combina con estrategias de formalización. De aquí a 2030, de los 15 millones de empleos que previsiblemente creará la descarbonización en la región, el 60\% será de cualificación media, el 36\% de baja cualificación y el $4 \%$ de alta cualificación. Esta tendencia refleja la variedad de la demanda de empleo en sectores que salen favorecidos (la agricultura y la producción de alimentos vegetales) o perjudicados (generación eléctrica con combustibles fósiles o distribución energética) en la transición (OIT/BID, 2020 $[75]$ ).

Unas infraestructuras de adaptación sostenibles pueden generan importantes ventajas económicas, sociales y medioambientales. La inversión en infraestructuras de adaptación, como las carreteras resistentes a la meteorología y las viviendas adaptadas al clima, puede tener efectos positivos inmediatos en el empleo generado por las actividades relacionadas con la construcción. La transición hacia una economía sostenible y con bajas emisiones de carbono podría aportar 535000 millones de USD al PIB de Brasil hacia 2030 (Banco Mundial, 2020 ${ }_{[76]}$ ).

Las mejoras del desarrollo adaptadas al clima son vitales para el crecimiento económico y la erradicación de la pobreza. Invertir en infraestructuras duraderas, saneamiento, agricultura o simplemente protegiendo los ecosistemas costeros puede generar efectos beneficiosos valorados en 7.1 billones de USD hasta 2030 (Mena-Carrasco y Dufey, $\left.2021_{[77]}\right)$. Las infraestructuras duraderas deben estar adaptadas al clima para que los países sean más seguros después de la recuperación. Hacerlo costaría aproximadamente 13000 millones de USD al año hasta 2030, pero se conseguirían efectos beneficiosos netos valorados en 700000 millones de USD (Banco Mundial, 2020 ${ }_{[76]}$ ).

El enfoque de economía circular complementa y refuerza las acciones para mitigar el cambio climático. Las conversaciones actuales en torno al clima se centran en la transición hacia las energías renovables y la eficiencia energética, lo que ayudará a reducir un $55 \%$ las emisiones totales de gases de efecto invernadero. La economía circular puede eliminar el $45 \%$ restante de las emisiones que se derivan de la forma en que los productos se fabrican y utilizan (Ellen MacArthur Foundation, $2019_{[78]}$ ).

La transición a una economía circular podría crear nuevos empleos y ayudar a promover una transición equitativa en la región. El enfoque de economía circular ha cobrado impulso en ALC desde 2019 y desde entonces se han implementado más de 80 iniciativas de política pública. La aplicación de los principios de la economía circular puede generar 4.8 millones 


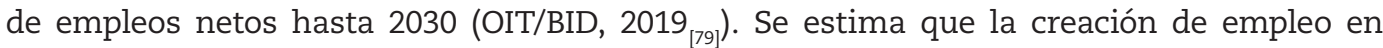
las actividades de tratamiento del acero, el aluminio, la madera y otros metales pueden compensar las pérdidas asociadas con la extracción de minerales y otros materiales (OIT/BID, $\left.2019_{[79]}\right)$. El Capítulo 3 se centra en cómo desarrollar una estrategia productiva para la región y ofrece más información sobre cómo la transición ecológica y, concretamente, la economía circular puede contribuir a la prosperidad socioambiental y económica de la región.

\section{Sistemas de protección social renovados para una transición justa}

La protección social puede paliar los efectos físicos del cambio climático (catástrofes naturales) y las consecuencias adversas de las políticas ecológicas para los trabajadores y las comunidades en sectores y actividades menos sostenibles, contribuyendo así a conseguir una transición justa (OIT/AFD, $2019_{[80]}$ ).

Los sistemas de protección social reforzados podrían comprender la protección frente al desempleo, los programas de garantía de empleo y las ayudas directas que sean flexibles y rápidamente ampliables para los trabajadores que pierdan su empleo, que vean reducida su jornada o que sufran la destrucción de su vivienda a causa de un desastre relacionado con el clima. Varios países de ALC ha comenzado a implantar programas que vinculan las medidas de protección social con aspectos medioambientales mediante programas de Pago por Servicios Medioambientales centrados, por ejemplo, en la conservación de los bosques en países como Brasil, Costa Rica y Ecuador, y en servicios hidrológicos en México (OIT, 2016 $\left.{ }_{[57]}\right)$.

Las políticas de protección social deberían estar coordinadas y ser coherentes y deberían reforzarse no solo con otras políticas socioeconómicas (p. ej., empleo, sanidad, educación, cuidados, macroeconomía y gasto público), sino también mediante la incorporación de aspectos medioambientales que den respuesta a los riesgos del ciclo de vida y faciliten una transición justa hacia economías y sociedades medioambientalmente sostenibles.

\section{¿Nuevos discursos para un futuro sostenible en ALC?}

Los conceptos de "comunes" y "justicia climática" podrían ofrecer nuevos discursos para replantear el modelo de desarrollo de la región. Las políticas de desarrollo han llevado a cabo sus acciones en torno a diferentes discursos. Estos discursos son formas de reunir a actores de muy diversa naturaleza en torno a visiones e intereses comunes, al tiempo que tratan de legitimar las reglas del juego y las instituciones intervinientes (AFD, $2019_{[81]}$ ). Los nuevos conceptos y marcos, como la "la transición justa", los "comunes" y la "justicia climática", podrían brindar nuevas formas de abordar los retos agravados por la crisis del COVID-19 en ALC en relación con una transición equitativa para el futuro del empleo y el diseño de formas innovadoras para proteger recursos naturales estratégicos y finitos y para reducir las desigualdades acentuadas por el cambio climático.

\section{Integrar las prioridades de los ciudadanos}

Durante la pandemia de COVID-19, a los ciudadanos de América Latina les preocupa perder su empleo, la eficacia de los mecanismos de protección social y la calidad y asequibilidad de los sistemas de salud. Las creencias e inquietudes de los ciudadanos pueden identificarse a través de varias fuentes, como los datos de la Encuesta CAF 2019, Gallup y Google Trends. La frecuencia, la recopilación de datos y la finalidad de estas bases de datos varían considerablemente. Por ejemplo, la Encuesta CAF es un cuestionario a particulares de 11 ciudades de América Latina que CAF ha realizado anualmente desde 2008, mientras que las búsquedas de Google pueden revelar cuáles son los problemas más acuciantes de la población de forma muy oportuna y con una cobertura mundial. 
Esta sección trata las percepciones de los ciudadanos sobre dimensiones sociales clave para la recuperación, poniendo de relieve varias inquietudes, como las perspectivas laborales, las reformas de los sistemas de pensiones y la calidad de la sanidad. Ayudar a centrar debates sobre los temas a tratar en los pactos sociales que necesita la región (Capítulo 4 sobre la reformulación del contrato social).

\section{A los latinoamericanos les preocupa mucho la crisis de empleo actual}

Después de la crisis económica que se desencadenó tras la pandemia de COVID-19, la preocupación de la población por sus perspectivas laborales aumentó y se mantuvo en niveles elevados en 2020. Las búsquedas en Google sobre temas como "currículum" se dispararon inmediatamente después de la crisis y tras un descenso repentino, subieron de forma constante al desvanecerse las expectativas de una rápida recuperación. Lo mismo ocurre con las búsquedas relacionadas con temas como "búsqueda de empleo" o "anuncios de empleo". De acuerdo con los cálculos más recientes de la OCDE, basados en datos de Gallup correspondientes a 2020, en promedio y para toda la región de ALC, el $73.4 \%$ de las personas pensaba que los mercados laborales de sus países estaban atravesando por un momento muy malo, ligeramente por encima del promedio de la OCDE (71.7\%). La proporción de personas preocupadas por la situación del mercado laboral en ALC aumentó en 8.4 puntos porcentuales en comparación con 2019, mientras que el aumento en la OCDE fue de 18.4 puntos porcentuales, lo que indica que la situación del mercado laboral se percibía como más precaria en ALC incluso antes de la crisis del COVID-19.

La inquietud sobre las políticas públicas en materia de prestaciones por desempleo o asistencia sociales ha descrito una tendencia similar, con un salto más evidente durante el primer periodo de la crisis del COVID-19 (Gráfico 2.2). Resulta interesante observar la proximidad de las tendencias en los países de ALC seleccionados, una señal de cómo la crisis económica tuvo un impacto simétrico en las percepciones de la gente en el conjunto de la región.

Incluso antes de la pandemia de COVID-19, los trabajadores latinoamericanos mostraron un alto grado de inquietud en torno a la evolución del mercado laboral. En una escala de 1 a 10, el riesgo de perder el empleo se percibe de forma homogénea en los diferentes grupos sociodemográficos, con la notable excepción de los trabajadores pobres, que están más preocupados por perder su empleo (3.5, en promedio).

Los trabajadores latinoamericanos también están preocupados por el posible cambio de tareas en sus puestos de trabajo. Eso concuerda con la rapidez de los cambios tecnológicos y la automatización (OCDE, 2019 ${ }_{[72]}$; OCDE, 2020 ${ }_{[82]}$ ). En promedio en ALC, el nivel de riesgo tecnológico percibido es de 5 en una escala de 1 a 10. Es excepcionalmente alto en Bolivia (6.1), Ecuador (5.9), México (5.4) y Perú (5.7). Es más elevado en hombres y trabajadores jóvenes (5.2), los más expuestos a empleos que requieren mayores competencias tecnológicas, y en trabajadores que viven por debajo de la línea de pobreza. No se observan diferencias notables en los trabajadores de la economía informal, ya que sus empleos generalmente requieren menos competencias (OCDE, 2019 ${ }_{[72]}$ ). Estas conclusiones sugieren que las políticas públicas deberían centrarse en el reciclaje profesional y otras políticas laborales activas en caso de pérdida de empleo o deberían brindar a los trabajadores una formación continua para ayudarles a afrontar los cambios en los mercados laborales de América Latina. 


\section{Gráfico 2.2. Búsquedas en Google sobre el tema "ayudas gubernamentales", selección de países de ALC, 2018-20}

Serie con el filtro de Hodrick-Prescott, número de búsquedas totales

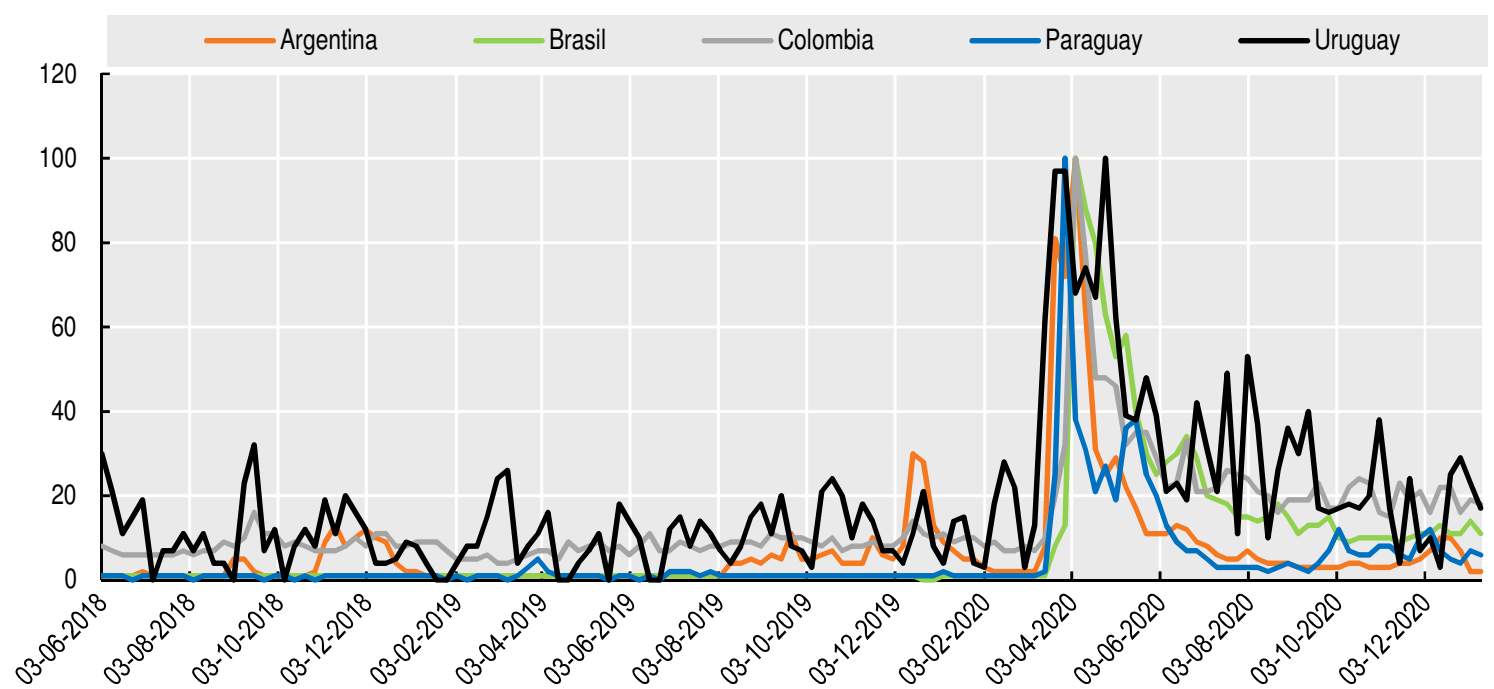

Notas: Todas las series sobre los temas se descargaron simultáneamente con una serie común a modo de control; el término migraña (enxaqueca en portugués brasileño) se mantiene relativamente estable durante el periodo estudiado en los países de ALC. Después, todas las series se depuraron usando el filtro de Hodrick-Prescott.

Fuente: Cálculos de la OCDE basados en los datos de Google Trends.

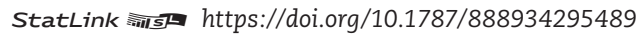

\section{Muchos trabajadores latinoamericanos no esperan poder jubilarse}

En promedio, más del $40 \%$ de los trabajadores de ALC o no saben o no creen que vayan a poder jubilarse (ECAF, 2019). Las expectativas son aún más bajas entre las mujeres (48.5\%) y los trabajadores de mayor edad cercanos a la jubilación (48.1\%). Además, los trabajadores que viven por debajo de la línea de pobreza relativa y los trabajadores informales tienen menos expectativas de estar cubiertos por la seguridad social, frente al conjunto de la población (59.6\% y 53.8\%, respectivamente) o no esperan en absoluto poder jubilarse. Los ciudadanos de Brasil, Bolivia, Panamá y Paraguay son aún menos optimistas.

Uno de cada tres trabajadores de ALC piensa que nunca cobrará una pensión (Gráfico 2.3). En línea con las pruebas anteriores, la proporción de opiniones pesimistas es más alta entre las mujeres (36.2\%), trabajadores de mediana edad (36.2\%), pobres $(39.7 \%)$ y trabajadores informales (45.2\%). Este indicador muestra las desigualdades arraigadas en el sistema de protección social y la desconfianza de los ciudadanos hacia él. Estos dos aspectos sugieren la necesidad de reformas para mejorar la cobertura de los trabajadores en el contexto del envejecimiento demográfico, los trabajadores informales y los trabajadores que viven por debajo de la línea de pobreza, lo que elevará aún más la presión sobre el sistema. El porcentaje de cotizantes o afiliados ronda el 50\% en ALC debido al alto grado de informalidad (OCDE/IDB/The World Bank, 2014 ${ }_{[83]}$ ). Ese es el caso especialmente de los trabajadores en el primer quintil de ingresos, donde predominan los trabajadores informales. 
Gráfico 2.3. Porcentaje de trabajadores que dudan que vayan a recibir una pensión, por características sociodemográficas, selección de países de ALC

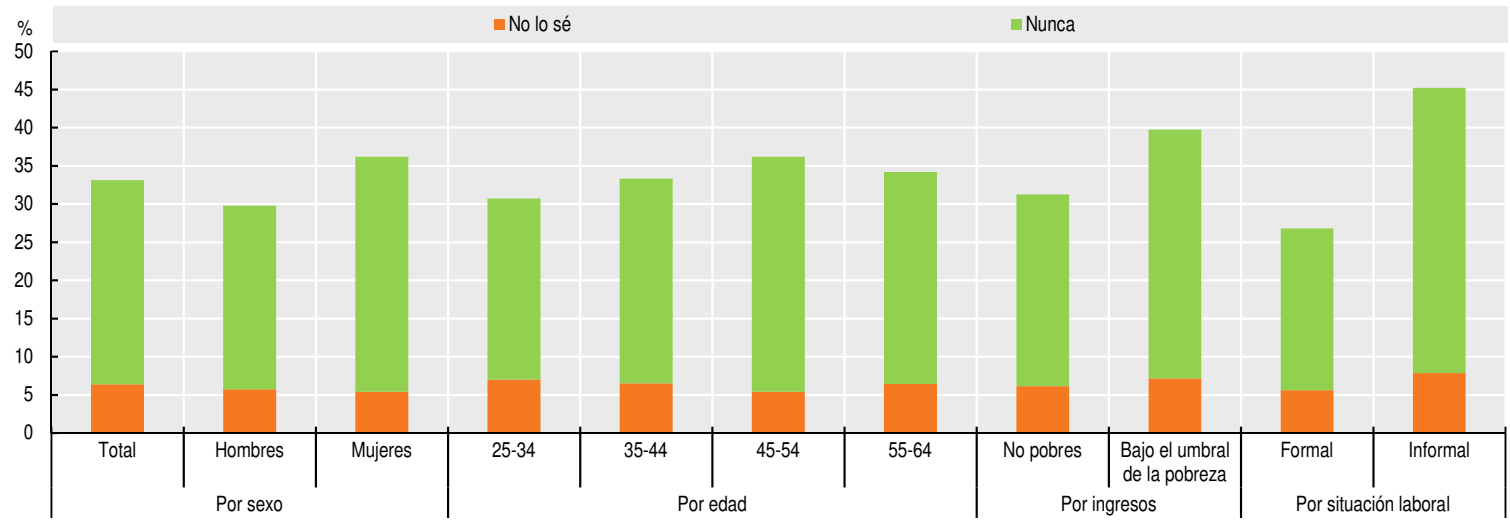

Notas: Los datos se refieren a un promedio ponderado de las siguientes ciudades: Asunción, Buenos Aires, Bogotá, Ciudad de México, Ciudad de Panamá, El Alto, La Paz, Lima, Montevideo, Quito, Santiago y Sao Paulo. Dado que los datos se refieren a áreas metropolitanas (normalmente, capitales) y no engloban las zonas rurales, el análisis debe realizarse con cierta cautela. Sin embargo, los indicadores se consideran representativos de cada país de ALC.

Fuente: Cálculos de la OCDE basados en (CAF, 2020 ${ }_{[84]}$ ), ECAF (2019). Percepciones de los Latinoamericanos sobre los Sistemas de Pensiones, Salud y Cuidados y el Avance Tecnológico en el Mercado Laboral, extraído de http://scioteca.caf.com/handle/ $123456789 / 1646$.

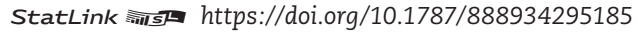

\section{Los trabajadores no siempre están a favor de amplias reformas de las pensiones}

Las preferencias en materia de políticas están conectadas y vienen a complementar las inquietudes de la población. Cuando se les pregunta por sus preferencias en materia de políticas de reforma de las pensiones, los trabajadores de América Latina suelen apostar por elevar la edad de jubilación uno o dos años, pero la magnitud varía en función de las características sociodemográficas. El Gráfico 2.4 muestra los resultados de una regresión a nivel de individuo en la que la variable dependiente es la conformidad con la reforma. El grupo de referencia está formado por varones argentinos con edades comprendidas entre 25 y 34 años, con empleo formal y que no viven por debajo de la línea de pobreza relativa. Se escogió este grupo por ser el que más probabilidades tenía de estar a favor de la reforma de las pensiones y por estar cubierto en un alto grado por el sistema público de pensiones (OCDE, 2019 ${ }_{[18)}$ ). Alrededor del $67.6 \%$ de estos trabajadores están a favor de una reforma que eleve la edad de jubilación.

El grado de conformidad no varía de forma significativa entre los sexos o grupos de edad. Los trabajadores informales son el único grupo que muestra un mayor grado de preferencia por la reforma (por más de cinco puntos porcentuales), probablemente porque tienen pocos años cotizados o no han cotizado en absoluto en el sistema de pensiones (OCDE/IDB/The World Bank, 2014 ${ }_{[83]}$ ). En general, en 4 de los 11 países de América Latina cubiertos (Brasil, Chile, Colombia y Panamá) no se observa una mayoría clara a favor de una eventual reforma de las pensiones, lo que indica la dificultad de cambiar las políticas en esos países, especialmente si el aumento previsto de la edad de jubilación es de más de dos años. 


\section{Gráfico 2.4. Efecto, expresado en puntos porcentuales, sobre la disposición a aceptar una reforma que eleve la edad de jubilación uno o dos años}

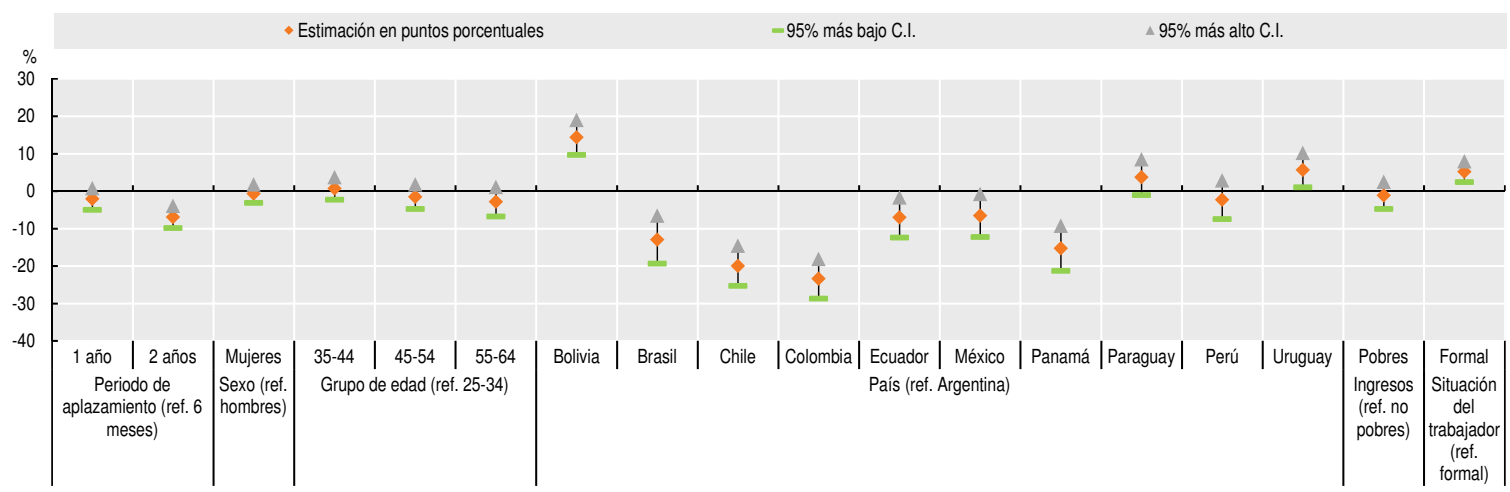

Notas: Los datos se refieren a un promedio ponderado de las siguientes ciudades: Asunción, Buenos Aires, Bogotá, Ciudad de México, Ciudad de Panamá, El Alto, La Paz, Lima, Montevideo, Quito, Santiago y Sao Paulo. Dado que los datos se refieren a áreas metropolitanas (normalmente, capitales) y no engloban las zonas rurales, el análisis debe realizarse con cierta cautela. Sin embargo, los indicadores se consideran representativos de cada país de ALC.

Fuente: Cálculos de la OCDE basados en (CAF, 2020 $\left.{ }_{[84]}\right)$, ECAF (2019), Percepciones de los Latinoamericanos sobre los Sistemas de Pensiones, Salud y Cuidados y el Avance Tecnológico en el Mercado Laboral, extraído de http://scioteca.caf.com/handle/ $123456789 / 1646$.

StatLink न्ता

Las preferencias de la población varían cuando se aporta información más detallada sobre la reforma. El equilibrio de las cuentas públicas, sobre todo en ALC, es una limitación grave. La elevada informalidad hace que los trabajadores posterguen las decisiones para garantizarse ingresos durante la vejez. Eso lleva a las personas a usar mecanismos de protección informales (Cecchini, 2019 ${ }_{[85]}$; OCDE, 2020 ${ }_{[6]}$ ) o no tener ningún tipo de seguro social. A la vista de las tendencias de envejecimiento e informalidad en ALC, muchos trabajadores podrían llegar a la jubilación sin ningún plan y sufrir pobreza y vulnerabilidad (OCDE/IDB/The World Bank, $2014_{[83]}$ ), lo que se traduciría en un enorme lastre para la economía.

Cuando se les pregunta sobre las posibles opciones para reformar las pensiones, teniendo en cuenta la sostenibilidad de las cuentas públicas, los trabajadores suelen preferir una combinación equilibrada de políticas consistentes en elevar la edad de jubilación, un aumento de las cotizaciones sociales y un recorte de las prestaciones (Gráfico 2.5). Ese es el caso especialmente de los jóvenes trabajadores: casi la mitad de los trabajadores con edades comprendidas entre los 25 y los 34 años suelen estar de acuerdo con estas opciones, frente a menos del $40 \%$ tanto en aquellos cercanos a la edad de jubilación como en aquellos que viven por debajo de la línea de pobreza.

En general, los trabajadores suelen ser mucho menos proclives, comparado con el conjunto de la población, a apoyar un recorte de las prestaciones y mucho más proclives a apoyar un abanico equilibrado de intervenciones. Los trabajadores próximos a la jubilación y los que viven por debajo de la línea de pobreza siguen mostrando un apoyo considerablemente menor, lo que indica la dificultad para conseguir la aprobación de una reforma de las pensiones que busque el equilibrio de las cuentas públicas entre aquellos que probablemente menos se beneficiarían de ella.

Las personas son muy conscientes de la necesidad de cambiar las políticas. Sin embargo, no siempre apoyan una protección social amplia cuando se les pregunta por políticas concretas. Gestionar los equilibrios y tener en cuenta la sostenibilidad fiscal de las posibles reformas será crucial, pero no será sencillo. Dirigir la intervención hacia aquellos que están más expuestos a la crisis actual podría ser una buena solución de compromiso. 
Las reformas deben centrarse en los trabajadores informales, aquellos que viven por debajo de la línea de pobreza y la clase media vulnerable que puede caer en la pobreza.

\section{Gráfico 2.5. Preferencias por una reforma de las pensiones tendiente al equilibrio de las cuentas públicas, por características sociodemográficas}

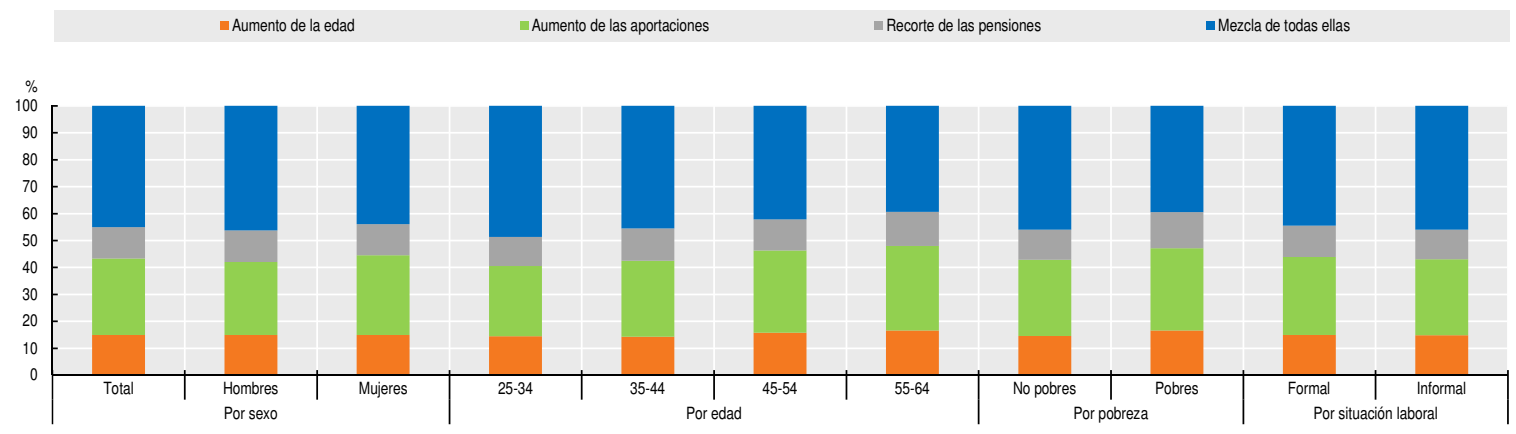

Notas: Los datos se refieren a la pregunta "Con el objetivo de mantener el equilibrio en las cuentas fiscales, entre la siguiente lista de reformas ¿con cuál estaría más de acuerdo?" Los datos se refieren a un promedio ponderado de las siguientes ciudades: Asunción, Buenos Aires, Bogotá, Ciudad de México, Ciudad de Panamá, El Alto, La Paz, Lima, Montevideo, Quito, Santiago y Sao Paulo. Dado que los datos se refieren a áreas metropolitanas (normalmente, capitales) y no engloban las zonas rurales, el análisis debe realizarse con cierta cautela. Sin embargo, los indicadores se consideran representativos de cada país de ALC.

Fuente: Cálculos de la OCDE basados en $\left(\right.$ CAF, 2020 $\left.{ }_{[84]}\right)$, ECAF (2019), Percepciones de los Latinoamericanos sobre los Sistemas de Pensiones, Salud y Cuidados y el Avance Tecnológico en el Mercado Laboral, extraído de http://scioteca.caf.com/handle/ $123456789 / 1646$.

StatLink न्ताIs https://doi.org/10.1787/888934295527

Sin embargo, fomentar entre la población una mayor concienciación sobre la situación real en relación con el envejecimiento demográfico de su país no parece aumentar su preferencia por una determinada política. Eso concuerda con las evidencias anteriores, que ilustran la idea de que ofrecer información detallada sobre algunos problemas económicos no varía de forma sustancial las preferencias de las personas en relación con las políticas de intervención (Alesina, Stantcheva y Teso, 2018 ${ }_{[86]}$; Kuziemko, Norton y Saez, $\left.2015_{[87]}\right)$, por ejemplo en lo que respecta a las políticas redistributivas que aborden el aumento de la desigualdad de ingresos.

\section{La población está muy descontenta con la calidad de los servicios de salud en ALC}

Después de que se desatara la crisis del COVID-19, la preocupación de la población por la calidad de la sanidad ha aumentado, aunque de forma desigual en los diferentes países de ALC (Gráfico 2.6). Eso podría tener que ver con la gravedad de la situación sanitaria. Las búsquedas de Google relacionadas con la salud revelan un grado particular de preocupación en Perú, aunque a medida que la pandemia fue golpeando con dureza a otros países, como Argentina, Chile y Uruguay, la población empezó a preocuparse más por la situación del sistema de salud.

La crisis sanitaria actual agravó el descontento de la población con el sistema de salud (Gráfico 2.7, Panel A; Capítulo 4). El grado de preocupación ante la calidad del acceso a los servicios sanitarios varía entre los grupos sociodemográficos. La preocupación es mayor entre las personas de mediana edad y mucho mayor entre los trabajadores informales o las personas que viven por debajo de la línea de pobreza, especialmente aquellas no cubiertas por seguros de salud públicos o privados (Gráfico 2.7, Panel B).

Estas preocupaciones se explican perfectamente con el nivel de gasto sanitario de bolsillo que debe asumir la población de América Latina (OCDE/The World Bank, $2020_{[13]}$ ). Los hogares de ALC presentan unos elevados niveles de gasto sanitario de bolsillo y en la mayoría de los países no existe una cobertura universal. En 2018, el gasto sanitario de 
bolsillo en ALC fue del 30.1\% en promedio, frente al 13.7\% de la OCDE (OMS, 2020 ${ }_{[88]}$ ). En promedio, el porcentaje de hogares que destinan más del 10\% de sus ingresos o consumo (dependiendo del indicador escogido) a gasto sanitario de bolsillo es de casi el 8\%. El porcentaje es bajo (inferior al 2\%) en algunos países, como El Salvador, Guatemala y México, pero se acerca al 17\% en Barbados, seguido de Chile y Nicaragua (alrededor del 15\%).

\section{Gráfico 2.6. Búsquedas en Google sobre el tema "salud", selección de países de ALC (2020-21)}

Serie con el filtro de Hodrick-Prescott, número total de búsquedas

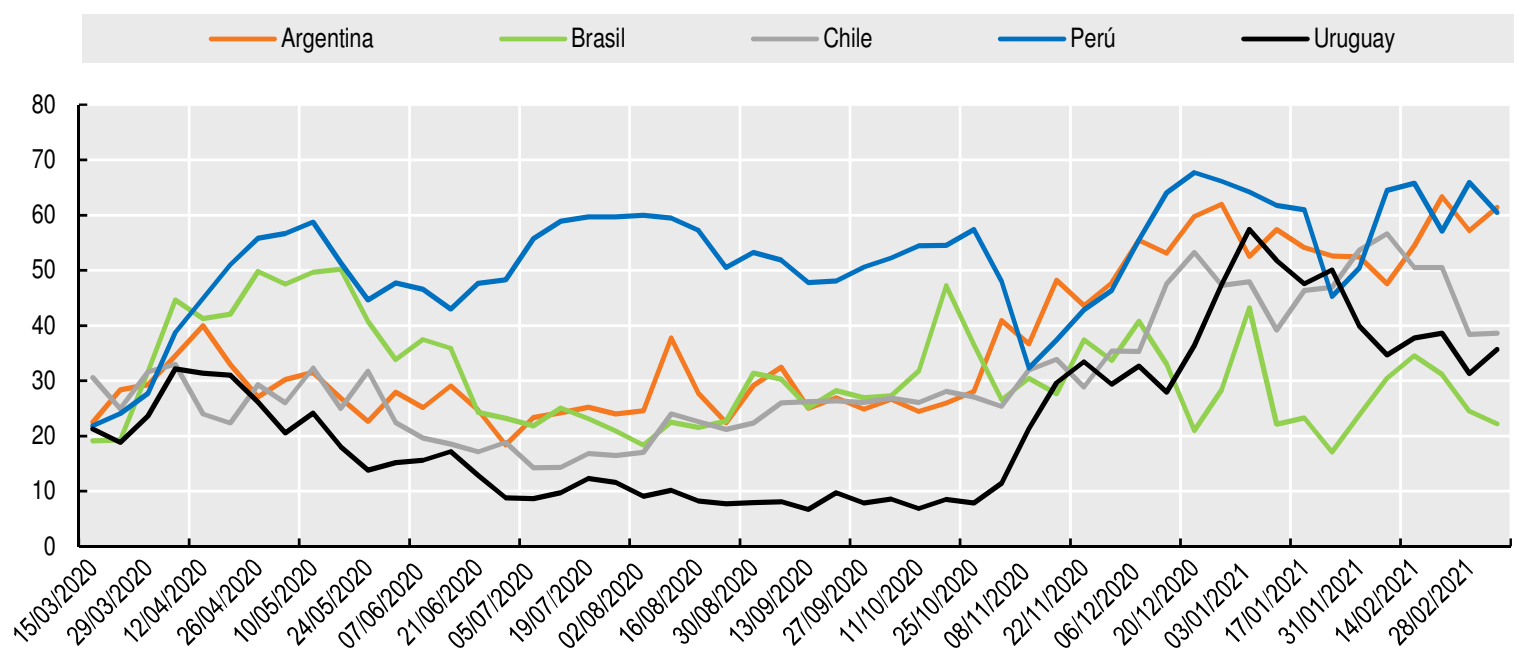

Notas: Todas las series sobre los temas se descargaron simultáneamente con una serie común a modo de control; el término migraña (enxaqueca en portugués brasileño) se mantiene relativamente estable durante el periodo seleccionado en los países de ALC. Después, todas las series se depuraron usando el filtro de Hodrick-Prescott.

Fuente: Cálculos de la OCDE basados en los datos de Google Trends.

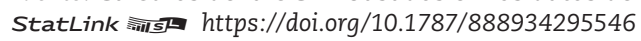

\section{Gráfico 2.7. Percepciones sobre la calidad del sistema de salud en ALC, 2019}

Media en una escala de 1 a 10
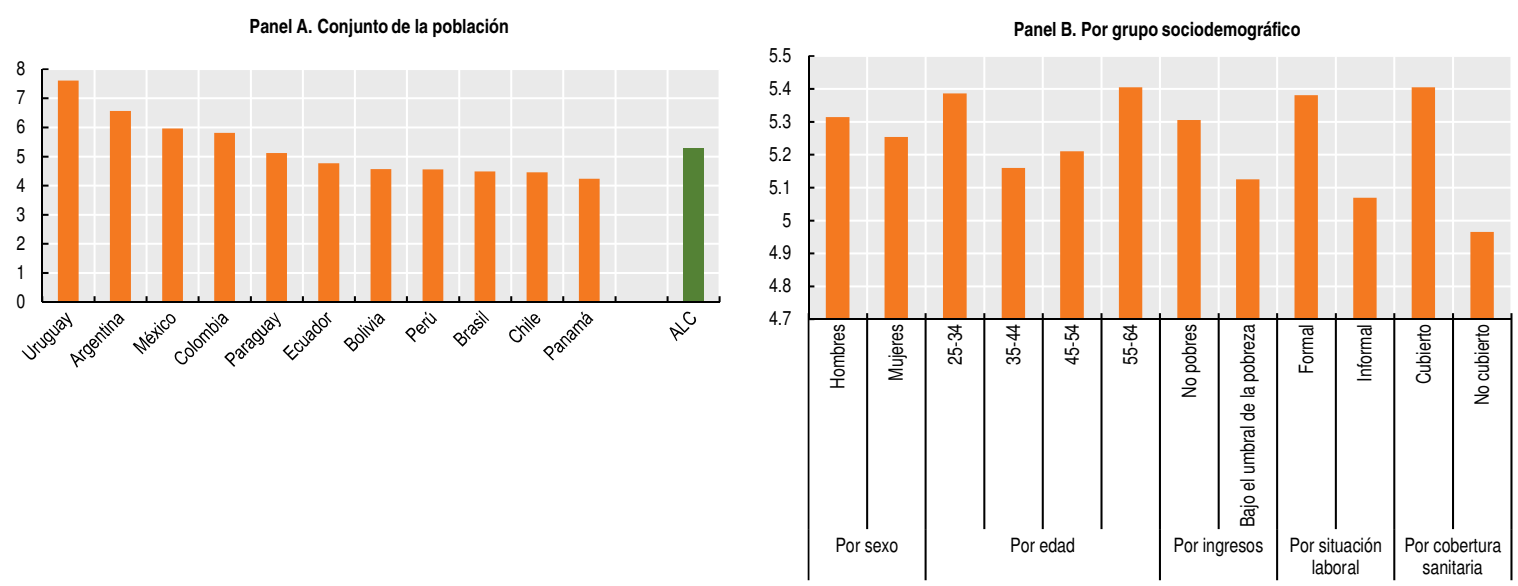

Notas: Los datos son un promedio en una escala de 1 a 10, donde 1 significa totalmente insatisfecho y 10 significa totalmente satisfecho. Los datos se refieren a un promedio ponderado de las siguientes ciudades: Asunción, Buenos Aires, Bogotá, Ciudad de México, Ciudad de Panamá, El Alto, La Paz, Lima, Montevideo, Quito, Santiago y Sao Paulo. Dado que los datos se refieren a áreas metropolitanas (normalmente, capitales) y no engloban las zonas rurales, el análisis debe realizarse con cierta cautela. Sin embargo, los indicadores se consideran representativos de cada país de ALC.

Fuente: Cálculos de la OCDE basados en (CAF, 2020 ${ }_{[84]}$ ), ECAF (2019), Percepciones de los Latinoamericanos sobre los Sistemas de Pensiones, Salud y Cuidados y el Avance Tecnológico en el Mercado Laboral, extraído de http://scioteca.caf.com/handle/ $123456789 / 1646$.

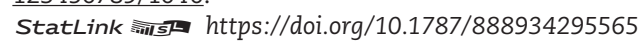




\section{Gráfico 2.8. Porcentaje de la población que destina más del $10 \%$ de sus ingresos o el $25 \%$ del consumo familiar a gasto sanitario de bolsillo}

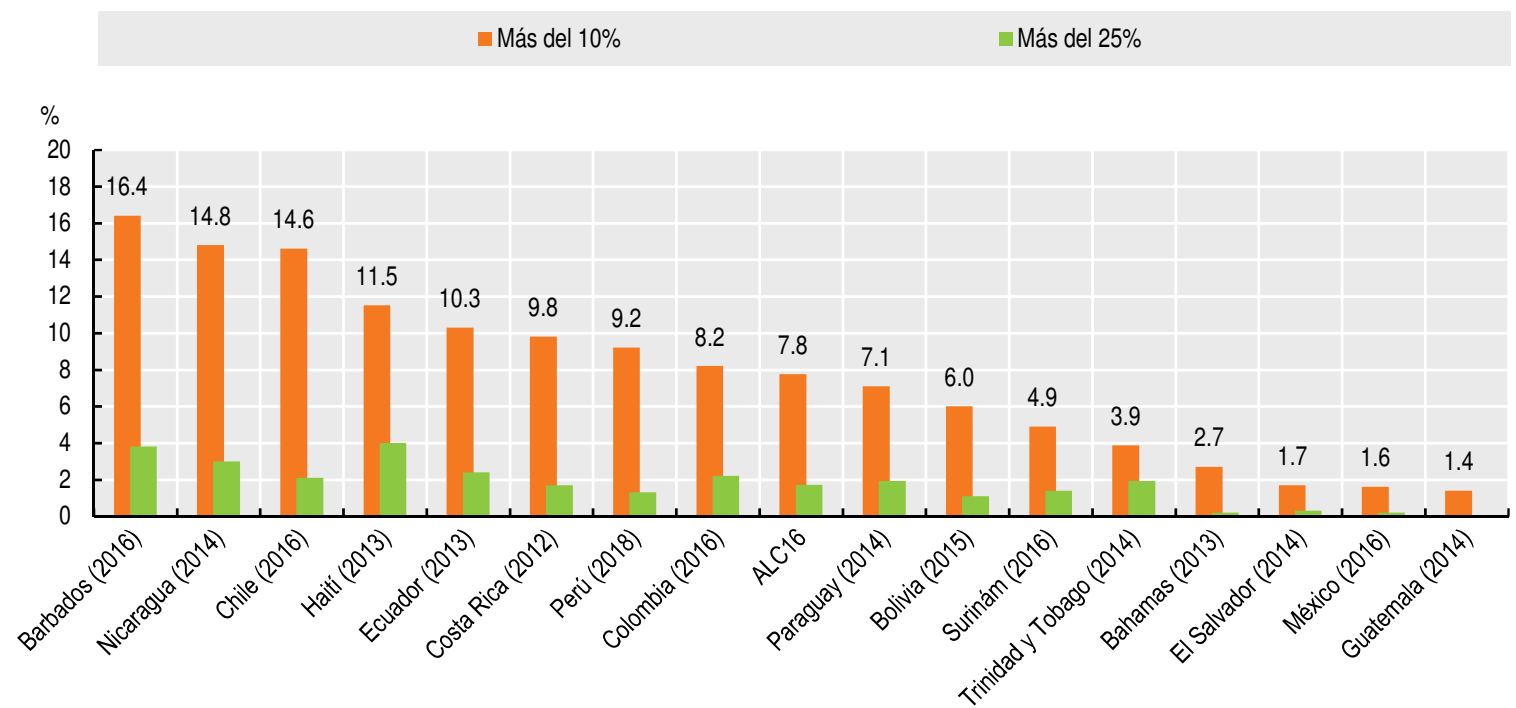

Nota: Se excluyeron los países con datos anteriores a 2010.

Fuente: OCDE/Banco Mundial $\left(2020_{[13]}\right)$, Health at a Glance: Latin America and the Caribbean 2020, http://dx.doi.org/10.1787/ 6089164f-en.

StatLink त्ताइ https://doi.org/10.1787/888934295584

Un porcentaje elevado de gasto sanitario de bolsillo tiene un efecto considerable en la pobreza. En 15 países de ALC, el 1.7\% de la población cayó por debajo de la línea de pobreza, frente al $1.2 \%$ en la OCDE. Para garantizar un acceso y una cobertura adecuados para todos los grupos, los gobiernos deben poner en marcha políticas de protección social que amortigüen los efectos negativos del gasto sanitario de bolsillo. Dentro de los aspectos comunes de las reformas de éxito, cabe mencionar la centralización y el uso coordinado de varias fuentes de ingresos, el aumento progresivo de los fondos pagados obligatoriamente por adelantado y la redistribución del dinero de los fondos pagados por adelantado.

\section{Conclusiones}

Este capítulo ha presentado el impacto socioeconómico de la pandemia de COVID-19 en la región de ALC y ha destacado varios mensajes en materia de políticas para configurar una recuperación más inclusiva, resiliente y sostenible. Ha abordado los principales retos sociales y las lecciones aprendidas con la crisis actual. Una recuperación inclusiva y sostenible en la región conllevará: i) colocar el bienestar como pilar del diseño de políticas; ii) crear puestos de trabajo de calidad para las personas (véase Capítulo 3, para más detalles) iii) avanzar hacia sistemas de protección social robustos y sostenibles, apoyados en mayores niveles de formalización; iv) proteger y dar apoyo a los grupos más vulnerables, y facilitar su acceso a empleos de calidad; v) aprovechar al máximo el potencial de la recuperación ecológica para garantizar una transición "justa". El Recuadro 2.2 presenta los mensajes clave en materia de políticas para conseguir una mejor recuperación en ALC.

\section{Colocar el bienestar en el centro del diseño de políticas}

La pandemia cambió las prioridades y las acciones de los gobiernos en la región de ALC. Antes de la crisis, los gobiernos se centraban en expandir las clases medias, que demandaban cada vez más servicios públicos y políticas de bienestar. Después del inicio 
de la crisis, muchos latinoamericanos se sumirán en la pobreza por primera vez desde 2010. Por lo tanto, se insta a los gobiernos a que reduzcan la pobreza y protejan a las poblaciones más vulnerables. Para ello, la productividad, el empleo y la protección social serán esenciales y deben formar parte de un contrato social renovado (Capítulo 4).

La crisis ofrece una oportunidad única para transformar el foco del diseño de las políticas y centrarlas en el bienestar de las personas y la comprensión de la naturaleza multidimensional del desarrollo. La pandemia ha convertido en una prioridad prestar servicios de salud y educativos de calidad y ha acentuado la necesidad de contar con sistemas de protección social más sólidos.

\section{Avanzar hacia sistemas de protección social universal sólidos}

Esta coyuntura brinda la posibilidad de avanzar hacia sistemas de protección social universal, es decir, que abarquen a los trabajadores informales. La expansión de los sistemas de protección social va de la mano de una fuerte y continua atención a la generación de empleo y a la formalización. Los mecanismos actuales de protección podrían adaptarse mejor a la dinámica de los mercados laborales de la región. Aumentar la adaptabilidad de las aportaciones a sistemas de protección social podría ayudar a crear un sector formal más inclusivo incorporando a los trabajadores a tiempo parcial, los que trabajan en la economía de las plataformas digitales, los que ganan por debajo del salario mínimo y los trabajadores agrícolas. Las tecnologías digitales ofrecen un gran potencial para desarrollar formas innovadoras de contribuir al sistema y llegar a las poblaciones vulnerables (OCDE et al., 2020 ${ }_{[2]}$ ). Facilitar el movimiento de los trabajadores entre los regímenes de protección social contributivos y no contributivos podría ayudar a ampliar la cobertura.

Las políticas de respuesta a la crisis del COVID-19 crean una base para avanzar hacia sistemas de protección social universal amplios y sostenibles. Los gobiernos respondieron rápidamente ante la crisis aprobando ayudas sociales específicas para poblaciones vulnerables no cubiertas por los programas sociales o los mecanismos de protección social tradicionales. Poner el foco de forma permanente en estas poblaciones y prestar protección social son condiciones esenciales de un estado del bienestar.

La protección social en la región de ALC necesita avanzar hacia unos mecanismos de financiación más potentes, flexibilizando las cotizaciones sociales con una combinación de aportaciones no contributivas, contributivas y voluntarias. Las cotizaciones a la seguridad social como porcentaje de los costos laborales son relativamente elevadas en ALC. Los promedios de los países de ALC son similares a los de la OCDE y excepcionalmente altos para los deciles más bajos (OCDE/BID/CIAT, 2016 ${ }_{[89]}$ ). Reducir los costos no laborales podría fomentar la creación de empleo formal, sobre todo entre las pequeñas y medianas empresas, lo que sostendría el emprendimiento. Sin embargo, para apoyar estas políticas se precisa una estrategia productiva clara (Capítulo 3). También podría mejorar la percepción de los ciudadanos sobre el sistema de protección social del estado, reforzando así los incentivos para la formalización y el pago de impuestos (OCDE et al., 2019 [90]). Una forma de conseguir este objetivo es crear una red de seguridad social desvinculada del empleo formal y financiada mediante la fiscalidad general.

\section{Entender las demandas de los ciudadanos para fundamentar las decisiones sobre las políticas}

Las personas, especialmente las más vulnerables, están muy preocupadas por las malas perspectivas actuales del mercado laboral, la falta de un sistema de pensiones sostenible y la falta de una sanidad de calidad. La pandemia ha acrecentado la preocupación de la población, que ya era muy elevada en muchos países de América Latina. La falta de 
protección social adecuada es un reto multidimensional para las políticas públicas que, de no abordarse, podría agravar la crisis económica actual debido al COVID-19.

Las personas son muy conscientes de la necesidad de introducir cambios en las políticas. Sin embargo, no siempre están a favor de una protección social amplia y de las reformas de los sistemas de salud si se les pregunta por políticas concretas. Gestionar los equilibrios y tener en cuenta la sostenibilidad fiscal serán factores cruciales, pero no será sencillo. Dirigir la intervención hacia aquellos que están más expuestos a la crisis actual podría ser una buena solución de compromiso. Las reformas deberían centrarse en los trabajadores informales, aquellas personas que viven por debajo de la línea de pobreza y la clase media vulnerable, que puede caer en la pobreza y está muy preocupada e insatisfecha con la situación económica actual y la calidad de los sistemas de protección social.

Aumentar la concienciación de la población sobre las políticas sociales y las limitaciones a las que se enfrentan las posibles reformas podría ser una forma de impulsar la inclusividad en el proceso de redefinición del contrato social y de evitar el descontento social o las protestas. Los ciudadanos bien informados son más proclives a apoyar reformas de calado, pero la información por sí sola no resolverá el problema, sobre todo si la confianza en las instituciones es limitada. La evidencia insta a la cautela en cuanto al alcance del cambio de preferencias de las personas. Además, los gobiernos de ALC deberían incluir a los ciudadanos y a las partes interesadas, especialmente a los que suelen estar excluidos de los debates políticos, en las fases de priorización y diseño de las políticas sociales posteriores a la crisis (Capítulo 4).

\section{Recuadro 2.2. Mensajes clave en materia de políticas}

Existen grandes divergencias entre los países de América Latina y el Caribe (ALC). El impacto de la pandemia de coronavirus (COVID-19) y la capacidad de los países para dar respuesta a los retos e impulsar una recuperación inclusiva variarán, dependiendo de la posición de desarrollo en la que se encuentren y sus características individuales. Estas particularidades demandan políticas adaptadas en respuesta a la crisis del COVID-19 que tengan en cuenta las características de los países y avancen hacia la superación de los retos estructurales. Los siguientes mensajes clave constituyen un conjunto compartido de políticas para abordar los retos comunes de la región y que las autoridades deben adaptar al contexto específico de sus países.

1. La región de ALC necesita consolidar unos sistemas de protección social sólidos y sostenibles para reforzar la capacidad de recuperación y dejar atrás los estragos sociales y económicos de la crisis.

- Avanzar hacia sistemas de protección social universales y sostenibles poniendo el foco en las poblaciones vulnerables no cubiertas por los mecanismos de asistencia socia y los sistemas de protección social tradicionales.

- Flexibilizar las cotizaciones a los sistemas de protección social. Avanzar hacia un sistema que permita a los trabajadores entrar en la economía formal incluso si ganan por debajo del salario mínimo, trabajan a través de plataformas digitales o trabajan a tiempo parcial, entre otras situaciones laborales.

- Avanzar hacia sistemas de protección social en los que la cobertura no dependa de la situación laboral. Para evitar desincentivar la formalización laboral, los sistemas de protección social podrían financiarse con impuestos generales en lugar de cotizaciones de los trabajadores. 


\section{Recuadro 2.2. Mensajes clave en materia de políticas (cont.)}

- Reforzar los sistemas de información de los programas de protección social. Contar con sistemas de información más eficientes e integrados en los programas de protección social podría permitir, por ejemplo, acelerar el paso de los trabajadores de un estatus contributivo a otro no contributivo. Los países han realizado importantes avances durante la pandemia y han puesto en marcha programas de emergencia.

2. Los impactos asimétricos de la crisis en los grupos de género, ingresos, edad y étnicos obligan a los gobiernos a ofrecer apoyo adicional a los más vulnerables.

- Mejorar los programas de protección social en apoyo de la tercera edad. En lo que respecta al sistema de salud, aumentar la cobertura económica, reducir el gasto de bolsillo y reforzar la plantilla sanitaria a largo plazo deberían ser los pilares de las actuaciones de las políticas públicas.

- Garantizar que las medidas de asistencia social responden a las necesidades de la población mayor que no tiene acceso a sistemas contributivos de jubilación. Mejorar la información para garantizar la cobertura de estos programas para todos los necesitados, priorizando y simplificando las ayudas para los hogares y aumentando el número de prestaciones, al menos hasta el nivel de la línea de pobreza, puede mejorar la eficacia de las políticas de protección social.

- Diseñar políticas para la recuperación con perspectivas de género e incluir una redistribución más equitativa del trabajo de prestación de cuidados para mejorar las condiciones socioeconómicas de las mujeres. Mejorar el acceso a bienes y servicios esenciales que den a las mujeres más oportunidades para participar en el mercado laboral y reforzar el capital humano (p. ej., acceso a tecnologías de la información y la comunicación [TIC]). A corto plazo, es esencial: i) dar prioridad a las mujeres vulnerables como receptoras de programas de ayuda, reducir las condiciones de acceso; ii) reabrir centros educativos y dar apoyo a los alumnos más desfavorecidos; y iii) dotar de recursos y apoyo a corto y largo plazo a las mujeres que sufren violencia doméstica.

- Promover el cambio de las normas sociales que imponen a las mujeres unas responsabilidades de cuidados desiguales. Para ello, es necesario ofrecer servicios de cuidados públicos y privados de calidad, aumentar la participación de las mujeres en el diseño de programas de protección social que tengan en cuenta las cuestiones de género, y concienciar sobre el valor social y económico de los cuidados y el trabajo doméstico.

- Poner en marcha políticas urgentes para atajar las desigualdades en educación y adquisición de competencias. Se necesita con urgencia mejorar la situación de los centros educativos para garantizar una reapertura segura y permanente. Es esencial dirigir las ayudas a los alumnos más desfavorecidos y ofrecer recursos digitales, formación y apoyo socioemocional para docentes y alumnos. Las brechas de aprendizaje agravadas por los cierres de los centros educativos debido a la crisis podrían abordarse, entre otras prácticas, mediante escuelas de verano, programas educativos acelerados y recursos adicionales para ayudar a los alumnos a recuperar el aprendizaje perdido, especialmente aquellos en situación de vulnerabilidad.

- Facilitar el acceso de los inmigrantes a las medidas de protección social a corto plazo y a la inclusión social a largo plazo. Dar acceso a programas de sustitución de ingresos, sistemas de salud y pruebas y vacunas contra el COVID-19 ha ayudado a los países a luchar contra la propagación del virus a corto plazo. Garantizar los derechos humanos fundamentales y promover la coordinación bilateral y multilateral de acciones para abordar las necesidades específicas de los inmigrantes podría reducir los efectos adversos y acentuar los efectos positivos de la inmigración. 


\section{Recuadro 2.2. Mensajes clave en materia de políticas (cont.)}

3. Los países de ALC deberían abordar la recuperación ecológica como una oportunidad para reducir la desigualdad y fomentar una transición justa hacia sistemas de protección social más amplios.

- Incorporar consideraciones relativas al cambio climático en los sistemas de protección social como temática transversal para el diseño de políticas, aplicando un enfoque que abarque toda la administración pública. Las consideraciones de tipo general en torno al medio ambiente y la mitigación del cambio climático como asunto transversal a las diferentes áreas de la administración pública, sobre todo en relación con los sistemas de protección social, son claves para desarrollar una respuesta coherente y coordinada ante el cambio climático. Los enfoques integrados permitirían tener plenamente en cuenta las cuestiones de desarrollo social y humano en la transición ecológica, con el objetivo de conseguir la neutralidad mundial en emisiones de carbono y reducir las desigualdades multidimensionales.

- Promover empleos verdes de calidad en sectores clave (p. ej., agricultura sostenible, silvicultura, energías limpias, industria y construcción) para una transición justa. Ofrecer protección frente al desempleo, programas de garantía de empleo y transferencias directas que sean flexibles y ampliables para los trabajadores que pierdan su empleo, que vean reducida su jornada o que sufran la destrucción de su vivienda a causa de un desastre relacionado con el cambio climático son medidas esenciales para promover empleos verdes que fomenten una transición justa. Los programas de jubilación anticipada podrían ser una opción para los trabajadores de edad avanzada en riesgo de perder su empleo debido a la desaparición progresiva de las industrias con altas emisiones de carbono. Las medidas con perspectiva de género deberían tener como objetivo incrementar la participación de las mujeres en el desarrollo de sectores sostenibles.

- Desarrollar programas que impartan nuevas competencias para los nuevos empleos y los empleos actuales que están evolucionando a lo largo de la transición. Los gobiernos y las empresas podrían crear alianzas para financiar el reciclaje profesional y garantizar que la formación cubra las necesidades cambiantes de cada sector. Las medidas de protección social podrían complementarse con políticas laborales activas sin dejar de invertir en formación continua, formación profesional y desarrollo de competencias, prestando especial atención a los grupos vulnerables.

- Invertir en infraestructuras sostenibles para reducir las desigualdades territoriales y mejorar la capacidad de recuperación en barrios vulnerables. Para construir infraestructuras sólidas o modernizar las existentes de manera que se reduzcan los impactos de los sucesos climáticos en los asentamientos informales, es preciso alinear mejor los planes de infraestructuras con los objetivos a largo plazo en materia de cambio climático, biodiversidad, agua y gestión de residuos, eficiencia de los recursos y transformación del uso del suelo.

- Involucrar a los ciudadanos y a la sociedad civil en la recuperación ecológica. Los gobiernos podrían diseñar políticas conjuntamente con varias partes interesadas para recabar apoyos y mejorar asentamientos reforzando la capacidad de recuperación ante los riesgos derivados del cambio climático en zonas vulnerables.

4. El estado y los diseñadores de políticas deben contar con la ciudadanía como aliada para reconstruir el contrato social; por lo tanto, es necesario entender las demandas de la ciudadanía y diseñar políticas más eficaces para mejorar su situación.

- Tener en cuenta las inquietudes de la población y concienciar sobre la necesidad de reformas. Abordar las preocupaciones de los trabajadores en relación con la crisis laboral 


\section{Recuadro 2.2. Mensajes clave en materia de políticas (cont.)}

actual. A la hora de diseñar redes de seguridad en el contexto de la crisis económica, los funcionarios deberían asegurarse de tener en cuenta la diversidad de las necesidades de los trabajadores. Para ello, será imprescindible rediseñar las políticas laborales hacia marcos más sólidos e inclusivos, especialmente para los trabajadores que carecen de las competencias necesarias.

- Colocar las opiniones y necesidades de las personas en el centro e incorporar un enfoque de interrelación a la hora de diseñar sistemas de protección social. Es preciso abordar formas múltiples e interrelacionadas de discriminación por motivos de raza, etnia, edad, género, situación socioeconómica, lugar de residencia o situación migratoria. Se deben conseguir avances para priorizar a los grupos que carecen de las redes de seguridad social adecuadas.

- Reforzar los sistemas de pensiones incorporando las preferencias de la población. En algunos países de ALC, la mayoría de la población es consciente de la falta de sistemas de jubilación sólidos en un contexto de envejecimiento demográfico y suele ser más proclive a reformarlos. En otros países, las reformas no concitan apoyos. Se deben conseguir avances en la sensibilización de la población sobre la importancia del equilibrio fiscal y la progresividad.

- Reformar los sistemas de salud. Los latinoamericanos estaban muy preocupados por la calidad de la sanidad, incluso antes de la pandemia. Se deberían conseguir progresos para aumentar la cobertura y la calidad de los sistemas de salud, aliviando la pesada carga que supone el gasto sanitario de bolsillo para los presupuestos familiares.

\section{Notas}

1. Este índice expone la frecuencia con la que los padres realizan las siguientes actividades con sus hijos: hablar sobre cómo les ha ido en clase, sentarse a comer con ellos, dedicar tiempo a hablar, ayudar con los deberes de ciencias, preguntar por los resultados del niño en las clases de ciencias, obtener materiales para las clases de ciencias, comentar cómo se utiliza la ciencia en la vida diaria y hablar sobre una carrera profesional relacionada con las ciencias. Más información en Jaramillo $\left(2020_{[36]}\right)$.

2. La percepción negativa de los migrantes ha sido especialmente alta en casos concretos, como las protestas de 2021 en Colombia, donde los problemas de la inmigración vinculados a los migrantes venezolanos se fusionaron con el descontento a raíz de la pandemia, o las elecciones presidenciales de 2021 en Perú, cuando los temas sobre inmigración estuvieron en el centro de los debates políticos.

\section{Referencias}

ACNUDH (2020), Joint Guidance Note on the Impacts of the COVID-19 Pandemic on the Human Rights of Migrants, Oficina del Alto Comisionado de las Naciones Unidas para los Derechos Humanos, Ginebra, Suiza, http://www.ohchr.org/Documents/Issues/Migration/CMWSPMJointGuidanceNoteCOVID19Migrants.pdf.

AFD (2019), Commons: Towards a New Narrative on Development Policies and Practices?, Agencia Francesa de Desarrollo, París, http://www.afd.fr/en/ressources/commons-towards-new-narrativedevelopment-policies-and-practices.

AFD (2019), Territorial transition and ecological Strategy 2020-2024, Agencia Francesa de Desarrollo, París, http://www.afd.fr/en/ressources/territorial-and-ecological-transition-2020-2024-strategy. [65]

AFD (2018), Climate change impacts the fight against inequality, Agencia Francesa de Desarrollo, París, https://ideas4development.org/en/climate-change-inequalities/.

Alesina, A., S. Stantcheva y E. Teso (2018), "Intergenerational Mobility and Preferences for Redistribution", American Economic Review 108, pp. 521-554, http://dx.doi.org/10.1257/aer.20162015. [86] 
Álvarez, F. (2020), RED 2020: Los sistemas de pensiones y salud en América Latina. Los desafíos del envejecimiento, el cambio tecnológico y la informalidad, Corporación Andina de Fomento, Caracas, http://scioteca.caf.com/handle/123456789/1652.

Arenas De Mesa, A. (2019), Los sistemas de pensiones en la encrucijada, CEPAL, Santiago, http://www. cepal.org/sites/default/files/publication/files/44851/S1900521_es.pdf.

Azevedo, J. et al. (2020), Simulating the potential impact of COVID-19 school closures on schooling and learning outcomes: a set of global estimates. Conference edition, Banco Mundial, Washington, DC, https://pubdocs.worldbank.org/en/798061592482682799/covid-and-education-June17-r6 .pdf.

Banco Mundial (2020), A green recovery of Latin America and the Caribbean is possible and necessary, Banco Mundial, Washington, DC, http://blogs.worldbank.org/latinamerica/green-recoverylatin-america-and-caribbean-possible-and-necessary?deliveryName=DM80874.

Basto-Aguirre, N., P. Cerutti y S. Nieto-Parra (2020), COVID-19 can widen educational gaps in Latin America: Some lessons for urgent policy action, VOXLACEA, Bogotá, https://vox.lacea.org/?q=blog/ covid19_widen_educational_gaps.

BID (2021), Diez puntos clave sobre el impacto, las oportunidades y las prioridades del cambio climático en América Latina y el Caribe, Banco Interamericano de Desarrollo, Nueva York, https://blogs. worldbank.org/es/latinamerica/diez-puntos-clave-sobre-el-impacto-las-oportunidades-y-lasprioridades-del-cambio.

Busso, M. (2021), Pandemic and Inequality: How Much Human Capital Is Lost When Schools Close?, Banco Interamericano de Desarrollo, Nueva York, https://blogs.iadb.org/ideas-matter/en/pandemic-a nd-inequality-how-much-human-capital-is-lost-when-schools-close/.

CAF (2020), ECAF 2019. Percepciones de los Latinoamericanos sobre los Sistemas de Pensiones, Salud y Cuidados y el Avance Tecnológico en el Mercado Laboral, http://scioteca.caf.com/handle/123456789/1646. [84]

CAF (2014), Vulnerability Index to climate change in the Latin American and Caribbean Region, Banco de Desarrollo de America Latina, Caracas, https://scioteca.caf.com/bitstream/handle/123456789/ 509/caf-vulnerability-index-climate-change.pdf.

CCI (2020), CCI COVID-19 Response: Guidance on Protection for Migrant Workers during the COVID-19 Pandemic, Cámara de Comercio Internacional, París, http://www.iom.int/sites/default/files/ defaul/2020_icc_guidance_for_migrant_workers_02.pdf?utm_source=IOM+External+Mailing+ List\&utm campaign=68bcfa2ccc-EMAIL CAMPAIGN $202008 \quad 1011$ 24\&utm medium= email\&utm term=0_9968056566-68bcfa2ccc-43608941.

Cecchini, S. (ed.) (2019), Universal Social Protection in Latin America and the Caribbean: Selected texts 2006-2019, Comisión Económica para América Latina y el Caribe, Santiago, https://repositorio. cepal.org/bitstream/handle/11362/45093/1/S1901140_en.pdf.

CEPAL (2021), Construir un futuro mejor: acciones para fortalecer la Agenda 2030 para el Desarrollo Sostenible. Cuarto informe sobre el progreso y los desafíos regionales de la Agenda 2030 para el Desarrollo Sostenible en América Latina y el Caribe, Publicación de las Naciones Unidas, Santiago, https://repositorio.cepal.org/bitstream/handle/11362/46682/6/S2100125 es.pdf.

CEPAL (2021), Panorama Social de América Latina 2020 [Social Outlook of Latin America 2020], Publicación de Naciones Unidas, Santiago, http://www.cepal.org/es/publicaciones/46687-panorama-socialamerica-latina-2020.

CEPAL (2021), "La autonomía económica de las mujeres en la recuperación sostenible y con igualdad", Informe especial Covid-19, No. 9, Publicación de las Naciones Unidas, Santiago, https://repositorio.cepal.org/bitstream/handle/11362/46633/5/S2000740 es.pdf.

CEPAL (2021), Las mediciones de uso del tiempo en América Latina y el Caribe, Publicación de las Naciones Unidas,Santiago,https://oig.cepal.org/sites/default/files/las_mediciones de_uso_el tiempo_en alyc 0.pdf.

CEPAL (2020), Enfrentar la violencia contra las mujeres y las niñas durante y después de la pandemia de COVID-19 requiere FINANCIAMIENTO, RESPUESTA, PREVENCIÓN Y RECOPILACIÓN DE DATOS, Publicación de las Naciones Unidas, Santiago, https://repositorio.cepal.org/bitstream/handle/ $11362 / 46422 / 5 /$ S2000875 es.pdf.

CEPAL (2020), Medidas y acciones a nivel nacional, Publicación de las Naciones Unidas, Santiago, http://www.cepal.org/es/temas/covid-19.

CEPAL (2020), Los efectos del COVID 19: una oportunidad para reafirmar la centralidad de los derechos humanos de las personas migrantes en el desarrollo sostenible, Publicación de las Naciones Unidas, Santiago, https://www.cepal.org/es/publicaciones/46353-efectos-covid-19-oportunidad-reafirmarla-centralidad-derechos-humanos-personas.

CEPAL (2020), "El desafío social en tiempos del COVID-19", Informe especial, No. 3, Publicación de las Naciones Unidas, Santiago, https://repositorio.cepal.org/handle/11362/45527. 
CEPAL (2019), CEPALSTAT (database), Publicación de las Naciones Unidas, Santiago, https://cepalstatprod.cepal.org/cepalstat/tabulador/ConsultaIntegrada.asp?idIndicador=2470\&idioma $=\mathrm{e}$ (accessed on 2 July 2021).

CEPAL/UNESCO (2020), "La educación en tiempos de la pandemia de COVID-19", Informe Covid 19: Agosto 2020, Comision Economica para America Latina y el Caribe/UNESCO, Santiago, https://repositorio.cepal.org/bitstream/handle/11362/45904/1/S2000510 es.pdf.

CEPAL/UNICEF (2020), "Violencia contra niñas, niños y adolescentes en tiempos de COVID-19", Informe Covid-19: Noviembre 2020, Comisión Ecónomica para América Latina/UNICEF, Santiago, https://www.unicef.org/lac/media/19611/file/violencia-contra-nna-en-tiempos-de-covid19 .pdf.

Chetty, R. (2020), "The Economic Impacts of COVID-19: Evidence from a New Public Database Built Using Private Sector Data", NBER Working Papers, No. 27431, National Bureau of Economic Research, Inc., Cambridge, MA, https://opportunityinsights.org/wp-content/uploads/2020/05/ tracker_paper.pdf.

Cucagna, E. y J. Romero (2021), The Gendered Impacts of COVID-19 on Labor Markets in Latin America and the Caribbean (English), World Bank, Washington, DC, https://documents.worldbank.org/en/ publication/documents-reports/documentdetail/675641612934705667/the-gendered-impacts-o f-covid-19-on-labor-markets-in-latin-america-and-the-caribbean.

DAES (2019), World Population Prospects 2019: Online edition Rev. 1 (database), Departamento de Asuntos Económicos y Sociales de las Naciones Unidas, Nueva York, https://population.un.org/ wpp/Download/Standard/Population/?.

Ellen MacArthur Foundation (2019), Completing the picture: How the circular economy tackles climate change, Ellen MacArthur Foundation, Cowes, UK, https://circulareconomy.europa.eu/platform/ sites/default/files/emf_completing_the_picture.pdf.

FMI (2020), World Economic Outlook Database April 2020: The Great Lockdown, Fondo Monetario Internacional, Washington, DC, http://www.imf.org/en/Publications/SPROLLs/world-economicoutlook-databases.

Gagnon, J. y M. Rodrigues (2020), "Towards more sustainable solutions to forced displacement: What measures are donor countries applying to forced?", No. 34, Publicaciones de la OCDE, París, https://doi.org/10.1787/d1d44405-en.

[60]

Gutiérrez, D. (2021), PNUD LAC C19 PDS No. 18. The Coronavirus and the challenges for women's work in Latin America, Programa de las Naciones Unidas para el Desarrollo en América Latina y el Caribe, Nueva York, http://www.latinamerica.undp.org/content/rblac/en/home/library/crisis prevention and recovery/el-coronavirus-y-los-retos-para-el-trabajo-de-las-mujeres-en-ame html.

Hidalgo, D. y C. Huizenga (2013), "Implementation of sustainable urban transport in Latin America", Vol. 40/1, pp. 66-77, http://dx.doi.org/10.1016/j.retrec.2012.06.034.

Jaramillo, S. (2020), PNUD LAC C19 PDS No. 20. COVID-19 and primary and secondary education: The impact of the crisis and public policy implications for Latin America and the Caribbean, Programa de Naciones Unidas para el Desarrollo en America Latina y el Caribe, Nueva York, http://www. latinamerica.undp.org/content/dam/rblac/Policy\%20Papers\%20COVID\%2019/undp-rblacCD19-PDS-Number20-UNICEF-Educacion-EN.pdf.

Kuziemko, I., M. Norton y E. Saez (2015), American Economic Review, Vol. 105/4, pp. 1478-1508, http://dx.doi.org/10.1257/aer.20130360.

Lusting, N. y M. Tommasi (2020), UNDP LAC C19 PDS No. 8. Covid-19 and social protection of poor and vulnerable groups in Latin America: A conceptual framework, Programa de las Naciones Unidas para el Desarrollo en América Latina y el Caribe, Nueva York, http://www.latinamerica.undp. org/content/rblac/en/home/library/crisis prevention and recovery/covid-19-and-socialprotection-of-poor-and-vulnerable-groups-in-.html.

Mena-Carrasco, M. y A. Dufey (2021), A green and resilient recovery for Latin America, Global Center on Adaptation, Rotterdam, the Netherlands/Government of Mexico, Mexico City/Community of Latin American and Caribbean States, Albany, NJ, https://reliefweb.int/sites/reliefweb.int/files/ resources/A\%20green\%20and\%20resilient\%20recovery\%20for\%20Latin\%20America.pdf. [77]

Migración Ministerio de Relaciones Exteriores (2021), ABC Estatuto Temporal de Protección - Migrantes Venezolanos, Ministerio de Relaciones Exteriores, Bogotá, https://www.migracioncolombia.gov. co/infografias/abc-estatuto-temporal-de-proteccion-migrantes-venezolanos.

Ministerio de Salud y Protección Social (2020), Lineamientos para la prevención, detección y manejo de casos de COVID-19 para población migrante en Colombia, Ministerio de Salud y Protección Social, Bogotá, https://covid19-evidence.paho.org/handle/20.500.12663/1278?locale-attribute=es. [63] 
Ministerio de Salud y Protección Social (2018), Boletín Electrónico Para Los Actores Del Sistema De Salud En Colombia, Ministerio de Salud y Protección Social, Bogotá, http://www.minsalud.gov.co/sites/ rid/Lists/BibliotecaDigital/RIDE/DE/COM/Enlace-MinSalud-97-Migrante-Venezolano.pdf. [62]

Muir, T. (2017), "Measuring social protection for long-term care”, OECD Health Working Papers, No. 93, Publicaciones de la OCDE, París, https://dx.doi.org/10.1787/a411500a-en.

OCDE (2021), Man Enough? Measuring Masculine Norms to Promote Women's Empowerment, Social Institutions and GenderIndex, Publicaciones dela OCDE, París, https://dx.doi.org/10.1787/6ffd1936 -en.

OCDE (2021), “The inequalities-environment nexus: Towards a people-centred green transition”, OECD Green Growth Papers, No. 2021/01, Publicaciones de la OCDE, París, https://dx.doi. org/10.1787/ca9d8479-en.

OCDE (2020), A helping hand: Education responding to the coronavirus pandemic, Publicaciones de la OCDE, París, https://oecdedutoday.com/education-responding-coronavirus-pandemic. [38]

OCDE (2020), "Combatting COVID-19's effect on children", OECD Policy Responses to Coronavirus (COVID-19), Publicaciones de la OCDE, París, http://dx.doi.org/10.1787/2e1f3b2f-en. [37]

OCDE (2020), COVID 19 in Latin America and the Caribbean: Regional socio-economic implications and policy priorities, Publicaciones de la OCDE, París, http://dx.doi.org/10.1787/93a64fde-en.

OCDE (2020), OECD Employment Outlook 2020: Worker Security and the COVID-19 Crisis, Publicaciones de la OCDE, París, https://dx.doi.org/10.1787/1686c758-en.

OCDE (2020), "Parental involvement in school activities", in PISA 2018 Results (Volume III): What School Life Means for Students' Lives, Publicaciones de la OCDE, París, https://dx.doi.org/10.1787/29fed428 -en.

OCDE (2020), Pension Policy Notes: Mexico. May 2020, Publicaciones de la OCDE, París, http://www. oecd.org/els/public-pensions/OECD-Pension-Policy-Notes-Mexico.pdf.

OCDE (2020), SIGI 2020 Regional Report for Latin America and the Caribbean, Social Institutions and Gender Index, Publicaciones de la OCDE, París, https://dx.doi.org/10.1787/cb7d45d1-en.

OCDE (2020), "The impact of COVID-19 on student equity and inclusion: Supporting vulnerable students during school closures and school re-openings", Policy Responses to Coronavirus (COVID-19), Publicaciones de la OCDE, París, http://dx.doi.org/10.1787/d593b5c8-en.

OCDE (2020), "What is the impact of the COVID-19 pandemic on immigrants and their children?", Policy Responses to Coronavirus (COVID-19), Publicaciones de la OCDE, París, http://dx.doi. org/10.1787/e7cbb7de-en.

OCDE (2020), "Women at the Core of the Fight Against COVID-19", Policy Responses to Coronavirus (COVID-19), Publicaciones de la OCDE, París, http://dx.doi.org/10.1787/553a8269-en.

OCDE (2019), Accelerating Climate Action: Refocusing Policies through a Well-being Lens, Publicaciones de la OCDE, París, https://dx.doi.org/10.1787/2f4c8c9a-en.

OCDE (2019), Can Social Protection Be an Engine for Inclusive Growth?, Development Centre Studies, Publicaciones de la OCDE, París, https://dx.doi.org/10.1787/9d95b5d0-en.

OCDE (2019), OECD Employment Outlook 2019: The Future of Work, Publicaciones de la OCDE, París, https://dx.doi.org/10.1787/9ee00155-en.

OCDE (2019), OECD Reviews of Pension Systems: Peru, OECD Reviews of Pension Systems, Publicaciones de la OCDE, París, https://dx.doi.org/10.1787/e80b4071-en.

OCDE (2019), Pensions at a Glance 2019: OECD and G20 Indicators, Publicaciones de la OCDE, París, https://dx.doi.org/10.1787/b6d3dcfc-en.

OCDE (2017), OECD Reviews of Labour Market and Social Policies: Costa Rica, OECD Reviews of Labour Market and Social Policies, Publicaciones de la OCDE, París, https://dx.doi.org/10.1787/9789264282773 -en.

OCDE (2015), 2015 Pension Policy Note: Colombia, Publicaciones de la OCDE, París, http://www.oecd. org/els/public-pensions/OECD-Pension-Policy-Notes-Colombia.pdf.

OCDE (próximo a publicarse), Labour informality and households' vulnerabilities in Latin America [provisional title], Publicaciones de la OCDE, París.

OCDE/BID/CIAT (2016), Taxing Wages in Latin America and the Caribbean 2016, Publicaciones de la OCDE, París, https://dx.doi.org/10.1787/9789264262607-en.

OCDE et al. (2020), Perspectivas económicas de América Latina 2020: Transformación digital para una mejor reconstrucción, Publicaciones OCDE, París, https://dx.doi.org/10.1787/e6e864fb-en.

OCDE et al. (2019), Perspectivas económicas de América Latina 2019: Desarrollo en transición, Publicaciones de la OCDE, París, https://dx.doi.org/10.1787/g2g9ff18-en. 
OCDE/BID/Banco Mundial (2014), Un Panorama de las Pensiones en America Latina y el Caribe, Publicaciones de la OCDE, Paris, https://www.oecd-ilibrary.org/docserver/9789264233195-es.pdf?expires= 1635435867\&id=id\&accname = guest \&checksum =5837763A9E910503B2A8D5C1D4287D8B. [83]

OCDE/ILO (2018), How Immigrants Contribute to Developing Countries' Economies, Publicaciones de la OCDE, París/Organizacion Internacional del Trabajo, Ginebra, https://dx.doi.org/10.1787/ 9789264288737-en.

OCDE/Banco Mundial (2020), Health at a Glance: Latin America and the Caribbean 2020, Publicaciones de la OCDE, París, https://dx.doi.org/10.1787/6089164f-en.

OIT (2021), Empleo e informalidad en América Latina y el Caribe: una recuperación insuficiente y desigual, Organización Internacional del Trabajo, Ginebra, https://www.ilo.org/wcmsp5/groups/public/--americas/---ro-lima/---sro-port_of_spain/documents/genericdocument/wcms_819029.pdf. [3]

OIT (2021), Resolución relativa a la segunda discusión recurrente sobre la protección social (seguridad social), Conferencia Internacional del Trabajo - 109th Sesion 2021, Organizacion Mundial del Trabajo, Ginebra, https://www.ilo.org/ilc/ILCSessions/109/reports/texts-adopted/WCMS 806098/lang-es/index.htm.

OIT (2020), Observatorio de la OIT - tercera edición: El COVID-19 y el mundo, Organización Internacional del Trabajo, Ginebra, Suiza, http://www.ilo.org/global/about-the-ilo/WCMS 743154/lang--es/ index.htm.

OIT (2019), Panorama laboral temático No. 5. Mujeres en el mundo del trabajo: Retos pendientes hacia una efectiva equidad en América Latina y el Caribe, Organización Internacional del Trabajo, Ginebra, Suiza, http://www.ilo.org/americas/publicaciones/WCMS_715183/lang--es/index.htm. [28]

OIT (2016), Protecting people and the environment: Lessons learnt from Brazil's Bolsa Verde, China, Costa Rica, Ecuador, Mexico, South Africa and 56 other experiences, Organización Mundial del Trabajo, Ginebra, Suiza, http://www.ilo.org/global/topics/green-jobs/publications/WCMS 516936/lang-en/index.htm.

OIT/AFD (2019), Social Transition for a just transition, Organizacion Internacional del Trabajo, Ginebra, Suiza/Agencia Francesa para el Desarrollo, París, http://www.social-protection.org/gimi/ RessourcePDF.action?ressource.ressourceId $=55905$.

OIT/BID (2020), El empleo en un futuro de cero emisiones netas en América Latina y el Caribe, Organizacion mundial del trabajo, Ginebra, Suiza/Banco Interamericano de Desarrollo, Nueva York, https://publications.iadb.org/publications/spanish/document/El-empleo-en-un-futuro-decero-emisiones-netas-en-America-Latina-y-el-Caribe.pdf.

OIT/BID (2019), El empleo en un futuro de cero emisiones netas en América Latina y el Caribe, Organizacion mundial del trabajo, Ginebra, Suiza/Banco Interamericano de Desarrollo, Nueva York, http://www.ilo.org/wcmsp5/groups/public/---americas/---ro-lima/documents/publication/ wcms_752069.pdf.

OIT/CEPAL (2020), Technical Note No. 1. The COVID-19 pandemic could increase child labour in Latin America and the Caribbean, Organización Internacional del Trabajo, Ginebra, Suiza/Comisión Económica para América Latina y el Caribe, Santiago, http://www.ilo.org/americas/publicaciones/ WCMS 747662/lang--en/index.htm.

OMS (2020), Checklist to support schools re-opening and preparation for COVID-19 resurgences or similar public health crises, Organización Mundial de la Salud, Ginebra, Suiza, http://www.who.int/ publications/i/item/9789240017467.

OMS (2020), Global Health Expenditure Database, Organización Mundial de la Salud, Ginebra, Suiza, http://apps.who.int/nha/database.

ONU Mujeres (2020), Prevención de la violencia contra las mujeres a COVID-19 en América Latina y el Caribe, ONU Mujeres, Nueva York, https://lac.unwomen.org/en/digiteca/publicaciones/2020/05/ respuesta-covid-19-transferencias-monetarias.

PNUD (2020), COVID 19 Policy Documents Series: Introduction, Programa de Naciones Unidas para el Desarrollo en America Latina y el Caribe, Nueva York, http://www.latinamerica.undp.org/ content/rblac/en/home/library/covid-19--policy-papers.html.

PNUD (2020), Early recovery responses to COVID-19 for migrants and host communities in Latin America and the Caribbean, Programa de Naciones Unidas para el Desarrollo en America Latina y el Caribe, Nueva York, http://www.latinamerica.undp.org/content/rblac/en/home/library/democratic governance/early-recovery-responses-for-migrants-and-host-communities-maxim.html. [59]

Szabo, G. y J. Edwards (2020), The Global Girlhood Report 2020: How COVID-19 is putting progress in peril, Save the Children, St Vincent House, https://www.savethechildren.org/content/dam/usa/ reports/ed-cp/global-girlhood-report-2020.pdf.

The LancetCommissions (2015), Health and climate change:policy responses to protect publichealth, Elsevier, Amsterdam, http://www.thelancet.com/action/showPdf?pii=S0140-6736\%2815\%2960854-6. [70] 
Tribin, A., C. Vargas y N. Ramírez (2019), "Unintended consequences of maternity leave legislation: The case of Colombia", World Development, Vol. 122, pp. 218-232, http://dx.doi.org/10.1016/j. worlddev.2019.05.007.

UNDESA (2019), International Migrant Stock 2019 (database), Departamento de Asuntos Económicos y Sociales, Nueva York, http://www.un.org/en/development/desa/population/migration/data/ estimates2/estimates19.asp.

UNICEF (2021), COVID-19 and school closures: One year of education disruption, UNICEF, Nueva York, https://data.unicef.org/wp-content/uploads/2021/03/COVID19-and-school-closures.pdf. [40]

UNICEF (2020), COVID-19: More than 95 per cent of children are out of school in Latin America and the Caribbean, UNICEF América Latina y el Caribe, Ciudad de Panamá, http://www.unicef.org/pressreleases/covid-19-more-95-cent-children-are-out-school-latin-america-and-caribbean.

UNICEF (2020), Marco para la reapertura de las escuelas, UNICEF, Nueva York, http://www.unicef.org/ es/documents/marco-para-la-reapertura-de-las-escuelas. 


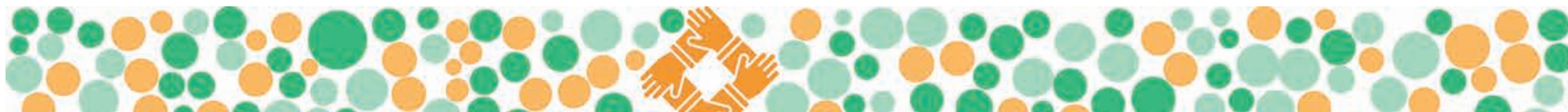
:00 O.

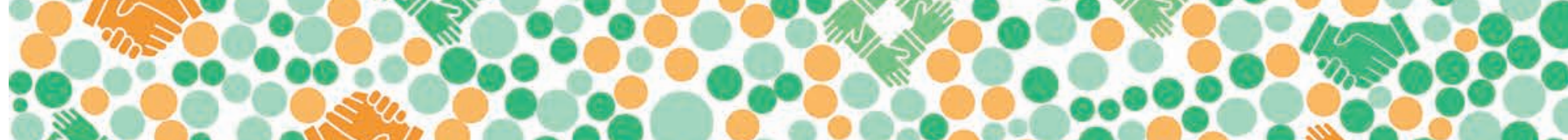

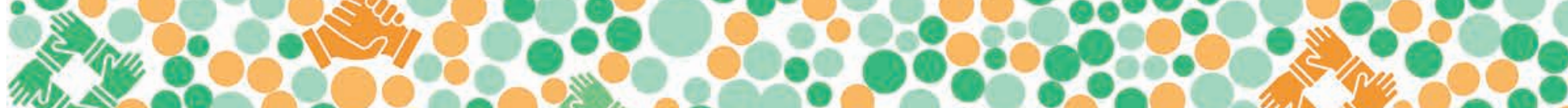

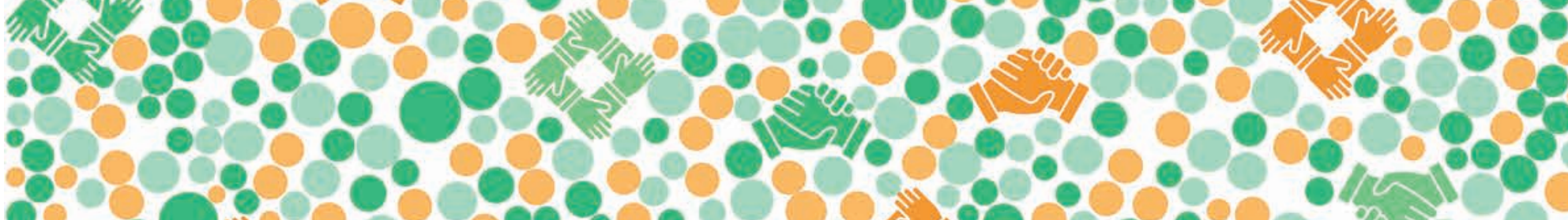

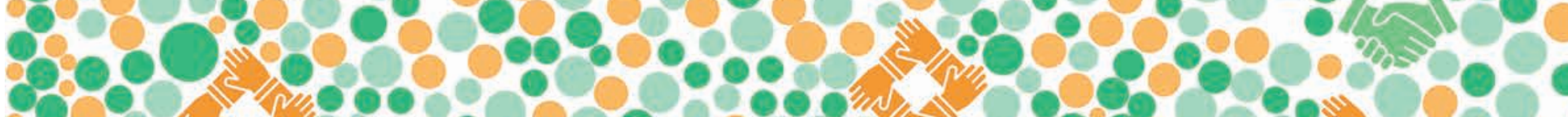

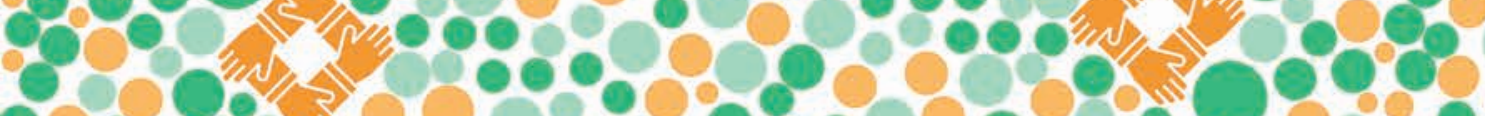

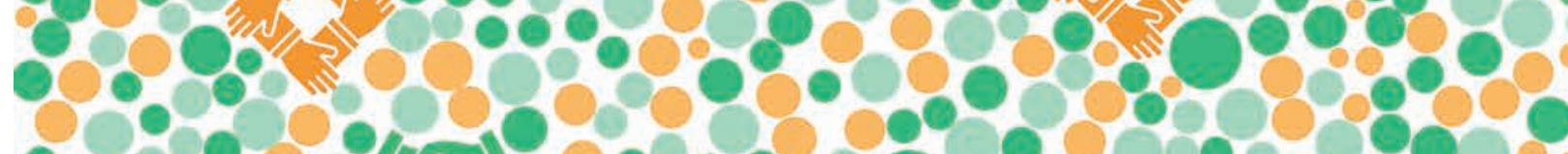
:36\%

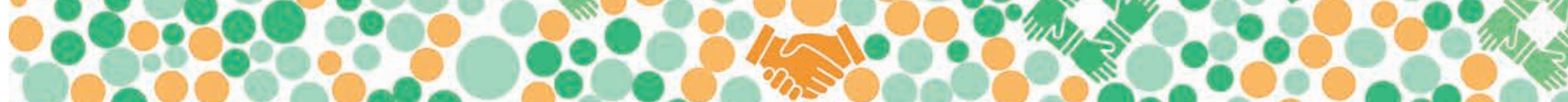
00000000000000000 :0\%

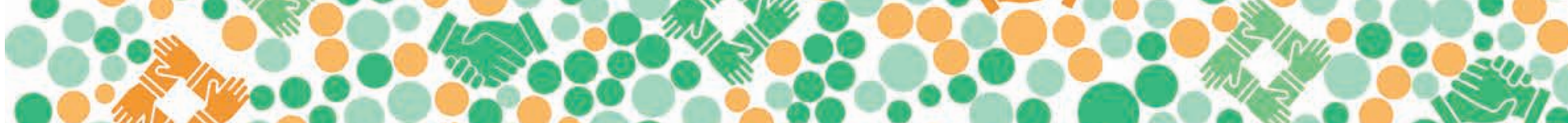

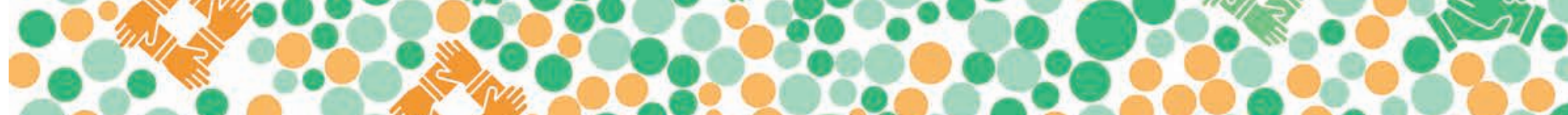

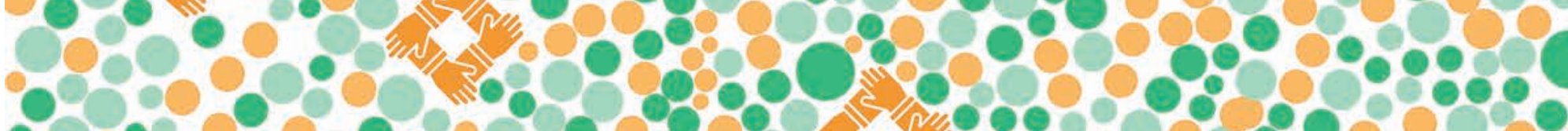

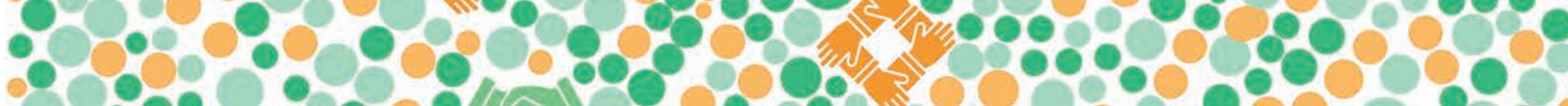

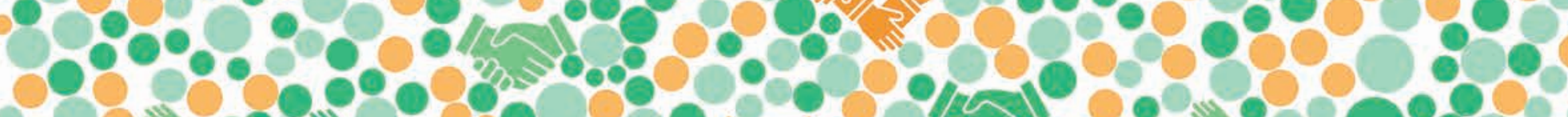
200 30003

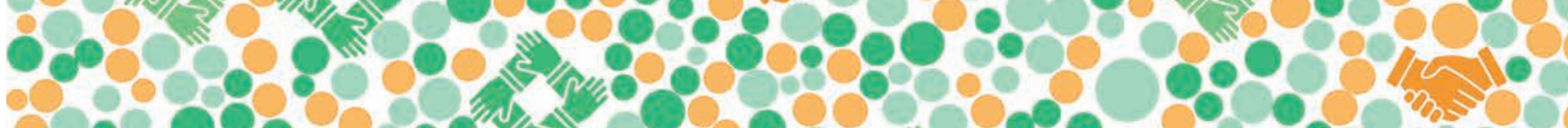
:080 0.000. 8.

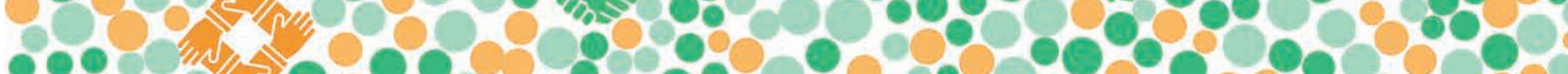

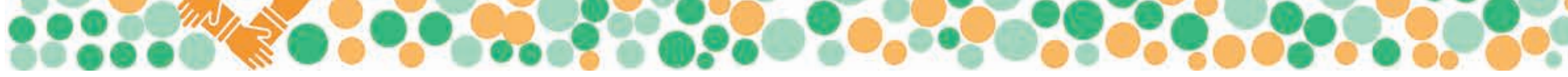




\section{Mayor integración regional y transformación productiva para superar las debilidades estructurales de ALC}

La integración regional podría ser el motor de la transformación productiva

\section{La participación de ALC en las exportaciones mundiales de bienes no ha superado el $6 \%$ desde los 60 s}

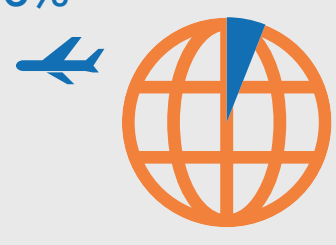

ALC tiene uno de los niveles más bajos de comercio

intrarregional

de todo el mundo

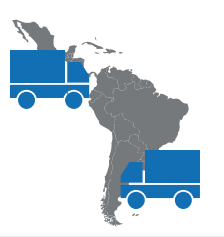

\section{$13 \%$}

de sus

exportaciones

se quedan

en la región

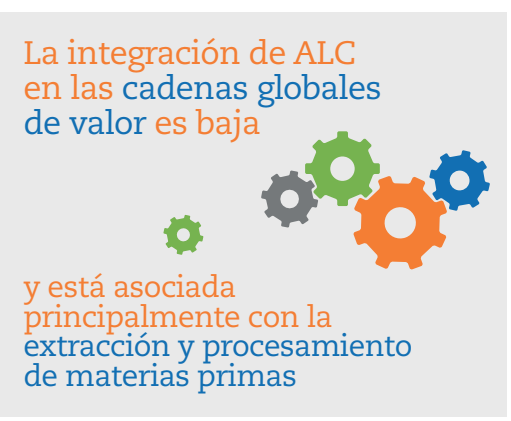

La transformación digital ha sido moderada

\section{En promedio, los productos} industrializados representaron

intrarregional tiene un mayor contenido manufacturero que las exportaciones al resto del mundo

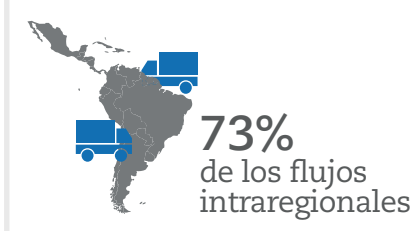

La integración de ALC en las cadenas globales de valor es baja

principalmente con la

extracción y procesamiento de materias primas

La estructura productiva, la especialización sectorial y la estructura empresarial de ALC no contribuyen a la integración regional

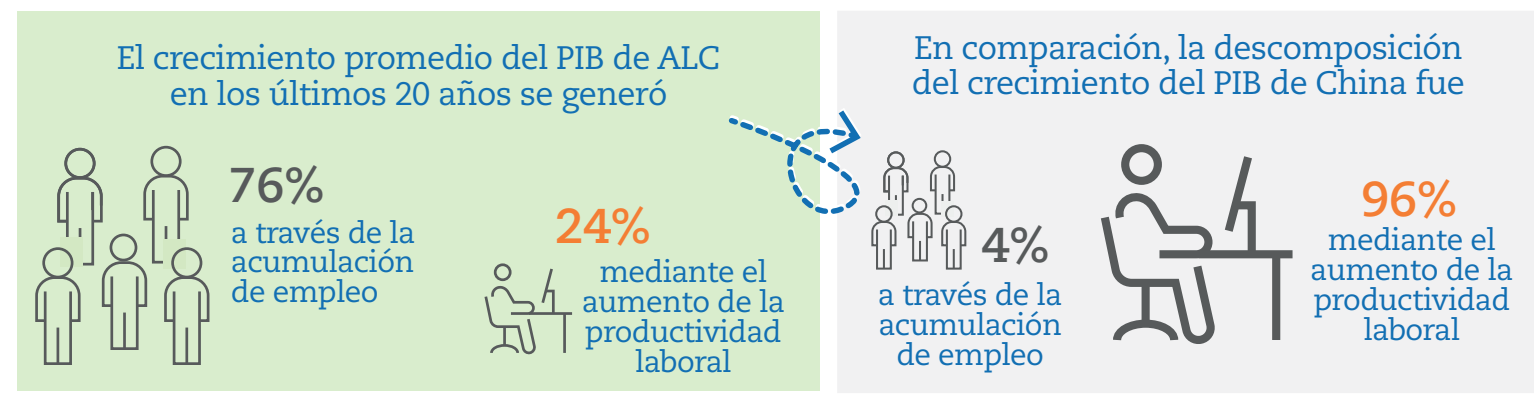

Sectores clave para la integración productiva y la transformación sostenible en ALC tras el COVID-19
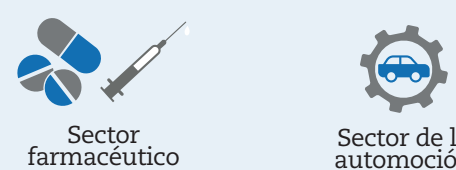

Sector de la automoción

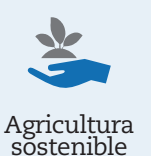

Agricultura
sostenible

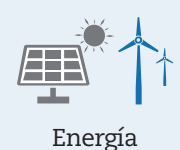

Energía

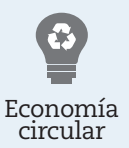




\title{
Promover las cadenas de valor regionales y aumentar la participación de ALC en el comercio internacional como medio para la recuperación
}

\author{
América Latina y el Caribe en las cadenas de valor mundiales. Una perspectiva \\ histórica
}

Desde la década de 1990, la creciente complejidad de la producción mundial ha transformado la idiosincrasia y las pautas del comercio internacional, dando lugar a las complejas cadenas de valor mundiales (CVM) actuales. Impulsados por el aumento de los costos laborales y la búsqueda de la eficiencia, los patrones de especialización de las exportaciones regionales y nacionales han cambiado. Esta evolución ha sido el resultado de los avances tecnológicos y los cambios geopolíticos y económicos que han permitido la fragmentación y deslocalización de la producción, la reducción de los costos relacionados con el comercio y la coordinación de complejas redes de abastecimiento transfronterizo (CEPAL, 2020 ${ }_{[1]}$ ). En algunas economías desarrolladas, como Estados Unidos y Japón, el peso de las manufacturas de media y alta tecnología en las exportaciones ha descendido como consecuencia de la reubicación de algunas actividades manufactureras a economías emergentes. Paralelamente, el peso de las exportaciones de media y alta tecnología ha aumentado en algunos países en desarrollo. Este es el caso de China, que ha evolucionado rápidamente y ha dejado atrás las exportaciones de manufacturas de baja tecnología para centrarse en las exportaciones de media y alta tecnología (CEPAL, 2020 ${ }_{[1]}$ ).

En las últimas décadas, los patrones de exportación de ALC también han cambiado. Se ha acentuado la especialización de América del Sur en productos primarios y manufacturas basadas en recursos naturales, y actualmente estas dos categorías representan casi el 75\% del total de las exportaciones (Gráfico 3.1): minerales en Bolivia, Chile y Perú; hidrocarburos en Colombia, Ecuador y Venezuela; y productos agrícolas en Argentina, Paraguay y Uruguay constituyeron las principales categorías de exportación. Aunque Brasil también es un importante exportador de bienes primarios, sus bienes de exportación están más diversificados e incluyen productos manufacturados de distinta intensidad tecnológica.

\section{Gráfico 3.1. Exportaciones de bienes, por tipo de producto en región y países seleccionados, 1995-2018}

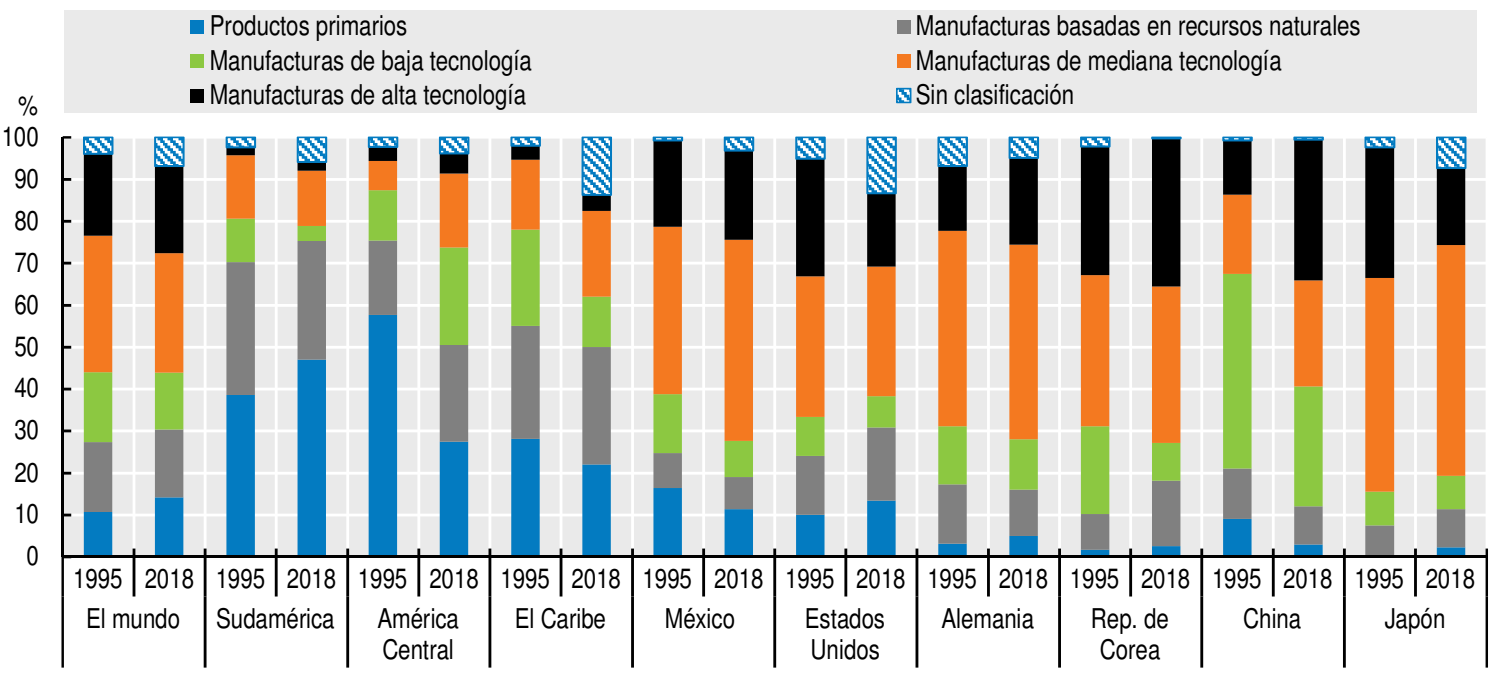

Fuente: CEPAL $\left(2020_{[22}\right)$ a partir de la base de datos de estadísticas sobre el comercio de productos básicos de las Naciones Unidas (COMTRADE) (en línea), https://comtrade.un.org/.

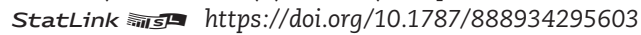


En América Central aumentaron las exportaciones de productos manufacturados (principalmente de aquellos de baja tecnología, como la vestimenta), mientras que disminuyó la importancia relativa de los productos primarios debido a su proximidad a Estados Unidos y a los bajos salarios relativos (Gráfico 3.1). Con la firma del Tratado de Libre Comercio de América del Norte (TLCAN), México se convirtió en un eslabón muy importante de las cadenas de valor regionales de América del Norte y aumentó progresivamente la intensidad tecnológica de sus exportaciones, sobre todo a Estados Unidos. América Central y el Caribe, así como México, mantienen una estrecha relación económica con Estados Unidos que va más allá del comercio y que incluye otros aspectos como la inversión extranjera directa (IED), la migración, el turismo y las remesas (CEPAL, 2014 ${ }_{[3]}$ ).

\section{Las cadenas de valor globales en un nuevo contexto económico}

La internacionalización de la producción ha experimentado una ralentización en ALC desde 2010. La crisis del COVID-19 ha profundizado esta tendencia aunque todavía no ha provocado una profunda reconfiguración en las cadenas de valor mundiales (Gráfico 3.2). Los avances tecnológicos, así como los cambios geopolíticos y otros cambios económicos, como el aumento del proteccionismo, son algunos de los factores que explican esta desaceleración.

Gráfico 3.2. Consecuencias inmediatas del COVID-19 para el comercio y la producción y oportunidades para reforzar la integración regional en América Latina y el Caribe

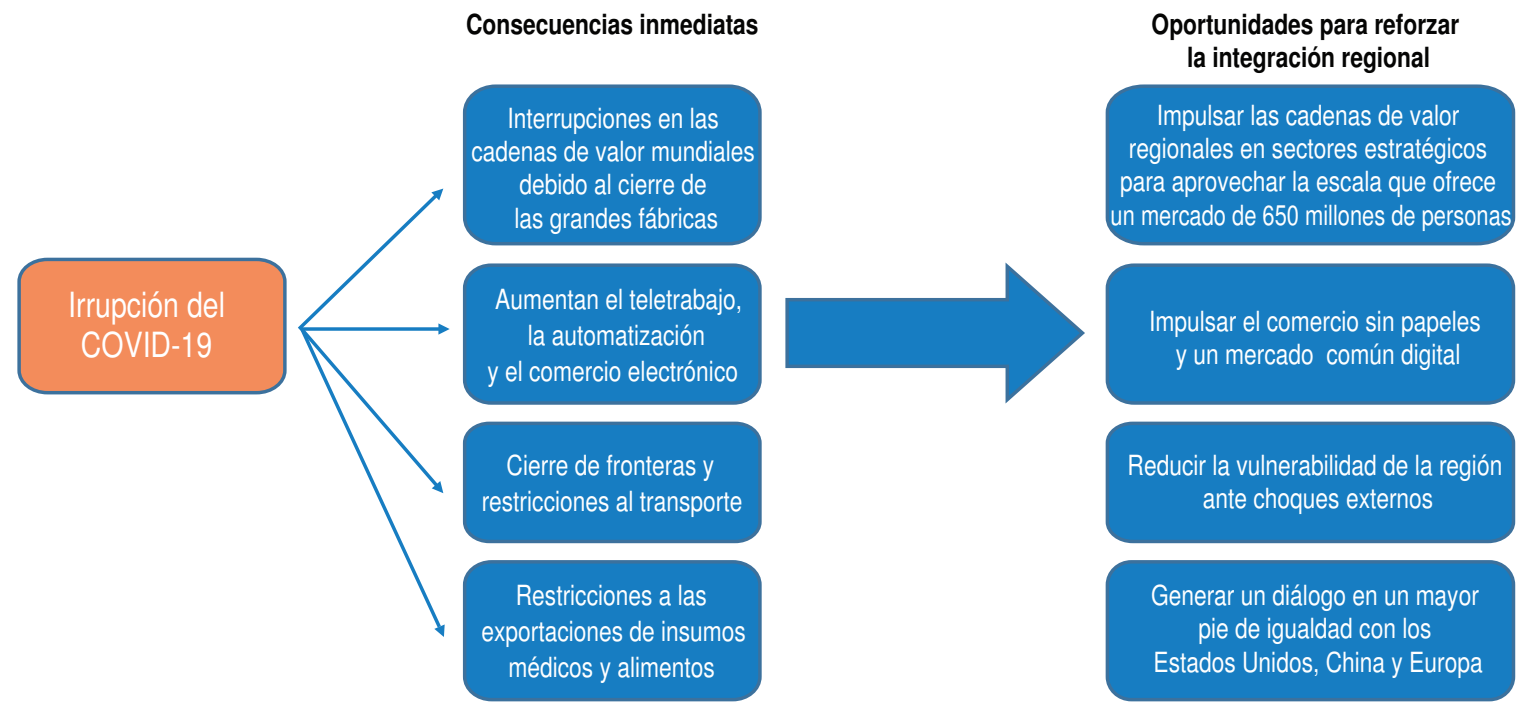

Fuente: CEPAL $\left(2020_{[4]}\right)$ Elaboración propia. "Los efectos del COVID-19 en el comercio internacional y la logística" https:// repositorio.cepal.org/bitstream/handle/11362/45878/1/S2000496_en.pdf.

Las transformaciones tecnológicas, sobre todo en las comunicaciones y el transporte, han hecho posible la creciente complejidad de las cadenas de valor mundiales desde la década de 1990. En la actualidad, la transformación digital está cambiando las posibilidades de producción en todo el mundo. Sin embargo, sus consecuencias para las cadenas de valor mundiales aún no están claras. Por ejemplo, el abaratamiento de los costos de las tecnologías que reducen la necesidad de mano de obra - como la digitalización, la automatización y la fabricación aditiva (impresión 3D) - tiende a anular las desventajas de los costos de mano de obra de los países más industrializados, lo que teóricamente permite devolver la producción y fabricación al país de origen de una empresa (reshoring) 
o bien acercarla a dicho país (nearshoring). La pandemia del COVID-19 y el impacto de las nuevas tecnologías en el mercado laboral se añaden a las crecientes preocupaciones de los trabajadores de ALC con respecto a la pérdida de puestos de trabajo o a los cambios que se producen en estos (Capítulo 2).

Además, la pandemia ha puesto de manifiesto la vulnerabilidad de las cadenas de valor mundiales, que han sido el principal canal de transmisión de los efectos económicos de la crisis del COVID-19 en el comercio mundial. Las restricciones impuestas por China en enero de 2020 (el confinamiento temporal de la provincia de Hubei y el cierre de las fronteras del país) provocaron la suspensión de las exportaciones de insumos en sectores como el automotriz, la electrónica, el farmacéutico y los suministros médicos. Dado que China es el principal exportador mundial de piezas y componentes, con el 15\% de los envíos mundiales en 2018 (CEPAL, 2020 ${ }_{[1]}$ ), la suspensión de las exportaciones desencadenó el cierre de fábricas durante varias semanas en América del Norte, Europa y Asia. En ALC, el comercio de bienes bajó un 17\% entre enero y mayo de 2020 y el comercio interregional cayó aún más, un $24 \%$, en el mismo período. La contracción del comercio intrarregional fue especialmente complicada para la industria manufacturera. El sector automotriz fue el más afectado, con una caída cercana al 55\% del valor de los intercambios entre enero y mayo de 2020. Además, la contracción del comercio intrarregional afectó a todos los bloques principales de integración económica, con un descenso interanual de entre el 20\% y el 31\% en dicho período. La única excepción fue el nivel de comercio entre los miembros del Mercado Común Centroamericano (MCCA), que mostró una mayor resiliencia al caer solo un 5.6\% (CEPAL, 2021 ${ }_{[5]}$ ).

Es probable que la pandemia refuerce dos tendencias interrelacionadas que ya estaban apareciendo antes de la crisis. La primera de ellas es una tendencia hacia un menor nivel de interdependencia productiva, comercial y tecnológica entre las principales economías mundiales, en concreto entre Estados Unidos y Europa, por un lado, y China, por otro. La segunda es una tendencia hacia un comercio mundial con un menor nivel de apertura, más impregnado de consideraciones geopolíticas y de seguridad nacional, más propenso a los conflictos y con una gobernanza multilateral más debilitada. En último término, esta tendencia no constituiría una marcha atrás en la globalización, sino una economía mundial más regionalizada y organizada en torno a tres grandes centros productivos: América del Norte, Europa y el Este y Sudeste Asiático.

En el caso de ALC, estas transformaciones supondrán retos importantes y también oportunidades sin precedentes. En un contexto de cambios geopolíticos, tecnológicos y en el entorno pos-COVID-19, la región se verá influida por dos fuerzas que actuarán en direcciones opuestas: una hacia la devolución de los procesos de producción y fabricación a los países de origen (reshoring), y la otra hacia la regionalización. De hecho, se prevé que la integración de la cadena de suministro crezca a nivel regional como respuesta al impacto del COVID-19. Cabe esperar que la integración regional desempeñe un papel clave en las estrategias de recuperación de la crisis en América Latina y el Caribe.

La participación de ALC en las cadenas de valor mundiales ha sido desigual. La mayoría de los países participan en las redes mundiales de producción como proveedores de materias primas y productos manufactureros básicos y solo unos pocos han diversificado su estructura productiva y se han convertido en actores clave de las redes mundiales de producción.

El modelo de inserción en la economía internacional, basado en la especialización en materias primas, manufacturas de ensamblaje y turismo, está siendo objeto de debate como nunca antes. Los impactos negativos de la pandemia en diversas cadenas de valor mundiales han puesto de manifiesto los riesgos que supone la excesiva dependencia regional de las manufacturas importadas. Al mismo tiempo, la pandemia ha dejado al 
descubierto la vulnerabilidad de la estructura productiva de la región. Se estima que más de 2.7 millones de empresas corren el riesgo de cerrar a causa de la crisis económica, lo que añadiría más de 8 millones de personas a las filas del desempleo (CEPAL, 2020 ${ }_{[6]}$ ). La magnitud del impacto y la capacidad de reacción de los países dependerán en gran medida de la estructura productiva de las economías de ALC, de la participación de las empresas en las cadenas de valor y de las capacidades productivas existentes (Recuadro 3.1). En este contexto, las políticas industriales y productivas son esenciales para que la región pueda fortalecer las capacidades existentes y generar otras nuevas en sectores estratégicos.

La integración regional y las cadenas de valor regionales deberán desempeñar un papel fundamental en la futura estrategia de desarrollo de la región. Un mercado integrado por 650 millones de habitantes constituiría un importante sistema de protección frente a las alteraciones de la oferta o la demanda que se produzcan fuera de la región, al tiempo que contribuiría a conseguir la escala necesaria para hacer viables nuevas industrias, promoviendo las redes de producción e investigación compartidas. La regionalización y las redes de producción regionales ofrecen la oportunidad de fomentar el crecimiento de la productividad, incrementar los salarios e impulsar unos mercados laborales inclusivos, al tiempo que redefinen la conexión e integración de la región en los centros internacionales de producción e innovación.

\section{Recuadro 3.1. El papel del sector exterior en el fomento de la actividad económica y el empleo: el caso de Costa Rica}

El sector exterior tiene el potencial de contribuir a una sólida recuperación. Durante la pandemia del COVID-19 se identificaron tres grupos de productos y servicios: procíclicos - los cuales han sufrido importantes contracciones en sus flujos de exportación-, anticíclicos - que aumentaron sus exportaciones-y neutros - que se han mantenido estables-.

En Costa Rica, las exportaciones de instrumentos y aparatos médicos, quirúrgicos y veterinarios (que representaron el $10.7 \%$ del total de las exportaciones de bienes en el período marzo-agosto de 2020), el café sin tostar y sin descafeinar (4.5\% del total de las exportaciones de bienes en dicho período) y los servicios empresariales (64.4\% del total de las exportaciones de servicios en el segundo trimestre de 2020) mostraron un comportamiento anticíclico. Por el contrario, las exportaciones de jeringuillas, agujas, catéteres, cánulas e instrumentos similares $(12 \%$ del total de las exportaciones de bienes en el periodo marzo-agosto de 2020) mostraron un comportamiento procíclico.

En el contexto posterior a la pandemia, Costa Rica dispone de una serie de políticas para reforzar la recuperación económica a través de la diversificación y el valor agregado nacional inducido por las exportaciones, así como a través del empleo:

a) Reforzar y profundizar sus vínculos con la producción nacional. Por ejemplo, mediante el aumento de los instrumentos y suministros médicos y dentales en las cadenas de producción local. Este sector no solo contribuye a la dinámica de las exportaciones brutas, dado su volumen de comercio y crecimiento, sino que también genera importantes cantidades de valor agregado nacional y de empleo.

b) Seguir profundizando en la diversificación de las exportaciones agrícolas. Los datos revelan que actividades agrícolas como las verduras, el chayote, la yuca y la sandía, entre otras, muestran un gran potencial en la generación de valor agregado nacional y de empleo.

c) Promover el aumento de las exportaciones en actividades que, a pesar de tener una menor capacidad de generación de empleo, aporten un alto valor agregado nacional. Entre ellas se encuentran los servicios informáticos o de gestión financiera, los recursos humanos y otros servicios empresariales sofisticados. 
Recuadro 3.1. El papel del sector exterior en el fomento de la actividad económica y el empleo: el caso de Costa Rica (cont.)

d) Desarrollar nuevas competencias y formación para fomentar la reubicación de la mano de obra en actividades más dinámicas, como el sector servicios. Dado el gran impacto indirecto de la actividad exportadora en la generación de valor agregado y de empleo en el sector servicios, el diseño y la aplicación de los programas de formación deberían facilitar la integración en actividades de servicios de aquellas personas que hayan perdido su empleo en actividades primarias y secundarias. En este sentido, es aconsejable facilitar la transición del empleo altamente cualificado, vinculado a servicios sofisticados, así como del empleo menos cualificado, que pueda ser absorbido por actividades como el turismo, con especial incidencia en las zonas no urbanas.

Fuente: A partir de (COMEX y CEPAL, 2021 ${ }_{[7]}$ ). Valor agregado y empleo inducido por el sector exportador de Costa Rica, Nota de política, https://www.cepal.org/es/publicaciones/46922-valor-agregado-empleo-inducido-sectorexportador-costa-rica-nota-politica.

\section{Integración regional: ¿una oportunidad para ALC?}

La integración regional siempre ha estado presente en la agenda de desarrollo de América Latina y el Caribe, aunque las experiencias de integración han tendido a priorizar la integración comercial y de los mercados sobre la integración productiva. El desarrollo de un mercado común ofrece la oportunidad de fomentar: "[...] una organización más racional del sistema productivo mediante la cual la industria alcance mayores dimensiones económicas, reduciendo así sus costos y utilizando más eficazmente los recursos naturales, [...] la puesta en funcionamiento del mercado común con la mayor celeridad posible contribuirá a ampliar y diversificar el comercio y a acelerar el desarrollo económico de todos y cada uno de los países latinoamericanos, con la consiguiente elevación del nivel de vida de sus pueblos" (CEPAL, 1959 ${ }_{[8]}$ ). En el contexto de la crisis del COVID-19, esta visión representa una estrategia de recuperación.

\section{Cinco décadas de comercio regional e integración de mercados en ALC}

La primera experiencia formal de integración regional se produjo en 1960 con el Mercado Común Centroamericano (MCCA) y la Asociación Latinoamericana de Libre Comercio (ALALC), que en 1980 se convirtió en la Asociación Latinoamericana de Integración (ALADI). Posteriormente se crearon la Comunidad Andina (CAN) en 1969 y la Comunidad del Caribe (CARICOM) en 1973.

Los esfuerzos de integración comercial cobraron un nuevo impulso político y económico tras la crisis de la deuda de los años 80, que derivó en la creación del Mercado Común del Sur (MERCOSUR) en 1991. Desde entonces han surgido nuevas iniciativas comerciales, como la Alianza del Pacífico (AP) en 2011.

La mayor parte de las iniciativas de integración de ALC desde 1960 se han centrado en la integración comercial y de mercado, mientras que a la integración productiva se le ha prestado una escasa atención. Esta estrategia de integración regional no ha impulsado la economía de la región ni ha estimulado su integración en el comercio mundial: el peso de la región en las exportaciones mundiales de bienes no supera el $6 \%$ desde mediados de los años 60. A pesar de los numerosos acuerdos comerciales intrarregionales, ALC tiene uno de los niveles de comercio intrarregional más bajos del mundo. En 2020, apenas el $13 \%$ de las exportaciones tuvieron como destino la propia región, y esa proporción ha ido disminuyendo paulatinamente desde 2014 (Gráfico 3.3). Por el contrario, la actividad comercial entre los países de la Unión Europea (en proporción al total del comercio de bienes) se situó entre el 34\% y el 80\% en 2020 (Eurostat, 2021 ${ }_{[9]}$ ). 
Gráfico 3.3. América Latina y el Caribe: Exportaciones intrarregionales, 1960-2020

Miles de mill USD y porcentaje del total de exportaciones de bienes

Exportaciones intrarregionales _ Proporción de exportaciones intrarregionales (eje derecho)

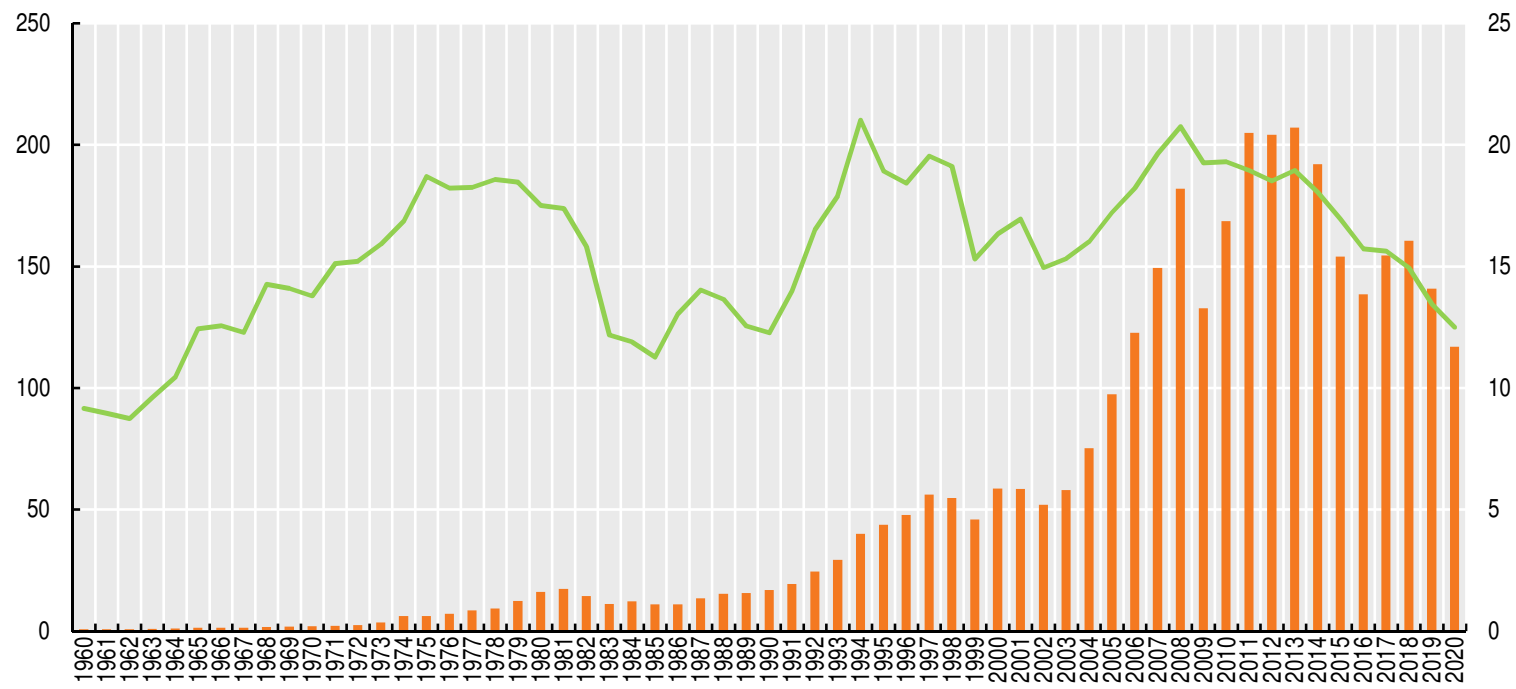

Fuente: CEPAL $\left(2020_{[2]}\right)$, a partir de la base de datos de estadísticas sobre el comercio de productos básicos de las Naciones Unidas (COMTRADE) (en línea) https://comtrade.un.org/, y América Latina y el Caribe en la Economía Mundial, Santiago, varios años. Los resultados de 2020 son proyecciones.

StatLink 刑Ist https://doi.org/10.1787/888934295204

La baja integración productiva existente entre los países de ALC se ve claramente a través del peso que tiene el contenido importado a escala intrarregional en el conjunto de las exportaciones, que se sitúa en el $6.0 \%$ de promedio. El contenido importado del resto de la región es especialmente bajo en las exportaciones de sus dos principales economías: Brasil (3.0\%) y México (2.0\%) (Gráfico 3.4).

\section{Gráfico 3.4. ALC: Estructura del contenido importado en las exportaciones totales por origen, países seleccionados, 2017}

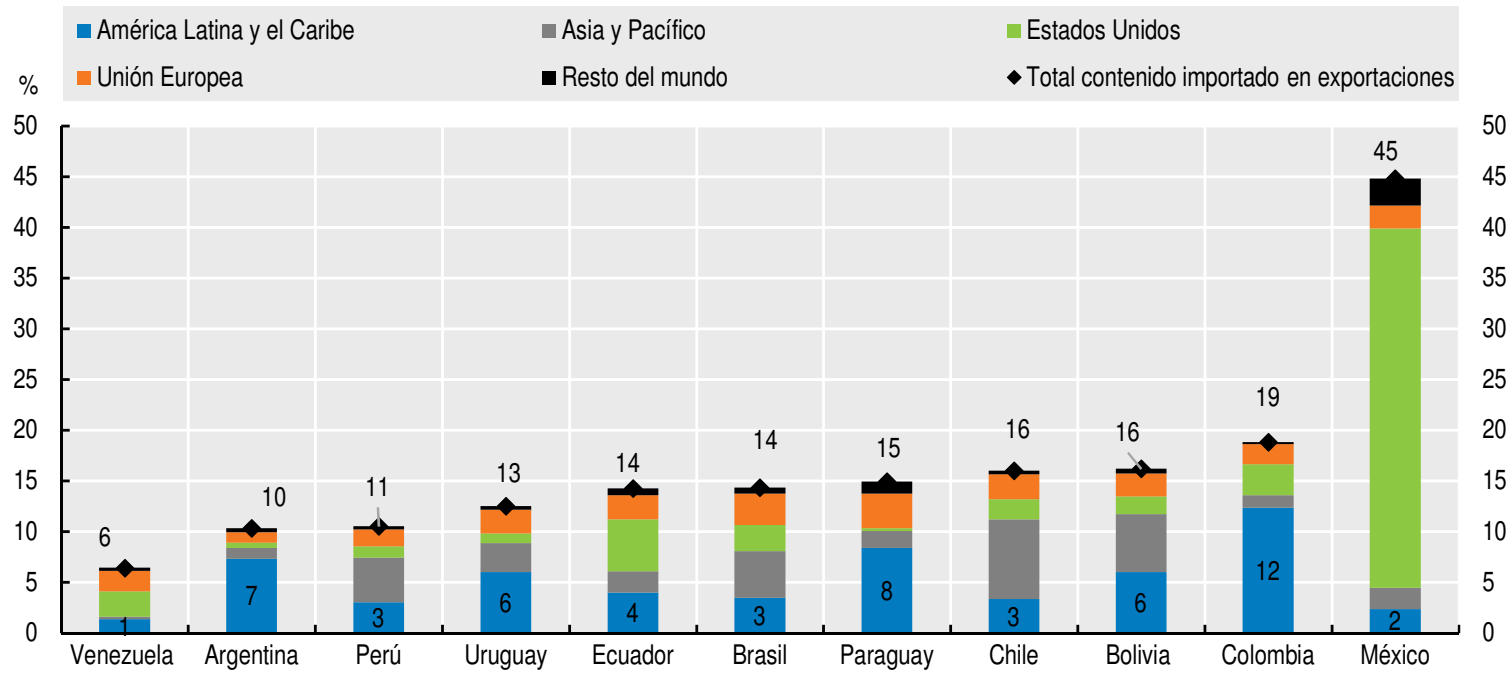

Fuente: CEPAL (2020 1 ), Matrices Globales de Insumo-Producto: Herramientas para facilitar el estudio de la Integración de América Latina con el mundo, https://www.cepal.org/en/events/global-input-output-tables-tools-analysis-integration-latin-america-world.

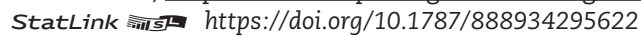


La integración de ALC en las cadenas de valor mundiales ha estado asociada principalmente a la extracción y procesamiento de materias primas. La excepción a este escenario es la participación de la industria manufacturera de exportación de México en las redes de producción norteamericanas en los sectores de la electrónica y la metalurgia (sobre todo en el automotriz). La minería es el sector más integrado en lo que se refiere a su "participación hacia adelante", esto es, la incorporación de las exportaciones de este sector a procesos productivos en otros países para su consumo final o reexportación (CEPAL, 2020 ${ }_{[1]}$ ). En consecuencia, los países de ALC están integrados mayoritariamente en actividades de cadenas sencillas en el ámbito de los recursos naturales y en "eslabonamientos hacia adelante", excluyendo así la posibilidad de vinculaciones regionales "hacia atrás".

Además, la tendencia a la baja del comercio intrarregional se ha visto acentuada por la aparición de China como segundo socio comercial de la región. Si bien la pujante demanda de productos básicos por parte de China ha reforzado el patrón histórico de exportaciones primarias de la región, sobre todo en el caso de América del Sur, la llegada a gran escala de manufacturas chinas ha desplazado el comercio intrarregional en una amplia gama de sectores industriales (CEPAL, 2021 ${ }_{[5]}$; OCDE, 2007 ${ }_{[11]}$ ).

Este escenario regional refleja que, aunque la integración de los mercados sea necesaria para impulsar los resultados comerciales, no es suficiente. El desarrollo de las capacidades productivas regionales y de las cadenas de valor regionales es clave para impulsar los vínculos productivos internacionales, fomentar el desarrollo económico y aumentar el bienestar de las sociedades.

\section{Vincular los procesos de integración e industrialización en ALC}

La principal razón de ser de la integración económica regional es la superación de los límites impuestos por el tamaño de los mercados nacionales, para aprovechar las economías de escala y lograr aumentos sostenidos de la productividad. El cambio tecnológico adquiere un papel fundamental al alterar el tamaño óptimo del mercado. El reto de la integración va mucho más allá de la agenda comercial y abarca una amplia gama de políticas de desarrollo. En particular, durante la pandemia ha habido en la región un creciente reconocimiento del papel crucial que debe desempeñar la integración para reducir la dependencia regional del comercio internacional y aumentar la resistencia a los choques externos. La persistencia de una estructura productiva poco sofisticada, caracterizada mayoritariamente por sectores impulsados por los recursos naturales, ha abierto un debate sobre cómo las políticas de integración deben basarse en políticas de cambio estructural, desencadenando procesos que dinamicen las ventajas comparativas regionales en sectores más sofisticados.

Históricamente, la industria manufacturera ha sido el núcleo productivo que más se ha beneficiado de la expansión del mercado por su capacidad de generar y aprovechar las economías de escala. La industria manufacturera es un motor para la integración de nuevos mercados, primero en las economías nacionales y luego en los grandes espacios regionales o mundiales. En ese sentido, la integración regional podría fomentar la industrialización de la región a través de la complementariedad productiva, lo que ampliaría el comercio intrarregional de productos manufacturados. Una de las ventajas adicionales de esta integración sería la reducción de su dependencia de las exportaciones de productos básicos, lo que ayudaría a superar las restricciones externas que han obstaculizado durante mucho tiempo el desarrollo regional (CEPAL, 2021 $1_{[5]}$ ).

Las limitaciones a las que se ha enfrentado la integración de América Latina son, en gran medida, las de su propio proceso de industrialización. La ralentización de la expansión industrial a finales de los años 70 supuso la pérdida de un motor fundamental 
para la integración. Por ejemplo, uno de los procesos de integración de mayor éxito en la región tuvo lugar en América Central; sin embargo, su integración productiva con la economía mundial se produce fundamentalmente a través de actividades manufactureras realizadas en el contexto de las zonas económicas especiales (ZEE). En comparación con la subregión de América Central y México, América del Sur registra menores niveles de comercio intrarregional y de integración productiva. Esto es resultado de varios factores: su gran extensión territorial, su compleja geografía, la deficiente infraestructura de transporte, la fragmentación institucional de su mercado y su especialización exportadora en recursos naturales.

La relación entre la industria manufacturera y la integración es esencial para entender los avances y las limitaciones de los procesos de integración económica. En Europa Occidental y Asia Oriental, han tenido éxito procesos con un fuerte componente industrial, a pesar de tratarse de modelos de articulación política muy diferentes. Con independencia de que existan o no instituciones formales centralizadas, los ejemplos de integración de mayor éxito se han basado en cadenas de producción industrial, entre ellas la electrónica, la metalurgia, el sector textil y de vestimenta.

En líneas generales, el contenido tecnológico de las exportaciones de ALC es bajo. Sin embargo, el comercio interregional de América Latina y el Caribe tiene un mayor contenido manufacturero que las exportaciones de la región al resto del mundo. En promedio, los productos industriales representaron el 73\% de los flujos intrarregionales en 2018-2019, pero solo el 63\% en el caso de las exportaciones extra-regionales (Gráfico 3.5). Se observa este mismo patrón en todos los mecanismos de integración, con un mayor peso de las manufacturas en las exportaciones dentro de cada grupo, sobre todo entre los países centroamericanos, donde la cifra se eleva a casi el 90\%. Estas cifras muestran el papel tan importante que desempeña el comercio intrarregional en la diversificación económica, el desarrollo de las capacidades manufactureras y la internacionalización de las pequeñas y medianas empresas (pymes).

\section{Gráfico 3.5. América Latina y el Caribe (principales mecanismos de integración): estructura sectorial de las exportaciones de bienes, 2018-19}

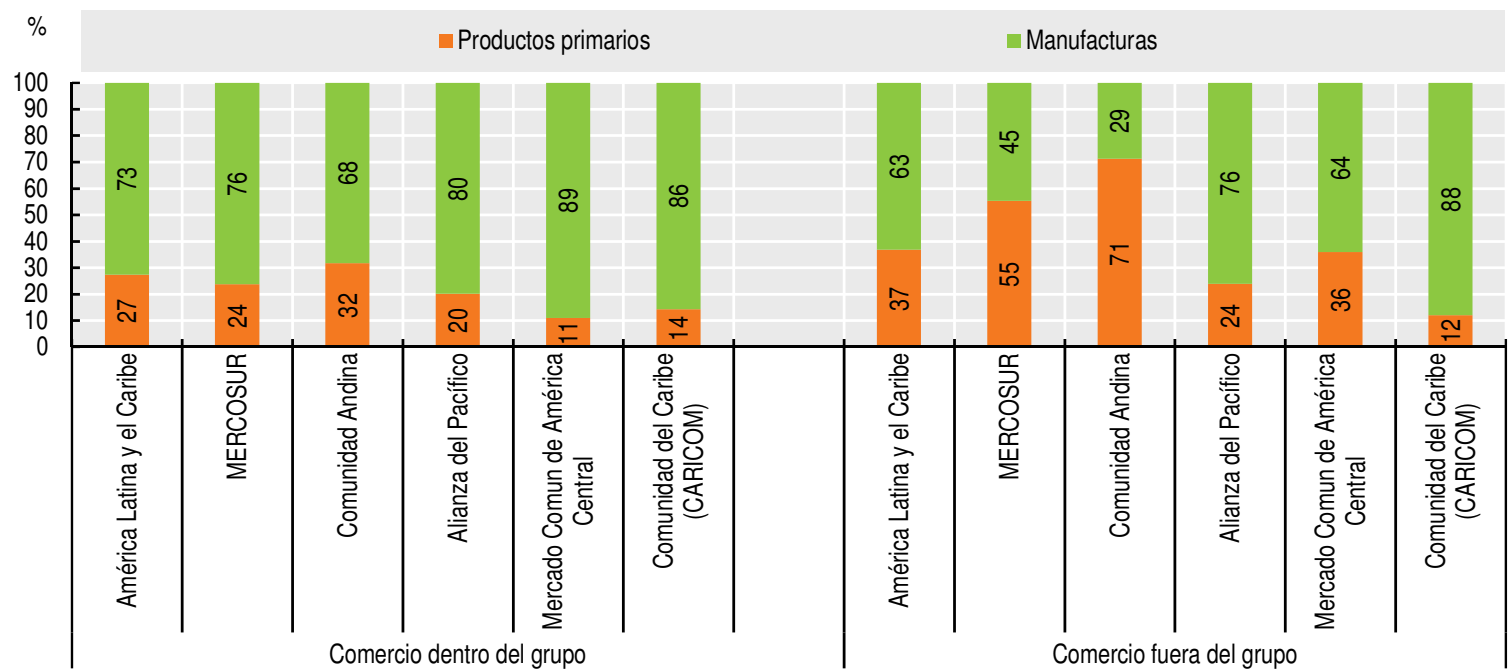

Fuente: CEPAL $\left(2021_{[5]}\right)$ Perspectivas del comercio internacional de América Latina y el Caribe, 2020 (LC/PUB.2020/- 21-P), Santiago, 2021, https://www.cepal.org/sites/default/files/publication/files/46614/S2000804_en.pdf.

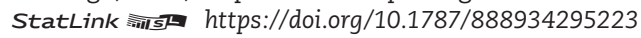

Hoy en día, las oportunidades de integración productiva no se limitan a la industria manufacturera, los sectores asociados a los recursos naturales también muestran un gran 
margen para la innovación y para agregar valor. El contenido tecnológico y la intensidad del conocimiento, ya sea en el sector manufacturero o en otros, son elementos centrales en la propuesta de integración y cambio estructural que se viene promoviendo en la región en los últimos años. No hay espacio para la integración regional sin diversificación productiva. Impulsar la integración regional implica fomentar la transición hacia nuevas actividades caracterizadas por mayores niveles de intensidad de conocimiento y productividad. Esto requiere políticas industriales específicas para reforzar las ventajas comparativas existentes (incorporando tecnologías en los sectores existentes) o para crear nuevas ventajas competitivas (invirtiendo en nuevos sectores).

\section{La debilidad de la integración de ALC está relacionada con su estructura productiva, la especialización sectorial y su estructura empresarial}

La región de América Latina y el Caribe (ALC) no ha sido capaz de lograr mejoras de productividad a largo plazo que le permitan mantener un mayor crecimiento (Capítulo 1). Si realizamos una descomposición del crecimiento del PIB para determinar las contribuciones del empleo y la productividad laboral a un grupo de países de la región y a otros países y regiones durante el período 2000-2019, observamos que en ALC el 76\% del crecimiento promedio alcanzado en las últimas dos décadas se generó a través de la acumulación de empleo y el $24 \%$ a través de aumentos en la productividad laboral. Este patrón contrasta con la descomposición del crecimiento en economías como China, India, Japón y la República de Corea. En el caso de China, la contribución de la productividad fue del $96 \%$ y la del empleo, del $4 \%$; en la India, la proporción es de casi el $80 \%$ y el $20 \%$, respectivamente.

Esta brecha de productividad se debe a la estructura productiva de los países de ALC y a su heterogeneidad estructural, que se define con una amplia variación de la productividad laboral entre sectores y dentro de ellos (Pinto, $1970_{[12]}$ ). La región tiene una estructura productiva poco diversificada, concentrada en sectores de bajo valor agregado, al tiempo que las exportaciones se concentran en bienes de bajo contenido tecnológico $\left(\right.$ CEPAL, $\left.2020_{[12]}\right)$. Además, existe una estrecha relación entre la estructura productiva y la heterogeneidad estructural de los países de ALC. Los impactos de la estructura productiva sobre el promedio de la productividad laboral a nivel de país tienen su origen en la heterogeneidad estructural (Porcile y Cimoli, 2013 ${ }_{[13]}$; Cimoli et al., 2005 ${ }_{[14]}$ ). Esto significa que el sector en el que opera una empresa influye en su nivel de productividad, pero también en la brecha de productividad entre empresas de distinto tamaño (Closset y Leiva, 2021 $1_{[15]}$ ). En México, algunos sectores tienen una productividad media 100 veces superior a la de otros y, dentro de dichos sectores, también se observa una elevada heterogeneidad productiva. La productividad media de las grandes empresas mineras es hasta 200 veces superior a la de las microempresas del sector (Closset y Leiva, 2021 $1_{[15]}$ ). Esta heterogeneidad estructural se observa entre los distintos sectores de los países de ALC y también dentro de los propios sectores. La literatura existente sobre la región muestra que, detrás del estancamiento de la productividad, existe un evidente contraste entre el importante dinamismo de las empresas grandes e intensivas en tecnología y el estancamiento o la caída de la productividad de la gran mayoría de las empresas pequeñas, lo cual suele deberse al retraso con el que adoptan las nuevas tecnologías. En todos los sectores económicos, el tamaño de la empresa es un factor fundamental de las decisiones de inversión en tecnologías de la información. El retorno sobre la inversión en innovación está vinculado a la existencia de otros insumos complementarios, como las competencias y los recursos financieros, lo cuales suelen encontrarse en las grandes empresas.

Las mayores empresas de ALC se concentran en la producción y exportación de productos agrícolas y mineros o de servicios de bajo costo. Las empresas que participan en actividades de manufactura avanzada (p. ej., EMBRAER o Tenaris) operan con una 
perspectiva de mercado mundial que va más allá de la integración regional y que, en todo caso, sería insuficiente para sus fines.

La estructura productiva impide que la región crezca a un ritmo suficiente para absorber el crecimiento de la población. Los bajos niveles de dinamismo y la escasa diversificación de la economía debido al predominio de sectores de baja intensidad tecnológica limitan el empleo formal y generan empleos de menor calidad, a menudo en el sector informal. Esto afecta negativamente a los salarios y a la demanda agregada, lo que mantiene a la región en un círculo vicioso de crecimiento volátil y baja productividad.

Asimismo, las características de la estructura productiva de la región limitan las oportunidades y los incentivos de cara a la adopción de cambios técnicos y diversificación. La inserción internacional de la región, caracterizada por un reducido número de grandes empresas en sectores intensivos en recursos naturales, ofrece escasas oportunidades para que exista una amplia participación en actividades de mayor valor agregado. Dada la escasa competencia internacional y los pocos incentivos que existen para invertir en capacidades productivas o tecnológicas, la productividad de las empresas se estanca, y la región no logra salir de la trampa de la baja productividad y la integración de bajo valor agregado.

El aumento de la productividad, mientras se promueve la creación de encadenamientos productivos intrarregionales, requiere políticas industriales que respondan al contexto global caracterizado por la creciente centralidad de las tecnologías digitales y la sostenibilidad ambiental. Estas tendencias emergentes hacen que la acción política a nivel nacional sea relevante pero insuficiente. Si el objetivo es promover el desarrollo de las capacidades productivas, a la vez que se avanza hacia sectores más sostenibles y sofisticados, las políticas industriales tienen que incluir componentes multinacionales, es decir, objetivos e instrumentos compartidos por varios países. Las oportunidades y políticas dependerán de las especificidades de cada sector y del número de países implicados, pero podrían incluir el desarrollo de normas técnicas comunes, programas de certificación de calidad, programas de formación, trazabilidad, desarrollo de normas medioambientales y de sostenibilidad, etc. Al mismo tiempo, debería promoverse la promoción de acciones de desarrollo multinacional, incluyendo acuerdos de facilitación del comercio y la inversión, mecanismos sectoriales conjuntos para atraer inversiones, financiación conjunta de infraestructuras regionales, acuerdos comerciales para promover las interconexiones regionales y el desarrollo de capacidades.

Un ejemplo concreto que ofrece la cooperación regional o subregional para la aplicación de políticas se refiere a la creación de un mercado único para fomentar la adopción y el desarrollo de las tecnologías digitales en América Latina y el Caribe. Para avanzar en las cadenas de valor regionales y en la competitividad de las pymes se requiere un esfuerzo decidido y sistemático para incorporar la tecnología en la agricultura, la minería, la silvicultura, la energía y los servicios.

\section{Un mercado único para fomentar el desarrollo tecnológico en América Latina y el Caribe}

El aumento de la productividad es el principal motor del crecimiento económico sostenido. Desde la primera revolución industrial, la introducción de nuevas tecnologías ha contribuido a mejorar la productividad (Dossi, 1984 ${ }_{[16]}$ ). El desarrollo y la incorporación de nuevas tecnologías a los procesos de producción son esenciales para el desarrollo. Las tecnologías digitales en general - el Internet de las Cosas, el análisis de macrodatos, la computación en la nube, la realidad aumentada y el uso de plataformas- están cambiando la microeconomía de la producción. Sin embargo, esas tecnologías se encuentran en diferentes fases de desarrollo y penetración en el entorno empresarial. 
Por un lado, benefician a las empresas de los países en desarrollo al reducir los costos de transacción y facilitar el acceso al mercado y la integración en las cadenas de valor mundiales; por otro lado, ponen de manifiesto y profundizan la brecha tecnológica con los países industrializados y acentúan el poder de mercado de las grandes plataformas digitales, estimulando fenómenos de concentración económica que penalizan a los países menos desarrollados. Aunque en los países en desarrollo el impacto de las tecnologías digitales sobre la productividad está condicionado por la estructura productiva y las características estructurales de las empresas, la transformación digital está generando importantes cambios en la organización de las empresas y en el funcionamiento de las dinámicas de los mercados.

Durante la última década, ALC ha experimentado importantes avances en materia de transformación digital. Las tecnologías digitales pueden desempeñar un papel importante en la recuperación de la región al abordar los persistentes desafíos de la baja productividad. En una región en la que las disparidades de productividad son considerables en función del tamaño de las empresas, la transformación digital trae consigo oportunidades, pero también el riesgo de reforzar estas diferencias (OCDE et al., 2020 ${ }_{[17]}$ ).

A pesar de los avances en el ámbito de la conectividad, el ritmo de transformación digital a la región ha sido moderado. La digitalización de los procesos productivos está muy rezagada en comparación con otras regiones. El crecimiento promedio de la adopción digital para la transformación productiva en la región ha sido relativamente moderado en comparación con los avances conseguidos en otras economías emergentes, sobre todo en China y en el Sudeste Asiático. En ALC, el promedio de la adopción digital en las empresas fue del 4.5\% entre 2014 y 2016, muy por debajo de los países más dinámicos del Sudeste Asiático (13.1\%) o de China (16.4\%). De igual manera, la adopción digital ha sido muy desigual entre las empresas de diferentes tamaños. Las empresas más grandes han conseguido disponer de mayores velocidades de conexión, lo cual también condiciona el tipo de servicios a los que pueden acceder y ofrecer, generando así mayores brechas de productividad.

Si bien la incorporación de las tecnologías digitales en los procesos productivos aún está rezagada en la región, la pandemia del COVID-19 ha acelerado el proceso en las actividades empresariales. La pandemia y las posteriores medidas de contención han puesto de manifiesto la creciente importancia de las nuevas tecnologías para los consumidores y las empresas. El interés por los servicios de entrega por Internet ha aumentado desde el inicio de las medidas de confinamiento en los países latinoamericanos, mostrando un potencial cambio de hábitos de consumo hacia el comercio electrónico tras la crisis $\left(\right.$ OCDE et al., $\left.2020_{[17]}\right)$. Este mayor uso también se ha reflejado en el aumento del número de empresas con presencia en Internet y en la sofisticación de los servicios ofrecidos, lo cual ha derivado en una transición de sitios web informativos a sitios web transaccionales (CEPAL, 2020 $\left.{ }_{[18]}\right)$.

Si se compara el período previo a la pandemia, febrero-agosto de 2019, con el mismo período de 2020, se observa un fuerte aumento de los sitios web de empresas. En Brasil, Chile, Colombia y México se registró un aumento significativo en abril de 2020, seguido de una disminución en mayo, pero con un aumento continuado durante los meses siguientes (CEPAL, 2020 $\left.{ }_{[18]}\right)$.

Las plataformas de comercio electrónico también han experimentado mayor participación de las empresas, especialmente de pymes. Durante la pandemia, los datos procedentes de MercadoLibre.com dejan claro el fuerte crecimiento de nuevos vendedores registrado durante dicho periodo. En los países que tienen mercados más desarrollados, los nuevos vendedores se multiplicaron por 4, mientras que en los países con menor desarrollo de esta plataforma, el crecimiento se multiplicó por 6 (Gráfico 3.6). 


\section{Gráfico 3.6. Número de vendedores comercio electrónico en ALC, países seleccionados, 2019-20}

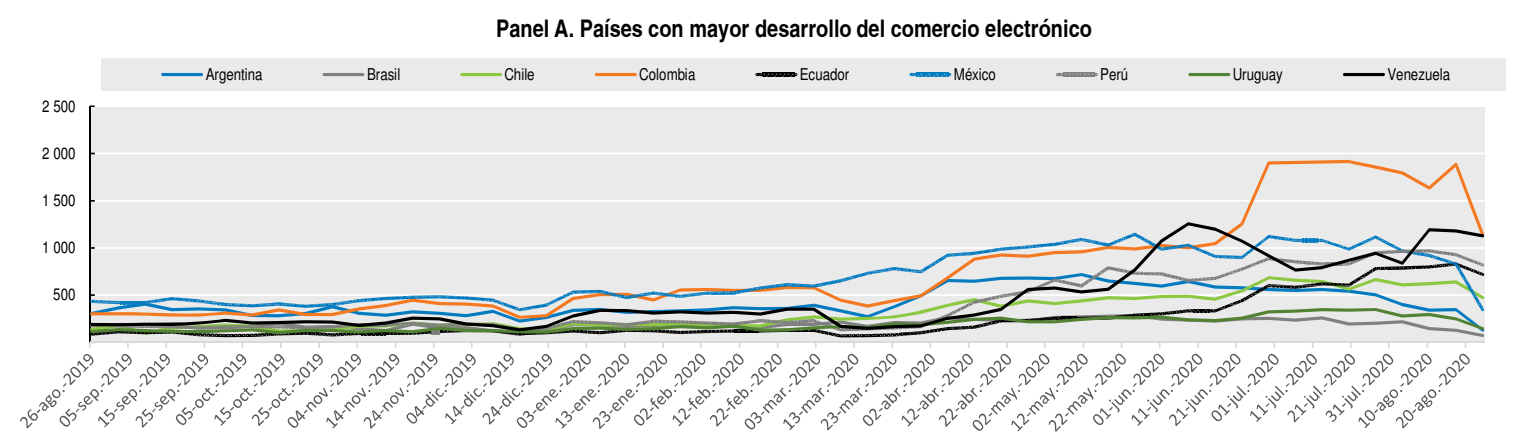

Panel B. Países con menor desarrollo del comercio electrónico

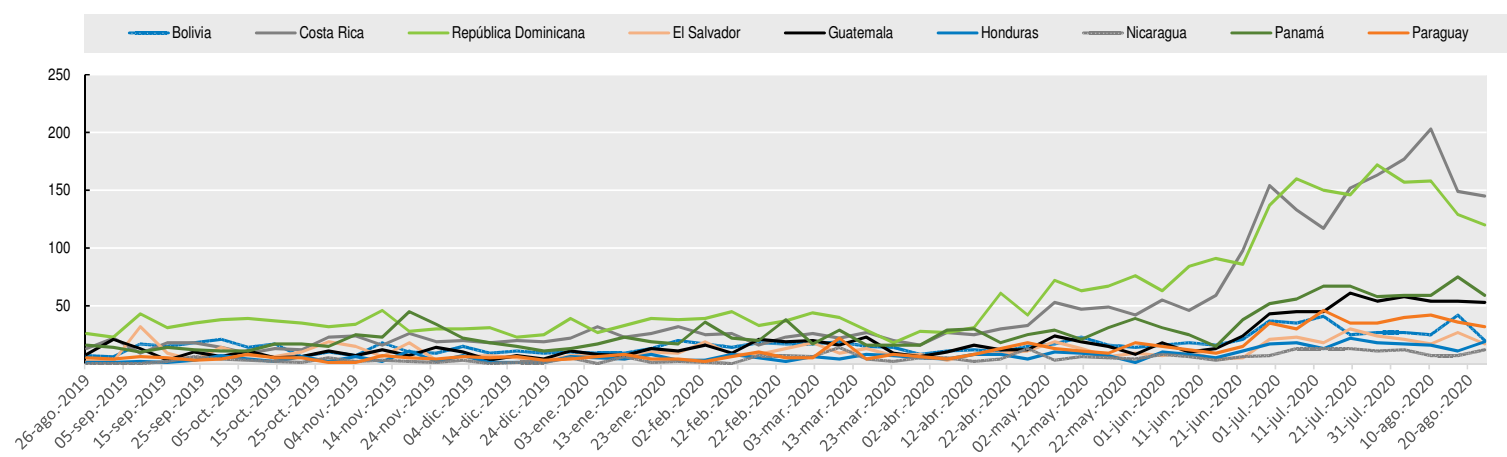

Fuente: CEPAL $\left(2021_{[19]}\right)$, Recuperación económica tras la pandemia COVID-19: empoderar a América Latina y el Caribe para un mejor aprovechamiento del comercio electrónico y digital. Elaboración propia, https://www.cepal.org/sites/default/files/publication/ files/46858/S2100269 en.pdf.

StatLink 需s https://doi.org/10.1787/888934295641

Asimismo, al analizar los catálogos de productos de las pymes que utilizan Shopify como plataforma de comercio electrónico, se observa que la mitad de los productos ofrecidos por las pymes de Brasil, Chile, Colombia y México a octubre de 2020 se comenzaron a vender por Internet poco después del inicio de la pandemia.

Esta digitalización acelerada se dio principalmente en eslabones de la cadena productiva relacionados sobre todo con la venta, comercialización y relación con proveedores y no en la incorporación de tecnologías digitales al propio proceso productivo. Además, esta digitalización está vinculada fundamentalmente al uso de tecnologías maduras como la banda ancha y no al uso de tecnologías avanzadas como los macrodatos, la inteligencia artificial, el aprendizaje automático o el Internet de las cosas (CEPAL, 2021 [20] $_{\text {) }}$.

Las estrategias de integración regional y de políticas coordinadas serán fundamentales para garantizar la creación de oportunidades en el entorno digital. La fragmentación en diferentes mercados para el desarrollo de infraestructuras de telecomunicaciones y la incorporación de tecnologías avanzadas puede constituir un obstáculo de cara a aprovechar las economías de escala y los mercados digitales integrados (Cullen International, 2016 ${ }_{[21]}$ ). La armonización, coordinación e interoperabilidad a nivel regional son esenciales para facilitar el desarrollo de un mercado único digital, en particular en ámbitos como la defensa del consumidor, la protección de los datos personales, la identidad digital, los pagos digitales, los valores digitales, las normas de transporte y logística y los regímenes fiscales (CEPAL y Red de Políticas de Internet y Jurisdicción, 2020 ${ }_{[22]}$ ).

Asimismo, contar con un mercado integrado también generaría beneficios económicos para la región. Por ejemplo, desde la creación de la estrategia de mercado único digital en la 
UE, su grado de digitalización creció más que el de otros países de la OCDE que no forman parte de ese espacio. La adopción de una estrategia de mercado digital entre los países de la Alianza del Pacífico (AP) podría aumentar el impacto anual de la digitalización en el PIB de 9620 millones de USD a 13886 millones de USD, teniendo en cuenta únicamente los efectos indirectos (CEPAL, 2021 $1_{[23]}$ ).

En la región existe un amplio consenso sobre la necesidad de fomentar la integración digital y, en ese sentido, varios bloques de integración ya están diseñando sus estrategias para apoyar la armonización normativa y la interoperabilidad. Por ejemplo, la estrategia de mercado digital de la AP permitiría una mayor escala del mercado, una mejor coordinación de los recursos y unos menores costos de transacción. El aumento de la escala del mercado permitiría un desarrollo más amplio de los productos y servicios digitales y facilitaría la creación de capacidades productivas digitales para competir en la industria de los contenidos y el desarrollo de plataformas a escala mundial. La estrategia del mercado digital podría ser un instrumento importante para coordinar los recursos de la investigación y el desarrollo tecnológico y la innovación a fin de reducir los costos de transacción de las empresas, que podrían operar así en un marco normativo armonizado.

Asimismo, la Agenda Digital Mesoamericana articula las estrategias digitales de los países miembros del Proyecto Mesoamérica. Uno de sus objetivos es desarrollar las infraestructuras de telecomunicaciones y la economía digital en esta subregión. La implantación de esta agenda digital mesoamericana podría generar un valor adicional de 3305 millones de USD en 5 años (CEPAL, 2021 ${ }_{[23]}$ ). En la CARICOM, la estrategia de mercado único incluye un capítulo específico sobre el desarrollo de un espacio digital único. El objetivo es crear un espacio de TIC sin fronteras que fomente la integración económica, social y cultural. Esta iniciativa incluye políticas, legislación, reglamentos, normas técnicas, mejores prácticas, redes y servicios de TIC que habrán de armonizarse a nivel regional (CEPAL et al., 2020 ${ }_{[17]}$ ).

Otra iniciativa es el Grupo Agenda Digital (GAD) del MERCOSUR, creado en 2017 para promover "el desarrollo de un MERCOSUR digital". En 2018, el GAD negoció su primer Plan de Acción (2018-2020), con compromisos en materia de infraestructura digital y conectividad; seguridad y confianza en el entorno digital; economía digital; competencias digitales; gobierno digital, gobierno abierto e innovación pública; aspectos técnicos y normativos, y coordinación en foros internacionales (MERCOSUR, 2020 ${ }_{[24]}$ ).

\section{La recuperación como oportunidad para promover una transformación sostenible}

La pandemia de COVID-19 está teniendo efectos negativos históricos en las esferas productiva y social, con consecuencias duraderas en las oportunidades de desarrollo y crecimiento para la región. Las capacidades productivas regionales están en riesgo, con cadenas productivas que enfrentan limitaciones para alcanzar los niveles de actividad anteriores a la pandemia, y la presión externa sobre los recursos naturales y los precios de las materias primas. Existe un riesgo creciente de cambio estructural regresivo con incentivos de mercado que empujan a la "reprimarización". En este escenario, se necesitarán políticas industriales políticas industriales activas para reanudar y apoyar el crecimiento y las actividades productivas y promover una agenda de transformación estructural.

Las estrategias de recuperación representan una oportunidad que la región no puede dejar pasar. Se necesitan políticas coordinadas a nivel regional para desarrollar las capacidades regionales, promover la transformación estructural y facilitar la integración de la región en las redes productivas globales. Para ser competitiva en el contexto internacional, la región debe ser capaz de anticiparse a los cambios estructurales en la organización productiva mundial. 
La crisis del COVID-19 ha dejado claro que la actual senda de desarrollo ha llegado a un punto que pone en riesgo la supervivencia del sistema ecológico que lo sustenta. Los mercados no pueden detener estos procesos, ya que las tasas de rentabilidad no tienen en cuenta la destrucción de la naturaleza ni muchos de sus efectos sobre la salud y el bienestar. El cambio climático provocado por la actividad humana es la expresión más clara y conocida de la incapacidad del modelo económico para incorporar las variables ambientales. Los ecosistemas y la biodiversidad se están reduciendo a un ritmo alarmante: más de un millón de especies están en proceso de extinción (IPBES, 2019 ${ }_{[25]}$ ). Los esfuerzos mundiales para frenar el cambio climático y la pérdida de biodiversidad determinarán las economías en el futuro. En el marco del Acuerdo de París, se espera que los países actualicen las Contribuciones Determinadas a Nivel Nacional (CDN) para combatir el cambio climático y se les invita a formular y comunicar estrategias de desarrollo a largo plazo destinadas a reducir las emisiones de gases de efecto invernadero y a fomentar un desarrollo resiliente.

En este contexto, una característica común de las estrategias de recuperación del COVID-19 son las orientaciones sectoriales específicas que hacen hincapié en la sostenibilidad y en la transición ecológica, otorgan un papel destacado a la política industrial y dan un gran impulso hacia una mayor autosuficiencia nacional o regional. Estas estrategias pretenden asignar recursos a sectores específicos para atender las necesidades de desarrollo nacional o regional, aprovechando las tendencias positivas aceleradas por la pandemia y adaptándose al entorno geopolítico actual.

En julio de 2021, la Comisión Europea reveló su ambicioso plan para hacer realidad el Pacto Verde Europeo. El plan para 2021-2027 reconoce la necesidad de transformar la economía hacia la neutralidad en materia de emisiones de carbono para el año 2050 y propone 13 políticas que, de ser aprobadas por el Parlamento Europeo, no solo remodelarán la economía europea sino que también tendrán un impacto en los socios comerciales de la UE. El plan incluye la puesta en marcha de un mecanismo de ajuste en frontera del carbono. Este plan también prohibirá de facto la venta de coches diésel y gasolina para el año 2035, lo que influirá en la transformación de la industria automovilística mundial.

El plan de China para 2021-2025, ratificado en marzo de 2021, tiene como objetivo aumentar la autosuficiencia e impulsar el mercado interno. Al mismo tiempo, la estrategia de "doble circulación" del país implica la mejora de las capacidades productivas nacionales mediante políticas industriales centradas en los sectores priorizados por la política "Made in China 2025" de 2015 y el mantenimiento del acceso a los mercados internacionales. El plan también incluye una estrategia para reducir las emisiones de $\mathrm{CO}_{2}$ de aquí a 2030 y controlar los gases de efecto invernadero distintos del $\mathrm{CO}_{2}$.

Desde el estallido de la pandemia, Estados Unidos ha asignado 4.2 miles de millones de USD en recursos presupuestarios a apoyar a los hogares, proteger a las empresas y reforzar el sistema de salud, al tiempo que el plan de empleo propuesto (American Jobs Plan) asignaría casi 2 billones de USD al ámbito de las infraestructuras de transporte, servicios públicos y digitalización, y a la fabricación e innovación, con especial hincapié en la mitigación del cambio climático y la transición energética. En los países del G-20, los compromisos en materia de energías limpias han ascendido a 245000 millones de USD, el $79 \%$ de los cuales se ha asignado como ayudas condicionadas (Energy Policy Tracker, $\left.2021_{[26]}\right)$.

En el contexto de la reconfiguración de la economía mundial, pueden verse afectados algunos de los actuales motores de crecimiento de América Latina, pero esta transición también trae consigo nuevas oportunidades. Un reto importante es transformar el objetivo de la neutralidad en materia de emisiones de carbono para que deje de ser un desafío y se convierta en una oportunidad económica para la región. Por ejemplo, las 
exportaciones de petróleo y carbón podrían verse muy afectadas a largo plazo, sobre todo porque la demanda internacional desempeña un papel importante en este sector (se exporta el $45 \%$ del petróleo y el 58\% del carbón producido en la región). Si la demanda mundial de combustibles fósiles desciende a niveles acordes con el objetivo de $1.5^{\circ} \mathrm{C}$, las importaciones de los mismos disminuirán drásticamente (se calcula que entre el $50 \%$ y el $70 \%$ de las reservas de petróleo se quedarán sin utilizar para el año 2035). Esta caída de la demanda reducirá los precios mundiales del petróleo, con graves consecuencias para la mano de obra del sector de los combustibles fósiles, y afectará de forma significativa a los ingresos fiscales de los países exportadores de petróleo (Solano-Rodríguez et al., $2019_{[27]}$ ).

Al mismo tiempo, los países de América Latina y el Caribe se enfrentan a retos medioambientales similares que están vinculados a su estructura productiva y a las características de su modelo de desarrollo. El crecimiento económico se ha basado mayoritariamente en una estructura productiva con ventajas competitivas estáticas basadas en los recursos naturales. A pesar de los avances de los últimos años y del compromiso de la región en cumplir con la agenda global, los recursos naturales se han utilizado a menudo de una manera que ha sido perjudicial tanto para el medio ambiente como para la sociedad: expansión irreversible de las tierras agrícolas, presión sobre los bosques, las zonas costeras y los ecosistemas biodiversos, contaminación del aire y del agua.

El cambio de modelo de desarrollo no se producirá a nivel nacional. Es necesario un cambio sistémico para desarrollar las ventajas competitivas que generen incentivos productivos hacia sectores más sostenibles.

La región se enfrenta al reto de la transición hacia la sostenibilidad dentro de sus propias fronteras y por sus propias necesidades, al tiempo que afronta el desafío de redefinir su economía para adaptarla al reto global de abordar el cambio climático y la transformación económica que ya está ocurriendo en otras partes del mundo. Al mismo tiempo, la región necesita un cambio estructural para superar las limitaciones impuestas por su modelo de desarrollo (CEPAL, 2020 ${ }_{[28]}$ ). La estructura productiva debe evolucionar hacia sectores más intensivos en tecnología que tienen mayores niveles de demanda y requieren empleo más cualificado. Esta transformación estructural debe acometerse al tiempo que se preservan los recursos naturales, la biodiversidad y el medioambiente. Dado que los mercados no pueden impulsar por sí solos una transformación estructural sostenible, estos cambios exigen un conjunto coordinado de políticas, que la Comisión Económica para América Latina y el Caribe (CEPAL) ha resumido como "un gran impulso a la sostenibilidad".

Este gran impulso consiste en una batería coordinada de políticas tecnológicas e industriales, fiscales, financieras, ambientales, sociales y regulatorias. Su objetivo es establecer una nueva estructura de incentivos a la inversión, impulsar la productividad y crear empleo mejor remunerado al tiempo que se desarrollan las cadenas de producción locales y regionales. Para ello, será necesario implantar mejoras tecnológicas y una mayor eficiencia ambiental y climática (CEPAL, 2020 ${ }_{[28]}$ ).

La transformación de la estructura productiva y el desarrollo de las capacidades de producción locales y regionales son elementos clave de este gran impulso hacia la sostenibilidad. Cada país, dada su estructura productiva y sus prioridades sociales, debe determinar las actividades y políticas necesarias para impulsar unos cambios estructurales progresivos y un gran impulso hacia la sostenibilidad (CEPAL, $2020_{[28]}$ ).

Un total de siete sistemas sectoriales pueden servir de base para lograr este gran impulso de la sostenibilidad en la región: las energías renovables no convencionales, la electromovilidad, la digitalización, la industria manufacturera sanitaria, la bio-economía, 
la economía circular y el turismo. Al coordinar las inversiones y las políticas industriales en torno a estos sectores se puede conseguir un amplio margen para generar empleos de mayor calidad, avanzar en la innovación, incorporar el progreso tecnológico, diversificar las exportaciones, adaptarse y mitigar los efectos del cambio climático y emprender esfuerzos de integración regional.

Partiendo del análisis realizado por la CEPAL en su informe Construir un nuevo futuro: Una recuperación transformadora con igualdad y sostenibilidad, en el siguiente apartado se analizan las oportunidades de desarrollo de capacidades e integración regional en cinco sectores: i) farmacéutico, ii) automotriz, iii) energías renovables, iv) agricultura sostenible y v) la economía circular.

Esta selección de sectores pretende ser una guía para conseguir una transformación sostenible que se base en el desarrollo de las capacidades regionales. Al combinar las inversiones con visión de futuro y la adopción de políticas industriales, fiscales, sociales y de desarrollo de capacidades, se puede estimular el crecimiento de nuevos sectores y fomentar la reconversión y el desarrollo de nuevas ramas en los sectores existentes. Además, la inversión dirigida a promover la eficiencia climática y la circularidad en los sectores existentes también puede ofrecer nuevas oportunidades para diversificar la economía al tiempo que se logra un desarrollo bajo en carbono. La integración de la producción en torno a cadenas de valor y sectores estratégicos acelerará la transición y disminuirá su costo al tiempo que aumenta su eficiencia.

\section{Del enfoque nacional al regional: las experiencias sectoriales como oportunidad de integración productiva y transformación sostenible}

No existe una receta única para la transformación estructural y la integración regional de la producción. Las características de cada sector determinan la forma en que los países integran y refuerzan sus capacidades productivas. La estructura industrial, el tamaño de las empresas, los acuerdos comerciales y la dotación de recursos son algunas de estas características. Por tanto, la adopción de políticas de integración productiva requiere un enfoque integrado que sea, en gran medida, específico para cada sector. Por ello, resulta útil centrarse en las experiencias sectoriales de la región para extraer lecciones e identificar futuras oportunidades mientras se generan los incentivos para desarrollar un modelo productivo más sofisticado y sustentable. Esta capítulo analiza cinco sectores que podrían desempeñar un papel clave en las estrategias de recuperación en ALC: la industria farmacéutica, el sector automotriz, las energías renovables, la agricultura sostenible y la economía circular.

\section{La industria farmacéutica: reforzar las capacidades regionales}

En los últimos 18 meses, todos los países de América Latina se han enfrentado al reto específico de abastecerse de los productos médicos necesarios para lanzar respuestas públicas y sistemáticas ante la emergencia del COVID-19. El acceso a los medicamentos en el contexto de la pandemia ha puesto de manifiesto las desigualdades sanitarias que existen a nivel mundial. La elevada dependencia de las importaciones de medicamentos en general, y de productos para cuidados intensivos del COVID-19 en particular, ha limitado la capacidad de los gobiernos para garantizar la necesaria protección de los trabajadores médicos, permitir el acceso a las pruebas, proporcionar respiradores y oxígeno en los casos necesarios, y recabar el arsenal de agentes farmacológicos utilizados para combatir los efectos del COVID-19 (Delgado et al., 2020 ${ }_{[29]}$ ). En resumen, la pandemia mundial ha puesto de manifiesto la vulnerabilidad de la cadena de suministro de América Latina. El diseño de políticas orientadas a fortalecer las industrias farmacéuticas locales y a invertir 
en el desarrollo de capacidades locales de producción permitirá, al mismo tiempo, reforzar la capacidad de reacción de la región y fomentar el conocimiento y el desarrollo industrial.

La industria farmacéutica está formada por entidades públicas y privadas cuyas actividades incluyen investigación y desarrollo, fabricación, envasado y comercialización de medicamentos destinados a la prevención y al tratamiento de afecciones médicas. En Europa y Estados Unidos, estas industrias son importantes motores del desarrollo económico y tecnológico. Encajan perfectamente en una red de actividades económicas complejas que incluyen procesadores de alimentos, cosméticos, productos químicos y pinturas, ingeniería y otras actividades tecnológicas interrelacionadas. ${ }^{1}$

En toda la región de América Latina, la producción farmacéutica está muy concentrada en las fases finales de la cadena de valor del sector, es decir, en la importación de principios activos farmacéuticos, su combinación, envasado, distribución y comercialización. Esta realidad determina los patrones de importación y exportación y el peso de la industria farmacéutica en el PIB nacional. ${ }^{2}$ América Latina no es una región líder en producción farmacéutica; en 2017, el peso de esta industria como porcentaje del PIB era del 0.37\%.

En cambio, en los países de la OCDE, el valor de las industrias farmacéuticas en el conjunto de la economía es superior, con un $0.83 \%$ del PIB. Ningún país de la región ALC cuenta con un alto valor agregado en dicha industria. Argentina (0.7\%) tiene el nivel más alto de la región, seguido de Brasil (0.54\%), México (0.46\%) y Chile (0.27\%). El mercado farmacéutico de América Latina como porcentaje del PIB contrasta notablemente con el de pequeños países europeos como Irlanda (7.6\%), Dinamarca (3.2\%) y Eslovenia (2.9\%), en donde las industrias farmacéuticas suministran productos de alto valor agregado y generan efectos indirectos en otras actividades económicas con un claro componente tecnológico (Feinberg y Majumdar, 2001 ${ }_{[30]}$; Grupp y Mogee, 2004 ${ }_{[31]}$; Grupp, 1996 ${ }_{[32]}$ ).

El valor total del mercado farmacéutico de América Latina está fuertemente orientado hacia tres países que representan el 80\% del mercado regional: Brasil (24 600 millones de USD), México (7 000 millones de USD) y Argentina (4 600 millones de USD) (Gráfico 3.7). En la región, el tamaño del mercado es un factor que determina la concentración de los sistemas de producción e innovación farmacéutica a nivel nacional. Sin embargo, Argentina, Brasil y México, que representan casi el $80 \%$ del valor total del mercado farmacéutico, no son mucho más competitivos en materia de exportaciones que sus vecinos de mercados más pequeños. Aunque el valor del mercado combinado de los países de América Central representa menos del 5\% del mercado regional, hay casos notables de países que han desarrollado plataformas de exportación especializadas en nichos, sobre todo en el caso de la industria de dispositivos médicos (Valverde, $2014_{[33]}$ ). El Gráfico 3.7 muestra la elevada concentración de valor existente en el mercado de la región, en donde estos tres países representan casi 8 de cada 10 dólares del mercado anual.

La región cuenta con algunos focos de producción farmacológica de alto valor, sobre todo en la producción de genéricos a gran escala en Brasil y el reciente repunte del sector de la biotecnología en Argentina. Sin embargo, en general, desde los años 80 y 90, la región ha seguido un modelo que se basa en importar productos farmacéuticos y dispositivos médicos, dependiendo sobre todo de productores extranjeros (Sweet, 2017 ${ }_{[35]}$; Sweet, $\left.2013_{[36]}\right)$. La dependencia de fuentes externas para el suministro de principios activos y productos terminados en la región se evidencia por el hecho de que gran parte de los países de la región cuentan con coeficientes de importación sobre el valor agregado sectorial superiores a uno. En 2014, este indicador se situaba en valores de 1.2 en Brasil, 1.1 en Argentina y 1.4 en Chile y Colombia. Por el contrario, los coeficientes de exportación sobre el valor agregado sectorial en los países de la OCDE (sin incluir miembros de América Latina) oscilan entre el $25 \%$ y el $45 \%$. 
Gráfico 3.7. Valor del mercado de la industria farmacéutica, países seleccionados de ALC, 2019

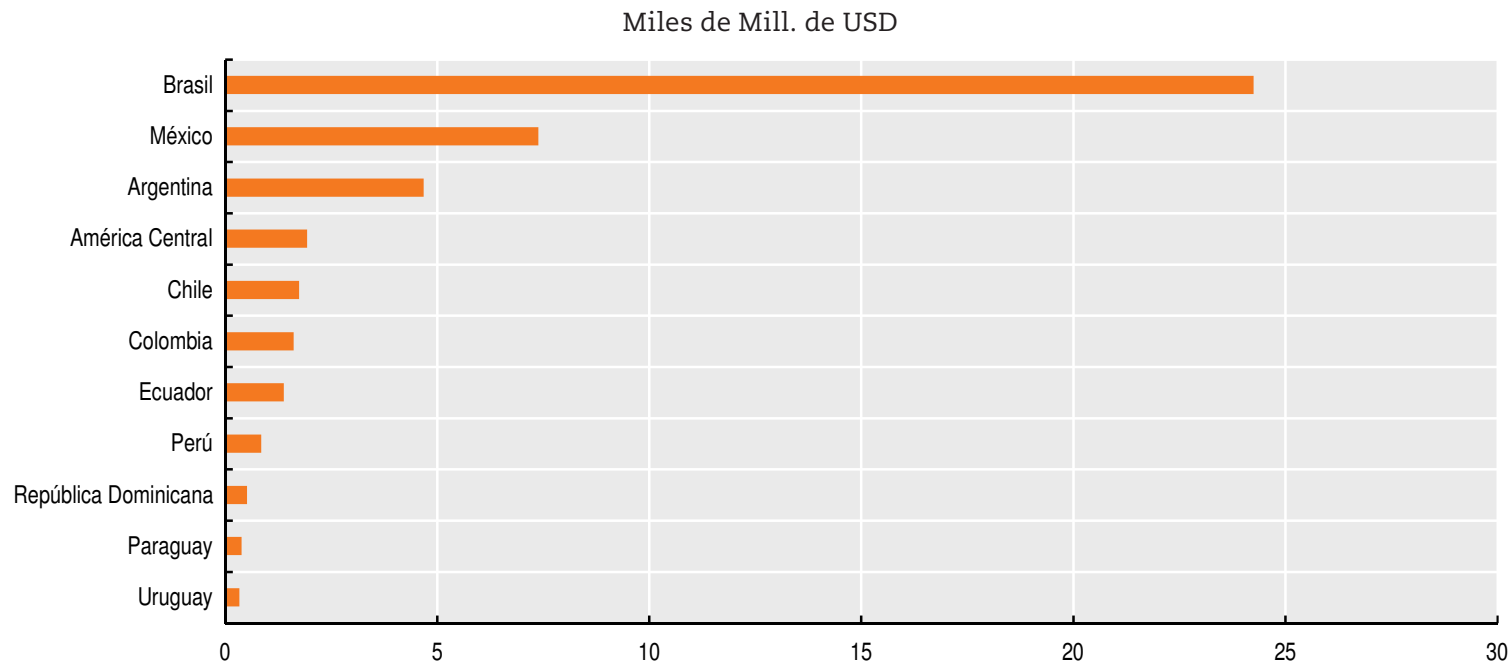

Fuente: Statista $\left(2020_{[34]}\right)$, Revenue of the worldwide pharmaceutical market from 2001 to 2020, https://www.statista.com/ statistics/263102/pharmaceutical-market-worldwide-revenue-since-2001.

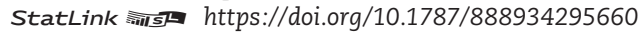

La falta de marcos regulatorios armonizados a nivel regional y el déficit de recursos humanos han dado lugar a un modelo de producción centrado en los mercados nacionales y concentrado fundamentalmente en el desarrollo de medicamentos convencionales de "pequeña molécula". Estas actividades productivas se ven reforzadas por los centros de formación repartidos por la región. Los gobiernos deben aprovechar la necesidad de invertir de forma continuada tanto en la calidad como en el número de investigadores en este ámbito. Para contar con sólidos sistemas de innovación se necesitan capacidades de recursos humanos variadas y profundas. Resulta clave contar con investigadores específicos tanto en determinados campos como en redes más amplias para poder crear ecosistemas en este ámbito. Existen indicios de que se están desarrollando segmentos cada vez mayores en profesiones sanitarias que trabajan en investigaciones científicas generales. Sin embargo, este desarrollo "no ha ido acompañado de un ritmo similar de patentes solicitadas y obtenidas, ni de nuevos productos lanzados al mercado" (CEPAL, 2020 $\left.{ }_{[28]}\right)$.

América Latina no cuenta actualmente con una plataforma regional para que los investigadores puedan cooperar con facilidad a nivel administrativo o institucional. Si se diera prioridad a los intercambios a nivel universitario para que los investigadores puedan aprovechar las ventajas respectivas de sus contextos nacionales, se reforzarían las actividades de innovación en el sector de las tecnologías médicas. Para ello, es necesario simplificar y agilizar los sistemas de cooperación para investigadores, de forma similar al programa ERASMUS de la UE, facilitando así la movilidad de los académicos en el ámbito de la salud y promoviendo la cooperación entre universidades y centros de investigación de la región. Otra ventaja de promover programas que faciliten la colaboración y el intercambio de investigadores sería la formación de equipos de trabajo de diferentes países de la región.

En las últimas décadas, ha habido un interés sostenido a nivel regional en promover políticas que armonicen las normas de seguridad y eficacia para aprovechar las ventajas de escala de un mercado latinoamericano más grande. De este modo, se conseguiría una mayor accesibilidad de los habitantes de la región a los nuevos productos, garantizando al mismo tiempo su calidad y seguridad. Ya desde 2006, la Organización Mundial de la Salud 
(OMS) y la Organización Panamericana de la Salud (OPS) han promovido la integración de estos sistemas para fortalecer a las agencias reguladoras a través del "intercambio de información, la convergencia y la confianza en los procesos regulatorios, no en la armonización absoluta de normas y estándares" (PAHO, 2010 ${ }_{[37]}$ ). En otras palabras, el objetivo de la OPS y otros organismos internacionales no ha sido hasta ahora el ambicioso proyecto de crear un único sistema de normas a través de la adopción de políticas, sino coordinar y entablar un diálogo entre esos sistemas.

Los sistemas de importación de la región también obstaculizan la entrada de nuevos productos. Los costos y la complejidad de estos sistemas constituyen por sí solos un problema. En el caso de Argentina, el anterior sistema de DJAI ("Declaración Jurada Anticipada de Importaciones") ha sido sustituido por un nuevo "Sistema Integral de Monitoreo de Importaciones" que permitirá la concesión automática de licencias de productos (SIMI, 2021 ${ }_{[38]}$ ). En los cinco años transcurridos desde su creación, esta normativa ha permitido la autorización automática de 18000 de los 19000 productos registrados en el sistema de importaciones. ${ }^{3}$ La agencia reguladora de Brasil, ANVISA, podría mejorarse ya que las certificaciones y las tasas relacionadas pueden llegar a duplicar el costo de los productos. Del mismo modo, entre las barreras de entrada al mercado farmacéutico de Colombia se incluye la aparición de unos requisitos más estrictos con el nuevo "Plan Nacional de Desarrollo", así como la existencia de "controles de precios, falsificaciones, criterios de patentabilidad, una débil aplicación de patentes y la emisión de una declaración de interés público para aplicar descuentos obligatorios de precios" (US Commercial Service, $2019_{[39]}$ ).

\section{El sector automotriz: integración y sostenibilidad}

La industria del automóvil es una de las más importantes de la región. Se caracteriza por sus amplios vínculos, en fases anteriores y posteriores, con muchas industrias y sectores diversos, al tiempo que desempeña un papel clave en el desarrollo de las capacidades industriales de la región. La pandemia ha afectado gravemente al sector y está impulsando una profunda transformación de su organización y posición geográfica en todo el mundo. Muchas empresas proveedoras de piezas han cerrado o bien no han podido mantener los niveles de producción anteriores a la pandemia, lo que ha afectado con fuerza a la fabricación de vehículos en todo el mundo. En 2020, la producción mundial de vehículos disminuyó un $15.8 \%$, hasta los 77.6 millones de unidades, una cifra similar a la registrada en 2010 (Gráfico 3.8). Entre las regiones que han experimentado mayores caídas se encuentran la UE (23.5\%), América del Norte (20.5\%) y América del Sur (30.4\%). En este escenario, es probable que la industria del automóvil esté atravesando la peor crisis de su historia.

Todos los cambios que se están produciendo en el sector automotriz podrían representar una oportunidad para reforzar las capacidades de fabricación de la región y crear puestos de trabajo de calidad. La industria del automóvil se concentra en torno a tres macro-regiones: América del Norte, la UE y Asia, al tiempo que un reducido grupo de países (Estados Unidos, Alemania, Japón, la República de Corea y China) mantienen una fuerte hegemonía en términos de producción, fabricantes de vehículos, proveedores y desarrollo tecnológico. A pesar del alto grado de concentración en la producción, la cadena de valor del sector automotriz está muy fragmentada, tanto geográficamente como por tareas. Esta característica del sector ofrece un margen para que la integración regional potencie las capacidades a lo largo de la cadena de valor, la investigación y el desarrollo, el diseño, las pruebas y el montaje y la producción.

La industria del automóvil está experimentando una de las mayores revoluciones de su historia, ya que sus fronteras se están expandiendo y están apareciendo nuevos 
actores, productos y modelos de negocio. La convergencia de la fabricación tradicional con la electrónica y el software está modificando la estructura de la cadena de producción y el liderazgo que sustenta. Aunque hay muchas expectativas sobre las nuevas formas de movilidad y el papel que desempeñará la industria del automóvil, también existen muchos interrogantes sobre el futuro del sector.

\section{Gráfico 3.8. Producción de vehículos, regiones y países seleccionados, 1950-2020}

\begin{tabular}{|c|c|c|c|c|}
\hline & América del Norte & América del Sur & - Unión Europea & - Federación Rusa y Turquía \\
\hline$e$ & - China & 图Japón-Rep. de Corea & ه Otros Asia & Otros \\
\hline
\end{tabular}

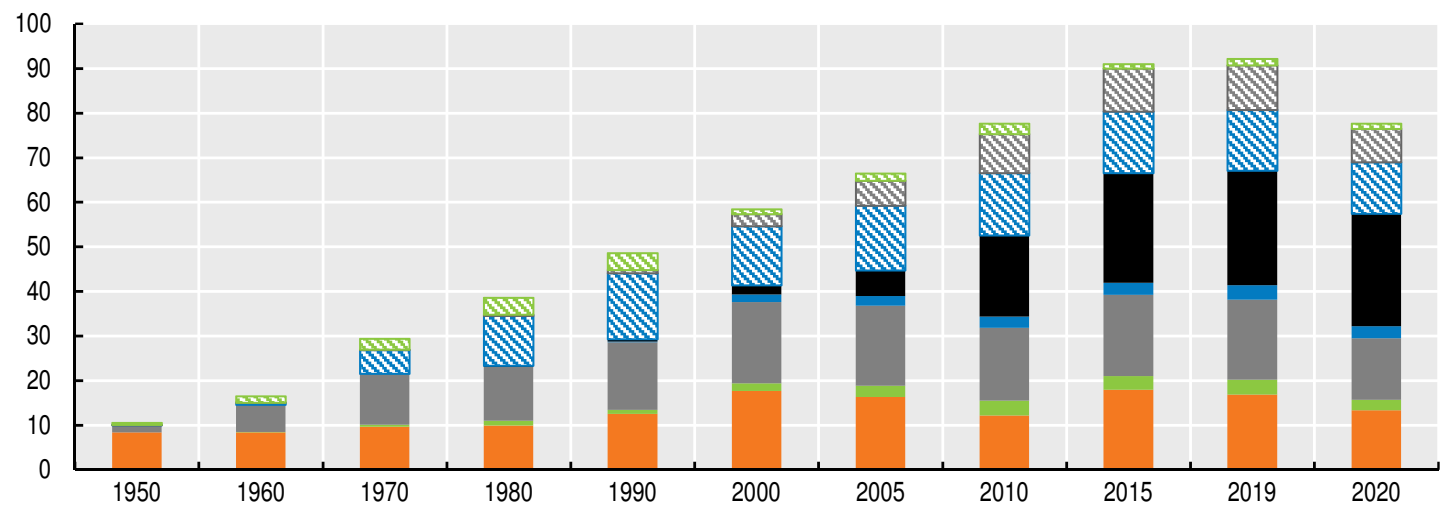

Fuente: Elaboración propia a partir de datos de la (Organisation Internationale des Constructeurs d'Automobiles -OICA-) (2021 [40]), Estadísticas de producción de automóviles 1950- 2020, https://www.oica.net/category/production-statistics/.

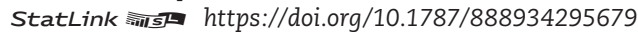

América Latina no ha sido inmune a los cambios que se han producido en la industria del automóvil a nivel mundial. En la década de 1990, la mayoría de los países abandonaron los modelos proteccionistas y, con ello, la industria automotriz prácticamente desapareció de América Latina, a excepción de las economías más grandes. Los fabricantes de vehículos de la región agruparon sus actividades en torno a tres polos mediante el despliegue de estrategias que combinaban eficiencia, complementariedad y especialización. La moderna plataforma de producción de México estaba fuertemente integrada con el mercado norteamericano. Las plantas de producción respaldadas por los modelos de integración de los mercados nacionales de América del Sur se centraron en el Mercosur, principalmente en Argentina y Brasil (Gráfico 3.9). Por último, el centro de la Comunidad Andina atendía a los mercados de Colombia, Ecuador y Venezuela. ${ }^{4}$

En los últimos años, sobre todo después de la crisis financiera mundial de 2008, la industria automotriz mexicana ha acelerado su proceso de transformación, pasando de ser una plataforma de exportación de bajo costo para el ensamblaje de vehículos de consumo masivo a convertirse en una cadena productiva mejor integrada, con mayor diversificación en productos y mayor sofisticación tecnológica. En 2017, la industria mexicana alcanzó su máximo histórico con casi 4 millones de unidades producidas. Este crecimiento le ha permitido conseguir una especialización y un mayor componente tecnológico, lo que fortalece la posición de México en una industria sujeta a grandes presiones procedentes de las nuevas tendencias y que generan un fuerte impacto económico.

El duro impacto de la crisis financiera en la industria del automóvil de Estados Unidos hizo que decenas de empresas modificaran sus estrategias de expansión y localización. Esta transformación provocó un enorme aumento de la inversión extranjera directa (IED), tanto de fabricantes y proveedores como del comercio con México. Entre 2009 y 2020, la industria automotriz mexicana recibió más de 56800 millones de USD en IED, de los cuales el 51\% se destinó al subsector de piezas para automóviles. 
Gráfico 3.9. Argentina, Brasil y México: producción de automóviles, 2000-2020

Miles de unidades producidas

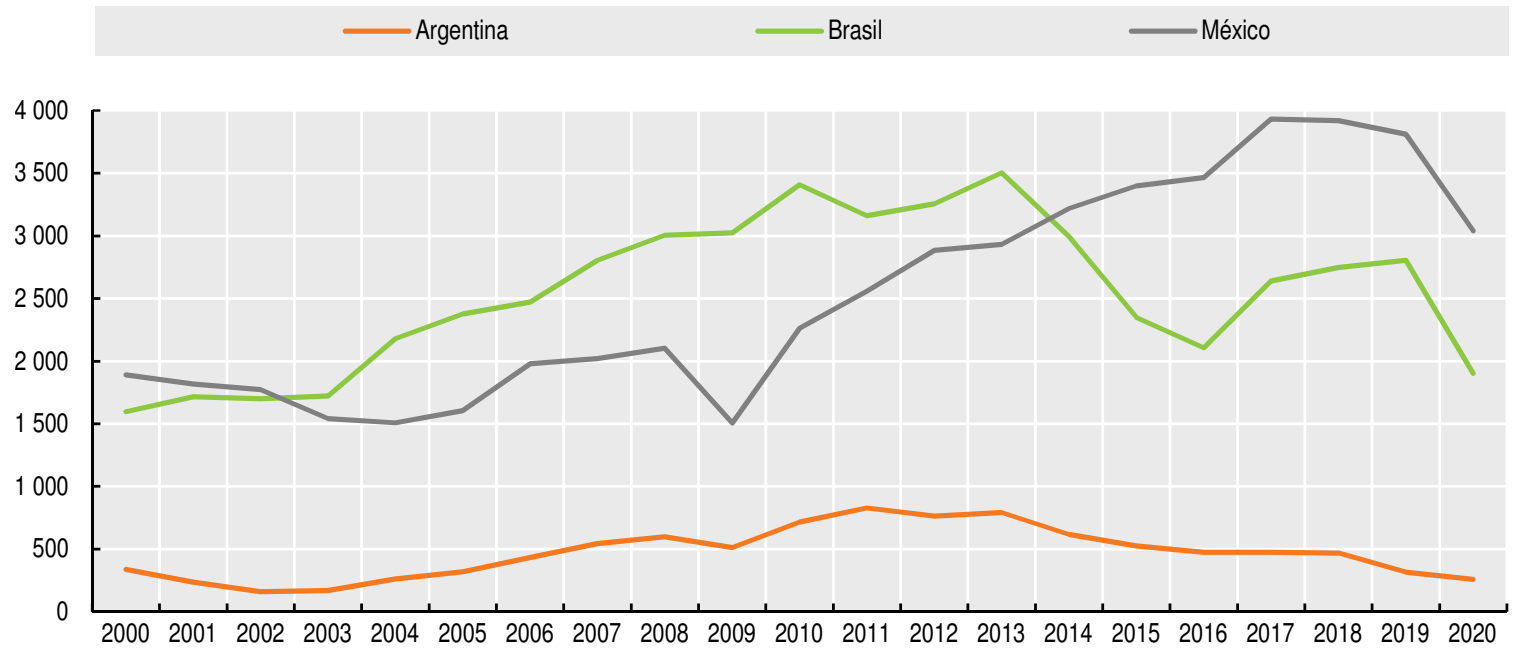

Fuente: Elaboración propia, basada en información de la Asociación de Fábricas de Automotores (ADEFA), http://www.adefa. org.ar/es/estadisticas-anuarios, Asociación Nacional dos Fabricantes de Vehículos Automotores (ANFAVEA), https://anfavea. com.br/site/edicoes-em-excel/, y Asociación Mexicana de La Industria Automotriz (AMIA), http://amia.com.mx/.

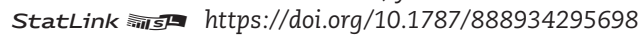

Gracias al aumento de la integración entre Canadá, Estados Unidos y México, la base de proveedores incrementó su amplitud y diversidad. La producción de automóviles en América del Norte está muy interconectada: los fabricantes y proveedores de vehículos compran piezas y componentes en toda la subregión, que pueden llegar a cruzar las fronteras de los países miembros hasta ocho veces antes de su instalación final en uno de estos tres países (Wilson, $2017_{[41]}$ ). El contenido estadounidense de un vehículo medio fabricado en México o Canadá es mayor que el de cualquier otro vehículo ensamblado en otro país del mundo, en gran parte debido a los estrictos regímenes de origen del Tratado de Libre Comercio de América del Norte (TLCAN) y, sobre todo, al acuerdo UMSCA. (CEPAL, 2018 ${ }_{[42]}$ ).

El modelo de integración productiva en el contexto del Mercosur y el tamaño de los mercados locales hicieron que las mayores empresas de la industria automotriz llevaran a cabo grandes inversiones en Brasil y, en menor medida, en Argentina. La producción se ha orientado al abastecimiento de los mercados nacionales y se rige por una clara política de especialización: automóviles compactos en Brasil y vehículos de mayor cilindrada, especialmente camiones de trabajo, en Argentina. En Brasil, la concentración de la producción en vehículos compactos ofrece a las empresas una mayor escala en la producción y, por tanto, menores costos y mayor competitividad.

Con la formación del Mercosur, se ha llevado a cabo una división del trabajo cada vez más clara entre Argentina y Brasil, sentando las bases para la creación de una cadena de valor automotriz regional. Entre los años 2000 y 2020, Brasil fue responsable del $84.5 \%$ de la producción de automóviles del bloque. En 2013, dicho país alcanzó un máximo histórico de cerca de 3.5 millones de unidades producidas y, posteriormente, experimentó una importante caída hasta los 1.9 millones de vehículos en 2020; Argentina registró una dinámica similar, al llegar a un récord de 830000 vehículos fabricados en 2011 y con una caída posterior hasta las 260000 unidades en 2020 (Gráfico 3.10).

Argentina y Brasil han adoptado un modelo de complementariedad en el comercio de bienes intermedios y finales para la industria automotriz. Desde la creación del Mercosur, el comercio bilateral automotor creció con fuerza hasta mediados de la década de 2010 
(Gráfico 3.10). Con el crecimiento de la industria, Argentina ha tendido a especializarse en la exportación de productos finales y Brasil en la exportación de bienes intermedios, productos de los que Argentina tenía un importante déficit comercial (Amar y García Díaz, $\left.2018_{[43]}\right)$.

\section{Gráfico 3.10. Brasil: exportación e importación de productos del sectore automotriz con Argentina, 1990-2020}

Millones de $\quad$ Exportaciones
USD

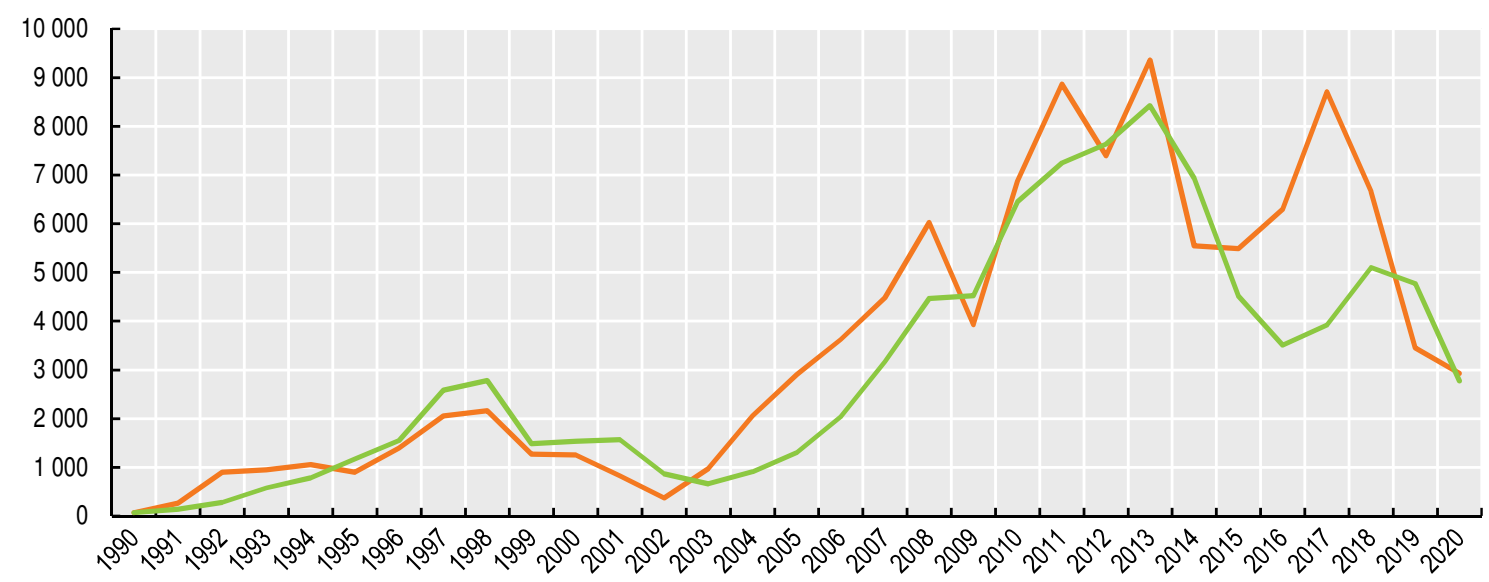

Fuente: CEPAL $(2020)$ a partir de la base de datos de estadísticas sobre el comercio de productos básicos de las Naciones Unidas (COMTRADE) (en línea), https://comtrade.un.org/.

StatLink - नilst https://doi.org/10.1787/888934295717

El concepto de la movilidad está cambiando rápidamente, lo que afectará a los países latinoamericanos en el futuro. Las políticas públicas y los compromisos adoptados a escala mundial están motivando a los fabricantes de vehículos hacia alternativas bajas en carbono y hacia una mayor eficiencia energética. Los próximos 20 años traerán consigo cambios significativos: electrificación, movilidad compartida, conectividad y digitalización, y en último término, vehículos autónomos. En este escenario, varios países compiten por construir nuevos clústeres industriales de alto valor para productos de movilidad.

En este contexto, la región se enfrenta a múltiples desafíos, comenzando por la reestructuración de la base productiva de la industria latinoamericana automotriz para adaptarla a las necesidades de la nueva realidad. De ahí que sean necesarias políticas públicas que fortalezcan las capacidades del ecosistema productivo y de innovación, y que favorezcan una mayor y más eficiente articulación entre los principales agentes de la cadena productiva para aprovechar las oportunidades que comienzan a surgir de estos cambios. De este modo, se pueden identificar nichos en los que puedan desarrollar ventajas competitivas con respecto a las nuevas demandas que surgirán en los próximos años. En el caso de los países de la región que tienen presencia en sectores de manufactura avanzada - como la industria automotriz - con la aparición de nuevos entornos que se caracterizarán por productos con ciclos de vida más cortos, un creciente nivel de sofisticación tecnológica y mayores exigencias de investigación, desarrollo e innovación, las empresas productoras de sistemas deberán reforzar sus capacidades tanto en tecnologías tradicionales como disruptivas.

Los nuevos y complejos sistemas productivos requieren una gran variedad de capacidades y no pueden depender de un único actor, por lo que cada vez será más importante desarrollar mecanismos para promover asociaciones y sinergias. La reducción 
de los ciclos de innovación y la necesidad de asignar grandes volúmenes de inversión han hecho que las alianzas y los asociaciones estratégicas resulten cada vez más atractivas. A diferencia de las entidades globales y de los países líderes en manufacturas avanzadas, Argentina, Brasil y México han tenido dificultades para avanzar en esta dirección, evidenciando la debilidad de sus empresas intermedias y una escasa participación de las entidades locales en la producción, sobre todo las de menor tamaño. Para aprovechar las capacidades existentes en la industria automotriz, la región cuenta con condiciones favorables para la producción de componentes en el ámbito de la movilidad eléctrica. La necesidad de avanzar en la renovación de los sistemas de transporte público ofrece una gran oportunidad para empezar a desarrollar nuevas capacidades de movilidad, sobre todo en materia de electromovilidad (CEPAL, 2020 ${ }_{[28]}$ ).

\section{El sector energético: fuentes de energía renovable e integración regional}

El sector energético está experimentando el mayor cambio tecnológico de los últimos cien años. La transición hacia fuentes de energía renovable y sostenibles constituye un reto mundial para el ámbito de las políticas públicas. A escala mundial, los combustibles fósiles seguirán desempeñando un papel relevante en la demanda de energía primaria en 2040, a pesar de que la energía derivada de fuentes renovables crecerá más rápido (EIA, 2018 ${ }_{[44]}$ ).

En América Latina, el peso de las energías renovables en la producción total de energía ha alcanzado el $29 \%$, superando así el promedio mundial. La energía hidroeléctrica y la biomasa (principalmente leña y carbón vegetal) son las principales responsables, al tiempo que Brasil se ha convertido en un actor destacado en la transformación de biomasa. Es necesario que se identifique a la transición energética como un medio de creación de oportunidades económicas para la región.

Aunque tradicionalmente la región ha contado con un mayor peso de las energías renovables, su porcentaje en el suministro total de energía primaria apenas creció marginalmente entre 2000 y 2018 (menos del 1\%), mientras que su índice de energías renovables ha variado muy poco, aumentando un $1.7 \%$ en dicho período (Gráfico 3.11). A nivel subregional, la Zona Andina, México y el Caribe han disminuido sustancialmente sus índices de renovabilidad, mientras que América Central, Brasil y América del Sur han aumentado sus índices.

\section{Gráfico 3.11. Índice de energías renovables, 2000-2019}

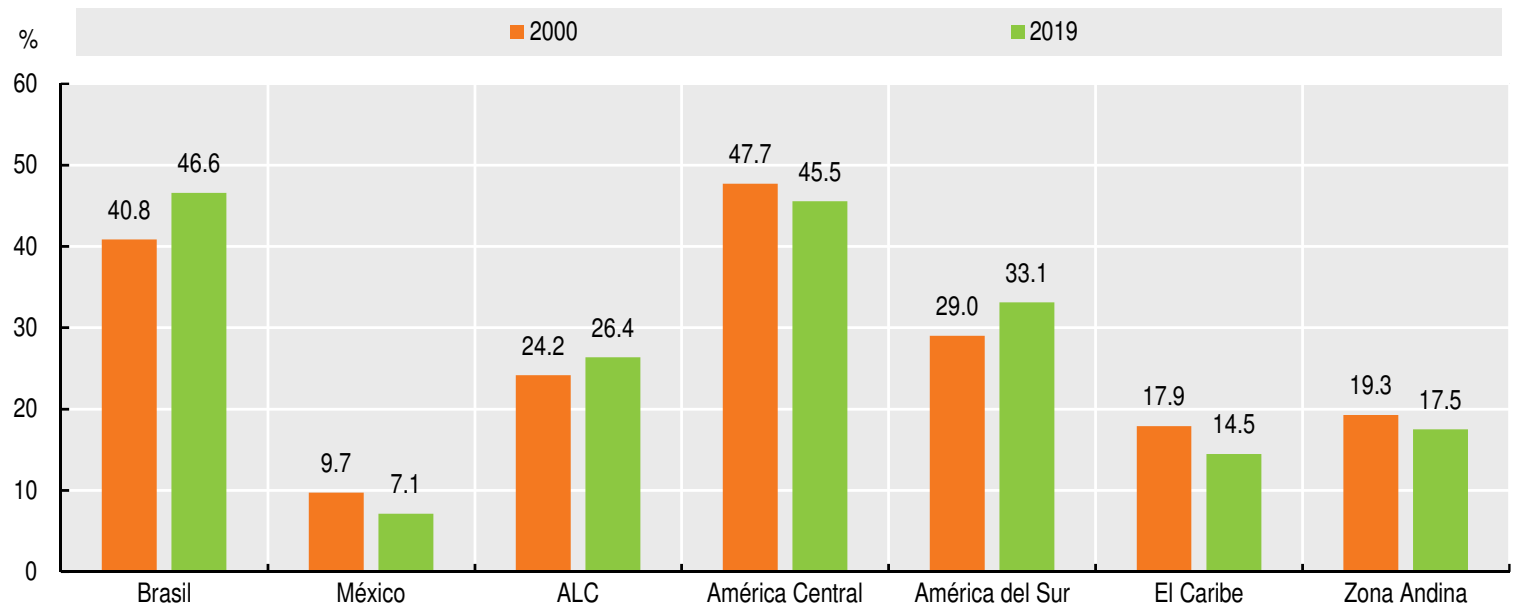

Fuente: Cálculos propios, CEPAL (2019), a partir de la base de datos de la Organización Latinoamericana de Energía, http:// www.olade.org/.

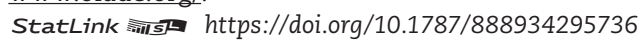


América Latina y el Caribe es una región dotada de vastos recursos para las energías renovables (Paredes, $2017_{[45]}$ ). Si bien la capacidad de generación eólica y solar está creciendo con fuerza y en 2017 representaba el 57\% de la capacidad adicional, en lo que se refiere a capacidad instalada tan solo representa el 6.5\% (IRENA, 2018 ${ }_{[46]}$ ). La región de América Latina y el Caribe podría generar hasta el $80 \%$ de su electricidad a partir de fuentes renovables de forma asequible, aprovechando el abundante potencial eólico y solar a medida que sus costos sigan disminuyendo. El enorme potencial de las energías renovables en la región se refleja en el volumen cada vez mayor de inversiones extranjeras directas que han entrado en el sector durante la última década. Durante la crisis del COVID-19, el único sector en el que aumentaron las previsiones de inversión fue el de las energías renovables (Gráfico 3.12).

Gráfico 3.12. Inversión anunciada en proyectos de energías renovables en ALC, 2020-2021

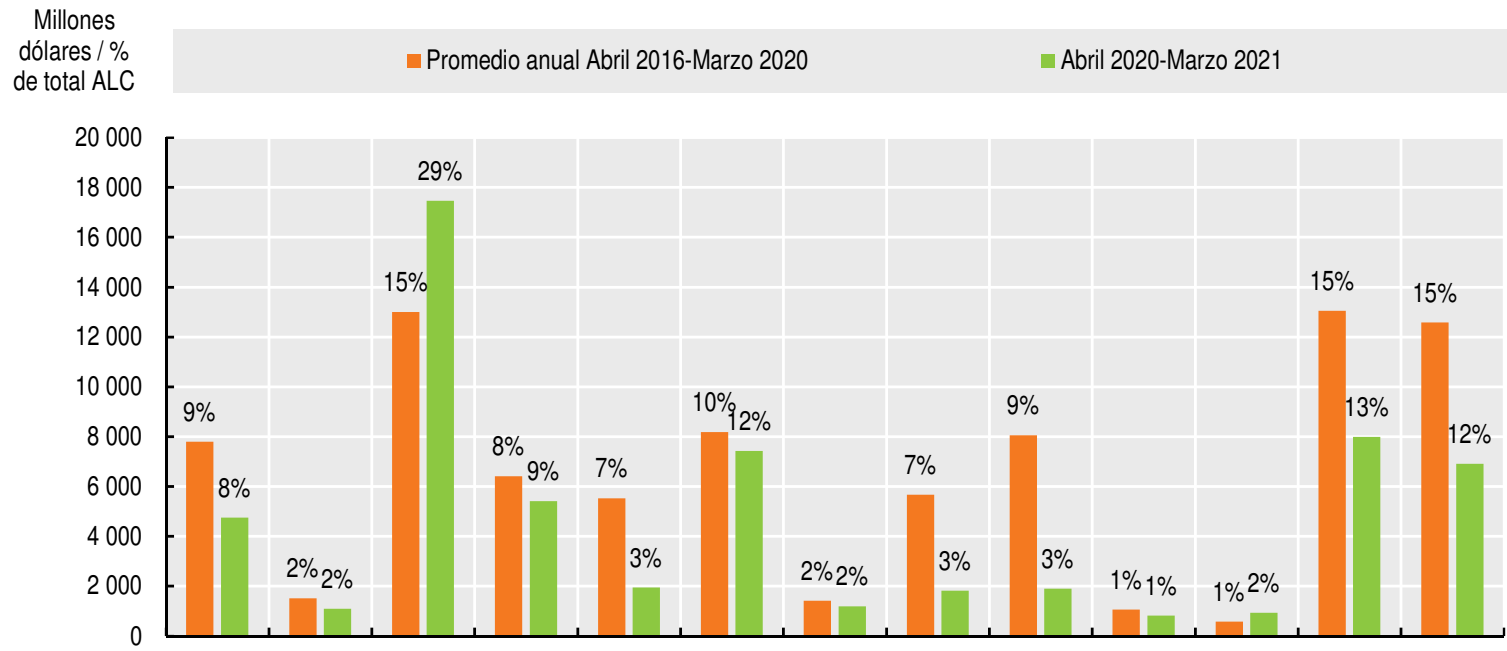

Fuente: Cálculos propios CEPAL (2021), a partir de la base de datos fDiMArket, https://www.fdimarkets.com/.

StatLink नilst https://doi.org/10.1787/888934295755

La elevada penetración de las energías renovables y una alta integración de la transmisión regional requerirán que se incorpore una mayor cuota de renovables a la red eléctrica, aumentando la generación de la carga básica gestionable y la integración regional. Por tanto, para los próximos diez años, será necesario incrementar la generación de electricidad principalmente a través de la energía hidroeléctrica, en la que países con un importante potencial hidráulico, como Paraguay, podrían desempeñar un papel clave de cara a la integración regional. Actualmente, la heterogeneidad de los recursos energéticos presentes en la región conlleva que la transición pueda resultar costosa y compleja para muchos países, a medida que abordan los retos de satisfacer el aumento de la demanda de electricidad en las próximas décadas, incluidas las cuestiones relacionadas con la electrificación del sector del transporte y el mayor uso industrial de la energía.

El aumento del uso de las fuentes de energía renovables y de la integración regional debería reducir los costos de generación de electricidad (combustible, transmisión, operación y mantenimiento) así como los costos de inversión en nueva capacidad de generación (solar, eólica, tecnología geotérmica y otras). Varios países de la región podrían acceder a los excedentes de generación de terceros países, por lo que podría no ser necesaria la construcción de nuevas plantas de generación eléctrica; sin embargo, este escenario requeriría voluntad política y una sofisticada planificación energética (Recuadro 3.2). 


\section{Recuadro 3.2. Cómo satisfacer la creciente demanda de energía con electricidad limpia y sostenible}

La CEPAL, en colaboración con la Organización Latinoamericana de Energía (OLADE), la Agencia Internacional de Energías Renovables (IRENA) y el Banco Interamericano de Desarrollo (BID), analizó la complementariedad de los sistemas eléctricos regionales y la penetración de las energías renovables. En el marco de esta iniciativa, se diseñaron tres escenarios del sector eléctrico para el año 2032 utilizando la metodología PLEXOS.

1. El escenario de referencia (BASE) se construye considerando los datos de la OLADE y los planes de expansión a largo plazo de los países. En este escenario, la penetración de las energías renovables se basa en los planes energéticos nacionales y existe una escasa integración entre países en el ámbito de la transmisión.

2. El segundo escenario (RE) incorpora una elevada proporción de energías renovables $(80 \%$, incluida la energía hidroeléctrica a gran escala), pero mantiene las mismas interconexiones regionales que en el escenario de referencia.

3. El tercer escenario (RE+INT) incorpora tanto una elevada penetración de renovables como un alto nivel de interconexión.

Los resultados son evidentes; la descarbonización eficiente del sector eléctrico implica una transición hacia las energías renovables y la promoción de iniciativas de integración en la red eléctrica regional. Los principales resultados son:

1. Escenario BASE: la planificación energética de los países de la región (2018-2032), sin aumento de las energías renovables (solar, geotérmica, minihidráulica, biomasa y oceánica) y sin incluir las grandes hidroeléctricas supone un aumento de su cuota total de generación eléctrica del $12.7 \%$ al $24.6 \%$;

2. Escenario RE: las energías renovables (excluida la hidroeléctrica) aumentan del $12.7 \%$ al $41.1 \%$, con un costo total del 1.35\% del PIB anual entre 2020 y 2032 y una reducción del 30.1\% de las emisiones de $\mathrm{CO}_{2}$;

3. Escenario RE+INT: las energías renovables (excluida la hidroeléctrica) aumentan del 12.7\% al 39.5\%, con un costo total del 1.33\% del PIB anual entre 2020 y 2032 y una reducción del $31.5 \%$ de las emisiones de $\mathrm{CO}_{2}$.

Aunque los costos de las energías renovables tienden a la baja (por ejemplo, el precio medio de los módulos fotovoltaicos cayó casi un 61\% entre 2011 y 2017), los costos actuales del almacenamiento a gran escala, que oscilan entre 1000 y 5000 dólares por megavatio-hora, limitan su uso a escala masiva. Sin embargo, a largo plazo, la caída de los costos del almacenamiento podría ser un incentivo para conseguir una mayor penetración directa de las fuentes de energía renovables. Los retos originados por el aumento de la demanda de electricidad en las próximas décadas parecen aún mayores si se tiene en cuenta la necesidad de electrificar el transporte y la industria. En este contexto, el fomento de la integración regional podría ser una forma de reducir el costo y de aumentar la eficiencia medioambiental de la generación de electricidad.

\begin{tabular}{lccc}
\hline Escenarios & $\begin{array}{c}\text { Proporción de energías renovables } \\
\text { no hidráulicas en la capacidad } \\
\text { instalada }\end{array}$ & $\begin{array}{c}\text { Costo total } \\
\text { (\% del PIB anual 2020-2032) }\end{array}$ & $\begin{array}{c}\text { Emisiones de C0 } \\
\text { (gigatoneladas 2020-2032) }\end{array}$ \\
\hline Escenario base & $12.7 \%$ & - & 6 \\
Planificación energética por países & $24.6 \%$ & $1.40 \%$ & 4.8 \\
Energía renovable sin integración & $41.1 \%$ & $1.35 \%$ & $-30.1 \%$ \\
Energía renovable con integración & $39.5 \%$ & $1.33 \%$ & $-31.5 \%$ \\
\hline
\end{tabular}

Fuente: CEPAL $\left(2020_{[28]}\right)$ Construir un nuevo futuro: Una recuperación transformadora con igualdad y sostenibilidad. Resumen (LC/SES.38/4), Santiago. 
La elevada penetración de las energías renovables y la importante integración regional muy probablemente redundarían en una mayor eficiencia, lo que se traduciría en menores pérdidas y una disminución de las emisiones. Asimismo, las inversiones necesarias para lograr la integración energética implican el desarrollo de una infraestructura eléctrica sostenible, y la posibilidad de crear aproximadamente 7 millones de nuevos empleos para el año 2032. Del mismo modo, si el sector de las energías renovables se ubicara en la región de ALC, la fabricación de paneles solares y turbinas eólicas representaría casi un millón de empleos más para la región (CEPAL, $2020_{[28]}$ ).

\section{Agricultura sostenible}

Las tendencias actuales en el ámbito de la sensibilización alimentaria han ejercido presiones sociales y de mercado sobre la agricultura para que desarrolle productos diferenciados. La producción de agroespecialidades orientadas a satisfacer las exigencias de los consumidores es más intensiva en conocimientos y tecnología y genera más valor para los productores. Las empresas que producen agroespecialidades tienden a ser las que fijan sus propios precios (Shapiro, $1987_{[47]}$ ).

Son muchos los factores que explican este proceso de diferenciación, entre ellos los cambios estructurales (p. ej., la globalización), la integración del mercado y la expansión del comercio minorista, así como los cambios culturales (sensibilización medioambiental y alimentaria). Este proceso se ha visto acelerado por la rápida digitalización, que ha facilitado el seguimiento de las cadenas de producción, y por las numerosas crisis alimentarias que se han producido desde la década de 1990. El resultado es un consumidor cada vez más sensibilizado y exigente, que busca una mayor calidad nutritiva, productos de comercio justo, orígenes agroecológicos acreditados, respeto a los derechos de las comunidades indígenas, etiquetas de origen local, y la reducción de la huella ambiental y del impacto climático, entre otros. Cada vez adquieren más importancia los productos que tienen una mayor densidad nutricional (proteínas, vitaminas, otros) y que mejoran la salud, como los productos frescos, así como los que cuidan el medioambiente o que inciden en otras causas globales. La pandemia generada por el COVID-19 puede acentuar aún más este proceso.

Por tanto, la tendencia se orienta hacia industrias agroalimentarias con más gasto en servicios y sostenibilidad (certificaciones, logística y marketing) que en materias primas agrícolas. Progresivamente, los productos agroalimentarios se transforman en "productos-servicios", que sirven para encontrar una "solución" a un determinado problema: calidad, salud, medioambiente, cultura, derechos de las comunidades e inclusión social.

Otra tendencia complementaria durante las últimas tres décadas ha venido generada por el desarrollo de la biotecnología y la aparición de la bioeconomía. Este fenómeno, al complementarse con las tecnologías y las ciencias de los materiales (sobre todo la nanotecnología) y las ciencias de la información (TIC) ha permitido avances antes impensables en la productividad de los recursos agrícolas y modelos de producción mucho más sostenibles en la bioeconomía que tienen el potencial de generar cambios sistémicos (Fraunhofer, $\left.2018_{[48]}\right)$. Ya son muchos los países que aplican estrategias nacionales de bioeconomía, como Estados Unidos, Alemania, Países Bajos, Suecia, Finlandia, Noruega y Dinamarca. Estas estrategias también se están potenciando en la Unión Europea, China e India. En la región de ALC, Argentina y Costa Rica llevan algunos años desplegando iniciativas para su desarrollo (Rodríguez, Mondaini y Hitschfeld, 2017 ${ }_{[49]}$ ).

La agricultura sostenible también puede contribuir a una transición verde y transformadora que aporte empleos de calidad y potencie el desarrollo socioeconómico. En los próximos años, todos los sectores, incluida la agricultura, se verán presionados 
para cumplir las normas medioambientales y las empresas se verán cada vez más obligadas a cumplir elevados estándares de seguridad y sostenibilidad para competir en el mercado mundial. En este escenario, la agricultura sostenible podría representar una alternativa válida para la diversificación de la producción a través de la innovación y el desarrollo de normas. Este tipo de agricultura implica la aplicación de métodos agronómicos, biológicos y mecánicos de producción en lugar del uso de insumos químicos sintéticos. El desarrollo de normas y certificaciones armonizadas es esencial para la comercialización y exportación de productos ecológicos. La literatura reciente muestra que los productores que no obtienen certificaciones no obtienen precios superiores por sus productos. Muchos pequeños agricultores de ALC no utilizan insumos químicos en sus procesos de producción. En este sentido, el desarrollo de normas y reglamentos para productos específicos podría ayudar a las pymes a integrarse en los mercados regionales e internacionales, especialmente el europeo.

Por ejemplo, para reducir la contribución de la agricultura a la deforestación y la degradación de los bosques a nivel mundial, la Comisión Europea está trabajando en una propuesta legislativa para evitar o minimizar la comercialización de productos asociados con la deforestación o la degradación de los bosques en el mercado de la UE. Las políticas agrícolas regionales deben anticiparse a estas tendencias y promover el cumplimiento de normas medioambientales más estrictas. Este proceso debe ir acompañado de inversiones específicas en el sector y de iniciativas que contribuyan a cumplir y adaptarse a las normas y a la regulación, así como a mejorar la transparencia. Si cuenta con el apoyo de una adecuada batería de políticas, la agricultura sostenible y especializada podría generar la triple ventaja de mejorar la sostenibilidad medioambiental, fomentar la incorporación de conocimientos y apoyar a las mipymes para que accedan a los mercados mundiales.

En América Latina y el Caribe, el sector agroalimentario representa el $25 \%$ de las exportaciones regionales y el 5\% del PIB regional. Los productos básicos ocupan entre el $70 \%$ y el $80 \%$ de la superficie cultivada de la región y generan un importante impacto económico, ecológico y social. Sin embargo, la región cuenta con un potencial importante para ampliar la producción de especialidades. Esta evolución hacia las especialidades y la agricultura sostenible podría generar puestos de trabajo de calidad y contribuir a la construcción de una agroindustria regional que incorpore conocimientos y genere industrias complementarias como los bioplásticos, los concentrados de proteínas o el tratamiento de residuos.

La producción de soja es la más importante en el sistema alimentario regional. Ocupa un tercio de la superficie plantada y genera exportaciones por un valor aproximado de 65000 millones de USD (17\% del total exportado por los cinco países productores de la región) (Gráfico 3.13, Tabla 3.1). La cadena de valor de la soja desempeña un papel estratégico en los equilibrios alimentarios y geopolíticos mundiales, sobre todo por su relación como proveedor privilegiado de grano para el consumo en Asia, principalmente en China. La soja destaca por sus posibilidades industriales, como proveedor de productos intermedios que son necesarios en grandes volúmenes por las empresas productoras de alimentos, biocombustibles y otros productos industriales. El patrón de producción de la soja en la región es el propio de un producto puramente primario (como grano y también a través de sus derivados). Sin embargo, existen incentivos cada vez mayores para incorporar más conocimientos y tecnologías de valor agregado gracias al aumento de la demanda de productos diferenciados que permitan la identificación del origen del producto, su trazabilidad y su huella ambiental.

La cadena de producción de soja se enfrenta a una creciente preocupación por la sostenibilidad de la agricultura de monocultivo intensivo a gran escala, incluyendo los impactos en la deforestación, la pérdida de biodiversidad y la degradación del suelo. 
La creciente preocupación de los consumidores internacionales de soja y la adopción de certificaciones orgánicas representan una oportunidad para de generar y adoptar innovaciones con un impacto medioambiental positivo, pero, como ocurre con como cualquier sistema de certificación comercial, también puede ser una causa de exclusión del mercado para aquellos productores que no pueden certificar una producción de soja sostenible u orgánica. En este escenario el desarrollo y reconocimiento internacional de las certificaciones agrícolas está adquiriendo una relevancia central en las relaciones comerciales (Recuadro 3.3).

\section{Gráfico 3.13. Superficie cosechada por cultivo en ALC, 2018}

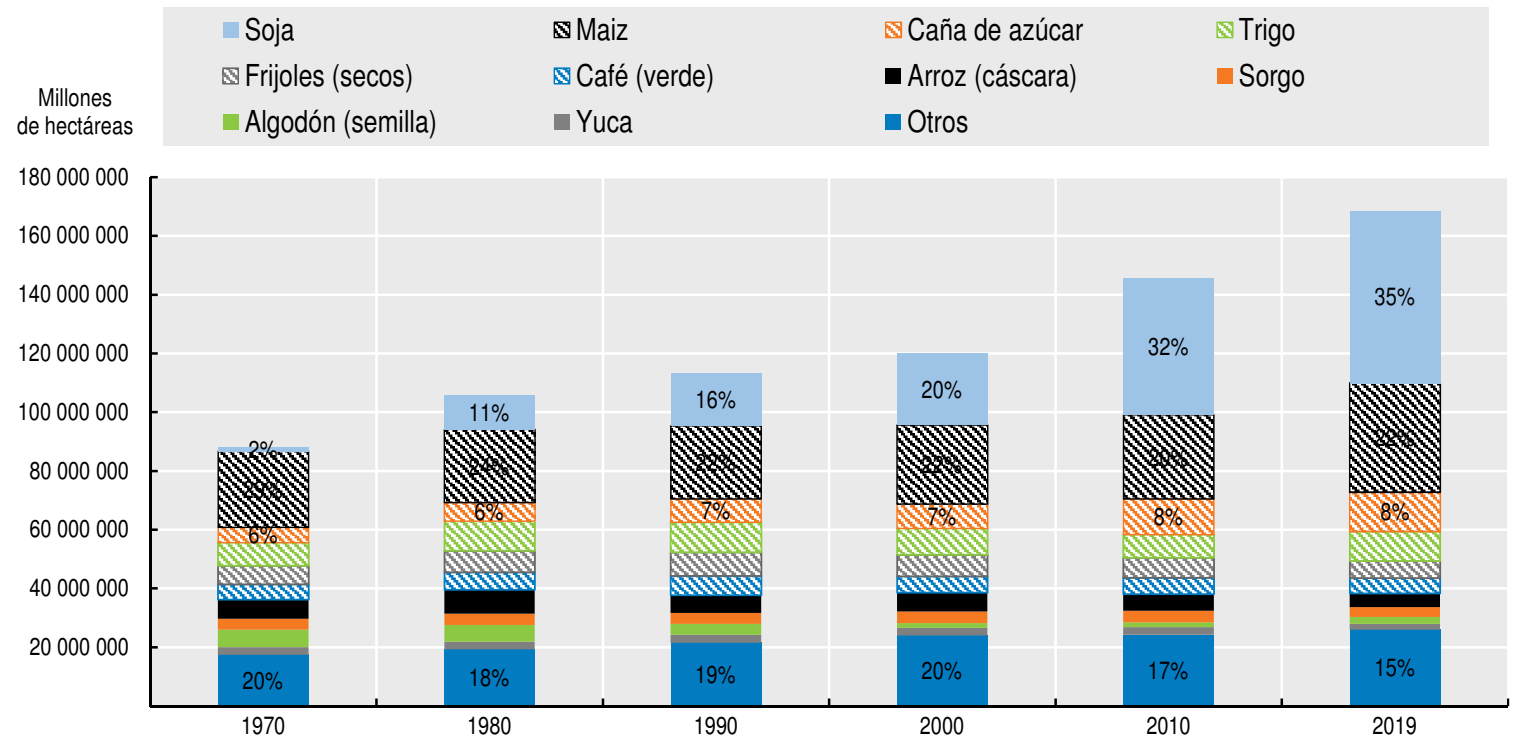

Fuente: FAO y CEPAL $\left(2020_{[50]}\right)$, Sistemas alimentarios y COVID-19 en América Latina y el Caribe: impacto y riesgos en el mercado laboral. Boletín 5. Santiago, http://www.fao.org/3/ca9237en/ca9237en.pdf); y FAO (2021 $\left.1_{[11]}\right)$ FAOSTAT [en línea], http://www.fao.org/faostat/en/\#home.

StatLink -ints https://doi.org/10.1787/888934295774

Tabla 3.1. Países productores de soja en la región de América: superficie cosechada, producción, rendimiento y número de productores, 2019

\begin{tabular}{|c|c|c|c|c|c|c|c|}
\hline \multirow{2}{*}{ País } & \multicolumn{2}{|c|}{ Superficie cosechada } & \multicolumn{2}{|l|}{ Producción } & \multirow{2}{*}{$\begin{array}{c}\text { Rendimiento } \\
\text { Toneladas/hectárea }\end{array}$} & \multirow{2}{*}{$\begin{array}{c}\text { Explotaciones } \\
n .^{\circ}\end{array}$} & \multirow{2}{*}{$\begin{array}{c}\text { Tamaño medio de explotaciones } \\
\text { Hectárea }\end{array}$} \\
\hline & & & Ione & & & & \\
\hline Estados Unidos & 30352150 & 25.2 & 96793180 & 29.0 & 3.2 & 302963 & 100.2 \\
\hline Canadá & 2270500 & 1.9 & 6045100 & 1.8 & 2.7 & 31.52 & 72.0 \\
\hline Brasil & 35881447 & 29.8 & 114269392 & 34.2 & 3.2 & 236245 & 151.9 \\
\hline Argentina & 16575887 & 13.8 & 55263891 & 16.6 & 3.3 & 58443 & 283.6 \\
\hline Paraguay & 3565000 & 3.0 & 8520350 & 2.6 & 2.4 & 27735 & 128.5 \\
\hline Bolivia & 1387973 & 1.2 & 2990845 & 0.9 & 2.2 & 14 & 99.1 \\
\hline Uruguay & 966 & 0.8 & 2828000 & 0.8 & 2.9 & 2229 & 433.4 \\
\hline $\begin{array}{l}\text { Otros (países } \\
\text { productores) }\end{array}$ & 62125321 & 51.6 & 149799214 & 44.9 & 2.4 & Sí & Sí \\
\hline Mundo & 120501628 & 100.0 & 333.671 .692 & 100.0 & 2.8 & Sí & Sí \\
\hline
\end{tabular}

Fuente: Cálculo propio a partir de datos de FAOSTAT 2021 por superficie cosechada, producción y rendimiento. Para el número de explotaciones: Estados Unidos, Censo Agropecuario 2017, mencionado en ERS-USDA, 2021; Canadá, Censo Agropecuario 2016, mencionado en Soy Canadá, 2021 2016; Brasil, Censo Agropecuario 2017, IBGE, 2019; Argentina, Censo Nacional Agropecuario 2018, INDEC, 2019; Paraguay, Censo Agropecuario, 2008 DCEA-MAG, 2009; Bolivia, Censo Agropecuario 2013, INE, 2015; Uruguay, Censo General Agropecuario, 2011 MGAP, 2011. 


\section{Recuadro 3.3. Soja certificada para la sostenibilidad, la experiencia de Argentina}

La Asociación Argentina de Productores en Siembra Directa (AAPRESID) ha trabajado con los productores de soja para monetizar el valor añadido de la producción de soja certificada a través del desarrollo de créditos de soja. Los productores que certifican una mayor sostenibilidad, transparencia y trazabilidad en toda la cadena de valor de la soja pueden acceder a la Certificación de Agricultura Sostenible (ASC). La certificación ASC argentina ya fue reconocida por la Federación Europea de Fabricantes de (FEFAC) por producir estándares compatibles con el mercado europeo. mercado europeo. Desde marzo de 2021, los compradores europeos pagaron una prima de precio en forma de créditos por tonelada de los productores de soja a los vendedores certificados. En esta primera instancia, el beneficio sólo cubre la soja, aunque se está trabajando para añadir otros cultivos como el maíz, el trigo y el algodón.

Por otro lado, Argentina también está promoviendo la certificación RTRS. La "Mesa Redonda sobre Soja Responsable" (RTRS) es una organización mundial sin ánimo de lucro fundada en 2006 en Zúrich, Suiza, que promueve la producción, el comercio y el uso de la soja responsable a través de la cooperación con los actores relevantes de la cadena de valor de la soja, desde la producción hasta el consumo. Garantiza cero deforestación y cero conversiones en la producción de soja.

Las normas de certificación ASC y RTRS comparten objetivos y son complementarias. complementarios. Este hecho hace que la doble certificación RTRS / ASC sea una ventaja competitiva para los productores argentinos porque permite la mejora continua de la gestión la transparencia de los procesos y la trazabilidad de la soja producida de forma sostenible.

Fuente: Elaboración propia a partir de AAPRESID $\left(2021_{[52]}\right)$, Asociación Argentina de Productores en Siembra Directa, https://www.aapresid.org.ar/ y RTRS (2021 $\left.{ }_{[53]}\right)$,Asociación Mesa de Soja Responsable, https:// responsiblesoy.org/soja-rtrs.

La producción y distribución del café representa otra prometedora cadena de valor. El mercado mundial de productos relacionados con el café crece de forma continuada, y la diferenciación de los productos se basa no solo en los atributos organolépticos del producto, sino también en su impacto ambiental y su grado de sostenibilidad. Se está desarrollando un complejo sistema de etiquetas de calidad, guías, clasificaciones, rankings y redes para ayudar a los consumidores a identificar sus productos. En América Central, se han desarrollado diferentes estrategias que se centran en especialidades y productos sostenibles. La cadena cafetera mesoamericana es una de las más sólidas desde un punto de vista económico y social, además de ser una de las mejor organizadas dentro del sistema alimentario regional. Constituida por unos 380000 productores (más del 90\% pequeños agricultores), esta cadena ocupaba en 2020 cerca de 1.15 millones de hectáreas en la región y representaba el 2.3\% de los ingresos por exportaciones (3 965 millones de USD), si bien en Honduras constituía el 8.61\% y en Guatemala casi el 5\% (Tabla 3.2). Esta cadena de valor atestigua el desarrollo de las especialidades, con un alto nivel de sofisticación en sus fases de producción primaria, acopio y almacenamiento para obtener un producto diferenciado y de alta calidad. Esta especialización cuenta con tecnologías avanzadas en la fase de producción, que son aplicadas por los productores más innovadores y de mayor tamaño. Este modelo permite aprovechar un ecosistema de bosques en altura, que resulta muy relevante y de gran valor desde el punto de vista de la biodiversidad. Las zonas de producción cuentan con infraestructuras básicas y están relativamente cerca del mercado estadounidense, lo que supone una importante ventaja competitiva. Otra peculiaridad de esta cadena es que está conectada con la "cadena de las cafeterías", que 
está evolucionando rápidamente hacia una economía de servicios, como demuestra el hecho de que más del $50 \%$ del volumen producido esté certificado, o que algunos países y empresas hayan evolucionado hacia el segmento más avanzado, la gestión de marcas y tiendas de consumo final, siendo el caso más destacado el de la Federación de Cafeteros de Colombia (500 000 asociados) y su marca Juan Valdez (Recuadro 3.4).

Tabla 3.2. Países productores de café en América Central: superficie cosechada, producción, rendimiento y número de productores, 2020

\begin{tabular}{lccc}
\hline Países & $\begin{array}{c}\text { Superficie cosechada (2020) } \\
\text { Hectárea }\end{array}$ & $\begin{array}{c}\text { Producción (2020) } \\
\text { Toneladas }\end{array}$ & $\begin{array}{c}\text { Explotaciones } \\
\text { n. }^{\circ}\end{array}$ \\
\hline Guatemala & 422445 & 225000 & 125000 \\
Honduras & 350000 & 377200 & 144000 \\
Nicaragua & 126154 & 150615 & 44519 \\
Costa Rica & 93697 & 86804 & 29918 \\
El Salvador & 140018 & 34045 & 24627 \\
Panamá & 1663060 & 9200 & 8973 \\
Total región & 1148944 & 884033 & 377037 \\
\hline
\end{tabular}

Fuente: Elaboración propia a partir de datos de: INE, 2020; USDA, 2020; ICO, 2021a; ICO, 2021b; INIDE, 2011; PROMECAFE, 2021; ICAFE, 2020; CSC, 2021; MIDA, 2020; ASAMBLEA NACIONAL, 2020; MIDA, 2020.

\section{Recuadro 3.4. Experiencias latinoamericanas de las nuevas tendencias - Juan Valdez y Britt}

\section{El caso de Colombia}

En 2002, la Federación Nacional de Cafeteros de Colombia creó la marca Juan Valdez para su red de cafeterías y negocios de valor agregado. El objetivo de estas cafeterías es vender café de primera calidad para posicionar el producto como parte del patrimonio de Colombia. A raíz de la popularidad de la marca y su distribución en tiendas nacionales, los productos Juan Valdez se expandieron al comercio minorista colombiano y a los mercados internacionales. Para el 2019, Juan Valdez contaba con 445 tiendas en todo el mundo, de las cuales 313 en Colombia y 132 en otros 13 países (Federación Nacional de Cafeteros de Colombia, $\left.2019_{[54]}\right)$.

Los productos que se ofrecen a través de estos canales de distribución son cafés selectos envasados; cafés premium, de origen y especiales; sobres y bolsitas (sobres individuales de café); y café liofilizado (Portafolio, $2017_{[55]}$ ).

\section{El caso de Costa Rica}

Costa Rica ha producido uno de los mejores cafés del mundo durante más de un siglo. Sin embargo, antes de Café Britt, todo el café gourmet se exportaba mientras que el café de baja calidad se distribuía en el mercado nacional. A diferencia de la mayor parte de la producción de café, que se vende en los países no productores, las variedades de Café Britt se cultivan, se tuestan y se envasan en el país de origen, Costa Rica (El Financiero, 2016 ${ }_{[56]}$ ). En la década de 1990, Britt optó por centrarse en el segmento de las terminales aéreas, utilizando carritos de golf como quioscos para vender su café preparado y embolsado. Esta estrategia demostró el potencial de estar presente en los aeropuertos, y en 2001, la empresa abrió su primera Britt Shop. En 2017, Britt inauguró su primera cafetería, y para el 2019 contaba con ocho establecimientos en Costa Rica y dos en el extranjero (Fallas Villalobos, $\left.2019_{[57]}\right)$. Asimismo, la empresa costarricense cuenta con 135 establecimientos en terminales aeroportuarias, que generan la mayor parte de sus ingresos. Los productos que ofrecen son café gourmet envasado, de origen, orgánico, espresso y en cápsulas, así como maquinaria para preparar café, entre otros (Mosere, 2021 ${ }_{[58]}$ ). 
Tanto la cadena de la soja como la del café presentan diferentes niveles de complejidad que varían en cada país, ya que siguen trayectorias tecnológicas específicas que responden a sus recursos naturales básicos, así como a sus leyes y esquemas institucionales. Ambas cadenas enfrentan severos desafíos ambientales e incluyen miles de empresas que están sujetas a la volatilidad de precios y otras inestabilidades propias de la actividad agrícola. La defensa y el desarrollo de estas cadenas de valor requiere de políticas públicas adecuadas, el desarrollo de normas regionales y nuevos acuerdos productivos y comerciales que permitan la creación de un mercado de productos agrícolas, para evitar la mercantilización de las especialidades en los mercados globales. La coordinación a nivel regional-sectorial es clave para añadir valor, desarrollar vínculos regionales, aumentar la incorporación de conocimientos y la sostenibilidad. El sector agroalimentario de la región requiere un conjunto de políticas coordinadas que combinen incentivos para estimular las inversiones en actividades innovadoras con subvenciones para absorber los cambios que se están produciendo a nivel mundial.

\section{Economía circular: nuevas oportunidades para crear valor}

La transición ecológica mundial ya no es un objetivo lejano. Los países están tomando medidas para lograr sus objetivos de cero emisiones netas y cumplir con el acuerdo de París. Aunque la transición a la energía sostenible dará lugar a importantes reducciones de las emisiones de carbono, no será suficiente para cumplir los objetivos climáticos mundiales. De hecho, las investigaciones han demostrado que si nos basamos únicamente en la eficiencia energética y en la transición a las energías renovables, solo abordaremos el 55\% de las emisiones mundiales de GEI. El 45\% restante es resultado directo de la forma en que fabricamos y utilizamos los productos y los alimentos, y este porcentaje puede reducirse significativamente mediante estrategias circulares (Ellen MacArthur Foundation, $2021_{[59]}$ ). El objetivo de conseguir cero emisiones es ambicioso y no puede alcanzarse con nuestro modelo económico actual.

Para construir un mundo sostenible, debemos rediseñar la economía de manera fundamental y sustituir nuestro enfoque lineal ("tomar, hacer, desperdiciar"), creando una economía circular que promueva la sostenibilidad por diseño. De este modo se reduciría el carbono, se disminuiría la contaminación y se protegería la biodiversidad. La economía circular es un elemento clave en la crisis climática, ya que puede contribuir a la vez a reducir las emisiones y a aumentar la resiliencia al cambio climático.

El enfoque de la economía circular ha ido ganando impulso en la región desde 2019. En el Foro de Ministros de Medio Ambiente de América Latina y el Caribe se anunciaron una serie de propuestas para establecer una Coalición Regional de Economía Circular. Esta coalición se creó oficialmente en 2021 para establecer una visión y una estrategia circular en la región (Recuadro 3.5) y se han implantado más de 80 iniciativas de políticas públicas en los países de ALC (p. ej., la estrategia nacional de economía circular en Colombia o el plan nacional de economía circular en Uruguay).

\section{Recuadro 3.5. Coalición regional sobre economía circular}

Colombia, Costa Rica, Perú y República Dominicana forman parte del primer comité rector de esta iniciativa, que busca avanzar hacia una economía respetuosa con el entorno en la que se elimine la contaminación y se permita la regeneración de los sistemas naturales, ayudando a proteger la biodiversidad y a combatir el cambio climático.

La iniciativa, coordinada por el Programa de las Naciones Unidas para el Medio Ambiente (PNUMA), está dirigida por un comité rector compuesto por cuatro representantes 


\section{Recuadro 3.5. Coalición regional sobre economía circular (cont.)}

gubernamentales de alto nivel que se renovarán cada dos años, empezando por Colombia, Costa Rica, Perú y la República Dominicana para el periodo 2021-2022.

La iniciativa cuenta con ocho socios estratégicos permanentes: el Centro y Red de Tecnología del Clima (CRTC), la Fundación Ellen MacArthur, el Banco Interamericano de Desarrollo (BID), la Fundación Konrad Adenauer (KAS), la Plataforma para Acelerar la Economía Circular (PACE), la Organización de las Naciones Unidas para el Desarrollo Industrial (ONUDI), el Foro Económico Mundial (FEM) y el PNUMA.

La coalición tiene como objetivo convertirse en una plataforma regional que permita mejorar la cooperación interministerial, multisectorial y de múltiples partes interesadas, y aumentar los conocimientos y la comprensión sobre la economía circular. Ya ha comenzado a trabajar con los países de ALC para desarrollar una visión circular regional 2030.

Fuente: Coalición de Economía Circular de América Latina y el Caribe $\left(2021_{[60]}\right)$, Estructura de Gobernanza, https://www.coalicioneconomiacircular.org/en/elementor-7/inicio-english/.

La economía circular se basa en tres principios, todos ellos impulsados por el diseño y la innovación en las fases iniciales: eliminar los residuos y la contaminación, mantener los productos y materiales en uso y regenerar los sistemas naturales. La sostenibilidad medioambiental también significa aumentar la eficiencia en la extracción y el uso de los recursos de una economía y reducir la producción de residuos. En una economía circular, se intenta mejorar la eficiencia y la vida útil de los materiales promoviendo la durabilidad y la capacidad de reparar, refabricar, reutilizar y reciclar los bienes y productos. Estos cambios se promueven a través del diseño de los productos y de los modelos de negocio, garantizando así que su reparación, reciclaje, refabricación o uso compartido resulte más fácil y rentable mediante la prestación de servicios (Ellen MacArthur Foundation, 2013 ${ }_{[61]}$ ).

Los escenarios de economía circular son especialmente relevantes para la región de América Latina y el Caribe, dado el peso económico de los sectores extractivos. Un escenario que incluya un aumento de las tasas de reciclaje implicará una reducción de la demanda de extracción y un aumento de la demanda de servicios asociados a la gestión de residuos y a la refabricación de materiales. Además, aun cuando se implantara plenamente la circularidad, la demanda de materiales vírgenes seguiría (CEPAL, $2020_{[28]}$ ). Estas tendencias pueden observarse como una oportunidad para ALC. El aumento de la circularidad en el sector de los minerales y metales no implica la desaparición de las actividades extractivas, sino que sería un complemento de las mismas.

En el contexto de la transformación económica mundial y la necesidad de transformación estructural de la región, las políticas e inversiones de economía circular podrían desempeñar un papel fundamental. La economía circular se considera un instrumento clave para alcanzar los Objetivos de Desarrollo Sostenible (ODS) de la Agenda 2030, dado que propone disociar el crecimiento económico de la explotación de unos recursos naturales finitos y del uso de la energía.

Por tanto, la economía circular es una estrategia importante para respaldar el desarrollo regional basado en la expansión de las actividades manufactureras en la región, al tiempo que constituye el marco en el que se fomentará la agricultura sostenible y la bioeconomía. ALC se enfrenta al doble reto de perseguir el desarrollo socioeconómico y reducir las emisiones de GEI. En ese contexto, Gramkow and Anger-Kraavi $\left(2019_{[62]}\right)$ pusieron de manifiesto que los estímulos fiscales "verdes" en los sectores manufactureros a nivel mundial deben considerarse una de las principales medidas de políticas para 
contribuir a la transformación hacia una economía baja en carbono, sobre todo en los países en desarrollo. Las políticas de recuperación basadas en los incentivos a la inversión en tecnologías de bajas emisiones de carbono en los sectores manufactureros pueden conseguir una importante reducción de las emisiones de $\mathrm{CO}_{2}$ al tiempo que ayudan a mejorar los resultados económicos al impulsar la actividad, contribuyendo así a diversificar la estructura productiva y mejorando la balanza comercial. Las políticas orientadas al denominado "Gran Impulso Ambiental" también ampliarían de forma considerable el tamaño relativo de la industria en la estructura económica. El valor agregado por todos los sectores manufactureros aumenta en mayor medida en las industrias de tecnologías bajas e intermedias (Gramkow y Anger-Kraavi, 2019 ${ }_{[62]}$; CEPAL, 2020 ${ }_{[28]}$ ). Este modelo muestra que la adopción de políticas acertadas podría ayudar a abordar las emisiones de GEI y contribuir al mismo tiempo al cambio estructural de la región.

$\mathrm{Al}$ abordar las ineficiencias estructurales en las cadenas de suministro, la economía circular ofrece abundantes oportunidades de creación de valor a nivel industrial. Los estudios realizados sugieren que la transición a una economía circular podría generar un beneficio económico neto de 1.8 billones de euros en Europa para el año 2030 (Ellen MacArthur Foundation, $\left.2021_{[63]}\right)$. La transición hacia una economía circular -en la que los materiales sean más eficientes y tengan una vida útil más prolongada al fomentar su durabilidad y su capacidad para reparar, remanufacturar, reutilizar y reciclar los productos-crearía puestos de trabajo en la región. En ALC, la adopción de un escenario de economía circular generaría un total neto de 4.8 millones de empleos para el año 2030 (OIT/BID, 2020 $\left.{ }_{[64]}\right)$. La creación de empleo en sectores como el reprocesamiento de madera, acero, aluminio y otros metales compensaría con creces las pérdidas asociadas a la extracción de minerales y otros materiales. Estos aumentos de empleo se deben a que la cadena de valor del reprocesamiento es más larga y más intensiva en mano de obra que la de la minería (CEPAL y OIT, $2018_{[65]}$ ).

\section{Conclusión}

La crisis del COVID-19 ha demostrado que la estructura de producción actual en América Latina y el Caribe actúa como un factor limitante para el crecimiento de la productividad, la profundización de la integración regional y la sostenibilidad. ALC no ha sido capaz de lograr ganancias de productividad a largo plazo que le permitan mantener un mayor crecimiento. Esta situación se debe principalmente a la escasa diversificación de la estructura productiva de la región, que se concentra en sectores de bajo valor agregado. La mayoría de los países de ALC participan en las redes de producción mundiales como proveedores de materias primas y productos manufactureros básicos, y solo unos pocos han diversificado su estructura productiva y se han convertido en actores clave de las redes de producción mundiales.

La integración regional sigue constituyendo una oportunidad desaprovechada para diversificar la estructura productiva y lograr un mayor crecimiento de la productividad. No obstante, la integración regional debe ir más allá de la integración de los mercados y aspirar a desarrollar las capacidades productivas y las cadenas de valor de la región. Para superar la fragmentación del mercado regional, será necesario adoptar importantes esfuerzos en materia de política industrial y facilitar la convergencia entre las instituciones y mecanismos de integración existentes. En este sentido, algunos sectores específicos clave como el farmacéutico, el automotriz, el energético, el de la economía circular o el de la agricultura sostenible pueden marcar el camino a seguir. Del mismo modo, la integración regional y la adopción de políticas coordinadas serán clave para garantizar la creación de oportunidades digitales que puedan transformar la estructura productiva y desarrollar las capacidades de producción locales y regionales (Recuadro 3.6). 


\section{Recuadro 3.6. Principales mensajes en materia de políticas}

- Promover las capacidades de producción y las cadenas de valor regionales.

- Impulsar un mayor comercio intrarregional que desempeñe un importante papel en la diversificación económica, el desarrollo de las capacidades manufactureras y la internacionalización de las pymes.

- Ir más allá de la integración de los mercados y los resultados comerciales. El desarrollo de las capacidades de producción y de las cadenas de valor regionales es clave para impulsar los vínculos productivos internacionales, fomentar el desarrollo económico y aumentar el bienestar de los ciudadanos.

- Promover la industrialización de la región a través de la complementariedad de la producción. De este modo se incrementaría el comercio intrarregional de productos manufacturados y se reduciría la dependencia de las exportaciones de productos básicos.

- Implantar políticas industriales y productivas para reforzar las capacidades existentes, generar nuevas industrias y promover la producción regional y las redes de investigación. La regionalización y las redes de producción regionales ofrecen la oportunidad de fomentar el crecimiento de la productividad, incrementar los salarios e impulsar unos mercados laborales inclusivos, al tiempo que redefinen la conexión e integración de la región en los centros internacionales de producción e innovación.

- Promover la convergencia de las instituciones y los mecanismos de integración, ofreciendo así una oportunidad para impulsar la inversión, desarrollar la capacidad productiva y superar la fragmentación del mercado regional.

- Promover la transformación digital, dado que puede desempeñar un papel importante en la recuperación de la región al abordar el persistente desafío de la baja productividad (OCDE et al., 2021). A pesar de que la pandemia del COVID-19 ha acelerado este proceso, la incorporación de las tecnologías digitales en los procesos productivos sigue estando rezagada en la región. Las estrategias de integración regional y la adopción de políticas coordinadas serán fundamentales para garantizar la creación de oportunidades en el entorno digital.

- Impulsar estrategias de recuperación del COVID-19 que se centren en la sostenibilidad y la transición ecológica, que promuevan un papel destacado de las políticas industriales y den un fuerte impulso hacia una mayor autosuficiencia nacional o regional.

- Identificar junto a actores relevantes los principales sectores que puedan liderar la integración y las capacidades de producción regionales. Las políticas de integración de la producción requieren un enfoque integrado que, en gran medida, deberá ser específico para cada sector. Por ello, resulta útil centrarse en las experiencias sectoriales de la región para extraer lecciones e identificar futuras oportunidades.

\section{Notas}

1. La importancia de los efectos indirectos interindustriales y transregionales ha cobrado cada vez más importancia en la literatura sobre organización industrial y desarrollo económico (Gao, Pentland e Hidalgo, 2021 $1_{[66]}$ ).

2. El mercado farmacéutico latinoamericano ha experimentado un crecimiento continuado en los últimos cinco años y en 2019 constituía cerca del 4\% de los ingresos del mercado farmacéutico mundial.

3. Aprobado a través de la resolución AFIP 3823/2015. 
4. En la actualidad Colombia es el único país andino que mantiene un sector automotriz de cierta relevancia.

\section{Referencias}

AAPRESID (2021), Asociación Argentina de Productores en Siembra Directa, https://www.aapresid.org. ar/.

Amar, A. y F. García Díaz (2018), Integración productiva entre la Argentina y el Brasil: Un análisis basado en metodologías de insumo-producto interpaís, Naciones Unidas, https://www.cepal.org/sites/default/ files/publication/files/43623/S1800116_es.pdf.

CEPAL (2021), La paradoja de la recuperación en América Latina y el Caribe. Crecimiento con persistentes problemas estructurales: desigualdad, pobreza, poca inversión y baja productividad, Publicación de las Naciones Unidas, Santiago, https://repositorio.cepal.org/bitstream/handle/11362/47043/5/ S2100379 es.pdf.

CEPAL (2021), Perspectivas del Comercio Internacional de América Latina y el Caribe 2020: la integración regional es clave para la recuperación tras la crisis, Publicación de las Naciones Unidas, Santiago, https://repositorio.cepal.org/bitstream/handle/11362/46613/1/S2000805_es.pdf.

CEPAL (2021), Post Pandemic Covid-19: Enabling Latin America And The Caribbean To Better, Publicación de las Naciones Unidas, Santiago, https:/www.cepal.org/sites/default/files/publication/ files/46858/S2100269 en.pdf.

CEPAL (2021), Tecnologías digitales para un nuevo futuro, Publicación de las Naciones Unidas, Santiago, https://repositorio.cepal.org/bitstream/handle/11362/46816/1/S2000961_es.pdf.

CEPAL (2020), Construir un nuevo futuro: una recuperación transformadora con igualdad y sostenibilidad, Publicación de las Naciones Unidas, Santiago, https://repositorio.cepal.org/bitstream/ handle/11362/46225/1/S2000667 es.pdf.

CEPAL (2020), International Trade Statistics Database, Publicación de las Naciones Unidas, Santiago, https://comtrade.un.org.

CEPAL (2020), La Inversión Extranjera Directa en América Latina y el Caribe 2020, Publicación de las Naciones Unidas, Santiago, https://repositorio.cepal.org/bitstream/handle/11362/46450/2/S2000595 es.pdf.

CEPAL (2020), Los efectos del COVID-19 en el comercio internacional y la logística, Publicación de las Naciones Unidas, Santiago, https://repositorio.cepal.org/bitstream/handle/11362/45877/1/ S2000497_es.pdf.

CEPAL (2020), Matrices Globales de Insumo-Producto: Herramientas para facilitar el estudio de la Integración de América Latina con el mundo, Publicacion de las Naciones Unidas, Santiago, https://www. cepal.org/es/eventos/matrices-globales-insumo-producto-herramientas-facilitar-estudio-laintegracion-america.

CEPAL (2020), Sectores y empresas frente al COVID-19: emergencia y reactivación, Publicación de las Naciones Unidas, Santiago, https://repositorio.cepal.org/bitstream/handle/11362/45734/4/ $\underline{\mathrm{S} 2000438 \text { es.pdf. }}$

CEPAL (2020), Universalizar el acceso a las tecnologías digitales para enfrentar los efectos del COVID-19, Publicación de las Naciones Unidas, Santiago, https://repositorio.cepal.org/bitstream/ handle/11362/45938/4/S2000550_es.pdf.

CEPAL (2018), La Inversión Extranjera Directa en América Latina y el Caribe 2018, Publicación de las Naciones Unidas, Santiago, https://repositorio.cepal.org/bitstream/handle/11362/43689/13/ S1800684 es.pdf.

CEPAL (2014), Integración regional: hacia una estrategia de cadenas de valor inclusivas, Publicación de las Naciones Unidas, Santiago, https://repositorio.cepal.org/bitstream/handle/11362/36733/1/ S2014216 es.pdf.

CEPAL (1959), The Latin American Common Market, Publicación de las Naciones Unidas, Santiago, https://repositorio.cepal.org/bitstream/handle/11362/29176/S5900027_en.pdf?sequence $=1 \&$ is Allowed $=\mathrm{y}$.

CEPAL y OIT (2018), Coyuntura Laboral en América Latina y el Caribe: sostenibilidad medioambiental con empleo en América Latina y el Caribe, Publicación de las Naciones Unidas, Santiago, https://repositorio.cepal.org/bitstream/handle/11362/44185/1/S1800886_es.pdf.

CEPAL y Red de Políticas de Internet y Jurisdicción (2020), Red de Políticas de Internet y Jurisdicción y Comisión Económica para América Latina y el Caribe (CEPAL): informe sobre la situación regional 2020, Publicación de las Naciones Unidas, Santiago, https://repositorio.cepal.org/bitstream/ handle/11362/46812/1/S1901093 es.pdf. 
Cimoli, M. et al. (2005), Cambio estructural, heterogeneidad productiva y tecnología en América Latina, Naciones Unidas, http://hdl.handle.net/11362/2800.

Closset, M. y V. Leiva (2021), La especialización sectorial, un determinante clave de la brecha de productividad entre mipymes y grandes empresas: El caso de México, Naciones Unidas, https://www.cepal.org/sites/ default/files/publication/files/46815/S2100216 es.pdf.

Coalición de Economía Circular(2021), "Estructura de Gobernanza”, https://www.coalicioneconomia circular.org/estructura-de-gobernanza/.

COMEX y CEPAL (2021), Valor agregado y empleo inducido por el sector exportador de Costa Rica, Nota de política, https://www.cepal.org/es/publicaciones/46922-valor-agregado-empleo-inducidosector-exportador-costa-rica-nota-politica.

Cullen International (2016), Hacia la estrategia para el mercado único digital de América Latina, Banco de Desarrollo de América Latina (CAF), Buenos Aires, http://scioteca.caf.com/handle/ $123456789 / 997$.

Delgado, D. et al. (2020), "Personal Safety during the COVID-19 Pandemic: Realities and Perspectives of Healthcare Workers in Latin America", Int. J Environ. Res. Public Health, 17 (2798), Vol. 17/8, http://dx.doi.org/10.3390/ijerph17082798. PMID: 32325718; PMCID: PMC7216115.

Dossi, G. (1984), Technical Change and Industrial Transformation: The theory and an Application to the semiconductor industry, Palgrave Macmillan, http://dx.doi.org/10.1007/978-1-349-17521-5. [16]

EIA (2018), International Energy Outlook 2018, U.S. Energy Information Administration, https://www. eia.gov/outlooks/ieo/executive_summary.php.

El Financiero (2016), Grupo Britt consolida su presencia en aeropuertos y llegará a nuevos países, https://www.elfinancierocr.com/negocios/grupo-britt-consolida-su-presencia-en-aeropuertos -y-llegara-a-nuevos-paises/S7J4FTWLRFBMNIZZAXUMQL5O34/story/.

Ellen MacArthur Foundation (2021), Growth within: a circular economy vision for a competitive Europe, https://ellenmacarthurfoundation.org/growth-within-a-circular-economy-vision-for-acompetitive-europe.

Ellen MacArthur Foundation (2021), The Big Food Redesign Study, https://ellenmacarthurfoundation. org/the-big-food-redesign-study.

Ellen MacArthur Foundation (2013), “Towards the circular economy”, Journal of Industrial Ecology 2, pp. 23-44.

Energy Policy Tracker (2021), Report, IISD International Institute for Sustainable Development, https://www.energypolicytracker.org/region/g20/.

Eurostat (2021), International trade in goods - a statistical picture, https://ec.europa.eu/eurostat/ statistics-explained/index.php?title=International trade_in_goods_-_a_statistical_picture. [9]

Fallas Villalobos, C. (2019), CEO de Britt confía en que abrirán más cafeterías dentro y fuera del país, https:/www.elfinancierocr.com/negocios/ceo-de-britt-confia-en-que-abriran-mas-cafeterias/ HLEQPBABB5BU7A44P4KRVMPUKE/story/.

FAO (2021), FAOSTAT [En línea], http://dx.doi.org/www.fao.org/faostat/en/\#home.

FAO y CEPAL (2020), Sistemas alimentarios y COVID-19 en América Latina y el Caribe: Impacto y riesgos en el mercado laboral, http://www.fao.org/3/ca9237en/ca9237en.pdf.

Federación Nacional de Cafeteros de Colombia (2019), Juan Valdez, 'La marca de todo un país', https://federaciondecafeteros.org/wp/listado-noticias/juan-valdez-la-marca-de-todo-unpais/\#: :text=\%C2\%B7\%20Juan\%20Valdez\%20ha\%20conquistado\%20el,132\%20en\%20otros \%2013\%20pa\%C3\%ADses (accessed on 2021).

Feinberg y Majumdar (2001), "Technology Spillovers from Foreign Direct Investment in the Indian Pharmaceutical Industry", Journal of International Business Studies, Vol. 32/3, pp. 421-437, http://dx.doi.org/doi:10.1057/palgrave.jibs.8490975.

Fraunhofer (2018), Biological Transformation and Bioeconomy, Fraunhofer, Munich, Alemania, http://www.fraunhofer.cn/en/uploads/soft/190806/whitepaper-biological-transformation-andbioeconomy.pdf.

Gao, J., Z. Pentland y C. Hidalgo (2021), “Spillovers across industries and regions in China's regional economic diversification”, Regional Studies, pp. 1-16, http://dx.doi.org/doi:10.1080/00343. [66]

Gramkow, C. y A. Anger-Kraavi (2019), "Developing green: a case for the Brazilian manufacturing industry”, Sustainibility, Vol. 11/23, https://doi.org/10.3390/su11236783.

Grupp, H. y M. Mogee (2004), "Indicators for national science and technology policy: how robust are composite indicators?”, Research Policy, Vol. 33/9, pp. 1373-1384, http://dx.doi.org/10.1016/j. [31]

Grupp, H. (1996), "Spillover effects and the science base of innovations reconsidered: an empirical approach", Journal of Evolutionary Economics, pp. 175-197, http://dx.doi.org/doi:10.1007/. 
IPBES (2019), Global assessment report on biodiversity and ecosystem services of the Intergovernmental Science-Policy Platform on Biodiversity and Ecosystem Services, https://doi.org/10.5281/zenodo. 3553579.

IRENA (2018), Estadísticas de Capacidad Renovable, International Renewable Energy Agency (IRENA), Abu Dhabi, https://www.irena.org/-/media/Files/IRENA/Agency/Publication/2018/Mar/IRENA RE Capacity Statistics 2018.pdf.

MERCOSUR (2020), Agenda Digital del Mercosur, 2018-2020, https://cetic.br/media/docs/publicacoes/ 17/20200804155338/Agenda_Digital_del_Mercosur_2018_2020\%20Panorama_de_los_Indicadores Disponibles.pdf.

Mosere (2021), Mosere: Spirit of taste, https://mosere.co/cafe-pod.

OCDE (2007), The Visible Hand of China in Latin America, Publicaciones de la OCDE, París, https://doi. org/10.1787/9789264028388-en.

OCDE et al. (2020), Perspectivas económicas de América Latina 2020: Transformación digital para una mejor reconstrucción, Publicaciones de la OCDE, París, https://doi.org/10.1787/f2fdced2-es.

OIT/BID (2020), El empleo en un futuro de cero emisiones netas en América Latina y el Caribe, https://publications.iadb.org/publications/spanish/document/El-empleo-en-un-futuro-decero-emisiones-netas-en-America-Latina-y-el-Caribe.pdf.

Organización Internacional de Constructores de Automóviles (2021), Estadísticas de producción de automóviles 1950-2020, https://www.oica.net/category/production-statistics/.

PAHO (2010), Resolución CD50.R9 Strengthening National Regulatory Authorities for Medicines and Biologicals, PAHO, Washington, DC, https://www.paho.org/en/documents/cd50r9-strengthening-nationalregulatory-authorities-medicines-and-biologicals-2010.

Paredes, J. (2017), La Red del Futuro: Desarrollo de una red eléctrica limpia y sostenible para América Latina, Banco Interamericano de Desarrollo, http://dx.doi.org/10.18235/0000937.

Pinto, A. (1970), Naturaleza e implicaciones de la "heterogeneidad estructural" de la América Latina, Fondo de Cultura Economica/CEPAL, Santiago, http://hdl.handle.net/11362/2055.

Porcile, G. y M. Cimoli (2013), Tecnología, heterogeneidad y crecimiento: una caja de herramientas estructuralistas, Naciones Unidas, https://repositorio.cepal.org/bitstream/handle/11362/4592/1/ S2013731 es.pdf.

Portafolio (2017), “¿Qué es el Café Drip, el nuevo ritual para una taza de café?”, Tendencias, https://www.portafolio.co/tendencias/cafe-drip-el-nuevo-ritual-para-una-taza-de-cafe-503594. [55]

Rodríguez, A., A. Mondaini y M. Hitschfeld (2017), Bioeconomía en América Latina y el Caribe: Contexto global y regional y perspectivas, Naciones Unidas, https:/www.cepal.org/sites/default/files/ publication/files/42427/S1701022_es.pdf.

RTRS (2021), Asociación Mesa de Soja Responsable, https://responsiblesoy.org/soja-rtrs.

Shapiro, B. (1987), "Specialties versus Commodities. The Battle for Profit Margins", Harvard Business School, Resvisado Abril 1987.

SIMI (2021), Sistema integral de monitoreo de importaciones (SIMI), http://www.afip.gob.ar/simi/. [38]

Solano-Rodríguez, B. et al. (2019), Implications of climate targets on oil production and fiscal revenues in Latin America and the Caribbean, Banco Interamericano de Desarrollo, Washington DC, http://dx.doi.org/10.18235/0001802.

Statista (2020), Revenue of the worldwide pharmaceutical market from 2001 to 2020, https://www. statista.com/statistics/263102/pharmaceutical-market-worldwide-revenue-since-2001/. [34]

Sweet, C. (2017), "The Politics and Policis of Regulating Generics in Latin America: A Survey of Seventeen States", Journal of Health Politics, Policy and Law, Vol. 42/3, pp. 485-512, http://dx.doi.org/ doi:10.1215/03616878-3802953.

Sweet, C. (2013), “The Political Economy of Pharmaceuticals in Brazil”, Global Pharmaceuticals Politics and Production, pp. 29-47, https://doi.org/10.1057/9781137315854 2.

US Commercial Service (2019), International Healthcare Technologies Resource Guide, https://2016. export.gov/industry/health/healthcareresourceguide/index.asp.

Valverde, J. (2014), "Latin American pharmaceutical overview", Pharmaceuticals, Policy and Law, Vol. 16, pp. 179-206, http://dx.doi.org/doi:10.3233/PPL-140384.

Wilson, C. (2017), Growing Together: Economic Ties between the United States and Mexico, https://www. wilsoncenter.org/publication/final-report-growing-together-economic-ties-between-theunited-states-and-mexico. (accessed on March). 


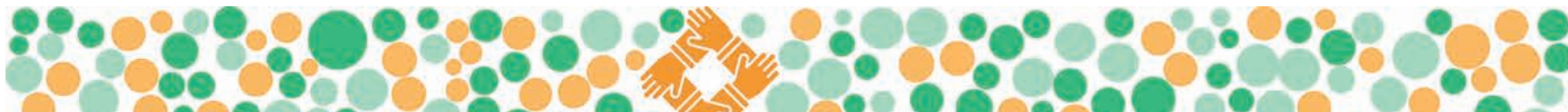
:00 O.

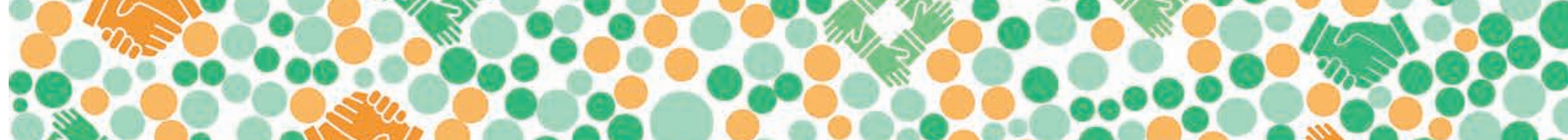

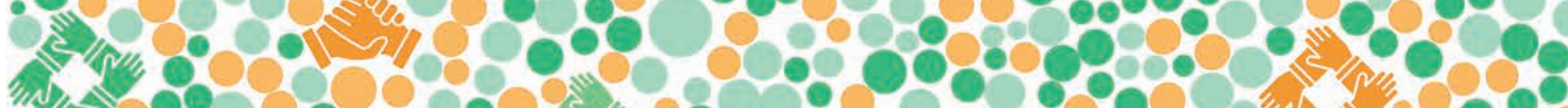

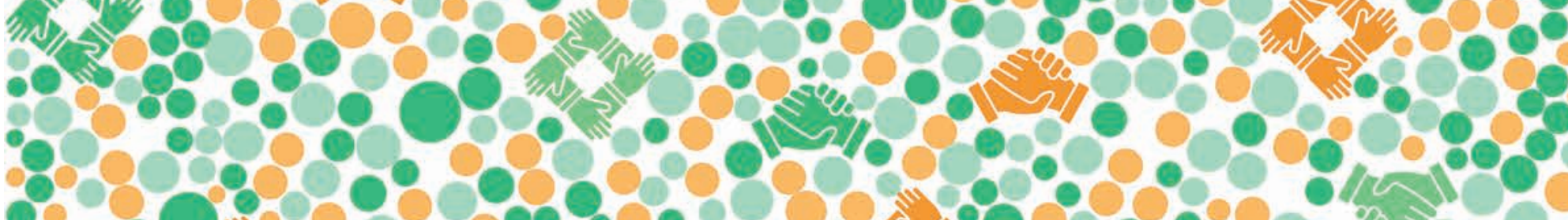

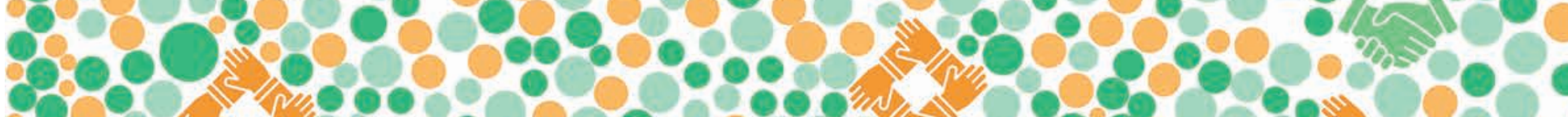

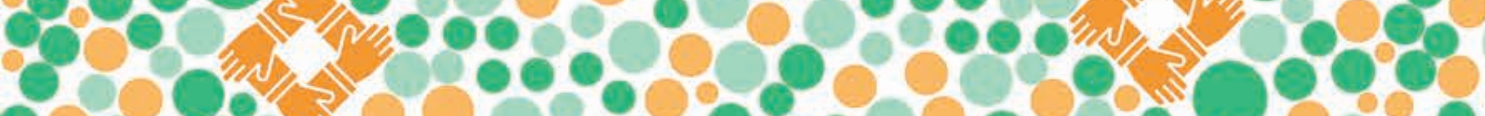

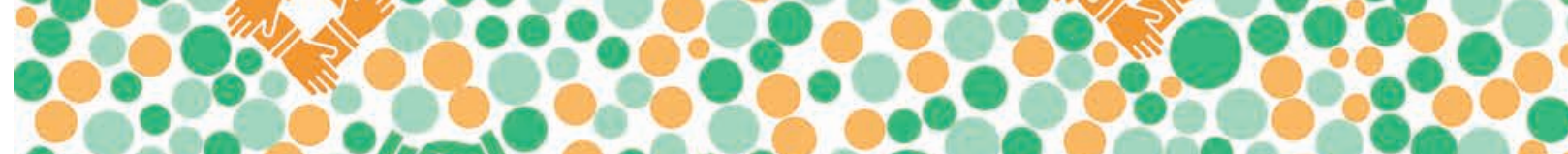
:36\%

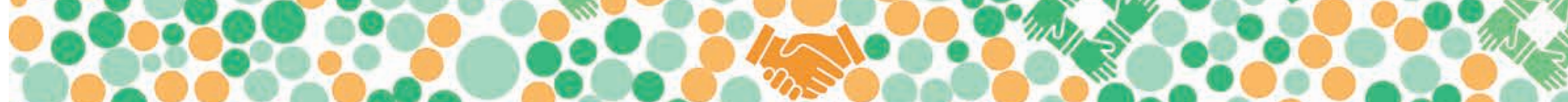
00000000000000000 :0\%

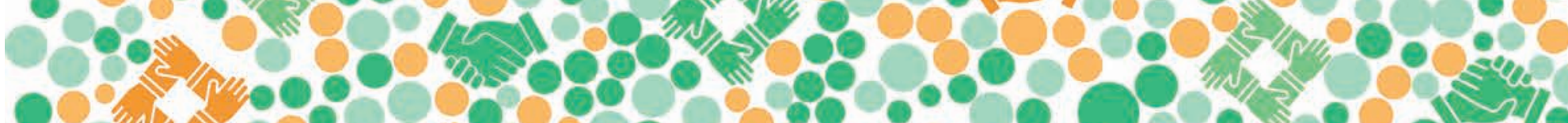

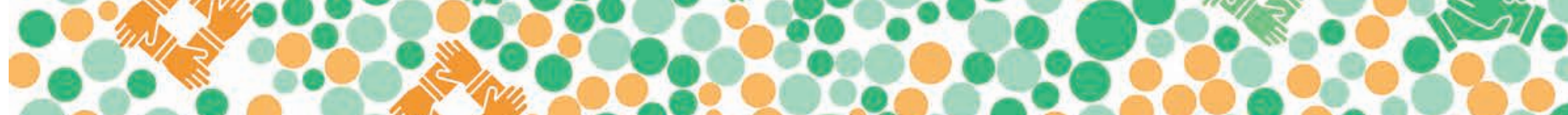

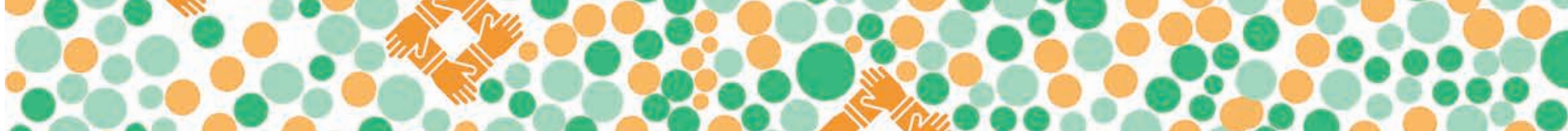

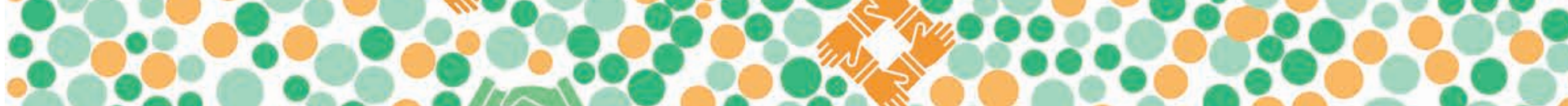

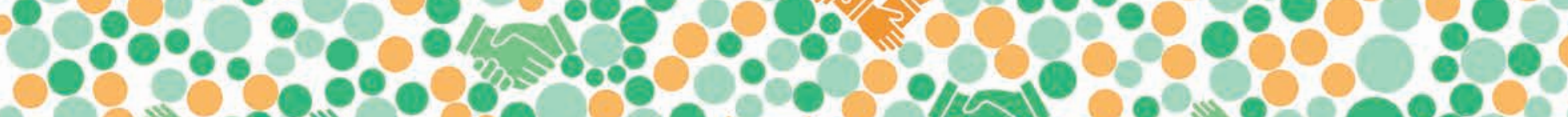
200 30003

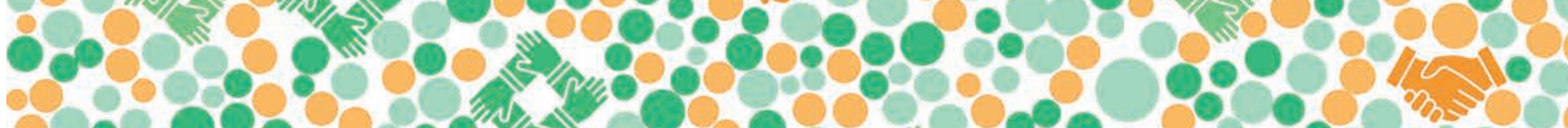
:080 0.000. 8.

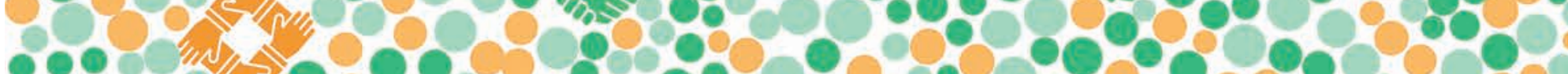

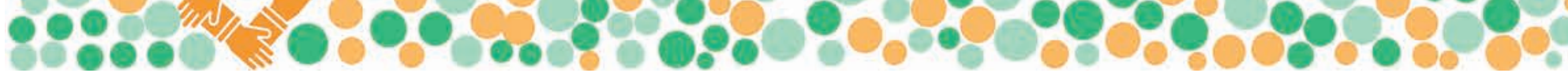




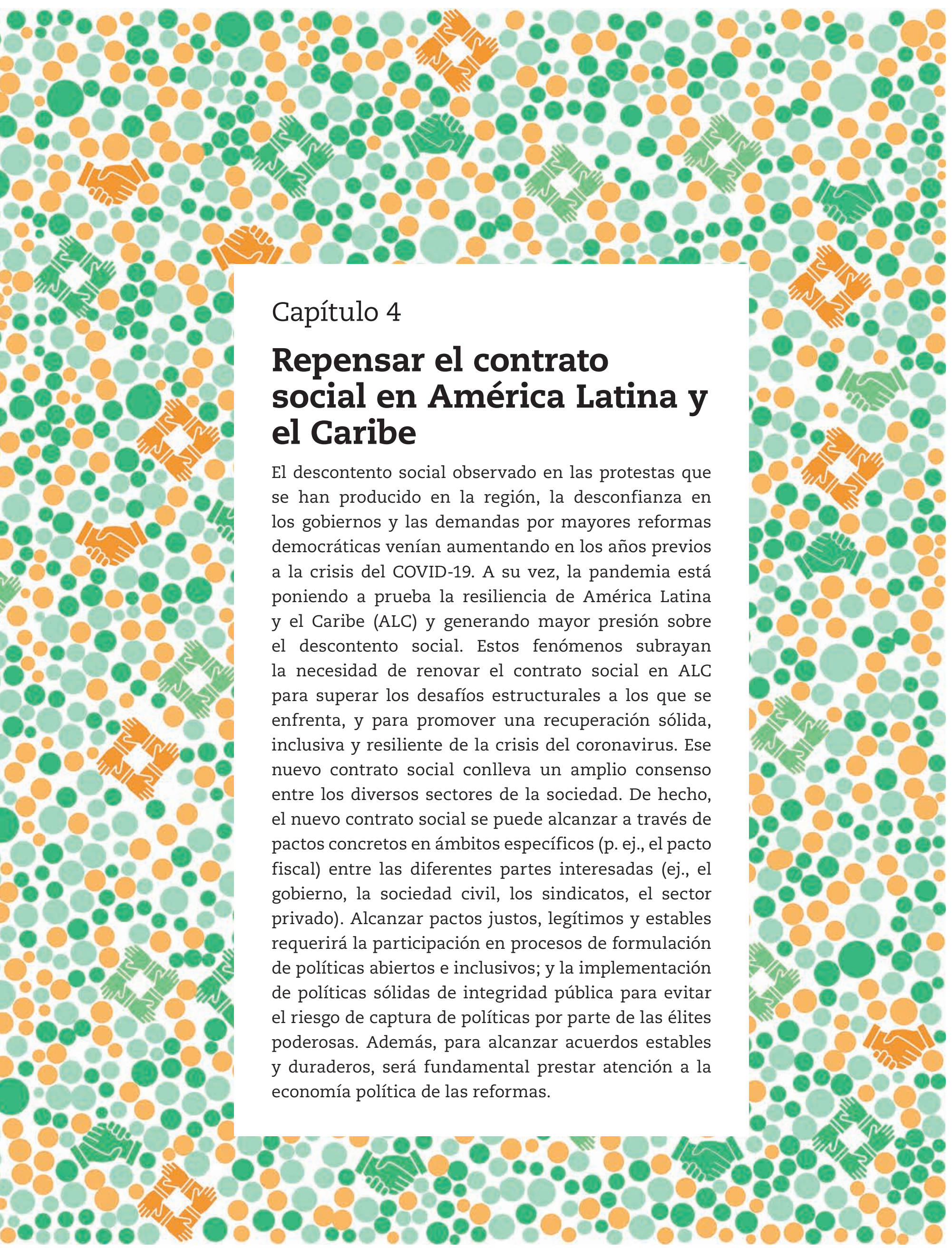




\section{Un nuevo contrato social para lograr una recuperación fuerte, inclusiva y resiliente}

¿Por qué un nuevo contrato social?

$$
\begin{gathered}
\text { Para reconstruir } \\
\text { la confianza } \\
\text { y reducir la } \\
\text { creciente brecha } \\
\text { entre los } \\
\text { ciudadanos y las } \\
\text { instituciones } \\
\text { públicas... }
\end{gathered}
$$

Media de satisfacción de ALC con:

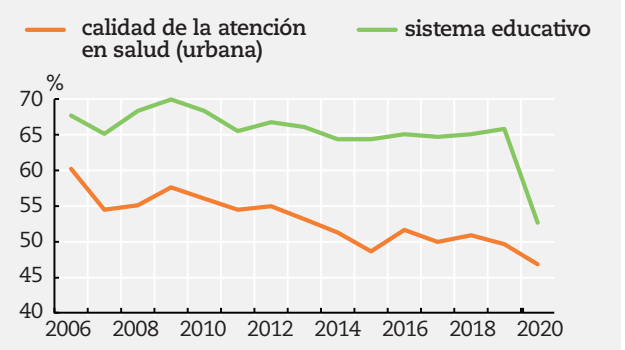

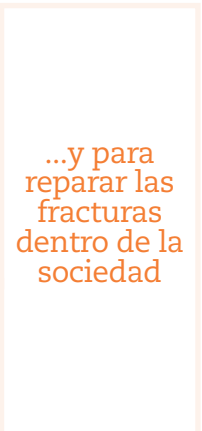

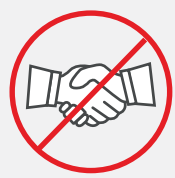

Solo el $12 \%$ de los ciudadanos de ALC confía en la mayoría de las personas

¿Qué tipo de contrato social se necesita?

Uno que construya un pacto transversal....
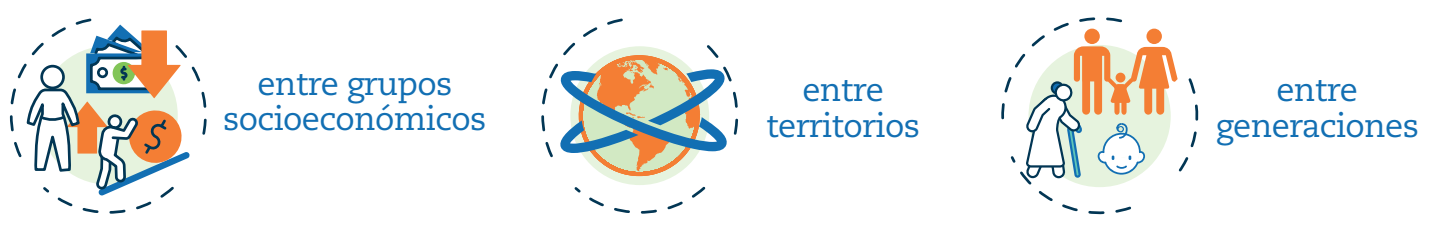

¿Cómo se puede implementar este contrato?

Mejorando el proceso y la secuencia de la reforma de políticas para lograr consensos

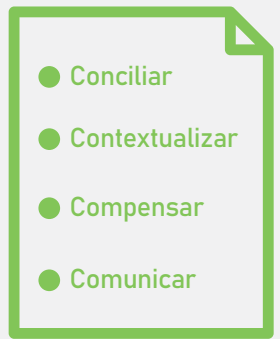

Superando las barreras estructurales para

la reforma de políticas

y su implementación

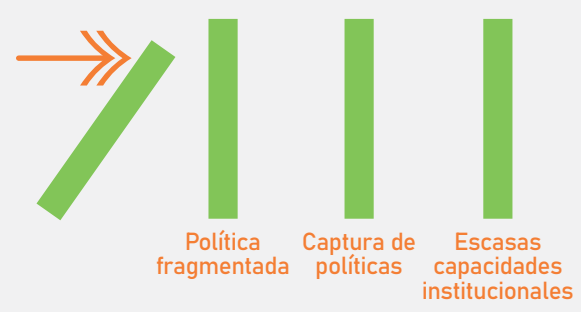

Enmarcándolo en un plan nacional de desarrollo a largo plazo
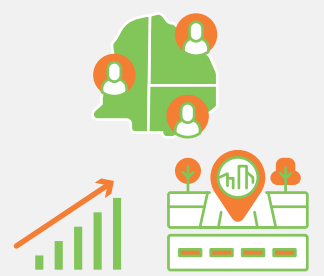


\section{Introducción}

Los tiempos de crisis exponen vulnerabilidades estructurales profundamente arraigadas. Este ha sido el caso en América Latina y el Caribe (ALC), donde el impacto del coronavirus (COVID-19) ha acentuado los desafíos multidimensionales estructurales en materia de desarrollo, lo que ha puesto a prueba la resiliencia de la región. De hecho, el fuerte impacto socioeconómico de la pandemia está agravando las cuatro trampas del desarrollo estructural a las que ya se enfrentaba ALC (OCDE, 2020 ${ }_{[1]}$; OCDE et al., 2019 ${ }_{[2]}$ ).

En este contexto, los fundamentos del modelo de desarrollo han demostrado su debilidad y han sido objeto de un especial escrutinio por parte de los ciudadanos. Antes de la pandemia, las crecientes aspiraciones de los ciudadanos por una mejora de las condiciones de vida ya apuntaban a la necesidad de rediseñar los pilares que habían sostenido el progreso socioeconómico durante los años de bonanza, desde mediados de la década del 2000. El aumento del descontento social, puesto de manifiesto por la ola de protestas que tuvo lugar a finales de 2019, confirmó la necesidad de alcanzar un nuevo consenso global entre los ciudadanos y de reducir la brecha entre la sociedad y las instituciones públicas. Si bien al inicio del COVID-19 hubo un aumento de la confianza en muchos gobiernos, impulsado por su rápida reacción para contrarrestar los efectos de la crisis, la confianza y la satisfacción de los ciudadanos continuaron debilitándose a medida que avanzaba la pandemia, como demostró la nueva ola de protestas que se extendió por toda la región en 2020 y 2021.

En este contexto, en el presente capítulo se argumenta que existe la necesidad de renovar el contrato social tras la pandemia como medio para lograr un mayor bienestar en ALC. Para que la recuperación pos-COVID-19 sea sólida, inclusiva y sostenible habrá que adoptar medidas audaces y realizar reformas ambiciosas. Para ello será necesario alcanzar nuevos pactos transversales en torno a las políticas sectoriales clave, tanto para hacer frente a los efectos específicos de la pandemia como para superar los desafíos en materia de desarrollo estructural de la región y avanzar hacia la consecución de los 17 Objetivos de Desarrollo Sostenible incluidos en la Agenda 2030 para el Desarrollo Sostenible (CEPAL, $2020_{[3]}$; Cabutto, Nieto-Parra y Vázquez-Zamora, 2021 $\left.{ }_{[4]}\right)$. Las reformas también requerirán alcanzar un alto grado de consenso entre todos los actores sociales y en los órganos legislativos pertinentes para hacerlas realidad. En este sentido, los gobiernos deben aprovechar el impulso para repensar el contrato social de forma que puedan hacer frente a los efectos de la pandemia y superar las vulnerabilidades estructurales - las trampas del desarrollo que representan la baja productividad, alta desigualdad e informalidad, servicios públicos e instituciones deficientes, y desafíos ambientales-que se acentuaron con la crisis COVID-19 (OCDE et al., 2019 [2] ).

El concepto de contrato social se utiliza en la literatura académica para diversos fines. El informe Perspectivas económicas de América Latina 2021 (LEO, por sus siglas en inglés) adopta una definición amplia del contrato social, que se entiende como el acuerdo integral, intangible e implícito, que une a la sociedad y que se enmarca dentro de un determinado conjunto de normas y prácticas formales e informales.

Este capítulo analiza la necesidad de un nuevo contrato social en ALC, y examina los siguientes temas. En primer lugar, analiza las principales razones por las que es necesario repensar el contrato social en la región. En segundo lugar, explora cuestiones críticas que deben examinarse para dar forma a un nuevo contrato social en ALC. En este sentido, primero analiza cuáles deben ser los principales componentes de ese nuevo contrato social para que esté adaptado a los desafíos y realidades del siglo XXI, desde la perspectiva del bienestar multidimensional. Finalmente, el capítulo se centra en el proceso, es decir, en la forma de alcanzar ese nuevo contrato social y de lograr que sea justo, legítimo y sostenible. 


\section{Un nuevo contrato social en ALC: el "porqué"}

Las diversas debilidades existentes demuestran la necesidad de repensar el contrato social en ALC. Antes de que el COVID-19 afectara a los países de la región, el aumento del descontento social, la disminución de la confianza en las instituciones y la creciente insatisfacción con los servicios públicos eran signos claros de la importancia de renovar los acuerdos fundacionales entre los ciudadanos y las instituciones públicas.

Muchas de estas tendencias resultaron de problemas estructurales. La mayoría de los países de ALC entraron a la crisis del COVID-19 cuando se enfrentaban a importantes trampas del desarrollo, en particular, a un bajo crecimiento potencial (trampa de la productividad), a una alta vulnerabilidad (trampa de la vulnerabilidad social), a la inestabilidad institucional (trampa institucional) y a un modelo de producción medioambientalmente insostenible (trampa ambiental) (OCDE et al., 2019 ${ }_{[2]}$ ). Estas vulnerabilidades fueron agravadas por el impacto de la pandemia.

La recuperación pos-COVID-19 exigirá un amplio consenso social en los países de ALC en torno a las reformas estructurales pendientes que es necesario llevar a cabo para hacer frente a los efectos de la crisis y para superar las trampas del desarrollo. Sin embargo, no todos los países tienen las mismas condiciones de partida ni avanzan hacia un nuevo contrato social a la misma velocidad. La heterogeneidad de la región y el impacto diferenciado de la crisis deben tenerse en cuenta a la hora de considerar los acuerdos necesarios para apuntalar la recuperación y construir una mejor sociedad para todos, así como el ritmo al que pueden implementarse. La evolución de los contratos sociales dependerá de las oportunidades creadas por la crisis, de la estructura del sistema político, de la eficacia de los mecanismos que obligan a los poderosos a rendir cuentas y de la aparición de coaliciones políticas (Shafik, 2021 ${ }_{[5]}$ ).

En este contexto, en la siguiente sección se examinan las principales razones por las que resulta necesario un nuevo contrato social en ALC.

\section{El descontento social es alto y sigue aumentando, caracterizado por los bajos niveles de confianza en las instituciones y de satisfacción con los servicios públicos}

A pesar de la recuperación temporal observada a lo largo de 2018-2020 (Gráfico 4.1, Panel A) las encuestas de opinión muestran que la confianza en el gobierno se mantuvo por debajo de los niveles anteriores a 2014 y que solo uno de cada tres ciudadanos confiaba en las instituciones públicas. En 2020, los episodios de mala gestión de los recursos públicos (p. ej., vacunas y equipo médico) afectaron negativamente a la opinión de los ciudadanos sobre su gobierno. En la mayoría de los países de la región, la satisfacción con respecto a la gestión del gobierno de la crisis del COVID-19 aumentó en la fase inicial y disminuyó a medida que la emergencia avanzaba (Gráfico 4.1, Panel B). La mayoría de los países de ALC adoptaron un enfoque cauteloso en marzo de 2020 y decretaron los primeros confinamientos, incluso antes de que la emergencia alcanzara los niveles observados en la República Popular de China y Europa. Por otra parte, el papel de los gobiernos en la lucha contra la pandemia les dio una visibilidad renovada. Los inesperados y profundos desafíos al statu quo aumentaron la confianza de los ciudadanos en los gobiernos, generando un efecto de "rally alrededor de la bandera" (Kritzinger, 2021 ${ }_{[6]}$ ).

A medida que la crisis evolucionaba, las percepciones comenzaron a variar de forma considerable en toda la región. La aprobación por parte de los líderes de opinión de la gestión por parte de su gobierno de la crisis del COVID-19 descendió en 7 de los 8 países encuestados en ALC entre abril y agosto de 2020 (Gráfico 4.1, Panel B) (CEPAL, 2021 [7] $_{\text {) }}$. Esta tendencia se confirma en otra encuesta de opinión que muestra una disminución significativa en la aprobación de los ciudadanos sobre la gestión de la crisis en Argentina, 
Colombia y México entre mayo y octubre de 2020 (Estefan, Hadid y Georges, $2020_{[8]}$ ). En adelante, los gobiernos de ALC que adopten programas de vacunación y recuperación más (o menos) ambiciosos podrán experimentar un nuevo incremento (o disminución) de la confianza, como se observó en el caso de en Chile tras un ambicioso programa de vacunación, según la encuesta de julio de 2021. Otros factores podrían explicar esos cambios en la confianza de los ciudadanos, (Gráfico 4.1, Panel B), como el cambio de gobierno, o la percepción de integridad, apertura y equidad de las instituciones públicas y de la fiabilidad de las políticas y la capacidad de respuesta de los servicios públicos (OCDE, 2017 $\left.{ }_{[9]}\right)$.

\section{Gráfico 4.1. La confianza en el gobierno nacional ha disminuido en los últimos años y se recuperó en 2020, aunque la aprobación de la gestión de los gobiernos de la crisis del COVID-19 se mantuvo altamente volátil}
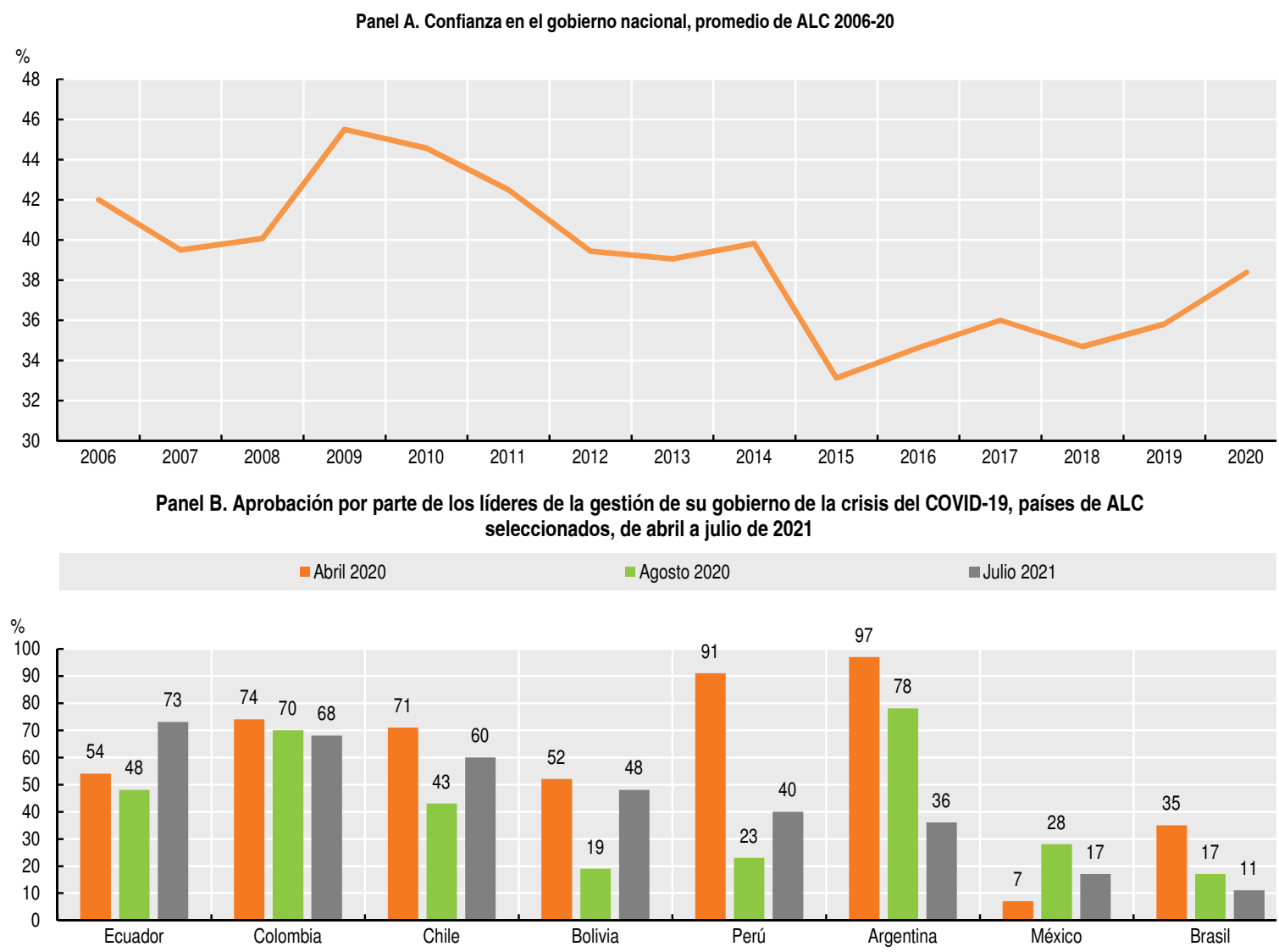

Notas: El Panel A representa el promedio no ponderado de ALC de 16 países. La recopilación de datos tuvo lugar entre agosto y noviembre de 2020 en el caso de la mayoría de los países, pero se prolongó hasta enero de 2021 en el caso de Costa Rica, Jamaica y Perú. En el Panel A, faltan los datos de 2020 de Guatemala, Honduras y Panamá. En el Panel B, los encuestados representan a 371 líderes de opinión y periodistas de América Latina que regularmente comparten sus opiniones en los medios de comunicación latinoamericanos. El Panel B muestra el porcentaje de encuestados que aprobaron la gestión de sus gobiernos de la crisis del COVID-19.

Fuentes: Panel A: Gallup $\left(2021_{[10]}\right)$, Gallup World Poll (base de datos), https://ga.gallup.com; Panel B: CEPAL (2021 $\left.1_{[7]}\right)$ Panorama Social de América Latina 2020, https://www.cepal.org/es/publicaciones/46687-panorama-social-america-latina-2020 y en IPSOS $\left(2021_{[11]}\right)$, Percepciones de los líderes de opinión de Latinoamérica a un año y medio de pandemia, www.ipsos.com/es-pe/ percepciones-de-los-lideres-de-opinion-de-latinoamerica-un-ano-y-medio-de-pandemia.

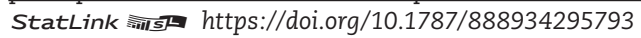

La satisfacción con los servicios públicos, incluidas la educación y la salud, disminuyó notablemente durante la pandemia. La insatisfacción con los servicios públicos siguió 
creciendo a lo largo de la crisis, agravada por las dificultades para garantizar la continuidad de los planes de estudio escolares durante los confinamientos, el aumento de la carga del cuidado de los niños durante los cierres de los centros escolares y la falta de recursos para responder a la crisis sanitaria (Gráfico 4.2). Los sistemas educativos de ALC, en particular, no estaban preparados para gestionar la educación a distancia masiva. La baja penetración de Internet, las escasas competencias digitales y la falta de equipos de tecnología de la información y de una plataforma eficaz de apoyo al aprendizaje en línea obstaculizaron de manera sustancial la capacidad de los estudiantes para seguir las clases a distancia en algunos países (OCDE et al., 2020 ${ }_{[12]}$ ). Estos obstáculos fueron especialmente graves en el caso de los estudiantes que asistían a escuelas de entornos desfavorecidos o que vivían en zonas rurales, lo que aumentó la desigualdad de oportunidades entre los estudiantes de la región (OCDE, 2020 ${ }_{[1]}$ ). Del mismo modo, los gastos de bolsillo para la atención sanitaria siguen representando una carga elevada para los presupuestos de las familias (Capítulo 2).

\section{Gráfico 4.2. La insatisfacción con los servicios públicos ha aumentado de forma constante en los últimos años y continuó creciendo durante la crisis del COVID-19}

Porcentaje de personas satisfechas con la disponibilidad de atención sanitaria de calidad y con el sistema educativo, promedio de ALC, 2006-2020

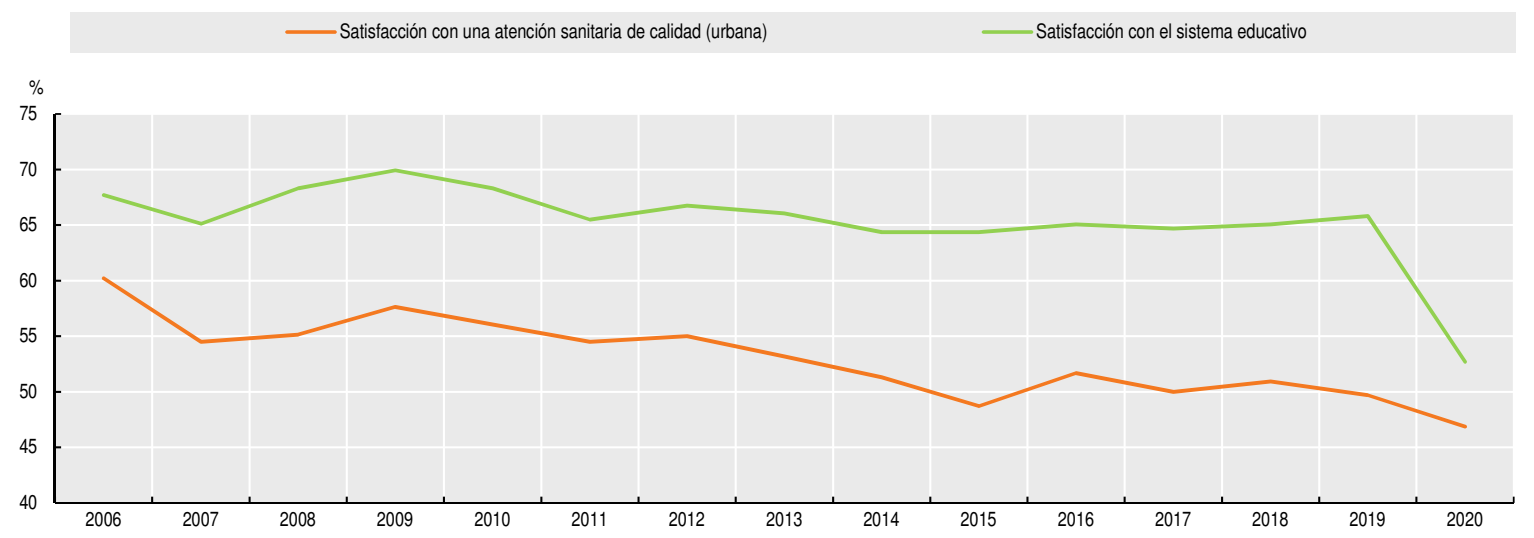

Notas: Promedio no ponderado de ALC que incluye 16 países. Faltan los datos de 2020 de Honduras y Panamá sobre la satisfacción con la atención sanitaria. Faltan los datos de 2020 de Guatemala, Honduras y Panamá sobre la satisfacción con el sistema educativo.

Fuente: Gallup $\left(2021_{[10]}\right)$, Gallup World Poll (base de datos), https://ga.gallup.com.

StatLink तinst https://doi.org/10.1787/888934295242

Las crecientes aspiraciones sociales agravan la insatisfacción ciudadana en ALC. La transformación digital y el auge de los "ciudadanos digitales" han desempeñado un papel importante en la configuración de las aspiraciones sociales. La expansión de los teléfonos inteligentes y la aparición de nuevas formas de comunicación han dado lugar a un profundo cambio cultural en las sociedades de ALC, especialmente entre los jóvenes y los urbanitas, que tienen un mayor nivel educativo y más aspiraciones que sus padres, pero se enfrentan a diversas dificultades por lo que se refiere a las oportunidades laborales. Estos jóvenes urbanos más conectados tienden ahora a comparar su estilo de vida con el de sus pares internacionales y no con el de la generación de sus padres, y sus expectativas insatisfechas provocan desilusión e ira (OCDE et al., 2020 ${ }_{[12]}$; OCDE, $2020_{[13]}$ ). Una encuesta sobre política y huelgas hecha a jóvenes colombianos entre enero de 2020 y mayo de 2021 mostró que la alegría había sido reemplazada por la tristeza como el sentimiento predominante entre este grupo (Universidad del Rosario, 2021 $1_{[14]}$ ). 
La persistencia de las desigualdades y la percepción de que el poder y la riqueza están cada vez más concentrados son determinantes fundamentales del descontento social

Aunque el aumento de la insatisfacción social observado en ALC antes del COVID-19 se produjo en paralelo a la desaceleración económica de los últimos años, el descontento social viene provocado también por otras causas que van más allá de lo económico. El fin del auge de las materias primas generó una ralentización de la reducción de la pobreza y un deterioro de las condiciones de vida, que se están viendo agravadas por la pandemia. No obstante, otras causas también han sido fundamentales en el descenso de la confianza y la satisfacción de los ciudadanos. La expansión de la clase media vulnerable a principios de la década del 2000 generó mayores esperanzas de más políticas redistributivas, creación de empleos de calidad, acceso universal a servicios públicos de calidad, como la atención sanitaria y la educación, eficiencia de las instituciones públicas y aumento de la representación. Sin embargo, dado que el progreso socioeconómico anterior se construyó sobre bases frágiles, en los últimos años, los ciudadanos no han visto satisfechas sus expectativas (OCDE et al., 2019 $\left.{ }_{[2]}\right)$. Según los expertos de la región, entre los principales factores determinantes de las protestas se encuentran el todavía elevado nivel de desigualdad social, la percepción de corrupción generalizada, la debilidad institucional y la escasa eficacia estatal para obtener resultados (Ipsos, 2019 ${ }_{[15]}$ ). Estos factores concurren en la creación de múltiples dimensiones de la desigualdad más allá de los ingresos, incluyendo un sistema educativo incapaz de ofrecer igualdad de oportunidades para todos; una provisión insuficiente de impuestos, transferencias y seguridad social para disminuir efectivamente la desigualdad de ingresos; y la sobrerrepresentación de los grupos acomodados en los espacios de toma de decisiones y políticas.

La percepción de vivir en una sociedad muy desigual está bien fundamentada y aviva el descontento social. A pesar de la importante disminución de la desigualdad de ingresos desde el comienzo del auge de las materias primas, la región sigue siendo una de las más desiguales del mundo. En ALC, el 1\% y el 10\% de la población más rica poseen el $21 \%$ y el $49 \%$ de los ingresos nacionales antes de impuestos, respectivamente, frente a alrededor del $13 \%$ y el $38 \%$ en la zona de la Organización para la Cooperación y el Desarrollo Económicos (OCDE) (promedios simples basados en World Inequality Database, 2020 ${ }_{[16]}$ ). Únicamente el Oriente Medio se aproxima a estos niveles de desigualdad (World Inequality Database, $2020_{[16]}$; Busso y Messina, 2020 $\left.[17]\right)$. Durante la pandemia, y en un contexto de creciente pobreza, el número de multimillonarios en ALC aumentó en 31 (de 76 a 107) y su patrimonio neto combinado aumentó en 196.000 millones de dólares estadounidenses (López-Calva, $\left.2021_{[18]}\right)$. A pesar de los llamados a la movilización colectiva, la pandemia ha impuesto los mayores costos a los que ya estaban en peor situación, como los ancianos, los jóvenes, las mujeres y los trabajadores mal pagados e informales (OCDE, 2020 ${ }_{[1]}$ ).

Algunas evidencias también sugieren que la reducción de la desigualdad durante la primera década del 2000 no fue tan elevada como se pensaba anteriormente, ya que las encuestas de hogares tienden a subestimar los ingresos de los hogares más ricos, que son más proclives a eludir las declaraciones de renta a efectos fiscales (Lustig, 2020 ${ }_{[19]}$ ). Por ejemplo, la tendencia descendente de la desigualdad en Brasil es menos pronunciada si se combinan diferentes fuentes de datos (Morgan, 2018 ${ }_{[20]}$ ). Del mismo modo, los datos ajustados del impuesto sobre la renta en Chile muestran que, entre 1990 y 2017, la concentración de ingresos en el 1\% superior siguió una tendencia en forma de U y no una tendencia decreciente, ya que los valores en ambos extremos rondaron el 21\% (Flores et al., $\left.2020_{[21]}\right)$. La comparación de los datos sobre hogares e impuestos en Uruguay muestra que las posiciones superiores por nivel de ingresos entre 2009 y 2016 se mantuvieron estables, mientras que el efecto igualador de la movilidad de los ingresos fue muy modesto (Burdin et al., $\left.2020_{[22]}\right)$. 
Dado que América Latina no pudo mantener el nivel de prosperidad compartida de la década anterior, el porcentaje de población que percibe la distribución de los ingresos como justa ha decrecido desde que alcanzó su punto más alto en 2013 (Gráfico 4.3).

Paralelamente, la propensión a manifestarse creció en varios países de ALC, y el número de protestas concretas y el descontento social han aumentado desde 2014 (Gráfico 4.3). Empezando por Haití en febrero de 2019, la región se vio sacudida por manifestaciones durante 2019, 2020 y 2021 en varios países, entre ellos Bolivia, Chile, Colombia, Cuba, Ecuador, Guatemala y Perú.

Además de la desigualdad de los ingresos, el aumento del descontento social es también un síntoma de la frustración creciente ante la concentración de riqueza y poder en la región (López-Calva, $2020_{[23]}$ ). Esto genera la percepción de formar parte de un sistema totalmente amañado, en especial entre los hogares pobres y vulnerables que no ven la posibilidad de mejorar su situación. En particular, el progreso socioeconómico experimentado en la región en las últimas décadas puede haber generado un "efecto túnel", según el cual los conductores en un túnel ven que el carril paralelo empieza a moverse mientras ellos siguen atascados o comienzan a conducir hacia atrás (Hirschman y Rothschild, $1973_{[24]}$ ). Las mayores expectativas de la clase media vulnerable se han tornado en descontento social.

Las enormes desigualdades que se extienden por la región incrementan la percepción de que los ingresos no se distribuyen equitativamente y otorgan a las élites un control sin precedentes sobre la agenda política y económica, perpetuando una cultura de privilegios y aumentando la percepción de la captura de políticas (véase la sección relativa a la captura de políticas más abajo). En 2020, el 73\% de los ciudadanos latinoamericanos creían que su país estaba gobernado en interés de unos pocos grupos poderosos, lo que representa el nivel más alto registrado desde 2004 (después del 79\% en 2018) (Latinobarómetro, 2021 ${ }_{[25]}$ ).

\section{Gráfico 4.3. Protestas en la calle y percepción de que los ingresos no están distribuidos equitativamente}

Porcentaje de la población que cree que los ingresos están distribuidos equitativamente y número de protestas en la calle (eje derecho), 2013-2018

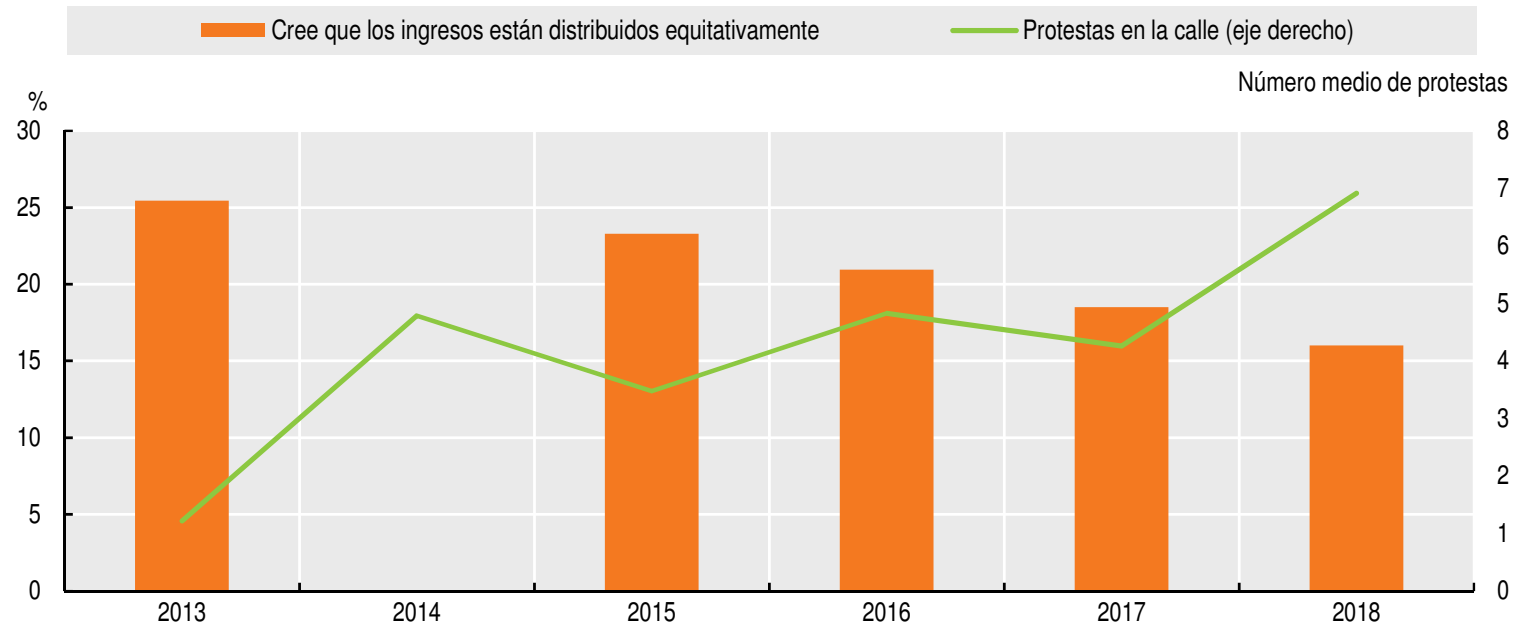

Nota: Promedio no ponderado de ALC.

Fuente: Elaboración propia a partir de Busso y Messina $\left(2020_{[17]}\right)$, La crisis de la desigualdad: América Latina y el Caribe en la encrucijada, http://dx.doi.org/10.18235/0002629; CTSN (2020 $\left.{ }_{[29]}\right)$, Domestic Conflict Database, www.cntsdata.com; Latinobarómetro $\left(2021_{[25]}\right)$, Encuesta Latinobarómetro 2020, www.latinobarometro.org/latOnline.jsp.

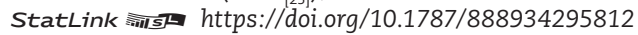


Del mismo modo, la percepción de corrupción sigue siendo elevada y ha aumentado ligeramente en la región, en particular entre principios de la década de 2000 y 2020 (Transparency International, $2021_{[26]}$ ). En 2019, se consideraba que los políticos y los funcionarios públicos eran el grupo más corrupto. Además, más de la mitad de los ciudadanos creían que su gobierno no estaba luchando eficientemente contra la corrupción (Transparency International, 2019 [27]). Esta percepción afecta directamente a los niveles de confianza en las instituciones públicas, el gobierno, los tribunales nacionales y la policía, al tiempo que erosiona su legitimidad a los ojos de sus ciudadanos. En cuanto a la impunidad, la región ocupó un lugar relativamente alto en el Índice Global de Impunidad en 2020, al presentar la mayoría de los países niveles de impunidad medios y altos (CESIJ, 2020 ${ }_{[148]}$ ).

\section{Debilitamiento de los lazos que unen a los ciudadanos de ALC}

Un contrato social sólido se basa no solo en una firme confianza vertical en las instituciones públicas, sino también en unos fuertes vínculos horizontales entre los ciudadanos. Sin embargo, y a pesar de que los tiempos excepcionales de pandemia exigen más ayuda mutua, los lazos que unen a los ciudadanos de ALC siguen siendo frágiles.

La cohesión social es débil en un momento en el que la acción colectiva y la unidad social son muy necesarias para la recuperación de la pandemia. Los cinco países latinoamericanos observados en el Índice de Cohesión Social de Ipsos se encuentran por debajo del promedio mundial, y al comparar los subíndices de cohesión social desglosados por país, el sentido del bien común (la ayuda a los demás, el respeto de las leyes y la percepción de la corrupción) es el más bajo en promedio (Ipsos, 2020 ${ }_{[30]}$ ) (Gráfico 4.4).

\section{Gráfico 4.4. La cohesión social es débil en los países latinoamericanos seleccionados}

Índice de Cohesión Social de Ipsos, subíndices netos ("Sentido de cohesión social sólido" menos "Sentido de cohesión social débil"), 2020

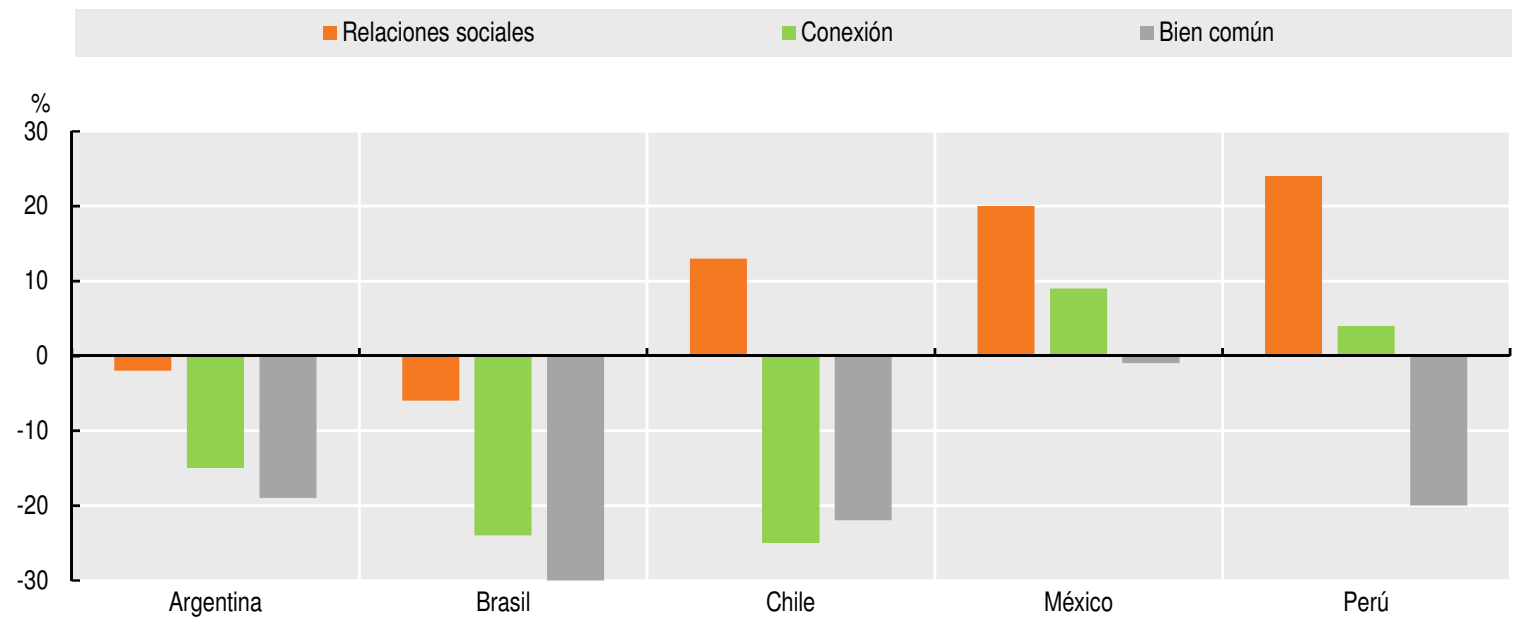

Nota: Los subíndices muestran el porcentaje de personas que tienen un sentido de cohesión social "fuerte" o "sólido" menos aquellos que tienen un sentido de cohesión social "débil". La encuesta se llevó a cabo en 27 países a través del Panel Online de Ipsos entre el 25 de septiembre y el 9 de octubre de 2020. Se encuestó aproximadamente a 1.000 personas o más por país, con excepción de Argentina y México, en cada uno de los cuales la muestra incluyó a unas 500 o más.

Fuente: Ipsos $\left(2020_{[30]}\right)$, Social Cohesion in the Pandemic Age: A Global Perspective, octubre de 2020, www.ipsos.com/sites/default/ files/ct/news/documents/2020-11/a global perspective of social cohesion in the pandemic age.pdf. StatLink तiा st https://doi.org/10.1787/888934295831

El debilitamiento del sentimiento de unidad y cohesión social también se refleja en el descenso de la confianza interpersonal entre los ciudadanos de ALC. La falta de confianza 
interpersonal ha caracterizado históricamente a la región, con una notable tendencia a la baja a partir de 2011 en paralelo a la disminución de la confianza en el gobierno, alcanzando niveles especialmente bajos en 2020 (12\%) (Gráfico 4.5).

\section{Gráfico 4.5. La falta de confianza interpersonal y de confianza en las instituciones públicas ha caracterizado a la región de ALC en la década pasada}

Porcentaje de población que tiene confianza en la mayoría de las personas y que confía mucho o algo en el Gobierno, promedio de ALC, 2002-2020

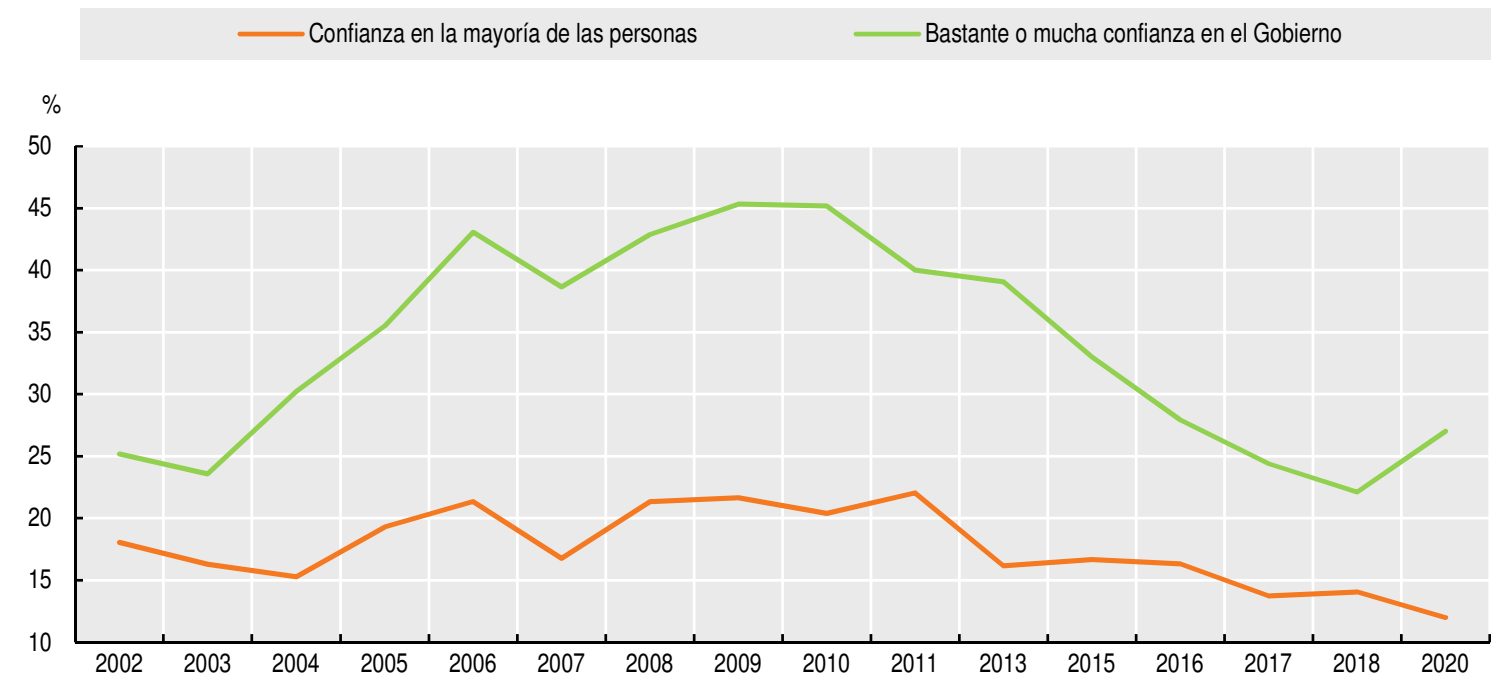

Nota: Promedio no ponderado de ALC.

Fuente: Latinobarómetro $\left(2021_{[25]}\right)$, Encuesta Latinobarómetro 2020, www.latinobarometro.org/latOnline.jsp. StatLink intsla https://doi.org/10.1787/888934295850

En comparación con otras regiones del mundo, ALC muestra niveles significativamente bajos de confianza interpersonal generalizada o confianza horizontal, por ejemplo, confianza en las personas que no pertenecen al círculo familiar o íntimo. Solo África Subsahariana tiene los mismos bajos niveles de confianza horizontal que ALC (Mattes y Moreno, $\left.2018_{[31]}\right]$. Sin embargo, los niveles de confianza interpersonal son muy heterogéneos en los países de ALC, ya que en 2020 oscilaron entre el 5\% alcanzado en Brasil y el 21\% en Uruguay (Latinobarómetro, 2021 $1_{[25]}$ ). El nivel de desigualdad parece ser uno de los factores fundamentales que explican la variación en los niveles de confianza interpersonal entre los distintos países (Mattes y Moreno, 2018 ${ }_{[31]}$; Uslaner, 2002 ${ }_{[32]}$ ). La violencia es otro factor que influye en la confianza interpersonal y la cohesión social en ALC (Recuadro 4.1). De hecho, la desigualdad de los ingresos y la percepción de la amenaza de violencia están estrechamente correlacionadas en ALC y reflejan un círculo vicioso que también incluye la inseguridad y los bajos niveles de desarrollo (Lloyd's Register Foundation/Gallup, $2019_{[33]}$ ).

\section{Recuadro 4.1. La violencia como obstáculo para el logro del contrato social en ALC}

ALC sigue siendo la región más violenta del mundo, lo que conlleva consecuencias negativas para su tejido económico, social e institucional. No obstante, la heterogeneidad entre los países de ALC sigue siendo considerable, siendo América Central donde se concentran las tasas de homicidios más elevadas por cada 100.000 habitantes (Gráfico 4.6). La delincuencia y la violencia también se caracterizan por su grado de concentración geográfica, y las ciudades de ALC tienden a verse más afectadas por estos fenómenos (Alvarado y Muggah, 2018 [34] ). 


\section{Recuadro 4.1. La violencia como obstáculo para el logro del contrato social en ALC (cont.)}

\section{Gráfico 4.6. ALC sigue siendo la región más violenta del mundo}

Tasa de homicidios por cada 100.000 habitantes, estimaciones regionales y de los países de ALC, 2018 o último año disponible

Tasa de homicidios - América Latina y el Caribe _-África _- Asia Europa - Oceanía

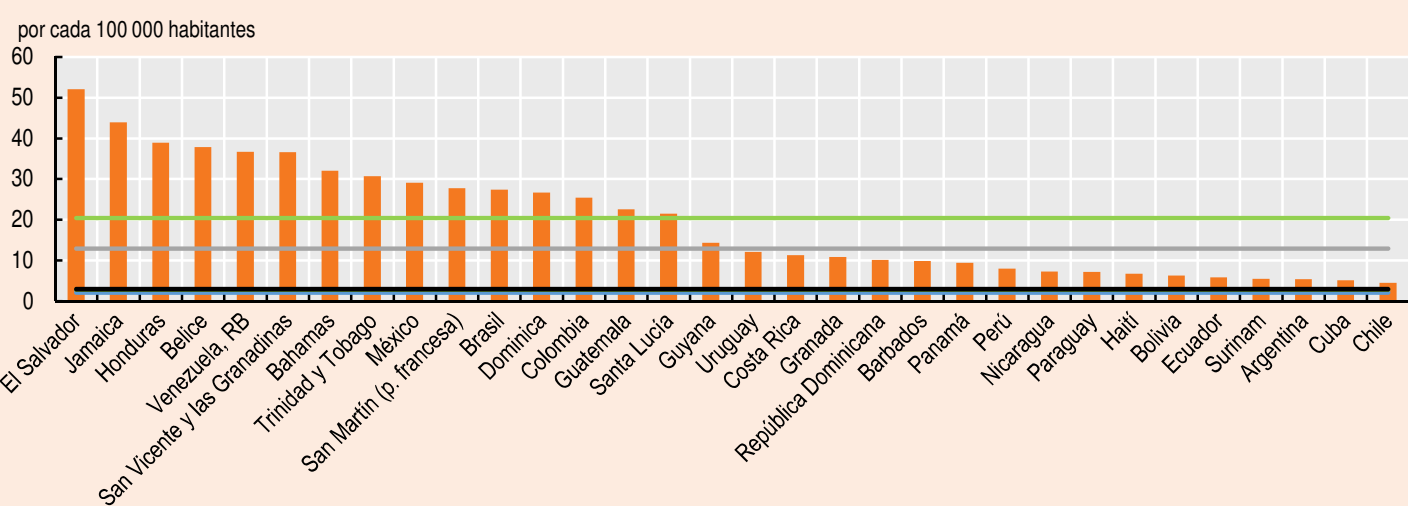

Nota: Los datos correspondientes a Bahamas, Belice, Dominica y Perú son de 2017; los datos correspondientes a Bolivia, Cuba, Nicaragua, San Martín y San Vicente y las Granadinas son de 2016; y los datos correspondientes a Trinidad y Tobago son de 2015.

Fuentes: Banco Mundial $\left(2020_{[35]}\right)$, Indicadores del Desarrollo Mundial (base de datos), https://data.worldbank.org/indicator/ VC.IHR.PSRC.P5; UNODC (2020 Homicide\%20victims\%20worldwide.

StatLink Aillst https://doi.org/10.1787/888934295869

Los costos directos de la delincuencia y la violencia en 17 países de ALC en 2010-2014 se estimaron en el 3.5\% del producto interno bruto de la región, pero los problemas indirectos también afectan a las esferas social e institucional (Jaitman et al., 2017 ${ }_{[37]}$ ). Especialmente en América Central, el bienestar de las comunidades se ve afectado negativamente por las actividades delictivas de las pandillas (maras), lo que se traduce en altas tasas de abandono escolar entre los adolescentes, en autorrestricciones a la libertad de circulación, en una mayor intención de migrar y en el desgaste de la cohesión social, todo lo cual conlleva consecuencias negativas para las redes sociales y comunitarias (Raderstorf et al., 2017 ${ }_{[38]}$; Maydeu-Olivares, 2016 ${ }_{[39]}$ ). La delincuencia y la violencia dificultan las actividades sociales, entre ellas las deportivas y recreativas, y dan lugar a la fragmentación de las comunidades, la desconfianza interpersonal y la disminución de la participación en las actividades democráticas (Imbusch, Misse y Carrión, 2011 [40]).

Al mismo tiempo, cuando los ciudadanos perciben que las instituciones son incapaces de garantizar su seguridad, son menos propensos a apoyar el sistema político y pueden recurrir a la violencia extrajudicial (Cruz y Kloppe-Santamaría, 2019 ${ }_{[41]}$ ).

Es clave hacer frente a la inseguridad para sentar las bases de un nuevo contrato social. Es importante adoptar un enfoque integral de lucha contra la violencia para restablecer la confianza entre los ciudadanos y de estos con las instituciones, lo que puede contribuir al logro de pactos estables y a largo plazo entre las partes interesadas. Además, centrarse en la prevención de la delincuencia desde la infancia a la edad adulta puede ayudar a reducir el incremento de los comportamientos delictivos. En particular, las actuaciones de prevención de la delincuencia a pequeña escala a nivel municipal han generado resultados positivos (Alvarado y Muggah, 2018 [34]; Chioda, $\left.2017_{[42]}\right)$. 


\section{Aumento de los niveles de polarización y de la movilización popular, acompañados de la disminución de la confianza en los canales tradicionales de participación política}

La politización, o identificación con una ideología política, ha aumentado en los últimos años en ALC. Al mismo tiempo, la desconfianza en los partidos políticos ha ido creciendo (Gráfico 4.7). La creciente orientación ideológica de los ciudadanos en los últimos años es especialmente evidente en Argentina, Bolivia, Brasil, Colombia, Ecuador y México. Por otro lado, países como la República Dominicana y Uruguay han mostrado unos niveles más elevados y estables de compromiso político a lo largo del tiempo (Latinobarómetro, $2021_{[25]}$ ).

\section{Gráfico 4.7. En promedio, la identificación con una ideología política ha aumentado en ALC en los últimos años, mientras que la confianza en los partidos políticos ha disminuido}

Porcentaje de personas que se identifican con una ideología política (de izquierdas o de derechas) y porcentaje de personas que tienen "mucha" o "alguna" confianza en los partidos políticos (eje derecho), promedio de ALC, 2002-2020

Identificación con una ideología política

Confianza en los partidos políticos (eje derecho)

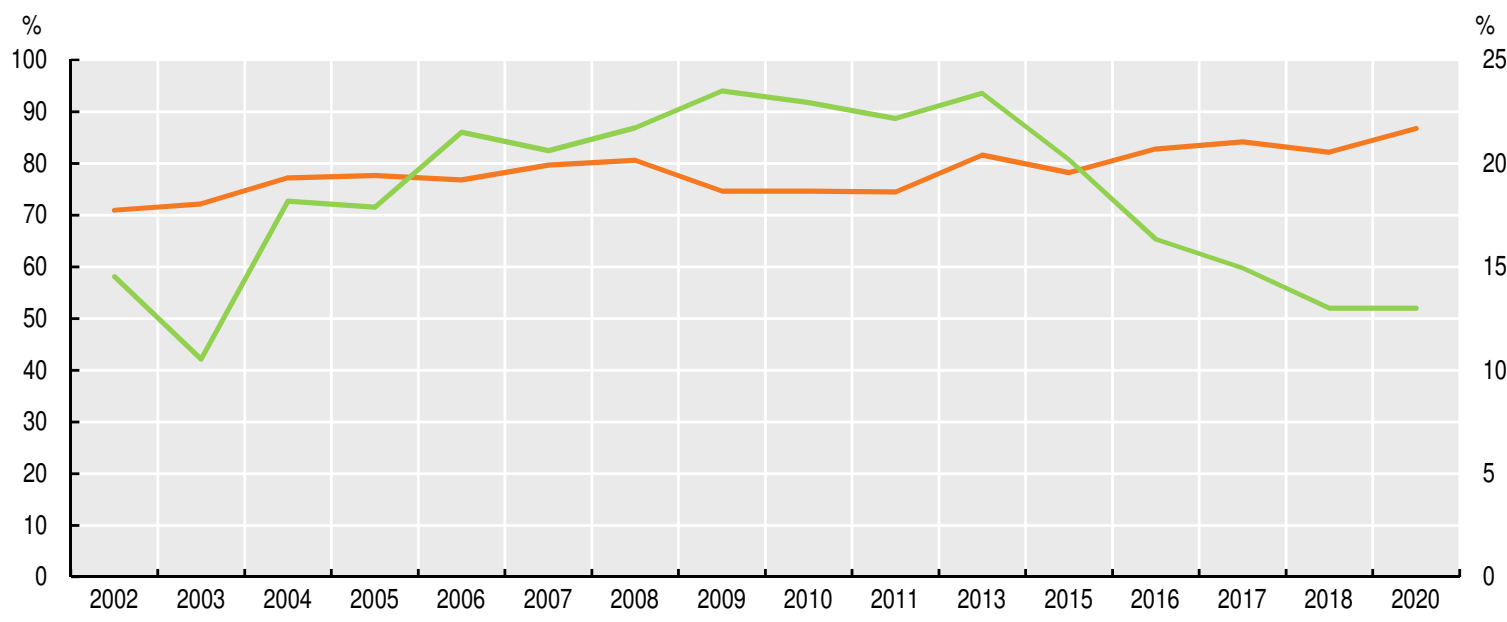

Notas: Promedio no ponderado de ALC. El porcentaje de personas que se identifican con una ideología política representa a aquellas personas que fueron capaces de ubicarse en una escala donde "0" es la "izquierda" y "10" la "derecha".

Fuente: Latinobarómetro $\left(2021_{[25]}\right)$, Encuesta Latinobarómetro 2020, www.latinobarometro.org/latOnline.jsp.

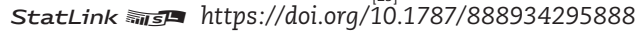

El aumento de la politización parece ser uno de los factores detrás del aumento en la movilización popular, dada la baja credibilidad en mecanismos tradicionales de representación, como los partidos políticos. Los niveles de legitimidad de los poderes legislativos y de los partidos políticos entre los ciudadanos, que ascienden al $20 \%$ y el $13 \%$, respectivamente, son los más bajos de la región (Latinobarómetro, $2021_{[25]}$; Prats y Meunier, 2021 ${ }_{[43]}$; González, 2020 $\left.{ }_{[44]}\right]$. Las dos tendencias de creciente descontento social y efervescencia política convergen en las protestas sociales de 2019 y podrían estar reflejando la movilización popular de un porcentaje cada vez mayor de la población que no se siente representada por los canales políticos tradicionales.

El creciente activismo político puede ser una expresión positiva del pluralismo político y fomentar la renovación democrática. En las recientes protestas, los activistas políticos y los manifestantes han abogado por mayores reformas democráticas para contrarrestar la erosión del espacio cívico, el debilitamiento de los controles y contrapesos y los ataques a los derechos humanos (openDemocracy, 2020 ${ }_{[45]}$; Zovatto, $2020_{[46]}$ ). Además, cuando se les pidió que comentaran las lecciones aprendidas de la crisis del COVID-19, la mayoría de los encuestados de diez países de ALC destacaron la necesidad de una mayor rendición 
de cuentas del gobierno y una protección más sólida de los derechos humanos en su país (Acuña-Alfaro y Sapienza, 2021 $1_{[47]}$ ). Las demandas de unas instituciones mejores y más justas ofrecen la oportunidad de debatir un nuevo contrato social (CEPAL, 2020 ${ }_{[3]}$ ).

Sin embargo, si no se canaliza bien, se corre el peligro de que una mayor politización resulte en una mayor polarización - que podría verse exacerbada por la pandemiay ponga a prueba la cohesión social. En la reciente ronda de elecciones, hasta 2021, la insatisfacción con el sistema político y el funcionamiento de las instituciones públicas, así como con los malos resultados económicos, dio lugar a votos en contra de las élites políticas tradicionales. En algunos países, esto ocasionó la aparición de candidatos antisistema (Zovatto, $2019_{[48]}$; Malamud y Núñez, 2018 ${ }_{[49]}$ ). Simultáneamente, los grupos religiosos, como los evangélicos, también están ganando influencia en la región y aprovechando su proximidad a las masas para difundir mensajes políticos. Su influencia fue clara en las recientes elecciones celebradas en algunos países, y en toda la región está creciendo su base de fieles, que actualmente representa el $20 \%$ de la población latinoamericana (Malamud, 2018 ${ }_{[50]}$ ).

Las redes sociales y las plataformas digitales también han desempeñado un doble papel en el aumento de la politización. Por un lado, el espacio digital ha facilitado el surgimiento y posterior organización de los movimientos sociales. Especialmente gracias a las redes sociales, los activistas pueden compartir sus ideas, interactuar con personas afines de todos los lugares y organizar rápidamente manifestaciones con millones de personas sin necesidad de intermediación o apoyo financieros (Billion y Ventura, $2020_{[51]}$ ). Una encuesta realizada a jóvenes colombianos entre enero de 2020 y mayo de 2021 mostró que las redes sociales (63\%) fueron el canal de expresión más común durante las protestas, seguido de las marchas callejeras (53\%) y los debates con la familia (49\%). Las redes sociales, junto con la iniciativa propia de los manifestantes, fueron también la forma más común de convocar las movilizaciones (58\%) (Universidad del Rosario, 2021 $1_{[14]}$ ).

Por otro lado, las plataformas digitales facilitan la creación de redes sociales homogéneas que actúan como cajas de resonancia o filtros burbuja, que aíslan a los usuarios de puntos de vista contrapuestos (OCDE et al., 2020 ${ }_{[12]}$ ). Permiten que las noticias falsas lleguen a grandes audiencias y fomentan la polarización social (Wardle y Derakhshan, 2017 ${ }_{[52]}$; Marwick y Lewis, $2017_{[53]}$; Lazer et al., 2018 ${ }_{[54]}$ ). Dado que las falsas afirmaciones sobre las medidas o políticas adoptadas por autoridades públicas para hacer frente a la pandemia es el tipo más común de desinformación sobre el COVID-19, se corre el riesgo de que en ALC las noticias falsas erosionen aún más la confianza en las instituciones (Brennen et al., 2020 ${ }_{[55]}$ ). Teniendo en cuenta la baja fiabilidad de los mensajes que circulan en Twitter en la región, también se corre el riesgo de que socaven el cumplimiento de las normas públicas (López-Calva, $2020_{[56]}$ ).

\section{Una serie de megatendencias impulsan aún más la necesidad de repensar el contrato social}

Varias megatendencias mundiales están generando nuevos desafíos y oportunidades. Estas tendencias están transformando las sociedades de ALC y, por lo tanto, deben integrarse en el contrato social renovado. Entre ellas, algunas de las más importantes son la transformación digital, el cambio climático y el aumento de los movimientos mundiales en favor de la justicia social (Capítulo 5).

En primer lugar, la pandemia de COVID-19 ha dado un impulso sin precedentes a la transformación digital. La expansión de Internet y la adopción de tecnologías digitales han sido fundamentales para garantizar una cierta continuidad en la actividad empresarial, los servicios públicos y el trabajo y el estudio desde el hogar durante los confinamientos. Sin embargo, la brecha digital —en particular la falta de Internet de banda ancha de alta 
velocidad y de competencias digitales adecuadas - ha impedido a muchos, especialmente a los más vulnerables, aprovechar las ventajas de estas soluciones (OCDE, 2020 ${ }_{[1]}$ ). Por ejemplo, más de 6 de cada 10 hogares con ingresos per cápita en el quintil inferior de la distribución de los ingresos no tienen acceso a la conexión fija a Internet de banda ancha de alta velocidad necesaria para trabajar o estudiar a distancia (Basto-Aguirre, Cerutti y NietoParra, $2020_{[57]}$ ). Además, garantizar una gestión de datos fiable y ética y una infraestructura digitalmente segura es fundamental para fomentar la confianza y facilitar la adopción de tecnología (OCDE et al., 2020 ${ }_{[12]}$ ). Es esencial asegurar una transformación digital inclusiva y segura durante el período de recuperación posterior a la pandemia.

En segundo lugar, los efectos del cambio climático son de alcance mundial y de una magnitud sin precedentes, y las medidas para hacerles frente no pueden seguir retrasándose. Ha aumentado a nivel global la conciencia sobre los riesgos del cambio climático, y el $41 \%$ de la población mundial considera que es una "amenaza muy grave" para su país. En ALC, la preocupación por el cambio climático es considerablemente superior al promedio mundial. ALC destaca como la segunda región más preocupada por el cambio climático después del sur de Europa, como pone de manifiesto que el $71 \%$ y el $73 \%$ de los encuestados en las dos regiones, respectivamente, afirmen que es una grave amenaza para su país en los próximos 20 años. Chile, Colombia, Costa Rica y Ecuador se encuentran entre los países más preocupados por el cambio climático a nivel mundial (Lloyd's Register Foundation, 2019 ${ }_{[58]}$ ). Además, los movimientos que abogan por la justicia climática y medioambiental han cobrado impulso en todo el mundo, incluida la región de ALC. Sin embargo, los activistas climáticos están pagando un alto precio en todo el mundo y particularmente en América Latina. Según Global Witness, que hace un seguimiento de los asesinatos de defensores de la tierra y el medioambiente, en 2019 se registró la mayor cifra mundial en un solo año (212). Más de dos tercios de los asesinatos tienen lugar en América Latina. La región se ha clasificado sistemáticamente como la más afectada desde que Global Witness comenzó a publicar datos en 2012 (Global Witness, $\left.2020_{[59]}\right)$. Los movimientos indígenas se han hecho oír especialmente en ALC para defender prácticas más sostenibles, en consonancia con su filosofía del buen vivir. Los gobiernos deberían aprovechar este aumento de la conciencia sobre el cambio climático e invertir en acción climática como parte de la recuperación del COVID-19 para ayudar al mundo a lograr el objetivo del Acuerdo de París de mantener el aumento de la temperatura por debajo de $2^{\circ} \mathrm{C}$ antes de finales de siglo. La entrada en vigor del Acuerdo de Escazú es un paso prometedor en la región, también por sus disposiciones sobre los defensores de los derechos humanos en materia medioambiental.

En tercer lugar, en los últimos años se han producido intensas movilizaciones a nivel mundial contra el racismo y las disparidades de género y a favor de la justicia social y los derechos humanos de los afrodescendientes y las mujeres. Los movimientos Black Lives Matter y \#MeToo han llamado la atención de los medios de comunicación sobre los temas de la discriminación y la violencia de género. Las protestas del movimiento Black Lives Matter en Estados Unidos inspiraron manifestaciones similares en ALC, principalmente en Brasil y Colombia, así como en las islas del Caribe, como Jamaica y Trinidad y Tobago. Del mismo modo, la considerable exposición mediática obtenida por el movimiento \#MeToo ha conseguido que se vuelva a apoyar a los movimientos feministas en toda ALC, aunque existieran mucho antes de la campaña. Primero en Argentina y después en toda la región, el movimiento \#NiUnaMenos ha hecho campaña desde 2015 para exigir más protección a los derechos de las mujeres. Las movilizaciones masivas dieron lugar a la adopción de medidas gubernamentales para poner fin a la violencia de género en Perú en 2016, en Uruguay en 2018 y en Argentina en 2020. En Chile, la mayor concienciación sobre las cuestiones de representación se refleja en el equilibrio de género del órgano encargado de redactar la nueva Constitución, una primicia mundial. La labor de concienciación llevada 
a cabo por estos movimientos implica que el futuro contrato social tendrá que centrarse en mayor medida en el empoderamiento, los derechos humanos y la igualdad.

\section{Definir el nuevo contrato social en ALC: el "qué"}

Una tarea difícil para los responsables de la formulación de políticas, los analistas y los observadores será definir qué dimensiones deben estar incluidas en ese nuevo contrato social.

En esta sección se analizan estas cuestiones y se examina cuáles deberían ser los principales componentes del nuevo contrato social en ALC. Para ello, i) se analiza el concepto histórico del contrato social y se propone una definición amplia del concepto, que se utiliza a lo largo de todo el informe LEO 2021; ii) se debaten los principales aspectos que deberían actualizarse para que el contrato social sea adecuado para un mundo pospandémico; y iii) se plantean una serie de dimensiones básicas - principios rectores y políticas sectoriales específicas-que deberían constituir el nuevo contrato social.

\section{El concepto de contrato social: evolución histórica y su definición actual}

El concepto de contrato social fue formulado por filósofos occidentales como Grocio (1625), Hobbes (1651), Locke (1689), Hume (1740) y Rousseau (1762) y posteriormente desarrollado por filósofos y académicos de los siglos XX y XXI, como David Lewis (1969), John Rawls (1971, 1993), Robert Nozick (1974) y David Gauthier (1986). Las primeras teorías propuestas por Hobbes, Locke y Rousseau diferían en su conceptualización, pero, en general, se referían al contrato social como el acuerdo racional por el que los seres humanos ceden parte de sus libertades a una autoridad central para abandonar el estado de naturaleza y convertirse en una sociedad civilizada. En este sentido, los seres humanos acordaron renunciar a parte de sus libertades y crear un Estado soberano que garantizara sus derechos y obligaciones, para perseguir la igualdad de oportunidades y la maximización del bienestar de la sociedad.

Esta idea inicial del contrato social se ha reconceptualizado en varias ocasiones, y ha ido cambiando progresivamente con la ampliación del Estado de bienestar y la movilización del sector laboral. Durante el siglo XIX, las reformas laborales y sociales reforzaron los derechos de los trabajadores frente a sus empleadores, y favorecieron que las personas fueran menos responsables de sus resultados económicos en favor de un mayor intervencionismo del sector público (Cosano, 2019 ${ }_{[60]}$ ). Desde entonces, el papel del Estado se ha ampliado y ha incluido responsabilidades no solo en materia de protección de las personas contra la violencia y de garantía de los derechos de propiedad, sino también en cuestiones tales como, por ejemplo, el fomento del acceso a mercados libres, la promoción del crecimiento económico y la salvaguardia del bienestar de los ciudadanos a través de un sistema integral de protección social (Manyika et al., 2020 ${ }_{[61]}$ ).

En vista de esta evolución, el informe LEO 2021 define el contrato social, en términos generales, como "el acuerdo integral, intangible e implícito, que une a la sociedad y que se enmarca en un determinado conjunto de normas y prácticas formales e informales". Las instituciones formales incluyen la constitución escrita, las leyes, las políticas y los reglamentos aplicados por las autoridades oficiales. Las instituciones informales incluyen las normas sociales (no escritas), las costumbres y las tradiciones.

Para hacer referencia al contrato social, en esta definición se utiliza en primer lugar el término "integral", puesto que comprende a múltiples agentes. El papel del Estado -y su interacción con la sociedad- ha evolucionado, y otras partes, como el sector privado y la sociedad civil, son cada vez más relevantes y no pueden dejarse al margen del concepto actualizado de contrato social. Se espera que el sector privado participe en la sociedad 
en mayor medida a través de una conducta empresarial más responsable, función que se institucionaliza cuando las normas relativas a dicha conducta se convierten en normas y obligaciones empresariales legítimas (Granda Revilla, 2018 ${ }_{[62]}$ ).

Además, la definición de contrato social incluida en el informe LEO tiene en cuenta las "normas y prácticas formales e informales". Las normas formales son esenciales, ya que definen los derechos y obligaciones mutuos de todas las partes fundamentales (Kaplan, 2017 ${ }_{[63]}$ ). Del mismo modo, los contratos sociales emanan de prácticas informales y consuetudinarias, como los valores y las normas compartidas (PNUD, 2018 ${ }_{[64]}$ ).

Asimismo, en la definición del informe LEO se hace referencia al contrato social como el acuerdo "que une a la sociedad y que está enmarcado [...]", lo que implica la interacción entre todas las partes y, por tanto, la búsqueda del equilibrio entre ellas. Este equilibrio supone, de hecho, una negociación constante entre los agentes sociales y las autoridades, que refleja el reparto de poderes entre todas las partes que componen la sociedad (Loewe, Zintl y Houdret, $\left.2020_{[65]}\right)$. Es fundamental alcanzar el equilibrio en la negociación de los contratos sociales, que solo prosperarán cuando los miembros de la sociedad realicen importantes esfuerzos de coordinación y encuentren soluciones para alcanzar los resultados comúnmente deseados, al tiempo que evitan el comportamiento oportunista (Kaplan, 2017 ${ }_{[63]}$; Vlerick, $2019_{[66]}$ ). De hecho, el contrato social también se ha definido como un "acuerdo de autocontrol implícito entre los miembros de la sociedad para coordinar un equilibrio específico en el juego de la vida" (Binmore, $1994_{[67]}$ ). Sin embargo, las personas solo concertarán contratos sociales si consideran que son beneficiosos, justos y fiables y, si bien las expectativas del contrato social han aumentado, la participación de la sociedad depende en gran medida del consenso y la justificación pública (D’Agostino, $1996_{[68]}$ ).

Por último, la definición de contrato social incluida en el informe LEO se presenta en términos generales y se refiere a un acuerdo "intangible e implícito". Por tanto, si bien se reconoce que el concepto de contrato social trasciende cualquier acuerdo explícitamente descrito de forma tangible, en el informe LEO también se reconoce que un contrato social sólido se compone, entre otras cosas, de múltiples pactos sociales específicos en políticas sectoriales concretas (Recuadro 4.2).

\section{Recuadro 4.2. Los pactos sociales dentro del contrato social}

Los pactos sociales se refieren a acuerdos específicos sobre políticas sectoriales concretas entre diversos agentes, como las organizaciones de la sociedad civil, los interlocutores sociales y los sindicatos, así como las instituciones gubernamentales y públicas. Por lo tanto, los pactos sociales difieren de la negociación colectiva (en la que participan solo dos partes) y de los acuerdos tripartitos institucionalizados (en los que la cooperación tiene lugar dentro de las instituciones), ya que son acuerdos más amplios entre múltiples partes interesadas en torno a cuestiones clave de política (p. ej., un pacto fiscal o un pacto ambiental en el que intervienen múltiples agentes e intereses). Se realizan en un momento determinado y requieren la voluntad de las partes (EurWork, 2019 ${ }_{[69]}$ ).

Con el tiempo, los pactos sociales se han convertido en instrumentos eficaces en materia de políticas para hacer frente a los desafíos sociales y económicos. En Europa, resultaron esenciales para reducir la pérdida de puestos de trabajo y minimizar el descontento social y, en el Oriente Medio, facilitaron el proceso de democratización (Baccaro y Galindo, 2018 ${ }_{[70]}$ ).

Los pactos sociales dependen del entorno internacional y económico en el que surjan (Baccaro y Galindo, $2018_{[70]}$ ). Es muy probable que el contexto actual de ALC requiera pactos sociales firmes, ya que los países tendrán que lograr un amplio consenso en áreas clave para que la recuperación 


\section{Recuadro 4.2. Los pactos sociales dentro del contrato social (cont.)}

pos-COVID-19 sea sólida, inclusiva y sostenible. Los pactos sociales, al contrario que las decisiones y reformas unilaterales por parte del gobierno, pueden conciliar diversos propósitos en materia de políticas, como el crecimiento económico, la cohesión social y la distribución equitativa, en un intento de alcanzar un consenso más amplio dentro de las sociedades (Baccaro y Galindo, $2018_{[70]}$ ). Asimismo, los pactos sociales pueden favorecer la participación de todas las partes interesadas y reflejar la diversidad de opiniones e intereses y, por lo tanto, dan una mayor legitimidad a las decisiones y reformas que implican y promueven su mayor sostenibilidad.

Los próximos pactos sociales de ALC pueden desempeñar un papel importante en el establecimiento de sistemas de protección social más justos, en la reactivación de las estrategias productivas y la creación de empleos de buena calidad, o en la movilización de recursos fiscales para financiar la recuperación. Por consiguiente, los pactos sociales pueden constituir los pilares de un nuevo contrato social destinado a unir a la sociedad y restaurar la confianza de los ciudadanos en las instituciones públicas.

Analíticamente, estos pactos deben incluir elementos de dos aspectos: la redistribución y el reconocimiento de derechos e identidades. La redistribución de los recursos y de las oportunidades materiales y el reconocimiento de las identidades y derechos de los grupos de población excluidos o discriminados son elementos importantes de un futuro contrato social en favor del bienestar inclusivo (Martínez Franzoni y Sánchez-Ancochea, 2020 ${ }_{[71]}$; CEPAL, $2021_{[7]}$ ).

\section{Actualización del concepto de contrato social en el mundo pospandémico}

El concepto de contrato social debe evolucionar, ya que importantes tendencias, como la demografía, la transformación digital y el cambio climático, están transformando las economías y las sociedades.

El dividendo demográfico de la región desaparecerá gradualmente, y la estructura demográfica se asemejará a la de las economías avanzadas para 2050 (Berganza et al., $\left.2020_{[72]}\right)$. El nuevo contrato social debe adaptarse a las consecuencias del envejecimiento de la población, en particular a través de sistemas de protección social más sólidos.

Como se ha señalado anteriormente, la transformación digital también ha creado nuevas desigualdades y desafíos. Los puestos de trabajo menos cualificados y los que requieren una formación media baja corren un mayor riesgo de desaparecer y automatizarse en un futuro próximo. Estos desafíos ponen de manifiesto la importancia de construir una transformación digital que funcione para todos, incluyendo las implicaciones fiscales de la digitalización de la economía (OCDE et al., 2020 ${ }_{[12]}$; Cosano, 2019 ${ }_{[60]}$; CEPAL/OEI, $2020_{[73]}$ ).

El cambio climático es probablemente el desafío más acuciante para el desarrollo sostenible y, por lo tanto, debe ser la piedra angular de la renovación del contrato social para crear una forma de crecimiento económico más igualitaria, integradora desde el punto de vista social y con bajas emisiones de carbono. La necesidad de abordar las causas y consecuencias del cambio climático y la degradación del medioambiente tiene importantes consecuencias para la elección de modos de consumo y producción sostenibles. También introduce en el debate sobre el contrato social la dimensión de la equidad y la solidaridad intergeneracional.

Por último, la pandemia está propiciando una profunda transformación, y debe diseñarse un nuevo contrato social que sea lo suficientemente resiliente y flexible para adaptarse a realidades en permanente cambio y que incluya más previsión y mecanismos sólidos para la gestión de crisis. 


\section{Las dimensiones del nuevo contrato social}

Las dimensiones del nuevo contrato social deben ser los pilares de una recuperación sólida, inclusiva y sostenible del COVID-19 (Tabla 4.1). Estas dimensiones se articulan en torno a dos consideraciones principales. Por un lado, el contrato social debe ser un acuerdo transversal entre: i) grupos socioeconómicos, mediante un enfoque interseccional que tenga en cuenta las diferencias de ingresos, de género, étnicas y raciales, entre otras (Capítulo 2); ii) territorios, teniendo en cuenta las diferentes necesidades y oportunidades locales y eliminando las divisiones territoriales; y iii) generaciones, para tener en cuenta que las políticas deben equilibrar los intereses de las generaciones presentes y futuras y basarse en el concepto de solidaridad intergeneracional. Tener en cuenta estos conceptos significa que las políticas deben diseñarse no solo para estas partes interesadas, sino también en colaboración con ellas, por ejemplo, implicando a la mujer en los procesos de formulación de políticas y apoyando su representación en los órganos de toma de decisiones (véase la sección "Configurar un nuevo contrato social en ALC: ¿cómo?").

Por otro lado, la renovación del contrato social debe contribuir a lograr tres objetivos clave en materia de políticas públicas, cuya pertinencia ha sido puesta de relieve por la crisis: i) estrategias productivas resilientes y sostenibles; ii) sistemas de bienestar más amplios y eficaces mediante la mejora de los sistemas de protección social y la prestación de servicios públicos de calidad; y iii) un modelo más sostenible de financiamiento para el desarrollo.

La intersección de estos dos ejes crea áreas específicas para el consenso político: en la práctica, como se ha mencionado anteriormente, el contrato social se compone de pactos sociales específicos en ámbitos de actuación concretos (Tabla 4.1).

Tabla 4.1. Los elementos básicos del nuevo contrato social

\begin{tabular}{|c|c|c|c|}
\hline & \multicolumn{3}{|c|}{ UN PACTO } \\
\hline & $\begin{array}{l}\text { Entre grupos } \\
\text { socioeconómicos } \\
\text { (incluidos ingresos, } \\
\text { género, etnia y raza) }\end{array}$ & Entre territorios & Entre generaciones \\
\hline $\begin{array}{l}\text { Reactivación de las } \\
\text { estrategias productivas } \\
\text { regionales }\end{array}$ & $\begin{array}{l}\text { Creación de empleos de } \\
\text { mejor calidad para todos y } \\
\text { aprovechamiento de la } \\
\text { transformación digital }\end{array}$ & $\begin{array}{c}\text { Adaptación de las } \\
\text { estrategias productivas al } \\
\text { potencial local }\end{array}$ & $\begin{array}{c}\text { Fomento del crecimiento } \\
\text { verde }\end{array}$ \\
\hline $\begin{array}{l}\text { Ampliación del alcance de } \\
\text { la protección social y los } \\
\text { servicios públicos }\end{array}$ & $\begin{array}{l}\text { Fortalecimiento de los } \\
\text { sistemas de protección } \\
\text { social y de los servicios } \\
\text { públicos }\end{array}$ & $\begin{array}{c}\text { Ampliación de la } \\
\text { territorial de la protección } \\
\text { social }\end{array}$ & $\begin{array}{l}\text { Reestructuración de los } \\
\text { sistemas de pensiones y } \\
\text { apoyo a niños, jóvenes, } \\
\text { personas con discapacidad } \\
\text { y mayores con sistemas } \\
\text { de bienestar más sólidos }\end{array}$ \\
\hline $\begin{array}{c}\text { Fortalecimiento de un } \\
\text { financiamiento sostenible } \\
\text { para el desarrollo }\end{array}$ & $\begin{array}{l}\text { Desarrollo de sistemas } \\
\text { tributarios más justos y } \\
\text { sólidos y mejora de la } \\
\text { eficacia del gasto público }\end{array}$ & $\begin{array}{l}\text { Sistemas de transferencias } \\
\text { entre territorios y } \\
\text { fortalecimiento de la } \\
\text { capacidad para recaudar } \\
\text { ingresos locales }\end{array}$ & $\begin{array}{c}\text { Gestión de la deuda } \\
\text { pública de manera } \\
\text { sostenible y responsable }\end{array}$ \\
\hline
\end{tabular}

Fuente: Elaboración propia. 
La buena gobernanza y la confianza mutua entre el gobierno y los ciudadanos, así como con la sociedad civil y el sector privado, son necesarias para lograr un contrato social firme y, por lo tanto, representan un pilar transversal. El papel de la gobernanza se desarrolla en mayor detalle en la siguiente sección. La cooperación internacional también desempeña un papel facilitador, ya que apoya y favorece el logro de pactos sociales mediante el intercambio multilateral de experiencias pertinentes, las transferencias técnicas y el diálogo sobre políticas en igualdad de condiciones, especialmente para apoyar la provisión de bienes públicos globales (Capítulo 5). Por ejemplo, los esfuerzos multilaterales serán esenciales para el logro de la Agenda 2030, especialmente los objetivos relacionados con el cambio climático y la conservación de los océanos. Al mismo tiempo, algunas alianzas internacionales pueden apoyar el logro de objetivos nacionales, como en el caso de la lucha contra la erosión de la base imponible y el traslado de beneficios (BEPS), dentro del Marco Inclusivo OCDE/G20 sobre BEPS (OCDE, 2019 ${ }_{[74]}$ ).

Un aspecto fundamental para una recuperación robusta, inclusiva y sostenible en ALC será avanzar hacia el cumplimiento de pactos fiscales sólidos. Esto requiere una mayor progresividad del sistema tributario, un mayor cumplimiento fiscal y una administración tributaria más fuerte con gastos fiscales eficientes. Antes de la pandemia, ALC ya enfrentaba una trampa institucional: la creciente desconfianza e insatisfacción de los ciudadanos con respecto a las instituciones y los servicios públicos afectaba negativamente a su moral tributaria, es decir, a su disposición a pagar impuestos. Esto crea un círculo vicioso, ya que los bajos ingresos fiscales limitan la capacidad del Estado para fortalecer las instituciones y proporcionar servicios públicos de mejor calidad, erosionand aún más la confianza social (OCDE et al., 2019 ${ }_{[2]}$ ). El impacto del COVID-19 añade complejidad, ya que se requiere una enorme necesidad de recursos públicos para financiar la recuperación en un contexto en el que los ingresos fiscales son relativamente bajos, los niveles de endeudamiento crecientes, y elespacio fiscal reducido (Capítulo 1).

Se necesita un amplio consenso para definir las fuentes de financiamiento necesarias para la recuperación, pero una crisis también puede ser un contexto favorable para impulsar reformas difíciles y alcanzar acuerdos complejos. Las crisis aumentan los costos de retrasar las reformas y pueden crear efectos distributivos disruptivos que faciliten impulsar reformas estructurales, al cambiar los equilibrios existentes y el statu quo (Dayton-Johnson, Londoño y Nieto Parra, 2011 ${ }_{[75]}$ ).

La política fiscal es tal vez el área de las políticas públicas con más intereses en juego y, por lo tanto, ilustra la importancia crítica de reforzar el proceso de diálogo y de creación de consenso - es decir la generación de pactos, que también será necesaria para impulsar otras reformas para la recuperación (Capítulo 1).

\section{Diseñar el nuevo contrato social en ALC: el "cómo"}

El impacto de la crisis puede haber generado un claro deseo y una percepción generalizada de la necesidad de renovar el contrato social en ALC. Además, la recuperación pos-pandemia y el avance hacia un modelo de desarrollo más inclusivo y sostenible requieren de grandes consensos sociales que permitan llevar a cabo las reformas necesarias. En este sentido, la región enfrenta importantes barreras para construir esos consensos y para poner en práctica reformas complejas y ambiciosas.

Esta sección se centra en el "cómo": es decir, en el proceso de elaboración de un contrato social renovado o de promover pactos sociales específicos que sean justos, legítimos y estables y que permitan impulsar una nueva agenda de reformas. Esto exigirá: i) mejorar la inclusión de diferentes grupos sociales en la formulación de políticas, para alcanzar un consenso amplio y representativo; ii) eliminar los obstáculos a la reforma y 
a la implementación de las políticas; y iii) adoptar un horizonte de largo plazo para que estos acuerdos sean duraderos (Cabutto, Nieto-Parra y Vázquez-Zamora, 2021 ${ }_{[4]}$ ).

Los procesos de formulación de políticas abiertos e inclusivos son fundamentales para lograr un nuevo contrato social que tenga en cuenta todos los puntos de vista y promueva una mayor rendición de cuentas

Es fundamental fomentar procesos de diseño y formulación de políticas de carácter abierto e inclusivo para crear políticas y servicios transparentes y tener en cuenta las necesidades de la sociedad en su conjunto. Si bien se ha dedicado un gran esfuerzo a la transparencia, es decir, a proporcionar información a los ciudadanos, los gobiernos deben ir más allá. Es necesario incluir una amplia variedad de opiniones en el proceso de formulación de políticas para que estas sean verdaderamente inclusivas. En aras de la equidad, es posible que los gobiernos tengan que hacer esfuerzos adicionales para llegar a los sectores de la sociedad que no pueden o no quieren participar en los debates públicos (p. ej., los grupos vulnerables, los jóvenes y los nuevos ciudadanos) (OCDE, 2009 ${ }_{[76]}$; OCDE, $2019_{[77]}$; OCDE, 2020 $\left.{ }_{[13]}\right)$.

Los beneficios de una mayor participación pública en la formulación de políticas van desde el aumento de la rendición de cuentas hasta el fortalecimiento de la evidencia de las políticas y el aprovechamiento de la innovación social. La formulación de políticas de carácter abierto e inclusivo puede dar lugar a una mayor rendición de cuentas y capacidad cívica al ampliar la esfera de acción en la que los ciudadanos pueden influir en el proceso público. En consecuencia, también puede reducir los costos de aplicación y cumplimiento, así como el riesgo de conflicto durante la aplicación de políticas o la prestación de servicios. Al aumentar la responsabilidad social, puede estimular a los ciudadanos a involucrarse en ámbitos en los que el éxito depende de los cambios en su propio comportamiento individual (p. ej., el cambio climático o las normas de distanciamiento social durante el COVID-19). La formulación de políticas de carácter abierto e inclusivo permite a los gobiernos comprender mejor la evolución de las necesidades de las personas y reducir las desigualdades a la hora de hacerse oír y de acceder tanto a los procesos de formulación de políticas como a los servicios públicos. Por último, puede ayudar a abordar cuestiones complejas de forma innovadora, al aprovechar la información, las ideas y los recursos de que disponen las empresas, las organizaciones de la sociedad civil y los ciudadanos (OCDE, 2009 ${ }_{[76]}$; OCDE, 2020 ${ }_{[78]}$; OCDE, $2017_{[79]}$ ).

En última instancia, la formulación de políticas de carácter inclusivo puede fortalecer la democracia, mejorar el aprendizaje colectivo y la experimentación, y ayudar a restablecer la confianza entre los ciudadanos y las instituciones públicas de ALC. La transparencia y la toma de decisiones colectiva pueden ayudar a reducir las dudas sobre la influencia indebida en las políticas públicas al dar voz precisamente a los grupos de población desatendidos y excluidos, cuyas reivindicaciones a menudo se ven paralizadas por grupos de interés poderosos y bien organizados. Puede ayudar a canalizar el potencial propositivo de una sociedad activa, informada y con una mayor propensión a la movilización, que en los últimos años se está haciendo oír con más fuerza (Naser, Williner y Sandoval, 2021 ${ }_{[80]}$ ).

Al mismo tiempo, los procesos inclusivos y participativos son importantes para garantizar el compromiso político de las diversas partes interesadas a lo largo del tiempo. El beneficio de la formulación de políticas de carácter inclusivo reside en la capacidad de lograr políticas estables y duraderas cuya sostenibilidad no se ve afectada por cambios en el gobierno. Por ejemplo, el Sistema Nacional de Competitividad e Innovación de Colombia es un marco institucional que combina la gobernanza multinivel con la participación de diferentes agentes que no forman parte del sector público, como la sociedad civil y el sector privado. Se encarga de fijar los objetivos de las políticas nacionales en la esfera de 
la innovación y la competitividad y de orientar las actividades de las entidades públicas, las empresas privadas y el mundo académico en un horizonte a medio y largo plazo.

La OCDE ha elaborado diez Principios Rectores relativos a la formulación de políticas de carácter abierto e inclusivo que pueden ayudar a los gobiernos a mejorar la ejecución de las políticas y la prestación de servicios (OCDE, 2009 ${ }_{[76]}$; OCDE, 2001 ${ }_{[81]}$ ) (Recuadro 4.3).

Los gobiernos deben diseñar cuidadosamente sus estrategias participativas para garantizar su éxito. Durante la fase preparatoria, el equipo técnico debe evaluar la viabilidad de los procesos participativos, es decir, debe tener en cuenta la disponibilidad de recursos, la voluntad política y el nivel de institucionalización de dichos procesos. A continuación, en la fase estratégica se debe definir el alcance de la intervención y los agentes involucrados y evaluar aspectos del contexto sociopolítico que puedan generar oportunidades o riesgos para la estrategia. En relación con esto último, durante la fase de elaboración, es importante definir el nivel de participación (p. ej., informativo, consultivo, resolutivo o de cogestión), que requiere diferentes concepciones y técnicas metodológicas. Tras su aprobación e implementación, es esencial sistematizar las aportaciones recibidas, analizar su fiabilidad técnica, política y económica y comunicar a los participantes las propuestas aceptadas. Por último, la estrategia debe establecer, mediante mecanismos de seguimiento y evaluación, el nivel de cumplimiento de los objetivos, el avance de las actividades y las posibles lecciones aprendidas, en particular a través de evaluaciones informales, opiniones de los participantes y análisis cuantitativos (Naser, Williner y Sandoval, 2021 ${ }_{[80]}$; OCDE, 2001 $[81]$; OCDE, 2021 $\left.1_{[82]}\right)$.

Las formas de participación pública son variadas, y los procesos de deliberación representativos son uno de los mecanismos existentes para involucrar a diversos sectores de la sociedad en procesos participativos basados en los insumos que aportan los ciudadanos. Los procesos de deliberación pueden ayudar a mejorar el impacto de las políticas públicas, facilitar la toma de decisiones a los responsables de la formulación de políticas y reforzar la confianza entre los ciudadanos y el gobierno. Los procesos de deliberación son particularmente apropiados para abordar cuestiones que conllevan decisiones de carácter ético, o elecciones complejas entre diversas opciones y que requieren soluciones de largo plazo (OCDE, 2020 ${ }_{[83]}$ ). Se centran en encontrar intereses comunes en cuestiones políticas mediante un debate justo y razonable entre los ciudadanos (Gastil y Levine, $2005_{[84]}$ ). En estos procesos participa un grupo de personas seleccionadas al azar que son ampliamente representativas de una comunidad ${ }^{1} \mathrm{y}$ que dedican un tiempo considerable a aprender y colaborar a través de la deliberación promovida para elaborar recomendaciones colectivas para los responsables de la formulación de políticas sobre un tema específico (OCDE, 2020 ${ }_{[83]}$; Cesnulaityte, $2021_{[85]}$ ). Un ejemplo de esta modalidad es la Asamblea Ciudadana Itinerante de Bogotá.

A nivel multilateral, existen varios marcos institucionales que promueven la participación ciudadana. La Recomendación sobre Gobierno Abierto del Consejo de la OCDE define el gobierno abierto como "una cultura de gobernanza que promueve los principios de transparencia, integridad, responsabilidad y participación de las partes interesadas en apoyo de la democracia y el crecimiento inclusivo" (OCDE, 2017 ${ }_{[79]}$ ). Para garantizar la participación de los ciudadanos interesados, la Iniciativa de la Alianza para el Gobierno Abierto (OGP) promueve la colaboración proactiva del gobierno con los ciudadanos a través de múltiples canales, como las consultas en línea, las audiencias públicas y los grupos focales. Estos elementos son fundamentales durante la formulación y la cocreación de un Plan de Acción de Gobierno Abierto, en el que el gobierno y la sociedad civil definen compromisos nacionales clave para lograr mejores servicios públicos mediante un proceso bien definido (Naser, Williner y Sandoval, $2021_{[80]}$ ). De los 78 países que integran la Alianza, 16 pertenecen a ALC. De este grupo, 15 países ya cuentan con planes de acción (Open Government Partnership, 2021 ${ }_{[86]}$ ). 
Los ejemplos históricos de procesos participativos e inclusivos ofrecen lecciones relevantes para la construcción de nuevos pactos sociales en ALC

Algunos ejemplos destacados de pactos sociales, recientes o pasados, que se caracterizan por ser participativos y favorecer la creación de consensos son: el actual proceso constituyente en Chile, la Constitución de la Ciudad de México, las Mesas Redondas de Medio Ambiente de Grenelle en Francia, los Pactos de la Moncloa y el Pacto de Toledo en España, el Pacto de Solidaridad Económica en México, el Acuerdo Nacional en Perú, así como algunos casos particulares de pactos sociales alcanzados en la región, como los acuerdos de paz.

El proceso para la redacción de una nueva constitución en Chile ha sido aclamado como un ejemplo prometedor de proceso legislativo inclusivo. Tras las protestas de 2019 y el referéndum nacional del 25 de octubre de 2020, en el que una gran mayoría de los chilenos votaron a favor de una nueva constitución, en 2021 se eligió una Convención Constitucional encargada de redactar el nuevo texto $\left(B C N, 2021_{[87]}\right)$. Este órgano, que está compuesto por 155 representantes de elección popular, es el primero en respetar la paridad de género, ya que la mitad de los miembros son mujeres. Además, se han reservado 17 escaños para representantes indígenas. Por último, el requisito del quorum de dos tercios para la aprobación del nuevo texto tiene por objeto hacer hincapié en la creación de consenso. A pesar de la atención prestada a la inclusión y la representación, la baja participación electoral registrada durante las elecciones apunta también al desafío de afianzar la formulación de políticas de carácter abierto e inclusivo, haciendo hincapié en la participación de los ciudadanos de los barrios desfavorecidos. Sin embargo, los contratos sociales también pueden alcanzarse a menor escala, mediante un enfoque gradual, como en el caso de la Constitución de la Ciudad de México. El Laboratorio para la Ciudad de México creó la plataforma digital Constitución CDMX, que ofrecía al público cuatro formas de participar en el proceso de redacción: 1) una encuesta, 2) peticiones en línea, 3) redacción colaborativa y 4) un registro de eventos. Estas aportaciones se reflejaron en el proyecto final (LabCDMX, 2016 ${ }_{[88]}$ ).

Los Acuerdos de Grenelle (Accords de Grenelle) se refieren a las negociaciones que tuvieron lugar entre el gobierno, las asociaciones empresariales y los sindicatos los días 25 y 26 de mayo de 1968 en medio de la huelga general de mayo de ese año. Concluidos el 27 de mayo, pero rechazados por los trabajadores, los acuerdos no entraron inmediatamente en vigor y la huelga continuó. Sin embargo, entre otros resultados, sentaron las bases para el aumento del salario mínimo, el establecimiento de secciones sindicales en las empresas y la reducción de la jornada laboral. A partir de estas negociaciones, el término "Grenelle" se ha utilizado para diseñar debates y negociaciones en los que participan diversos sectores de la sociedad con el fin de lograr un amplio consenso, como en el caso de la Mesa Redonda sobre Medioambiente de Grenelle, que tuvo lugar en 2007 en Francia por iniciativa del presidente y que dio lugar a que el Parlamento aprobara en 2009 un proyecto de ley de programación ambiental, conocido como "Loi Grenelle 1" (OCDE, 2016 ${ }_{[89]}$ ). Fue una iniciativa única en la que participaron múltiples actores, ya que concede a los ciudadanos un papel central en la aprobación o el rechazo de las propuestas resultantes de las deliberaciones de cinco grupos de trabajo nacionales colegiados, integrados por sindicatos, empleadores, organizaciones no gubernamentales, autoridades locales y representantes de la administración pública.

Los Pactos de la Moncloa fueron dos acuerdos sociales y económicos aprobados en 1977 en España para consolidar la transición a la democracia y estabilizar la economía afectada por la crisis del petróleo de 1973. Establecieron una política de recuperación económica consistente en controlar el gasto público y la inflación y reformar la administración tributaria. En materia social y política, fueron decisivos para garantizar los derechos 
civiles y políticos, como el derecho de reunión y la libertad de expresión, así como para promover los derechos de la mujer mediante la despenalización del adulterio. Estos dos pactos constituyen un ejemplo histórico del gobierno y las fuerzas de oposición trabajando juntos para llegar a un entendimiento y renunciar a la confrontación sistemática que caracterizó ese período. El clima de diálogo creado a través de los Pactos de la Moncloa fue esencial para la elaboración de la Constitución española en 1978 (Cabrera, 2011 [90]). El Pacto de Toledo fue otro acuerdo extraordinario y duradero alcanzado por los partidos políticos españoles en 1995 para poner fin a la inestabilidad del sistema de pensiones y seguridad social. Una negociación similar entre el gobierno, los sindicatos y los gremios en México llevó a la adopción del Pacto de Solidaridad Económica de 1987. El Pacto tuvo éxito en algunos ámbitos, como el de garantizar la estabilidad económica, en particular en lo que respecta a la estabilidad monetaria mediante la contención de la inflación.

El Acuerdo Nacional de Perú comenzó en 2002 y desarrolló y aprobó un conjunto de políticas estatales a largo plazo para el desarrollo sostenible sobre la base del diálogo y el consenso tras un proceso de talleres, consultas y foros temáticos y descentralizados. Las partes involucradas en el acuerdo son el gobierno, los partidos políticos con representación en el Congreso y las organizaciones de la sociedad civil. Las políticas aprobadas incluyen compromisos para fortalecer la democracia, garantizar la equidad y la justicia social, promover la competitividad y desarrollar instituciones públicas eficientes, transparentes y descentralizadas (Acuerdo Nacional, $2014_{[91]}$ ). El Acuerdo Nacional informó el Plan Estratégico Nacional de Desarrollo (Plan Bicentenario: El Perú hacia el 2021) y los planes de desarrollo sectoriales y regionales que dependían de él. Sin embargo, se necesitan vínculos más fuertes entre las agendas políticas y el presupuesto basado en resultados para asegurar que su implementación sea coherente (OCDE, 2016 ${ }_{[92]}$ ).

Experiencias pasadas relacionadas con los procesos de los acuerdos de paz en ALC, como los casos de Colombia (2016) y Guatemala (1996), podrían arrojar luz sobre algunas características de la estructura de estos pactos sociales específicos. La metodología de los acuerdos de paz consistente en seleccionar a agentes que se sentarán en la misma mesa con intereses diferentes y a menudo opuestos para encontrar soluciones compartidas puede, ciertamente, inspirar el diseño de futuros procesos de pacto social en la región y mejorar la confianza entre los ciudadanos y en las instituciones políticas. Esta metodología podría complementarse con una dinámica más participativa y abierta. Otra lección clave que se debe tener en cuenta es la importancia de anticipar en el proceso de diálogo las etapas que tendrán lugar después de alcanzar cada acuerdo. Con ello se garantizaría un amplio apoyo a las coaliciones, que son fundamentales para legitimar los resultados e incorporar su posible impacto en el bienestar de las personas. Por último, tras llegar a un acuerdo, la voluntad política y las capacidades institucionales son fundamentales para lograr su implementación y los resultados previstos (Martínez Franzoni y Sánchez-Ancochea, 2020 ${ }_{[71]}$ ).

\section{Es fundamental superar las barreras que persisten a la creación de consensos y que dificultan las reformas y la implementación de las políticas públicas}

En ALC persisten varios desafíos, tanto a nivel político como técnico, que dificultan la creación de consensos y obstaculizan la reforma y la implementación de las políticas públicas. Estos desafíos ponen en riesgo el éxito y la sostenibilidad de los nuevos pactos sociales en la región y, por tanto, han de ser analizados para darles una respuesta efectiva.

El papel los medios de comunicación y de las tecnologías digitales para favorecer procesos de deliberación y de formulación de políticas inclusivos puede ser fortalecido

Las tecnologías digitales e Internet son esenciales para facilitar procesos de formulación de políticas abiertos e inclusivos y facilitar la participación pública. En primer 
lugar, los datos públicos abiertos pueden crear una cultura de transparencia, rendición de cuentas y acceso a la información pública. Al compartir información con los ciudadanos, pueden favorecer la participación cívica y la vigilancia social en esferas susceptibles de corrupción como se observó en la respuesta temprana a la pandemia de COVID-19 (OCDE and The GovLab, $\left.2021_{[93]}\right)$. La legislación sobre el acceso a la información aprobada en ALC es una condición necesaria para garantizar la buena gobernanza y prevenir la corrupción en la era digital ya que establece las normas para la divulgación proactiva y reactiva de la información. Sin embargo, la capacidad de compartir información y datos es necesaria, aunque insuficiente por sí sola. Además, los gobiernos deben proporcionar la oportunidad y las herramientas para procesar los datos abiertos, así como la capacidad y los incentivos para que los ciudadanos y las pymes actúen e innoven sirviéndose de la información obtenida de ellos. Al mismo tiempo, las tecnologías digitales también pueden beneficiar a los gobiernos al facilitar la interacción con las partes interesadas (consultas en línea) y la participación ciudadana en la toma de decisiones (toma de decisiones por medios digitales). Las plataformas digitales pueden constituir un medio de costo reducido para que los gobiernos interactúen con las partes interesadas durante la formulación, el seguimiento y la aplicación de políticas. Si se combina con inversiones en el desarrollo de infraestructuras y talento y competencias digitales, la transformación digital puede ayudar a las administraciones a prestar servicios públicos más inclusivos, de manera que las instituciones públicas resulten más accesibles y se centren más en la ciudadanía (OCDE et al., 2020 ${ }_{[12]}$ ).

En un contexto de caída de la confianza en los gobiernos y los servicios públicos, las tecnologías y los datos digitales pueden ser fundamentales para permitir un mejor diseño de los servicios públicos y estrategias de prestación que promuevan servicios públicos integrados y centrados en el ser humano que beneficien a todos (OCDE, 2020 ${ }_{[94]}$; OCDE, $\left.2020_{[95]}\right)$. Esto incluye la adopción de los principios del diseño digital en la implementación de los servicios públicos, el uso de las tecnologías digitales para romper los silos de las políticas y los servicios, la unificación de la experiencia de los ciudadanos con el sector público, la reducción de la carga de proporcionar información que ya está en manos de las organizaciones del sector público, y el respeto de las preferencias de los individuos para acceder a los servicios a través de su canal preferido (p. ej., en persona, digital, quioscos, teléfono, etc.). Por último, en el marco de un enfoque integral de diseño y prestación de servicios en la era digital, los gobiernos otorgan un papel central a los ciudadanos a la hora de expresar sus preferencias, necesidades y expectativas, y las reflejan en el diseño y la prestación de los servicios públicos, contribuyendo a reducir la brecha entre los ciudadanos y el sector público mediante servicios más pertinentes y centrados en el ser humano (OCDE, 2021 $1_{[163]}$ ).

Junto con las tecnologías digitales, los medios de comunicación también desempeñan un papel importante en la conformación de la opinión pública, en la canalización de la atención hacia cuestiones sociales importantes y en la motivación de los ciudadanos para que actúen. Sin embargo, ALC presenta uno de los niveles más elevados de concentración de la propiedad de los medios de comunicación del mundo (Rodríguez y Zechmeister, $2018_{[97]}$; Reporteros sin Fronteras, $\left.2019_{[98]}\right)$. El "pluralismo limitado" del entorno mediático latinoamericano significa que las prioridades industriales, comerciales o gubernamentales a menudo limitan la representación de las diversas perspectivas sociales, económicas y políticas (Segura y Waisbord, $2016_{[99]}$ ).

La falta de pluralismo y la concentración de los medios de comunicación constituyen obstáculos importantes para crear un debate productivo y bien fundado en la sociedad, así como para llamar la atención sobre los abusos de gobernanza y la asignación inadecuada de los recursos. Los países en los que la libertad de prensa está más restringida también suelen mostrar mayores niveles de corrupción en el sector público (Gráfico 4.8). En ALC 
está aumentando la preocupación por la libertad de prensa, y el porcentaje de encuestados que responden tener gran confianza en los medios de comunicación cayó a su nivel más bajo en la ronda 2016/2017 del Barómetro de las Américas (Rodríguez y Zechmeister, $\left.2018_{[97]}\right)$. Permitir una mayor competencia en el sector de los medios de comunicación es un primer paso para propiciar un debate pluralista y diverso en la sociedad (Mendel, Castillejo y Gómez, $2017_{[100]}$ ).

\section{Gráfico 4.8. Unas mayores restricciones a la libertad de prensa van acompañadas de mayores niveles de corrupción en el sector público}

Clasificación Mundial de la Libertad de Prensa (2021) de Reporteros sin Fronteras frente al índice de corrupción del sector público (2020) de V-Dem

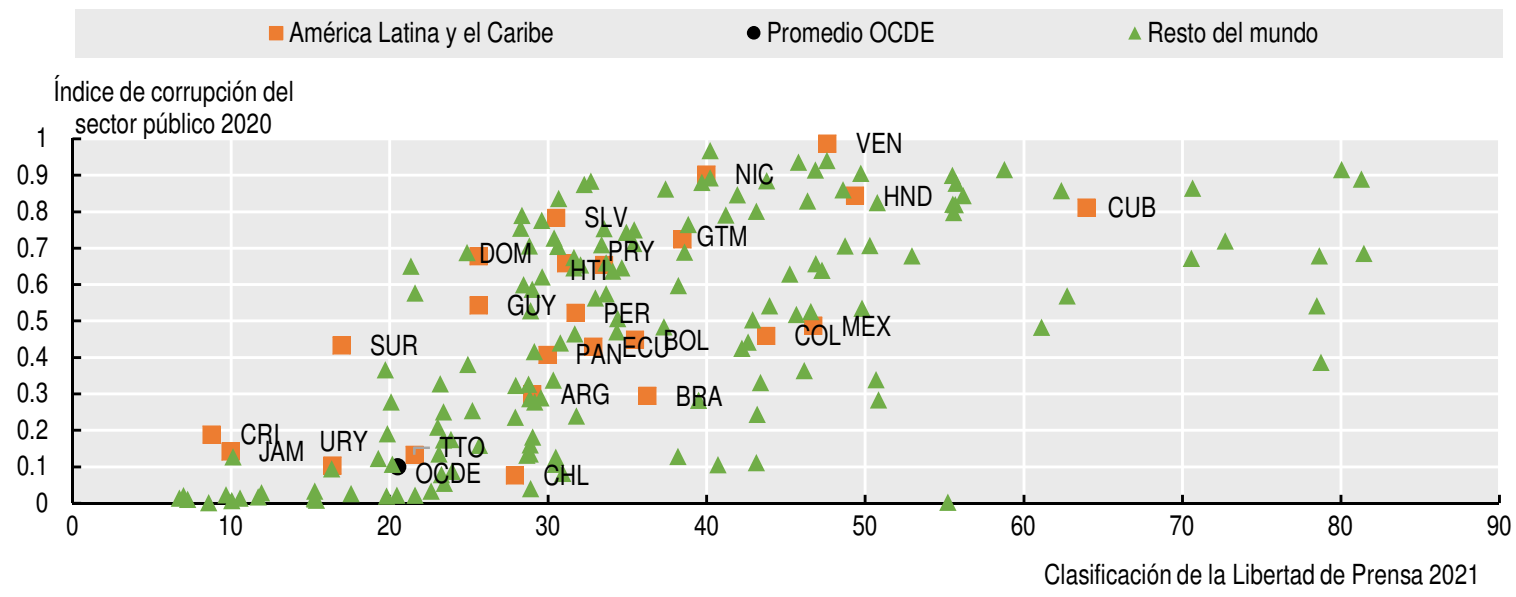

Notas: La Clasificación Mundial de la Libertad de Prensa tiene en cuenta las respuestas de los expertos a un cuestionario sobre el comportamiento de los países en relación con el pluralismo, la independencia de los medios de comunicación y el respeto de la seguridad y la libertad de los periodistas y las combina con datos cuantitativos sobre abusos y actos de violencia contra los periodistas durante el período evaluado. Oscila entre 0 (mejor situación) y 100 (peor situación). El índice de corrupción del sector público oscila entre 0 (menos corrupto) y 1 (más corrupto). La expresión "resto del mundo" incluye a todos los países excepto los de ALC.

Fuentes: Coppedge et al. (2021 $\left.{ }_{[101]}\right)$, V-Dem 2020 Dataset v11.1, https://doi.org/10.23696/vdemds21; Reporteros sin Fronteras $\left(2021_{[102]}\right)$, Clasificación Mundial de la Libertad de Prensa 2021 (base de datos), https://rsf.org/es/clasificacion.

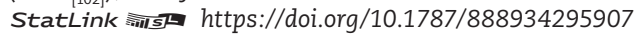

La fragmentación y la polarización de los partidos pueden dificultar la creación de consensos, subrayando así la necesidad de estructuras intermedias sólidas

Es fundamental contar con instituciones intermedias eficaces para lograr el consenso y para, una vez alcanzado, garantizar la sostenibilidad a largo plazo del nuevo contrato social. Al actuar como interlocutores entre los ciudadanos y el Estado, las instituciones intermedias, como los partidos políticos, los sindicatos y las asociaciones, ofrecen a los ciudadanos la oportunidad de expresar sus quejas y favorecen una mayor rendición de cuentas de las instituciones públicas (OCDE, 2021 $[103])$. De hecho, en general no es posible que los ciudadanos se comuniquen directamente con el Estado. Estas redes les permiten comunicar sus intereses de manera colectiva y organizada y también les ofrecen una forma de identificarse como grupo. Este diálogo bidireccional puede promover la cohesión social y proporcionar observaciones útiles a los responsables de la formulación de políticas durante la fase de implementación y posible ajuste de una reforma. Por otro lado, como se observa en la región con respecto a la pérdida de confianza en los partidos políticos, la incapacidad de efectuar cambios y de mediar entre los ciudadanos y el Estado puede dar lugar al desinterés cívico y a la desconfianza en las instituciones. 
La fragmentación y la polarización desvirtúan la función representativa de los partidos políticos

La fragmentación y la polarización de los partidos pueden suponer un problema para llegar a acuerdos y y encontrar intereses comunes sobre desafíos políticos compartidos. Esto es de vital importancia en un contexto de recuperación pos-pandemia, que va a requerir alcanzar grandes consensos en torno a las reformas necesarias. La volatilidad electoral en ALC es elevada debido a la creciente fragmentación de los partidos, y estos, en un contexto de alta incertidumbre perciben que los costos de la polarización son bajos y, por tanto, tienden a extremar sus posiciones (Moraes, $2015_{[104]}$ ). Esta estrategia dificulta la creación de consenso y afecta a la capacidad de los ciudadanos para entender los programas de los partidos (Carreras y Acácio, 2019 ${ }_{[105]}$ ).

La proliferación de partidos políticos en ALC está relacionada con su crisis de legitimidad y representación. Los nuevos partidos políticos suelen aparecer cuando no se atienden las demandas de la población o como consecuencia de crisis económicas y escándalos de corrupción que han provocado el rechazo de candidatos más tradicionales $\left(\right.$ Cyr y Liendo, $\left.2020_{[106]}\right)$. La proliferación de partidos políticos con representación efectiva en el poder legislativo caracteriza a muchos países de ALC y puede suponer un problema para la creación de consensos. En promedio, entre 2005 y las últimas elecciones, en ALC ha aumentado el número efectivo de partidos con representación en el poder legislativo (Gráfico 4.9). Algunos países, entre ellos Brasil, Chile, Guatemala y Perú, han observado un aumento considerable en el número de partidos con representación en el Congreso, mientras que otros han observado que los partidos con gran representación en el poder legislativo han disminuido a menos de dos, lo que demuestra que, en algunos países, la crisis de legitimidad también puede dar lugar a una mayor concentración de poder.

\section{Gráfico 4.9. Crisis de legitimidad y representación de los partidos políticos en América Latina}

Índice del número efectivo de partidos con representación en el poder legislativo en América Latina, en 2005 frente a las últimas elecciones, 2016-2021

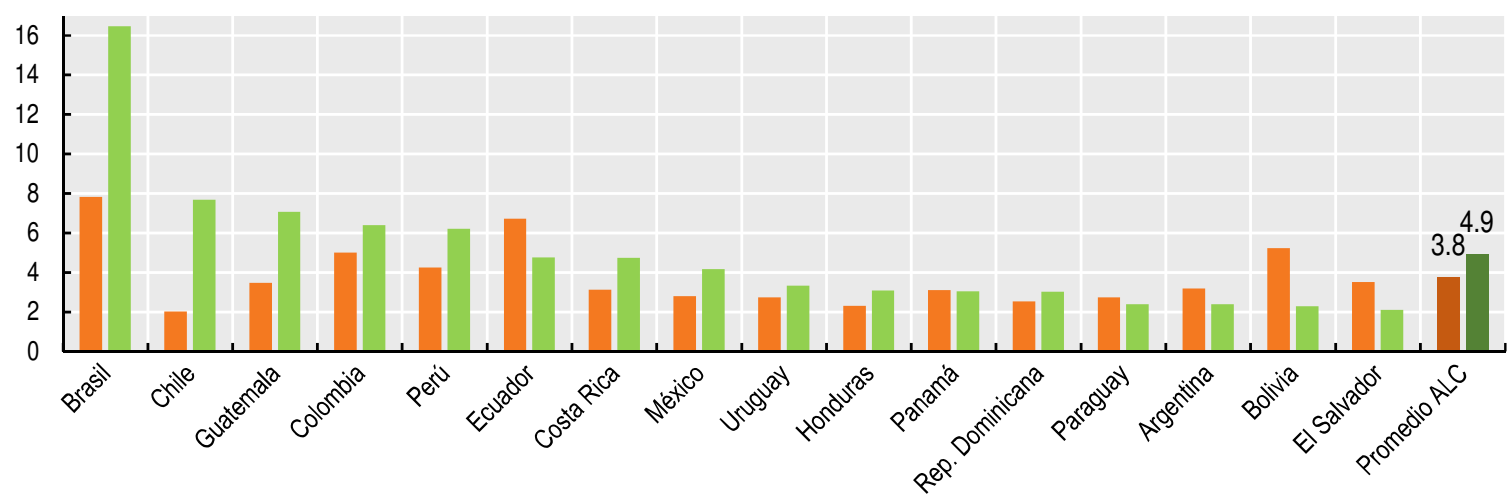

Notas: El índice no refleja el número real de partidos, sino su número efectivo teniendo en cuenta la proporción de escaños que cada uno de ellos posee. Mide la fragmentación legislativa en la cámara baja (o asamblea nacional). Los valores más altos indican que un mayor número de partidos poseen escaños en el órgano legislativo que les permiten tener voz en el proceso de formulación de políticas. Los cálculos tienen en cuenta las últimas elecciones legislativas, que tuvieron lugar entre noviembre de 2016 (Nicaragua) y junio de 2021 (México). Hay que tener en cuenta que la reforma del sistema electoral de 2015 en Chile puede haber afectado a los resultados del país.

Fuente: Elaboración propia a partir de la metodología de Laakso y Taagepera $\left(1979_{[107)}\right)$, “The 'effective' number of parties: A measure with application to West Europe", http://dx.doi.org/10.1177/001041407901200101 y Jones (2005 $\left.{ }_{[108]}\right)$, The Role of Parties and Party Systems in the Policymaking Process, https://citeseerx.ist.psu.edu/viewdoc/download?doi=10.1.1.542.1866\&rep=rep1 \&type $=$ pdf.

StatLink नints https://doi.org/10.1787/888934295926 
La elevada heterogeneidad afecta no solo al número de partidos capaces de influir eficazmente en el proceso de formulación de políticas en ALC, sino también al grado de polarización y al nivel de competencia entre partidos. Si el nivel de polarización es bajo, las coaliciones son más frecuentes, y la fragmentación tiende a disminuir (Wills-Otero, $\left.2020_{[109]}\right)$. En algunas democracias, como Chile, Costa Rica, Honduras y Uruguay, las pautas de la competencia entre partidos han sido mucho más estables, lo que sugiere que hay que evitar las generalizaciones sobre la volatilidad y la institucionalización del sistema en la región (Carreras y Acácio, $2019_{[105]}$ ).

Las reivindicaciones identitarias de los grupos minoritarios e infrarrepresentados, como los pueblos indígenas o afrodescendientes, han contribuido al surgimiento de nuevos partidos políticos, por ejemplo, en Bolivia, Colombia y Ecuador. Los procesos de descentralización política que tuvieron lugar en algunos países de ALC han contribuido aún más a la proliferación de los partidos. Estas tendencias pueden percibirse como un avance hacia la consolidación democrática y la competitividad electoral, ya que los ciudadanos pueden elegir entre distintos partidos políticos y opiniones, lo que aumenta la inclusión, la diversidad y la representación de los grupos minoritarios. Sin embargo, estas tendencias también pueden dar lugar a la fragmentación al aumentar los costos de la coordinación y la competencia entre partidos, lo que añade dificultades a la gobernanza. Asimismo, dada la baja institucionalización de los partidos políticos, estas tendencias pueden ser incapaces de canalizar eficazmente los intereses de los ciudadanos. También los bajos niveles de apoyo de los partidos pueden ser peligrosos para la legitimidad democrática, especialmente cuando proliferan los discursos populistas (Cyr y Liendo, $\left.2020_{[106]}\right)$.

En cerca de la mitad de los países de ALC analizados, la volatilidad electoral ha aumentado recientemente con respecto al período anterior, mientras que en otros ha disminuido, gracias a la mayor institucionalización del sistema de partidos, como en Uruguay (Gráfico 4.10). La proliferación de partidos y la fragmentación de los sistemas políticos están contribuyendo a la volatilidad electoral (Mainwaring, $2018_{[110]}$ ) y, a medida que pasa el tiempo, está aumentando el porcentaje de voto de los partidos nuevos y no tradicionales en las elecciones nacionales y subnacionales (Cyr y Liendo, 2020 ${ }_{[106]}$; Carreras y Acácio, 2019 ${ }_{[105]}$; Laroze, 2019 ${ }_{[111]}$; Gerring, 2005 ${ }_{[112]}$ ). Durante las últimas décadas, los líderes independientes que no se ven condicionados por partidos fuertemente estructurados han aumentado sus posibilidades de ser elegidos. También pueden surgir nuevos líderes independientes como consecuencia de la crisis del COVID-19 (Murillo, $\left.2020_{[113]}\right)$.

La alta volatilidad electoral y la frágil institucionalización del sistema de partidos desestabilizan la representación democrática y dificultan el proceso de rendición de cuentas de los partidos, además de que pueden reprimir la creación de consensos y favorecer la adopción de políticas más radicales, ya que los partidos están menos preocupados por su reputación a largo plazo o limitados por su organización política. También afectan a la capacidad de los ciudadanos para entender la política programática y aumentan la frustración de los votantes. Por último, la alta volatilidad electoral menoscaba la representación democrática, ya que es más difícil para los votantes exigir responsabilidades a los partidos y a los políticos por su desempeño en el cargo (Carreras y Acácio, $2019_{[105]}$ ). Como consecuencia, en varios países de ALC ha proliferado la desconfianza entre el electorado (Wills-Otero, 2020 ${ }_{[109]}$; Lupu, 2016 ${ }_{[114]}$ ). 


\section{Gráfico 4.10. Volatilidad electoral en América Latina}

Índice de Pedersen de volatilidad electoral en las elecciones legislativas, 1998-2017*

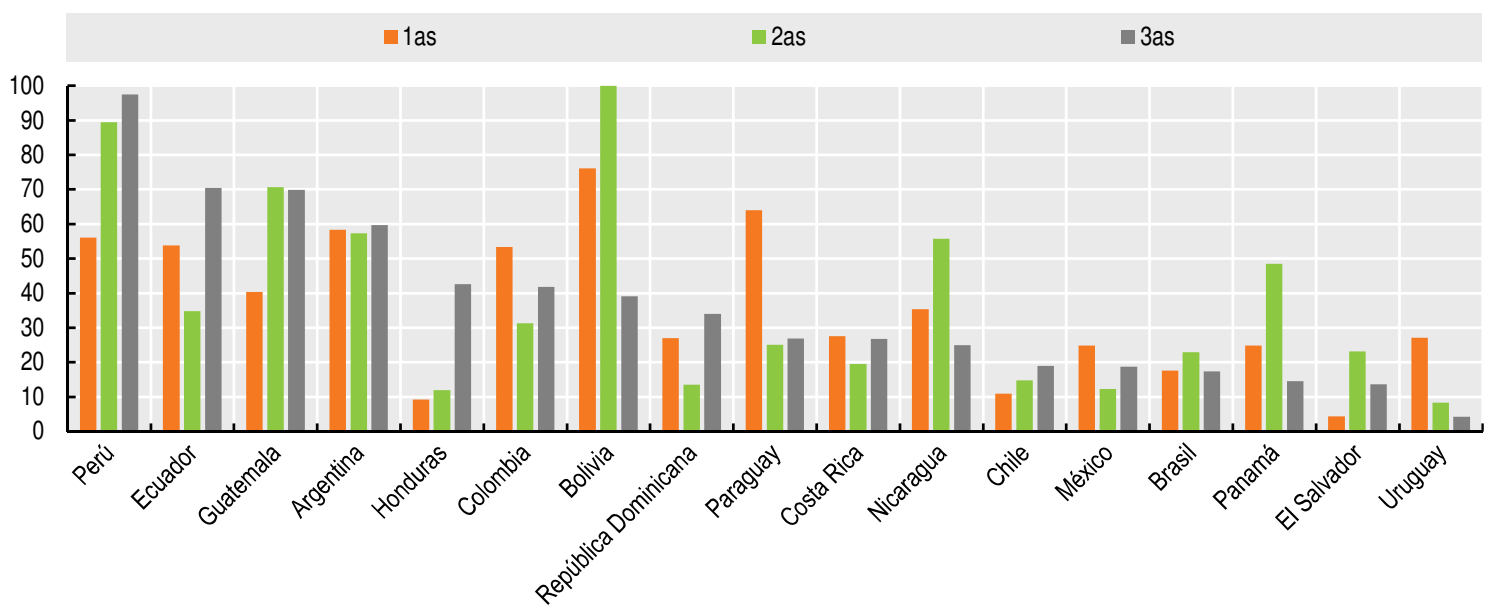

Nota: *Las cifras comparan el cambio en la volatilidad electoral en cuatro elecciones legislativas consecutivas durante el período 1998-2017. La barra naranja tiene en cuenta el cambio que tuvo lugar a principios de la década de 2000; la barra verde, el de mediados de la década de 2000; y la barra gris se refiere al de principios de la década de 2010. El índice de Pedersen oscila entre 0 y 100, que corresponden a la variación neta de los porcentajes de voto: 0 significa que ningún partido ha perdido o ha aumentado su porcentaje de votos (o escaños); 100 significa que un nuevo conjunto de partidos ha obtenido todos los votos (o escaños). El índice de Pedersen sigue siendo la medida de referencia para reflejar la estabilidad en las pautas agregadas de la competencia entre partidos, ya que mide el grado de transferencia de votos entre partidos políticos en dos elecciones consecutivas.

Fuente: Cálculos propios basados en datos de Roberts y Wibbels (1999 $\left.{ }_{[117]}\right)$, "Party Systems and Electoral Volatility in Latin America" y (Cohen, $2018_{[118]}$ ), conjunto de datos Latin American Presidential and Legislative Elections, www.molliecohen.com/ data.html.

StatLink तiाst https://doi.org/10.1787/888934295945

Además, los sistemas multipartidistas y el presidencialismo pueden representar una ecuación inestable para la democracia (Mainwaring, $1997_{[115]}$ ). A raíz de la proliferación de los partidos políticos en ALC, pueden desarrollarse otras formas de gobierno más tendentes al parlamentarismo para beneficiar a partidos programáticos y más institucionalizados (Croissant y Merkel, 2004 ${ }_{[116]}$ ).

La captura de políticas puede desvirtuar de manera considerable el impacto de las políticas públicas

En una democracia, las consultas públicas, el cabildeo o el financiamiento de los partidos políticos y las campañas son medios legales y legítimos a través de los cuales las partes interesadas pueden expresar sus puntos de vista y preocupaciones. Sin embargo, estas prácticas también pueden dar lugar a "zonas grises" en las que los intereses de grupos específicos pueden ejercer una influencia indebida en la toma de decisiones públicas a expensas del bien común. La captura de políticas se define como "aquel proceso mediante el cual las decisiones de política pública se desvían constante y sistemáticamente del interés público hacia intereses particulares de personas o grupos específicos" (OCDE, 2017 ${ }_{[119]}$; Carpenter y Moss, 2014 ${ }_{[120]}$ ). La captura de políticas puede adoptar muchas formas, como el financiamiento de partidos políticos, las campañas mediáticas con información manipulada, el cabildeo feroz y la puerta giratoria entre el sector privado y el público (Cañete Alonso, 2018 ${ }_{[121]}$ ). Los altos niveles de corrupción y desigualdad, así como la gran concentración de poder económico y mediático, aumentan el riesgo de captura de políticas en ALC, ya que facilitan el acceso de grupos privilegiados a los responsables de la toma de decisiones políticas (OCDE, 2017 ${ }_{[119]}$; OCDE et al., 2019 ${ }_{[2]}$ ). 
La captura tiene efectos negativos en la economía y la sociedad. Va en contra de la idea fundamental de una toma de decisiones democrática y justa basada en el diálogo, el consenso y la apertura, y erosiona la cohesión social y la confianza en las instituciones. También provoca una asignación inadecuada de los recursos públicos, lo cual es perjudicial para el crecimiento de la productividad y puede aumentar las desigualdades.

El financiamiento político y el cabildeo a funcionarios son las formas más comunes en que los grupos poderosos pueden socavar la integridad de la toma de decisiones públicas. Uno de los ejemplos más paradigmáticos de estos mecanismos es el conocido escándalo de Odebrecht. A excepción de algunos países de América Central, en ALC el financiamiento político está ampliamente regulado (International IDEA, 2020 ${ }_{[122]}$ ), pero todavía existe una brecha en su implementación, y en 11 de los 12 países encuestados, se permitieron contribuciones en efectivo en 2018, facilitando de este modo la elusión de las regulaciones políticas financieras. Por otra parte, países como Argentina (2003), Colombia (2011), Chile (2014), México (2010) y Perú (2003) han aprobado leyes o reglamentos sobre el cabildeo. Chile, Colombia y México tienen un registro de cabilderos, y de estos tres países, Colombia no impone sanciones por incumplimiento. Solo cuatro países (Argentina, Chile, México y Perú) requieren que las agendas de los funcionarios sean públicas, y cinco países (Argentina, Colombia, Costa Rica, México y Perú) requieren revelar los nombres de los miembros de los órganos consultivos permanentes (OCDE, 2020 ${ }_{[123]}$ ). ${ }^{2}$ Las primeras observaciones confirman que los países con un marco normativo para mejorar la transparencia de las actividades de cabildeo, y de la elaboración de políticas en general, garantizaron un mayor grado de responsabilidad en las decisiones políticas durante la crisis de COVID-19 (OCDE, 2021 $\left.1_{[124]}\right)$.

Para mitigar los riesgos de captura de políticas, es fundamental un sistema integral que fomente una cultura de integridad y rendición de cuentas en la toma de decisiones públicas. Cuatro estrategias complementarias pueden contribuir a salvaguardar la imparcialidad y la inclusión en la formulación de políticas. En primer lugar, asegurar la transparencia y el acceso a información confiable, oportuna y relevante puede facilitar la participación y el compromiso de las partes interesadas y el control social sobre los procesos de toma de decisiones públicas (OCDE, 2017 ${ }_{[119]}$ ). Sin embargo, una mayor transparencia debe ir acompañada de reformas institucionales más amplias, en particular en los países altamente corruptos donde la información puede incluso resultar contraproducente y causar resignación (p. ej., menos participación cívica) o indignación (Bauhr y Grimes, 2014 ${ }_{[125]}$; Corbacho et al., 2016 ${ }_{[164]}$; Peiffer, 2018 ${ }_{[165]}$ ). En segundo lugar, requiere la participación de actores con intereses divergentes para ayudar a equilibrar los puntos de vista y garantizar un campo de juego nivelado menos proclive a la captura. Asimismo, requiere reforzar la legislación en materia de cabildeo y financiamiento político. En tercer lugar, las autoridades que defienden la competencia, las agencias reguladoras y las entidades fiscalizadoras superiores pueden promover la rendición de cuentas tanto en el sector público como en el privado. Por último, unas políticas de integridad organizacional adecuadas pueden ayudar a identificar y controlar el riesgo de captura. Establecer normas de conducta claras, promover una cultura de la integridad y garantizar un control sano y un marco de gestión de riesgos puede contribuir a que las organizaciones públicas sean más resistentes a la captura (OCDE, 2017 ${ }_{[119]}$ ).

La economía del comportamiento ha generado gran evidencia que los responsables de la formulación de política pública pueden aprovechar para desarrollar políticas de integridad innovadoras y bien orientadas. Alejarse de un enfoque estrecho basado en la disuasión y la aplicación de la ley puede ayudar a promover decisiones íntegras basadas en un conjunto de valores que se arraiguen en el sector público y en la sociedad. Por ejemplo, la economía del comportamiento muestra que inducir la reflexión ética y preparar a los responsables de la toma de decisiones para las tentaciones éticas puede ser más eficaz 
que un control excesivamente estricto de una norma basada en la confianza, que puede llevar a las personas a desatender e incumplir la norma (OCDE, 2018 ${ }_{[126]}$ ).

La economía política de las reformas desempeña un papel clave, especialmente en el contexto de la recuperación posterior a la crisis

En los procesos de formulación de políticas intervienen múltiples agentes con diferentes horizontes temporales, y con diversas cuotas de poder y motivaciones (Spiller, Stein y Tommasi, $\left.2008_{[127]}\right)$. Esta complejidad es la causa de que resulte difícil implementar las reformas, a pesar de sus efectos positivos a largo plazo, porque a menudo entrañan la negociación de costos transitorios o distributivos. Las buenas políticas públicas pueden dar malos resultados en su fase de implementación si no se tienen en cuenta estas limitaciones de la economía política. En primer lugar, en las reformas hay ganadores y perdedores. Estos últimos tienen importantes motivaciones para bloquear las reformas que van en contra de sus intereses (Martínez Franzoni y Sánchez-Ancochea, 2020 ${ }_{[71]}$ ). En segundo lugar, las reformas pueden ocasionar costos a corto plazo a pesar de su potencial para aumentar el bienestar a largo plazo, lo que las hace menos populares en el futuro inmediato (Rodrik, 1996 ${ }_{[128]}$; Williamson, $1994_{[129]}$; OCDE, 2018 ${ }_{[130]}$ ). Aprender de experiencias anteriores puede ser importante para que el diseño y la ejecución de las reformas sean un éxito (Caldera Sánchez, de Serres y Yashiro, 2016 ${ }_{[131]}$; OECD, 2010 ${ }_{[134]}$; Tompson, 2009 ${ }_{[28]}$ ).

Para superar la resistencia de las personas, es clave tener en cuenta políticas complementarias que mitiguen el impacto distributivo de una reforma o compensen sus costos a corto plazo. A fin de obtener un amplio apoyo político, tal vez sea preciso elaborar sistemas adecuados de compensación o amortiguación para las personas que puedan verse afectadas negativamente por la reforma (OECD, 2010 ${ }_{[134]}$; OCDE, 2018 ${ }_{[130]}$ ). Por ejemplo, a medida que en la región se vayan introduciendo los impuestos medioambientales, la incorporación de programas de ayuda a los ingresos para los hogares pobres en paquetes más amplios de reformas de la subvención de la energía puede ayudar a mitigar el efecto negativo inmediato sobre las finanzas de los hogares derivado de la eliminación gradual de las subvenciones. Además, algunas reformas pueden ser más eficaces cuando se combinan en paquetes que aumentan sus sinergias que cuando se llevan a cabo aisladamente (Caldera Sánchez, de Serres y Yashiro, 2016 ${ }_{[131]}$; Dayton-Johnson, Londoño y Nieto Parra, $\left.2011_{[75]}\right)$.

Dado que en ALC está aumentando la desconfianza en las instituciones, para que las reformas tengan éxito es fundamental un mandato claro y un liderazgo firme. Si el gobierno no tiene un mandato electoral claro, solo suelen hacerse reformas cuando hay evidencia de que las políticas vigentes no están funcionando, lo que puede ser el caso en el contexto posterior a una crisis. Sin embargo, con este enfoque se corre el riesgo de que las políticas sean más reactivas que proactivas y de que las reformas se retrasen hasta que sean imprescindibles debido a las crisis (Rodrik, $1996_{[128]}$ ). La falta de mandato también socava la titularidad de las reformas y aumenta la probabilidad de que estas se reviertan a causa del cambio de gobierno, especialmente dado el alto nivel de volatilidad electoral y de fragmentación de los partidos observado en ALC. El firme liderazgo de un único responsable de la formulación de políticas o de una institución también contribuye a que no se disipe el impulso de las reformas (OECD, 2010 ${ }_{[134]}$; OCDE, 2018 ${ }_{[130]}$ ).

Al mismo tiempo, en un contexto caracterizado por la polarización de los discursos políticos y el aumento de la desinformación en las redes sociales, el análisis y la evaluación con base empírica y la comunicación eficaz son aspectos importantes para arrojar luz sobre los beneficios de una reforma (Matasick, Alfonsi y Bellantoni, 2020 ${ }_{[132]}$ ). Es esencial que los argumentos se basen en análisis e investigaciones sólidos llevados a cabo por 
instituciones con autoridad e imparciales, especialmente a la luz de la poca confianza en los partidos políticos y las instituciones públicas observada en ALC. Para ello también es necesario invertir en la recopilación de datos, crear oficinas nacionales de estadística sólidas y comprometerse a realizar evaluaciones a posteriori. Por lo tanto, una estrategia de comunicación eficaz basada en el conocimiento de la audiencia y la transmisión de mensajes específicos a través de una multitud de plataformas es importante para concienciar sobre los beneficios de la reforma de las políticas, que a menudo pueden ser menos evidentes que las desventajas (OCDE, 2018 ${ }_{[130]}$; OCDE DevCom, 2020 ${ }_{[133]}$; OCDE, $2010_{[134]}$; Tompson, 2009 ${ }_{[28]}$ ). Por ejemplo, en algunos países de ALC debería avanzarse en la sensibilización sobre la importancia de la progresividad y la solidez de los regímenes de jubilación en vista del envejecimiento de la población (Capítulo 2). Las instituciones públicas que traten de hacer participar a los ciudadanos en las reformas tendrán que invertir en nuevas asociaciones y técnicas de comunicación, y elegir los medios y formatos apropiados para atraer a distintas audiencias, en línea (p. ej., en las redes sociales) y fuera de línea (OCDE DevCom, 2020 ${ }_{[133]}$; OCDE, Próximo a publicarse $\left.{ }_{[135]}\right)$.

La secuencia adecuada de las reformas y su ritmo también desempeñan un papel esencial para que su implementación sea un éxito. Por ejemplo, se aconseja generalmente que la estabilización fiscal y monetaria, así como las reformas institucionales, precedan a reformas más complejas, como la liberalización del comercio o de la cuenta de capital (Nsouli, Rached y Funke, $2005_{[136]}$ ). El éxito de las reformas iniciales puede ayudar a aumentar el apoyo y facilitar la implementación de las reformas posteriores. Una secuencia adecuada también debería evitar los brotes de desigualdad, que probablemente impidan seguir avanzando en el proceso de reforma (Guriev, $2018_{[137]}$; Aristei y Perugini, $2014_{[138]}$ ). Además, el ritmo óptimo de las reformas es específico para cada país, y es esencial elegir entre impulsar tantas reformas como sea posible a la vez (lo que se conoce como "big bang approach" en inglés) o implementarlas una por una ("unbundling strategy" en inglés). Según el contexto, los responsables de la formulación de políticas pueden preferir agrupar las reformas en un paquete integral para compensar las pérdidas derivadas de una reforma con los beneficios obtenidos en otras (Dayton-Johnson, Londoño y Nieto Parra, 2011 ${ }_{[75]}$ ) o, si esto no es posible, lograr acuerdos específicos y avances en políticas sectoriales en las que exista posibilidad de acuerdo.

La credibilidad y el apoyo a la política también son esenciales para el éxito de las reformas y el control de los costos que se deriven de ellas. Cuando las reformas son creíbles, el anuncio anticipado de las políticas tendrá el efecto de alinear el comportamiento de los agentes privados con los objetivos esperados por los responsables de la formulación de políticas (Nsouli, Rached y Funke, $2005_{[136]}$ ). El compromiso político genera un entorno estable en el que los agentes pueden llegar a acuerdos en materia de políticas que sobrevivan al cambio de gobierno o de gabinete (Spiller, Stein y Tommasi, $2008_{[127]}$ ).

Por último, el momento es especialmente importante y, aunque según la literatura académica las reformas suelen ser más frecuentes en tiempos negativos, los desafíos a corto plazo de las reformas también suelen ser mayores durante las crisis que en épocas de bonanza económica (Ciminelli et al., 2019 ${ }_{[139]}$ ). Las reformas emprendidas en épocas prósperas pueden encontrarse con una mayor oposición, pero también permiten tener más tiempo de preparación, del que puede que no se disponga durante las emergencias. Los costos de ajuste y la compensación de los perdedores también tienden a ser más asequibles durante los buenos tiempos (OCDE, 2018 ${ }_{[130]}$ ). Sin embargo, la historia muestra que las reformas estructurales y normativas son más frecuentes durante los malos tiempos (Ranciere y Tornell, $2015_{[140]}$ ). Como ejemplos cabe destacar las reformas realizadas en Europa a raíz de la crisis del euro o las reformas comerciales llevadas a cabo en ALC en las décadas de 1980 y 1990. 
La sensibilización sobre la magnitud de la crisis actual puede aumentar la percepción de la necesidad de cambios significativos. Una crisis bien gestionada supone una enorme oportunidad para que los países adopten medidas exigentes (BID, 2020 ${ }_{[141]}$; OCDE, 2020 ${ }_{[1]}$ ). La renovación del contrato social implicaría pasar del actual statu quo fragmentado a un nuevo equilibrio basado en la igualdad de oportunidades a largo plazo (Larraín, $2021_{[142]}$ ). Un contrato social más amplio contribuiría a abordar el profundo sentimiento de descontento causado por las crecientes desigualdades y las políticas obsoletas, al incluir a todos los agentes en el debate y al reforzar las instituciones democráticas y la economía abierta de mercado.

Estas consideraciones son particularmente pertinentes en el contexto posterior a la pandemia, en el que la reconstrucción entrañará un fuerte impulso político y una gestión racional de las complejidades de la economía política de las reformas.

\section{Las escasas capacidades institucionales pueden limitar la implementación de las políticas}

Los gobiernos deben seguir fortaleciendo sus funciones básicas para asegurar un impacto óptimo de las políticas públicas. Entre las áreas de trabajo importantes figuran la mejor coordinación de políticas, el fortalecimiento de la capacidad y las competencias administrativas, especialmente en los gobiernos subnacionales y locales, la simplificación de los procesos administrativos, el fortalecimiento de la contratación pública y la inversión, la garantía de la rendición de cuentas interna y externa y el fomento de una administración pública basada en los méritos. En gran medida, la calidad de la aplicación de las políticas depende de la solidez del poder judicial y de la Administración, así como de los recursos y los incentivos de que disponen (Spiller, Stein y Tommasi, $2008_{[127]}$ ).

La contratación pública puede ser una herramienta estratégica para alcanzar los ODS. La integración de los objetivos de la política económica, social y medioambiental en los procesos de contratación pública-como los criterios de selección y adjudicación de contratos, las especificaciones técnicas y las cláusulas contractuales-puede incentivar a las empresas a alinearse con la agenda gubernamental sobre desarrollo sostenible y las normas de RBC. Por ejemplo, ChileCompra introdujo un programa para promover la participación de las empresas de propiedad femenina en el mercado de la contratación pública (OCDE, 2020 ${ }_{[143]}$ ).

Además, los datos de contratación abiertos pueden hacer que la gobernanza sea más inclusiva y democrática. Por ejemplo, inmediatamente después del brote de COVID-19, países como Costa Rica, Ecuador, Paraguay y Perú crearon portales de transparencia para divulgar la información sobre las contrataciones realizadas en respuesta a la emergencia de COVID-19, incluida la información sobre los procedimientos de adjudicación directa. La creación de una cultura de transparencia, rendición de cuentas y acceso a la información pública también puede estimular la participación ciudadana en el proceso de contratación pública. Por ejemplo, los testigos sociales en México están obligados a participar en todas las etapas de los procedimientos de contratación pública federal por encima de ciertos umbrales, como forma de promover el escrutinio público. Perú puso en marcha un mecanismo de control ciudadano (Monitores Ciudadanos de Control) que permite a los ciudadanos visitar las obras al principio, durante y/o al final de las mismas para supervisar el progreso de la construcción. Colombia introdujo una aplicación móvil anticorrupción llamada Elefantes Blancos para promover el control ciudadano de los proyectos de elefantes blancos (proyectos de obras públicas descuidados, abandonados o sobrefacturados) (OCDE, 2020 $\left.{ }_{[144]}\right)$.

Las políticas públicas solo alcanzarán sus objetivos si se sustentan en un marco institucional sólido que favorezca la rendición de cuentas, la inclusión, la eficiencia y la accesibilidad (Staats, Bowler y Hiskey, $2008_{[145]}$ ). A este respecto, es fundamental contar 
con un sistema judicial independiente y fiable para mantener los controles y contrapesos entre el poder ejecutivo y el legislativo. Un poder judicial que garantice una aplicación imparcial del Estado de Derecho e impida que la violencia se repita sentará las bases para un desarrollo económico sostenible y una democracia duradera (Hilbink y Prillaman, $\left.2002_{[146]}\right)$.

Durante la última década del siglo XX, los países de ALC carecieron de un mecanismo institucional sólido y de un poder judicial fiable para garantizar la observancia efectiva de los derechos humanos y civiles conducentes al crecimiento económico. Haciéndose eco de estos problemas, la mayoría de los países de la región emprendieron un largo proceso de reforma institucional y judicial que continúa a día de hoy (DeShazo y Vargas, $2006_{[147]}$ ). A pesar de los esfuerzos realizados, la impunidad de los autores de crímenes pasados, la corrupción y la falta de voluntad política y los recursos limitados siguen siendo problemas difíciles en toda la región. Es necesario realizar un diagnóstico preciso de las deficiencias de cada sistema judicial antes de implementar cualquier reforma a fin de comprender las causas de los fallos pasados y los escasos resultados. El Índice Global de Impunidad, que mide el funcionamiento y la estructura de los sistemas de seguridad y justicia nacionales, así como el respeto de los derechos humanos, sitúa a los países de ALC en mayores niveles de impunidad que en el promedio de la OCDE (Gráfico 4.11).

\section{Gráfico 4.11. El nivel de impunidad en ALC sigue siendo entre medio y alto}

Índice Global de Impunidad 2020

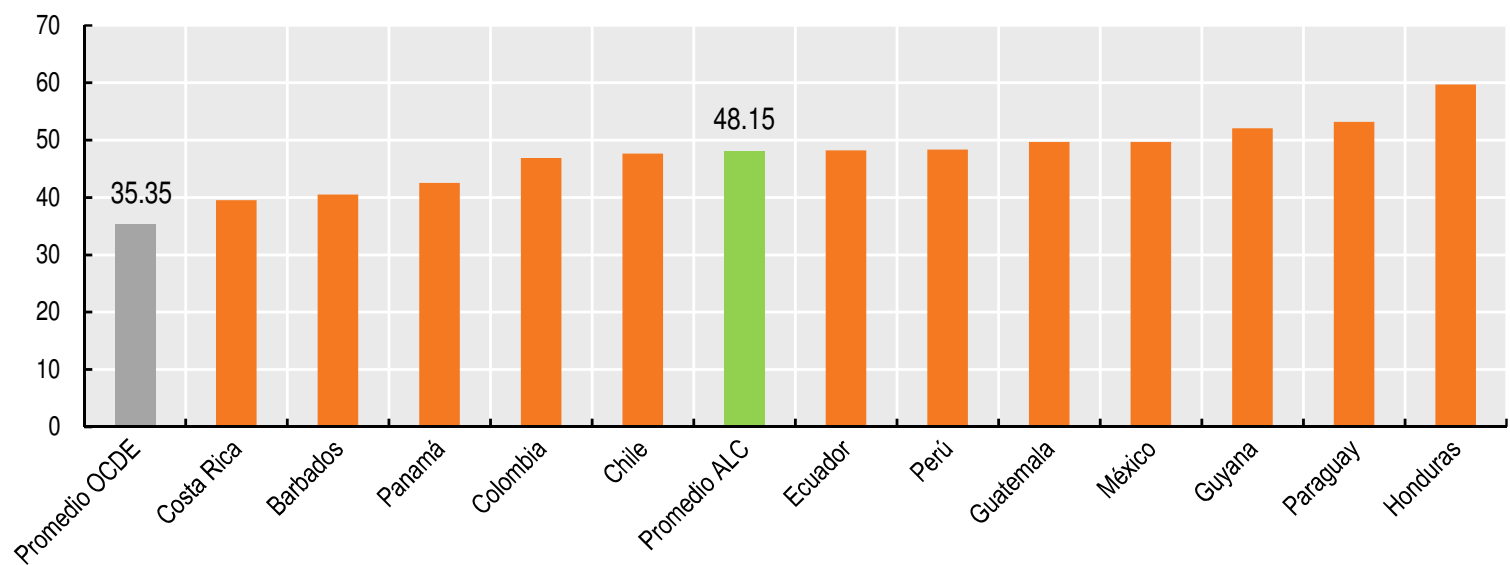

Notas: Promedio no ponderado de ALC de 16 países. Debido a las incoherencias detectadas en los datos, no se dispone de los de 2020 para Argentina, Brasil, El Salvador, Granada, Nicaragua, República Dominicana, Trinidad y Tobago y Venezuela. El Índice Global de Impunidad oscila entre 0 y 100, donde 0 equivale a la falta de impunidad y 100 al máximo nivel de impunidad en un período concreto de tiempo.

Fuentes: CESIJ $\left(2020_{[148]}\right)$, Índice Global de Impunidad 2020 (IGI-2020) (base de datos), www.udlap.mx/cesij; CESIJ (2017 ${ }_{[149]}$ ), Índice Global de Impunidad 2017 (IGI-2017) (base de datos), www.udlap.mx/cesij.

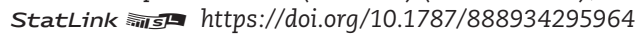

El Centro de Gobierno (CdG) también desempeña un papel clave en el apoyo al jefe de gobierno y al Gabinete o Consejo de Ministros. Entre las funciones del CdG figuran la coordinación y el seguimiento de las políticas públicas para asegurar que las acciones de los ministerios competentes se ajusten a las prioridades gubernamentales. El CdG es también responsable de la gestión estratégica y del diseño de políticas que promuevan el gobierno abierto, la buena gobernanza, la rendición de cuentas y la transparencia (OCDE, $\left.2020_{[123]}\right)$.

Sector público basado en datos y gobernanza de datos en ALC

Un sector público basado en datos es clave para una gobernanza de los datos que promueva el diseño, la implementación, el seguimiento y la evaluación de los nuevos 
pactos sociales. La crisis del COVID-19 en ALC ha demostrado el potencial de los datos para generar valor público de varias maneras: i) anticipación y planificación, por ejemplo, para pronosticar la evolución de los contagios y la ocupación de las unidades de cuidados intensivos; ii) ejecución, por ejemplo, utilizando datos sobre los trabajadores informales para diseñar políticas específicas de ayuda a través de transferencias de renta durante los confinamientos; y iii) seguimiento y evaluación, por ejemplo, utilizando datos sobre la contratación pública para auditar las compras de emergencia. Unos datos abiertos y fiables también pueden apoyar el proceso de formulación de políticas y ayudar a sentar las bases de reformas complejas durante la recuperación. En el futuro, será importante no solo invertir en el fortalecimiento de los sistemas estadísticos, sino también adoptar un enfoque de "apertura por defecto" en todo el gobierno. Este último enfoque se centra en potenciar la publicación de datos gubernamentales abiertos para su reutilización y la cocreación de valor con el objetivo de aumentar la transparencia e integridad del sector público, fomentar el desarrollo y la innovación social y luchar contra la corrupción (OCDE, $2017_{[150]} ;$ OCDE, 2020 $\left.{ }_{[151]}\right)$.

Sin embargo, los resultados del Índice de Datos Abiertos, Útiles y Reutilizables (OURdata) de la OCDE para ALC siguen mostrando grandes disparidades en relación con la publicación de datos gubernamentales abiertos y su uso para la rendición de cuentas, la formulación de políticas y el diseño y la prestación de servicios (OCDE, 2020 ${ }_{\text {[96] }}$ ). Además, el Índice de Gobierno Digital de la OCDE de 2019 muestra que, entre todos los países participantes, incluidos 7 gobiernos de ALC, lograr un sector público impulsado por los datos sigue siendo uno de los desafíos clave para un gobierno digital competente y orientado a los datos (OCDE, 2020 ${ }_{[94]}$ ).

Los gobiernos también deberían adoptar medidas para garantizar el uso eficiente y ético de los datos a fin de aprovechar los beneficios de la generación exponencial de datos en la era digital sin comprometer la intimidad de los ciudadanos (OCDE, 2020 ${ }_{[151]}$; OCDE, 2019 $[152]$ ) o la exclusión de grupos de población específicos debido a sesgos en la generación de datos o el desarrollo de algoritmos (OCDE, 2021 ${ }_{[153]}$; OCDE et al., 2020 ${ }_{[12]}$ ). Con unos marcos de gobernanza de datos deficientes se corre el riesgo de debilitar aún más la confianza pública en los gobiernos, que ya es baja en ALC. Los avances en los marcos regulatorios de protección de datos en ALC son desiguales (OCDE et al., 2020 ${ }_{[12]}$; OCDE, Próximo a publicarse $\left.{ }_{[154]}\right)$.

Además, a pesar de los avances, en promedio, ALC muestra un nivel básico en términos de seguridad digital (BID/OEA, $2020_{[155]}$ ). En el futuro, será esencial garantizar la gestión ética y segura de los datos, con el respaldo de unos marcos eficaces de privacidad y de seguridad digital.

\section{Las estrategias nacionales de desarrollo son un instrumento necesario para garantizar una visión coherente y a largo plazo}

Para que el contrato social sea sostenible a lo largo del tiempo se requiere una planificación minuciosa y estratégica a nivel nacional. Los planes nacionales de desarrollo (PND) constituyen un instrumento de gran utilidad para garantizar que las reformas comprendidas en el nuevo contrato social estén bien diseñadas y adopten una visión coherente a largo plazo. Hacer frente a desafíos en materia de desarrollo cada vez más complejos e interconectados requiere una lógica clara e integral, a fin de hacer partícipes a lo largo del tiempo al conjunto de las instituciones públicas de todos los ámbitos. Las principales dimensiones que contribuyen a la eficacia de los PND son: i) indicadores y objetivos claros para definir prioridades, asignar recursos financieros y monitorear e identificar brechas pendientes; ii) un marco jurídico sólido que dote al plan de autoridad; iii) un vínculo con el presupuesto nacional, que permita valorar la viabilidad de cada política; 
iv) inclusión de una dimensión subnacional y participación pública en la formulación del plan, que le confiera mayor legitimidad; v) un organismo especializado responsable de la formulación de los PND para aumentar el compromiso y los conocimientos técnicos necesarios; y vi) seguimiento y evaluación, que son fundamentales para valorar la implementación y posibilitar el aprendizaje, la determinación de prioridades y la mejora de las políticas a lo largo del tiempo (OCDE et al., 2020 ${ }_{[12]}$ ).

El logro de un contrato social más amplio puede conllevar varios pactos sociales, y los PND pueden ayudar a mantener una visión integral en todos los sectores. En la elaboración del contrato social, es importante tener en cuenta las interacciones entre las diferentes políticas, como, por ejemplo, la forma en que las políticas de protección social y del mercado laboral, así como las políticas productivas, pueden respaldar la creación de empleos formales y de buena calidad que logren un mayor bienestar social. En comparación con el enfoque compartimentado, los PND son esenciales para evaluar los posibles efectos indirectos de las políticas, coordinar los ámbitos de intervención y establecer objetivos transversales claros para orientar las actuaciones en materia de políticas, como la sostenibilidad, la inclusión y la resiliencia (Soria Morales, 2018 [156]; OCDE, 2019 ${ }_{[157]}$ ). Los gobiernos de ALC están haciendo muchos esfuerzos para promover una visión centrada en el bienestar y la sostenibilidad de las personas, pero se puede hacer más para fortalecer los aspectos no económicos de los PND, y para vincular la visión plasmada en los PND con los procesos reales de implementación (OCDE, Próximo a publicarse $\left._{[158]}\right)$.

Los PND son fundamentales para garantizar la coherencia no solo entre las políticas sectoriales, sino también entre los distintos niveles de gobierno. Los PND pueden ayudar a promover las sinergias entre las políticas nacionales, regionales y locales a fin de mejorar la armonización de los objetivos económicos, sociales y ambientales con el fin de garantizar un enfoque integrado para lograr la Agenda 2030 (OCDE, Próximo a publicarse ${ }_{[158]}$ ). La planificación multinivel es importante para promover acciones coordinadas en todos los niveles de gobierno (OCDE, 2019 ${ }_{[159]}$ ). En ALC, la reactivación de la planificación del desarrollo desde principios de la década de 2000 ha ido acompañada de una creciente participación subnacional, en comparación con el enfoque más centralizado de la década de 1960 (Sandoval, Sanhueza y Williner, $2015_{[160]}$ ). Esta tendencia también ofrece margen para la implicación y la participación de las partes interesadas en la formulación, la implementación y la evaluación de la planificación del desarrollo (Naser, Williner y Sandoval, $2021_{[80]}$ ). En ALC, alrededor de 35 PND han incluido una consulta pública (CEPAL, 2021 $1_{[161]}$ ). Entre los ejemplos de procesos de planificación participativa cabe señalar el Sistema Nacional Descentralizado de Planificación Participativa de Ecuador (OCDE, Próximo a publicarse ${ }_{[154]}$ ), el PND K'atun Nuestra Guatemala 2032 de Guatemala (Sandoval, Sanhueza y Williner, $2015_{[160]}$ ) y el Plan Estatal de Desarrollo 2013-2033 del estado de Jalisco, México (Meza Canales, Gómez-Álvarez y Gutiérrez Pulido, 2016 ${ }_{[162]}$ ).

\section{Conclusiones}

La crisis del COVID-19 agravó las vulnerabilidades estructurales existentes en ALC en un contexto de aspiraciones ciudadanas insatisfechas, de profundización de la desconfianza en las instituciones públicas y de descontento social, como se ha visto en las protestas sociales. En este capítulo se ha expuesto por qué la región tiene que repensar su contrato social, y también se ha sugerido qué forma podría adoptar un contrato social renovado en ALC y cómo ha de ser el proceso para diseñarlo e implementarlo.

Los componentes de un contrato social pospandémico deben girar en torno a dos dimensiones interconectadas. Por un lado, debe ser un acuerdo transversal: i) entre 
grupos socioeconómicos, que tenga en cuenta, en particular, las diferencias de ingresos, de género y étnicas; ii) entre territorios, que reconozca las necesidades y oportunidades locales específicas y elimine las divisiones territoriales; y iii) entre generaciones, que garantice que las decisiones políticas equilibren los intereses de las generaciones actuales y futuras y promuevan la solidaridad intergeneracional. Por otra parte, el contrato debe avanzar hacia: i) estrategias productivas resilientes y sostenibles que prioricen la creación de empleos verdes y de calidad e incluyan la transformación digital; ii) sistemas de protección social más amplios y eficaces que mejoren los mecanismos de selección de beneficiarios, apoyen la formalización y pongan remedio a los desafíos planteados por las reformas del sistema de pensiones (Capítulo 2); y iii) un modelo más sostenible de financiamiento para el desarrollo que permita aplicar reformas fiscales tanto en materia de ingresos como de gastos y que fortalezca la gestión de la deuda pública. La intersección de estas dimensiones genera diversas áreas de política pública en las que se pueden dar pactos sociales más concretos y específicos que cada país debe adaptar a sus necesidades y objetivos específicos.

Para lograr pactos justos, legítimos y estables, es fundamental prestar atención a todo el proceso, desde la concepción de las políticas hasta su aplicación. Los procesos de formulación de políticas inclusivos y abiertos ayudan a elaborar políticas que atiendan las necesidades de la sociedad en su conjunto y puedan generar una mayor rendición de cuentas. Sin embargo, algunos desafíos pueden obstaculizar la creación de consensos. En primer lugar, la falta de pluralismo en los medios de comunicación y las burbujas de filtros en las redes sociales pueden impedir que en la sociedad se produzca un debate productivo y bien fundado en torno a importantes reformas políticas. A su vez, la fragmentación de partidos políticos en un contexto de alto nivel de volatilidad electoral de ALC aumenta el riesgo de polarización de las campañas políticas y obstaculiza la creación de consenso. En tercer lugar, la falta de confianza en los partidos políticos debido a su incapacidad para efectuar cambios y mediar entre los ciudadanos y el Estado puede transformarse en desinterés cívico. En cuarto lugar, la captura de las políticas por parte de grupos específicos con grandes cuotas de poder, puede desviar las reformas del interés general y atender solo a intereses particulares. Por estas razones, los siguientes mensajes en materia de políticas tienen por objeto orientar a los responsables de la formulación de políticas en sus esfuerzos por promover un nuevo contrato social, ayudando a navegar por la compleja economía política de las reformas (Recuadro 4.3).

\section{Recuadro 4.3. Principales mensajes en materia de políticas}

\section{Potenciar los procesos inclusivos de formulación de políticas para generar consensos}

- Construir consensos mediante un acuerdo transversal entre grupos socioeconómicos, territorios y generaciones para lograr objetivos clave en materia de políticas, en particular estrategias productivas resilientes y sostenibles, sistemas de protección social más amplios y eficaces y un modelo más sostenible de financiamiento para el desarrollo.

- Garantizar la buena gobernanza y la confianza mutua entre el gobierno y los ciudadanos, así como con la sociedad civil y el sector privado, para lograr un contrato social firme.

- Mejorar el papel de los procesos participativos en todas las etapas del proceso de formulación de políticas. Los diez Principios Rectores de la OCDE para potenciar la formulación de políticas de carácter abierto e inclusivo arrojan luz sobre la importancia del compromiso firme; el derecho de los ciudadanos a la información; la claridad del proceso; la dedicación de tiempo suficiente a las consultas y la participación; los esfuerzos dirigidos 


\section{Recuadro 4.3. Principales mensajes en materia de políticas (cont.)}

a que el proceso sea lo más inclusivo posible; los recursos financieros, humanos y técnicos adecuados; la coordinación dentro de los distintos niveles de gobierno y entre ellos, así como con redes externas; la rendición de cuentas de las administraciones públicas; la evaluación; y la ciudadanía activa (OCDE, $2009_{[76]}$ ).

- Reforzar el papel de las prácticas deliberativas, en las que participa un grupo de personas seleccionadas al azar que son ampliamente representativas de una comunidad y que dedican un tiempo considerable a aprender y colaborar para elaborar recomendaciones colectivas para los responsables de la formulación de políticas sobre un tema específico. Estas prácticas son especialmente valiosas para abordar cuestiones de carácter ético o que se basan en valores, que requieren elecciones difíciles y que exigen soluciones a largo plazo (Cesnulaityte, 2021 $1_{[85]}$; OCDE, 2020 ${ }_{[83]}$ ).

- Fomentar el papel de los medios de comunicación y de las tecnologías digitales para mejorar la transparencia, la participación y la rendición de cuentas:

- Reforzar la publicación proactiva de datos abiertos sobre el trabajo y las acciones del gobierno. El fortalecimiento de las políticas relativas a los datos públicos abiertos, teniendo en cuenta la reutilización de los datos, es un paso clave para posibilitar una mayor transparencia y rendición de cuentas frente a los ciudadanos, así como para estimular la participación cívica y la vigilancia social en esferas particularmente susceptibles de corrupción.

- La mitigación de la concentración de los medios de comunicación y la reducción de los obstáculos a la entrada de nuevos medios de comunicación pueden contribuir a la creación de un debate productivo y bien fundado en la sociedad gracias a la representación de diversas perspectivas sociales, económicas y políticas (Mendel, Castillejo y Gómez, $\left.2017_{[100]}\right)$.

- Racionalizar el uso de las tecnologías digitales para comunicar los resultados de las iniciativas gubernamentales y para apoyar los debates inclusivos y proporcionar canales adicionales de participación e implicación ciudadana (p. ej., videoconferencias, plataformas sociales, foros en línea).

- Apoyar el desarrollo de bases sólidas de gobernanza de datos que permitan el acceso, el intercambio y el uso eficiente y fiable de los datos por parte de las organizaciones del sector público y entre sectores (p. ej., G2B). Estas bases de gobernanza de datos incluyen la definición de marcos éticos de datos en el sector público en relación con el desarrollo y la aplicación de políticas e iniciativas de IA por parte de los organismos públicos.

- Aprovechar al máximo las estrategias nacionales o los planes nacionales de desarrollo (PND) para garantizar que los pactos sociales adopten una visión coherente a largo plazo, focalizada en mejorar el bienestar de las personas y la sostenibilidad en todas sus dimensiones (OCDE, Próximo a publicarse $\left.{ }_{[158]}\right)$. Unos objetivos e indicadores claros, el vínculo con el presupuesto nacional y los mecanismos de seguimiento y evaluación son características clave que contribuyen a la eficacia de los PNDs (OCDE et al., 2020 ${ }_{[12]}$; OCDE et al., $\left.2019_{[2]}\right)$.

\section{Superar los obstáculos a la reforma y la implementación de las políticas}

- Definir claramente la secuencia y el ritmo de las reformas, puesto que el éxito de las primeras puede ayudar a aumentar el apoyo y facilitar la implementación de las reformas posteriores. 


\section{Recuadro 4.3. Principales mensajes en materia de políticas (cont.)}

- Reforzar el papel de intermediación política de los partidos políticos y los mecanismos innovadores para canalizar las demandas sociales y evitar la posibilidad de discursos infundados.

- Luchar contra la captura de políticas a través de un enfoque integral (OCDE, 2017 ${ }_{[119]}$ ), que incluya estrategias complementarias para:

- Garantizar la transparencia y el acceso a la información para facilitar la participación y la vigilancia social durante el proceso de formulación de políticas.

- Alentar la participación de las partes interesadas a fin de garantizar un campo de juego nivelado menos proclive a la captura.

- Promover la rendición de cuentas de los responsables de la toma de decisiones a través de instituciones clave, como las entidades fiscalizadoras superiores, las autoridades que defienden la competencia y las agencias regulatorias.

- Incorporar políticas de integridad organizacional adecuadas para ayudar a identificar y controlar el riesgo de captura de políticas.

Estas políticas están en línea con el Plan de Acción de la OCDE-ALC sobre Integridad y Anticorrupción.

- Tener en cuenta la economía política de las reformas, incluidos los costos transitorios o distributivos que pueden aumentar la resistencia a algunas políticas. En particular, para que la implementación sea un éxito, es importante contar con sistemas complementarios de amortiguación para los grupos de población vulnerables afectados negativamente, así como con la firme determinación de mejorar la credibilidad de las reformas y un análisis sólido con base empírica que siente las bases de la reforma.

- Fortalecer las capacidades institucionales para que la implementación de las reformas sea un éxito. Por ejemplo:

- Promover la independencia del poder judicial y dotarlo de los recursos adecuados para llevar a cabo su función a fin de preservar el Estado de Derecho y el funcionamiento de la democracia.

- Centrarse en la contratación basada en los méritos y en la mejora de la gestión con base en los resultados para garantizar una administración pública eficiente.

- Simplificar los procesos administrativos, adoptar enfoques de diseño y prestación de servicios y avanzar hacia un gobierno digital para ayudar a la administración pública a mejorar y acelerar sus procesos internos, y hacer que sus servicios estén más centrados en el ser humano y sean más eficientes.

- Reforzar la entidad nacional encargada de la implementación y el seguimiento de los pactos sociales (p. ej., el centro de gobierno) garantizando una gestión más estratégica, entre otras herramientas.

\section{Notas}

1. Normalmente, el método de selección de los participantes consiste en una lotería cívica que combina la selección aleatoria con la estratificación para reunir a un grupo de personas pequeño pero representativo (OCDE, 2020 ${ }_{[83]}$ ).

1. Los datos se recopilaron a través del Cuestionario de la OCDE de 2018 sobre Integridad Pública en América Latina, que abarca 12 países. Se encuestó predominantemente a altos funcionarios del Gobierno central, entidades fiscalizadoras superiores y comisiones electorales. 


\section{Referencias}

Acuerdo Nacional (2014), Políticas de Estado, Secretaría Ejecutiva del Acuerdo Nacional, Lima, Perú, http://www.acuerdonacional.pe/politicas-de-estado-del-acuerdo-nacional/politicas-deestado\%e2\%80\%8b/politicas-de-estado-castellano/.

Acuña-Alfaro, J. y E. Sapienza (2021), COVID-19 y el contrato social en América Latina: Visiones de la ciudadanía sobre las respuestas nacionales un año después, Programa de las Naciones Unidas para el Desarrollo en América Latina y el Caribe, Nueva York, https://www.latinamerica.undp.org/ content/rblac/es/home/blog/2021/covid-19-y-el-contrato-social-en-america-latina--visionesde-la-.html.

Alvarado, N. y R. Muggah (2018), Crimen y violencia: Un obstáculo para el desarrollo de las ciudades de América Latina y el Caribe, Banco Interamericano de Desarrollo, Washington, DC, https://publications.iadb.org/publications/spanish/document/Crimen-y-violencia-Unobstaculo-para-el-desarrollo-de-las-ciudades-de-America-Latina-y-el-Caribe.pdf.

Aristei, D. y C. Perugini (2014), "Speed and sequencing of transition reforms and income inequality: A panel data analysis", The Review of Income and Wealth, Vol. 60/3, http://dx.doi.org/10.1111/ roiw.12090.

Baccaro, L. y J. Galindo (2018), Are social pacts still viable in today's world of work?, Organización Internacional del Trabajo, Ginebra, http://www.ilo.org/wcmsp5/groups/public/---ed_dialogue/ ---dialogue/documents/publication/wcms 648000.pdf.

Banco Mundial (2020), Indicadores de Desarrollo Mundial (base de datos), Banco Mundial, Washington, DC, https://data.worldbank.org/indicator/VC.IHR.PSRC.P5.

Basto-Aguirre, N., P. Cerutti y S. Nieto-Parra (2020), COVID-19 can widen educational gaps in Latin America: Some lessons for urgent policy action, VOXLACEA, Bogotá, https://vox.lacea.org/?q=blog/ covid19 widen educational gaps.

Bauhr, M. y M. Grimes (2014), "Indignation or Resignation: The implications of transparency for societal accountability", Governance: An international journal of policy, administration, and institutions, Vol. 27/2, pp. 291-320, http://dx.doi.org/10.1111/gove.12033.

BCN (2021), Proceso Constituyente, Biblioteca del Congreso Nacional de Chile, Santiago, http://www. bcn.cl/procesoconstituyente. [78].

Berganza, J. et al. (2020), "El agotamiento del dividendo demográfico en Latinoamérica: retos para las políticas económicas y sociales", Boletín Económico, n 1/2020, Banco de España, Bilbao, España, https://repositorio.bde.es/handle/123456789/11806.

BID (2020), Salir del túnel pandémico con crecimiento y equidad: Una estrategia para un nuevo compacto social en América Latina y el Caribe, Banco Interamericano de Desarrollo, Washington, DC, https://publications.iadb.org/publications/english/document/Emerging-from-the-PandemicTunnel-with-Faster-Growth-and-Greater-Equity-A-Strategy-for-a-New-Social-Compact-inLatin-America-and-the-Caribbean.pdf.

BID/OEA (2020), Ciberseguridad: Riesgos, avances y el camino a seguir en América Latina y el Caribe, Banco Interamericano de Desarrollo/Organización de los Estados Americanos, Washington, DC, http://dx.doi.org/10.18235/0002513.

Billion, D. y C. Ventura (2020), “¿Por qué protesta tanta gente a la vez?”, Nueva Sociedad, № 286, Buenos Aires, https://nuso.org/articulo/por-que-protesta-tanta-gente-la-vez/.

Binmore, K. (1994), Playing Fair: Game Theory and the Social Contract: Volume 1, The MIT Press, Cambridge, MA, https://mitpress.mit.edu/books/game-theory-and-social-contract-volume-1. [67]

Brennen, S. et al. (2020), “Types, sources, and claims of COVID-19 misinformation”, Reuters Institute for the Study of Journalism, Oxford, Reino Unido, https://reutersinstitute.politics.ox.ac.uk/typessources-and-claims-covid-19-misinformation.

Burdin, G. et al. (2020), "Was falling inequality in all Latin American countries a data-driven illusion? Income distribution and mobility patterns in Uruguay 2009-2016", Documento de debate de IZA, n' 13070 , IZA - Instituto de Economía Laboral, Bonn, Alemania, http://www.iza.org/ publications/dp/13070/was-falling-inequality-in-all-latin-american-countries-a-data-drivenillusion-income-distribution-and-mobility-patterns-in-uruguay-2009-2016.

Busso, M. y J. Messina (2020), La crisis de la desigualdad: América Latina y el Caribe en la encrucijada, Banco Interamericano de Desarrollo, Washington, DC, http://dx.doi.org/10.18235/0002629. [17]

Cabrera, M. (2011), "Los Pactos de la Moncloa: Acuerdos políticos frente a la crisis", Historia y política: Ideas, procesos y movimientos sociales, pp. 81-110, https://dialnet.unirioja.es/servlet/ articulo? codigo $=3741463$. 
Cabutto, C., S. Nieto-Parra y J. Vázquez-Zamora (2021), "A post-pandemic social contract for Latin America: the why, the what, the how", Vox.LACEA (blog), http://www.lacea.org/vox/?q=blog/ social contract latam.

Caldera Sánchez, A., A. de Serres y N. Yashiro (2016), Reforming in a difficult macroeconomic context: A review of the issues and recent literature, Publicaciones de la OCDE, París, http://dx.doi. org/10.1787/5jlzgj45b3q0-en.

Cañete Alonso, R. (2018), Captured Democracies: A Government for the Few, Oxfam International, Oxford, Reino Unido, http://www.oxfam.org/en/research/captured-democracies-government-few. [121]

Carpenter, D. y D. Moss (2014), Preventing Regulatory Capture: Special Interest Influence and How to Limit It, Cambridge University Press, Nueva York, http://dx.doi.org/10.1017/CBO9781139565875. [120]

Carreras, M. y I. Acácio (2019), Electoral Volatility in Latin America, Oxford Research Encyclopedia: Politics, Oxford, Reino Unido, https://oxfordre.com/politics/view/10.1093/ acrefore/9780190228637.001.0001/acrefore-9780190228637-e-1684.

CEPAL (2021), Observatorio Regional de Planificación para el Desarrollo, Instituto Latinoamericano de Planificación Económica y Social, Santiago, https://observatorioplanificacion.cepal.org/es/ planning-development.

CEPAL (2021), Panorama Social de América Latina 2020, Publicación de las Naciones Unidas, Santiago, http://www.cepal.org/en/publications/46688-social-panorama-latin-america-2020.

CEPAL (2020), "Pactos politicos y sociales para la igualdad y el desarrollo sostenible en America Latina y el Caribe en la recuperacion pos-COVID-19", Informe Especial COVID-19 n 8, Publicación de las Naciones Unidas, Santiago, http://www.cepal.org/es/publicaciones/46102-pactospoliticos-sociales-la-igualdad-desarrollo-sostenible-america-latina.

CEPAL/OEI (2020), Educación, juventud y trabajo: habilidades y competencias, Comisión Económica para América Latina y el Caribe/La Organización de Estados Iberoamericanos para la Educación, la Ciencia y la Cultura, Publicación de las Naciones Unidas, Santiago, https://repositorio.cepal.org/ handle/11362/46066.

CESIJ (2020), Índice Global de Impunidad 2020 (GII-2020), Center of Studies on Impunity and Justice, UDLAP Jenkins Graduate School, Universidad de las Américas Puebla, Puebla, México, http://www.udlap.mx/cesij.

CESIJ (2017), Índice Global de Impunidad 2017 (GII-2017), Center of Studies on Impunity and Justice, UDLAP Jenkins Graduate School, Universidad de las Américas Puebla, Puebla, México, http://www.udlap.mx/cesij.

Cesnulaityte, I. (2021), “A deliberative wave for development?”, OECD Development Matters blog, https://oecd-development-matters.org/2021/03/16/a-deliberative-wave-for-development/ \#more-14323.

Chioda, L. (2017), Fin a la violencia en América Latina: Una mirada a la prevención desde la infancia a la edad adulta, Banco Mundial, Washington, DC, https://openknowledge.worldbank.org/ handle/10986/25920.

Ciminelli, G. et al. (2019), “The political costs of reforms: Fear or reality?", Nota de discusión del personal del FMI SDN/19/0, http://www.imf.org/-/media/Files/Publications/SDN/2019/SDNEA19008 ashx.

CNTS (2020), Domestic Conflict Event Database, Cross-National Time-Series Data Archive, Databanks International, Jerusalem, http://www.cntsdata.com.

Cohen, M. (2018), Latin American Presidential and Legislative Elections (LAPALE) Conjunto de datos, http://www.molliecohen.com/data.html.

Coppedge, M. et al. (2021), V-Dem 2020 Dataset v11.1, Varieties of Democracy Institute, Universidad de Gothenburg, Gothenburg, Suecia, https://doi.org/10.23696/vdemds21.

Corbacho, A. et al. (2016), "Corruption as a Self-Fulfilling Prophecy: Evidence from a Survey Experiment in Costa Rica", American Journal of Political Science, Vol. 60/4, pp. 1077-1092, http://www.jstor.org/stable/24877473.

Cosano, P. (2019), “El Nuevo Contrato Social desde la perspectiva de la Ciencia Política”, Información Comercial Española (ICE): Revista de economía, Vol. 911, https://doi.org/10.32796/ice.2019.911.6935. [60]

Croissant, A. y W. Merkel (2004), Political Party Formation in Presidential and Parliamentary Systems, Instituto de Ciencias Políticas de la Universidad de Heidelberg, Heidelberg, Alemania, https://library.fes.de/pdf-files/bueros/philippinen/50072.pdf.

Cruz, J. y G. Kloppe-Santamaría (2019), "Determinants of Support for Extralegal Violence in Latin America and the Caribbean", Latin American Research Review, Vol. 54/1, pp. 50-68, http://doi.org/10.25222/larr.212. 
Cyr, J. y N. Liendo (2020), Party Change and Adaptation in Latin America, Oxford Research Encyclopedia: Politics, Oxford, Reino Unido, http://dx.doi.org/10.1093/acrefore/9780190228637.013.1687. [106]

D’Agostino, F. (1996), Free Public Reason: Making it Up as We Go, Oxford University Press, Oxford, Reino Unido, https://philpapers.org/rec/DAGFPR.

Dayton-Johnson, J., J. Londoño y S. Nieto Parra (2011), “The process of reform in Latin America: A review essay", OECD Development Centre Working Papers, N 304, Publicaciones de la OCDE, París, https://dx.doi.org/10.1787/5kg3mkvfcjxv-en.

DeShazo, P. y J. Vargas (2006), Judicial Reform in Latin America: An Assessment, Center for Strategic and International Studies (CSIS) and Justice Studies Center of the Americas (JSCA), Washington, DC y Santiago, https://biblioteca.cejamericas.org/bitstream/handle/2015/5190/ JudicialReforminLatinAmericaENGLISH_CEJA.pdf?sequence=1\&isAllowed=y.

Estefan, F., G. Hadid y R. Georges (2020), "Midiendo percepciones sobre democracia en América Latina durante la pandemia de COVID-19", Luminate blog, Londres, https://luminategroup.com/ posts/blog/measuring-perceptions-of-democracy-in-latin-america-during-covid-19/es.

[8]

EurWork (2019), Pacto Social, Observatorio Europeo de la Vida Laboral, Dublín, http://www. eurofound.europa.eu/observatories/eurwork/industrial-relations-dictionary/social-pact. [69]

Flores, I. et al. (2020), “Top Incomes in Chile: A Historical Perspective on Income Inequality, 19642017", Review of Income and Wealth, Vol. 66, pp. 850-874, https://doi.org/10.1111/roiw.12441. [21]

Gallup (2021), Gallup World Poll (base de datos), Gallup Inc., Washington, DC, https://ga.gallup.com. [10]

Gastil, J. y P. Levine (eds.) (2005), The Deliberative Democracy Handbook: Strategies for Effective Civic Engagement in the Twenty-First Century, Jossey-Bass, San Francisco, California, http://www.wiley. com/en-us/The+Deliberative+Democracy+Handbook\%3A+Strategies+for+Effective+Civic+Engagement+in+the+Twenty+First+Century-p-9781118105108.

Gerring, J. (2005), "Minor Parties in Plurality Electoral Systems”, Party Politics, Vol. 11/1, pp. 79-107, https://doi.org/10.1177/1354068805048474.

Global Witness (2020), Defending Tomorrow, Global Witness, London, www.globalwitness.org/en/ campaigns/environmental-activists/defending-tomorrow/.

González, S. (2020), "Testing the evidence, how good are public sector responsiveness measures and how to improve them?", OECD Working Papers on Public Governance, N³8, Publicaciones de la OCDE, París, https://doi.org/10.1787/c1b10334-en.

Granda Revilla, G. (2018), "CSR in Europe: A New Micro-Social Contract?", Ramon Llull Journal of Applied Ethics Iss. 9, pp. 75-94, https://search.proquest.com/openview/197477ab29a86c82217732d a7230928c/1?cbl=2035658\&pq-origsite = gscholar.

Guriev, S. (2018), "Fairness and support for the reforms: Lessons from the transition economies", SUERF Policy Note, $\mathrm{N}^{\circ} 24$, Foro Europeo de Dinero y Finanzas, Viena, http://www.suerf.org/docx/ f_c5a4e7e6882845ea7bb4d9462868219b_1993_suerf.pdf.

Hilbink, E. y W. Prillaman (2002), "The Judiciary and Democratic Decay in Latin America: Declining Confidence in the Rule of Law", Latin American Politics and Society, Vol. 44/1, http://dx.doi.org/10.2307/3177118.

Hirschman, A. y M. Rothschild (1973), "The Changing Tolerance for Income Inequality in the Course of Economic Development", The Quarterly Journal of Economics, Vol. 87/4, pp. 544-566, http://dx.doi.org/doi:10.2307/1882024.

Imbusch, P., M. Misse y F. Carrión (2011), "Violence Research in Latin America and the Caribbean: A Literature Review", International Journal of Conflict and Violence, Vol. 5/1, https://doi.org/10.4119/ijcv-2851. [40]

International IDEA (2020), Political Finance Database (base de datos), International Institute for Democracy and Electoral Assistance, Estocolmo, http://www.idea.int/data-tools/data/politicalfinance-database.

Ipsos (2021), Percepciones de los líderes de opinión de Latinoamérica a un año y medio de pandemia, Ipsos, París, http://www.ipsos.com/es-pe/percepciones-de-los-lideres-de-opinion-de-latinoamericaun-ano-y-medio-de-pandemia.

Ipsos (2020), La cohesión social en la era de la pandemia: Una perspectiva global, octubre de 2020, Ipsos, París, http://www.ipsos.com/sites/default/files/ct/news/documents/2020-11/a_global perspective of social_cohesion_in the pandemic_age.pdf.

Ipsos (2019), La Crisis en América Latina: Encuesta a líderes de opinión de Latinoamérica, Ipsos, París, http://www.ipsos.com/sites/default/files/ct/news/documents/2019-12/la crisis en_america latina.pdf.

Jaitman, L. et al. (2017), Los costos del crimen y de la violencia: Nueva evidencia y hallazgos en América Latina y el Caribe, Banco Interamericano de Desarrollo, Washington, DC, http://dx.doi.org/ $10.18235 / 0000615$. 
Jones, M. (2005), The Role of Parties and Party Systems in the Policymaking Process, Documento preparado para el Taller del Banco Interamericano de Desarrollo sobre Reforma del Estado, Políticas Públicas y Procesos de Elaboración de Políticas, 28 de febrero-2 de marzo de 2005, Washington, DC, https://citeseerx.ist.psu.edu/viewdoc/download?doi=10.1.1.542.1866\&rep= rep1\&type $=$ pdf.

Kaplan, S. (2017), Inclusive social contracts in fragile state in transition: Strengthening the building blocks of success, Institute for Integrated Transitions, Barcelona, España, https://ifit-transitions.org/ publications/inclusive-social-contracts-in-fragile-states-in-transition-strengthening-thebuilding-blocks-of-success/.

Kritzinger, S. (2021), "'Rally around the flag': the COVID-19 crisis and trust in the national government", Vol. 44/5-6, pp., pp. 1205-1231, http://dx.doi.org/10.1080/01402382.2021. 1925017.

Laakso, M. y R. Taagepera (1979), “The 'effective' number of parties: A measure with application to West Europe", Comparative Political Studies, Vol. 12/1, pp. 3-27, http://dx.doi.org/ $10.1177 / 001041407901200101$.

LabCDMX (2016), Constitución CDMX, https://labcd.mx/experimentos/constitucion-cdmx/. [88]

Laroze, D. (2019), "Party collapse and new party entry", Party Politics, Vol. 25/4, pp. 559-568, https://doi.org/10.1177/1354068817741286.

Larraín, G. (2021), "La estabilidad del contrato social en Chile", Fondo de Cultura Económica, Santiago, Chile.

Latinobarómetro (2021), Encuesta Latinobarómetro 2020 (base de datos), Corporación Latinobarómetro, Santiago, http://www.latinobarometro.org/latOnline.jsp.

Lazer, D. et al. (2018), "The science of fake news", Science, Vol. 359/6380, pp. 1094-1096, https://science.sciencemag.org/content/359/6380/1094.full.

Lloyd's Register Foundation (2019), Lloyd's Register Foundation World Risk Poll (base de datos), Lloyd's Register Foundation, Londres, https://wrp.lrfoundation.org.uk/explore-the-poll/the-majorityof-people-around-the-world-are-concerned-about-climate-change/.

Lloyd's Register Foundation/Gallup (2019), The Lloyd's Register Foundation World Risk Poll: Full report and analysis of the 2019 poll, Lloyd's Register Foundation/Gallup Inc., Londres/Washington, DC, https://wrp.lrfoundation.org.uk/LRF_WorldRiskReport_Book.pdf.

Loewe, M., T. Zintl y A. Houdret (2020), “The social contract as a tool of analysis: Introduction to the special issue on "Framing the evolution of new social contracts in Middle Eastern and North African countries'", World Development, http://www.die-gdi.de/en/others-publications/article/ the-social-contract-as-a-tool-of-analysis-introduction-to-the-special-issue-on-framing-theevolution-of-new-social-contracts-in-middle-eastern-and-north-african-countries/.

López-Calva, L. (2021), COVID-19 y la riqueza en la cima: más multimillonarios y más ricos en ALC tras la crisis, Programa de las Naciones Unidas para el Desarrollo América Latina y el Caribe, Nueva York, https://www.latinamerica.undp.org/content/rblac/es/home/presscenter/director-s-graphfor-thought/covid-19-and-wealth-at-the-top--more-and-wealthier-billionaires-.html.

López-Calva, L. (2020), Donde la pandemia se encuentra con la infodemia: El desafío de la desinformación en la lucha contra COVID-19 en ALC, Programa de las Naciones Unidas para el Desarrollo América Latina y el Caribe, Nueva York, https://www.latinamerica.undp.org/content/rblac/es/home/ blog/2021/covid-19-y-el-contrato-social-en-america-latina--visiones-de-la-.html.

López-Calva, L. (2020), Reflexiones sobre papel de fallas de gobernanza en disturbios sociales en América Latina, Inter Press Service, Panamá, http://www.ipsnoticias.net/2020/03/reflexiones-papelfallas-gobernanza-disturbios-sociales-america-latina/.

Lupu, N. (2016), Party brands in crisis: Partisanship, brand dilution, and the breakdown of political parties in Latin America, Cambridge University Press, Nueva York, http://www.cambridge.org/core/books/ party-brands-in-crisis/FF3A9C59D329AE74A5712254DF2C5BAF.

Lustig, N. (2020), The 'missing rich' in household surveys: causes and correction approaches, Society for the Study of Economic Inequality, Londres, http://www.ecineq.org/milano/WP/ECINEQ2020520.pdf.

Mainwaring, S. (ed.) (2018), Party Systems in Latin America: Institutionalization, Decay, and Collapse, Cambridge University Press, Cambridge, Reino Unido, http://dx.doi.org/doi:10.1017/ 9781316798553.

Mainwaring, S. (1997), Presidentialism, multiparty systems, and democracy: the difficult equation, Helen Kellogg Institute for International Studies, Universidad de Notre Dame, Notre Dame, IN, https://kellogg.nd.edu/documents/1338.

[115] 
Malamud, C. (2018), La expansión política de las iglesias evangélicas en América Latina, Real Instituto Elcano, Bruselas, http://www.realinstitutoelcano.org/wps/portal/rielcano_es/contenido?WCM GLOBAL CONTEXT=/elcano/elcano es/zonas es/ari127-2018-malamud-expansion-politicaiglesias-evangelicas-america-latina.

Malamud, C. y R. Núñez (2018), "El voto del enojo: el nuevo (o no tan nuevo) fenómeno electoral latinoamericano", Real Instituto Elcano, http://www.realinstitutoelcano.org/wps/portal/rielcano es/contenido?WCM_GLOBAL_CONTEXT=/elcano/elcano_es/zonas_es/ARI99-2018-MalamudNunez-Voto-enojo-fenomeno-electoral-lationamericano.

Manyika, J. et al. (2020), The social contract in the 21st century: Outcomes so far for workers, consumers and savers in advanced economies, Instituto Global McKinsey, http://www.mckinsey.com/industries/ public-and-social-sector/our-insights/the-social-contract-in-the-21st-century\#.

Martínez Franzoni, J. y D. Sánchez-Ancochea (2020), Pactos sociales al servicio del bienestar en América Latina y el Caribe: ¿qué son y qué papel tienen en tiempos de crisis?, Comisión Económica para América Latina y el Caribe, Santiago, http://www.cepal.org/es/publicaciones/46527-pactos-sociales-alservicio-bienestar-america-latina-caribe-que-son-que-papel.

Marwick, A. y R. Lewis (2017), Media Manipulation and Disinformation Online, Data \& Society Research Institute, Nueva York, https://datasociety.net/library/media-manipulation-anddisinfo-online.

Matasick, C., C. Alfonsi y Bellantoni (2020), "Governance responses to disinformation: How open government principles can inform policy options", OECD Working Papers on Public Governance, $\mathrm{N}^{\circ} 39$, Publicaciones de la OCDE, París, https://doi.org/10.1787/d6237c85-en.

Mattes, R. y A. Moreno (2018), Social and Political Trust in Developing Countries: Sub-Saharan Africa and Latin America, Oxford University Press, Oxford, Reino Unido, http://dx.doi.org/10.1093/ oxfordhb/9780190274801.013.10.

Maydeu-Olivares, S. (2016), La violencia, el talón de Aquiles de Centroamérica, Centro de Asuntos Internacionales de Barcelona, Barcelona, España, http://www.cidob.org/ca/publicacions/ series de publicacio/notes internacionals/n_142_la_violencia_el_talon_de_aquiles_de centroamerica/violence central america s achilles heel.

Mendel, T., Á. Castillejo y G. Gómez (2017), Concentración de Medios y Libertad de Expresión: Normas Globales y Consecuencias para las Américas, Oficina de la UNESCO en Montevideo/Oficina Regional de Ciencia para América Latina y el Caribe, Montevideo, https://unesdoc.unesco.org/ark:/48223/ pf0000248091.

Meza Canales, O., D. Gómez-Álvarez y H. Gutiérrez Pulido (2016), La planificación participativa desde lo subnacional: El caso de Jalisco, México, Programa de las Naciones Unidas para el Desarrollo/Estado de Jalisco, México, http://www.latinamerica.undp.org/content/rblac/es/home/library/democratic governance/la-planificacion-participativa-desde-lo-subnacional--el-caso-de-.html.

Moraes, J. (2015), "Las bases electorales de la polarización ideológica en América Latina”, Working Paper, $n^{\circ} 403$, Kellogg Institute for International Studies, Notre Dame, IN, https://kellogg.nd.edu/ documents/1721.

[104]

Morgan, M. (2018), "Falling Inequality beneath Extreme and Persistent Concentration: New Evidence for Brazil Combining National Accounts", WID.world Working Paper Series, n 2017/12, World Inequality Database, https://wid.world/document/extreme-persistent-inequality-newevidence-brazil-combining-national-accounts-surveys-fiscal-data-2001-2015-wid-worldworking-paper-201712/.

Murillo, M. (2020), Coming Next to Latin America: Even More Political Fragmentation, Americas Quarterly, Nueva York, http://www.americasquarterly.org/article/coming-next-to-latin-america-evenmore-political-fragmentation/.

Naser, A., A. Williner y C. Sandoval (2021), Participación ciudadana en los asuntos públicos: Un elemento estratégico para la Agenda 2030 y el gobierno abierto, Comisión Económica para América Latina y el Caribe, Santiago, https://repositorio.cepal.org/bitstream/handle/11362/46645/1/S2000907 es.pdf.

Nsouli, S., M. Rached y N. Funke (2005), "The speed of adjustment and the sequencing of economic reforms: Issues and guidelines for policymakers", International Journal of Social Economics, Vol. 32/9, pp. 740-766, https://doi.org/10.1108/0306829.

OCDE (2021), Good Practice Principles for Data Ethics in the Public Sector, Publicaciones de la OCDE, París, http://www.oecd.org/gov/digital-government/good-practice-principles-for-data-ethics-in-thepublic-sector.pdf.

OCDE (2021), Guía sobre Gobierno Abierto para Funcionarios Públicos Peruanos, Publicaciones de la OCDE, París, http://www.oecd.org/gov/open-government/guia-de-la-ocde-sobre-gobierno-abierto-parafuncionarios-publicos-peruanos.htm. 
OCDE (2021), Lobbying in the 21st Century: Transparency, Integrity and Access, Publicaciones de la OCDE, París, https://dx.doi.org/10.1787/c6d8eff8-en.

OCDE (2021), Perspectives on Global Development 2021: From Protest to Progress?, Publicaciones de la OCDE, París, http://dx.doi.org/10.1787/405e4c32-en.

OCDE (2020), COVID-19 en América Latina y el Caribe: Implicaciones socioeconómicas regionales y prioridades políticas, Actualizado el 8 de diciembre de 2020, Publicaciones de la OCDE, París, http://www.oecd. org/coronavirus/policy-responses/covid-19-in-latin-america-and-the-caribbean-regionalsocio-economic-implications-and-policy-priorities-93a64fde/.

OCDE (2020), Digital Government in Chile - Improving Public Service Design and Delivery, Publicaciones de la OCDE, París, https://doi.org/10.1787/b94582e8-en.

OCDE (2020), "Digital Government Index: 2019 results”, OECD Public Governance Policy Papers, $\mathrm{n}^{\circ} 03$, Publicaciones de la OCDE, París, https://doi.org/10.1787/4de9f5bb-en.

OCDE (2020), Governance for Youth, Trust and Intergenerational Justice: Fit for All Generations?, Publicaciones de la OCDE, París, https://doi.org/10.1787/c3e5cb8a-en.

OCDE (2020), Government at a Glance: Latin America and the Caribbean 2020, Publicaciones de la OCDE, París, https://dx.doi.org/10.1787/13130fbb-en.

OCDE (2021), Government at a Glance 2021, Publicaciones de la OCDE, París, https://doi.org/10.1787/ 1c258f55-en.

OCDE (2020), "Inclusive social dialogue and citizen engagement to enhance social cohesion and ownership of recovery measures", Informality and Social Inclusion in Times of Covid-19, OECD-LAC Virtual Social Inclusion Ministerial Summit, Publicaciones de la OCDE, París, http://www.oecd. org/latin-america/events/lac-ministerial-on-social-inclusion/2020-OECD-LAC-MinisterialInclusive-social-dialogue-and-citizen-engagement-to-enhance-social-cohesion-backgroundnote.pdf.

OCDE (2020), Innovative Citizen Participation and New Democratic Institutions: Catching the Deliberative Wave, Publicaciones de la OCDE, París, https://dx.doi.org/10.1787/339306da-en.

OCDE (2020), Integrating Responsible Business Conduct in Public Procurement, https://doi.org/10.1787/ 02682b01-en.

OCDE (2020), Panorama de las Administraciones Públicas América Latina y el Caribe 2020, Publicaciones de la OCDE, París, https://dx.doi.org/10.1787/13130fbb-en.

OCDE (2020), Public procurement and infrastructure governance: Initial policy responses to the coronavirus (Covid-19) crisis, http://www.oecd.org/coronavirus/policy-responses/public-procurement-andinfrastructure-governance-initial-policy-responses-to-the-coronavirus-covid-19-crisisc0ab0a96/.

OCDE (2020), "The OECD Digital Government Policy Framework: Six dimensions of a Digital Government", Estudios de la OCDE sobre Gobernanza Pública, nº 02, Publicaciones de la OCDE, París, https://doi.org/10.1787/f64fed2a-en.

[151]

OCDE (2019), Colaboración internacional para acabar con la evasión fiscal, Publicaciones de la OCDE, París, http://www.oecd.org/tax/beps/.

OCDE (2019), "Engaging Citizens for Sustainable Development in the Ibero-American Region", Nota de política conjunta, Publicaciones de la OCDE, París, http://www.oecd.org/dev/pgd/Engaging Citizens_for_Sustainable_Development_in_IberoAmerica_0919.pdf.

OCDE (2019), Recomendación del Consejo sobre coherencia de las políticas para el desarrollo sostenible, OCDE/LEGAL/0381, Publicaciones de la OCDE, París, https://legalinstruments.oecd.org/en/ instruments/OECD-LEGAL-0381.

OCDE (2019), "Recommendation of the Council on Policy Coherence for Sustainable Development (PCSD)", OECD/LEGAL/0381, https://legalinstruments.oecd.org/en/instruments/OECD-LEGAL -0381.

OCDE (2019), The Path to Becoming a Data-Driven Public Sector, Estudios de Gobierno Digital de la OCDE, Publicaciones de la OCDE, París, https://doi.org/10.1787/059814a7-en.

OCDE (2018), Behavioural Insights for Public Integrity: Harnessing the Human Factor to Counter Corruption, Publicaciones de la OCDE, París, https://dx.doi.org/10.1787/9789264297067-en.

OCDE (2018), Good Jobs for All in a Changing World of Work: The OECD Jobs Strategy, Publicaciones de la OCDE, París, https://doi.org/10.1787/9789264308817-en.

OCDE (2017), Compendium of good practices on the use of open data for Anti-corruption: Towards data-driven public sector integrity and civic auditing, Publicaciones de la OCDE, París, http://www.oecd.org/gov/ digital-government/g20-oecd-compendium.pdf.

OCDE (2017), Preventing Policy Capture: Integrity in Public Decision Making, Publicaciones de la OCDE, París, https://doi.org/10.1787/9789264065239-en. 
OCDE (2017), Recommendation of the Council on Open Government, https://legalinstruments.oecd.org/ en/instruments/OECD-LEGAL-0438.

OCDE (2017), Trust and Public Policy: How Better Governance Can Help Rebuild Public Trust, Publicaciones de la OCDE, París, https://doi.org/10.1787/9789264268920-en.

OCDE (2016), Multi-dimensional Review of Peru: Volume 2. In-depth Analysis and Recommendations, OECD Development Pathways, Publicaciones de la OCDE, París, https://doi.org/10.1787/9789264264670-en. [92]

OCDE (2016), Pilot database on stakeholder engagement practices in regulatory policy, Publicaciones de la OCDE, París, http://www.oecd.org/gov/regulatory-policy/measuring-regulatory-performance. $\underline{\mathrm{htm}}$.

OCDE (2010), Making Reform Happen: Lessons from OECD Countries, Publicaciones de la OCDE, París, https://dx.doi.org/10.1787/9789264086296-en.

OCDE (2009), Focus on Citizens: Public Engagement for Better Policy and Services, Studies on Public Engagement, Publicaciones de la OCDE, París, https://dx.doi.org/10.1787/9789264048874-en. [76]

OCDE (2001), Citizens as Partners: OECD Handbook on Information, Consultation and Publica Participation in Policy-Making, Publicaciones de la OCDE, París, https://doi.org/10.1787/9789264195578-en. [81]

OCDE (Próximo a publicarse), How's Life in Latin America? Measuring Well-being for Policy Making, Publicaciones de la OCDE, París.

OCDE (Próximo a publicarse), Multi-Dimensional Country Review of Ecuador: Phase I, Publicaciones de la OCDE, París. OCDE, París, https://sdg-communicator.org/toolkit/.

OCDE et al. (2020), Perspectivas Económicas de América Latina 2020: Transformación digital para una mejor reconstrucción, Publicaciones de la OCDE, París, https://dx.doi.org/10.1787/e6e864fb-en.

OCDE et al. (2019), Perspectivas económicas de América Latina 2019: Desarrollo en transición, Publicaciones de la OCDE, París, https://dx.doi.org/10.1787/g2g9ff18-en.

OCDE and The GovLab (2021), Open data in action: initiatives during the initial stage of the COVID-19 pandemic, http://www.oecd.org/gov/digital-government/open-data-in-action-initiatives-duringthe-initial-stage-of-the-covid-19-pandemic.pdf.

ONUDD (2020), Víctimas de homicidio doloso, 1990-2018, Oficina de Naciones Unidas contra la Droga y el Delito, Viena, https://dataunodc.un.org/data/homicide/Homicide\%20victims\%20 worldwide.

Open Government Partnership (2021), Members, Open Government Partnership, Nueva York, http://www.opengovpartnership.org/es/our-members/.

openDemocracy (2020), 2019: Movilizaciones ciudadanas y cambios disruptivos en América Latina, Democracia Abierta, Londres, https://www.opendemocracy.net/es/democraciaabierta-es/2019movilizaciones-ciudadanas-y-cambios-disruptivos-en-am\%C3\%A9rica-latina/.

Peiffer, C. (2018), "Message Received? Experimental Findings on How Messages about Corruption Shape Perceptions", British Journal of Political Science, Vol. 50/3, pp. 1207-1215, https://doi.org/10. 1017/S0007123418000108.

PNUD (2018), Forging Resilient Social Contracts: Preventing Violent Conflict and Sustaining Peace, Programa de las Naciones Unidas para el Desarrollo, Centro de Gobernanza de Oslo, Oslo, http://www. undp.org/content/undp/en/home/librarypage/democratic-governance/oslo_governance centre/forging-resilient-social-contracts--preventing-violent-conflict-html.

Prats, M. y A. Meunier (2021), Political efficacy and participation: An empirical analysis in European countries, Publicaciones de la OCDE, París, https://doi.org/10.1787/4548cad8-en.

Raderstorf, B. et al. (2017), Beneath the Violence: How insecurity shapes daily life and emigration in Central America, Latin America Public Opinion Project/The Inter-American Dialogue, Washington, DC, http://www.thedialogue.org/analysis/beneath-the-violence-how-insecurity-shapes-daily-lifeand-emigration-in-central-america/.

Ranciere, R. y A. Tornell (2015), "Why do reforms occur in crises times?", Working Paper, Departamento de Economía, Universidad de California, Los Angeles, CA, http://www.econ.ucla. edu/people/papers/Tornell/Tornell702.pdf.

Reporteros sin Fronteras (2019), Medios de comunicación en América Latina: bajo control de familias, elites económicas y políticas, Reporters without Borders, París, https://rsf.org/es/noticias/medios-decomunicacion-en-america-latina-bajo-control-de-familias-elites-economicas-y-politicas. [98]

Reporters without Borders (2021), 2021 Índice Mundial de Libertad de Prensa (base de datos), Reporteros Sin Fronteras, París, https://rsf.org/en/ranking. 
Roberts, K. y E. Wibbels (1999), "Party Systems and Electoral Volatility in Latin America: A Test of Economic, Institutional, and Structural Explanations", The American Political Science Review, Vol. 93/3, pp. 575-590, http://dx.doi.org/10.2307/2585575.

Rodríguez, M. y E. Zechmeister (2018), Pluralismo en los medios, confianza pública y democracia: nueva evidencia de Latinoamérica y El Caribe, Center for International Media Assistance National Endowment for Democracy, Washington, DC, https:/www.cima.ned.org/wp-content/ uploads/2018/07/CIMA-Media-Perceptions-in-the-Americas_Spanish_web150ppi.pdf. [97]

Rodrik, D. (1996), "Understanding Economic Policy Reform”, Journal of Economic Literature, Vol. 34/1, pp. 9-41, http://www.jstor.org/stable/2729408.

Sandoval, C., A. Sanhueza y A. Williner (2015), La planificación participativa para lograr un cambio estructural con igualdad: las estrategias de participación ciudadana en los procesos de planificación multiescalar, Comisión Económica para América Latina y el Caribe, Santiago, http://www.cepal. org/sites/default/files/publication/files/39055/S1501278 es.pdf.

[160]

Segura, M. y S. Waisbord (2016), Media Movements: Civil Society and Media Policy Reform in Latin America, Zed Books, Londres, http://www.bloomsbury.com/uk/media-movements-9781783604623. [99]

Shafik, M. (2021), "What We Owe Each Other: A New Social Contract for a Better Society”, The Forum Network, Publicaciones de la OCDE, París, http://www.oecd-forum.org/posts/what-we-oweeach-other-a-new-social-contract-for-a-better-society-by-minouche-shafik.

Soria Morales, E. (2018), "Why is policy coherence essential for achieving the 2030 Agenda?", UN System Staff College blog, http://www.unssc.org/news-and-insights/blog/why-policy-coherenceessential-achieving-2030-agenda/.

Spiller, P., E. Stein y M. Tommasi (2008), “Chapter 1. Political Institutions, Policymaking, and Policy: An Introduction", Policymaking in Latin America: How politics shapes policies, Banco Interamericano de Desarrollo, Washington, DC, https://publications.iadb.org/publications/english/document/ Policymaking-in-Latin-America-How-Politics-Shapes-Policies.pdf.

Staats, J., S. Bowler y J. Hiskey (2008), "Measuring Judicial Performance in Latin America", Latin American Politics and Society, Vol. 47/4, pp. 77-106, https://doi.org/10.1111/j.1548-2456.2005. tb00329.x.

Tompson, W. (2009), The Political Economy of Reform: Lessons from Pensions, Product Markets and Labour Markets in Ten OECD Countries, Publicaciones de la OCDE, París, https://dx.doi.org/10.1787/ 9789264073111-en.

Transparency International (2021), Índice de Percepción de la Corrupción 2020: América, Transparency International, Berlín, http://www.transparency.org/en/news/cpi-2020-americas.

Transparency International (2019), Barómetro Global de Corrupción para América Latina y el Caribe 2019: Opiniones y experiencias ciudadanas sobre la corrupción, Transparency International, Berlín, https://images.transparencycdn.org/images/2019_GCB_LatinAmerica_Caribbean_Full Report 200409 091428.pdf.

Universidad del Rosario (2021), Panorama Regional de la Tercera Medición de la Gran Encuesta Nacional sobre Jóvenes, Cifras y Conceptos, Universidad del Rosario y El Tiempo, http://www.urosario.edu. co/Periodico-NovaEtVetera/Documentos/079-21-Presentacion-de-resultados-finales V6/. [14]

Uslaner, E. (2002), The Moral Foundations of Trust, Cambridge University Press, Cambridge, Reino Unido, http://dx.doi.org/10.1017/CBO9780511614934.

Vlerick, M. (2019), “The Evolution of Social Contracts”, Journal of Social Ontology, Vol. 5/2, pp. 181-203, https://doi.org/10.1515/jso-2019-0041.

Wardle, C. y H. Derakhshan (2017), Information Disorder: Toward an Interdisciplinary Framework for Research and Policy Making, Consejo de Europa, Estrasburgo, Francia, https://rm.coe.int/ information-disorder-toward-an-interdisciplinary-framework-for-researc/168076277c. [52]

Williamson, J. (ed.) (1994), The political economy of policy reform, Institute for International Economics, Washington, DC, http://www.piie.com/bookstore/political-economy-policy-reform. [129]

Wills-Otero, L. (2020), Party Systems in Latin America, Oxford University Press, Oxford, Reino Unido, https://oxfordre.com/politics/view/10.1093/acrefore/9780190228637.001.0001/acrefore9780190228637-e-1683.

[109]

World Inequality Database (2020), WID.world (base de datos), World Inequality Database, https://wid.world/.

Zovatto, D. (2020), “The rapidly deteriorating quality of democracy in Latin America”, The Brookings Institution, Washington, DC, http://www.brookings.edu/blog/order-from-chaos/2020/02/28/therapidly-deteriorating-quality-of-democracy-in-latin-america/.

Zovatto, D. (2019), "Latin America: political change in volatile and uncertain times", International Institute for Democracy and Electoral Assistance, Estocolmo, http://www.idea.int/news-media/ news/latin-america-political-change-volatile-and-uncertain-times. 



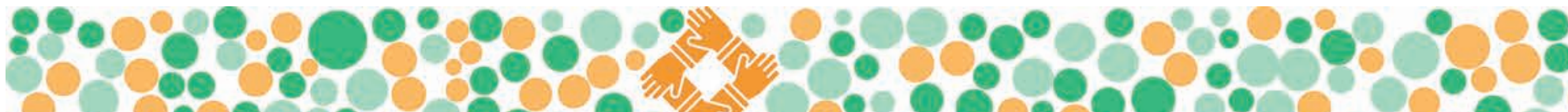
:00 O.

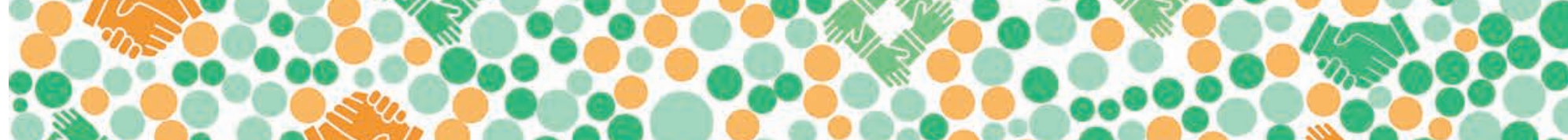

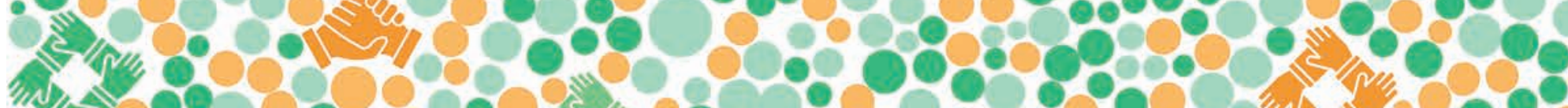

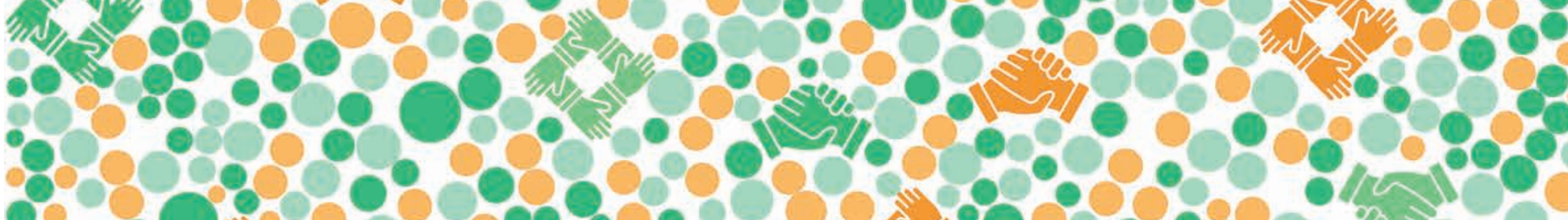

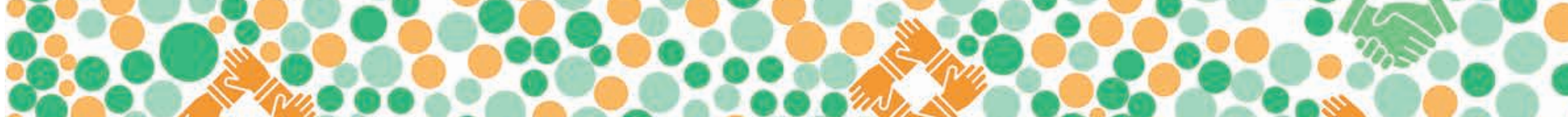

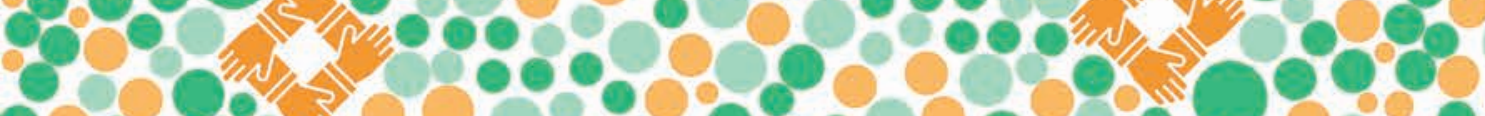

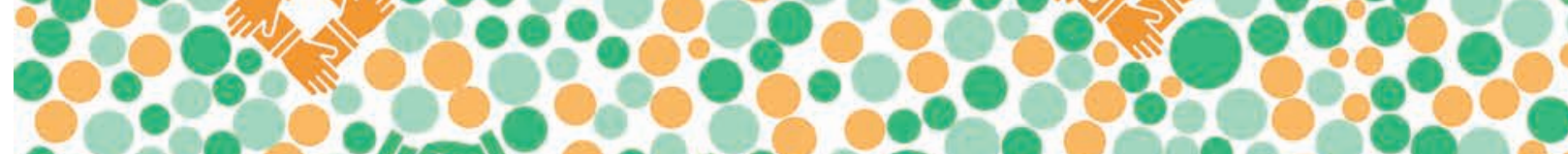
:36\%

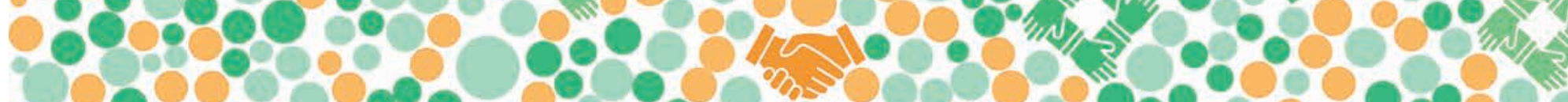
00000000000000000 :0\%

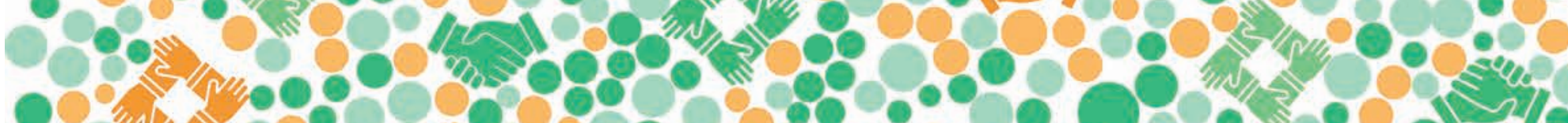

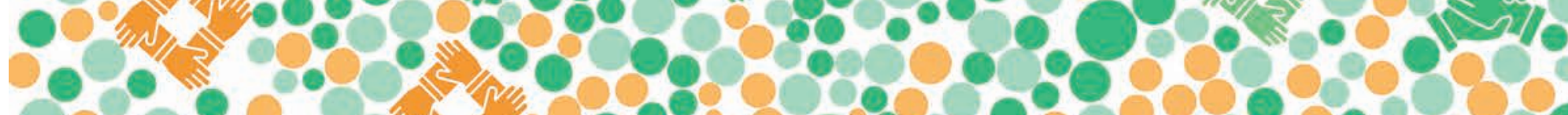

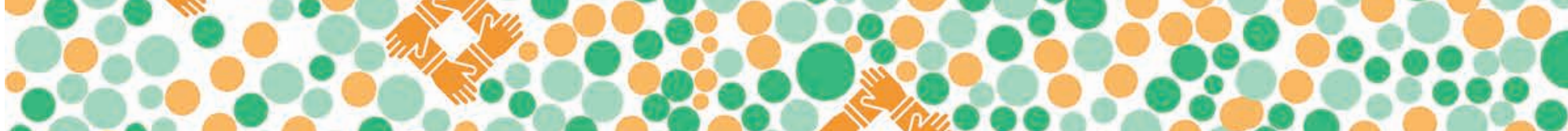

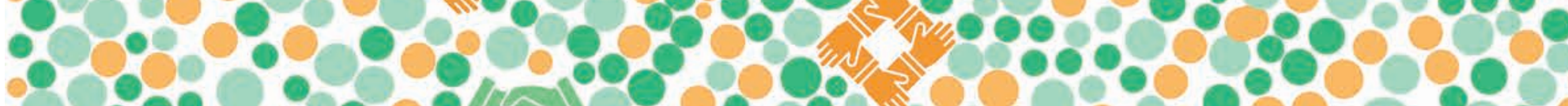

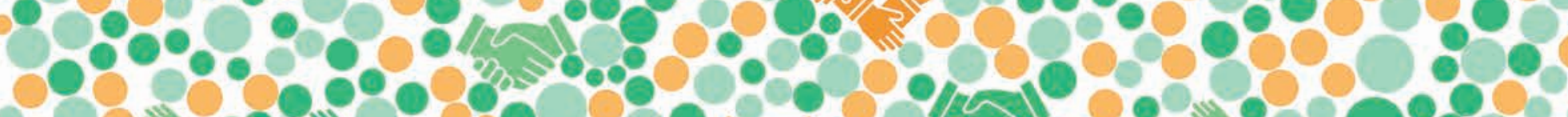
200 30003

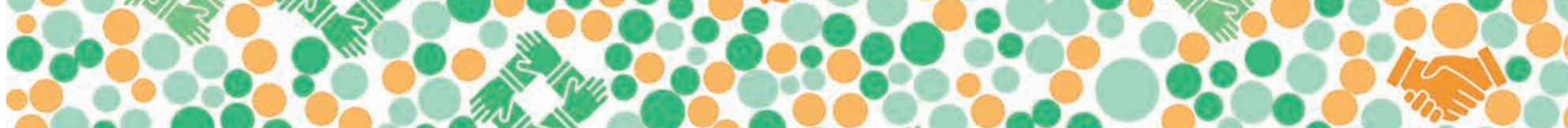
:080 0.000. 8.

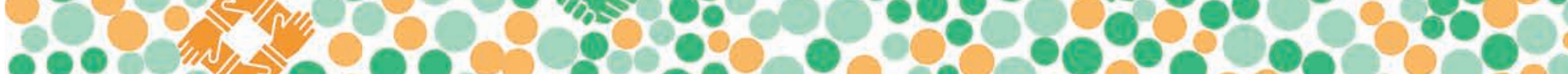

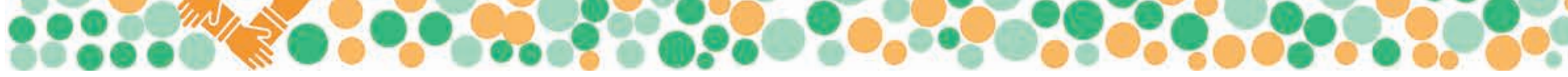




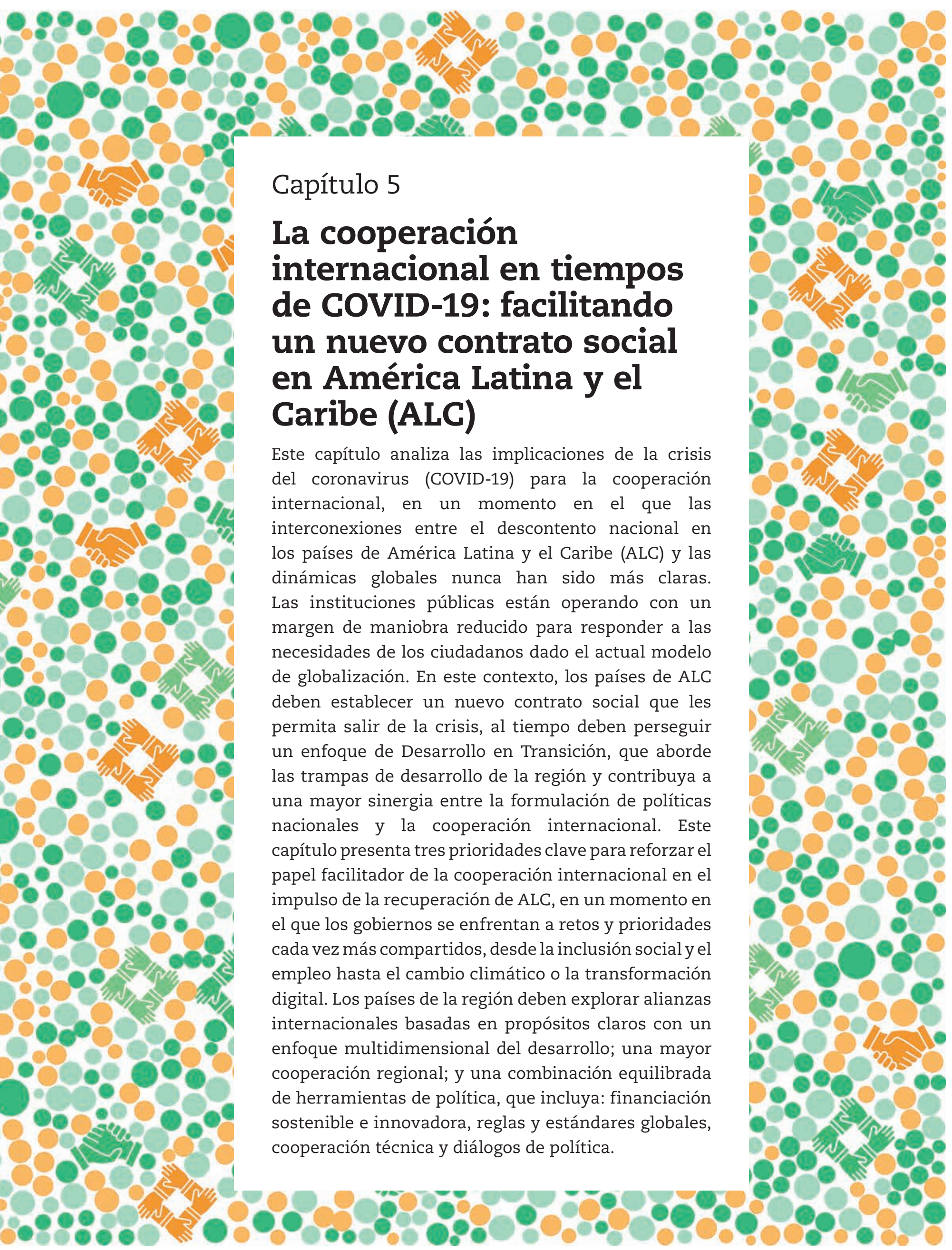




\section{Nuevas alianzas para facilitar la recuperación en ALC}

\section{Se requieren políticas internacionales audaces para avanzar hacia un nuevo contrato social}

La mayoría de los ciudadanos entienden que la cooperación internacional es la vía para avanzar

$70 \%$ de los latinoamericanos cree que es esencial que los países trabajen juntos para atender las dinámicas globales

Casi $50 \%$ de los latinoamericanos reportó que la crisis del COVID-19 los llevó a entender que es necesaria una mayor cooperación internacional

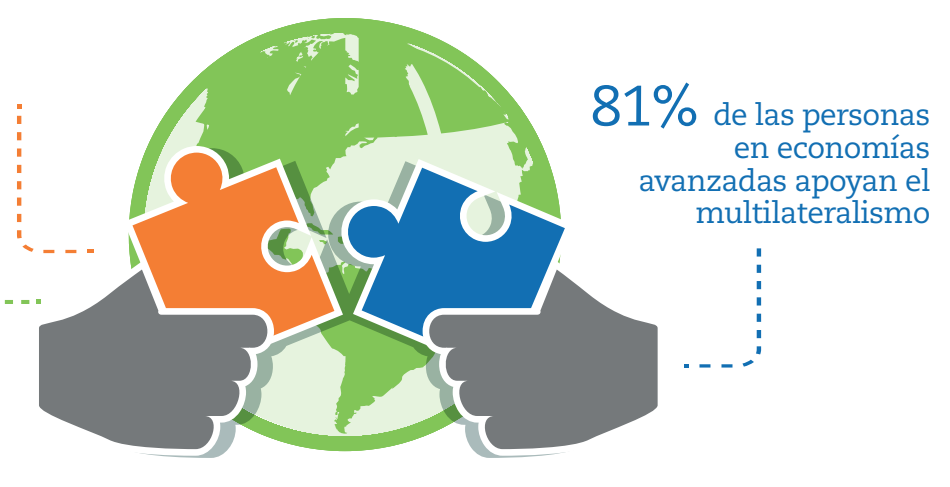

¿Cómo?

Estructurando la cooperación internacional a través de alianzas enfocadas en las metas

Promoviendo la cooperación regional como un pilar fundamental

\section{Promoviendo abordajes integrales para un uso equilibrado de instrumentos, como:}

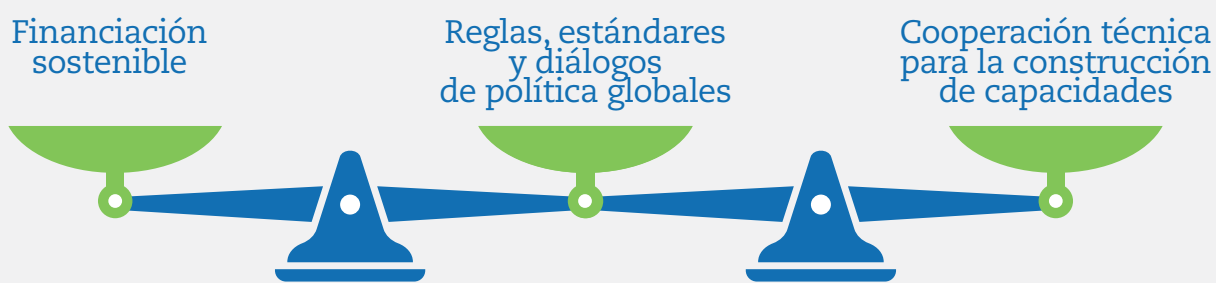




\section{Introducción}

El alcance mundial de la pandemia ha demostrado que, a medida que el margen de maniobra de los gobiernos se debilita ante desafíos cada vez más globales, las respuestas nacionales resultan insuficientes. El multilateralismo ha ocupado un primer plano en esta crisis, mostrando su capacidad de actuación colectiva, pero también exponiendo sus limitaciones.

En América Latina y el Caribe (ALC), la crisis ha resaltado lo que los recientes estallidos sociales habían mostrado: la creciente interconexión entre los retos para el desarrollo nacional e internacional requiere un cambio en la cooperación internacional, en el ámbito multilateral y dentro de ALC. En este contexto, el marco de Desarrollo en transición (DiT, por sus siglas en inglés) que se planteó en el reporte Perspectivas económicas de América Latina 2019 adquiere relevancia e impulso para su consolidación (OCDE et al., $\left.2019_{[1]}\right)$. DiT propone plantear el desarrollo desde un punto de vista multidimensional; requiere ir más allá del producto interno bruto (PIB) y utilizar indicadores que reflejen mejor los niveles de desarrollo de los países para orientar la formulación, implementación, seguimiento y evaluación de las políticas públicas. Mediante el DiT se propone que la cooperación internacional se desempeñe como facilitadora de la transformación de los retos estructurales de ALC en oportunidades de desarrollo que apoyen a la región en la consecución de la Agenda 2030.

Por un lado, este enfoque más específico apoyaría de manera más eficaz a ALC en la redefinición de su contrato social para hacer frente a las trampas de desarrollo de la región, como la baja productividad, la vulnerabilidad social, la debilidad institucional y la sostenibilidad medioambiental, todas ellas exacerbadas durante la pandemia.

Por otro lado, la salida de la crisis de ALC a través de un nuevo contrato social es una oportunidad para poner en práctica plenamente el papel facilitador de la cooperación internacional, incluso asegurando la coherencia entre las acciones nacionales, regionales y globales. El contrato social, entendido como un equilibrio entre los actores de la sociedad y las autoridades públicas, refleja la distribución del poder en las relaciones entre el Estado y la sociedad (Loewe, Zintl, y Houdret, $2020_{[2]}$ ) y consiste en pactos específicos que engloban todas las áreas del desarrollo: medioambientales, sociales, productivas e institucionales (Capítulo 4). Un nuevo contrato social supondría pasar del actual statu quo fragmentado a un nuevo equilibrio, basado en la igualdad de oportunidades para todos los ciudadanos de todos los países a largo plazo (Larraín, 2021 $1_{[3]}$ ). Las cuestiones contempladas en los pactos sociales específicos integrantes del contrato social están relacionadas directa o indirectamente con las dinámicas del desarrollo internacional (p. ej., la deslocalización de la producción) y las acciones de cooperación para abordarlas (p. ej., la fiscalidad global). Una cooperación internacional renovada debería captar mejor estas interconexiones y comprenderlas en alianzas renovadas para afrontar el carácter multidimensional del desarrollo mundial a través de respuestas igualmente multidimensionales.

En primer lugar, este capítulo expone lo que la crisis del COVID-19 ha puesto de manifiesto: analiza cómo las dinámicas mundiales arraigadas, junto con los retos estructurales nacionales, han formado la tormenta perfecta que podría conducir a un nuevo rebrote de protestas sociales, y la necesidad, por tanto, de que los países de ALC se comprometan a construir un nuevo contrato social. Se argumenta por qué el marco de DiT es altamente relevante para repensar la cooperación internacional en ALC y apoyar la recuperación de la región. El capítulo analiza qué tipo de alianzas internacionales podrían facilitar un nuevo contrato social en la región, incluyendo prácticas innovadoras que podrían adoptarse con este fin. En particular, se propone explorar el valor: 1) de las alianzas multi-actor y multidimensionales basadas en propósitos claros y 2) de una 
mayor cooperación regional, así como 3) alcanzar un uso integral y equilibrado de tres herramientas clave para garantizar la coherencia de las políticas y la mejora de los resultados: financiación sostenible e innovadora para el desarrollo, reglas y estándares mundiales y cooperación técnica. El capítulo finaliza proponiendo mensajes prácticos de política para las alianzas pos-COVID-19.

\section{Lo que la crisis del COVID-19 ha revelado: dinámicas globales arraigadas y el surgimiento de nuevos retos que requieren la adaptación de la cooperación internacional}

La crisis del COVID-19 ha ejercido presiones sobre las vulnerabilidades estructurales del desarrollo de ALC. La pandemia golpeó cuando la región ya se encontraba en un proceso adverso de bajo crecimiento potencial, desigualdades persistentes e incremento de la pobreza y de las tensiones sociales, todo ello acompañado de un creciente deterioro medioambiental. Las necesidades sanitarias creadas por la pandemia han puesto de manifiesto la cobertura insuficiente y desigual de los sistemas nacionales de salud, en tanto que la crisis económica afectó a los trabajadores pobres y vulnerables, en especial a los trabajadores informales de América Latina que representan el 58\% de la fuerza laboral (con $65 \%$ del total de los trabajadores que no reciben ningún tipo de protección social) (OCDE et al., 2019 ${ }_{[1]}$ ).

Mientras tanto, los esfuerzos de la comunidad internacional por poner la solidaridad en primera línea de su respuesta a la crisis sanitaria y económica mundial han sido limitados. Se están llevando a cabo nuevas reflexiones y acciones para contrarrestar la falta de flexibilidad y capacidad de adaptación de la cooperación internacional a la pandemia, pero se necesitan más esfuerzos para explorar prácticas innovadoras que transformen la cooperación internacional, como la incorporación de las voces de los ciudadanos, la implicación de un mayor número de actores clave y la creación de espacios para la creación de políticas innovadoras para la recuperación.

La pandemia ha dejado claro que los países no pueden afrontar los retos mundiales por sí solos y que un número creciente de desafíos globales influyen en el descontento nacional en los países de ALC. Aun antes de la irrupción del coronavirus, la creciente insatisfacción social había dado lugar a protestas en varios países de América Latina, como Chile, Colombia y Ecuador. Estas manifestaciones descontento están relacionadas principalmente con las respuestas de los gobiernos a las vulnerabilidades estructurales y con los mercados financieros internacionales, la desigualdad global y los retos medioambientales. Las instituciones públicas, por ejemplo, no han dado una respuesta plena a las crecientes demandas de los ciudadanos, creando desconfianza y una baja satisfacción con los servicios públicos. Entre 2006 y 2020, el porcentaje de la población de ALC satisfecha con la calidad de los servicios sanitarios descendió de un $57 \%$ a un $47 \%$, muy por debajo del promedio de la Organización para la Cooperación y el Desarrollo Económicos (OCDE) que se sitúa en torno al 70\%. Igualmente, solo el $38 \%$ de la población tiene confianza en el gobierno nacional (Nieto-Parra y Da Costa, 2021 $1_{[4]}$ ).

Junto a los desafíos domésticos, las protestas del 2019 surgieron como un movimiento común contra "el sistema", que debilitó el papel del Estado, las instituciones internacionales y la participación de los movimientos sociales. El proceso de globalización desde la caída del Muro de Berlín se ha centrado en las fuerzas del mercado como elemento clave para un orden mundial pacífico y de cooperación, lo que ha ocasionado el doble efecto de un debilitamiento de la capacidad de los Estados para regular la economía global y una frustración de las fuerzas sociales. La agitación social es, por tanto, el resultado de 
desconectar la economía mundial de su contexto sociopolítico y de la falta de vínculos intersociales horizontales en el sistema interestatal (Badie, $2020_{[5]}$ ).

Además, las asimetrías económicas globales, como la concentración económica, las cadenas de valor globales, los centros financieros o las redes digitales, son cada vez más difíciles de ignorar, ya que todas ellas contribuyen a una creciente polarización y sirven como vehículos para aprovechar las ventajas económicas (Pisani-Ferry, 2021 ${ }_{[6]}$ ), Comprender estas asimetrías y cómo afectan al descontento nacional será fundamental para definir un nuevo sistema de cooperación internacional.

La inestabilidad en ciertos países de ALC se contagia al resto de la región y del mundo. Un ejemplo es la crisis de refugiados e inmigrantes que proceden de diversas latitudes de ALC y su impacto en países que no están preparados para acogerlos. Además, la falta de rendición de cuentas y la debilidad de las instituciones públicas, junto con la falta de confianza de los ciudadanos, han creado un contexto favorable para la depredación de los bienes públicos medioambientales. Por ejemplo, la deforestación de la selva tropical amazónica aumentó un 17\% en 2020, al producirse 2500 grandes incendios en todo el Amazonas (Conservación Amazónica, 2020 [7] ).

El creciente descontento, en especial en ALC, probablemente se intensificará después de la pandemia. Las medidas de distanciamiento social pueden tener un efecto mitigador de las protestas, pero estas y otras respuestas a la pandemia pueden ocasionar también efectos sociales persistentes, incrementando la probabilidad de la agitación social, como se ha visto recientemente en Chile, Paraguay (Mander, $2021_{[8]}$ ) y Colombia $\left(B B C, 2021_{[9]}\right)$. En efecto, la evidencia histórica muestra una relación positiva entre las epidemias y la agitación social. Las tendencias recientes de las protestas inmediatamente antes y después de la pandemia del COVID-19 están en consonancia con este hallazgo (Barrett y Chen, $2021_{[10]}$ ). Esta hipótesis se ve reforzada por el aumento de la desigualdad de la renta que ha tenido lugar durante la pandemia en ALC, en donde 22 millones de personas más cayeron en la pobreza en 2020 (CEPAL, 2020 ${ }_{[11]}$ ), mientras que las fortunas de 73 multimillonarios crecieron en 48200 millones de USD (dólares estadounidenses) (Oxfam International, 2020 ${ }_{[12]}$ ).

El COVID-19 impone una lucidez colectiva acerca de la profunda interdependencia global, esto es, el hecho de que el mundo solo es tan resiliente como el país y la persona menos resiliente, y el hecho de que el mundo está llegando a un punto de inflexión en numerosos aspectos (ONU, 2020 ${ }_{[13]}$ ). Las tensiones que sufre el planeta reflejan las que padecen las sociedades, y estos desequilibrios se potencian entre sí, intensificando los retos para el desarrollo (PNUD, 2020 $\left.{ }_{[14]}\right)$.

La mayoría de los latinoamericanos consideran que la cooperación internacional es parte de la solución y hoy, tras los efectos del brote del coronavirus, son más conscientes de la necesidad de una mayor cooperación internacional como parte de la solución. Esto ha llegado a ser una reivindicación popular y legítima en la región. Casi el 50\% de los ciudadanos de ALC encuestados están a favor de una mayor cooperación tras el COVID-19, y el $70 \%$ piensan que es esencial para abordar los actuales desafíos globales (Gráfico 5.1). Ha quedado claro en todo el mundo que los países no pueden afrontar por sí solos los retos globales. Los ciudadanos son cada vez más conscientes de esto: el 81\% de las personas de las economías avanzadas son partidarias del multilateralismo y apoyan que los países deben actuar como parte de una comunidad mundial colaborando juntos para resolver problemas comunes (Pew Research Center, 2020 ${ }_{[15]}$ ). 


\section{Gráfico 5.1. Percepción de los ciudadanos de América Latina y el Caribe acerca de la cooperación internacional}
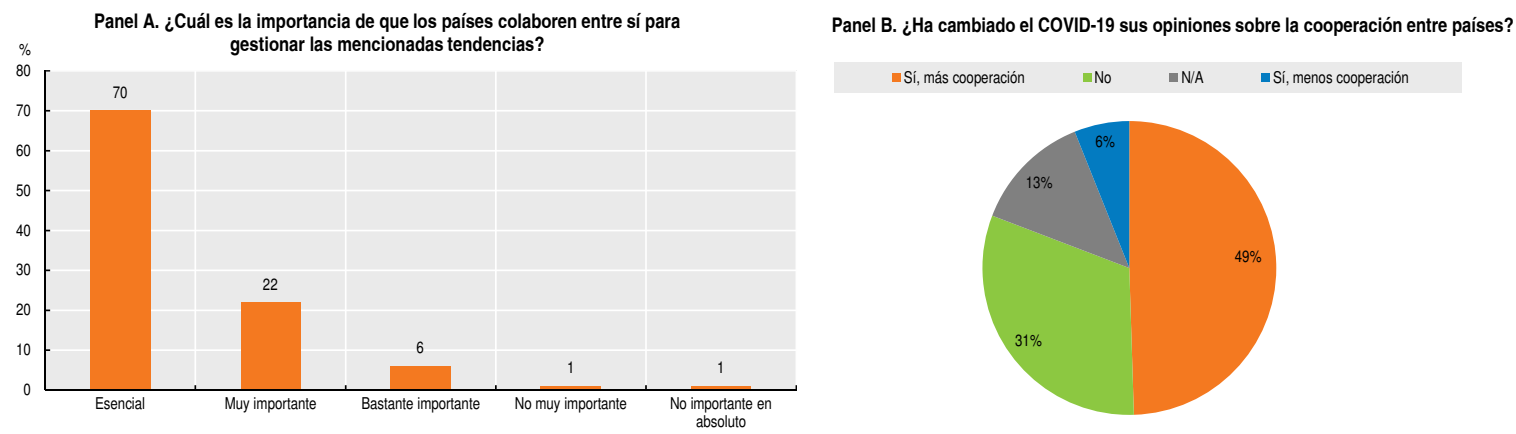

Fuente: ONU $\left(2020_{[16]}\right)$, UN75 2020 and beyond: Shaping our future together, https://un75.online/es/data/.

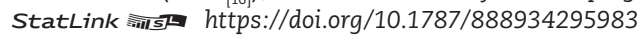

Cuando se reconocen los crecientes vínculos entre las políticas nacionales y las dinámicas mundiales, la cooperación internacional se presenta como un instrumento esencial para realizar el pleno potencial de un nuevo contrato social en ALC. Este debería abordar los retos nacionales y mundiales, equilibrando los resultados de mercado de las economías interdependientes y su interrelación con las agendas políticas nacionales, a la luz de los Objetivos de Desarrollo Sostenible (ODS) de la Agenda 2030 para el Desarrollo Sostenible de las Naciones Unidas y su compromiso de no dejar a nadie atrás (ONU, $\left.2020_{[13]}\right)$. Para ello, actores de los distintos niveles local, nacional, regional e internacional, necesitan reflexionar sobre la mejor manera de situar una transición equitativa, ecológica y social en el núcleo de los esfuerzos internacionales, superando los actuales modelos de cooperación, crecimiento y desarrollo.

El marco de DiT ofrece una concepción renovada y un enfoque útil para iniciar esta reflexión (OCDE et al., 2019 ${ }_{[1]}$ ). Una mejor comprensión de las necesidades y los desafíos actuales a los que se enfrentan los países de ALC y una mejor delimitación de las interrelaciones del nuevo contrato social con las dinámicas internacionales puede ser uno de los puntos centrales del debate acerca de qué tipo de cooperación internacional y nuevas alianzas son necesarias para el mundo pos-COVID-19 en ALC. Con el fin de afrontar los crecientes retos comunes e interconectados que afectan también a los países de la región, es preciso establecer enfoques innovadores de financiación, transformar los que son lineales en multidimensionales, encontrar nuevas herramientas y actualizar los acuerdos de gobernanza.

\section{El marco de Desarrollo en Transición cobra mayor relevancia en tiempos de COVID-19}

Los dramáticos efectos de la pandemia en ALC ponen de manifiesto las raíces del descontento social generalizado y la insuficiencia de los estándares actuales sobre cooperación internacional que se centran en el PIB como única medida del progreso del desarrollo. Con solo el $8.4 \%$ de la población mundial, y con 28 países de ingresos medios de los 33 de la región, ALC representa el 30\% de las muertes totales por COVID-19 (PNUD, $\left.2020_{[17]}\right)$, lo que demuestra que la toma de decisiones basadas en el PIB per cápita medio pasa por alto las desigualdades estructurales y los retos de desarrollo que van más allá de los ingresos. Centrarse en el PIB de los países de ALC no solo contradice el concepto integral de desarrollo de los ODS, sino que también se ha demostrado insuficiente por las carencias que han presentado estos países a la hora de hacer frente a la pandemia, pese a sus niveles de renta comparativamente superiores a los de los países de ingresos bajos. 
En el núcleo del marco de DiT está la exigencia de ir más allá del PIB como medida del desarrollo, adoptando enfoques multidimensionales y utilizando la cooperación internacional como elemento facilitador para transformar las trampas de desarrollo en oportunidades. Este señala cuatro trampas principales que la actual crisis ha revelado y agravado (OCDE et al., 2019 ${ }_{[1]}$ ). La trampa de la productividad explica por qué las empresas más vulnerables, que son principalmente las microempresas y las pequeñas y medianas empresas, han sido las más afectadas durante la pandemia: 2.7 millones de empresas cerraron en 2020 (CEPAL, 2021 ${ }_{[18]}$ ) Al mismo tiempo, la persistente heterogeneidad de la estructura productiva de la región incrementa su dependencia de sectores intensivos en recursos, acentuando la trampa medioambiental. La trampa de la vulnerabilidad social está detrás del desigual impacto socioeconómico de la pandemia, que ha dejado a 22 millones de personas más por debajo del umbral de la pobreza y ha afectado las condiciones de vida del $40 \%$ de los trabajadores y sus familias que no están protegidos por ninguna forma de seguridad social. Por último, la trampa institucional ha agravado la escasa capacidad de los servicios públicos de responder a las necesidades de las personas durante la pandemia, aumentando con ello el descontento social.

El proceso de recuperación representa una coyuntura única para que ALC ponga plenamente en práctica la función facilitadora de la cooperación internacional y transforme el círculo vicioso de las trampas de desarrollo en oportunidades para conseguir un modelo de desarrollo más inclusivo y sostenible. Una comparación de los diversos escenarios de recuperación indica que una estrategia de salida que suponga un fuerte impulso a la sostenibilidad medioambiental en el contexto de un acuerdo de cooperación internacional tendría un impacto positivo considerable en las emisiones de dióxido de carbono (-23\% en 2030). También tendría un impacto en el crecimiento del PIB (alrededor de un $2.5 \%$ más que en el escenario COVID-19), la desigualdad (aproximadamente un $0.5 \%$ menos que en el escenario COVID-19) y el empleo (cerca del $0.75 \%$ más que en el escenario COVID-19) (CEPAL, 2020 ${ }_{[19]}$ ).

Por tanto, la cooperación internacional es esencial, pero no cualquier tipo de cooperación. El marco de DiT requiere que esta actúe como facilitadora, contribuya a fortalecer capacidades en los países de ALC promoviendo procesos impulsados a nivel nacional basados en planes de desarrollo nacional, armonice las prioridades nacionales y globales y promueva la participación activa de ALC en la agenda global (OCDE et al., $\left.2019_{[1]}\right)$. Una función facilitadora puede también fomentar el uso de herramientas de colaboración diversas, como una mayor cooperación técnica basada en conocimientos, una cooperación triangular y sur-sur, y enfoques integrales de gobierno. Por último, mediante alianzas en condiciones de igualdad, una función facilitadora fomentaría un trabajo más inclusivo (Tabla 5.1).

Tabla 5.1. Dimensiones fundamentales para repensar la cooperación internacional como facilitadora del desarrollo sostenible de ALC

\begin{tabular}{ll}
\hline Dimensiones & Descripción \\
\hline Trabajo inclusivo & $\begin{array}{l}\text { Participación de los países en todos los niveles de desarrollo en condiciones de igualdad como pares, a fin de construir } \\
\text { e intervenir en alianzas multilaterales y con múltiples partes interesadas para abordar los retos comunes del desarrollo } \\
\text { multidimensional con respuestas multidimensionales }\end{array}$ \\
$\begin{array}{l}\text { Fortalecimiento } \\
\text { de capacidades nacionales }\end{array}$ & $\begin{array}{l}\text { Fortalecimiento de las capacidades de los países para diseñar, implementar y evaluar sus prioridades y planes sobre } \\
\text { políticas de desarrollo, fomentando la armonización entre las prioridades nacionales e internacionales y proporcionando } \\
\text { unos enfoques integrados a los retos más complejos e interrelacionados. }\end{array}$ \\
$\begin{array}{l}\text { Operar con más } \\
\text { herramientas y actores }\end{array}$ & $\begin{array}{l}\text { Ampliación de los instrumentos para una mayor cooperación internacional, como el intercambio de conocimientos, } \\
\text { diálogos sobre políticas, fortalecimiento de capacidades, transferencia de tecnología, con inclusión de actores } \\
\text { adicionales, como los actores públicos, en un enfoque integral de gobierno. }\end{array}$ \\
\hline
\end{tabular}

Fuente: (OCDE et al., 2019 ${ }_{[1]}$ ), Perspectivas económicas de América Latina 2019: Desarrollo en transición, https://doi.org/10.1787/ g2g9ff1a-es. 
A fin de transformar el paradigma de desarrollo en la región, la cooperación internacional debe ayudar a los países a abordar los efectos de la globalización y sus interrelaciones con las agendas políticas nacionales. Son muchos los desafíos comunes para los que las políticas nacionales resultan insuficientes: la prevención y control de las pandemias, el cambio climático, la transformación digital y -algo muy importante en el caso de ALC— la gestión de la deuda. Ello no solo es legítimo desde el punto de vista de los ciudadanos y beneficioso para la transición del desarrollo de ALC, sino también necesario para el suministro de bienes públicos globales.

\section{La urgente necesidad de adaptar el multilateralismo}

La irrupción del COVID-19 como emergencia sanitaria mundial y la crisis socioeconómica resultante han dado lugar a nuevas formas de solidaridad y alianzas transnacionales. No obstante, la comunidad internacional reconoce también que las iniciativas y respuestas no han sido suficientes $\mathrm{y}$, en muchos casos, se han visto obstaculizadas por la gobernanza y los estándares internacionales establecidos que impiden afrontar una crisis de alcance global.

Así sucede con las asignaciones de Derechos Especiales de Giro (DEG). A pesar de que ha surgido la necesidad de mejorar la cooperación en relación con la sostenibilidad de la deuda, los estándares internacionales y la estructura de gobernanza impiden el apoyo integral a la región a través de este mecanismo. Esto es especialmente importante para ALC ya que todos los países de la región han aumentado sus niveles de endeudamiento debido a la presión sobre los sistemas fiscales. En el contexto actual, se espera que el endeudamiento haya aumentado de un ya elevado $68.9 \%$ a un $79.3 \%$ del PIB entre 2019 y 2020 a nivel regional, convirtiendo a ALC en la región más endeudada del mundo en desarrollo y la que tiene el mayor servicio de la deuda externa en relación con las exportaciones de bienes y servicios (57\%) (CEPAL, 2021 $1_{[20]}$ ).

A pesar del alivio y la liquidez inmediata que proporciona la Iniciativa de Suspensión del Servicio de la Deuda (DSSI), no es suficiente para las necesidades actuales de la región. Los estándares mundiales no prevén un reparto igualitario de los DEG, ni una distribución basada en las necesidades de cada país, sino en proporción a sus cuotas existentes en el Fondo Monetario Internacional (FMI). Esto puede ser problemático ante una crisis mundial como la actual. De hecho, a la región se le concedió el 6.7\% de la nueva asignación de DEG, lo que supone cerca de 50000 millones de dólares en reservas internacionales adicionales para las economías de ALC (CGD, 2021 ${ }_{[21]}$ ). Esto ha beneficiado a varias economías de ALC, incluidas las altamente endeudadas, pero la nueva asignación de DEG tendría más impacto si se complementara con una reasignación de otros DEG existentes a los países de renta media de ALC. Además, la cooperación internacional multiactor es de suma importancia, ya que la deuda de muchos países de renta media es mayoritariamente con acreedores privados.

Ante una crisis de alcance mundial, los estándares internacionales y la gobernanza global pueden jugar un papel significativo permitiendo una cooperación internacional con vistas a una recuperación rápida, inclusiva y resiliente. Las respuestas integrales son, por tanto, esenciales a la hora de abordar desafíos que son multidimensionales, interconectados y comunes a todo el mundo. Las megatendencias mundiales no reguladas, una gobernanza mundial debilitada y una toma de decisiones asimétrica y jerárquica en la cooperación internacional siguen siendo algunos de los obstáculos que impiden que el multilateralismo ayude eficazmente a los países que se enfrentan a los retos mundiales actuales.

El cambio acelerado ha pasado a ser el leitmotiv de nuestro tiempo. En el ámbito internacional, esto se pone de manifiesto en megatendencias no reguladas, como el 
cambio climático, la deslocalización, la digitalización y el incremento de la importancia de las actividades financieras en la economía y los consiguientes retos que plantea a la tributación internacional. A pesar de los esfuerzos realizados a través de la actual arquitectura de la gobernanza mundial, estos fenómenos siguen sin estar regulados y dirigidos principalmente por los poderes fácticos y la dinámica del mercado, lo que socava la consecución de los ODS y los esfuerzos actuales para acabar con la pandemia. Un claro ejemplo en el contexto del COVID-19 es el incremento de las actividades financieras de las farmacéuticas privadas. Estas grandes compañías han recortado la inversión en investigación y han aumentado el gasto en recompras de acciones, una estrategia usada para impulsar la cotización de las acciones que va en detrimento de los descubrimientos científicos necesarios para asegurar la salud mundial (Mazzucato, 2018 ${ }_{[22]}$ ).

La intensificación exponencial de estas tendencias mundiales debilita la gobernanza global. La producción y distribución de las vacunas contra el COVID-19 ofrece un claro ejemplo al respecto. Aunque la plataforma internacional para la compra y distribución de vacunas - llamada Acceso Global a las Vacunas contra COVID-19 (COVAX) - representa un paso trascendental, su impacto está siendo contrarrestado por los contratos bilaterales de compra anticipada masiva por los países ricos que pueden permitirse apostar por múltiples vacunas (Mazzucato, Lishi Li, y Torreele, 2020 ${ }_{[23]}$ ). Además, la oposición de los países más desarrollados a las peticiones de muchos países en desarrollo a la Organización Mundial del Comercio (OMC) para que se autorice una exención del Acuerdo sobre los Aspectos de los Derechos de Propiedad Intelectual relacionados con el Comercio (ADPIC) para las vacunas contra el COVID-19, está obstaculizando las oportunidades de aumentar la producción y luchar contra las nuevas variantes (John Hopkins, 2020 [24]). Como consecuencia de todo esto, los contratos relativos a las vacunas se distribuyen de forma desigual en el planeta.

Estas tendencias se fundamentan en una toma de decisiones asimétrica y vertical en el ámbito internacional. Los países en desarrollo han visto limitada su voz en las organizaciones de Bretton Woods, a pesar de que su número creció sustancialmente en los años posteriores al final de la Segunda Guerra Mundial (OCDE, $\left.2021_{[25]}\right)$. Como argumenta el Grupo de los 24, los países de renta media - categoría a la que pertenecen la mayoría de los países de ALC- no han recibido suficientes asignaciones, y sus voces no han sido escuchadas en el contexto de estas instituciones, que han sido acusadas de operar sobre la base de un dólar-un voto (Singer, $\left.1995_{[26]}\right)$. La oposición de los países desarrollados a aplicar una exención del ADPIC para las vacunas contra el COVID-19 solo es un ejemplo. Otro caso en el contexto de la crisis actual son las asignaciones de DEG del FMI. En muchos aspectos, el descontento es un fenómeno mundial que subraya la necesidad de unos sistemas más equitativos, inclusivos y eficientes de cooperación internacional (Pezzini y Pick, 2021 $[27]$.

La eficacia y la legitimidad están entrelazadas: como demuestra el éxito de la cooperación de la comunidad científica internacional en el COVID-19, no es posible idear soluciones a los retos globales sin los aportes y la experiencia de los países de todo el mundo. Las instituciones multilaterales han de promover un proceso experimental que permita la intervención de una gama más amplia de actores, aplique un número considerable de modalidades y se inspire en una mayor variedad de opiniones, incluidas las de los descontentos (Pezzini y Pick, 2021 ${ }_{[27]}$ ).

Para marcar la diferencia, las reformas que promueva la cooperación internacional han de ir más allá de la reconstrucción y la recuperación. Deben más bien dirigirse a transformar la globalización a fin de maximizar su contribución a un desarrollo inclusivo, resiliente y sostenible en ALC (Nieto-Parra y Da Costa, 2021 ${ }_{[4]}$ ). 
Además, el proceso de recuperación requerirá un consenso transformador no solo a nivel nacional y subnacional, sino también en el ámbito regional y multilateral. La amplia movilización multisectorial que supondrá un nuevo contrato social en ALC debe ser de abajo hacia arriba, para enriquecer el desarrollo internacional con la participación de grupos colectivos representativos de la sociedad civil (Gráfico 5.2). Ello debería permitir superar las trampas de desarrollo y el descontento social en ALC, y así la región podría establecer un nuevo contrato social que sitúe a las personas en un primer plano y ofrezca bienes públicos globales.

\section{Gráfico 5.2. Un círculo vicioso entre las dinámicas de desarrollo global y nacional en ALC}

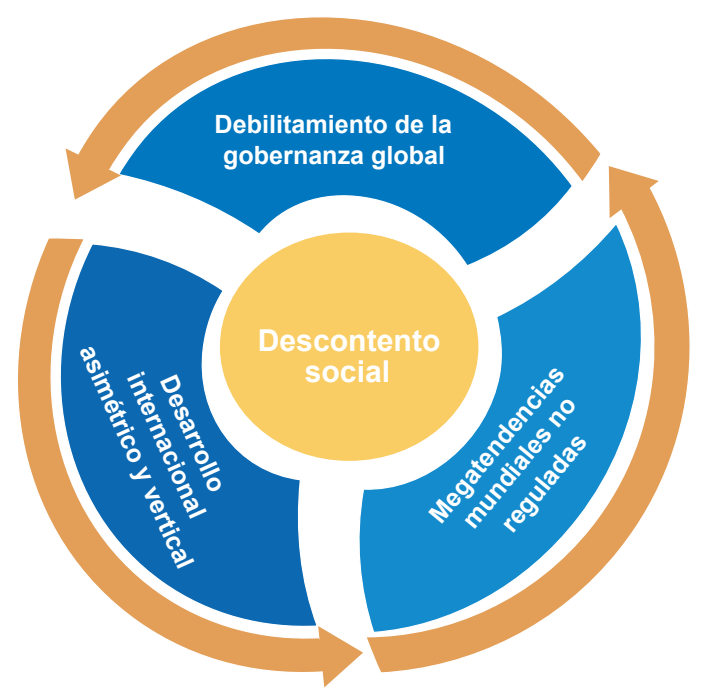

Fuente: Elaboración propia.

Es hora de replantear los sistemas, no sólo de arreglarlos. Los esfuerzos internacionales desencadenados durante la pandemia del COVID-19, que se analizan a continuación, reflejan algunos cambios en esta dirección, así como cuestiones pendientes. Se puede aprender mucho de ambos para avanzar mejor en el marco de un nuevo contrato social.

\section{La respuesta internacional a la crisis no ha sido suficiente}

A fin de superar las trampas de vulnerabilidad de ALC y contrarrestar los efectos negativos de las megatendencias globales en la región, mientras los países de ALC se preparan para la recuperación, es preciso un sistema de cooperación internacional y un multilateralismo dinámico que responda de forma rápida, eficiente y con perspectiva multidimensional a largo plazo (OCDE et al., 2019 ${ }_{[1]}$ ). Para aprovechar esta ventana de oportunidad, será necesario determinar lo que ha funcionado y lo que no durante la pandemia. Este apartado resume las principales conclusiones sobre la cooperación financiera y no financiera, la cooperación con el sector privado y la cooperación regional, y presenta las prácticas innovadoras que tuvieron lugar durante la pandemia.

\section{La ayuda financiera internacional durante la pandemia}

La ayuda financiera internacional se ha multiplicado desde el comienzo de la pandemia, aun cuando la crisis ha afectado también a las economías desarrolladas. Las instituciones multilaterales, los bancos de desarrollo, los donantes de cooperación bilateral y el sector privado han desplegado unos esfuerzos excepcionales para luchar contra la crisis y acelerar la recuperación económica. Un análisis del total de financiación 
anunciada entre el 1 de enero de 2020 y el 28 de febrero de 2021 para responder a la pandemia y sus efectos muestra que se han comprometido más de 20.7 miles de millones de USD (DEVEX, 2021 ${ }_{[28]}$ ). Los niveles de financiación y las áreas prioritarias no están claros y son difíciles de seguir y determinar, sobre todo en lo que respecta al importe efectivamente desembolsado y qué cantidad es extrapresupuestaria o se ha reasignado desde los programas existentes (OCDE, 2020 $\left.{ }_{[29]}\right)$.

A pesar de que ALC ha empeorado su ya crítico déficit fiscal, convirtiéndose en la región más endeudada del mundo, se beneficia de una parte relativamente pequeña de los esfuerzos globales de cooperación al desarrollo. En el mundo en desarrollo, ALC sufrió la peor crisis que se recuerda y la contracción más acusada (aproximadamente del -7.0\% del PIB y un -20\% en el crecimiento de la inversión en 2020) (CEPAL, 2021 $1_{[30]}$ ). El gasto fiscal total aumentó para hacer frente a los impactos de la crisis del COVID-19 en los hogares pobres y otras poblaciones vulnerables, así como en el sector privado, mientras que los ingresos fiscales cayeron, lo que resultó en un aumento del déficit fiscal global de -3.0\% del PIB en 2019 alrededor de $-7.0 \%$ del PIB en 2020 (CEPAL, 2021 ${ }_{[31]}$ ).

Un análisis de los flujos de cooperación por socios muestra que, en comparación con el resto del mundo, la recuperación de ALC se basa más en el apoyo de los bancos de desarrollo regional y recibe una asistencia relativamente menor de los socios tradicionales y de los no tradicionales, como el sector privado (DEVEX, 2021 ${ }_{[28]}$ ). Por ejemplo, el Banco Interamericano de Desarrollo (BID) es el segundo mayor contribuyente en ALC, mientras que es el número 12 en el mundo. Además, si bien la Unión Europea y el Banco Europeo de Inversiones ocupan los puestos tercero y cuarto entre los mayores contribuyentes a escala mundial, se sitúan en la posición 13 y 11, respectivamente, en ALC. El sector privado es el séptimo mayor contribuyente del mundo, aunque solo ocupa el puesto número 24 en la región.

Un análisis de las áreas prioritarias pone de relieve que, al igual que en el resto del mundo, la cooperación y otras fuentes de financiamiento con ALC ha dado prioridad a la recuperación económica y a las respuestas inmediatas, pero ha atribuido una mayor importancia a la población vulnerable en comparación con el resto del mundo, aunque otras cuestiones clave del pacto social no están claras. Las respuestas económicas suponen un $60 \%$ de los esfuerzos mundiales y un 37\% fueron dirigidos a ALC. En la región, el financiamiento destinado a las poblaciones vulnerables ocupa el segundo puesto (17\%), seguida por la respuesta inmediata (14\%), los sistemas de salud (11\%) y la dimensión de género (7\%) (Gráfico 5.3).

La ayuda oficial para el desarrollo (AOD) alcanzó un máximo histórico en 2020, y el G20 ha adoptado medidas importantes para incrementar la financiación a los países en desarrollo en el marco de las instituciones de Bretton Woods. La ayuda exterior de donantes del CAD ascendió a 161200 millones de USD en 2020, un incremento del 3.5\% en términos reales con respecto a 2019, gracias al gasto adicional movilizado para ayudar a los países en desarrollo a combatir la crisis del COVID-19 (OCDE, 2021 $1_{[32]}$ ). Las contribuciones de AOD a organizaciones multilaterales, que representan en torno a un tercio de la AOD total, aumentaron un 9\% a nivel mundial en 2020 en comparación con 2019 (OCDE, 2020 ${ }_{[29]}$ ). No obstante, estos niveles incluyen un aumento de la proporción de préstamos e inversiones de capital frente a las subvenciones por parte de algunos países donantes (OCDE, 2021 $1_{[33]}$ ). Esta asistencia juega un papel esencial y único a la hora de afrontar y abordar los retos; se centra en el bienestar de las personas y se dirige a aspectos que no están cubiertos por otra financiación (privada), y ha sido un recurso relativamente estable y predecible en tiempos de crisis. Sin embargo, la ayuda oficial al desarrollo no puede responder por sí sola a la crisis del COVID-19. 


\section{Gráfico 5.3. Financiamiento total por ámbito de políticas en ALC}

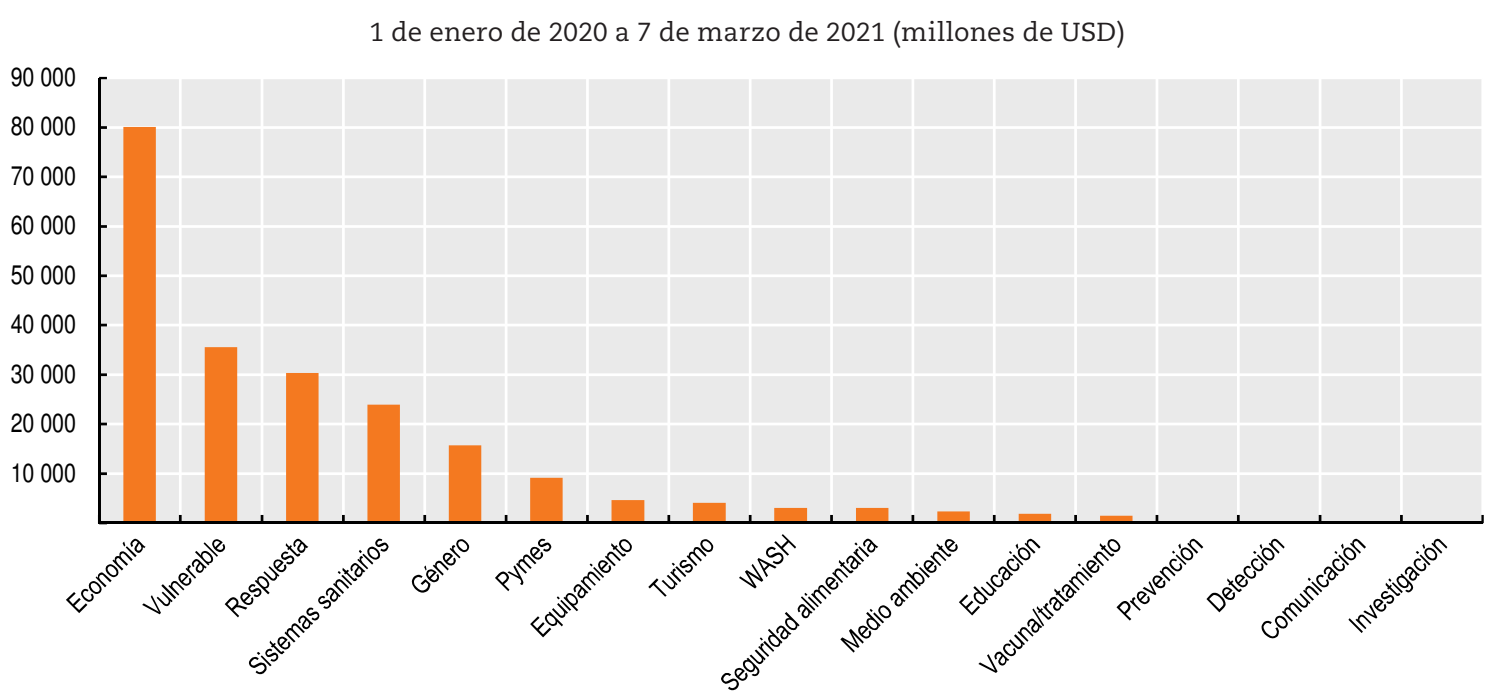

Nota: Pymes = pequeñas y medianas empresas. WASH = agua, saneamiento e higiene.

Fuente: DEVEX $\left(2021_{[28]}\right)$, Funding the response to COVID-19: Analysis of funding opportunities, www.devex.com/news/ interactive-who-s-funding-the-covid-19-response-and-what-are-the-priorities-96833.

StatLink (inlst https://doi.org/10.1787/888934296002

Los países de ALC han recurrido a los bancos de desarrollo y se han beneficiado de las rápidas líneas de crédito y financiación establecidas para responder a la pandemia que no imponen condiciones a los países prestatarios. Entre las noticias positivas contenidas en la nota de prensa del G20 del 7 de abril de 2021, es importante señalar el acuerdo de emitir 650000 millones en DEG, el activo de reserva mundial del Fondo Monetario Internacional (FMI). Además, las ampliaciones de la Iniciativa de Suspensión del Servicio de la Deuda (DSSI, por sus siglas en inglés), el Marco Común del G20 para las Reestructuraciones de Deuda y el Fondo para Alivio y Contención de Catástrofes ofrecen ayudas a los países de bajos ingresos especialmente castigados (Ocampo, 2021 ${ }_{[34]}$ ).

Pese a estos esfuerzos, la cuantía de la cooperación ha sido insuficiente (Kharas y Dooley, 2020 ${ }_{[35]}$; OCDE, 2021 ${ }_{[32]}$; Ocampo, 2020 $\left.{ }_{[36]}\right)$. Las líneas de financiación concedidas por el FMI a los países de ALC para hacer frente a los efectos de la pandemia sólo han cubierto, en promedio, entre el $23.1 \%$ y el $32.3 \%$ de las necesidades de financiación de los países solicitantes (CEPAL, 2021 ${ }_{[31]}$ ). Por su parte, la financiación prometida por el Banco Mundial y el BID, equivalente a 8000 y 7700 millones de USD, respectivamente, ha sido inferior a la concedida por los bancos de desarrollo subregionales, a saber, el Banco de Desarrollo de América Latina (CAF), el Banco Centroamericano de Integración Económica (BCIE) y el Banco de Desarrollo del Caribe (BDC), estimada en 12300 millones de USD (Bárcena, 2021 ${ }_{[37]}$; CEPAL, 2021 $1_{[30]}$ ).

La cooperación financiera ha sido especialmente insuficiente para cubrir las necesidades de los países de ingresos medios. A diferencia de los efectos del COVID-19, la arquitectura de la cooperación internacional distingue entre niveles de renta, dando prioridad a los países de bajos ingresos. Por lo tanto, la mayoría de los países de ALC no son elegibles, por ejemplo, para el DSSI del G20. El impacto multidimensional de la pandemia del COVID-19 en las vidas de los latinoamericanos requiere financiación y para ello la comunidad internacional necesita reflexionar sobre qué mecanismos podrían estimular una recuperación sostenible, justa y resiliente. 
Más allá de la financiación, la cooperación internacional con, dentro y desde ALC presenta diversos ejemplos e innovaciones

La crisis del COVID-19 ha ofrecido algunos ejemplos interesantes y positivos de cooperación. Un examen más atento de la calidad de la respuesta pone también de relieve que la cooperación internacional ha utilizado una amplia gama de modalidades y mecanismos. En efecto, existen experiencias relevantes de instituciones multilaterales, bancos de desarrollo y países desarrollados y en desarrollo en materia de cooperación técnica, cooperación con un enfoque integral de gobierno o con múltiples partes interesadas, transferencia de conocimientos y fortalecimiento de capacidades.

Con respecto a la cooperación técnica, ALC ha aprovechado su experiencia en cooperación sur-sur. Por ejemplo, Argentina y México intercambiaron cooperación no financiera para acelerar los procedimientos administrativos de aprobación y administración de la vacuna Sputnik-V (El País, 2021 ${ }_{[38]}$ ) y colaboraron para coproducir y distribuir la vacuna AstraZeneca en ALC. Venezuela donó 136000 litros de oxígeno al estado brasileño de Amazonas cuando este sufrió carencias para tratar un pico de pacientes de COVID-19 (Reuters, 2021 $\left.{ }_{[39]}\right)$. Argentina y Chile colaboraron para reforzar sus sectores de pequeñas y medianas empresas (pymes) apoyando su proceso de digitalización y fomentando su participación en el mercado de licitaciones públicas.

Fuera de ALC, los socios del sur también han mostrado ejemplos de solidaridad con la región. Uno de ellos es Marruecos, que ofreció apoyo financiero a El Salvador para construir una red nacional de oxígeno medicinal en su sistema de salud.

La región ha aprovechado también las oportunidades para adaptar las iniciativas de cooperación triangular al contexto de la pandemia. Esta ofrece una oportunidad de abordar conjuntamente la pandemia mundial, aprendiendo de la experiencia de las distintas regiones en la lucha contra el impacto del COVID-19. Por ejemplo, entre las iniciativas de cooperación triangular, Uruguay está preparando y adaptando junto con España una iniciativa para ofrecer asistencia técnica a Bolivia a fin de evaluar su situación en relación con el software de telemedicina. El Fondo Regional Alemán de Cooperación Triangular con ALC también ha reorientado sus programas a la luz de la pandemia. La UE, a través de su Mecanismo de Cooperación Triangular con ALC, ha dado prioridad a las iniciativas presentadas a la Ventana ADELANTE 2021 que pretendían responder a los retos de desarrollo relacionados con las circunstancias derivadas de la pandemia.

Los bancos de desarrollo regional y los socios tradicionales de cooperación para el desarrollo también han aportado apoyo estratégico para el fortalecimiento de capacidades. El BID ha proporcionado ayuda financiera para desarrollar prototipos de respiradores a bajo costo en Colombia y utilizando materiales y suministros fácilmente accesibles. Luxemburgo ha apoyado la creación de la primera clínica universitaria en El Salvador, en el seno del hospital nacional. El Banco de Desarrollo de América Latina (CAF) ha fortalecido las capacidades de la República Dominicana para mejorar el Centro de Operaciones de Emergencia, y el BID ha facilitado asistencia para la construcción de la Plataforma de Rendición de Cuentas de Costa Rica, por medio de la cual los ciudadanos pueden consultar los datos de las inversiones públicas en respuesta a la pandemia.

Durante la crisis del coronavirus, ALC ha ofrecido también ejemplos innovadores de cooperación y propuestas transformadoras de cooperación multilateral. Por ejemplo, los médicos cubanos colaboraron con Italia y Sudáfrica a través del programa médico internacional de ese país (Bhattacharya y Sabin Khan, 2020 ${ }_{[40]}$ ). Costa Rica lanzó dos ambiciosas iniciativas de cooperación a nivel multilateral. En primer lugar, el Acceso Mancomunado a Tecnología contra la COVID-19 (C-TAP) en el seno de la Organización Mundial de la Salud (OMS), a fin de facilitar un acceso ágil, equitativo y asequible a los 
productos sanitarios relacionados con el COVID-19 compartiendo propiedad intelectual y know-how sobre el tratamiento, diagnóstico, vacunas y otros productos sanitarios. En segundo lugar, el Fondo para Aliviar la Economía COVID-19 (Fund to Alleviate COVID-19 Economics - FACE), una alternativa a los marcos de cooperación actuales. Esta iniciativa pretende ofrecer a los países en desarrollo los fondos necesarios para hacer frente a los efectos socioeconómicos de la pandemia en la economía y en las personas, en condiciones favorables y solidarias (Recuadro 5.1).

Asimismo, algunos socios han promovido la cooperación con un enfoque integral de gobierno para emprender con eficacia las primeras etapas de la recuperación. CAF está trabajando con Paraguay en un programa multidimensional destinado a financiar el Plan de Reactivación Económica “Ñapu'ã Paraguay". Dicho plan prevé un programa contra-cíclico con tres ejes: i) protección social; ii) inversión pública en empleo y créditos para el desarrollo; y iii) reformas para la transformación de las instituciones públicas $\left(\right.$ CAF, 2021 $\left.{ }_{[41]}\right)$. El "Equipo Europa" ha adoptado también un enfoque integral de gobierno, emprendido por la iniciativa Mesas COVID-19.

\section{Recuadro 5.1. Fondo para Aliviar la Economía COVID-19}

El Fondo para Aliviar la Economía COVID-19 (Fund to Alleviate COVID-19 Economics FACE) fue propuesto en primer lugar por el gobierno de Costa Rica en el marco de la 75 Asamblea General de las Naciones Unidas como vehículo de solidaridad internacional ante la recesión económica causada por la pandemia e instrumento para impulsar una recuperación sostenible (CEPAL, 2020 ${ }_{[42]}$ ).

Es un fondo de apoyo extraordinario de medio trillón de USD y está financiado con el $0.7 \%$ del PIB de las economías más grandes y fuertes del mundo - representan el $80 \%$ del PIB mundial- que será intermediado por uno o varios bancos multilaterales de desarrollo, como préstamos en condiciones favorables a países en desarrollo.

Los fondos se prestarán en condiciones favorables y solidarias: un plazo de reembolso de 50 años, un plazo de carencia de 5 años y un tipo de interés fijo del $0 \%$. Como contribución en estas circunstancias especiales, las organizaciones financieras no percibirán comisiones por la intermediación y administración de los recursos del FACE. La asignación de estos recursos no estará sujeta a las condiciones monetarias o estructurales tradicionales, sino que tendrá en cuenta normas de buen gobierno y la lucha firme contra la corrupción.

El Fondo equivaldrá a un 3\% del PIB de los países beneficiarios, una cifra representativa de la caída de los ingresos tributarios más los costos extrapresupuestarios para luchar contra la pandemia. Los recursos se prestarán a largo plazo a tipos fijos para proporcionar financiación a los países en desarrollo que disponen de limitadas herramientas políticas para responder a la crisis.

El desembolso de los recursos estará totalmente alineado con el cumplimiento de la Agenda 2030 y los ODS, de forma que se fortalezca la resiliencia y se alcancen los objetivos de los acuerdos medioambientales multilaterales, como las Contribuciones Determinadas a Nivel Nacional, a fin de acelerar el progreso hacia el desarrollo sostenible en esta Década de Acción.

\section{Se ha reforzado la incipiente colaboración internacional con el sector privado}

A medida que el COVID-19 se extendía y su impacto global sobre la salud y la economía se hacía más evidente, algunas empresas multinacionales trataron de complementar los esfuerzos del gobierno para luchar contra la pandemia. Las empresas de tecnología de la información y las comunicaciones, como AT\&T y Telefónica, colaboraron con los 
gobiernos de los países de ALC para apoyar las iniciativas de educación a distancia durante el cierre de las escuelas. Los esfuerzos por lograr una mayor inclusión financiera a través de iniciativas financieras digitales innovadoras permitieron a los proveedores actuar con rapidez para facilitar los pagos digitales, incluso en apoyo de los programas de protección social, lo que, según las investigaciones, redujo la población no bancarizada en toda América Latina en un 25\% (Americas Market Intelligence, $2020_{[43]}$ ). Muchas empresas asumieron la responsabilidad de actuar, tal como muestran las iniciativas del sector privado en la región (EMnet, 2021 $[44]$ ), por ejemplo, modificando las cadenas de suministro para producir artículos básicos, sosteniendo la prestación de servicios esenciales y la oferta de productos gratuitos o pagos flexibles.

A nivel internacional, el sector privado está colaborando con el Centro de Comercio Internacional, el BID, el Programa de las Naciones Unidas para el Desarrollo y otras instituciones a fin de apoyar la recuperación económica mediante la introducción del Acuerdo sobre Facilitación del Comercio (AFC). El AFC es un motor del crecimiento que se basa en las mejores prácticas acordadas por los miembros de la OMC. Los comités nacionales de facilitación del comercio han resultado ser un factor impulsor clave del crecimiento en las economías en desarrollo, impulsando el diálogo con los gobiernos. Además, donantes y organizaciones como la Alianza Global para la Facilitación del Comercio están buscando activamente socios para proyectos piloto de reforma en ALC.

Las actuales iniciativas de recuperación son una oportunidad importante para introducir reformas significativas e invertir en sectores estratégicos (p. ej., la salud pública) como motores del crecimiento futuro. En este sentido, en colaboración con los gobiernos, muchas empresas han buscado identificar y promover iniciativas que produzcan un impacto inmediato y estén en consonancia con las estrategias de crecimiento a largo plazo. Durante la pandemia, muchos países interactuaron abiertamente con instituciones regionales e internacionales y mitigaron los impactos mediante el diálogo con el sector privado (p. ej., facilitando el comercio de productos esenciales). Existe la oportunidad de construir sobre esta base para diseñar planes a largo plazo de modernización, digitalización y reforma normativa en la región. Algunos ejemplos de fomento de la digitalización son la agilización de los procedimientos aduaneros, las políticas laborales que permiten el trabajo a distancia, la reducción de los requisitos de información y la disponibilidad de espectro adicional (EMnet, 2021 $1_{[45]}$ ).

\section{Alianzas de política regional en ALC ante el COVID-19}

Las redes de cooperación, plataformas einstituciones de integración de ALC han lanzado estrategias de respuesta para hacer frente a los impactos inmediatos de la pandemia. La más destacada es la Secretaría General del Sistema de Integración Centroamericana (SICA), cuyos países miembros acordaron un Plan Regional de Contingencia para luchar contra la pandemia (con un 85\% finalizado en los primeros nueve meses de ejecución) y lanzaron un Observatorio Regional COVID-19. SICA recibe apoyo también de la Unión Europea para ejecutar su Plan para la Recuperación, Reconstrucción Social y Resiliencia de Centroamérica y República Dominicana (Recuadro 5.2).

\section{Recuadro 5.2. Plan 3R: Plan para la Recuperación, Reconstrucción Social y Resiliencia de Centroamérica y República Dominicana}

Ante el enorme impacto económico y social de la pandemia en América Central y la República Dominicana, el Consejo de la Integración Social Centroamericana (CIS) aprobó la Segunda Declaración Especial en abril de 2020: Unidos por la recuperación y la reconstrucción social de la región, en la que se señaló la necesidad urgente de establecer 


\section{Recuadro 5.2. Plan 3R: Plan para la Recuperación, Reconstrucción Social y Resiliencia de Centroamérica y República Dominicana (cont.)}

mecanismos no solo para mitigar los daños, sino también para sentar las bases de una recuperación y reconstrucción social sostenible, abordando los factores que han socavado la resiliencia de la región.

El CIS instruyó a la Secretaría de la Integración Social Centroamericana a desarrollar una respuesta articulada y elaborar un Plan para la Recuperación, Reconstrucción Social y Resiliencia de Centroamérica y República Dominicana, con el apoyo del programa de la UE EUROsociAL+ y en alianza con agencias especializadas de las Naciones Unidas (EUROsociAl, 2021 $\left.{ }_{[46]}\right)$.

El Plan contempla una serie de proyectos estratégicos organizados en tres ejes de intervención: i) protección social; ii) empleo; y iii) asentamientos irregulares y desarrollo urbano sostenible. Cada uno de los proyectos incluye acciones estratégicas y transformadoras que pretenden dar respuestas amplias y articuladas a problemáticas priorizadas por los países, impulsando su reactivación y recuperación. El proyecto pretende generar las condiciones para unas sociedades más resilientes, socialmente justas y ambientalmente sostenibles.

La experiencia derivada del Plan demuestra la importancia de las políticas y los marcos regionales para fomentar la resiliencia e inspirar los planes de recuperación nacional, reforzando y renovando los pactos sociales necesarios para su implementación.

Sin embargo, la pandemia aún no se ha transformado en una oportunidad para que ALC en su conjunto emprenda acciones de solidaridad regional más amplias, refuerce una voz común en la esfera multilateral e impulse una estrategia de cooperación regional transformadora hacia una senda de desarrollo inclusivo y sostenible. No todos los países de ALC han sido capaces de alinear su apoyo en torno a las propuestas más transformadoras que surgieron en la región durante la pandemia, como el FACE y C-TAP propuestos por Costa Rica. La insuficiente alineación política de los gobiernos de ALC para impulsar una respuesta regional contrasta con la voluntad de los ciudadanos, ya que el $61.8 \%$ de las personas se declara algo o muy a favor de la integración política de su país con otros de la región (Gráfico 5.4).

\section{Gráfico 5.4. Percepciones sobre la integración política en América Latina (a favor o en contra)}

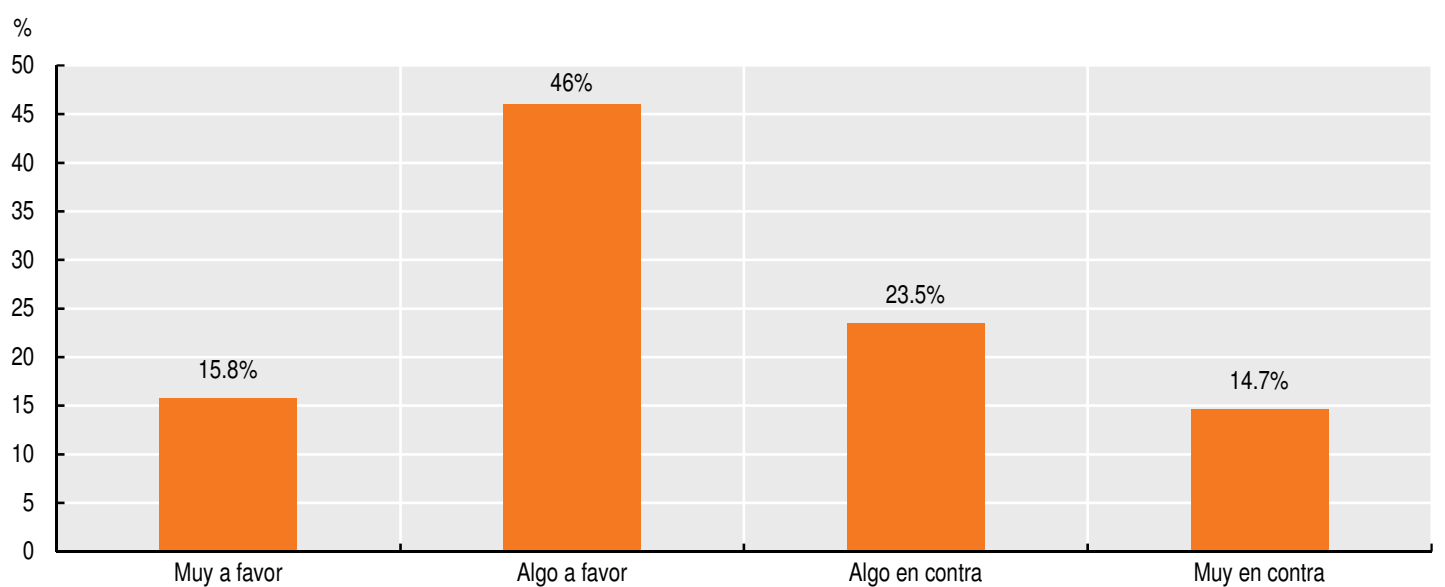

Fuente: Nieto-Parra y Da Costa $\left(2021_{[4]}\right)$, “Desarrollo en transición en América Latina en tiempos de la COVID-19”, Documentos de Trabajo Fundación Carolina.

StatLink iㅔsम https://doi.org/10.1787/888934296021 
Los países de ALC deben reaccionar ante las manifestaciones de descontento social y el apoyo de los ciudadanos en favor de una mayor cooperación regional. La región podría elaborar una agenda de desarrollo regional con ambiciosos acuerdos políticos y operativos que incluyan diálogos con múltiples actores. Dicha cooperación incrementaría la magnitud de las respuestas políticas respecto a la recuperación. Por una parte, contribuiría a situar las necesidades y particularidades de la región en el contexto mundial de los marcos de negociación y gobernanza. Por la otra, contribuiría a alinear los esfuerzos de los países hacia una mayor integración regional que podría ayudar a los países a responder mejor a las agendas de recuperación. Una cooperación regional que respalde adecuadamente la negociación del contrato social permitiría la creación de sistemas de protección social más equitativos, la mitigación de los efectos del cambio climático y la promoción de las cadenas regionales de valor con vistas a impulsar la productividad y la innovación, lo cual constituye el objeto del siguiente apartado.

Una señal alentadora en este es la aprobación del Plan de Autosuficiencia Sanitaria regional por parte de los 33 países de ALC reunidos en la reciente IV Cumbre de Jefes de Estado y de Gobierno de la Comunidad de Estados Latinoamericanos y del Caribe (ONU, $\left.2021_{[47]}\right)$. Este plan, que cuenta con el apoyo de la CEPAL, abordará las capacidades de investigación, desarrollo y producción de vacunas y medicamentos a nivel regional. Esto reforzará la soberanía científica y sanitaria de ALC y abordará los principales factores de vulnerabilidad estructural de la región mediante la integración y la cooperación regionales.

\section{¿Qué tipo de alianzas internacionales podrían facilitar los esfuerzos hacia un nuevo contrato social en ALC?}

El mundo se acerca rápidamente al final de la Agenda 2030 con escasos resultados que satisfagan sus ambiciones iniciales. La crisis del COVID-19 ha acentuado las dificultades para alcanzar los ODS. Las acciones internacionales deben adoptar una postura más ambiciosa si se pretende que el mundo se acerque a estos objetivos. Los países de ALC no son diferentes. El contexto pos-COVID-19 impone nuevas formas de interacción con la región, y esto es muy importante. Un nuevo contrato social que englobe a los distintos grupos socioeconómicos (incluidos los de ingresos, raza, etnia y género), a los sectores, a los territorios y a las generaciones puede constituir los pilares de una nueva vía de desarrollo que cohesione a la sociedad y restablezca la confianza de los ciudadanos en las instituciones públicas nacionales e internacionales.

Los esfuerzos de la cooperación internacional deben abordar el debilitamiento de las instituciones de gobernanza mundial y las estructuras de toma de decisiones asimétricas y jerárquicas que conducen a una mayor desregulación de las megatendencias, lo que afecta especialmente a las poblaciones vulnerables de todo el mundo y provoca el descontento social. De forma complementaria, el sistema de cooperación internacional debe trabajar de manera más inclusiva entre los socios de desarrollo, mejorar la creación de capacidades nacionales para conectar mejor las agendas nacionales e internacionales, y operar con más herramientas y actores.

Algunas opciones aparecen como prioritarias. En primer lugar, promover alianzas enfocadas en las metas que aumenten la participación de los ciudadanos y proporcionen mecanismos y marcos de gobernanza en igualdad de condiciones, al tiempo que se fomenta el diálogo político; en segundo lugar, reforzar la cooperación regional; en tercer lugar, aplicar un uso equilibrado de la financiación, los reglamentos y las normas, y la cooperación técnica para el desarrollo de capacidades.

Este apartado presenta consideraciones sobre las opciones de políticas para una actualización continuada de los sistemas de cooperación regional, interregional y multilateral con y dentro de ALC, a fin de construir un futuro mejor. 


\section{Alianzas internacionales basadas en propósitos claros}

Las alianzas internacionales basadas en propósitos implican pensar más allá de las áreas e instituciones actualmente definidas para incluir todos los recursos, herramientas y actores pertinentes en coaliciones basadas en temas que logren resultados de desarrollo medibles. En primer lugar, en cuanto a la finalidad o los objetivos, las alianzas internacionales pueden estar enfocadas en las metas multidimensionales u objetivos de desarrollo, en lugar de estar estructuradas por sectores o instituciones, lo que permite una coherencia de políticas entre los distintos esfuerzos internacionales. En segundo lugar, en cuanto a las herramientas, deben desplegarse todos los recursos pertinentes, por ejemplo, la financiación, los conocimientos y la tecnología, garantizando un enfoque de gobierno completo, como se propone en el marco del DiT. En tercer lugar, en cuanto a la participación, esta debe estar dirigida por una clara voluntad política y un enfoque bottom-up, con el apoyo de los mecanismos pertinentes de investigación y rendición de cuentas, las nuevas alianzas serán un motor clave del ciclo virtuoso a nivel multilateral para garantizar la consecución de los ODS y, especialmente en el caso de ALC, la implementación efectiva de un nuevo contrato social. Durante la pandemia se han multiplicado las experiencias innovadoras que reflejan esta visión (Recuadro 5.3).

\section{Recuadro 5.3. Equipo Europa: una iniciativa orientada a las metas creada en el contexto del COVID-19}

Equipo Europa (Team Europe) se lanzó en medio de las condiciones excepcionales creadas en 2020 por la pandemia del COVID-19, como una respuesta europea unificada a las importantes necesidades que surgieron en los países socios. Equipo Europa refuerza la contribución de la Unión Europea mediante una mejor coordinación y coherencia. Aúna los recursos colectivos de desarrollo de la Unión Europea, los Estados miembros de la UE, el Banco Europeo de Inversiones y el Banco Europeo para la Construcción y el Desarrollo. Los miembros de Equipo Europa trabajan conjuntamente, de forma inclusiva y coordinada, para dar apoyo a los socios.

La respuesta al COVID-19 de Equipo Europa para ALC comprendió un redireccionamiento de los programas y fondos existentes, en lo posible, y una aceleración de los pagos a nivel nacional y multinacional. El plan inicial de Equipo Europa tenía por objeto aproximadamente 900 millones de euros para ALC.

Desde abril de 2020 en adelante, la Unión Europea lanzó un programa piloto de mesas redondas nacionales de Equipo Europa en Argentina, Costa Rica y Ecuador. Bajo el liderazgo conjunto de la delegación de la UE y el gobierno socio, en estas reuniones participan un amplio espectro de partes interesadas nacionales y representantes de los Estados miembros de la UE activos en el país, programas promovidos por la Comisión Europea y la administración local, con el fin de debatir la mejor forma de aunar esfuerzos y proporcionar un apoyo coherente de la UE a la gestión de la pandemia de COVID-19 y la recuperación del país. De este modo, Equipo Europa actúa en consonancia con las necesidades y prioridades de los países socios y facilita la transición a economías y sociedades inclusivas y sostenibles, promoviendo la digitalización para el desarrollo, fomentando la resiliencia y reduciendo el riesgo de crisis futuras.

Las "Iniciativas Equipo Europa" se integrarán en el Programa Indicativo Multianual 2021-2027 de la UE. Basándose en un diálogo sobre políticas estratégicas, perseguirán fomentar el cambio transformador generando resultados concretos para los países socios. Aprovecharán la mejor combinación de modalidades de apoyo y se establecerán al nivel más adecuado. El objetivo consiste en maximizar el impacto y el efecto 
Recuadro 5.3. Equipo Europa: una iniciativa orientada a las metas creada en el contexto del COVID-19 (cont.)

transformador de los fondos europeos aunando las capacidades de los Estados miembros de la UE, la Comisión Europea y sus diversas instituciones. Las puertas están abiertas a la incorporación de otros socios o instituciones de desarrollo.

La estructuración de la cooperación internacional a través de alianzas basadas en las metas puede ayudar a comprender la multidimensionalidad del desarrollo y promover una mayor coherencia de políticas (ODS 17). Centrar los esfuerzos en la resolución de problemas de desarrollo complejos puede ser un catalizador para que la arquitectura internacional adopte enfoques más flexibles centrados en resultados. Es esencial promover enfoques intersectoriales y una mejor comprensión de las múltiples dimensiones del desarrollo para crear sinergias entre las políticas de todos los sectores y niveles y el mayor número posible de escenarios en los que todos resulten beneficiados. Estas sinergias a las que nos referimos son horizontales (p. ej., los diferentes pilares del contrato social), así como verticales (entre los niveles de gobernanza globales, regionales nacional y subnacional) (Knoll, 2014 ${ }_{[48]}$ )

Centrarse en una misión específica también puede impulsar un uso más flexible de herramientas y ayudar a crear otras nuevas. ALC necesita ampliar el conjunto de herramientas, más allá de las tradicionales, que incluya una conversación más técnica entre los socios basada en el intercambio de conocimientos, el diálogo sobre políticas, los intercambios para el desarrollo de capacidades, las transferencias de tecnología y la cooperación sur-sur y triangular (OCDE et al., 2019 [1] ). Además, las nuevas herramientas de otras formas de asociación (p. ej., las alianzas público-privadas) podrían integrarse en las nuevas alianzas internacionales, a través de las plataformas amplias que estructuren los procesos de elaboración de políticas internacionales. Por lo tanto, es fundamental permitir y dirigir la participación de múltiples niveles y partes interesadas. Este enfoque podría desencadenar un círculo virtuoso que permita el éxito y la sostenibilidad de un nuevo contrato social en ALC.

Las alianzas enfocadas en las metas podrían ser una parte esencial en la exploración de nuevas formas de incluir a los ciudadanos en los esfuerzos de cooperación internacional. Es preciso examinar varias consideraciones estratégicas para poner en práctica de forma más general dichas alianzas. Las preguntas fundamentales son: ¿Qué beneficios aporta este nuevo enfoque en comparación con los mecanismos actuales? ¿Quién debe participar en el proceso de formulación de políticas y definir las metas que llevarán a cabo las alianzas internacionales? ¿Cuándo y cómo deben ser incluidas las diversas partes interesadas?

Los enfoques integrales de gobierno siguen siendo necesarios, pero el contexto actual exige enfoques de la cooperación internacional que abarquen a toda la sociedad. Resulta compleja la combinación de voluntad política al más alto nivel y la apertura del proceso de elaboración de políticas de cooperación internacional a los actores no estatales y subnacionales. Aun así, hay mucho que ganar si los países de ALC aprovechan las oportunidades de las amplias negociaciones que suponen los nuevos contratos sociales y las extiendan con éxito en los escenarios internacionales. La participación activa de grupos representativos de la sociedad civil, el sector privado, los gobiernos subnacionales y la academia en el proceso de elaboración de la agenda de la cooperación internacional politizaría positivamente y aumentaría la legitimidad de sus metas, convirtiéndola en una oportunidad para conectar más estrechamente la gobernanza global con las preocupaciones cotidianas de los ciudadanos. Estos actores tienen proyectos sobre 
el terreno que les proporcionan información a nivel del territorio y perspectivas de aplicación que podrían ser útiles para los responsables de las políticas multilaterales (Chatham House, $2021_{[49]}$ ) Además, por lo general son más efectivos en la ejecución que los actores tradicionales de la cooperación. Este sistema fomentaría los tan necesarios vínculos intersociales horizontales (Badie, $2020_{[5]}$ ).

Es necesario reflexionar sobre cómo serían los nuevos mecanismos de participación y cómo podrían garantizar un diálogo sobre políticas inclusivo y eficaz. Deben organizarse plataformas con múltiples partes interesadas con un objetivo claro y deben desplegarse esfuerzos para asegurar la participación de los grupos infrarrepresentados. Este punto es especialmente importante en ALC, por sus múltiples y fuertes desigualdades, que dan lugar a diversas capacidades de representación entre varios tipos de actores. Las nuevas plataformas han de evitar la agrupación de partes interesadas sin tomar en consideración los desequilibrios de poder, incluso dentro del sector privado. Por ejemplo, las PYMES representan el $99 \%$ de todas las empresas, y en las microempresas se concentran la mayoría de los cierres empresariales y pérdidas de puestos de trabajo que se han producido durante la pandemia del COVID-19 (CEPAL, 2021 ${ }_{[18]}$ ).

Si se instauran los mecanismos institucionales adecuados, las nuevas alianzas internacionales resultantes mejorarían la transparencia en la toma de decisiones, incrementarían la coherencia de las políticas nacionales e internacionales y facilitarían su ejecución. La transparencia y rendición de cuentas promoverían una mayor coherencia de las políticas. Algunas de las lecciones aprendidas apuntan a que los procesos de abajo hacia arriba funcionan mejor cuando se estructuran con un árbitro dotado de autoridad, mecanismos integrados de rendición de cuentas y agentes de poder comprometidos con el proceso y dispuestos a ejecutar sus decisiones (Chatham House, 2021 ${ }_{[49]}$ ).

La concepción del desarrollo después de la pandemia ha de descartar antiguas prácticas verticales e incorporar las perspectivas de las naciones del sur y de actores no estatales que doten de contextualización y contenido local a la cooperación internacional (Bhattacharya y Sabin Khan, $\left.2020_{[40]}\right)$. Son especialmente importantes unas alianzas internacionales más participativas para los asuntos de política que plantean las megatendencias mundiales. La gobernanza eficaz del cambio climático, la migración internacional, la digitalización de la economía y otras cuestiones de aplicación apremiante requiere un cambio social significativo, un diálogo en pie de igualdad y una colaboración de abajo hacia arriba que proporcione una visión temprana y pertinente a los responsables de políticas multilaterales (Chatham House, 2021 $1_{[49]}$ ).

\section{Cooperación regional a fin de potenciar la voz de la región en el mundo}

Las iniciativas regionales van a jugar un papel importante a la hora de apoyar los esfuerzos nacionales que buscan un nuevo modelo de desarrollo, incluyan megatendencias como la transformación digital como herramientas para la recuperación y generen resiliencia ante futuras crisis. La colaboración regional constituye un espacio único en el que los Estados que se enfrentan a desafíos similares pueden intercambiar mejores prácticas y orientaciones sobre cómo diseñar las políticas y comparar los resultados.

La forma en que la pandemia ha expuesto las trampas estructurales de desarrollo de la región debería ser aprovechada por los gobiernos de ALC como catalizador para superar las causas del actual "vacío latinoamericano". Esto se refiere a la falta de actuación colectiva en la región, que podría intensificar en el futuro su ya débil influencia internacional (González et al., 2021 $1_{[50]}$ ). ALC ha ido perdiendo su capacidad de cooperar y actuar colectivamente a nivel regional y global, habiendo desmantelado parte de sus organizaciones regionales debido a la polarización y fragmentación política (Sanahuja, $2020_{[51]}$ ). Esto se evidencia en el caso del impasse de cuatro años de la Comunidad de 
Estados Latinoamericanos y Caribeños (CELAC), que acogió su última Reunión de Jefes de Estado en septiembre de 2021. Esta polarización ha dificultado una voz unida en el ámbito multilateral, así como la sostenibilidad de los esfuerzos regionales y subregionales en curso.

Algunos ejemplos de fuera de la región podrían ayudar a prever el tipo de esfuerzos que tienen por delante los gobiernos de ALC en el ámbito regional. En 2020, la Unión Europea aprobó el mayor paquete de estímulo de su historia. El presupuesto a largo plazo de la Unión Europea, junto con el Fondo de la UE de Nueva Generación (el instrumento temporal diseñado para impulsar la recuperación), será el mayor paquete de estímulo jamás financiado a través del presupuesto de la UE (UE, 2020 ${ }_{[52]}$ ). Un total de 1.8 billones de euros ayudarán a reconstruir una Europa pos-COVID-19 con la misión de hacerla más ecológica, más digital y más resiliente. Más del 50\% del importe apoyará la modernización a través de: i) investigación e innovación (Horizonte Europa); ii) clima justo y transiciones digitales (Fondo de Transición Justa y Programa Europa Digital); y iii) preparación, recuperación y resiliencia (Mecanismo de Recuperación y Resiliencia, rescEU y EU4Health). Además, el paquete presta atención a la modernización de las políticas tradicionales, como las políticas de cohesión y agrícola, la lucha contra el cambio climático (30\% de los fondos de la UE), la protección de la biodiversidad y la igualdad de género.

La Unión Africana, por su parte, ha movilizado su estrategia de recuperación en torno a su marco de desarrollo continental, la Agenda 2063 (Unión Africana, 2020 ${ }_{[53]}$ ). Este marco tiene como objetivo lograr un desarrollo inclusivo y sostenible y es una manifestación concreta del impulso panafricano hacia la unidad, la autodeterminación, la libertad, el progreso y la búsqueda de la prosperidad colectiva. La agenda es una visión de 50 años que resume las aspiraciones de África para el futuro e identifica los principales programas emblemáticos que pueden impulsar el crecimiento económico y el desarrollo de África. La agenda identifica las actividades clave que se llevarán a cabo a través de sus planes de implementación de diez años, que garantizarán que se obtengan resultados de transformación tanto cuantitativos como cualitativos para los africanos.

La Asociación de Naciones del Sudeste Asiático (ASEAN) puso en marcha una evaluación rápida del impacto del COVID-19 en los medios de subsistencia de toda la región y un Marco Integral de Recuperación de la ASEAN (ACRF). La ASEAN ha reconocido que para hacer frente a la crisis se necesitan tanto acciones coordinadas dentro de la región como la cooperación con sus socios. El ACRF sirve como estrategia consolidada de salida de la crisis del COVID-19. Articula la respuesta de la ASEAN a través de las etapas de recuperación, centrándose en los sectores clave y en los segmentos de la sociedad más afectados por la pandemia, estableciendo estrategias generales e identificando medidas para la recuperación en línea con las prioridades sectoriales y regionales. Su enfoque de la recuperación es proactivo, global (para toda la comunidad), flexible y ágil. También se ha desarrollado un plan de implementación (ASEAN, 2020 ${ }_{[54]}$ ).

La coordinación regional es fundamental para potenciar la voz de los países de ALC en el ámbito internacional, así como su capacidad de afrontar las vulnerabilidades estructurales de la región en un mundo interconectado. Los acuerdos minilaterales ${ }^{1}$ han ayudado a los países con ideas afines a impulsar su potencial diplomático en negociaciones complejas sobre gobernanza (Chatham House, 2021 $1_{[49]}$ ). Este ha sido el caso de la Alianza de los Pequeños Estados Insulares durante las negociaciones multilaterales sobre el clima. Los países de la región deberían emular esta estrategia en los temas que necesitan más apoyo de la comunidad internacional, como la sostenibilidad de la deuda, la evasión fiscal y la migración internacional. Además, una mayor integración y coordinación también ayudaría a alinear los esfuerzos internacionales hacia las prioridades estratégicas clave y los retos compartidos por la región, como las inversiones que promueven la integración a 
nivel regional. Este podría ser el momento para que la comunidad internacional innovara en lo que respecta a los instrumentos de deuda externa, especialmente teniendo en cuenta las inversiones necesarias para alcanzar los ODS y la Agenda 2030 (Capítulo 1).

ALC es un terreno fértil para potenciar alianzas renovadas. Puede aprender de pasadas experiencias regionales y subregionales y coordinar en consecuencia los procesos en curso. ALC cuenta con una amplia gama de mecanismos de cooperación y procesos de integración, con diversos miembros, capacidades y mandatos. Las alianzas regionales basadas en propósitos en ALC deben evitar los solapamientos haciendo converger los actuales mecanismos y procesos mediante el "enfoque de gobernanza 3M", iniciativas multinivel, multilaterales y con múltiples partes interesadas (Bianchi y Lara, 2021 ${ }_{[55]}$ ). Esta convergencia regional deberá innovar de forma decidida en la integración de los actores no estatales de ALC, los gobiernos subnacionales y los bancos de desarrollo desde el principio a través de esquemas de cooperación funcionales para las metas de cada alianza. Las instituciones regionales dotadas de conocimientos y capacidades financieras serán decisivas en el liderazgo de estos procesos.

Las experiencias de participación social a nivel subregional en ALC pueden ofrecer lecciones importantes, centrándose en las estrategias para involucrar a los grupos con menos recursos y menos representados. Desde las Cumbres Sociales y el Parlamento Juvenil del Mercado Común del Sur (Mercosur) hasta el Foro Regional y los Encuentros Juveniles del SICA, la región cuenta con diferentes enfoques para una formulación participativa de las políticas regionales, que deben aprovecharse en una estrategia de recuperación regional que ponga a las personas primero. Los resultados logrados por el instrumento participativo más importante en la actualidad de la región, el Acuerdo de Escazú sobre los derechos humanos y el medioambiente (Recuadro 5.4), deben ser objeto de un seguimiento estrecho a fin de garantizar un aprendizaje continuo en materia de cooperación regional participativa. Además, la cooperación regional con las organizaciones de la sociedad civil puede ayudar a proteger los derechos humanos y fortalecer las organizaciones de la sociedad civil, como es el caso del plan conjunto entre OXFAM y la Comisión Interamericana de Derechos Humanos firmado en 2019 (Oxfam International, 2019 $\left.{ }_{[56]}\right)$.

\section{Recuadro 5.4. La experiencia participativa del Acuerdo de Escazú}

El Acuerdo Regional sobre el Acceso a la Información, la Participación Pública y el Acceso a la Justicia en Asuntos Ambientales en América Latina y el Caribe, más conocido como Acuerdo de Escazú, destaca por la amplia participación de la sociedad civil en su proceso de negociación y promoción (Naser, Williner y Sandoval, 2021 ${ }_{[57]}$ ). Acordado en Escazú, Costa Rica, en marzo de 2018, después de un proceso de negociación de cuatro años con el apoyo técnico de la CEPAL, el acuerdo ha sido firmado por 24 países de ALC, ratificado por 12, y entró en vigor el 22 de abril de 2021.

Durante la fase preparatoria del proceso de negociación (2012-2014), los países miembros acordaron las modalidades de participación del público en el Comité de Negociación, en tres niveles (asistencia, información y realización de declaraciones) y garantizaba formalmente la participación pública mediante dos representantes, con cuatro suplentes, que eran elegidos a través de un sistema de votación acordado.

Asimismo, la participación está profundamente implantada en el texto del acuerdo, ya que la participación pública es uno de los tres derechos que regula. En sus artículos, el documento establece los principios, sujetos y características de la participación, imponiendo unos estándares exigentes a los países que lo adopten. Este acuerdo regional 


\section{Recuadro 5.4. La experiencia participativa del Acuerdo de Escazú (cont.)}

se atiene al principio 10 de la Declaración de Río sobre el Medio Ambiente y el Desarrollo (1992), que establecía que "el mejor modo de tratar las cuestiones ambientales es con la participación de todos los ciudadanos interesados".

Facilitar un nuevo contrato social mediante el uso equilibrado de herramientas: financiación sostenible, reglas y estándares mundiales y cooperación técnica para el desarrollo de capacidades

Tal como propone el marco de DiT, la cooperación internacional como instrumento facilitador supone, entre otras cosas, la utilización de herramientas de cooperación diversas (OCDE et al., 2019 ${ }_{[1]}$ ). En concreto, en el escenario de una salida de la crisis del COVID-19 a través de un nuevo contrato social, los socios de desarrollo deben fomentar las alianzas internacionales que proporcionan la mejor combinación de herramientas para garantizar la coherencia entre las políticas nacionales e internacionales.

Diálogos de políticas fortalecidos deberían apuntalar las alianzas internacionales enfocadas en las metas con la región y dentro de ella para garantizar un enfoque global e integrado que incluya las siguientes herramientas principales (Tabla 5.2): i) financiación sostenible; ii) reglas y estándares globales; y iii) mejora de la cooperación técnica para el desarrollo de capacidades. Además, estas herramientas deberían aplicarse para lograr los pactos sociales más específicos que sustentan el contrato social (p. ej., ampliar el alcance de la protección social y los servicios públicos, revigorizar las estrategias productivas regionales) y otros de alcance global (p. ej., la integración de la sostenibilidad medioambiental), incluyendo una perspectiva interseccional que atraviese los distintos grupos socioeconómicos (incluidos los de ingresos, género, etnia y raza), las generaciones y los territorios. Es fundamental reforzar los diálogos sobre políticas que incluyan debates relacionados con estas herramientas y garanticen un enfoque orientado a las metas que las integre y tenga en cuenta sus interconexiones, ya que la mayoría de las veces estas herramientas se diseñan y aplican por separado.

Tabla 5.2. Enfoques integrados para que la cooperación internacional facilite un nuevo contrato social en ALC

\begin{tabular}{|c|c|c|c|}
\hline & $\begin{array}{c}\text { Integración de la sostenibilidad } \\
\text { medioambiental }\end{array}$ & $\begin{array}{c}\text { Ampliar el alcance de la protección social } \\
\text { y los servicios públicos }\end{array}$ & $\begin{array}{l}\text { Reforzar las estrategias } \\
\text { productivas regionales }\end{array}$ \\
\hline $\begin{array}{l}\text { Financiación } \\
\text { sostenible }\end{array}$ & $\begin{array}{l}\text { Integrar la sostenibilidad } \\
\text { medioambiental en todos los } \\
\text { instrumentos de financiación. }\end{array}$ & $\begin{array}{l}\text { Garantizar que los planes de reembolso de la deuda no } \\
\text { comprometan la ampliación del alcance de la protección } \\
\text { social y la prestación de servicios públicos. }\end{array}$ & $\begin{array}{l}\text { Garantizar una financiación } \\
\text { pública y privada suficiente para } \\
\text { la producción estratégica. }\end{array}$ \\
\hline $\begin{array}{l}\text { Reglas y } \\
\text { estándares } \\
\text { globales }\end{array}$ & $\begin{array}{l}\text { Adoptar reglamentos y estándares } \\
\text { ambientales, siguiendo el } \\
\text { principio de responsabilidades } \\
\text { compartidas, pero diferenciadas. }\end{array}$ & $\begin{array}{c}\text { Adoptar una normativa internacional para la transferencia } \\
\text { transfronteriza de las cotizaciones a la seguridad social y un } \\
\text { tipo impositivo global para las empresas. Acordar estándares } \\
\text { internacionales de protección social, trabajo justo, fiscalidad, } \\
\text { migración internacional, etc. }\end{array}$ & $\begin{array}{l}\text { Acordar y aplicar estándares } \\
\text { que favorezcan la diversifica- } \\
\text { ción productiva de ALC. }\end{array}$ \\
\hline $\begin{array}{l}\text { Cooperación } \\
\text { técnica } \\
\text { para el } \\
\text { desarrollo de } \\
\text { capacidades }\end{array}$ & $\begin{array}{l}\text { Proporcionar cooperación técnica } \\
\text { sobre prácticas de sostenibilidad, } \\
\text { investigación y conocimientos; } \\
\text { promover diálogos sobre políticas } \\
\text { centrados en la sostenibilidad } \\
\text { ambiental. }\end{array}$ & $\begin{array}{l}\text { Intercambiar experiencias de políticas en materia de } \\
\text { protección social y prestación de servicios públicos; fomentar } \\
\text { el desarrollo de capacidades en las instituciones públicas, } \\
\text { entre otras cosas, mejorando la comprensión de las inter- } \\
\text { conexiones entre las estrategias nacionales de desarrollo y la } \\
\text { dinámica mundial. }\end{array}$ & $\begin{array}{l}\text { Transferir conocimientos y } \\
\text { tecnología para aumentar la } \\
\text { productividad; impulsar los } \\
\text { diálogos sobre políticas a nivel } \\
\text { regional y global para fomentar } \\
\text { las cadenas de valor regionales. }\end{array}$ \\
\hline
\end{tabular}




\section{Financiación sostenible para el desarrollo}

La financiación sostenible para el desarrollo sigue siendo una herramienta esencial para la cooperación internacional con la región, en particular para la recuperación posterior a la crisis del COVID-19. La capacidad de movilizar recursos internos y externos sigue siendo un reto clave para los países de ALC. La movilización de recursos internos sigue siendo baja, con un 22.9\% del PIB, frente al 33.8\% de los países de la OCDE (OCDE et al., 2021 $\left.{ }_{[58]}\right)$. Además, el acceso a la financiación internacional del desarrollo es un elemento clave para hacer posible un nuevo contrato social en la región que promueva el desarrollo inclusivo y sostenible. Esto es especialmente esencial dado el choque económico y financiero que la pandemia ha infligido en ALC, al reducir su ya débil capacidad fiscal y liquidez.

Los retos financieros para un nuevo contrato social deben abordarse teniendo en cuenta la estructura anterior de entradas financieras de la región y actuando sobre las tendencias previstas. La mayor parte de los flujos de financiación externa que reciben las economías de ALC provienen de la inversión extranjera directa (IED), y representan más del 3\% del PIB de la región. La dinámica de los flujos financieros hacia ALC muestra que la participación de los flujos privados en el total de los flujos financieros hacia la región ha aumentado en contraste con la AOD, que ha disminuido hasta representar menos del 1\% del PIB de la región (CEPAL, 2021 ${ }_{[31]}$ ) y ha quedado por debajo de las necesidades de gasto para alcanzar los ODS en 2030. Durante el 2020, las diferentes fuentes de financiación externa evolucionaron de manera diferente. La AOD aumentó a nivel global, las remesas hacia ALC aumentaron un 6.5\% (Banco Mundial, 2021 ${ }_{[59]}$ ) pero la IED, principal recurso de financiamiento externo de la región, cayó un 34.7\%, retrocediendo a los niveles de 2005 (CEPAL, 2021 $[30]$ ).

Diversificar la financiación externa, impulsar mecanismos de financiación innovadores y canalizar la financiación hacia la superación de las trampas de desarrollo multidimensional y la consecución de los ODS debe ser una prioridad para ALC y sus socios. Los gobiernos de la región y las organizaciones intergubernamentales deberían proponer más innovaciones de financiación externa para construir una recuperación sostenible, impulsando la financiación pública y apalancando la privada hacia la consecución de los ODS y la Agenda 2030. En particular, deberían dedicarse esfuerzos a catalizar los importantes volúmenes de activos privados, así como los fondos de pensiones o las compañías de seguros. La IED y otras fuentes de inversión deben canalizarse hacia sectores que puedan promover un nuevo patrón de desarrollo, impulsar la competitividad y el empleo y reducir la huella medioambiental. Por ejemplo, entre los sectores prometedores se encuentran las energías renovables, la movilidad sostenible en las ciudades, la revolución digital para universalizar el acceso a la tecnología, la industria manufacturera de la salud, la bioeconomía y los servicios ecosistémicos, la economía del cuidado, la economía circular y el turismo sostenible (CEPAL, 2021 ${ }_{[60]}$ ).

Los esfuerzos de innovación deben centrarse en aumentar la financiación climática, que actualmente es insuficiente. A septiembre de 2020, Brasil, Chile, Colombia y México lideran la región en relación con los mercados financieros sostenibles, con la emisión de bonos verdes y el diálogo activo con inversores e instituciones financieras sobre prácticas sostenibles. El monto total de la financiación del cambio climático necesario para costear las medidas de mitigación y adaptación después de 2020 se ha estimado en más de 100000 millones de USD anuales, un objetivo global ambicioso para afrontar escenarios actuales (The Independent Expert Group on Climate Finance, $2020_{[61]}$ ). A pesar del déficit de financiación, aparece una tendencia prometedora. Durante 2020, el volumen de bonos verdes, sociales y sostenibles emitidos en la región se duplicó hasta alcanzar los 12693000 millones de USD. Este crecimiento puede atribuirse a las primeras emisiones de 
bonos sociales, que ascendieron a 3876000 millones de USD, y a las primeras emisiones de bonos sostenibles, que ascendieron a 1689000 millones de USD (CEPAL, 2021 ${ }_{[20]}$ ).

La región debe contribuir y aprovechar los esfuerzos innovadores en curso en materia de financiación para el desarrollo. Las interrelaciones entre los retos nacionales y mundiales —como la inclusión y el empleo, la salud mundial, la transformación digital o el cambio climático - hacen que sea aún más relevante para ALC aunar esfuerzos para movilizar la inversión privada en línea con los objetivos de desarrollo de la región de forma coherente. Ya están surgiendo innovaciones positivas. Entre ellas, el desarrollo de mecanismos de financiación mixta, como el Mecanismo de Inversión en América Latina (MIAL) y el Mecanismo de Inversión en el Caribe (FIC) de la Unión Europea. Otro ejemplo innovador es la Alianza de Propietarios de Activos Netos Cero de las Naciones Unidas, cuyos miembros - que representan una acción inversora unida de 6.6 billones de USDse comprometen a realizar la transición de sus carteras de inversión a emisiones netas de GEI para 2050, en consonancia con un aumento máximo de la temperatura de $1.5^{\circ} \mathrm{C}$ por encima de las temperaturas preindustriales (UNEPFI, 2021 ${ }_{[62]}$ ). Por último, LAGREEN, el primer fondo latinoamericano de bonos verdes creado por el LAIF de la UE, el Ministerio de Cooperación alemán y el Banco de Desarrollo alemán, impulsará una inversión de aproximadamente 450 millones de euros (CE, 2020 ${ }_{[63]}$ ).

Una solución coordinada para gestionar el desafío de la deuda debería ser una prioridad, especialmente teniendo en cuenta las inversiones que se deben realizar a medio y largo plazo para alcanzar los ODS. El Foro de los Países de ALC sobre el Desarrollo Sostenible 2021 (en adelante, el Foro) tomó acuerdos clave sobre las medidas financieras internacionales necesarias para hacer frente al limitado espacio fiscal de los países de ALC y a los altos niveles de deuda, que tienen en cuenta la heterogeneidad de los países de la región. El Foro hizo un llamado a los Estados miembros de la ONU y a las instituciones financieras internacionales para que proporcionen más liquidez al sistema financiero, especialmente en todos los países en desarrollo (CEPAL, 2021 ${ }_{[64]}$ ).

Las instituciones regionales y los expertos piden aprovechar el actual espacio de políticas para impulsar la reforma de la estructura de la deuda internacional e integrar medidas a corto plazo en la financiación para una estrategia de desarrollo dirigida a construir un futuro mejor (CEPAL, 2021 ${ }_{[30]}$; Ocampo, 2021 $\left.{ }_{[65]}\right)$. Ello podría incluir la creación de un mecanismo multilateral de reestructuración de la deuda soberana y el establecimiento de una agencia de calificación crediticia multilateral (CEPAL, $\left.2021_{[30]}\right)$. Otras propuestas a largo plazo incluyen la eliminación de la doble contabilidad del FMI y la consolidación de las cuentas de los DEG de modo que los no utilizados puedan considerarse depósitos de los países en el Fondo, de los cuales la institución podría disponer para financiar sus programas. Los futuros instrumentos financieros deberían también contemplar la mejora de la capacidad de los países para el pago de la deuda y evitar un endeudamiento insostenible que ponga en peligro la ampliación de la protección social y los servicios públicos, por ejemplo, vinculando los reembolsos de la deuda a la exposición y vulnerabilidad de cada país a las catástrofes (tal como sucede actualmente con las cláusulas relativas a huracanes) (Nieto-Parra y Da Costa, $2021_{[4]}$ ). Por último, las emisiones de deuda soberana deben gestionarse en un horizonte a largo plazo mediante el diseño de un mecanismo institucional para facilitar la reestructuración de la deuda soberana (Ocampo, 2021 ${ }_{[65]}$ ). La sostenibilidad medioambiental debe integrarse en los mecanismos de deuda innovadores, por ejemplo, mediante ODS, bonos ecológicos y permutas de deuda (Nieto-Parra y Da Costa, 2021 $1_{[4]}$ ).

Los países de ALC representados en el Foro destacaron también la importancia de tratar las necesidades específicas de los países de ingresos medios mediante sistemas innovadores de financiación para el desarrollo. Estos países (y también los de ingresos 
altos) de la región necesitan una respuesta precisa que vaya más allá de los actuales criterios de graduación y tenga en cuenta sus vulnerabilidades estructurales. Una de las últimas propuestas contempla introducir una ambiciosa idea, la Inversión Pública Global (IPG) (Recuadro 5.5) (Glennie, 2020 $\left.{ }_{[66]}\right)$.

\section{Recuadro 5.5. Inversión Pública Global}

La pandemia ha puesto de manifiesto los profundos problemas de financiación que impiden a la comunidad internacional garantizar bienes públicos globales y lograr un desarrollo sostenible. El período pospandemia ofrecerá una oportunidad única para impulsar un cambio de paradigma en la forma en que la financiación pública internacional en condiciones favorables puede complementar otras fuentes de financiación con vistas a promover un desarrollo sostenible, asegurar bienes, servicios e infraestructuras públicos globales y proteger el patrimonio mundial.

La Inversión Pública Global (IPG) es una nueva modalidad de financiación pública internacional concesional para el siglo XXI (Glennie, $2020_{[66]}$ ). Partiendo de los ODS, que toman en consideración el desarrollo en su diversidad y multidimensionalidad, y la evolución de ALC hacia el DT, el enfoque IPG propone un sistema basado en una corresponsabilidad continuada. En este sistema, todos los países colaborarían entre sí y contribuirían de forma sostenida, y todos tendrían la oportunidad de ser beneficiarios en función de una evaluación de sus necesidades. Como contribuyentes, todos los países desempeñarían un papel en la decisión de la asignación de los fondos. Para que el mundo se aproxime a los objetivos de desarrollo acordados en el ámbito internacional, es necesario aprovechar al máximo los diversos tipos de financiación. Los recursos nacionales (incluyendo los impuestos), la financiación privada, los fondos filantrópicos y las transferencias de remesas son todos cruciales, pero la financiación pública internacional en condiciones favorables es también un componente crítico y necesita evolucionar para satisfacer las modernas expectativas de gobernanza y objetivos. Esto es lo que ofrece el enfoque IPG.

La IPG propone cinco grandes evoluciones (o cambios de paradigmas) en: ambición, función, geografía, gobernanza y concepción. Comprende cuatro pilares fundamentales: i) contribuciones universales; ii) compromisos continuados; iii) control representativo; y iv) creación conjunta entre gobiernos y pueblos del mundo.

Este nuevo enfoque de la financiación podría constituir una herramienta estratégica, en especial para los países de ALC, ya que muchos están alcanzando los niveles de ingresos medios-altos y de ingresos altos. En lugar de la "graduación", que afectaría al progreso en muchos países de ALC, la IPG propone una "gradación" conforme a la cual todos los países seguirían recibiendo apoyo financiero dependiendo de sus necesidades específicas. Este nuevo enfoque permitiría también a la región crear formas de redistribución de la riqueza a fin de afrontar el creciente problema de la desigualdad.

\section{Reglas y estándares globales}

Promover el desarrollo inclusivo y sostenible requiere que las alianzas regionales e internacionales adopten enfoques integrados que combinen la financiación y la transferencia de conocimientos con la creación y aplicación de reglas y estándares mundiales pertinentes para hacer frente a los desafíos globales compartidos. La naturaleza transfronteriza de los principales problemas de desarrollo no solo exige la mejora de las capacidades nacionales, sino que también, o incluso más importante, requiere acuerdos 
multilaterales sobre criterios y acciones políticas compartidas que reduzcan la desigualdad global y promuevan la coherencia política a nivel nacional, bilateral y multilateral.

Por ejemplo, la erradicación de la evasión fiscal es un requisito para lograr nuevos contratos sociales en ALC que requiere normas transfronterizas. En 2018, la evasión fiscal ascendió a 325000 millones de USD, lo que equivale a un 6.1\% del PIB de ese año de ALC (Pezzini, 2020 ${ }_{[67]}$; ONU, 2020 ${ }_{[68]}$ ). Los recursos no sometidos a tributación perpetúan los altos niveles de desigualdad de la región en ingresos y patrimonio, y desvían los fondos necesarios para invertir en una recuperación inclusiva y sostenible. Se han derivado resultados prometedores de los recientes acuerdos relativos a la adopción de una tasa global de impuestos para las compañías y de los trabajos en curso de la OCDE mediante instrumentos como el Estándar Común de Información (OCDE, 2021 ${ }_{[69]}$ ), el Marco Inclusivo sobre la Erosión de la Base Imponible y el Traslado de Beneficios (BEPS por sus siglas en inglés) y la Iniciativa Fiscal de ALC. Los estándares regionales y globales contribuirían a fomentar la ejecución de políticas fiscales orientadas al género y otras actuaciones políticas innovadoras en materia fiscal (Capítulo 1).

El éxito del desarrollo de ALC por medio de un nuevo contrato social depende de la capacidad del sistema multilateral de regular esta y otras megatendencias mundiales, como la digitalización, la desigualdad y el cambio climático, en virtud de una actuación colectiva. A su vez, la región estará mejor preparada para contribuir al logro de los ODS y para el suministro de bienes públicos regionales y globales.

\section{Cooperación técnica para el fortalecimiento de capacidades}

La cooperación técnica continúa siendo esencial, en especial para salir de esta crisis mediante nuevos contratos sociales. Los esfuerzos de cooperación internacional podrían incluir la transferencia de capacidades y el fortalecimiento del diálogo sobre políticas acerca de opciones innovadoras para la reducción de las brechas de protección social -especialmente los pobres y pobres extremos, los trabajadores informales, los vulnerables al cambio climático, las mujeres y los migrantes-, así como el intercambio de experiencias en relación con la forma de mejorar la calidad y cobertura de los servicios públicos básicos, por ejemplo, a través de la digitalización. En el ámbito productivo, las nuevas alianzas deberían promover espacios de debate a escala regional sobre las cadenas de valor y la diversificación de la matriz productiva con el objeto de ayudar a los países de ALC a aumentar las capacidades de producción, mejorar la preparación y resiliencia ante futuras pandemias y acelerar la industrialización, incluso en el sector sanitario. La transferencia de tecnología y conocimientos será también un instrumento fundamental.

Esta crisis ha mostrado que las estrategias de desarrollo no pueden concebirse aisladamente en el plano nacional. A fin de que los países en desarrollo reduzcan su exposición a los choques externos y refuercen sus capacidades fiscales o socioeconómicas, estas estrategias tendrán que comprender mejor los desafíos globales. El diálogo sobre políticas, la formación, el intercambio de conocimientos y mejores prácticas, y la cooperación técnica, en especial la cooperación sur-sur y triangular, podrían aportar lecciones valiosas a este respecto (Nieto-Parra y Da Costa, 2021 ${ }_{[4]}$ ).

El fortalecimiento de capacidades debe seguir también un enfoque multinivel, multilateral y entre múltiples partes interesadas. Los gobiernos nacionales, así como los subnacionales, la sociedad civil, el sector productivo y los grupos vulnerables deben participar en los programas de fortalecimiento de capacidades. Las mesas redondas multilaterales que favorecen la observación y el aprendizaje mutuo pueden constituir un mecanismo eficaz para promover un intercambio de conocimientos más fructífero a escala internacional. 


\section{Alianzas entre la Unión Europea y ALC para construir un futuro mejor}

La Unión Europea es un socio interregional clave de ALC, tal como se ha comprobado durante la pandemia. La Unión Europea ha suscrito acuerdos de asociación, de libre comercio, políticos y de cooperación con 27 de los 33 países de ALC, y es la institución que proporciona a ALC más cooperación al desarrollo, es su tercer mayor socio comercial y su primer inversor extranjero (EEAS, 2019 ${ }_{[70]}$ ).

Sin embargo, es preciso reforzar y modernizar la alianza birregional. En abril de 2019, la Comisión Europea publicó un documento para revitalizar los diálogos sobre políticas uniendo fuerzas en torno a un futuro común a través de cuatro prioridades que se refuerzan mutuamente: prosperidad, democracia, resiliencia y gobernanza global eficaz (EEAS, $\left.2019_{[70]}\right)$. El comunicado afirma que la rápida evolución del entorno geopolítico introduce nuevos desafíos y oportunidades a los que la Unión Europea y ALC deben responder trabajando juntos para preservar el multilateralismo y un orden mundial basado en normas compartidas (EEAS, 2019 ${ }_{[70]}$ ).

ALC y la Unión Europea deberían aprovechar la coyuntura mundial creada por la pandemia para seguir forjando una alianza que ofrezca autonomía estratégica a ambas regiones, un espacio para el diálogo sobre políticas, convergencia normativa y, en el caso de ALC, una transformación productiva para cambiar el modelo económico y una reconstrucción del contrato social (Sanahuja y Rodríguez, 2021 $1_{[71]}$ ). Es importante mantener el apoyo de la Unión Europea, a través del fortalecimiento de capacidades y diálogo sobre políticas, para la revisión de los contratos sociales nacionales en ALC, como es el caso de la cooperación de EUROsociAL dirigida al proceso constitucional de Chile y a Argentina y Costa Rica en la creación y fortalecimiento de sus Consejos Económicos y Sociales. La cooperación triangular será un instrumento clave para la alianza birregional, facilitada por el programa Adelante 2 y su Ventana de Cooperación Triangular 2021-2024.

Las alianzas basadas en propósitos claros entre ALC y la Unión Europea deberían reforzar un enfoque multidimensional y coherente para enfrentar las trampas de desarrollo de la región y promover una voz más fuerte y coordinada que permita abordar los problemas comunes en el ámbito multilateral. La nueva generación de acuerdos ha de ser un instrumento fundamental en la implantación de estas nuevas alianzas, ya que cubren todas las áreas de la relación birregional (cooperación, diálogo sobre políticas, comercio, inversión), ayudando así a identificar sinergias y promover una mayor coherencia de las políticas nacionales e internacionales. Equipo Europa es una innovación institucional que sirve de ejemplo para este proceso.

\section{Conclusiones}

La cooperación internacional es indispensable para que América Latina salga de la crisis del COVID-19 redireccionando la senda de la región hacia el logro de los ODS y completando e impulsando los esfuerzos nacionales. Es necesario crear un nuevo contrato social que permita a los países de ALC romper los círculos viciosos creados por las trampas del desarrollo y reforzar el papel facilitador de la cooperación internacional - como se indica en el marco del DiT- en un contexto de mayor interconexión entre las esferas nacional e internacional.

La pandemia ha demostrado que la región es un terreno fértil para poner en práctica la función facilitadora de la cooperación internacional, pero existe margen para mejorar. ALC cuenta con una amplia gama de iniciativas norte-sur, sur-sur, triangulares, con múltiples partes interesadas e incluso sur-norte, que han abordado los desafíos fundamentales durante la pandemia y de cara a la etapa de recuperación, proporcionando no solo apoyo financiero, sino también asistencia técnica e intercambio de experiencias. No obstante, 
ALC aún carece de una cooperación y una coordinación regionales más ambiciosas, así como de iniciativas de cooperación internacional financiera y no financiera que aseguren su recuperación a largo plazo.

Este momento supone una oportunidad para fortalecer la cooperación regional e internacional con y dentro de ALC, revaluando y renovando el multilateralismo. Esta coyuntura crítica, junto con la posibilidad de que los países de la región establezcan nuevos contratos sociales, requiere la definición de nuevas alianzas. Estas han de resolver algunos problemas que bloquean el pleno potencial de la cooperación internacional, como la necesidad de una mayor participación de los ciudadanos, de mecanismos y marcos de gobernanza en condiciones de igualdad, incluido el refuerzo de la cooperación regional y de abordar los actuales niveles de fragmentación entre instituciones y entre herramientas.

Las alianzas basadas en propósitos claros podrían ser un enfoque innovador para experimentar nuevas formas de integrar todos los recursos, herramientas y actores relevantes en coaliciones basadas en temas que logren resultados de desarrollo medibles. Esto podría permitir una mayor coherencia de las políticas en los esfuerzos de cooperación internacional, fomentar un enfoque de toda la sociedad en el diseño y la implementación de alianzas internacionales, y promover un ciclo virtuoso a nivel multilateral para garantizar la consecución de los ODS y la aplicación efectiva de un nuevo contrato social. Aprovechar los esfuerzos de cooperación regional y las redes para aumentar la integración regional parece ser un paso clave. Por último, igualmente relevante sería explorar la mejor manera de adoptar enfoques holísticos que consideren diferentes herramientas para resolver desafíos multidimensionales. Un esfuerzo especial debe enfocarse en encontrar el equilibrio adecuado entre la financiación sostenible, las reglas y estándares mundiales y la cooperación técnica para el desarrollo de capacidades, con el fin de hacer frente a los desafíos globales compartidos. Los diálogos sobre políticas, bien articulados, son una condición necesaria para apuntalar los esfuerzos mencionados.

ALC puede contribuir a fortalecer y experimentar nuevas formas de multilateralismo impulsando los diálogos sobre políticas dentro de la región y fuera de ella a través de alianzas internacionales y horizontales, que den prioridad a las personas y a las políticas. La alianza ALC-Unión Europea es un espacio de política privilegiado para poner en práctica esta agenda, pues ya ha dado pasos decisivos en esta dirección.

\section{Recuadro 5.6. Mensajes clave}

- La crisis ocasionada por la pandemia ha puesto de manifiesto la interconexión entre las megatendencias mundiales no reguladas y el descontento nacional en América Latina.

- La consolidación del enfoque de Desarrollo en Transición puede contribuir a impulsar una agenda multidimensional para la recuperación que tome en consideración la interrelación entre áreas de políticas, actores y niveles de gobernanza.

- La naturaleza multidimensional del desarrollo global exige respuestas multidimensionales, incluyendo esfuerzos para medir el desarrollo más allá del PIB, tanto a nivel nacional como internacional, proporcionando una guía renovada para los esfuerzos de cooperación.

- La cooperación internacional puede facilitar y complementar los esfuerzos nacionales para definir y poner en práctica el pleno potencial de un nuevo contrato social en la región, permitiendo romper el círculo vicioso creado por las trampas de desarrollo de ALC.

- La pandemia ha reactivado los esfuerzos de los países de ALC y los socios internacionales, ofreciendo lecciones importantes en cuanto a la función facilitadora de la cooperación internacional (en especial, mediante la cooperación técnica sur-sur y triangular), pero han 


\section{Recuadro 5.4. Mensajes clave (cont.)}

existido carencias significativas en la financiación y la coordinación de políticas en el ámbito regional y multilateral.

- Las alianzas basadas en propósitos claros pueden promover una gobernanza multilateral más participativa e igualitaria. Pueden aumentar la participación de los ciudadanos y garantizar la coherencia de las políticas a nivel nacional, regional e internacional, así como entre los objetivos sociales, medioambientales y económicos. Se trata de elementos críticos de un entorno global propicio para salir de la crisis con modelos de desarrollo más inclusivos y sostenibles.

- El fortalecimiento de la cooperación regional será fundamental para potenciar la voz de ALC en el ámbito internacional, así como su capacidad de afrontar las trampas de desarrollo en un mundo interconectado.

- El fortalecimiento de los diálogos sobre políticas será crucial a fin de establecer nuevos contratos sociales para la recuperación de la región.

- Dentro de estos diálogos, el equilibrio de las tres herramientas clave: 1) financiación sostenible; 2) reglas y estándares mundiales; y 3) cooperación técnica para el desarrollo de capacidades, será crucial para garantizar la coherencia entre las políticas nacionales e internacionales y facilitar un nuevo contrato social.

- Una nueva cooperación entre ALC y la Unión Europea, basada en diálogos de políticas, podría ofrecer a ambas regiones autonomía estratégica y un aprendizaje mutuo para abordar los retos comunes de desarrollo, así como proporcionar a ALC los recursos y las capacidades para transformar su modelo económico y reconstruir su contrato social.

\section{Notas}

1. Los acuerdos minilaterales o los compromisos voluntarios de pequeños grupos pueden ofrecer sendas para lograr estándares globales (Chatham House, $2021_{[49]}$ ).

\section{Referencias}

Americas Market Intelligence (2020), The Acceleration of Financial Inclusion during the COVID-19 Pandemic, https://newsroom.mastercard.com/latin-america/files/2020/10/Mastercard Financial Inclusion_during_COVID_whitepaper_EXTERNAL_20201012.pdf.

ASEAN (2020), ASEAN Comprehensive Recovery Framework and its Implementation Plan, Asociación de Naciones del Sudeste Asiático, https://asean.org/asean-comprehensive-recovery-frameworkimplementation-plan/.

Badie, B. (2020), Inter-socialités. Le monde n'est plus géopolitique, CNRS Editions, https://www. cnrseditions.fr/catalogue/relations-internationales/inter-socialites/.

Banco Mundial (2021), Los flujos de remesas desafían las previsiones y siguen siendo sólidos durante la crisis provocada por la COVID-19, https://www.bancomundial.org/es/news/press-release/2021/05/12/ defying-predictions-remittance-flows-remain-strong-during-covid-19-crisis.

Bárcena, A. (2021), Retos de financiación para sostener una política fiscal expansiva y ampliar el espacio, CEPAL, https://www.cepal.org/sites/default/files/presentations/webinar 3- 210423 final alicia barcena_ffd. viernes_23 de_abril.pdf.

Barrett, P. y S. Chen (2021), Social Repercussions of Pandemics, Documentos de trabajo del FMI, https://www.imf.org/en/Publications/WP/Issues/2021/01/29/Social-Repercussions-ofPandemics-50041.

BBC (2021), Why Colombia's protests are unlikely to fizzle out, https://www.bbc.com/news/world-latinamerica-56986821.

Bhattacharya, D. y S. Sabin Kahn, COVID-19: A game changer for the Global South and international co-operation?, https:/oecd-development-matters.org/2020/09/02/covid-19-a-game-changer-forthe-global-south-and-international-co-operation/. 
Bianchi, M. y I. Lara (2021), Gobernanza Regional 3M: Hacia una convergencia del multilateralismo en América Latina en tiempos pandémicos, Colabora.Lat, Ciudad Autonoma de Buenos Aires, https://colabora.lat/wp-content/uploads/2021/04/PAPER-BIANCHI-LARA.pdf.

CAF (2021), Se aprueban USD 250 millones para apoyar el plan de reactivación económica del Paraguay., https://www.caf.com/es/actualidad/noticias/2021/03/caf-destinara-usd-250-millones-paraapoyar-el-plan-de-reactivacion-economica-del-paraguay/?parent=2198.

CE (2020), Team Europe: A new Green Bond fund for Latin America, Comisión Europea, https://ec.europa. eu/international-partnerships/news/team-europe-new-green-bond-fund-latin-america_en. [63]

CEPAL (2021), Conclusiones y recomendaciones acordadas entre los gobiernos reunidos en la Cuarta Reunión del Foro de los Países de América Latina y el Caribe sobre Desarrollo Sostenible, Publicación de las Naciones Unidas, Santiago, https://www.cepal.org/es/publicaciones/46733-conclusionesrecomendaciones-acordadas-gobiernos-reunidos-la-cuarta-reunion-foro.

CEPAL (2021), Desarrollo en transición: propuesta de concepto y medición para una cooperación renovada en América Latina y el Caribe, Publicación de las Naciones Unidas, Santiago, https://repositorio.cepal. org/bitstream/handle/11362/47156/5/S2100501_es.pdf.

CEPAL (2021), Estudio Económico de América Latina y el Caribe 2021: dinámica laboral y políticas de empleo para una recuperación sostenible e inclusiva más allá de la crisis del COVID-19, Publicación de las Naciones Unidas, Santiago, https://repositorio.cepal.org/bitstream/handle/11362/47192/58/ S2100608 es.pdf.

CEPAL (2021), Financiamiento para el desarrollo en la era de la pandemia de COVID-19 y después, Publicación de las Naciones Unidas, Santiago, https://www.cepal.org/en/publications/46711-financingdevelopment-era-covid-19-and-beyond.

CEPAL (2021), Mipymes y el COVID-19, Publicación de las Naciones Unidas, Santiago, https://www. cepal.org/es/euromipyme/mipymes-covid-19.

CEPAL (2021), Panorama Fiscal de América Latina y el Caribe, 2021, Publicación de las Naciones Unidas, Santiago, https://repositorio.cepal.org/bitstream/handle/11362/46808/1/S2100170_es.pdf. [20]

CEPAL (2020), Construir un nuevo futuro. Una recuperación transformadora con igualdad y sostenibilidad, Publicación de las Naciones Unidas, Santiago, https://repositorio.cepal.org/bitstream/handle/ 11362/46225/1/S2000667 es.pdf.

CEPAL (2020), Costa Rica presenta propuesta de Fondo para Aliviar la Economía COVID-19, https://www. cepal.org/en/pressreleases/costa-rica-presents-proposal-covid-19-economic-relief-fund. [42]

CEPAL (2020), Panorama social de América Latina 2020, Publicación de las Naciones Unidas, Santiago, https://repositorio.cepal.org/bitstream/handle/11362/46687/8/S2100150_es.pdf.

CGD (2021), Los DEG y el espacio fiscal, XXXIII Seminario Regional de Política Fiscal CEPAL, XXXIII Seminario Regional de Política Fiscal, Cepal, https://www.cepal.org/sites/default/files/ presentations/mark_plant.pdf.

Chatham House (2021), Reflections on building more inclusive global governance -Ten insights into emerging practice, https://www.chathamhouse.org/2021/04/reflections-building-more-inclusive-globalgovernance/03-ten-insights-reflections-building.

Conservación Amazónica (2020), MAAP \#129: Fuego en la Amazonía 2020 - Resumen de Otro Intenso Año, MAAP, https://www.amazonconservation.org/2020-fires-recap/.

DEVEX (2021), Funding the response to COVID-19: Analysis offunding opportunities, http://www.devex.com/ news/interactive-who-s-funding-the-covid-19-response-and-what-are-the-priorities-96833. [28]

EEAS (2019), Joint Communication to the European Parliament and the Council European Union, Comisión Europea, https://eeas.europa.eu/sites/default/files/joint communication to the european parliament and the council - european union latin america and the caribbean joining_forces_for_a_common_future.pdf. [70]

El País (2021), La conexión México-Buenos Aires-Moscú: así se disparó la Sputnik V en América Latina, https://elpais.com/sociedad/2021-02-03/la-conexion-mexico-buenos-aires-moscu-asi-sedisparo-la-sputnik-v-en-america-latina.html.

EMnet (2021), "Business Insights on Emerging Markets 2021", OECD Emerging Markets Network, Centro de Desarrollo de la OCDE, París, http://www.oecd.org/dev/oecdemnet.htm.

EMnet (2021), Business Sustainability in Emerging Markets, Publicaciones de la OCDE, París, https://www. oecd.org/dev/EMnet_Policy_Note_Business Sustainability_Emerging_Markets.pdf.

EUROsociAl (2021), Plan para la recuperación, reconstrucción social y resiliencia de Centroamérica y República Dominicana, Programa para la Cohesion Social EUROsociAL, https://eurosocial.eu/eurosocial-tv/ plan-para-la-recuperacion-reconstruccion-social-y-resiliencia-de-centroamerica-y-republicadominicana/. 
Glennie, J. (2020), The Future of Aid, Global Public Investment, Routledge, https://www.routledge.com/ The-Future-of-Aid-Global-Public-Investment/Glennie/p/book/9780367404970.

González et al. (2021), "Coyuntura crítica, transción de poder y vaciamiento latinoamericano", Vol. 291, pp. 49-65, https://nuso.org/articulo/coyuntura-critica-transicion-de-poder-y-vaciamientolatinoamericanol.

John Hopkins (2020), OMC Exención de ADPIC para vacunas COVID-19, https://www.jhsph.edu/ covid-19/articles/wto-trips-waiver-for-covid-19-vaccines.html.

Kharas, H. y M. Dooley, Sustainable development finance proposals for the global COVID-19 response, Brookings: Global Working Papers, https://www.brookings.edu/research/sustainabledevelopment-finance-proposals-for-the-global-covid-19-response/.

Knoll, A. (2014), Bringing policy coherence for development into the post-2015 agenda - Challenges and prospects, ECDPM, Documento de debate, https://ecdpm.org/wp-content/uploads/DP-163-PolicyCoherence-for-Development-Post-2015-Agenda-Challenges-Prospects-2014.pdf.

Larraín, G. (2021), "La estabilidad del contrato social en Chile", Fondo de Cultura Económica, Santiago, Chile.

Loewe, M., T. Zintl y A. Houdret (2020), “The social contract as a tool of analysis: Introduction to the special issue on 'Framing the evolution of new social contracts in Middle Eastern and North African countries'”, World Development, http://dx.doi.org/10.1016/j.worlddev.2020.104982.

Mander, B. (2021), Protesters take to Paraguay's streets as Covid cases climb, Financial Times, https://www.ft.com/content/425f05d0-0931-4394-b559-bf6b9beed3f9.

Mazzucato, M., H. Lishi Li y E. Torreele (2020), Designing vaccines for people, not profits, Project Syndicate, https://www.project-syndicate.org/commentary/covid-vaccines-for-profit-not-forpeople-by-mariana-mazzucato-et-al-2020-12.

Mazzucato, M. (2018), The Entrepeneurial State. Debunking public us private sector myths.

Naser, A., A. Williner y C. Sandoval (2021), Participación ciudadana en los asuntos públcos: un elemento estratégico para la Agenda 2030 y el gobierno abierto, https:/www.cepal.org/sites/default/files/ publication/files/46645/S2000907_es.pdf.

Nieto Parra, S. y R. Da Costa (2021), "Desarrollo en Transición en América Latina en tiempos de la COVID-19”, Documentos de Trabajo Fundación Carolina, http://www.fundacioncarolina.es/wpcontent/uploads/2021/06/DT FC 49.pdf.

Ocampo, J. (2021), Significant but insufficient progress in financial support for developing countries, OECD Development Matters, https://oecd-development-matters.org/2021/04/13/significant-butinsufficient-progress-in-financial-support-for-developing-countries/.

Ocampo, J. (2021), Significant but insufficient progress in financial support for developing countries, OECD Development Matters, OCDE, París, https://oecd-development-matters.org/2021/04/13/ significant-but-insufficient-progress-in-financial-support-for-developing-countries/.

Ocampo, J. (2020), UNDP LAC C19 PDS No. 7, International financial cooperation in the face of Latin America's economic crisis, Programa de las Naciones Unidas para el Desarrollo, https://www. latinamerica.undp.org/content/rblac/en/home/library/crisis prevention and recovery/lacooperacion-financiera-internacional-frente-a-la-crisis-econo.html.

OCDE (2021), Automatic Exchange Portal, Online support for the implementation of automatic exchange of information in tax matters, Publicaciones de la OCDE, París, https://www.oecd.org/tax/automaticexchange/common-reporting-standard/.

OCDE (2021), COVID-19 spending helped to lift foreign aid to an all-time high in 2020 but more effort needed, Publicaciones de la OCDE, París, https://www.oecd.org/newsroom/covid-19-spending-helpedto-lift-foreign-aid-to-an-all-time-high-in-2020-but-more-effort-needed.htm.

OCDE (2021), Development co-operation during the COVID-19 pandemic: An analysis of 2020 figures and 2021 trends to watch, Publicaciones de la OCDE, París, https://www.oecd-ilibrary.org/ sites/2dcf1367-en/1/3/1/1/index.html?itemId=/content/publication/2dcf1367-en\&_csp_=

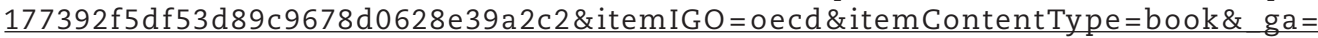
2.80395223.1975534698.1630687949-1355889696.1626703359.

OCDE (2021), Perspectives on Global Development 2021: From Protest to Progress?, Publicaciones de la OCDE, París, https://doi.org/10.1787/405e4c32-en.

OCDE (2020), Development Co-operation Report 2020: Learning from crises, building resilience, Publicaciones de la OCDE, París, https://doi.org/10.1787/f6d42aa5-en.

OCDE et al. (2021), Estadísticas tributarias en América Latina y el Caribe, Publicaciones de la OCDE, París, https://www.oecd-ilibrary.org/taxation/revenue-statistics-in-latin-america-and-the-caribbean2021_96ce5287-en-es?mlang=es. 
OCDE et al. (2019), Perspectivas económicas de América Latina 2019: Desarrollo en transición, Publicaciones de la OCDE, París, https://doi.org/10.1787/g2g9ff1a-es.

ONU (2021), La CELAC aprueba un proyecto para reducir la dependencia externa en el sector de la salud, https://news.un.org/es/story/2021/09/1496932.

ONU (2020), Development Policy and Multilateralism after COVID-19, Comisión de Política de Desarrollo - Nota de Política, https://www.un.org/development/desa/dpad/wp-content/uploads/sites/45/ CDP-Covid-19-and-Multilateralism.pdf.

ONU (2020), La evasión fiscal en América Latina, un obstáculo para la recuperación de la crisis del coronavirus, https://news.un.org/es/story/2020/07/1477031.

ONU (2020), UN75 2020 and beyond: Shaping our future together, Naciones Unidas, https://un75.online/ es/data/.

Oxfam International (2020), Latin American billionaires surge as world's most unequal region buckles under coronavirus strain, https://www.oxfam.org/en/press-releases/latin-american-billionairessurge-worlds-most-unequal-region-buckles.

Oxfam International (2019), La Comisión Interamericana de Derechos Humanos y Oxfam establecen convenio de cooperación en respuesta a diversas crisis de DDHH en América Latina y el Caribe, https://www.oxfam.org/en/press-releases/iachr-and-oxfam-sign-agreement-cooperationlatin-american-and-caribbean-human-rights.

Pew Research Center (2020), Verano 2020 Encuesta septiembre 21, https://www.pewresearch.org/global/ wp-content/uploads/sites/2/2020/09/PG_2020.09.21_UN-Multilateralism_TOPLINE.pdf.

Pezzini, M. y A. Pick (2021), From protest to progress?, Publicaciones de la OCDE, París, https://oecddevelopment-matters.org/2021/07/21/from-protest-to-progress/.

Pezzini, M. (2020), Citizens' raising expectations: A call to rebuild the social contract?, in "Trapped in the middle? Developmental Challenges for Middle-Income Countries”, Oxford University Press.

Pisani-Ferry, J. (2021), Global asymmetries strike back, Bruegel Essay and Lecture Series, https://www. bruegel.org/wp-content/uploads/2021/08/Asymmetries_essay-2508-online.pdf.

PNUD (2020), Human Development Report 2020: The Next Frontier, Human Development and the Anthropocene, Programa de las Naciones Unidas para el Desarrollo, Nueva York, http://hdr.undp. org/en/content/human-development-report-2020.

PNUD (2020), Lo que sabíamos entonces, lo que sabemos ahora: Mirando hacia atrás el COVID-19 en 5 gráficos, Programa de las Naciones Unidas para el Desarrollo, Nueva York, https://www. latinamerica.undp.org/content/rblac/es/home/presscenter/director-s-graph-for-thought/whatwe-knew-then--what-we-know-now--looking-back-on-covid-19-in.html.

Reuters (2021), Oxygen from Venezuela arrives in Amazon city for COVID-19 patients, https://www. reuters.com/article/us-health-coronavirus-brazil-amazon-idUSKBN29P1U4.

Sanahuja, J. (2020), "América Latina y la Unión Europea: agendas sociales, competencia geopolítica y COVID-19", Araucaria. Revista Iberoamericana de Filosofía, Política, Humanidades y Relaciones Internacionales, https://www.academia.edu/44460023/Am\%C3\%A9rica_Latina_y_la Uni\%C3\%B3n Europea agendas sociales competencia geopol\%C3\%ADtica y COVID 19. [51]

Sanahuja, J.A. y J.D. Rodríguez (2021), El Acuerdo MERCOSUR-Unión Europea: Escenarios y opciones para la autonomía estratégica, Fundación Carolina, https://www.fundacioncarolina.es/wp-content/ uploads/2021/06/AC-20.2021.pdf.

Singer, H. (1995), "Half a century of economic and social development policies of the UN and Bretton", The Pakistan Development Review, Vol. 34/4 Parte 1, http://www.jstor.org/stable/41260131 (accessed on 17 febrero 2021).

The Independent Expert Group on Climate Finance (2020), Delivering on The \$100 Billion Climate Finance Commitment and Transforming Climate Finance, Naciones Unidas, https://www.un.org/sites/ un2.un.org/files/100_billion_climate_finance_report.pdf.

UE (2020), Recovery plan for Europe, Unión Europea, https://ec.europa.eu/info/strategy/recoveryplan-europe en.

UNEPFI (2021), The Net-Zero Asset Owner Alliance FAQ, Naciones Unidas, https://www.unepfi.org/ wordpress/wp-content/uploads/2019/09/AOA_FAQ.pdf.

Unión Africana (2020), Agenda 2063: The Africa We Want, Comisión de la Unión Africana, Addis Ababa, https://au.int/en/agenda2063/overview. 


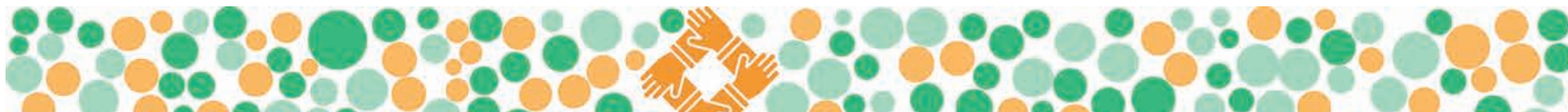
:00 O.

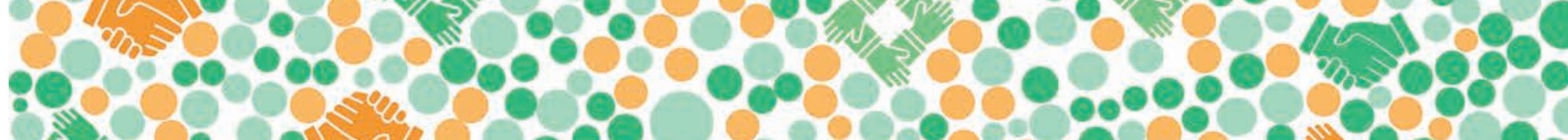

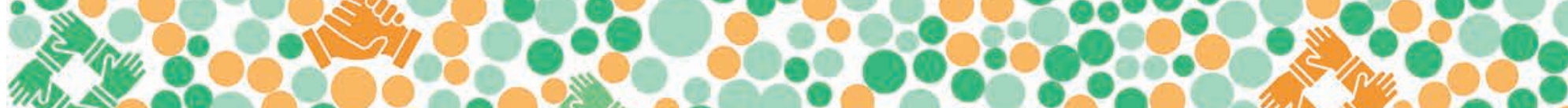

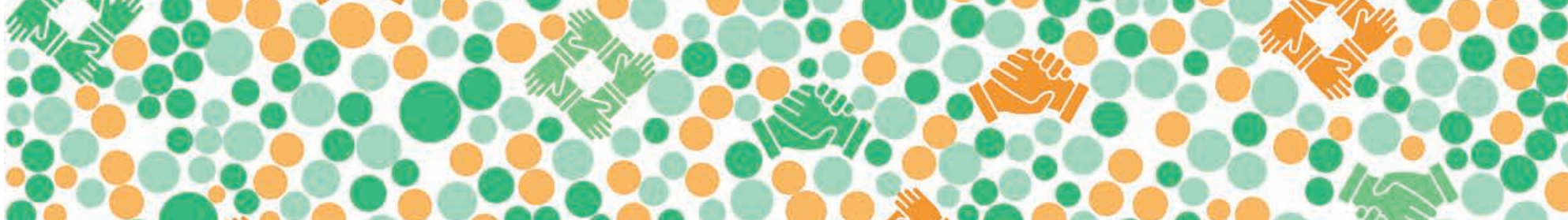

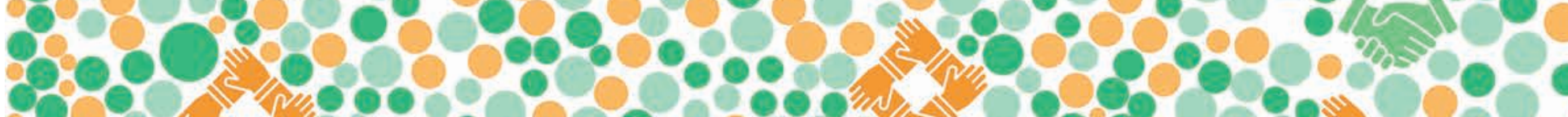

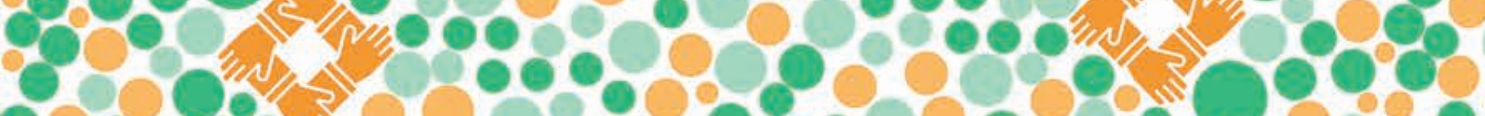

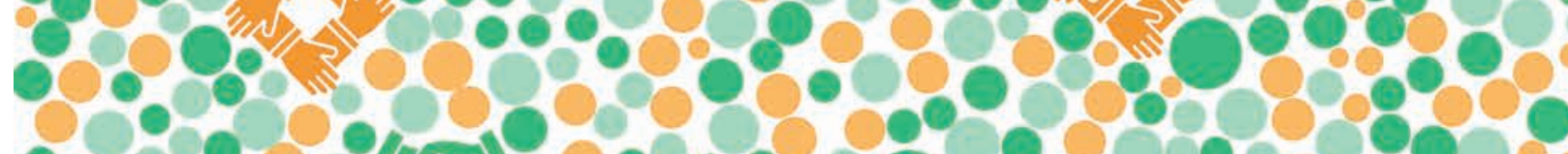
:36\%

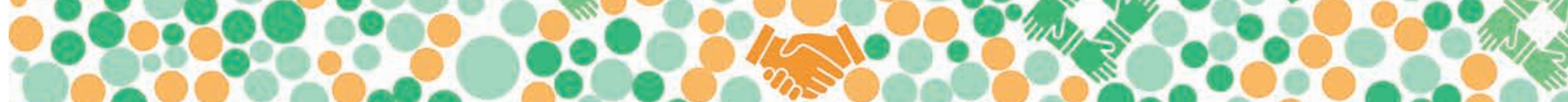
00000000000000000 :0\%

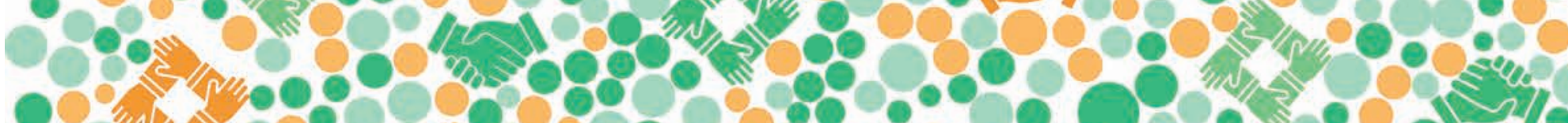

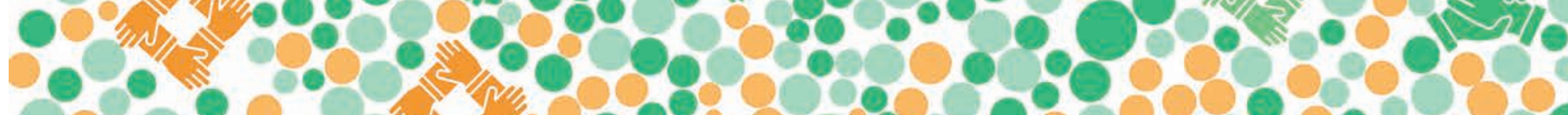

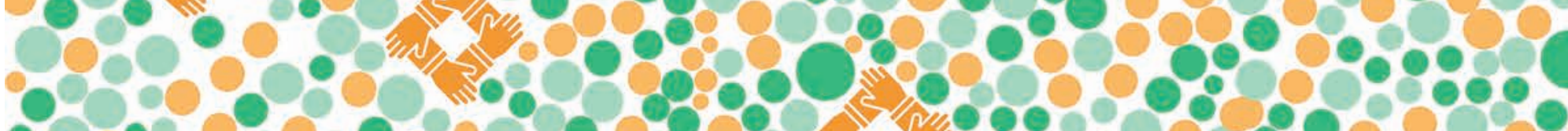

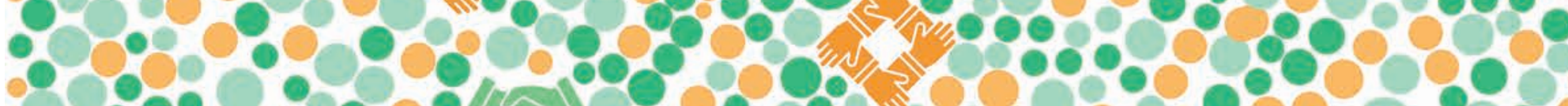

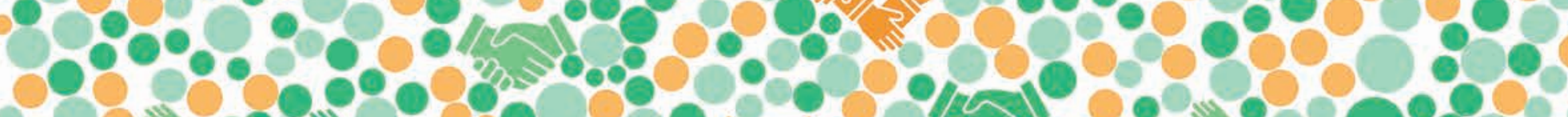
200 30003

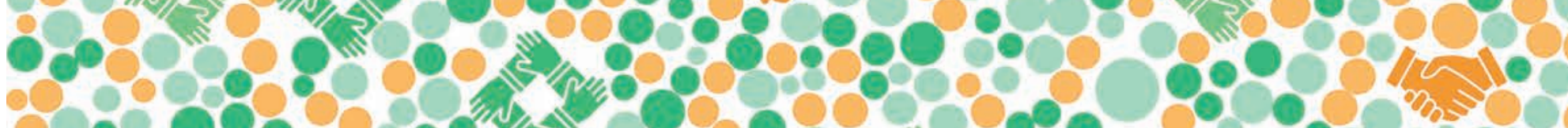
:080 0.000. 8.

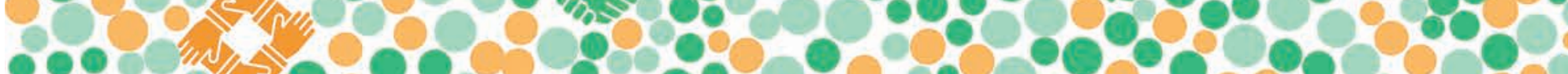

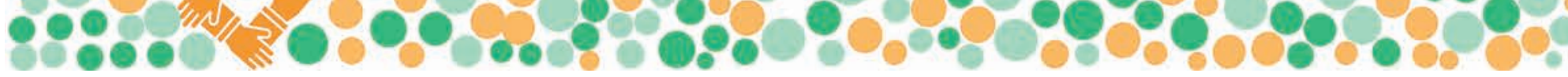




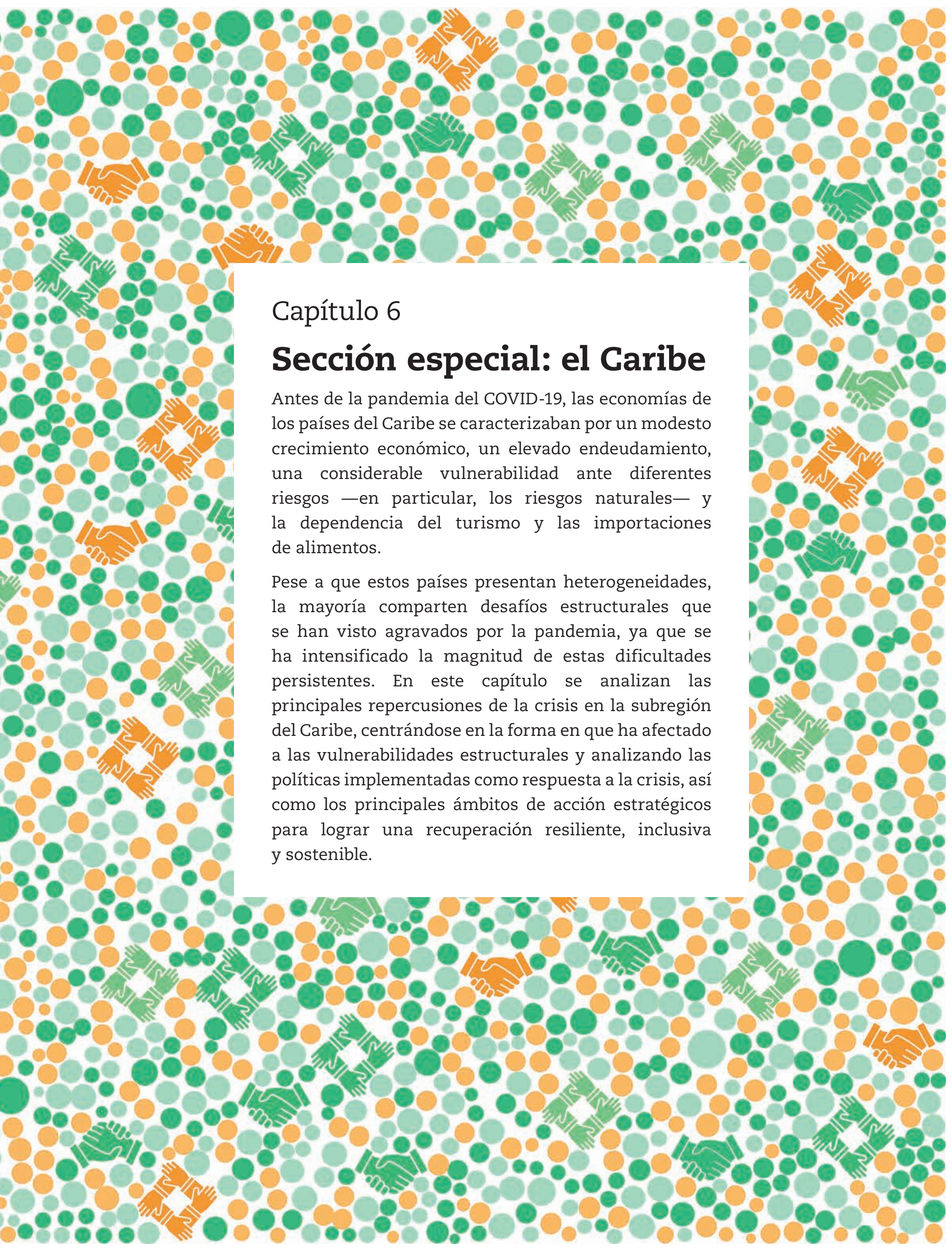




\section{Las políticas para la recuperación en el Caribe deben concentrarse en superar los desafíos económicos, sociales y medioambientales pendientes}

La crisis del COVID-19 ha agravado los desafíos estructurales

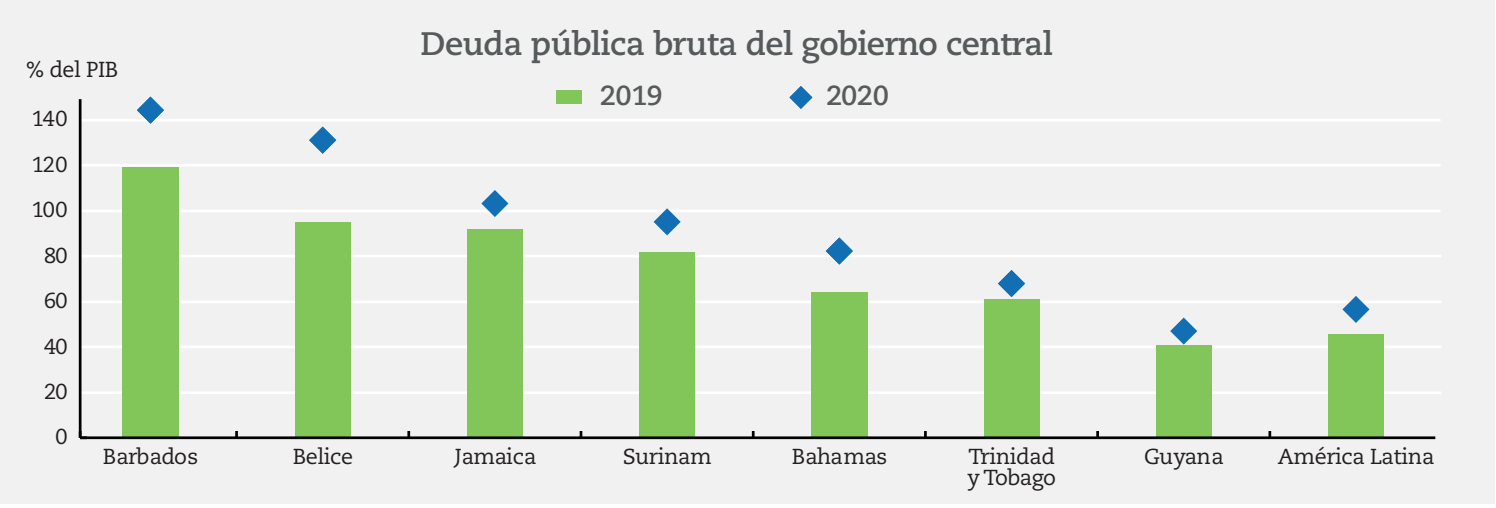

Las escuelas han estado cerradas por un período largo, dejando un fuerte impacto socioeconómico

Número de semanas de cierre completo de escuelas

Marzo 2020 - Mayo 2021
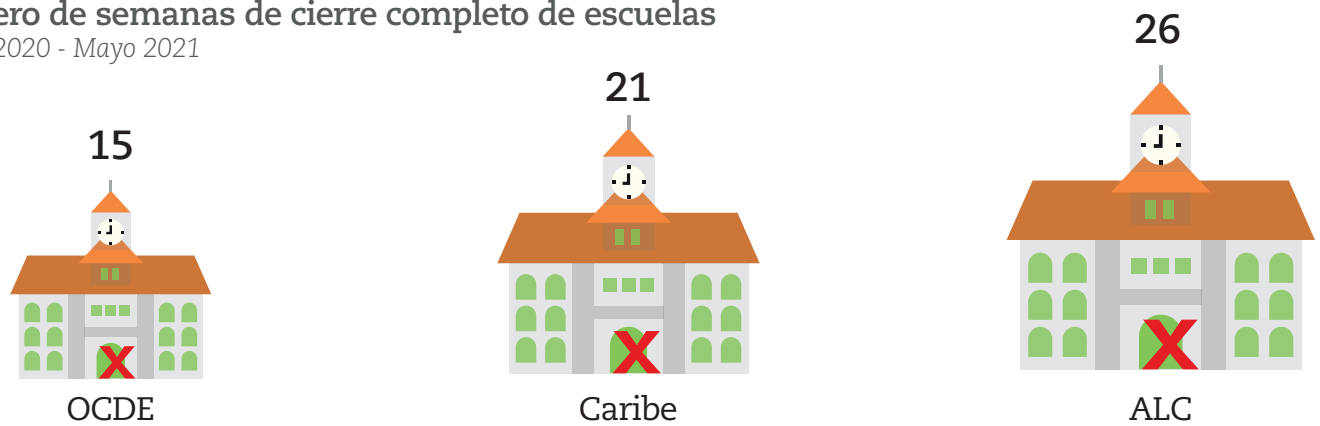

El espacio fiscal para abordar la recuperación es limitado

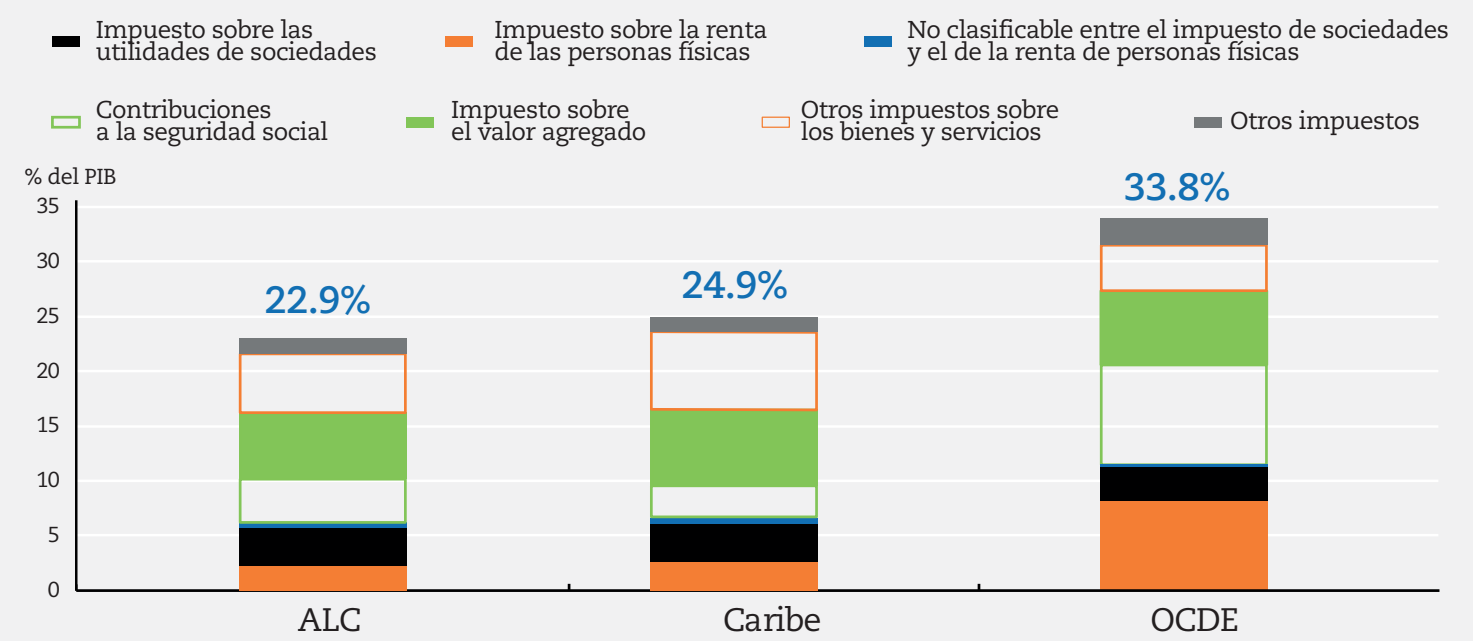




\section{Los desafíos estructurales del Caribe se han visto agravados por el impacto de la pandemia del coronavirus}

La pandemia del coronavirus (COVID-19) ha tenido una enorme repercusión en las economías del Caribe, y ha agravado las vulnerabilidades persistentes en esta subregión, como el lento desarrollo económico, los escasos ingresos tributarios y los altos niveles de deuda.

En lo que atañe al desarrollo económico, está previsto que el crecimiento alcance en 2021 el 5.2\%, lo cual no bastará para compensar la contracción del 7.6\% que se produjo en 2020 y recuperar el nivel de producción registrado en 2019. El crecimiento económico será heterogéneo entre las diferentes economías de esta subregión, aunque prácticamente todas ellas crecerán en 2021 (Gráfico 6.1).

\section{Gráfico 6.1. El Caribe: tasa de crecimiento del PIB en 2020 y proyecciones para 2021 y 2022}

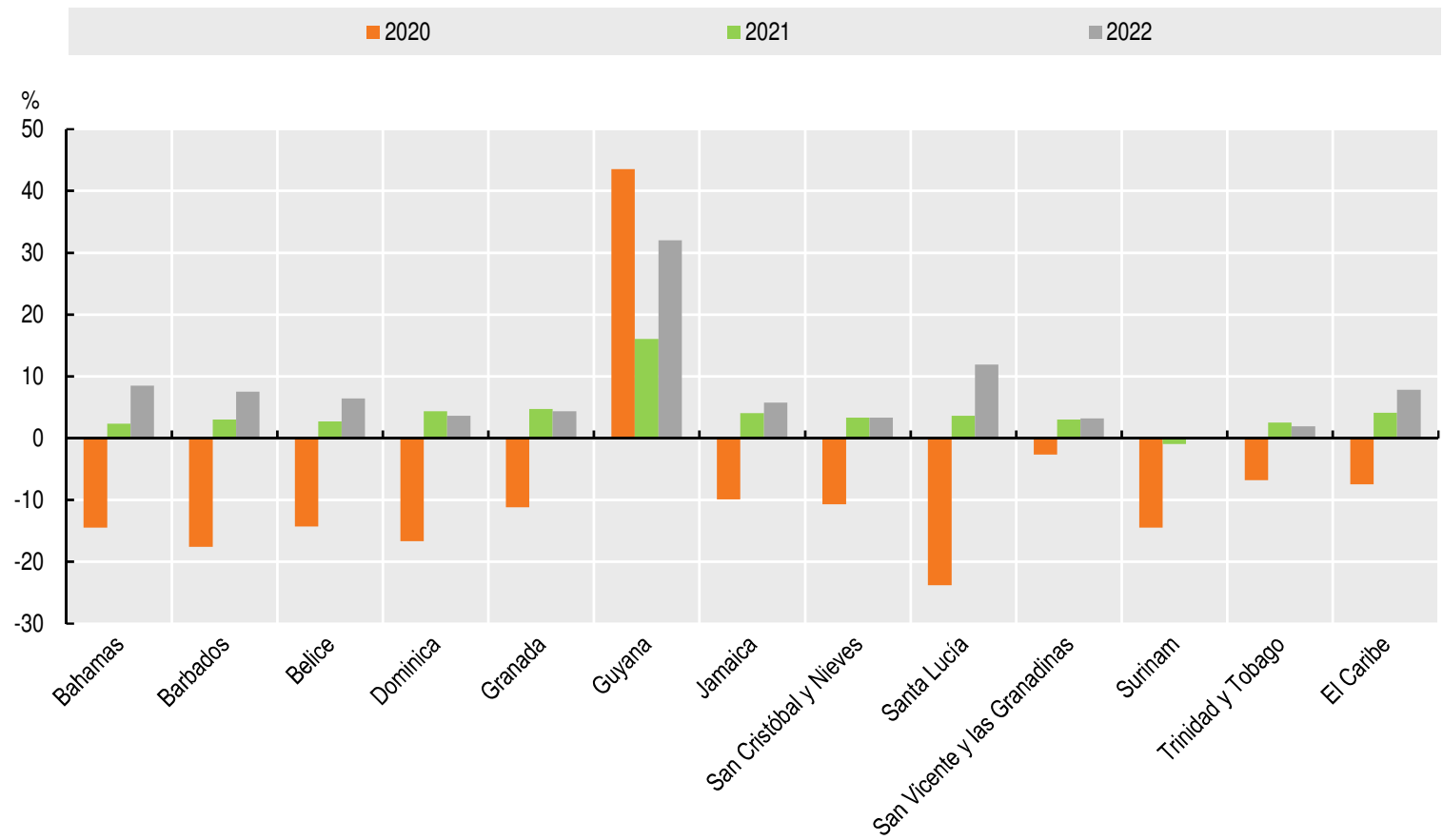

Fuente: (CEPAL, 2020 ${ }_{[1]}$ ), Panorama Fiscal de América Latina y el Caribe, 2020: la política fiscal ante la crisis derivada de la pandemia de la enfermedad por coronavirus (COVID-19).

StatLink inis https://doi.org/10.1787/888934296040

La actividad económica del Caribe se ha visto golpeada por varias perturbaciones externas (CEPAL, 2020 ${ }_{[2]}$ ). En primer lugar, un descenso de la actividad económica de los principales socios comerciales de la región y una contracción del comercio internacional (Capítulo 1). En segundo lugar, la evolución de los precios de los productos básicos (Capítulo 1). Los países caribeños (excepto Trinidad y Tobago) se han beneficiado de caídas temporales en los precios de la energía y los productos agrícolas. En consecuencia, la mayoría de los países de esta subregión han podido amortiguar los impactos recibidos a través de otros canales. Sin embargo, los precios de los productos básicos han recuperado los niveles previos a la crisis -e incluso los han superado-, por lo que se ha reducido toda ventaja posible. En tercer lugar, han descendido las remesas. La zona euro y los Estados Unidos son los destinos principales de los migrantes del Caribe. Las economías de esta subregión más afectadas por el descenso de las remesas han sido Haití, país en 
el que representan un 33\% del PIB; Jamaica, donde representan un 16\%, y San Vicente y las Granadinas, Dominica y la República Dominicana, donde las remesas representan entre un $5 \%$ y un $10 \%$ del PIB. En cuarto lugar, se ha reducido la demanda de servicios de turismo y la actividad turística podría tardar varios años en recuperar los niveles de 2019. A corto plazo, se observa una recuperación gradual conforme se reabren las fronteras, pero el tráfico será muy inferior al registrado antes de la pandemia. Además, estará el temor a la posibilidad de contagiarse durante el viaje, acompañado de la incertidumbre sobre la capacidad hospitalaria de los países de destino y nuevos cierres de fronteras, todo lo cual podría motivar que los turistas pospusiesen sus viajes.

La pandemia está teniendo un impacto negativo en sectores clave de la economía caribeña (CEPAL, 2021 ${ }_{[3]}$ ), entre ellos el turismo, la aviación, la hostelería, la restauración, el ocio y el comercio, aunque es menor en el caso de los supermercados, las farmacias y otros servicios considerados "esenciales" en el ámbito nacional. Los sectores de productos no esenciales también enfrentan problemas derivados de las medidas de confinamiento, que comportaron la suspensión de sus actividades. Los ingresos de las empresas han descendido considerablemente, lo que ha dificultado su acceso al crédito y, en muchos casos, ha provocado cierres definitivos. En algunos países, la construcción también se ha visto resentida por los paros y por la considerable incertidumbre respecto a nuevos proyectos (CEPAL, 2021 ${ }_{[3]}$ ).

Se prevé que la crisis económica aumente la desigualdad de ingresos en todos los países del Caribe. Habida cuenta de los escasos datos disponibles en esta subregión, solo hay estimaciones sobre la repercusión de la pandemia en la pobreza y la distribución de ingresos relativos a la República Dominicana. En ese país, con respecto a 2020, se calcula que la pobreza aumentó 4.4 puntos porcentuales, la pobreza extrema 2.2 puntos porcentuales y el índice de Gini entre un 3\% y un 3.9\%. Además de la desigualdad en los ingresos, el COVID-19 ha agravado otras vulnerabilidades y desigualdades del Caribe, incluido el acceso a tecnologías de la información y las comunicaciones (TIC); el acceso a servicios educativos; la inseguridad alimentaria; y la vulnerabilidad de las mujeres y las niñas, con un importante aumento de la violencia de género.

De cara al futuro, sigue existiendo incertidumbre respecto a la recuperación debido a factores internos y externos. La dinámica del crecimiento a partir de 2021 dependerá en buena medida del avance de los procesos de vacunación dentro de la subregión, así como en los principales países asociados, y de la capacidad de las diferentes naciones caribeñas para corregir los problemas estructurales que subyacen a la senda de crecimiento lento en la que se encontraban antes de la pandemia (CEPAL, 2021 $1_{[4]}$ ).

Los gobiernos deben hacer frente al tremendo desafío que supone impulsar la recuperación en un contexto de escaso margen fiscal y con grandes desafíos estructurales, como los bajos niveles de recaudación de impuestos y los elevados niveles de deuda pública. Aunque con una enorme heterogeneidad, en todas las economías del Caribe las balanzas fiscales (y balanzas primarias) empeoraron en 2020. Por ejemplo, en Belice el déficit fiscal global se deterioró, al pasar del -3.5\% del PIB en 2019 al -11.4\% en 2020. A menor escala, el déficit fiscal global de Surinam pasó del -9.8\% del PIB en 2019 al -10\% en 2020. Las balanzas primarias también empeoraron en la mayoría de las economías, salvo en Barbados y Jamaica. El aumento del déficit primario y la caída del PIB agravaron además la dinámica negativa de la deuda (CEPAL, 2021 $1_{[5]}$ ).

Como consecuencia de la pandemia, se produjo un considerable aumento de los niveles de deuda en el Caribe, que es una de las regiones más endeudadas del mundo. De los siete países sobre los que había datos disponibles, tres tenían una relación deuda-PIB superior al $100 \%$ al cierre de 2020 , a saber, Barbados (144\%), Belice (131\%) y Jamaica (103\%) (Gráfico 6.2). El aumento de la deuda en 2020 varió en función del país, ya que en economías 
como Barbados y Belice, la deuda se incrementó en más de 25 puntos porcentuales del PIB, mientras que en Trinidad y Tobago y la Guyana, en menos de 10 puntos porcentuales (CEPAL, 2021 $1_{[5]}$ ).

La deuda ya suponía un problema central en la región caribeña antes de la pandemia. Las dificultades políticas y el derroche fiscal no han sido los causantes de la acumulación de deuda de esta subregión, sino que más bien han sido resultado del impacto de perturbaciones económicas externas negativas, sucesos extremos y problemas originados por el cambio climático (CEPAL, $2020_{[11]}$ ). El gran endeudamiento se ha traducido en un elevado servicio de la deuda que consume una parte importante de los ingresos tributarios. Durante el período comprendido entre 2009 y 2018, el servicio de la deuda promedio, como porcentaje de los ingresos públicos, superó el $40 \%$ en tres países del Caribe: Antigua y Barbuda, Barbados y Jamaica. En Jamaica, el porcentaje promedio fue elevado, del $68 \%$. En las Bahamas, Granada, San Cristóbal y Nieves, Santa Lucía y San Vicente y las Granadinas, este indicador se situó entre el 20\% y el 40\% (Bárcena, 2020 ${ }_{[7]}$ ). Esta coyuntura fiscal supuso que los países tuviesen muy poco margen para compensar cualquier impacto negativo, como las catástrofes naturales, que son frecuentes en el Caribe.

\section{Gráfico 6.2. Deuda pública bruta del gobierno central en economías seleccionadas del Caribe y promedio de América Latina (\% del PIB)}

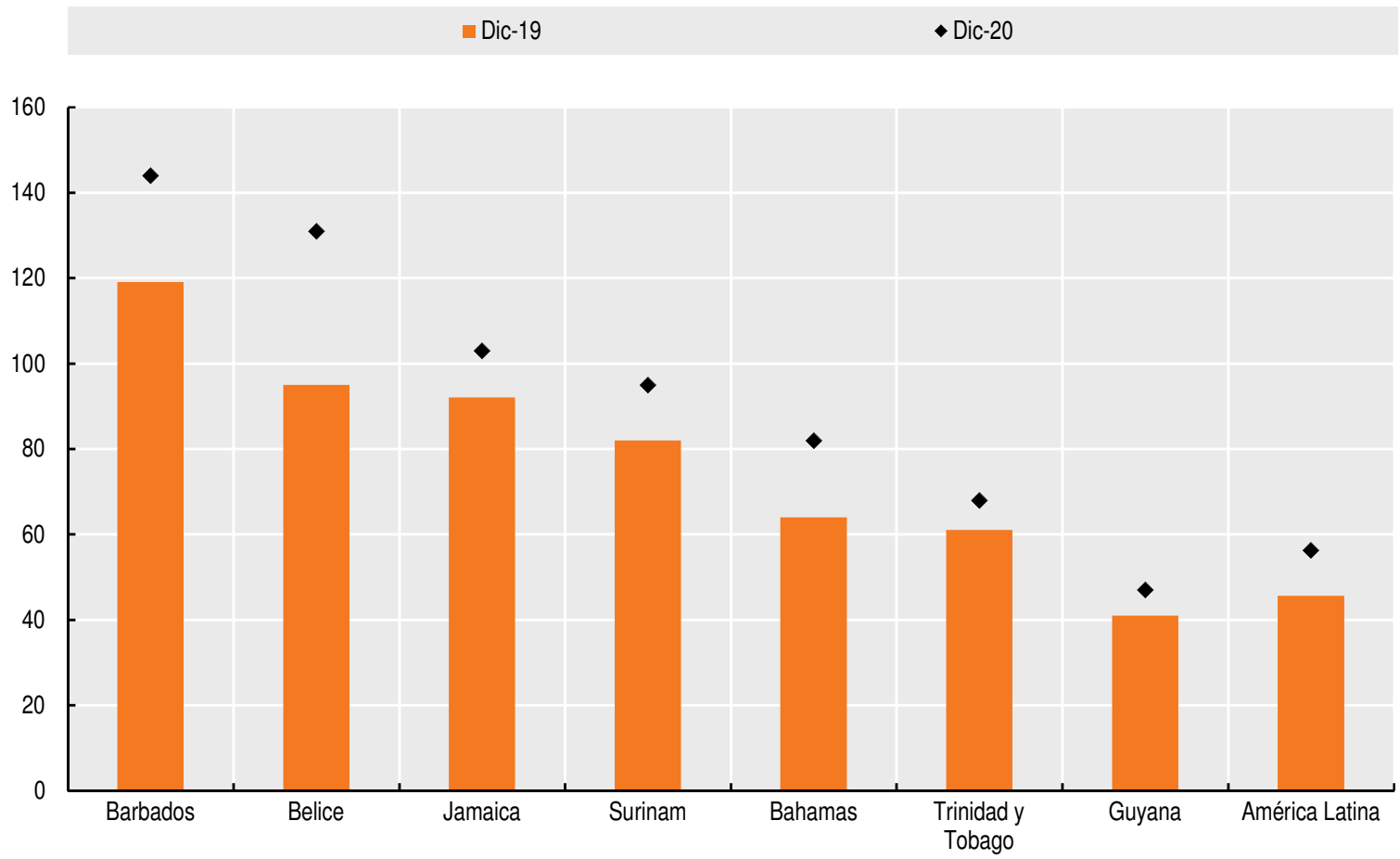

Fuente: (CEPAL, 2021 $1_{[5]}$ ), Panorama Fiscal de América Latina y el Caribe, 2021: los desafíos de la política fiscal en la recuperación transformadora pos-COVID-19.

StatLink iनाडs https://doi.org/10.1787/888934296059

Aunque con una enorme heterogeneidad entre las diferentes economías caribeñas, los bajos ingresos tributarios también han limitado el espacio fiscal para hacer frente a la pandemia e impulsar la recuperación. Las relaciones impuestos-PIB fueron relativamente bajas en esta subregión, situándose el promedio en un 24.9\% del PIB en 20191. Esta cifra fue ligeramente superior al promedio regional de ALC (22.9\%), pero considerablemente inferior a la de las economías de la OCDE (33.8\%) (Gráfico 6.3) (OCDE et al., 2021 ${ }_{[8]}$ ). Desde 1990, la relación impuestos-PIB promedio de las economías del Caribe ha aumentado 
5.6 puntos del PIB, un nivel inferior al de Sudamérica (9.2 p.p.) y América Central (5.9 p.p.). El incremento de la recaudación de impuestos se debió principalmente a la introducción del IVA en 1991 en Jamaica, en 1997 en Barbados, en 2006 en Belice (impuesto general sobre ventas), en 2007 en la Guyana y Antigua y Barbuda, en 2012 en Santa Lucía y en 2015 en las Bahamas. En general, en 2019, los ingresos tributarios totales variaron enormemente entre las economías de esta subregión, desde el 16.6\% del PIB en Bahamas al 33.1\% del PIB en Barbados (OCDE et al., 2021 $1_{[8]}$ ).

Además de los efectos a corto y mediano plazo de la crisis del COVID-19, los países del Caribe se enfrentan a vulnerabilidades a más largo plazo, entre otras los impactos negativos del cambio climático, riesgos de catástrofes naturales y fenómenos meteorológicos extremos, que son de especial importancia en el caso del Caribe, ya que es la segunda región del mundo más propensa a sufrir desastres ambientales (OCDE, 2019 ${ }_{[9]}$ ). Las catástrofes naturales son los principales desafíos ambientales, así como los problemas relacionados con el cambio climático, la pérdida de biodiversidad, factores antropogénicos causantes de estrés hídrico y fuentes terrestres de contaminación. La industria turística, que es el principal sector exportador de la economía, también ha provocado tensiones en los ecosistemas naturales.

\section{Gráfico 6.3. Estructura tributaria de economías seleccionadas del Caribe y promedios de ALC y de la OCDE, 2019}

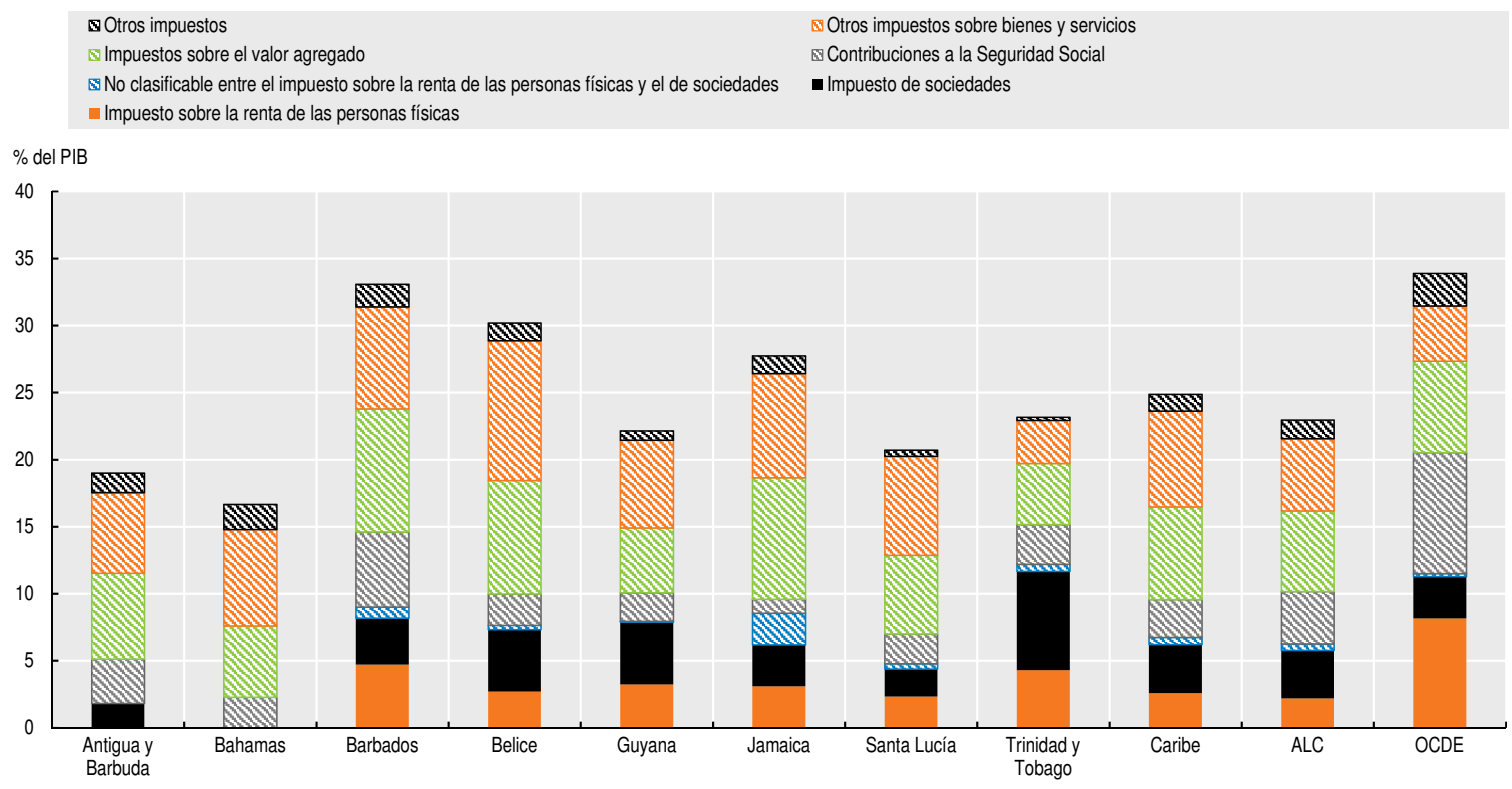

Fuente: (OCDE et al., 2021 ${ }_{[8]}$ ), Estadísticas tributarias en América Latina y el Caribe 2021, https://doi.org/10.1787/96ce5287-en-es. StatLink 完正四 https://doi.org/10.1787/888934296078

La pandemia podría haber aumentado la sensibilización sobre la necesidad de actuar de manera colectiva para hacer frente al que es, posiblemente, el desafío global más acuciante de cara al futuro: el cambio climático. Los países de ALC tienen la oportunidad de aprovechar esta coyuntura para impulsar una recuperación ambientalmente más sostenible. Los complejos retos ambientales requerirán la coordinación de las políticas económicas, sociales y ambientales, así como marcos de gobernanza congruentes. Algunos de estos retos están relacionados con la adaptación al cambio climático, los recursos hídricos y la gestión de residuos sólidos, la transición energética y el transporte sostenible (OCDE, 2020 $\left.{ }_{[10]}\right)$. 


\section{Políticas públicas implementadas como respuesta a la crisis del COVID-19 y principales ámbitos de acción para la recuperación}

Los países caribeños han implementado ambiciosas medidas para responder a las consecuencias inmediatas de la crisis del COVID-19 y proteger tanto las vidas como los empleos. Sin embargo, al tiempo que atienden las necesidades más urgentes con medidas específicas, los países caribeños tendrán que impulsar reformas estructurales en ámbitos de política cruciales que permitan sentar las bases de una recuperación resiliente, inclusiva y sostenible. Este proceso comportará, entre otras cosas, un cambio estructural progresivo, la expansión de los sistemas de protección social, y el avance hacia estados de bienestar en la región (CEPAL, 2021 $1_{[5]}$ ).

\section{Mantenimiento de las transferencias monetarias de emergencia para las poblaciones más vulnerables y apoyo al sector productivo}

En algunos países del Caribe, las medidas para hacer frente a la emergencia y proteger tanto las vidas como las formas de sustento han sido importantes y tendrán que mantenerse para apoyar a las familias, los trabajadores y las empresas más vulnerables mientras sea necesario.

Las transferencias monetarias temporales deben acompañarse de otras medidas, como la congelación de los pagos de suministros básicos o el diferimiento del pago de deudas. A medio y largo plazo, deben construirse sistemas de protección social universales, integrales y sostenibles, como parte de sociedades del cuidado que garanticen unos niveles de bienestar para la población y que no dependan exclusivamente del trabajo no remunerado de las mujeres. De hecho, podrían utilizarse medidas de apoyo temporales para avanzar hacia una transformación más permanente de los sistemas de protección social. El carácter universal, integral, suficiente y sostenible de la protección social es ahora más importante que nunca.

Dentro del marco de las estrategias de recuperación, resulta crucial considerar opciones para reforzar los sistemas de pensiones. Debería hacerse hincapié en aumentar la cobertura y el tamaño de las prestaciones, la sostenibilidad económica y la solidaridad social como criterios transversales para su formulación.

Además de las transferencias monetarias y otras medidas de apoyo, algunos países del Caribe han puesto en marcha programas de alimentos de emergencia. El gobierno de Antigua y Barbuda introdujo el Programa de Asistencia Alimentaria de Emergencia COVID-19 (COVID-19 Emergency Food Assistance Programme), destinado específicamente a personas mayores que viven solas, personas con discapacidad y personas sin empleo con hijos. El gobierno de Trinidad y Tobago aumentó los pagos a los actuales beneficiarios de programas de asistencia pública, entre otros las ayudas para atender a personas con discapacidad. Además, varios países optaron por sustituir programas de comedores escolares por otras modalidades como, por ejemplo, una tarjeta de alimentos en Trinidad y Tobago y un paquete de comida semanal en Antigua (CEPAL, 2021 ${ }_{[3]}$ ).

Será esencial mantener el apoyo a los sectores productivos para evitar una quiebra del sector de las mipymes y promover políticas que favorezcan el empleo. Algunos países del Caribe han implantado programas de apoyo para el sector productivo. Jamaica, por ejemplo, ha introducido el programa de transferencias monetarias y apoyo a empleados de empresas "BEST Cash" y una ayuda COVID-19 destinada a empresas del sector turístico. Granada también ha introducido un programa de ayuda salarial para el sector turístico y está ofreciendo, además, crédito adicional a hosteleros y pequeñas empresas (CEPAL, 2020 $[11]$ ). 
Barbados y Bahamas complementaron las prestaciones por desempleo que forman parte de sus sistemas de seguridad social con prestaciones temporales para contribuyentes y empleados por cuenta propia. En San Cristóbal y Nieves y San Vicente y las Granadinas, la nueva prestación temporal por desempleo facilitada a través del sistema de seguridad social está restringida únicamente a trabajadores asegurados (CEPAL, 2021 ${ }_{[3]}$ ).

También ha habido programas de ayuda para el pago de la vivienda destinados a trabajadores que han perdido ingresos por la pandemia y podrían ser objeto de embargos o desahucios, por lo que los gobiernos están trabajando con las instituciones financieras para evitar la ejecución de dichos procesos. El gobierno de Trinidad y Tobago, por ejemplo, ofrece una ayuda temporal de asistencia para pagar el alquiler a personas y familias afectadas por una suspensión o rescisión de su empleo. Reducir las facturas de los suministros públicos o permitir su pago diferido son otras formas relativamente sencillas de aliviar la presión a la que se encuentran sometidos los presupuestos familiares y que han adoptado algunos países del Caribe (CEPAL, 2020 ${ }_{[11]}$ ).

\section{Sostenimiento de políticas fiscales expansivas}

La respuesta de política pública de los países del Caribe al COVID-19 se ha visto restringida por un espacio fiscal limitado, provocado por el elevado endeudamiento y servicio de la deuda. Pese a esta restricción, se ha aumentado el gasto y se ha prestado apoyo crediticio y garantizado (CEPAL, 2020 $[1]$; Bárcena, 2020 ${ }_{[12]}$ ).

Para apuntalar la recuperación, resultará esencial promover la inversión en sectores esenciales, como las fuentes de energía renovable no convencionales, la electromovilidad urbana, la universalización de la transformación digital (OCDE, 2020 ${ }_{[10]}$ ), la industria farmacéutica, en especial con respecto a las vacunas, la bioeconomía, la economía asistencial, la economía circular y el turismo sostenible. En todos ellos hay margen para políticas productivas y tecnológicas que generen empleo de calidad y favorezcan la innovación y la diversificación de las exportaciones, así como la adaptación al cambio climático y la mitigación de sus efectos, e iniciativas de cooperación regional.

Dado el reducido espacio fiscal y los elevados niveles de endeudamiento de las economías caribeñas, para sostener una política de gasto expansiva se necesitarán medidas de acceso a financiación a través de una gestión de la deuda coordinada a escala mundial, una reducción de las pérdidas tributarias a corto plazo y la consolidación de los ingresos tributarios a medio plazo. A corto plazo, resulta esencial erradicar la evasión de impuestos, que es responsable de una pérdida de recursos que asciende a 325000 millones de USD (6.1\% del PIB regional) y reducir los gastos tributarios, que representan una pérdida de ingresos equivalente al 3.7\% del PIB. Del mismo modo, serán esenciales un adecuado manejo de la deuda, marcos fiscales apropiados, incluyendo reglas fiscales si es necesario, y una gestión de la deuda coordinada a nivel mundial de acuerdo con directrices básicas para obtener y gestionar los recursos necesarios (Capítulo 1) (Nieto-Parra y Orozco, $\left.2020_{[13]}\right)$. En general, para que la política fiscal sea efectiva, debe tener en cuenta el complejo contexto actual a través de una secuenciación de acciones bien definida. Todo esto se ha de respaldar además con un amplio consenso, alcanzado mediante un diálogo nacional y una clara comunicación (Mora, Nieto-Parra y Orozco, 2021 $1_{[14]}$ ) (Capítulo 1).

A medio plazo, deben incrementarse progresivamente los ingresos tributarios para que el gasto público sea sostenible. En el complejo contexto actual, los plazos, la rapidez y la forma en que se produzcan dichos incrementos deberán adaptarse a la situación de cada país y respaldarse con un amplio consenso alcanzado a través del diálogo nacional y de una comunicación clara. Para ello es necesario mejorar el poder redistributivo del sistema tributario aumentando los impuestos sobre la renta de forma progresiva, ampliando el alcance de los impuestos a la propiedad y el patrimonio, revisando y actualizando los 
cánones por la explotación de recursos no renovables y considerando impuestos a la economía digital y sobre los bienes y servicios que dañen el entorno o la salud pública (Mora, Nieto-Parra y Orozco, 2021 $1_{[14]}$ ).

La sostenibilidad y la orientación de la política fiscal requieren un nuevo pacto social y fiscal (véase el Capítulo 4), necesarios para alcanzar el consenso preciso para avanzar en reformas estructurales pendientes para reactivar la inversión, el empleo, la igualdad, la protección social, la reducción de la brecha de género y la acción por el clima, entre otras cosas (Cabutto, Nieto-Parra y Vázquez-Zamora, 2021 ${ }_{[15]}$ ).

\section{Financiación para el desarrollo: impulso de nuevas iniciativas}

Las iniciativas de alivio de la deuda exigen cambios en la arquitectura de la deuda internacional que atribuyan especial importancia a las economías más endeudadas, independientemente de su nivel de ingresos. Tradicionalmente, las economías del Caribe, como Haití, San Vicente y las Granadinas y Dominica, han emitido deuda a través de acreedores bilaterales o bancos multilaterales (Nieto-Parra y Orozco, $2020_{[13]}$ ). Se necesita un mecanismo de reestructuración de la deuda soberana internacional para gestionar las obligaciones con acreedores privados, así como una agencia de calificación crediticia multilateral. Al mismo tiempo, la heterogeneidad de los perfiles de deuda y vulnerabilidad de la región hace necesario el diseño de una estrategia de reducción de la deuda que no adopte un enfoque universal (Nieto-Parra y Orozco, 2020 ${ }_{[13]}$ ) (Capítulo 1). Las economías del Caribe se beneficiarán del reciente acuerdo de emisión de Derechos Especiales de Giro (DEG), que es una asignación histórica de DEG equivalente a 650000 millones de USD (cerca de 456000 millones de DEG) (Capítulo 1). Las asignaciones de DEG se distribuyen de forma proporcional a la participación de los países en el capital del FMI, que también está estrechamente vinculada al tamaño de sus economías. En términos generales, las economías del Caribe se beneficiarán de unos 1806 millones de DEG para complementar las reservas internacionales de los países y aumentar su resiliencia financiera, así como para garantizar que, en caso de necesidad urgente, puedan echar mano de sus ahorros (importación de vacunas) (FMI, 2021 $\left.{ }_{[16]}\right)$.

La reasignación de DEG se realizaría en tres partes. La primera se destinaría a aumentar la financiación del Fondo Fiduciario para el Crecimiento y la Lucha contra la Pobreza, que ya se financia ampliamente con préstamos de DEG otorgados por países desarrollados. Los DEG canalizados a este Fondo solo beneficiarían a los países de ingresos más bajos. La segunda consistiría en un fondo fiduciario para financiar acciones de lucha contra el cambio climático, la transformación digital y el gasto sanitario. La tercera parte respaldaría préstamos de bancos multilaterales de desarrollo a través de la creación de otro fondo fiduciario.

América Latina y el Caribe se beneficiarían de una nueva asignación de DEG que reforzaría la posición externa de algunas de las economías más pequeñas y endeudadas, lo que reduciría su prima de riesgo y liberaría recursos para financiar la lucha contra la pandemia.

La puesta en marcha de fondos multilaterales, como el Fondo para Aliviar la Economía COVID-19 (Fund to Alleviate COVID-19 Economics o FACE) propuesto por el gobierno de Costa Rica, puede complementar iniciativas para inyectar liquidez de los países desarrollados a los países en desarrollo. Los bancos de desarrollo también pueden ayudar a incrementar la liquidez aumentando la capitalización y la flexibilidad de sus criterios para la concesión de préstamos.

Las actividades de financiación deberían ir acompañadas de un mayor uso de instrumentos innovadores como las cláusulas sobre huracanes e instrumentos de deuda 
contingente, vinculados a la capacidad de pago, en aras de evitar el endeudamiento excesivo y aumentar la capacidad de los países para devolver y amortizar su deuda. Este es un tema de enorme relevancia en una subregión con una elevada exposición al impacto del cambio climático.

\section{Refuerzo de la salud y la educación como áreas clave}

Durante la pandemia, los países caribeños han aumentado el gasto sanitario en pruebas de diagnóstico del COVID-19, el tratamiento de casos graves y críticos, y un mayor control de la salud pública. Debería seguir promoviéndose la coordinación y la cooperación regional entre países del Caribe, y entre estos y el resto de ALC, para reforzar y acelerar los procesos de vacunación.

Dadas las limitaciones en materia de logística de la distribución local de las vacunas, la disponibilidad de insumos críticos y la reducida cobertura de los sistemas de salud, debería aumentarse la inversión en atención sanitaria, en concreto en atención primaria, con programas sostenibles que refuercen el sector de salud público (CEPAL/OPS, $2020_{[17]}$ ).

Las instituciones educativas de todo el Caribe se vieron obligadas a cerrar ya a mediados de marzo de 2020 como parte de las medidas para frenar la propagación del COVID-19. Se suministraron a los estudiantes sin conexión a Internet dispositivos móviles para acceder a plataformas online y, en primaria y secundaria, se están facilitando paquetes de actividades (CEPAL, 2020 ${ }_{[11]}$ ).

Es una necesidad apremiante que se produzca un regreso seguro y gradual a los centros educativos, en coordinación con el sector de la salud. Muchos países del Caribe se vieron obligados a cerrar por completo los centros educativos para contener la pandemia. En promedio, estuvieron cerrados durante 20 semanas en toda esta subregión, una cifra inferior a las 26 de toda ALC pero superior a las 15 semanas que se mantuvieron cerrados en promedio en las economías de la OCDE (Gráfico 6.4). Dado el impacto que ha tenido la pandemia en la salud mental de niños y adolescentes, tanto por el aumento de su exposición a Internet como por el aislamiento social, las estrategias encaminadas a continuar con la educación y regresar a los centros escolares deberían dar prioridad al bienestar socioemocional de estudiantes y docentes.

También se necesita urgentemente invertir en la atención y el bienestar de niños y adolescentes. La región no se puede permitir perder a una generación porque sus trayectorias educativas se hayan visto truncadas y por la falta de acceso a unas condiciones básicas que garanticen sus derechos y su bienestar. 


\section{Gráfico 6.4. Cierres totales de centros escolares en las economías del Caribe en comparación con ALC y la OCDE}

Número de semanas de cierre total de los centros educativos por el COVID-19

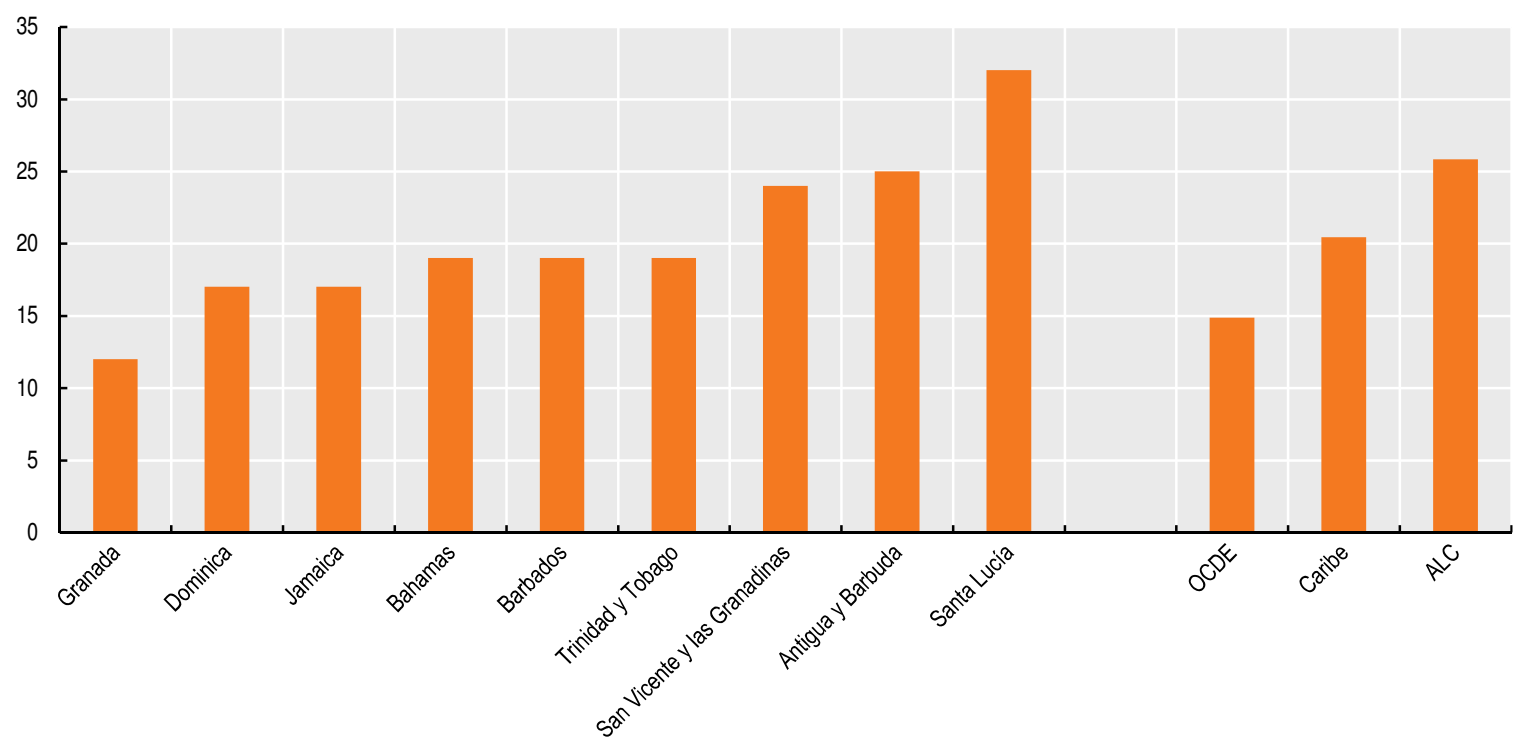

Nota: El promedio de la OCDE incluye a los 37 países miembros en ese momento. El promedio ALC incluye a Brasil, Chile, Colombia, Costa Rica, Cuba, la República Dominicana, Ecuador, El Salvador, Guatemala, Haití, Honduras, México, Nicaragua, Panamá, Perú, Uruguay y Venezuela. Actualización hasta el 1 de marzo de 2021.

Fuente: (UNESCO, 2020 ${ }_{[18)}$ ), Seguimiento mundial de los cierres de escuelas causados por el COVID-19, https://es.unesco.org/covid19/ educationresponse.

StatLink तilst https://doi.org/10.1787/888934296097

\section{Nota}

1. Promedio simple que incluye ocho países caribeños: Antigua y Barbuda, Bahamas, Barbados, Belice, Guyana, Jamaica, Santa Lucía y Trinidad y Tobago.

\section{Referencias}

Bárcena, A. (2020), Mobilizing international solidarity, accelerating action and embarking on new pathways to realize the 2030 Agenda and the Samoa Pathway: Small Island Developing States, Presentación de la Secretaria Ejecutiva de la CEPAL, Alicia Bárcena, en el Foro Político de Alto Nivel 2020, https://www.cepal.org/en/presentations/mobilizing-international-solidarity-acceleratingaction-and-embarking-new-pathways.

Bárcena, A. (2020), Regional dialogue to share experiences on fiscal responses to the crisis generated by the COVID-19 pandemic: The Caribbean perspective, Presentación de Alicia Bárcena, Secretaria Ejecutiva de la CEPAL, en la Reunión Virtual de Ministros de Finanzas para discutir el impacto económico de la pandemia de COVID-19 en el Caribe, https://www.cepal.org/sites/ default/files/presentation/files/200428 final covid19 caribbean reg dailogue of finance ministers.pdf.

Cabutto, C., S. Nieto-Parra y J. Vázquez-Zamora (2021), “A post-pandemic social contract for Latin America: the why, the what, the how", Vox LACEA, http://www.lacea.org/vox/?q=blog/social contract latam.

CEPAL (2021), La pandemia de enfermedad por coronavirus (COVID-19): una oportunidad de aplicar un enfoque sistémico al riesgo de desastres en el Caribe, Publicación de las Naciones Unidas, Santiago, https://repositorio.cepal.org/bitstream/handle/11362/46731/1/S2100024 es.pdf.

CEPAL (2021), La paradoja de la recuperación en América Latina y el Caribe. Crecimiento con persistentes problemas estructurales: desigualdad, pobreza, poca inversión y baja productividad, Publicación de las Naciones Unidas, Santiago, https://repositorio.cepal.org/bitstream/handle/11362/47043/5/ $\underline{\text { S2100379 es.pdf. }}$ 
CEPAL (2021), Panorama Fiscal de América Latina y el Caribe 2021: los desafíos de la política fiscal en la recuperación transformadora pos-COVID-19, Publicación de las Naciones Unidas, Santiago, https://repositorio.cepal.org/bitstream/handle/11362/46808/1/S2100170_es.pdf.

CEPAL (2020), COVID-19 Reporte Especial, No. 1. América Latina y el Caribe ante la pandemia del COVID-19: efectos económicos y sociales, Publicación de las Naciones Unidas, Santiago, https://repositorio. cepal.org/bitstream/handle/11362/45337/6/S2000264 es.pdf.

CEPAL (2020), Panorama Fiscal de América Latina y el Caribe, 2020: la política fiscal ante la crisis derivada de la pandemia de la enfermedad por coronavirus (COVID-19), Publicación de las Naciones Unidas, Santiago, https://repositorio.cepal.org/bitstream/handle/11362/45730/5/S2000154 es.pdf. [1]

CEPAL (2020), The Caribbean Outlook: Forging a People-centred Approach to Sustainable Development PostCOVID-19, Publicación de las Naciones Unidas, Santiago, https://www.cepal.org/fr/node/ $\underline{52477 .}$.

CEPAL (2018), The Caribbean Outlook, Publicación de las Naciones Unidas, Santiago, https://www. cepal.org/en/publications/43581-caribbean-outlook.

CEPAL/OPS (2020), Salud y economía: una convergencia necesaria para enfrentar el COVID-19 y retomar la senda hacia el desarrollo sostenible en América Latina y el Caribe, Publicación de las Naciones Unidas, Santiago, https://repositorio.cepal.org/bitstream/handle/11362/45840/4/S2000462 es.pdf. [17]

FMI (2021), 2021 Asignación general de DEG, https://www.imf.org/en/Topics/special-drawing-right/ 2021-SDR-Allocation.

Mora, S., S. Nieto-Parra y R. Orozco (2021), Fiscal policy to drive the recovery in Latin America: the "when" and "how" are key, Vox LACEA, https://vox.lacea.org/?q=blog/fiscal policy latam.

Nieto-Parra, S. y R. Orozco (2020), Public debt and COVID-19. Paying for the crisis in Latin America and the Caribbean, Le Grand Continent, https://legrandcontinent.eu/fr/2020/07/22/public-debt-andcovid-19-paying-for-the-crisis-in-latin-america-and-the-caribbean/.

OCDE (2020), Perspectivas económicas de América Latina 2020: Transformación digital para una mejor reconstrucción, Publicaciones de la OCDE, París, https://doi.org/10.1787/f2fdced2-es.

OCDE (2019), Perspectivas económicas de América Latina 2019: Desarrollo en transición, Publicaciones de la OCDE, París, https://doi.org/10.1787/g2g9ff1a-es.

OCDE et al. (2021), Estadísticas tributarias en América Latina y el Caribe 2021, Publicaciones de la OCDE, París, https://doi.org/10.1787/96ce5287-en-es.

UNESCO (2020), Seguimiento mundial de los cierres de escuelas causados por el COVID-19, UNESCO, https://es.unesco.org/covid19/educationresponse. 



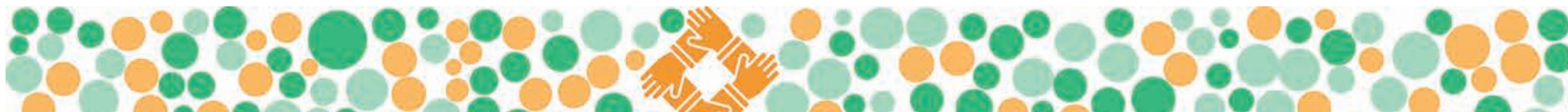
:00 O.

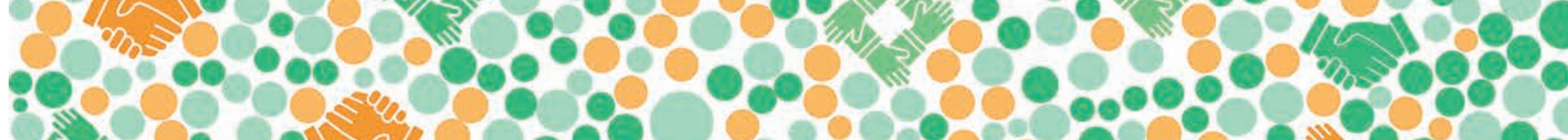

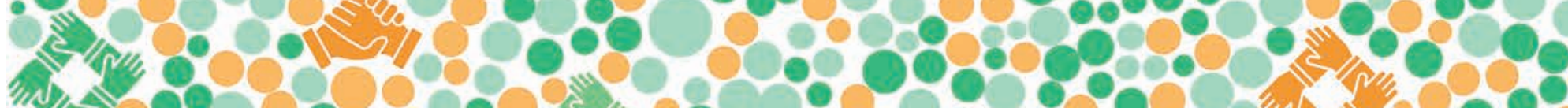

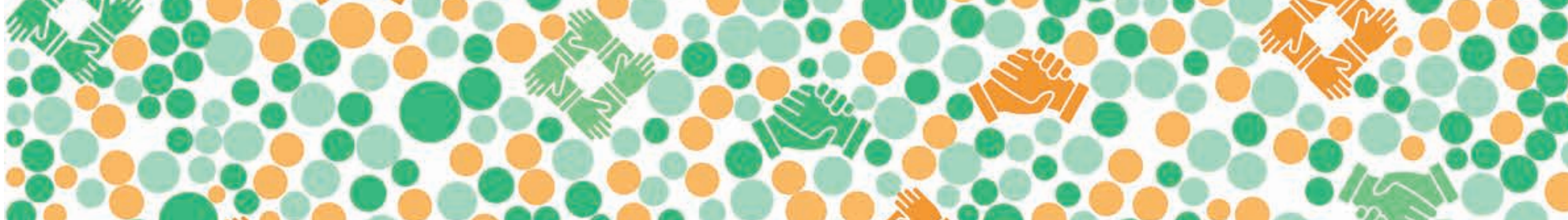

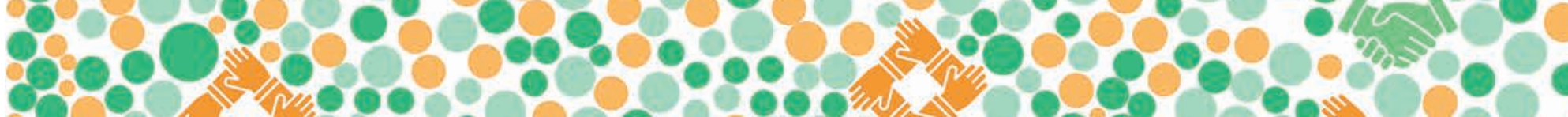

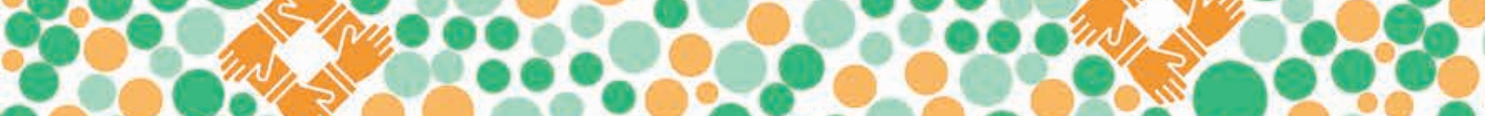

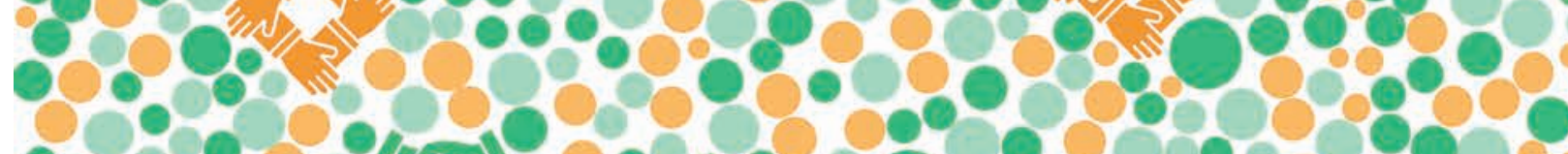
:36\%

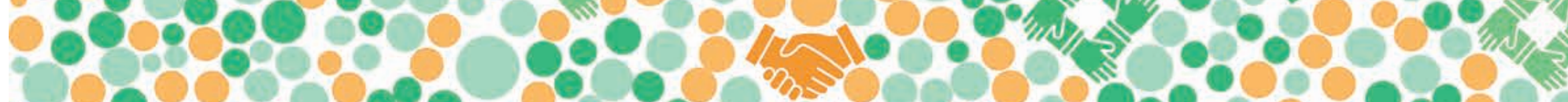
00000000000000000 :0\%

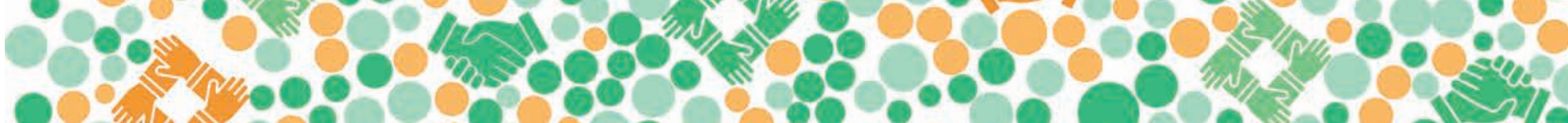

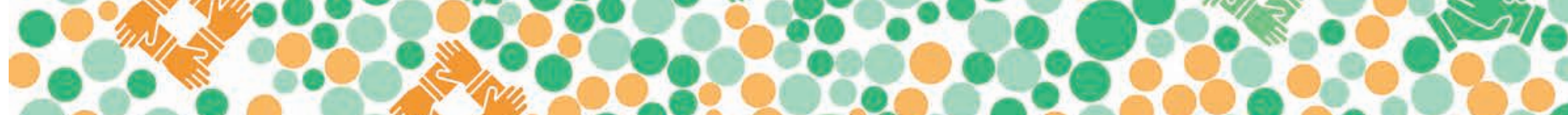

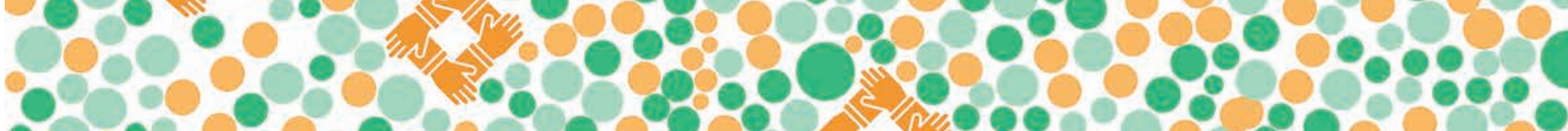

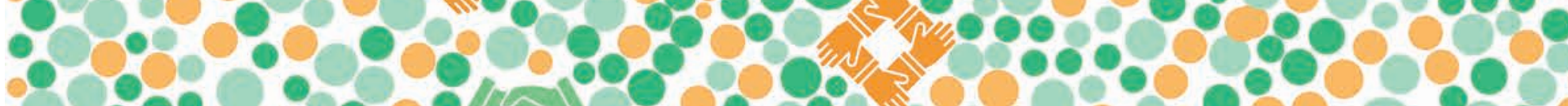

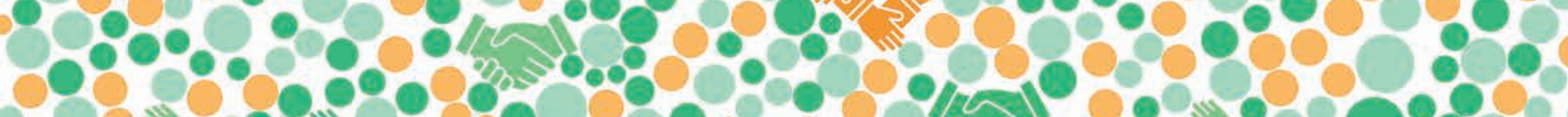
200 30003

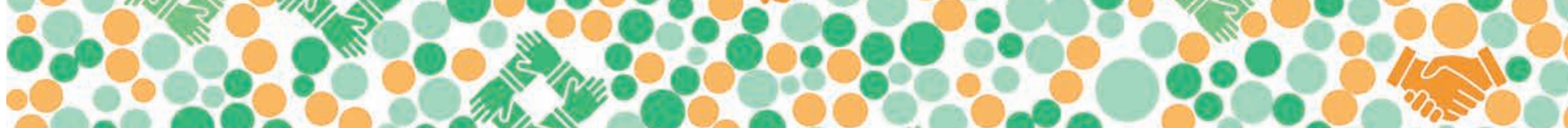
:080 0.000. 8.

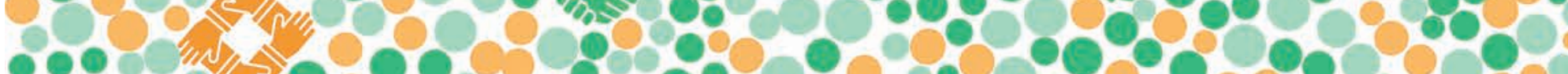

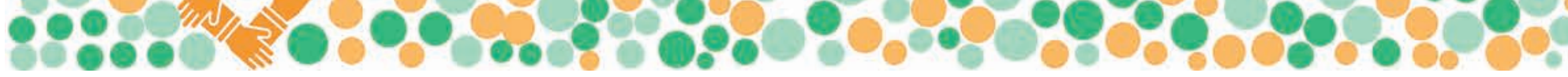




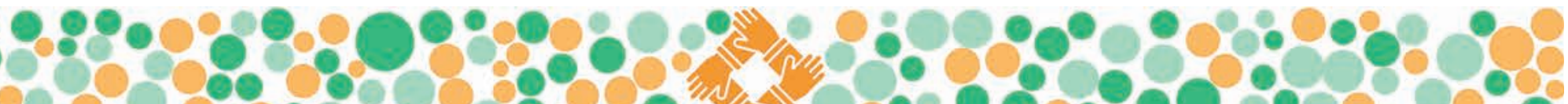


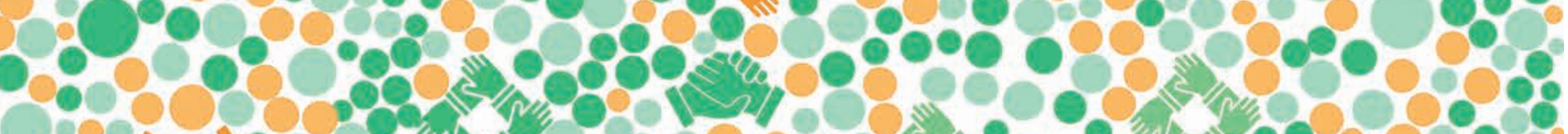

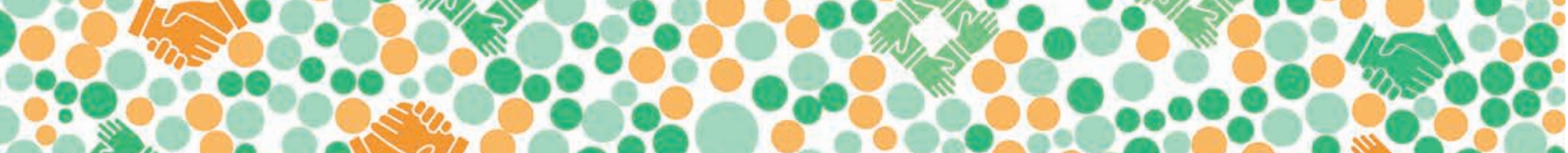

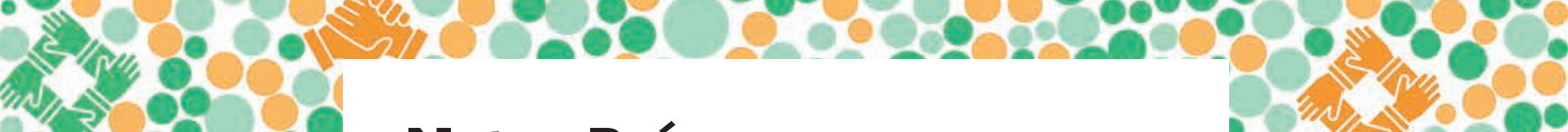

\section{Notas País}

1000

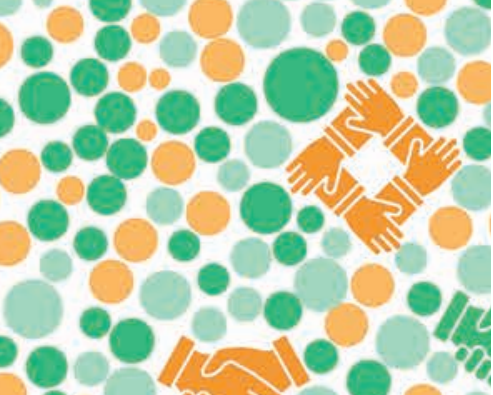

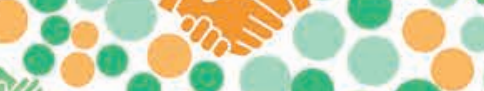
\% 800080 시 800000 年 80000.13 0.08 , 000 " (1)

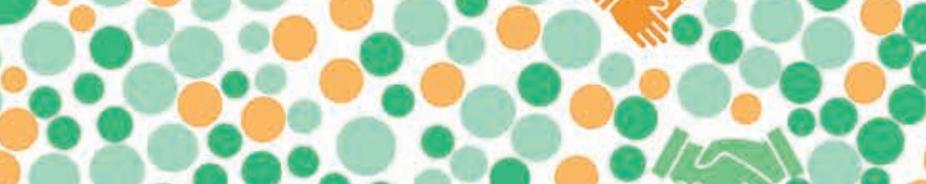

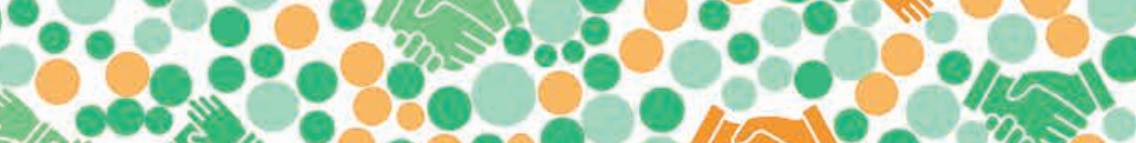

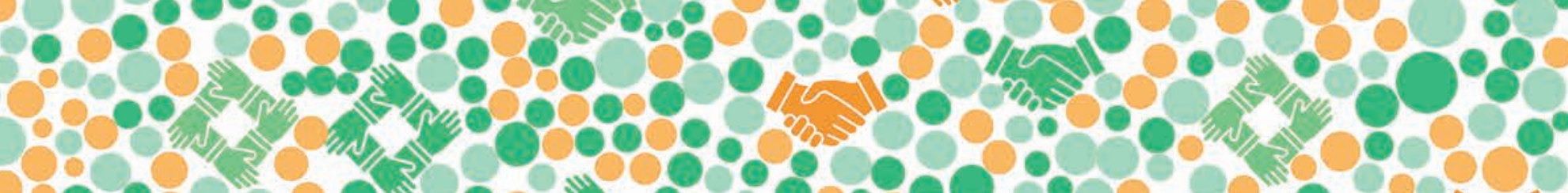

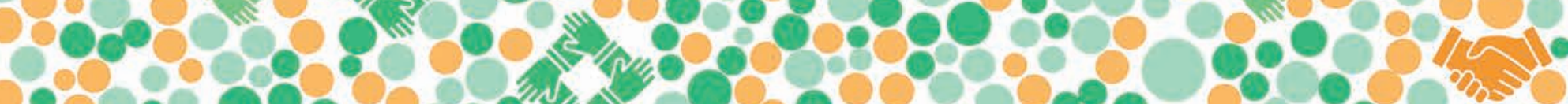

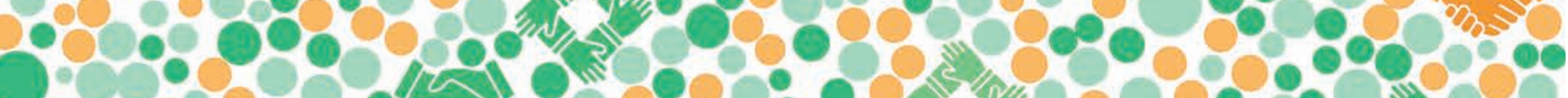

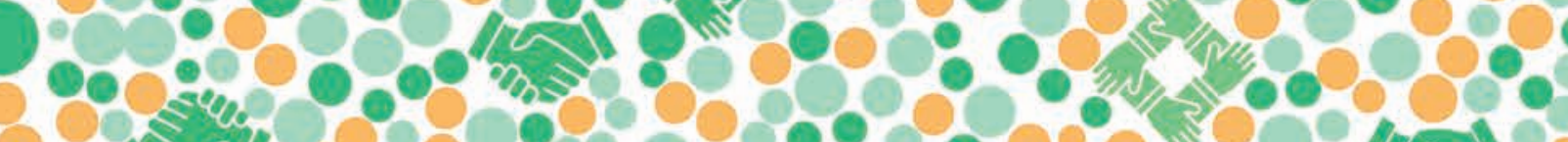

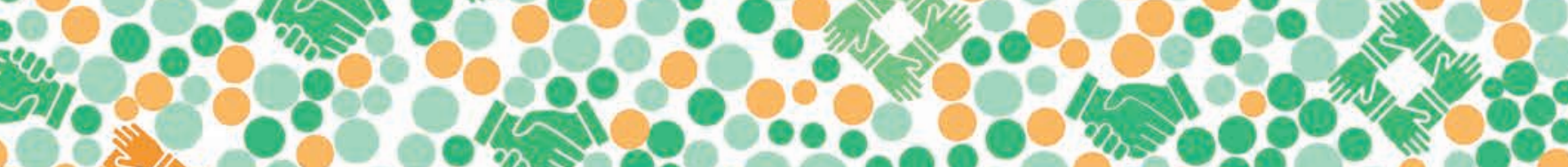

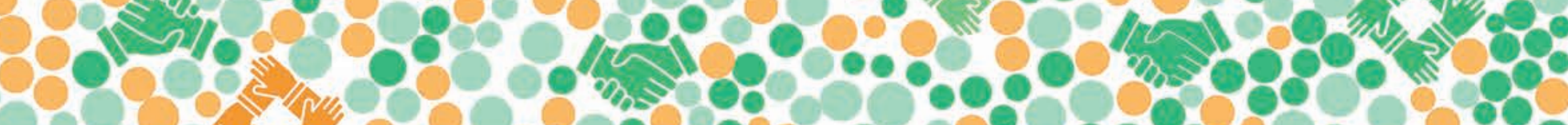

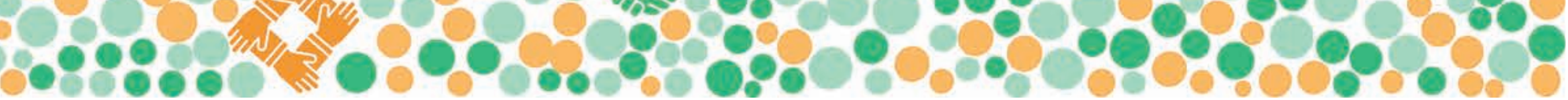




\section{ARGENTINA}

\section{Repercusiones socioeconómicas de la pandemia de coronavirus (COVID-19)}

Argentina se ha visto muy afectada por la pandemia de COVID-19. En 2020, el producto interno bruto (PIB) se contrajo un $9.9 \%$ anual. A pesar de los considerables esfuerzos de las políticas puestas en marcha, la crisis del COVID-19 disminuyó los ingresos de las personas más desfavorecidas, aumentando la pobreza en casi diez puntos porcentuales y la pobreza extrema en más de un punto porcentual, de acuerdo con las últimas estimaciones internacionales comparables. Entre marzo de 2020 y mayo de 2021, las escuelas han estado totalmente cerradas durante 22 semanas, frente a 26 semanas en la región de ALC y 15 semanas en los países de la Organización para la Cooperación y el Desarrollo Económicos (OCDE). El gasto público en salud aumentó 0.5 puntos porcentuales en el último decenio. En 2020, alrededor del $57.3 \%$ de las personas estaban satisfechas con la atención sanitaria pública, casi 2.5 puntos porcentuales menos que en 2009. Esta cifra es superior a la media de ALC (48.2\%) pero inferior al promedio de la OCDE (70.7\%). La percepción del gobierno entre las personas ha mejorado en el último decenio. El porcentaje de personas que creen que el gobierno es corrupto se redujo casi diez puntos porcentuales en el último decenio, hasta alcanzar el $76.0 \%$ en 2020. Este resultado es superior al de ALC (72.4\%) y la OCDE (58.8\%).

\section{Iniciativas nacionales e internacionales de cooperación orientadas a construir un futuro mejor}

Argentina ha adoptado medidas significativas para apoyar a los hogares, los trabajadores y las empresas más afectados durante la crisis. En atención a los hogares, Argentina adoptó transferencias de efectivo de emergencia (Ingreso Familiar de Emergencia) para proteger a los trabajadores informales, los trabajadores por cuenta propia, los trabajadores domésticos y los desempleados. Adicionalmente, Argentina realizó transferencias de efectivo adicionales a las familias que percibían la Asignación Universal por Hijo, las beneficiarias de la Asignación Universal por Embarazo, los perceptores de Asignaciones Familiares y los trabajadores por cuenta propia de ingresos bajos. Estas medidas incorporan un enfoque género. Además, se amplió y se extendió la cobertura de los programas de transferencia monetaria existentes, como: Tarjeta Alimentar, Progresar y Potenciar Trabajo. En atención a los trabajadores, Argentina extendió prestaciones de desempleo para las personas que perdieron su trabajo durante la crisis, así como programas de asistencia de emergencia para trabajadores de la industria de la alimentación (Programa de Asistencia de Emergencia al Sector Gastronómico), el sector del turismo (Programa Promover Turismo Federal y Sostenible) y el sector sanitario (otorgando exenciones del pago de las cotizaciones a la seguridad social). Por último, para apoyar a las empresas más afectadas, Argentina puso en marcha el Programa de Asistencia de Emergencia al Trabajo y la Producción, que tenía por objeto proteger los empleos y garantizar la producción durante la crisis del COVID-19.

De cara al futuro, Argentina ha establecido el Programa de Recuperación Productiva 2 para acelerar su recuperación económica. El programa tiene como objetivo mantener el empleo mediante la asignación de una cuantía fija individual que se abonará a los trabajadores de los sectores más afectados, en particular del turismo y la cultura. En atención al sector educativo, en agosto de 2020 se lanzó el Plan Federal "Juana Manzo", una plataforma para aprendizaje en línea disponible para todas las escuelas primarias y secundarias del país.

Las iniciativas de cooperación de Argentina dentro y fuera de la región se centran en las respuestas inmediatas a la crisis del COVID-19 y tienen perspectivas a mediano y largo plazo. Dentro de la región de ALC, Argentina participó en programas de cooperación no financiera con México para acelerar los procesos administrativos de la vacuna y su producción. Junto con Chile, apoyó a las pequeñas y medianas empresas en el proceso de digitalización para que puedan acceder al mercado de contratación pública. En el mismo sentido, creó junto con el Mercado Común del Sur (MERCOSUR) una red de institutos de investigación biomédica para hacer frente a los problemas sanitarios. Argentina también ha estado activa fuera de la región de ALC. En el marco del intercambio de experiencias sobre las estrategias de vacunación con el Reino Unido, el Ministerio de Salud argentino mantiene reuniones periódicas con científicos de Oxford para informarse sobre los avances de las estrategias de producción, las nuevas variantes, los refuerzos y los ensayos clínicos con niños y adolescentes. Argentina creó, junto con la Unión Europea, el Consejo Económico y Social como foro consultivo para ayudar a formular políticas públicas avaladas por consenso que fomenten la cohesión social y promuevan la igualdad de género. 


\section{Socioambientales}

Pobreza extrema ${ }^{4}$

Pobreza ${ }^{5}$

Coeficiente de Gini ${ }^{6}$

Población total en hogares informales por quintil. $2018^{7}$

Gasto en salud ${ }^{8}$

Gasto en salud por cuenta propia ${ }^{9}$

Semanas de cierre total de las escuelas ${ }^{10}$

Aprendizaje en línea efectivo ${ }^{11}$

Aprendizaje en línea efectivo en escuelas de entornos desfavorecidos ${ }^{11}$

Proporción de usuarios de Internet ${ }^{12}$

Número de alumnos por ordenador ${ }^{13}$

Exposición a PM $2.5^{14}$

$\%$ de cambio en el paisaje forestal intacto ${ }^{15}$

\section{Competitividad e innovación}

Productividad laboral ${ }^{16}$

Exportaciones de productos de alta tecnología ${ }^{17}$

Gasto en $1+D^{18}$

Patentes TIC $^{19}$

\section{Percepción de los ciudadanos e instituciones}

Percepción de la corrupción en el gobierno entre los ciudadanos ${ }^{20}$

Percepción entre los ciudadanos de que el país está gobernado en interés de unos pocos ${ }^{21}$

Satisfacción con la atención sanitaria22

Satisfacción con la calidad del agua ${ }^{23}$

$\%$ de personas víctimas de delincuencia ${ }^{24}$

Puesto en la Clasificación Mundial de la Libertad de Prensa ${ }^{25}$

Cambio en la polarización política ${ }^{26}$

Índice de Instituciones Sociales y Género (SIGI) ${ }^{27}$

\section{Situación fiscal}

Total de ingresos tributarios ${ }^{28}$

Proporción del IVA en el total de ingresos ${ }^{29}$

Gasto social ${ }^{30}$

Las fuentes, las notas al pie y los detalles técnicos pueden consultarse al final de las notas por países.

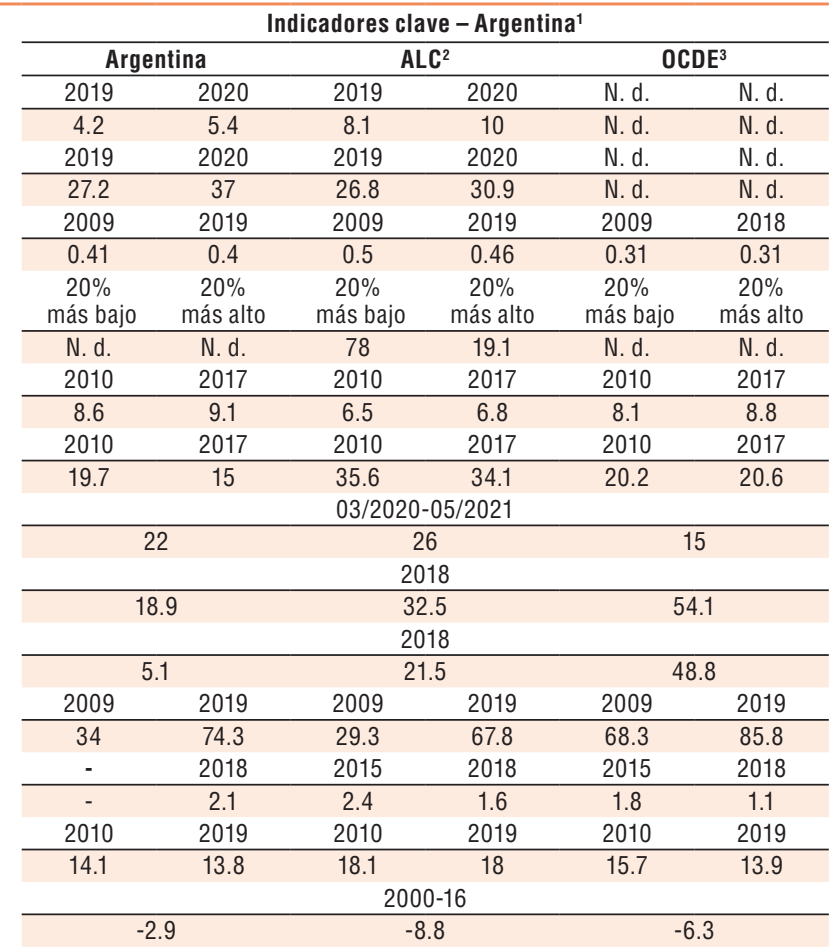

\begin{tabular}{cccccc}
\multicolumn{2}{c}{ Argentina } & \multicolumn{2}{c}{ ALC $^{2}$} & \multicolumn{2}{c}{ OCDE $^{3}$} \\
\hline 2009 & 2019 & 2009 & 2019 & 2009 & 2019 \\
\hline 42.2 & 36.9 & 29.3 & 26.7 & 72.2 & 70.7 \\
2009 & 2019 & 2009 & 2019 & 2009 & 2019 \\
\hline 9.1 & 5.2 & 8.7 & 8.3 & 19.5 & 17.9 \\
2009 & 2017 & 2009 & 2017 & 2009 & 2017 \\
\hline 0.6 & 0.5 & 0.4 & 0.4 & 2.4 & 2.5 \\
2009 & 2017 & 2009 & 2017 & 2009 & 2017 \\
\hline 69 & 43 & 726 & 521 & 173.44 & 141.358
\end{tabular}

\begin{tabular}{|c|c|c|c|c|c|}
\hline \multicolumn{2}{|c|}{ Argentina } & \multicolumn{2}{|c|}{ ALC $^{2}$} & \multicolumn{2}{|c|}{$\mathrm{OCDE}^{3}$} \\
\hline 2009 & 2020 & 2009 & 2020 & 2009 & 2020 \\
\hline 85.8 & 76 & 72 & 72.4 & 67.5 & 58.8 \\
\hline 2009 & 2018 & 2009 & 2018 & - & - \\
\hline 92.8 & 84.9 & 64.8 & 82 & - & - \\
\hline 2009 & 2020 & 2009 & 2020 & 2009 & 2020 \\
\hline 59.8 & 57.3 & 56.9 & 48.2 & 69.2 & 70.7 \\
\hline 2009 & 2020 & 2009 & 2020 & 2009 & 2020 \\
\hline 72.7 & 77.9 & 74.8 & 76 & 77.9 & 79.4 \\
\hline 2010 & 2016 & 2010 & 2016 & N. d. & N. d. \\
\hline 26.2 & 25.6 & 19.6 & 23.8 & N. d. & N. d. \\
\hline \multicolumn{6}{|c|}{2021} \\
\hline \multicolumn{2}{|c|}{69} & \multicolumn{2}{|c|}{82} & \multicolumn{2}{|c|}{36} \\
\hline \multicolumn{6}{|c|}{ 2009-18 } \\
\hline \multicolumn{2}{|c|}{4.1} & \multicolumn{2}{|c|}{9.6} & \multicolumn{2}{|c|}{ N. d. } \\
\hline \multicolumn{6}{|c|}{2019} \\
\hline \multicolumn{2}{|c|}{ N. d. } & \multicolumn{2}{|c|}{25.6} & \multicolumn{2}{|c|}{16.3} \\
\hline \multicolumn{2}{|c|}{ Argentina } & \multicolumn{2}{|c|}{ ALC $^{2}$} & \multicolumn{2}{|c|}{$\mathrm{OCDE}^{3}$} \\
\hline 2009 & 2019 & 2009 & 2019 & 2009 & 2019 \\
\hline 28.9 & 28.6 & 20.6 & 22.9 & 31.6 & 33.8 \\
\hline 2009 & 2019 & 2009 & 2019 & 2009 & 2019 \\
\hline 24.2 & 24.9 & 25.3 & 27.7 & 19.8 & 20.7 \\
\hline 2009 & 2018 & 2009 & 2018 & 2009 & 2018 \\
\hline 11.2 & 13.5 & 11.3 & 11.4 & 21 & 19.7 \\
\hline
\end{tabular}




\section{BRASIL}

\section{Repercusiones socioeconómicas de la pandemia de coronavirus (COVID-19)}

Brasil se ha visto muy afectado por la pandemia de COVID-19, pero experimentó una de las menores contracciones del producto interno bruto (PIB) de la región. En 2020, el PIB se contrajo un $4.1 \%$ anual y los niveles de pobreza y pobreza extrema alcanzaron el $16.3 \%$ y el $1.4 \%$, respectivamente, aun siendo elevados, eran más bajos que el promedio de la región de América Latina y el Caribe (ALC), del 30.9\% y el 10.0\%.

Entre marzo de 2020 y mayo de 2021, las escuelas han estado totalmente cerradas durante 38 semanas, frente a 26 semanas en la región de ALC y 15 semanas en los países de la Organización para la Cooperación y el Desarrollo Económicos (OCDE). Antes de la pandemia, el aprendizaje en línea efectivo estaba presente en el 35.0\% de las escuelas, frente al 54.1\% en la OCDE. El gasto público en salud representaba el $8.7 \%$ del PIB, un porcentaje superior a la media de la región de ALC (6.8\%) y similar al promedio de la OCDE (8.8\%). Sin embargo, según los datos de Gallup, en 2020 solo el 34.4\% de las personas estaban satisfechas con la atención sanitaria pública, 7 puntos porcentuales menos que en 2009. Esta cifra es inferior a la correspondiente a la región de ALC (48.2\%) y la OCDE (70.7\%). El porcentaje de personas que creen que el gobierno es corrupto aumentó más de cinco puntos porcentuales en el último decenio, alcanzando el $71.0 \%$ en 2020. Esta cifra es inferior a la de ALC (72.4\%), pero superior a la de OCDE (58.8\%).

\section{Iniciativas nacionales e internacionales de cooperación destinadas a construir un futuro mejor}

Brasil respondió con rapidez a la crisis del COVID-19. El despliegue de medidas para proteger a los hogares, los trabajadores y las empresas más vulnerables ayudó considerablemente a limitar el deterioro de la economía. En 2020, Brasil creó uno de los mayores programas de transferencias monetarias del mundo (Ayuda de Emergencia), al tiempo que amplió los programas existentes de transferencias monetarias condicionadas (Programa Bolsa Família) y visitas a hogares para el desarrollo en la primera infancia (Criança Feliz). Adicionalmente, Brasil puso en marcha un programa de adquisición de alimentos (Programa de Adquisiçao de Alimentos) para fomentar y sostener la producción de los pequeños agricultores, y apoyo a las poblaciones vulnerables mediante el sistema de asistencia social. En cuanto a los trabajadores y las empresas, Brasil ejecutó el mayor programa de mantenimiento de ingresos y conservación del empleo jamás desplegado en el país (Programa de Emergencia de Mantenimiento del Empleo y la Renta). El programa, dirigido en particular a las pequeñas y medianas empresas, permitía suspender los contratos en lugar de resolverlos, al tiempo que los trabajadores recibían el equivalente al seguro de desempleo.

De cara al futuro, Brasil seguirá una agenda de reformas estructurales cuyo objetivo es recuperar el balance fiscal, aumentar la productividad y preparar a los trabajadores y las empresas para hacer frente a las dificultades de la economía posterior a la pandemia. Las plataformas digitales ahora permiten a los ciudadanos examinar su situación laboral y obtener el seguro de desempleo. Por último, Brasil propuso reformas de gran envergadura, como la reforma de la administración pública, para reducir los costos salariales y mejorar la calidad de los servicios públicos, y la reforma fiscal, para reducir las complejidades de los sistemas tributarios actuales.

Los proyectos de cooperación internacional de Brasil dan prioridad al aumento de la competitividad del país, centrándose en las reformas del actual sistema tributario, el fomento de la competencia del mercado y una mayor apertura de la economía al comercio exterior. Fuera de la región de ALC, Brasil participa en programas internacionales de inmunización, como el Proyecto Acelerador de Vacunas, y colabora en la iniciativa de Acceso Mundial a las Vacunas contra el COVID-19 (COVAX). Adicionalmente, Brasil preside la Plataforma Biofuturo, una iniciativa internacional que tiene como objetivo promover una bioeconomía sostenible, entre otras cosas definiendo programas generales de recuperación económica tras el COVID-19. Por otro lado, las estrategias de cooperación de alto nivel de Brasil con la República Popular China, la India, España, el Reino Unido y los Estados Unidos han permitido al país obtener donaciones significativas para hacer frente al COVID-19 e impulsar su producción de vacunas. Por último, en el marco de la última fase (2020-2021) del programa de cooperación con la Unión Europea EUROsociAL+, el país recibió apoyo para la creación de nuevos servicios de orientación en medio de la pandemia. Dicho apoyo consistió en una serie de medidas de comunicación para asistir a la población vulnerable a través del Núcleo de Apoyo Contable y Fiscal. 


\section{Socioambientales}

Pobreza extrema ${ }^{4}$

Pobreza $^{5}$

Coeficiente de Gini ${ }^{6}$

Población total en hogares informales por quintil. $2018^{7}$

Gasto en salud ${ }^{8}$

Gasto en salud por cuenta propia ${ }^{9}$

Semanas de cierre total de las escuelas ${ }^{10}$

Aprendizaje en línea efectivo ${ }^{11}$

Aprendizaje en línea efectivo en escuelas de entornos desfavorecidos ${ }^{11}$

Proporción de usuarios de Internet ${ }^{12}$

Número de alumnos por ordenador ${ }^{13}$

Exposición a PM $2.5^{14}$

$\%$ de cambio en el paisaje forestal intacto $0^{15}$

\section{Competitividad e innovación}

Productividad laboral ${ }^{16}$

Exportaciones de productos de alta tecnología17

Gasto en $1+D^{18}$

Patentes TIC $^{19}$

\section{Percepción de los ciudadanos e instituciones}

Percepción de la corrupción en el gobierno entre los ciudadanos ${ }^{20}$

Percepción entre los ciudadanos de que el país está gobernado en interés de unos pocos ${ }^{21}$

Satisfacción con la atención sanitaria²2

Satisfacción con la calidad del agua ${ }^{23}$

$\%$ de personas víctimas de delincuencia ${ }^{24}$

Puesto en la Clasificación Mundial de la Libertad de Prensa ${ }^{25}$

Cambio en la polarización política ${ }^{26}$

Índice de Instituciones Sociales y Género (SIGI)27

\section{Situación fisca}

Total de ingresos tributarios ${ }^{28}$

Proporción del IVA en el total de ingresos ${ }^{29}$

Gasto social ${ }^{30}$

Las fuentes, las notas al pie y los detalles técnicos pueden consultarse al final de las notas por países.

\begin{tabular}{cccccc}
\multicolumn{7}{c}{ Indicadores clave - Brasil } \\
\hline \multicolumn{2}{c}{ Brasil } & \multicolumn{2}{c}{ ALC $^{2}$} & \multicolumn{2}{c}{ OCDE $^{3}$} \\
\hline 2019 & 2020 & 2019 & 2020 & N. d. & N. d. \\
\hline 5.5 & 1.4 & 8.1 & 10 & N. d. & N. d. \\
2019 & 2020 & 2019 & 2020 & N. d. & N. d. \\
\hline 19.2 & 16.3 & 26.8 & 30.9 & N. d. & N. d. \\
2009 & 2019 & 2009 & 2019 & 2009 & 2018 \\
\hline 0.53 & 0.54 & 0.5 & 0.46 & 0.31 & 0.31 \\
$20 \%$ & $20 \%$ & $20 \%$ & $20 \%$ & $20 \%$ & $20 \%$ \\
más bajo & más alto & más bajo & más alto & más bajo & más alto \\
\hline 70.5 & 10.7 & 78 & 19.1 & N. d. & N. d. \\
2010 & 2017 & 2010 & 2017 & 2010 & 2017 \\
\hline 9.2 & 8.7 & 6.5 & 6.8 & 8.1 & 8.8 \\
2010 & 2017 & 2010 & 2017 & 2010 & 2017 \\
\hline 29.4 & 27.4 & 35.6 & 34.1 & 20.2 & 20.6
\end{tabular}

\begin{tabular}{|c|c|c|c|c|c|}
\hline \multicolumn{2}{|c|}{38} & \multicolumn{2}{|c|}{26} & \multicolumn{2}{|c|}{15} \\
\hline \multicolumn{6}{|c|}{2018} \\
\hline \multicolumn{2}{|c|}{35} & \multicolumn{2}{|c|}{32.5} & \multicolumn{2}{|c|}{54.1} \\
\hline \multicolumn{6}{|c|}{2018} \\
\hline \multicolumn{2}{|c|}{19} & \multicolumn{2}{|c|}{21.5} & \multicolumn{2}{|c|}{48.8} \\
\hline 2009 & 2019 & 2009 & 2019 & 2009 & 2019 \\
\hline 39.2 & 73.9 & 29.3 & 67.8 & 68.3 & 85.8 \\
\hline 2015 & 2018 & 2015 & 2018 & 2015 & 2018 \\
\hline 3.7 & 6 & 2.4 & 1.6 & 1.8 & 1.1 \\
\hline 2010 & 2019 & 2010 & 2019 & 2010 & 2019 \\
\hline 14.1 & 11.7 & 18.1 & 18 & 15.7 & 13.9 \\
\hline \multicolumn{6}{|c|}{$2000-16$} \\
\hline & & & & & \\
\hline
\end{tabular}

\begin{tabular}{cccccc}
\multicolumn{2}{c}{ Brasil } & \multicolumn{2}{c}{ ALC $^{2}$} & \multicolumn{2}{c}{ OCDE $^{3}$} \\
\hline 2009 & 2019 & 2009 & 2019 & 2009 & 2019 \\
\hline 29.1 & 30.9 & 29.3 & 26.7 & 72.2 & 70.7 \\
2009 & 2019 & 2009 & 2019 & 2009 & 2019 \\
\hline 14.5 & 13.3 & 8.7 & 8.3 & 19.5 & 17.9 \\
2009 & 2017 & 2009 & 2017 & 2009 & 2017 \\
\hline 1.1 & 1.3 & 0.4 & 0.4 & 2.4 & 2.5 \\
2009 & 2017 & 2009 & 2017 & 2009 & 2017 \\
\hline 346 & 223 & 726 & 521 & 173.44 & 141.358
\end{tabular}

\begin{tabular}{cccccc}
\multicolumn{2}{c}{ Brasil } & \multicolumn{2}{c}{ ALC $^{2}$} & \multicolumn{2}{c}{ OCDE $^{3}$} \\
\hline 2009 & 2020 & 2009 & 2020 & 2009 & 2020 \\
\hline 65.7 & 71 & 72 & 72.4 & 67.5 & 58.8 \\
2009 & 2018 & 2009 & 2018 & - & - \\
\hline 55.2 & 92.3 & 65 & 83.8 & - & - \\
2009 & 2020 & 2009 & 2020 & 2009 & 2020 \\
\hline 41.5 & 34.4 & 56.9 & 48.2 & 69.2 & 70.7 \\
2009 & 2020 & 2009 & 2020 & 2009 & 2020 \\
\hline 70.7 & 64.8 & 74.8 & 76 & 77.9 & 79.4 \\
2010 & 2016 & 2010 & 2016 & N. d. & N. d. \\
\hline 15.8 & 23.9 & 21.3 & 25 & N.d. & N. d. \\
\hline
\end{tabular}

\begin{tabular}{|c|c|c|c|c|c|}
\hline \multicolumn{2}{|c|}{111} & \multicolumn{2}{|c|}{82} & \multicolumn{2}{|c|}{36} \\
\hline \multicolumn{6}{|c|}{ 2009-18 } \\
\hline \multicolumn{2}{|c|}{9.3} & \multicolumn{2}{|c|}{9.6} & \multicolumn{2}{|c|}{-} \\
\hline \multicolumn{6}{|c|}{2019} \\
\hline \multicolumn{2}{|c|}{21.2} & \multicolumn{2}{|c|}{25.6} & \multicolumn{2}{|c|}{16.3} \\
\hline \multicolumn{2}{|c|}{ Brasil } & \multicolumn{2}{|c|}{ ALC $^{2}$} & \multicolumn{2}{|c|}{$\mathrm{OCDE}^{3}$} \\
\hline 2009 & 2019 & 2009 & 2019 & 2009 & 2019 \\
\hline 32 & 33.1 & 20.6 & 22.9 & 31.6 & 33.8 \\
\hline 2009 & 2019 & 2009 & 2019 & 2009 & 2019 \\
\hline 20.8 & 21.2 & 25.3 & 27.7 & 19.8 & 20.7 \\
\hline 2009 & 2018 & 2009 & 2018 & 2009 & 2018 \\
\hline 15.2 & 17.7 & 11.3 & 11.4 & 21 & 19.7 \\
\hline
\end{tabular}

21 


\section{CHILE}

\section{Repercusiones socioeconómicas de la pandemia de coronavirus (COVID-19)}

La crisis en Chile ha sido dura. El producto interno bruto (PIB) se contrajo alrededor de un $5.8 \%$ en 2020 con respecto a 2019. En 2020 la pobreza aumentó 0.2 puntos porcentuales, hasta alcanzar el 10.9\%, de acuerdo con las últimas estimaciones internacionales comparables disponibles, una de las tasas más bajas (30.9\%) de la región de América Latina y el Caribe (ALC) . La tasa de pobreza extrema, (1.6\%) es también una de las más bajas de ALC (10.0\% en promedio). Entre marzo de 2020 y mayo de 2021, las escuelas chilenas estuvieron totalmente cerradas durante 14 semanas, muy por debajo de la media de la región (26 semanas) y cercano al promedio de la Organización para la Cooperación y el Desarrollo Económicos (OCDE) (15 semanas). El impacto negativo en la educación se compensó parcialmente con el aprendizaje en línea, que ya estaba presente en el $38.7 \%$ de las escuelas, un porcentaje superior al de ALC (32.5\%) pero considerablemente inferior al de la OCDE (54.1\%). La pandemia presionó al sistema sanitario, pero la inversión gubernamental previa actuó como amortiguador. El gasto público en salud aumentó dos puntos porcentuales en el último decenio, hasta alcanzar el 8.9\% del PIB, un porcentaje similar al promedio de la OCDE (8.8\%) y muy superior al promedio de ALC (6.8\%). Sin embargo, la percepción ciudadana de la calidad de los servicios sanitarios se ha deteriorado. En 2020, solo el $34.2 \%$ de las personas se declararon satisfechas con la atención sanitaria, una disminución de seis puntos porcentuales en un decenio. Esta cifra es inferior a la de ALC (48.2\%) y la OCDE (70.7\%). De acuerdo con los datos de Gallup sobre la percepción de los ciudadanos, en 2020, el 84.9\% de los chilenos consideraba que el gobierno era corrupto. Esta cifra es superior a la de ALC (72.4\%) y la OCDE (58.8\%).

\section{Iniciativas nacionales e internacionales de cooperación destinadas a construir un futuro mejor}

Desde el inicio de la pandemia de COVID-19, Chile aplicó una estrategia coordinada de gran alcance para apoyar a los hogares, los trabajadores y las empresas más vulnerables. El país movilizó eficazmente recursos para ampliar y reforzar la red de protección social en favor de casi 17.8 millones de chilenos. Para apoyar a los hogares, Chile destinó alrededor de 1.2 billones de dólares a través del programa de emergencia de transferencias monetarias (Ingreso Familiar de Emergencia) para los hogares formales e informales cuyos ingresos se vieron afectados negativamente por la crisis. Asimismo, hizo efectivo el Bono COVID-19, un plan especial de transferencias destinado a apoyar a las familias más vulnerables. Adicionalmente, para proteger a los hogares de ingresos medios, Chile proporcionó el Bono Clase Media. Para sostener a los trabajadores, Chile estableció medidas transitorias extraordinarias (Ley de Protección del Empleo) con el fin de proteger la estabilidad de ingresos y el empleo de los trabajadores formales. Además, puso en marcha un subsidio para fomentar la contratación y la retención de trabajadores. Para apoyar a las microempresas y pequeñas y medianas empresas (mipymes), Chile creó un fondo de préstamos mediante garantías (FOGAPE), estableciendo líneas de crédito adicionales y aplicando devoluciones de impuestos. Por último, Chile fomentó programas que prestan asistencia técnica y promoción de competencias digitales buscando aumentar la productividad de las mipymes (Digitaliza tu Pyme, Ruta Digital, Pymes en Línea, Pymes de Barrio, Elijo Pyme, Espacio del Emprendedor y Despega Mipe).

Para avanzar hacia la recuperación, Chile diseñó un plan de inversión pública para el período 2020-2022, que tiene como objetivo atender a las demandas de transformación social y productiva y encontrar soluciones a las amenazas de escasez de agua. Se ha hecho especial hincapié en proyectos que contribuyan a acelerar la transición al desarrollo sostenible, mitigar el cambio climático y adaptarse a sus efectos. Además, Chile está adoptando una serie de medidas para apoyar la competitividad, entre las que figuran nuevos requisitos de transparencia y un nuevo modelo digital en relación con los medios de pago.

En el marco de las iniciativas de cooperación internacional de Chile dentro de ALC, el Fondo de Cooperación Conjunta Chile-México transfirió más de 1 millón de USD al país para la adquisición de suministros médicos para hacer frente a la pandemia. Fuera de la región, Chile participa en el Fondo Bilateral para el Desarrollo en Transición Chile-Unión Europea, que asignó 365 millones de EUR a su proyecto más reciente para prestar apoyo a la recuperación de sectores productivos prioritarios de la macro región centro-sur del país en el marco del COVID-19. El proyecto tiene por objeto apoyar la recuperación económica de cuatro regiones del país y desarrollar acciones específicas para impulsar la generación de empleo. Además, a raíz de la colaboración con el programa de desarrollo socioeconómico de Japón, el país fue beneficiario de una donación financiera no reembolsable de 4.6 millones de USD para comprar equipos médicos. 


\section{Socioambientales}

Pobreza extrema ${ }^{4}$

Pobreza $^{5}$

Coeficiente de Gini ${ }^{6}$

Población total en hogares informales por quintil, $2018^{7}$

Gasto en salud ${ }^{8}$

Gasto en salud por cuenta propia ${ }^{9}$

Semanas de cierre total de las escuelas ${ }^{10}$

Aprendizaje en línea efectivo ${ }^{11}$

Aprendizaje en línea efectivo en escuelas de entornos desfavorecidos ${ }^{11}$

Proporción de usuarios de Internet ${ }^{12}$

Número de alumnos por ordenador ${ }^{13}$

Exposición a PM $2.5^{14}$

$\%$ de cambio en el paisaje forestal intacto $0^{15}$

\section{Competitividad e innovación}

Productividad laboral ${ }^{16}$

Exportaciones de productos de alta tecnología ${ }^{17}$

Gasto en $I+D^{18}$

Patentes TIC ${ }^{19}$

\section{Percepción de los ciudadanos e instituciones}

Percepción de la corrupción en el gobierno entre los ciudadanos ${ }^{20}$

Percepción entre los ciudadanos de que el país

está gobernado en interés de unos pocos ${ }^{2}$

Satisfacción con la atención sanitaria ${ }^{22}$

Satisfacción con la calidad del agua ${ }^{23}$

$\%$ de personas víctimas de delincuencia ${ }^{24}$

Puesto en la Clasificación Mundial de la Libertad de Prensa ${ }^{25}$

Cambio en la polarización política ${ }^{26}$

Índice de Instituciones Sociales y Género (SIGI) ${ }^{27}$

\section{Situación fiscal}

Total de ingresos tributarios ${ }^{28}$

Proporción del IVA en el total de ingresos ${ }^{29}$

Gasto social ${ }^{30}$

Las fuentes, las notas al pie y los detalles técnicos pueden consultarse al final de las notas por países.

\begin{tabular}{cccccc}
\multicolumn{7}{c}{ Indicadores clave - Chile } \\
\hline \multicolumn{2}{c}{ Chile } & \multicolumn{2}{c}{ ALC $^{2}$} & \multicolumn{2}{c}{ OCDE $^{3}$} \\
\hline 2017 & 2020 & 2019 & 2020 & 2019 & 2020 \\
\hline 1.4 & 1.6 & 8.1 & 10 & N. d. & N. d. \\
2017 & 2020 & 2019 & 2020 & 2019 & 2020 \\
\hline 10.7 & 10.9 & 26.8 & 30.9 & N. d. & N. d. \\
2009 & 2019 & 2009 & 2019 & 2009 & 2018 \\
\hline 0.48 & 0.45 & 0.5 & 0.46 & 0.31 & 0.31 \\
$20 \%$ & $20 \%$ & $20 \%$ & $20 \%$ & $20 \%$ & $20 \%$ \\
más bajo & más alto & más bajo & más alto & más bajo & más alto \\
\hline 34.9 & 9.4 & 78.8 & 19.3 & N. d. & N. d. \\
2010 & 2017 & 2010 & 2017 & 2010 & 2017 \\
\hline 6.8 & 8.9 & 6.5 & 6.8 & 8.1 & 8.8 \\
2010 & 2017 & 2010 & 2017 & 2010 & 2017 \\
\hline 34.5 & 33.5 & 35.6 & 34.1 & 20.2 & 20.6
\end{tabular}

\begin{tabular}{|c|c|c|c|c|c|}
\hline \multicolumn{6}{|c|}{$03 / 2020-05 / 2021$} \\
\hline \multicolumn{6}{|c|}{2018} \\
\hline \multicolumn{2}{|c|}{38.7} & \multicolumn{2}{|c|}{32.5} & \multicolumn{2}{|c|}{54.1} \\
\hline \multicolumn{6}{|c|}{2018} \\
\hline \multicolumn{2}{|c|}{25.2} & \multicolumn{2}{|c|}{21.5} & \multicolumn{2}{|c|}{48.8} \\
\hline 2009 & 2019 & 2009 & 2019 & 2009 & 2019 \\
\hline 41.6 & 82.3 & 29.3 & 67.8 & 68.3 & 85.8 \\
\hline 2015 & 2018 & 2015 & 2018 & 2015 & 2018 \\
\hline 1.7 & 1.1 & 2.4 & 1.6 & 1.8 & 1.1 \\
\hline 2010 & 2019 & 2010 & 2019 & 2010 & 2019 \\
\hline 21.9 & 23.7 & 18.1 & 18 & 15.7 & 13.9 \\
\hline \multicolumn{6}{|c|}{$2000-16$} \\
\hline & & & & & \\
\hline
\end{tabular}

\begin{tabular}{cccccc}
\multicolumn{2}{c}{ Chile } & \multicolumn{2}{c}{ ALC $^{2}$} & \multicolumn{2}{c}{ OCDE $^{3}$} \\
\hline 2009 & 2019 & 2009 & 2019 & 2009 & 2019 \\
\hline 53.1 & 56.2 & 29.3 & 26.7 & 72.2 & 70.7 \\
2009 & 2019 & 2009 & 2019 & 2009 & 2019 \\
\hline 6.6 & 7.5 & 8.7 & 8.3 & 19.5 & 17.9 \\
2009 & 2017 & 2009 & 2017 & 2009 & 2017 \\
\hline 0.4 & 0.4 & 0.4 & 0.4 & 2.4 & 2.5 \\
2009 & 2017 & 2009 & 2017 & 2009 & 2017 \\
\hline 68 & 19 & 726 & 521 & 173.44 & 141.358
\end{tabular}

\begin{tabular}{|c|c|c|c|c|c|}
\hline \multicolumn{2}{|c|}{ Chile } & \multicolumn{2}{|c|}{ ALC $^{2}$} & \multicolumn{2}{|c|}{$\mathrm{OCDE}^{3}$} \\
\hline 2009 & 2020 & 2009 & 2020 & 2009 & 2020 \\
\hline 65.8 & 84.9 & 72 & 72.4 & 67.5 & 58.8 \\
\hline 2009 & 2018 & 2009 & 2018 & N.d. & N. d. \\
\hline 61 & 77.4 & 64.8 & 82 & N. d. & N. d. \\
\hline 2009 & 2020 & 2009 & 2020 & 2009 & 2020 \\
\hline 40.8 & 34.2 & 56.9 & 48.2 & 69.2 & 70.7 \\
\hline 2009 & 2020 & 2009 & 2020 & 2009 & 2020 \\
\hline 61 & 53.3 & 76.2 & 75.2 & 77.9 & 79.4 \\
\hline 2010 & 2016 & 2010 & 2016 & N. d. & N. d. \\
\hline 16.3 & 22.4 & 19.6 & 23.8 & N. d. & N. d. \\
\hline \multicolumn{6}{|c|}{2021} \\
\hline \multirow{2}{*}{\multicolumn{2}{|c|}{54}} & \multicolumn{2}{|c|}{82} & \multicolumn{2}{|c|}{36} \\
\hline & & \multicolumn{2}{|c|}{$2009-18$} & & \\
\hline & & & & \multicolumn{2}{|c|}{ N. d. } \\
\hline \multicolumn{6}{|c|}{2019} \\
\hline & & & & & \\
\hline
\end{tabular}

\begin{tabular}{cccccc}
\multicolumn{2}{c}{ Chile } & \multicolumn{2}{c}{ ALC $^{2}$} & \multicolumn{2}{c}{ OCDE $^{3}$} \\
\hline 2009 & 2019 & 2009 & 2019 & 2009 & 2019 \\
\hline 17.3 & 20.7 & 20.6 & 22.9 & 31.6 & 33.8 \\
2009 & 2019 & 2009 & 2019 & 2009 & 2019 \\
\hline 42.1 & 39.9 & 25.3 & 27.7 & 19.8 & 20.7 \\
2009 & 2018 & 2009 & 2018 & 2009 & 2018 \\
\hline 15.7 & 16.4 & 11.3 & 11.4 & 21 & 19.7
\end{tabular}

11.4 


\section{COLOMBIA}

\section{Repercusiones socioeconómicas de la pandemia de coronavirus (COVID-19)}

Tras años de mejoras socioeconómicas en Colombia, la crisis del COVID-19 ha tenido repercusiones considerables en los resultados económicos y las condiciones sociales. El crecimiento del producto interno bruto (PIB) se redujo un 6.8\% en 2020. De acuerdo con las últimas estimaciones internacionales comparables, la pobreza aumentó casi seis puntos porcentuales en 2020 con respecto al año anterior, alcanzando el 37.5\%, un porcentaje superior al promedio de América Latina y el Caribe (ALC), del 30.9\%. La pobreza extrema en 2020 aumentó $4 \%$, hasta alcanzar el 16.9\%, una tasa superior al promedio de ALC, del 10.0\%. La crisis también afectó al sistema educativo, entre marzo de 2020 y mayo de 2021, las escuelas estuvieron totalmente cerradas durante 23 semanas, menos tiempo que en ALC (26 semanas) pero más que en los países de la Organización para la Cooperación y el Desarrollo Económicos (OCDE) (15 semanas). Esto se tradujo en dificultades para los alumnos y las familias, puesto que el aprendizaje en línea efectivo solo estaba presente en el $36.2 \%$ de las escuelas. Esta cifra se acerca a la media de ALC (32.5\%) pero es inferior al promedio de la OCDE (54.1\%). Colombia entró en la crisis del COVID-19 con un gasto público en salud (7.2\% del PIB) superior a la media de ALC (6.8\%), pero inferior al promedio de la OCDE (8.8\%). En 2020, el 47.7\% de las personas estaban satisfechas con los servicios sanitarios, lo que supone una reducción de más de siete puntos porcentuales en diez años. Este porcentaje es ligeramente inferior al de ALC (48.2\%) y considerablemente más bajo que el promedio de la OCDE (70.7\%). En cuanto a las preocupaciones de la población por las acciones de gobierno, en 2020 el 78.7\% de los colombianos creía que el gobierno era corrupto, un porcentaje superior al de la región de ALC (72.4\%) y al promedio de la OCDE (58.8\%).

\section{Iniciativas nacionales e internacionales de cooperación destinadas a construir un futuro mejor}

Colombia emprendió medidas audaces y oportunas para mitigar el impacto de la crisis del COVID-19 en los hogares y las empresas. Respecto a los hogares, las medidas aplicadas se basaron principalmente en transferencias monetarias para facilitar el acceso al consumo durante la crisis. En primer lugar, Colombia amplió el plan de compensación del IVA. El plan se diseñó como una política pública permanente en forma de reembolso bimensual de una cantidad fija al millón de hogares más pobres. En segundo lugar, Colombia estableció un programa nacional de transferencias monetarias no condicionadas (Ingreso Solidario) dirigido a 3 millones de hogares colombianos pobres y vulnerables que no eran beneficiarios de ningún otro programa nacional. En cuanto a las empresas, como estrategia de conservación del empleo, el gobierno creó programas nacionales (Programa de Apoyo al Empleo Formal y Programa de Apoyo a la Prima) para ayudar a las empresas del país subvencionando un porcentaje de sus cotizaciones a la seguridad social.

De cara al futuro, en 2020, Colombia lanzó un plan de recuperación económica para revitalizar la industria y promover la creación de empleo. En 2021, el gobierno nacional anunció la "Política de Recuperación Económica y Social" que establece una inversión equivalente al 12.5\% del PIB de Colombia distribuida en 5 compromisos sobre: creación de empleo; crecimiento limpio y sostenible; hogares vulnerables; zonas rurales, paz y legalidad; y salud.

Los proyectos de cooperación internacional de Colombia dentro y fuera de la región durante la pandemia fueron flexibles y tuvieron continuidad, pese a las dificultades derivadas de la crisis. Los proyectos dentro de ALC se basaron en el intercambio de mejores prácticas y experiencias con Honduras y Perú. Los proyectos con Honduras estaban relacionados con la certificación y legalización electrónicas de documentos y la promoción de empresas verdes a través de mecanismos financieros. Los proyectos con Perú incluían la promoción de la participación política de los jóvenes y el refuerzo de la capacidad de los sistemas de producción en las zonas fronterizas protegidas. Fuera de la región de ALC, Colombia participó en proyectos de cooperación con diversos actores, centrándose en la crisis y las necesidades más acuciantes. Los proyectos incluían el aumento de la capacidad y el acceso a sistemas sanitarios integrales (Salud para la paz: fortaleciendo comunidades); una propuesta de desarrollo territorial en el departamento de Chocó por la Agencia Española de Cooperación Internacional y Desarrollo (AECID); el desarrollo de prototipos de respiradores a bajo costo, con la ayuda del Banco Interamericano de Desarrollo (INNspiraMed); y el desarrollo de capacidades para prevenir la violencia contra los jóvenes en el marco del COVID-19 (Colombia enseña a Colombia [Col-Col]). Por último, en el marco de la última fase (2020-2021) del programa de cooperación con la Unión Europea EUROsociAL+, se concedió apoyo para afrontar problemas relacionados con el COVID-19. Se contemplaban acciones para: i) reforzar las Comisarías de Familia para apoyar a las víctimas de violencia de género; ii) aplicar estrategias de empleabilidad para jóvenes; y iii) apoyar la respuesta a la crisis migratoria venezolana, en particular en el ámbito del género. 


\section{Socioambientales}

Pobreza extrema ${ }^{4}$

Pobreza $^{5}$

Coeficiente de Gini ${ }^{6}$

Población total en hogares informales por quintil. $2018^{7}$

Gasto en salud ${ }^{8}$

Gasto en salud por cuenta propia ${ }^{9}$

Semanas de cierre total de las escuelas ${ }^{10}$

Aprendizaje en línea efectivo ${ }^{11}$

Aprendizaje en línea efectivo en escuelas de entornos desfavorecidos ${ }^{11}$

Proporción de usuarios de Internet ${ }^{12}$

Número de alumnos por ordenador ${ }^{13}$

Exposición a PM $2.5^{14}$

$\%$ de cambio en el paisaje forestal intacto $0^{15}$

\section{Competitividad e innovación}

Productividad laboral ${ }^{16}$

Exportaciones de productos de alta tecnología ${ }^{17}$

Gasto en $1+D^{18}$

Patentes TIC ${ }^{19}$

\section{Percepción de los ciudadanos e instituciones}

Percepción de la corrupción en el gobierno entre los ciudadanos ${ }^{20}$

Percepción entre los ciudadanos de que el país está gobernado en interés de unos pocos ${ }^{2}$

Satisfacción con la atención sanitaria ${ }^{22}$

Satisfacción con la calidad del agua ${ }^{23}$

$\%$ de personas víctimas de delincuencia ${ }^{24}$

Puesto en la Clasificación Mundial de la Libertad de Prensa ${ }^{25}$

Cambio en la polarización política ${ }^{26}$

Índice de Instituciones Sociales y Género (SIGI) ${ }^{27}$

\section{Situación fiscal}

Total de ingresos tributarios ${ }^{28}$

Proporción del IVA en el total de ingresos 29

Gasto social ${ }^{30}$

Las fuentes, las notas al pie y los detalles técnicos pueden consultarse al final de las notas por países.

\begin{tabular}{cccccc}
\multicolumn{7}{c}{ Indicadores clave - Colombia ${ }^{1}$} \\
\hline \multicolumn{2}{c}{ Colombia } & \multicolumn{2}{c}{ ALC $^{2}$} & \multicolumn{2}{c}{ OCDE $^{3}$} \\
\hline 2019 & 2020 & 2019 & 2020 & 2019 & 2020 \\
\hline 12.8 & 16.9 & 8.1 & 10 & N. d. & N. d. \\
2019 & 2020 & 2019 & 2020 & 2019 & 2020 \\
\hline 31.7 & 37.5 & 26.8 & 30.9 & N. d. & N. d. \\
2009 & 2019 & 2009 & 2019 & 2009 & 2018 \\
\hline 0.56 & 0.53 & 0.5 & 0.46 & 0.31 & 0.31 \\
$20 \%$ & $20 \%$ & $20 \%$ & $20 \%$ & $20 \%$ & $20 \%$ \\
más bajo & más alto & más bajo & más alto & más bajo & más alto \\
\hline 91.9 & 21.6 & 78 & 19.1 & N. d. & N. d. \\
2010 & 2017 & 2010 & 2017 & 2010 & 2017 \\
\hline 6.3 & 7.2 & 6.5 & 6.8 & 8.1 & 8.8 \\
2010 & 2017 & 2010 & 2017 & 2010 & 2017 \\
\hline 20.9 & 16.3 & 35.6 & 34.1 & 20.2 & 20.6
\end{tabular}

\begin{tabular}{|c|c|c|c|c|c|}
\hline \multicolumn{2}{|c|}{23} & \multicolumn{2}{|c|}{26} & \multicolumn{2}{|c|}{15} \\
\hline \multicolumn{6}{|c|}{2018} \\
\hline \multicolumn{2}{|c|}{36.2} & \multicolumn{2}{|c|}{32.5} & \multicolumn{2}{|c|}{54.1} \\
\hline \multicolumn{6}{|c|}{2018} \\
\hline \multicolumn{2}{|c|}{27.6} & \multicolumn{2}{|c|}{21.5} & \multicolumn{2}{|c|}{48.8} \\
\hline 2009 & 2019 & 2009 & 2019 & 2009 & 2019 \\
\hline 30 & 65 & 29.3 & 67.8 & 68.3 & 85.8 \\
\hline 2015 & 2018 & 2015 & 2018 & 2015 & 2018 \\
\hline 1.6 & 1.1 & 2.4 & 1.6 & 1.8 & 1.1 \\
\hline 2010 & 2019 & 2010 & 2019 & 2010 & 2019 \\
\hline 25.7 & 22.5 & 18.1 & 18 & 15.7 & 13.9 \\
\hline \multicolumn{6}{|c|}{$2000-16$} \\
\hline & & & & & \\
\hline
\end{tabular}

\begin{tabular}{cccccc}
\multicolumn{2}{c}{ Colombia } & \multicolumn{2}{c}{ ALC $^{2}$} & \multicolumn{2}{c}{ OCDE $^{3}$} \\
\hline 2009 & 2019 & 2009 & 2019 & 2009 & 2019 \\
\hline 29 & 34.5 & 29.3 & 26.7 & 72.2 & 70.7 \\
2009 & 2019 & 2009 & 2019 & 2009 & 2019 \\
\hline 5.6 & 9.1 & 8.7 & 8.3 & 19.5 & 17.9 \\
2009 & 2017 & 2009 & 2017 & 2009 & 2017 \\
\hline 0.2 & 0.2 & 0.4 & 0.4 & 2.4 & 2.5 \\
2009 & 2017 & 2009 & 2017 & 2009 & 2017 \\
\hline 24 & 13 & 726 & 521 & 173.44 & 141.358
\end{tabular}

\begin{tabular}{|c|c|c|c|c|c|}
\hline \multicolumn{2}{|c|}{ Colombia } & \multicolumn{2}{|c|}{$\mathrm{ALC}^{2}$} & \multicolumn{2}{|c|}{$\mathrm{OCDE}^{3}$} \\
\hline 2009 & 2020 & 2009 & 2020 & 2009 & 2020 \\
\hline 77.7 & 78.7 & 72 & 72.4 & 67.5 & 58.8 \\
\hline 2009 & 2018 & 2009 & 2018 & N. d. & N. d. \\
\hline 62.4 & 83.4 & 64.8 & 82 & N. d. & N. d. \\
\hline 2009 & 2020 & 2009 & 2020 & 2009 & 2020 \\
\hline 55.0 & 47.7 & 56.9 & 48.2 & 69.2 & 70.7 \\
\hline 2009 & 2020 & 2009 & 2020 & 2009 & 2020 \\
\hline 69.5 & 71.5 & 74.8 & 76.0 & 77.9 & 79.4 \\
\hline 2010 & 2016 & 2010 & 2016 & N. d. & N. d. \\
\hline 20.5 & 25.1 & 19.6 & 23.8 & N.d. & N.d. \\
\hline \multicolumn{6}{|c|}{2021} \\
\hline \multicolumn{2}{|c|}{134} & \multicolumn{2}{|c|}{82} & \multicolumn{2}{|c|}{36} \\
\hline \multicolumn{6}{|c|}{$2009-18$} \\
\hline \multicolumn{2}{|c|}{3.0} & \multicolumn{2}{|c|}{9.6} & \multicolumn{2}{|c|}{ N.d. } \\
\hline \multicolumn{6}{|c|}{2019} \\
\hline \multicolumn{2}{|c|}{15.0} & \multicolumn{2}{|c|}{25.6} & \multicolumn{2}{|c|}{16.3} \\
\hline
\end{tabular}

\begin{tabular}{cccccc}
\multicolumn{2}{c}{ Colombia } & \multicolumn{2}{c}{ ALC $^{2}$} & \multicolumn{2}{c}{ OCDE $^{3}$} \\
\hline 2009 & 2019 & 2009 & 2019 & 2009 & 2019 \\
\hline 18.8 & 19.7 & 20.6 & 22.9 & 31.6 & 33.8 \\
2009 & 2019 & 2009 & 2019 & 2009 & 2019 \\
\hline 27.5 & 29.6 & 25.3 & 27.7 & 19.8 & 20.7 \\
2009 & 2018 & 2009 & 2018 & 2009 & 2018 \\
\hline 13.3 & 12.6 & 11.3 & 11.4 & 21 & 19.7 \\
\hline
\end{tabular}




\section{COSTA RICA}

\section{Repercusiones socioeconómicas de la pandemia de coronavirus (COVID-19)}

A pesar de los grandes esfuerzos por mitigar los impactos del COVID-19, Costa Rica se ha visto muy afectada por la pandemia, en particular su sector turístico. Se prevé que la crisis haga retroceder algunos de los logros socioeconómicos y ambientales alcanzados por el país con anterioridad. En 2020, la tasa de pobreza aumentó más de dos puntos porcentuales con respecto a 2019 y la pobreza extrema, un punto porcentual, de acuerdo con las últimas estimaciones internacionales comparables. La población total en hogares informales en el quintil más bajo de ingresos, era del 75.6\%, un porcentaje ligeramente inferior al de la región de ALC (78.0\%). Entre marzo de 2020 y mayo de 2021 las escuelas han estado totalmente cerradas durante 39 semanas, frente a 26 semanas en la región de ALC y 15 semanas en los países de la Organización para la Cooperación y el Desarrollo Económicos (OCDE). Además, el aprendizaje en línea efectivo solo estaba presente en el $20.0 \%$ de las escuelas.

Costa Rica entró en la pandemia con un gasto público relativamente más alto en atención sanitaria (7.5\% del PIB) en comparación con ALC (6.8\%). De acuerdo con los datos de Gallup, el 64.8\% de las personas estaban satisfechas con la atención sanitaria pública en 2020, ocho puntos porcentuales menos que en 2009. Este porcentaje es superior al de la región de ALC (48.2\%), pero inferior al de la OCDE (70.7\%). La percepción de corrupción en el gobierno aumentó más de seis puntos porcentuales en el último decenio, alcanzando el 85.1\% en 2020. Este resultado es superior al de ALC (72.4\%) y la OCDE (58.8\%).

\section{Iniciativas nacionales e internacionales de cooperación destinadas a construir un futuro mejor}

Costa Rica ha realizado esfuerzos considerables para hacer frente a la crisis del COVID-19 y ayudar a proteger a los hogares, los trabajadores y las empresas más vulnerables. Con respecto a los hogares, se proporcionaron alimentos y atención domiciliaria para ayudar a los más vulnerables, incluidas las familias y los ancianos más afectados. En cuanto a los trabajadores, Costa Rica puso en marcha el programa de transferencias monetarias directas (Bono Proteger) para ofrecer alivio económico temporal a los trabajadores formales e informales cuyos ingresos se vieron afectados por la crisis. Por último, para mitigar el impacto de la crisis en las empresas, el gobierno aplicó un régimen de retención del empleo a corto plazo para las empresas que declararon pérdidas de ingresos anualizadas y prorrogó las moratorias fiscales para las empresas, en particular en el sector del turismo.

De cara al futuro, los objetivos de Costa Rica a mediano y largo plazo son impulsar el crecimiento económico y mejorar la distribución de ingresos, manteniendo al mismo tiempo su plan de cero emisiones netas para 2050. Costa Rica puso en marcha, con apoyo internacional, una estrategia territorial productiva que traza el camino hacia una economía descentralizada, digitalizada y descarbonizada para 2050. Esta estrategia incluye acciones fundamentales para acelerar la trayectoria de desarrollo del país, crear empleo y eliminar las desigualdades sociales existentes.

Los proyectos de cooperación internacional de Costa Rica dentro y fuera de la región dan prioridad a la cooperación financiera para hacer frente a las consecuencias de la pandemia, impulsando al mismo tiempo su trayectoria de desarrollo a largo plazo. Dentro de la región de ALC, Costa Rica participó durante la pandemia en programas de cooperación en materia de asistencia financiera para responder a la crisis. Además, Costa Rica participa en plataformas del Banco Interamericano de Desarrollo que buscan fomentar la transparencia y la rendición de cuentas del gasto público asociado a las medidas políticas contra el COVID-19 (Rendir Cuentas/ Mapa Inversiones + COVID-19). El objetivo es que los ciudadanos puedan acceder a los detalles de las inversiones y actividades de las instituciones públicas para responder a la pandemia. Fuera de la región de ALC, Costa Rica participa en fondos para atenuar el impacto de la crisis y financiar la recuperación. En particular, el país es uno de los patrocinadores del Fondo para Aliviar la Economía COVID-19, iniciativa que tiene por objeto ofrecer, con carácter solidario, fondos de los países desarrollados para financiar la recuperación de los países emergentes y en desarrollo. Otras iniciativas tienen por objeto la aplicación de estrategias productivas nacionales a largo plazo y el cumplimiento de sus objetivos (por ejemplo, un fondo creado por la Unión Europea y la fase IV de la cooperación triangular con España). Estas iniciativas de cooperación pretenden que Costa Rica se responsabilice del plan de recuperación a largo plazo, además de promover la ejecución de proyectos para cumplir los Objetivos de Desarrollo Sostenible de las Naciones Unidas. 


\section{Socioambientales}

Pobreza extrema ${ }^{4}$

Pobreza $^{5}$

Coeficiente de Gini ${ }^{6}$

Población total en hogares informales por quintil. $2018^{7}$

Gasto en salud ${ }^{8}$

Gasto en salud por cuenta propia ${ }^{9}$

Semanas de cierre total de las escuelas ${ }^{10}$

Aprendizaje en línea efectivo ${ }^{11}$

Aprendizaje en línea efectivo en escuelas de entornos desfavorecidos ${ }^{11}$

Proporción de usuarios de Internet ${ }^{12}$

Número de alumnos por ordenador ${ }^{13}$

Exposición a PM $2.5^{14}$

$\%$ de cambio en el paisaje forestal intacto $0^{15}$

\section{Competitividad e innovación}

Productividad laboral ${ }^{16}$

Exportaciones de productos de alta tecnología ${ }^{17}$

Gasto en $I+D^{18}$

Patentes TIC ${ }^{19}$

\section{Percepción de los ciudadanos e instituciones}

Percepción de la corrupción en el gobierno entre los ciudadanos ${ }^{20}$

Percepción entre los ciudadanos de que el país

está gobernado en interés de unos pocos ${ }^{2}$

Satisfacción con la atención sanitaria ${ }^{22}$

Satisfacción con la calidad del agua ${ }^{23}$

$\%$ de personas víctimas de delincuencia ${ }^{24}$

Puesto en la Clasificación Mundial de la Libertad de Prensa ${ }^{25}$

Cambio en la polarización política ${ }^{26}$

Índice de Instituciones Sociales y Género (SIGI) ${ }^{27}$

\section{Situación fiscal}

Total de ingresos tributarios ${ }^{28}$

Proporción del IVA en el total de ingresos ${ }^{29}$

Gasto social ${ }^{30}$

Las fuentes, las notas al pie y los detalles técnicos pueden consultarse al final de las notas por países.

\begin{tabular}{cccccc}
\multicolumn{6}{c}{ Indicadores clave - Costa Rica ${ }^{1}$} \\
\hline \multicolumn{2}{c}{ Costa Rica } & \multicolumn{2}{c}{ ALC $^{2}$} & \multicolumn{2}{c}{ OCDE $^{3}$} \\
\hline 2019 & 2020 & 2019 & 2020 & 2019 & 2020 \\
\hline 3.4 & 4.4 & 8.1 & 10 & N. d. & N. d. \\
2019 & 2020 & 2019 & 2020 & 2019 & 2020 \\
\hline 16.5 & 18.9 & 26.8 & 30.9 & N. d. & N. d. \\
2009 & 2019 & 2009 & 2019 & 2009 & 2018 \\
\hline 0.51 & 0.49 & 0.5 & 0.46 & 0.31 & 0.31 \\
$20 \%$ & $20 \%$ & $20 \%$ & $20 \%$ & $20 \%$ & $20 \%$ \\
más bajo & más alto & más bajo & más alto & más bajo & más alto \\
\hline 75.6 & 6.1 & 78 & 19.1 & N. d. & N. d. \\
2010 & 2017 & 2010 & 2017 & 2010 & 2017 \\
\hline 8.1 & 7.5 & 6.5 & 6.8 & 8.1 & 8.8 \\
2010 & 2017 & 2010 & 2017 & 2010 & 2017 \\
\hline 25.4 & 22 & 35.6 & 34.1 & 20.2 & 20.6
\end{tabular}

\begin{tabular}{|c|c|c|c|c|c|}
\hline \multicolumn{2}{|c|}{39} & \multicolumn{2}{|c|}{26} & \multicolumn{2}{|c|}{15} \\
\hline \multicolumn{6}{|c|}{2018} \\
\hline \multicolumn{2}{|c|}{20} & \multicolumn{2}{|c|}{32.5} & \multicolumn{2}{|c|}{54.1} \\
\hline \multicolumn{6}{|c|}{2018} \\
\hline \multicolumn{2}{|c|}{12.6} & \multicolumn{2}{|c|}{21.5} & \multicolumn{2}{|c|}{48.8} \\
\hline 2009 & 2019 & 2009 & 2019 & 2009 & 2019 \\
\hline 34.3 & 81.2 & 29.3 & 67.8 & 68.3 & 85.8 \\
\hline 2015 & 2018 & 2015 & 2018 & 2015 & 2018 \\
\hline 2.8 & 1.3 & 2.4 & 1.6 & 1.8 & 1.1 \\
\hline 2010 & 2019 & 2010 & 2019 & 2010 & 2019 \\
\hline 18.2 & 17.4 & 18.1 & 18 & 15.7 & 13.9 \\
\hline \multicolumn{6}{|c|}{$2000-16$} \\
\hline & & & & & \\
\hline
\end{tabular}

\begin{tabular}{cccccc}
\multicolumn{2}{c}{ Costa Rica } & \multicolumn{2}{c}{ ALC $^{2}$} & \multicolumn{2}{c}{ OCDE $^{3}$} \\
\hline 2009 & 2019 & 2009 & 2019 & 2009 & 2019 \\
\hline 38.7 & 48.3 & 29.3 & 26.7 & 72.2 & 70.7 \\
2009 & 2019 & 2009 & 2019 & 2009 & 2019 \\
\hline 44.3 & 17.6 & 8.7 & 8.3 & 19.5 & 17.9 \\
2009 & 2017 & 2009 & 2017 & 2009 & 2017 \\
\hline 0.5 & 0.4 & 0.4 & 0.4 & 2.4 & 2.5 \\
2009 & 2017 & 2009 & 2017 & 2009 & 2017 \\
\hline 3 & 3 & 726 & 521 & 173.44 & 141.358
\end{tabular}

\begin{tabular}{cccccc}
\multicolumn{2}{c}{ Costa Rica } & \multicolumn{2}{c}{ ALC $^{2}$} & \multicolumn{2}{c}{ OCDE $^{3}$} \\
\hline 2009 & 2020 & 2009 & 2020 & 2009 & 2020 \\
\hline 78.9 & 85.1 & 72 & 72.4 & 67.5 & 58.8 \\
2009 & 2018 & 2009 & 2018 & 2009 & 2008 \\
\hline 62.4 & 83.4 & 64.8 & 82 & N. d. & N. d. \\
2009 & 2020 & 2009 & 2020 & 2009 & 2020 \\
\hline 72.9 & 64.8 & 56.9 & 48.2 & 69.2 & 70.7 \\
2009 & 2020 & 2009 & 2020 & 2009 & 2020 \\
\hline 84.5 & 84.2 & 74.8 & 76 & 77.9 & 79.4 \\
2010 & 2016 & 2010 & 2016 & 2010 & 2016 \\
\hline 19 & 22.1 & 19.6 & 23.8 & . d. & d.
\end{tabular}

\begin{tabular}{cccccc}
\hline 19 & 22.1 & 19.6 & 23.8 & N. d. & N. d. \\
& & 2021 & & \\
\hline & 5 & 82 & 36 & \\
\hline 5.7 & $2009-18$ & N. d. \\
\hline & 9.6 & & \\
\hline 27.9 & 2019 & 16.3
\end{tabular}

\begin{tabular}{cccccc}
\multicolumn{2}{c}{ Costa Rica } & \multicolumn{2}{c}{ ALC $^{2}$} & \multicolumn{2}{c}{ OCDE $^{3}$} \\
\hline 2009 & 2019 & 2009 & 2019 & 2009 & 2019 \\
\hline 22.1 & 23.6 & 20.6 & 22.9 & 31.6 & 33.8 \\
2009 & 2019 & 2009 & 2019 & 2009 & 2019 \\
\hline 21.3 & 18.5 & 25.3 & 27.7 & 19.8 & 20.7 \\
2009 & 2018 & 2009 & 2018 & 2009 & 2018 \\
\hline 12.1 & 12.2 & 11.3 & 11.4 & 21 & 19.7
\end{tabular}




\section{REPÚBLICA DOMINICANA}

\section{Repercusiones socioeconómicas de la pandemia de coronavirus (COVID-19)}

La pandemia de COVID-19 ha impactado fuertemente la economía de la República Dominicana. El producto interno bruto (PIB) se contrajo en 2020 un 6.7\% con respecto al año anterior. La tasa de pobreza alcanzó el 21.8\% en 2020 de acuerdo con las últimas estimaciones internacionales comparables, 1.5 puntos porcentuales superior al año anterior, aunque inferior al promedio (30.9\%) de América Latina y el Caribe (ALC). El nivel de pobreza extrema se situaba en torno al 4.6\%, lo que supone un aumento de 0.3 puntos porcentuales con respecto a 2019 aunque inferior al de ALC (10.0\%). Entre marzo de 2020 y mayo de 2021, las escuelas han estado totalmente cerradas durante 33 semanas, frente a una media de 26 semanas en la región de ALC y 15 semanas en los países de la Organización para la Cooperación y el Desarrollo Económicos (OCDE). Los efectos negativos del cierre de escuelas en los niños y sus familias se han compensado parcialmente con el acceso a un aprendizaje en línea efectivo. La República Dominicana registra una de las coberturas de aprendizaje en línea más altas de la región de ALC (el 46.7\% de las escuelas), cercana a la de la OCDE (54.1\%). Al comenzar la pandemia, la República Dominicana tenía un nivel de gasto público en atención sanitaria relativamente bajo, del 6.1\% del PIB, inferior al de ALC (6.8\%), aunque ha aumentado 0.5 puntos porcentuales en el último decenio. La percepción de la calidad de la atención en salud entre los ciudadanos es relativamente moderada. En 2020, el 52.2\% de las personas se declaraban satisfechas con los servicios de salud, un porcentaje ligeramente superior al de ALC (48.2\%), pero inferior al de la OCDE (70.7\%). Una de las mejoras más notables en los últimos años está relacionada con la percepción de la corrupción entre la población. En 2020, el 57.7\% de las personas consideraban que el gobierno era corrupto, más de 20 puntos porcentuales menos que un decenio antes, cuando se registró una de las cifras más elevadas de ALC (72.4\%).

\section{Iniciativas nacionales e internacionales de cooperación destinadas a construir un futuro mejor}

La República Dominicana aplicó políticas para afrontar la crisis y aliviar las pérdidas de salarios y la inseguridad alimentaria. Con respecto a la protección de los hogares, el gobierno nacional utilizó y amplió el régimen de protección social existente (Tarjeta de Solidaridad) para realizar transferencias monetarias a la población más vulnerable. Además, amplió y mejoró la calidad de la educación y la atención sanitaria y procuró conseguir una vivienda digna y adecuada para la población vulnerable. En cuanto a las empresas, la República Dominicana adoptó medidas para reforzar la capacidad de las microempresas y pequeñas y medianas empresas, las más afectadas por la crisis, manteniendo sus ingresos y su acceso al mercado.

De cara al futuro, la República Dominicana estableció el Plan Nacional Plurianual del Sector Público. Para ayudar a la recuperación, el gobierno pretende mejorar las condiciones de vida, especialmente entre la población más vulnerable afectada por la pandemia. Las iniciativas consisten, entre otras cosas, en garantizar la igualdad de género, fomentar la capacidad de producción de las industrias relacionadas con la agricultura, impulsar la oferta de bienes manufacturados con alto valor añadido y promover el turismo, todo ello en el marco de la transformación digital y el desarrollo sostenible.

Los proyectos de cooperación internacional del país dentro y fuera de la región están armonizados con las prioridades de la agenda nacional, que incluyen la recuperación posterior a la crisis y el desarrollo sostenible. Dentro de ALC, la República Dominicana participó en programas de cooperación con el Banco de Desarrollo de América Latina (CAF) para reducir las vulnerabilidades destapadas por la pandemia y minimizar los riesgos de los Estados del CARIFORUM (Fortalecimiento de Capacidades del Centro de Operaciones de Emergencia para hacer frente al COVID-19). Además, el país recibió donaciones de países de ALC, el Banco Centroamericano de Integración Económica, la Secretaría General Iberoamericana, el Banco Interamericano de Desarrollo, Costa Rica y Perú para responder a la crisis sanitaria. Fuera de la región de ALC, la República Dominicana participa en programas de cooperación internacional con otros países. Con respecto a las necesidades estructurales, los proyectos se centran en el refuerzo de la capacidad institucional del "Observatorio de Cambio Climático y Resiliencia", la facilitación del entendimiento mutuo entre la República Dominicana y Haití y la formación de redes integradas de servicios sanitarios. En el marco de la tercera fase (2020-2021) del programa de cooperación con la Unión Europea EUROsociAL+, se ha concedido apoyo al Ministerio de Trabajo y el Ministerio de Economía, Planificación y Desarrollo para diseñar políticas destinadas a proteger a los trabajadores informales, prestando especial atención a las repercusiones de la pandemia de COVID-19. 


\section{Socioambientales}

Pobreza extrema ${ }^{4}$

Pobreza ${ }^{5}$

Coeficiente de Gini ${ }^{6}$

Población total en hogares informales por quintil. $2018^{7}$

Gasto en salud ${ }^{8}$

Gasto en salud por cuenta propia ${ }^{9}$

Semanas de cierre total de las escuelas ${ }^{10}$

Aprendizaje en línea efectivo ${ }^{11}$

Aprendizaje en línea efectivo en escuelas de entornos desfavorecidos ${ }^{11}$

Proporción de usuarios de Internet ${ }^{12}$

Número de alumnos por ordenador ${ }^{13}$

Exposición a PM 2.514

$\%$ de cambio en el paisaje forestal intacto ${ }^{15}$

\section{Competitividad e innovación}

Productividad laboral16

Exportaciones de productos de alta tecnología ${ }^{17}$

Gasto en $1+D^{18}$

Patentes $\mathrm{TIC}^{19}$

\section{Percepción de los ciudadanos e instituciones}

Percepción de la corrupción en el gobierno entre los ciudadanos ${ }^{20}$

Percepción entre los ciudadanos de que el país está gobernado en interés de unos pocos ${ }^{2}$

Satisfacción con la atención sanitaria ${ }^{22}$

Satisfacción con la calidad del agua ${ }^{23}$

$\%$ de personas víctimas de delincuencia ${ }^{24}$

Puesto en la Clasificación Mundial de la Libertad de Prensa25

Cambio en la polarización política ${ }^{26}$

Índice de Instituciones Sociales y Género (SIGI)27

\section{Situación fiscal}

Total de ingresos tributarios ${ }^{28}$

Proporción del IVA en el total de ingresos ${ }^{29}$

Gasto social ${ }^{30}$

Las fuentes, las notas al pie y los detalles técnicos pueden consultarse al final de las notas por países.

\begin{tabular}{|c|c|c|c|c|c|}
\hline \multicolumn{6}{|c|}{ Indicadores clave - República Dominicana1 } \\
\hline \multicolumn{2}{|c|}{ República Dominicana } & \multicolumn{2}{|c|}{$\mathrm{ALC}^{2}$} & \multicolumn{2}{|c|}{$\mathrm{OCDE}^{3}$} \\
\hline 2019 & 2020 & 2019 & 2020 & 2019 & 2020 \\
\hline 4.3 & 4.6 & 8.1 & 10 & N.d. & N.d. \\
\hline 2019 & 2020 & 2019 & 2020 & 2019 & 2020 \\
\hline 20.3 & 21.8 & 26.8 & 30.9 & N. d. & N.d. \\
\hline 2009 & 2019 & 2009 & 2019 & 2009 & 2018 \\
\hline 0.49 & 0.43 & 0.5 & 0.46 & 0.31 & 0.31 \\
\hline $\begin{array}{l}20 \% \\
\text { más bajo }\end{array}$ & $\begin{array}{c}20 \% \\
\text { más alto }\end{array}$ & $\begin{array}{c}20 \% \\
\text { más bajo }\end{array}$ & $\begin{array}{c}20 \% \\
\text { más alto }\end{array}$ & $\begin{array}{c}20 \% \\
\text { más bajo }\end{array}$ & $\begin{array}{c}20 \% \\
\text { más alto }\end{array}$ \\
\hline N. d. & N.d. & 78 & 19.1 & N. d. & N.d. \\
\hline 2010 & 2017 & 2010 & 2017 & 2010 & 2017 \\
\hline 5.6 & 6.1 & 6.5 & 6.8 & 8.1 & 8.8 \\
\hline 2010 & 2017 & 2010 & 2017 & 2010 & 2017 \\
\hline 43.9 & 44.7 & 35.6 & 34.1 & 20.2 & 20.6 \\
\hline \multicolumn{6}{|c|}{$03 / 2020-05 / 2021$} \\
\hline \multirow{2}{*}{\multicolumn{2}{|c|}{33}} & \multicolumn{2}{|c|}{26} & \multicolumn{2}{|c|}{15} \\
\hline & & \multirow{2}{*}{\multicolumn{2}{|c|}{$\frac{2018}{32.5}$}} & & \\
\hline \multicolumn{2}{|c|}{46.7} & & & \multicolumn{2}{|c|}{54.1} \\
\hline \multirow{2}{*}{\multicolumn{2}{|c|}{33.4}} & \multicolumn{2}{|c|}{2018} & \\
\hline & & \multicolumn{2}{|c|}{21.5} & \multicolumn{2}{|c|}{48.8} \\
\hline 2009 & 2019 & 2009 & 2019 & 2009 & 2019 \\
\hline 27.7 & 74.8 & 29.3 & 67.8 & 68.3 & 85.8 \\
\hline 2015 & 2018 & 2015 & 2018 & 2015 & 2018 \\
\hline 3.2 & 1.4 & 2.4 & 1.6 & 1.8 & 1.1 \\
\hline 2010 & 2019 & 2010 & 2019 & 2010 & 2019 \\
\hline 17.1 & 18.1 & 18.1 & 18 & 15.7 & 13.9 \\
\hline \multicolumn{6}{|c|}{$2000-16$} \\
\hline \multicolumn{2}{|c|}{-29.0} & \multicolumn{2}{|c|}{-8.8} & \multicolumn{2}{|c|}{-6.3} \\
\hline \multicolumn{2}{|c|}{ República Dominicana } & \multicolumn{2}{|c|}{$\mathrm{ALC}^{2}$} & \multicolumn{2}{|c|}{$\mathrm{OCDE}^{3}$} \\
\hline 2009 & 2019 & 2009 & 2019 & 2009 & 2019 \\
\hline 32.3 & 40.9 & 29.3 & 26.7 & 72.2 & 70.7 \\
\hline 2009 & 2019 & 2009 & 2019 & 2009 & 2019 \\
\hline 2.5 & 7 & 8.7 & 8.3 & 19.5 & 17.9 \\
\hline 2009 & 2017 & 2009 & 2017 & 2009 & 2017 \\
\hline N. d. & N. d. & N. d. & N. d. & N. d. & N.d. \\
\hline 2009 & 2017 & 2009 & 2017 & 2009 & 2017 \\
\hline N. d. & N.d. & N. d. & N.d. & N. d. & N.d. \\
\hline
\end{tabular}

\begin{tabular}{|c|c|c|c|c|c|}
\hline \multicolumn{2}{|c|}{ República Dominicana } & \multicolumn{2}{|c|}{$\mathrm{ALC}^{2}$} & \multicolumn{2}{|c|}{$\mathrm{OCDE}^{3}$} \\
\hline 2009 & 2020 & 2009 & 2020 & 2009 & 2020 \\
\hline 78 & 57.7 & 72 & 72.4 & 67.5 & 58.8 \\
\hline 2009 & 2018 & 2009 & 2018 & 2009 & 2018 \\
\hline 89.8 & 85.1 & 64.8 & 82 & N. d. & N. d. \\
\hline 2009 & 2020 & 2009 & 2020 & 2009 & 2020 \\
\hline 55.3 & 52.2 & 56.9 & 48.2 & 69.2 & 70.7 \\
\hline 2009 & 2020 & 2009 & 2020 & 2009 & 2020 \\
\hline 73 & 77.2 & 74.8 & 76 & 77.9 & 79.4 \\
\hline 2010 & 2016 & 2010 & 2016 & 2010 & 2016 \\
\hline 16.6 & 26.2 & 19.6 & 23.8 & N. d. & N. d. \\
\hline \multicolumn{6}{|c|}{2021} \\
\hline \multirow{2}{*}{\multicolumn{2}{|c|}{50}} & \multicolumn{2}{|c|}{82} & \multicolumn{2}{|c|}{36} \\
\hline & & \multicolumn{2}{|c|}{ 2009-18 } & \\
\hline \multirow{2}{*}{\multicolumn{2}{|c|}{48}} & \multicolumn{2}{|c|}{9.6} & \multicolumn{2}{|c|}{ N. d. } \\
\hline & & \multirow{2}{*}{\multicolumn{2}{|c|}{$\frac{2019}{25.6}$}} & & \\
\hline \multicolumn{2}{|c|}{18.2} & & & \multicolumn{2}{|c|}{16.3} \\
\hline \multicolumn{2}{|c|}{ República Dominicana } & \multicolumn{2}{|c|}{$\mathrm{ALC}^{2}$} & \multicolumn{2}{|c|}{$\mathrm{OCDE}^{3}$} \\
\hline 2009 & 2019 & 2009 & 2019 & 2009 & 2019 \\
\hline 12.8 & 13.5 & 20.6 & 22.9 & 31.6 & 33.8 \\
\hline 2009 & 2019 & 2009 & 2019 & 2009 & 2019 \\
\hline 31.3 & 34.7 & 25.3 & 27.7 & 19.8 & 20.7 \\
\hline 2009 & 2018 & 2009 & 2018 & 2009 & 2018 \\
\hline 6.7 & & 2000 & 11.4 & 21 & 20,0 \\
\hline
\end{tabular}




\section{ECUADOR}

\section{Repercusiones socioeconómicas de la pandemia de coronavirus (COVID-19)}

La economía de Ecuador se ha visto muy afectada por la pandemia de COVID-19. En 2020, el producto interno bruto (PIB) se contrajo más de un $7 \%$ anual con respecto al año anterior y, de acuerdo con las últimas estimaciones internacionales comparables, la tasa de pobreza alcanzó el 33.5\%, casi diez puntos porcentuales más que en 2019. A su vez, la tasa de pobreza extrema fue del $12.8 \%$, lo que supone un aumento de más de cinco puntos porcentuales con respecto al año anterior. Estas cifras están entre las más altas de América Latina y el Caribe (ALC), donde las tasas de pobreza y pobreza extrema en 2020 eran, en promedio, del $30.9 \%$ y el 10.0\%, respectivamente. Entre marzo de 2020 y mayo de 2021, las escuelas estuvieron totalmente cerradas durante 39 semanas, más que la media de la región de ALC, de 26 semanas, y el promedio de la Organización para la Cooperación y el Desarrollo Económicos (OCDE), de 15 semanas. Teniendo en cuenta la baja tasa global de uso de Internet (un 54.1\%), el cierre de las escuelas tuvo una repercusión negativa en la educación de los niños y en las familias. Ecuador entró en la pandemia con un creciente gasto público en salud. En el último decenio, el gasto aumentó en 1.2 puntos porcentuales del PIB y había alcanzado el $8.3 \%$ del PIB antes de la crisis. Esta cifra es superior a la de la región de ALC (6.8\%), pero inferior a la de la OCDE (8.8\%). Sin embargo, la percepción de la calidad de los servicios sanitarios entre los ciudadanos es negativa. En 2020, solo el $44.3 \%$ de las personas se declararon satisfechas con la atención sanitaria, frente al 48.2\% en la región de ALC y el 70.7\% en la OCDE. En 2020, el $86.0 \%$ de los ciudadanos creían que el gobierno era corrupto. Este porcentaje es alto en comparación con la región de ALC (72.4\%) y la OCDE (58.8\%).

\section{Políticas nacionales e iniciativas internacionales de cooperación destinadas a construir un futuro mejor}

La respuesta de Ecuador a la crisis del COVID-19 comenzó con un anuncio inicial en mayo de 2019 de un paquete integral destinado a recortar 4000 millones de USD del presupuesto nacional. Entre las medidas figuraban la reducción de la jornada laboral de la mayoría de los trabajadores, el cierre o la fusión de 10 entidades públicas, el cierre de 11 embajadas y la reestructuración de la deuda pública de Ecuador. En junio entró en vigor una nueva Ley de Apoyo Humanitario, cuya principal novedad de la ley es que permite reducir las horas de trabajo y los salarios hasta un $50 \%$ y un $45 \%$, respectivamente, durante dos años seguidos. Para ayudar a las empresas a hacer frente a la crisis de liquidez, se pospusieron los pagos a la seguridad social durante 90 días y se aplazaron los impuestos para los sectores del turismo y la exportación, así como para las microempresas y pequeñas y medianas empresas (mipymes), entre abril y junio. Se promulgó un decreto ejecutivo que exigía a unas 1200 empresas que registraron beneficios en el primer semestre de 2020 el pago del impuesto sobre la renta con al menos cinco meses de antelación. La autoridad tributaria del país calculó que con esta medida se recaudarían 280 millones de USD, que se distribuirán a 125000 mipymes afectadas por la pandemia. Para sostener la renta de los hogares, el gobierno estableció una moratoria del corte de suministros por falta de pago y se amplió un programa que entregaba 60 USD durante dos meses a 950000 familias con ingresos inferiores a 400 USD al mes para llegar a 2 millones de personas en el marco del paquete.

Respecto a las iniciativas de cooperación internacional para afrontar la crisis del COVID-19, en septiembre de 2020 se aprobó un acuerdo para un nuevo programa con el Fondo Monetario Internacional bajo la modalidad de Servicio Ampliado del Fondo, que prevé un total de 6500 millones de USD, de los cuales en 2020 se desembolsaron 4000 millones de USD. El programa tiene como objetivos principales proteger las condiciones de vida de las personas, expandir la cobertura de la protección social y garantizar la estabilidad macroeconómica, y viene asociado con la aplicación de un paquete de reforma tributaria y una ordenación del gasto público. A su vez, han comprometido recursos el Banco Mundial, el Banco Interamericano de Desarrollo y el CAF-Banco de Desarrollo de América Latina, alcanzando 2320 millones de USD a finales de 2020. En cuanto a la Unión Europa, la última fase (2020-2021) del programa EUROsociAL+ apoyó al consejo judicial a garantizar el acceso a los servicios a las víctimas de violencia de género y lanzó un programa piloto de mesas redondas nacionales de Equipo Europa con el fin de debatir la mejor forma de aunar esfuerzos y proporcionar un apoyo coherente de la UE a la gestión de la crisis del COVID-19 y la recuperación del país. 


\section{Socioambientales}

Pobreza extrema ${ }^{4}$

Pobreza $^{5}$

Coeficiente de Gini ${ }^{6}$

Población total en hogares informales por quintil. $2018^{7}$

Gasto en salud ${ }^{8}$

Gasto en salud por cuenta propia ${ }^{9}$

Semanas de cierre total de las escuelas ${ }^{10}$

Aprendizaje en línea efectivo ${ }^{11}$

Aprendizaje en línea efectivo en escuelas de entornos desfavorecidos ${ }^{11}$

Proporción de usuarios de Internet ${ }^{12}$

Número de alumnos por ordenador ${ }^{13}$

Exposición a PM $2.5^{14}$

$\%$ de cambio en el paisaje forestal intacto $0^{15}$

\section{Competitividad e innovación}

Productividad laboral ${ }^{16}$

Exportaciones de productos de alta tecnología ${ }^{17}$

Gasto en $I+D^{18}$

Patentes TIC ${ }^{19}$

\section{Percepción de los ciudadanos e instituciones}

Percepción de la corrupción en el gobierno entre los ciudadanos ${ }^{20}$

Percepción entre los ciudadanos de que el país

está gobernado en interés de unos pocos ${ }^{2}$

Satisfacción con la atención sanitaria ${ }^{22}$

Satisfacción con la calidad del agua ${ }^{23}$

$\%$ de personas víctimas de delincuencia ${ }^{24}$

Puesto en la Clasificación Mundial de la Libertad de Prensa ${ }^{25}$

Cambio en la polarización política ${ }^{26}$

Índice de Instituciones Sociales y Género (SIGI) ${ }^{27}$

\section{Situación fiscal}

Total de ingresos tributarios ${ }^{28}$

Proporción del IVA en el total de ingresos ${ }^{29}$

Gasto social ${ }^{30}$

Las fuentes, las notas al pie y los detalles técnicos pueden consultarse al final de las notas por países.

\begin{tabular}{cccccc}
\multicolumn{7}{c}{ Indicadores clave - Ecuador $^{1}$} \\
\hline \multicolumn{2}{c}{ Ecuador } & \multicolumn{2}{c}{ ALC $^{2}$} & \multicolumn{2}{c}{ OCDE $^{3}$} \\
\hline 2019 & 2020 & 2019 & 2020 & 2019 & 2020 \\
\hline 7.6 & 12.8 & 8.1 & 10 & N. d. & N. d. \\
2019 & 2020 & 2019 & 2020 & 2019 & 2020 \\
\hline 25.7 & 33.5 & 26.8 & 30.9 & N. d. & N. d. \\
2009 & 2019 & 2009 & 2019 & 2009 & 2018 \\
\hline 0.48 & 0.46 & 0.5 & 0.46 & 0.31 & 0.31 \\
$20 \%$ & $20 \%$ & $20 \%$ & $20 \%$ & $20 \%$ & $20 \%$ \\
más bajo & más alto & más bajo & más alto & más bajo & más alto \\
\hline N. d. & N. d. & 78 & 19.1 & N. d. & N. d. \\
2010 & 2017 & 2010 & 2017 & 2010 & 2017 \\
\hline 7.1 & 8.3 & 6.5 & 6.8 & 8.1 & 8.8 \\
2010 & 2017 & 2010 & 2017 & 2010 & 2017 \\
\hline 47.5 & 39.4 & 35.6 & 34.1 & 20.2 & 20.6
\end{tabular}

\begin{tabular}{|c|c|c|c|c|c|}
\hline \multicolumn{2}{|c|}{39} & \multicolumn{2}{|c|}{26} & \multicolumn{2}{|c|}{15} \\
\hline \multicolumn{6}{|c|}{2018} \\
\hline \multicolumn{2}{|c|}{ N. d. } & \multicolumn{2}{|c|}{32.5} & \multicolumn{2}{|c|}{54.1} \\
\hline \multicolumn{6}{|c|}{2018} \\
\hline \multicolumn{2}{|c|}{ N. d. } & \multicolumn{2}{|c|}{21.5} & \multicolumn{2}{|c|}{48.8} \\
\hline 2009 & 2019 & 2009 & 2019 & 2009 & 2019 \\
\hline 24.6 & 54.1 & 29.3 & 67.8 & 68.3 & 85.8 \\
\hline 2009 & 2019 & 2009 & 2019 & 2009 & 2019 \\
\hline N. d. & N. d. & 2.4 & 1.6 & 1.8 & 1.1 \\
\hline 2010 & 2019 & 2010 & 2019 & 2010 & 2019 \\
\hline 22.1 & 20.6 & 18.1 & 18 & 15.7 & 13.9 \\
\hline \multicolumn{6}{|c|}{$2000-16$} \\
\hline & & & & & \\
\hline
\end{tabular}

\begin{tabular}{cccccc}
\multicolumn{2}{c}{ Ecuador } & \multicolumn{2}{c}{ ALC $^{2}$} & \multicolumn{2}{c}{ OCDE $^{3}$} \\
\hline 2009 & 2019 & 2009 & 2019 & 2009 & 2019 \\
\hline 25.4 & 26.1 & 29.3 & 26.7 & 72.2 & 70.7 \\
2009 & 2019 & 2009 & 2019 & 2009 & 2019 \\
\hline 4.6 & 5.5 & 8.7 & 8.3 & 19.5 & 17.9 \\
2009 & 2017 & 2009 & 2017 & 2009 & 2017 \\
\hline 0.4 & 0.4 & 0.4 & 0.4 & 2.4 & 2.5 \\
2009 & 2017 & 2009 & 2017 & 2009 & 2017 \\
\hline 3 & 2 & 726 & 521 & 173.44 & 141.358
\end{tabular}

\begin{tabular}{cccccc}
\multicolumn{2}{c}{ Ecuador } & \multicolumn{2}{c}{ ALC $^{2}$} & \multicolumn{2}{c}{ OCDE $^{3}$} \\
\hline 2009 & 2020 & 2009 & 2020 & 2009 & 2020 \\
\hline 80.3 & 86 & 72 & 72.4 & 67.5 & 58.8 \\
2009 & 2018 & 2009 & 2018 & N. d. & N. d. \\
\hline 58 & 82.8 & 64.8 & 82 & N. a. & N. d. \\
2009 & 2020 & 2009 & 2020 & 2009 & 2020 \\
\hline 48.5 & 44.3 & 56.9 & 48.2 & 69.2 & 70.7 \\
2009 & 2020 & 2009 & 2020 & 2009 & 2020 \\
\hline 63.7 & 78.6 & 74.8 & 76 & 77.9 & 79.4 \\
2010 & 2016 & 2010 & 2016 & N. d. & N. d. \\
\hline 29.1 & 30.6 & 19.6 & 23.8 & N. d. & N. d. \\
\hline
\end{tabular}

\begin{tabular}{ccc}
\hline 96 & 82 & 36 \\
& $2009-18$ & \\
\hline 5.6 & 9.6 & N. d. \\
\hline 28.9 & 2019 & 16.3
\end{tabular}

\begin{tabular}{cccccc}
\multicolumn{2}{c}{ Ecuador } & \multicolumn{2}{c}{ ALC $^{2}$} & \multicolumn{2}{c}{ OCDE $^{3}$} \\
\hline 2009 & 2019 & 2009 & 2019 & 2009 & 2019 \\
\hline 15.7 & 20.1 & 20.6 & 22.9 & 31.6 & 33.8 \\
2009 & 2019 & 2009 & 2019 & 2009 & 2019 \\
\hline 33.8 & 30.3 & 25.3 & 27.7 & 19.8 & 20.7 \\
2009 & 2018 & 2009 & 2018 & 2009 & 2018 \\
\hline 8.1 & 9 & 11.3 & 11.4 & 21 & 19.7 \\
\hline
\end{tabular}

11.3

11.4 


\section{EL SALVADOR}

\section{Repercusiones socioeconómicas de la pandemia de coronavirus (COVID-19)}

La crisis golpeó duramente la economía de El Salvador. En 2020, el producto interno bruto (PIB) se contrajo un $7.9 \%$ anual, y de acuerdo con las últimas estimaciones internacionales comparables, la tasa de pobreza alcanzó el 36.4\%, una de las más altas de América Latina y el Caribe (ALC), cuyo promedio es del 30.9\%. La tasa de pobreza ha aumentado seis puntos porcentuales en un año, frente a un aumento de cuatro puntos porcentuales en ALC. La tasa de pobreza extrema alcanzó $8 \%$, lo que supone un aumento de 2.4 puntos porcentuales, frente a un $10.0 \%$, equivalente a un aumento de 1.9 puntos porcentuales, respectivamente, en ALC. El gasto público en salud antes de la crisis representaba el 7.2\% del PIB, un porcentaje ligeramente superior al 6.8\% de la región, pero inferior al 8.8\% correspondiente a los países de la Organización para la Cooperación y el Desarrollo Económicos (OCDE). Respecto a la percepción de calidad de los servicios sanitarios, en 2020 el 54.8\% de las personas se declararon satisfechas con la atención sanitaria (frente a un $48.2 \%$ en ALC), cifra 11 puntos porcentuales más baja que diez años atrás y una disminución mayor que en ALC (8.7 puntos porcentuales). Entre marzo de 2020 y mayo de 2021, las escuelas han estado totalmente cerradas durante 46 semanas, más que en ALC (26 semanas) y en la OCDE (15 semanas). En 2020, el 41.4\% de los salvadoreños consideraban que el gobierno era corrupto, un porcentaje menor que en ALC (72.4\%) y la OCDE (58.8\%).

\section{Iniciativas nacionales e internacionales de cooperación destinadas a construir un futuro mejor}

El Salvador ha adoptado medidas para atenuar el impacto de la crisis del COVID-19 en las personas, los trabajadores y las empresas más vulnerables. Con respecto a los hogares, desde el inicio de las medidas de confinamiento, el gobierno anunció un subsidio de 300 USD para más de 1 millón de familias, así como la entrega de paquetes de alimentos a los más vulnerables. Además, se permitió el aplazamiento temporal de los pagos de suministros, teléfono e Internet y la congelación de los pagos de hipotecas, préstamos y tarjetas de crédito. A fin de proteger a los trabajadores y empresas más afectados, establecieron un subsidio para la retención del empleo para empleados de microempresas y pequeñas y medianas empresas (mipymes), un programa de concesión de préstamos a empresas del sector formal y un programa para ayudar a financiar a propietarios de pequeñas empresas del sector informal. En cuanto a la recuperación, El Salvador se ha comprometido a adoptar un nuevo enfoque mediante la modernización tecnológica y la transparencia institucional para responder a los problemas estructurales agravados por la crisis. El gobierno propuso el Plan de Bienestar Económico y Social 2019-2024, una herramienta flexible con base empírica que permitirá al país trabajar en la Agenda 2030 de las Naciones Unidas. Además, entregaron 1.2 millones de ordenadores a estudiantes, se puso en marcha un plan para transformar el desarrollo territorial en zonas rurales y se estableció como prioridades la inclusión financiera y la transformación digital. En cuanto a los planes a largo plazo, pretenden construir un futuro mejor mediante la ejecución de políticas para aumentar la inversión privada y pública e impulsar la formalización y el crecimiento de las mipymes, centrándose en la innovación y la adopción de nuevas tecnologías.

Los proyectos de cooperación internacional dentro y fuera de ALC se centraron en aprovechar los conocimientos y los recursos regionales e internacionales para hacer frente a la crisis del COVID-19. Dentro de la región, los programas de cooperación de El Salvador incluyeron una alianza con Colombia para reforzar la capacidad de los hospitales salvadoreños para afrontar la pandemia y, a través del Sistema de la Integración Centroamericana, una donación al Ministerio de Salud de las herramientas necesarias para la detección del virus. Fuera de ALC, las iniciativas consistieron en la creación del primer hospital universitario del país, con el apoyo de Luxemburgo, y la construcción de un hospital especial dedicado a pacientes de COVID-19, con el apoyo de Marruecos. Además, participó en proyectos para reforzar la línea de atención telefónica a mujeres víctimas de la violencia (Iniciativa Spotlight) y en el intercambio de experiencias para el fortalecimiento y creación de programas de empleabilidad juvenil. Junto con la Unión Europea y organizaciones de mujeres salvadoreñas, desarrollaron el programa "Fortalecimiento de cooperativas agropecuarias y organizaciones de mujeres campesinas para la exigibilidad del Derecho Humano a la Alimentación y la soberanía alimentaria en El Salvador" (2021-2023) con el objetivo de mejorar la resiliencia y la sostenibilidad de los procesos de desarrollo agroproductivo en situación de vulnerabilidad tras la emergencia climática y sanitaria en el país. 


\section{Socioambientales}

Pobreza extrema ${ }^{4}$

Pobreza $^{5}$

Coeficiente de Gini ${ }^{6}$

Población total en hogares informales por quintil. $2018^{7}$

Gasto en salud ${ }^{8}$

Gasto en salud por cuenta propia ${ }^{9}$

Semanas de cierre total de las escuelas ${ }^{10}$

Aprendizaje en línea efectivo ${ }^{11}$

Aprendizaje en línea efectivo en escuelas de entornos desfavorecidos ${ }^{11}$

Proporción de usuarios de Internet ${ }^{12}$

Número de alumnos por ordenador ${ }^{13}$

Exposición a PM $2.5^{14}$

$\%$ de cambio en el paisaje forestal intacto $0^{15}$

\section{Competitividad e innovación}

Productividad laboral ${ }^{16}$

Exportaciones de productos de alta tecnología ${ }^{17}$

Gasto en $I+D^{18}$

Patentes TIC ${ }^{19}$

\section{Percepción de los ciudadanos e instituciones}

Percepción de la corrupción en el gobierno entre los ciudadanos ${ }^{20}$

Percepción entre los ciudadanos de que el país

está gobernado en interés de unos pocos ${ }^{2}$

Satisfacción con la atención sanitaria ${ }^{22}$

Satisfacción con la calidad del agua ${ }^{23}$

$\%$ de personas víctimas de delincuencia ${ }^{24}$

Puesto en la Clasificación Mundial de la Libertad de Prensa ${ }^{25}$

Cambio en la polarización política ${ }^{26}$

Índice de Instituciones Sociales y Género (SIGI) ${ }^{27}$

\section{Situación fiscal}

Total de ingresos tributarios ${ }^{28}$

Proporción del IVA en el total de ingresos ${ }^{29}$

Gasto social ${ }^{30}$

Las fuentes, las notas al pie y los detalles técnicos pueden consultarse al final de las notas por países.

\begin{tabular}{|c|c|c|c|c|c|}
\hline \multicolumn{6}{|c|}{ 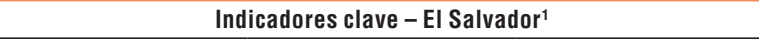 } \\
\hline \multicolumn{2}{|c|}{ El Salvador } & \multicolumn{2}{|c|}{ ALC $^{2}$} & \multicolumn{2}{|c|}{$\mathrm{OCDE}^{3}$} \\
\hline 2019 & 2020 & 2019 & 2020 & 2019 & 2020 \\
\hline 5.6 & 8 & 8.1 & 10 & N. d. & N. d. \\
\hline 2019 & 2020 & 2019 & 2020 & 2019 & 2020 \\
\hline 30.4 & 36.4 & 26.8 & 30.9 & N. d. & N. d. \\
\hline 2009 & 2019 & 2009 & 2019 & 2009 & 2018 \\
\hline 0.48 & 0.41 & 0.5 & 0.46 & 0.31 & 0.31 \\
\hline $\begin{array}{c}20 \% \\
\text { más bajo }\end{array}$ & $\begin{array}{c}20 \% \\
\text { más alto }\end{array}$ & $\begin{array}{c}20 \% \\
\text { más bajo }\end{array}$ & $\begin{array}{c}20 \% \\
\text { más alto }\end{array}$ & $\begin{array}{c}20 \% \\
\text { más bajo }\end{array}$ & $\begin{array}{c}20 \% \\
\text { más alto }\end{array}$ \\
\hline 90.8 & 24.4 & 78 & 19.1 & N. d. & N.d. \\
\hline 2010 & 2017 & 2010 & 2017 & 2010 & 2017 \\
\hline 8.2 & 7.2 & 6.5 & 6.8 & 8.1 & 8.8 \\
\hline 2010 & 2017 & 2010 & 2017 & 2010 & 2017 \\
\hline 33.6 & 29.2 & 35.6 & 34.1 & 20.2 & 20.6 \\
\hline \multicolumn{6}{|c|}{$03 / 2020-05 / 2021$} \\
\hline \multicolumn{2}{|c|}{46} & \multicolumn{2}{|c|}{26} & \multicolumn{2}{|c|}{15} \\
\hline \multicolumn{6}{|c|}{2018} \\
\hline \multicolumn{2}{|c|}{ N. d. } & \multicolumn{2}{|c|}{32.5} & \multicolumn{2}{|c|}{54.1} \\
\hline \multicolumn{6}{|c|}{2018} \\
\hline \multicolumn{2}{|c|}{ N. d. } & \multicolumn{2}{|c|}{21.5} & \multicolumn{2}{|c|}{48.8} \\
\hline 2009 & 2019 & 2009 & 2019 & 2009 & 2019 \\
\hline 12.1 & 50.5 & 29.3 & 67.8 & 68.3 & 85.8 \\
\hline 2015 & 2018 & 2015 & 2018 & 2015 & 2018 \\
\hline N. d. & N. d. & 2.4 & 1.6 & 1.8 & 1.1 \\
\hline 2010 & 2019 & 2010 & 2019 & 2010 & 2019 \\
\hline 24.3 & 22.3 & 18.1 & 18 & 15.7 & 13.9 \\
\hline \multicolumn{6}{|c|}{$2000-16$} \\
\hline & & & & & \\
\hline
\end{tabular}

\begin{tabular}{cccccc}
\multicolumn{2}{c}{ El Salvador } & \multicolumn{2}{c}{ ALC $^{2}$} & \multicolumn{2}{c}{ OCDE $^{3}$} \\
\hline 2009 & 2019 & 2009 & 2019 & 2009 & 2019 \\
\hline N. d. & N. d. & 29.3 & 26.7 & 72.2 & 70.7 \\
2009 & 2019 & 2009 & 2019 & 2009 & 2019 \\
\hline 6.5 & 5.1 & 8.7 & 8.3 & 19.5 & 17.9 \\
2009 & 2017 & 2009 & 2017 & 2009 & 2017 \\
\hline 0.1 & 0.2 & 0.4 & 0.4 & 2.4 & 2.5 \\
2009 & 2017 & 2009 & 2017 & 2009 & 2017 \\
\hline 1 & 0 & 726 & 521 & 173.44 & 141.358
\end{tabular}

\begin{tabular}{cccccc}
\multicolumn{2}{c}{ El Salvador } & \multicolumn{2}{c}{ ALC $^{2}$} & \multicolumn{2}{c}{ OCDE $^{3}$} \\
\hline 2009 & 2020 & 2009 & 2020 & 2009 & 2020 \\
\hline 66 & 41.4 & 72 & 72.4 & 67.5 & 58.8 \\
2009 & 2018 & 2009 & 2018 & 2009 & 2018 \\
\hline 46.1 & 89 & 64.8 & 82 & N. d. & N. d. \\
2009 & 2020 & 2009 & 2020 & 2009 & 2020 \\
\hline 65.8 & 54.8 & 56.9 & 48.2 & 69.2 & 70.7 \\
2009 & 2020 & 2009 & 2020 & 2009 & 2020 \\
\hline 80.5 & 85.8 & 74.8 & 76 & 77.9 & 79.4 \\
2010 & 2016 & 2010 & 2016 & 2010 & 2016 \\
\hline 24.2 & 23.1 & 19.6 & 23.8 & . d. & d.
\end{tabular}

\begin{tabular}{llllll}
24.2 & 23.1 & 19.6 & 23.8 & N.d. & N. d. \\
\hline
\end{tabular}

\begin{tabular}{ccc}
\hline 82 & 82 & 36 \\
& $2009-18$ & \\
\hline 8.5 & 9.6 & N. d. \\
\hline 22.9 & 2019 & 16.3
\end{tabular}

\begin{tabular}{cccccc}
\multicolumn{2}{c}{ El Salvador } & \multicolumn{2}{c}{ ALC $^{2}$} & \multicolumn{2}{c}{ OCDE $^{3}$} \\
\hline 2009 & 2019 & 2009 & 2019 & 2009 & 2019 \\
\hline 17.9 & 20.8 & 20.6 & 22.9 & 31.6 & 33.8 \\
2009 & 2019 & 2009 & 2019 & 2009 & 2019 \\
\hline 39.7 & 37.5 & 25.3 & 27.7 & 19.8 & 20.7 \\
2009 & 2018 & 2009 & 2018 & 2009 & 2018 \\
\hline 9.2 & 9 & 11.3 & 11.4 & 21 & 19.7
\end{tabular}

11.4 


\section{GUATEMALA}

\section{Repercusiones socioeconómicas de la pandemia de coronavirus (COVID-19)}

La crisis golpeó fuertemente la economía de Guatemala y contrajo el producto interno bruto (PIB) un 1.5\% anual. Esta recesión provocó un aumento de más de tres puntos porcentuales de la pobreza extrema, que alcanzó el $18.7 \%$ en 2020, mientras que la tasa de pobreza se mantuvo relativamente estable, en un $50.9 \%$, de acuerdo con las últimas estimaciones internacionales comparables. Previo a la crisis, el gasto público en salud era del $5.8 \%$ del PIB, porcentaje que se mantuvo constante a lo largo de un decenio, en comparación con los promedios del 6.8\% en la región de América Latina y el Caribe (ALC) y del 8.8\% en los países de la Organización para la Cooperación y el Desarrollo Económicos (OCDE). En 2020, el 56.0\% de los guatemaltecos se declaraban satisfechos con los servicios sanitarios, valor similar al de la región de ALC (48.2\%) y muy inferior al de la OCDE (70.7\%). La pandemia afectó en particular a la educación ya que, entre marzo de 2020 y mayo de 2021, las escuelas han estado totalmente cerradas durante 33 semanas, frente a 26 semanas en la región de ALC y 15 semanas en la OCDE. Los niños y sus familias sufrieron en consecuencia, debido a la interrupción de la educación y al aumento de la carga del cuidado infantil, sobre todo teniendo en cuenta que solo el $40.7 \%$ de la población tenía acceso a Internet en 2019.

\section{Iniciativas nacionales e internacionales de cooperación destinadas a construir un futuro mejor}

La respuesta del gobierno tuvo como objetivo apoyar a los hogares, los trabajadores y las empresas más afectadas durante la crisis. En mayo de 2020, el gobierno puso en marcha nuevos programas dirigidos a los grupos más golpeados, entre los que se destaca el Fondo de "Protección del Empleo", que efectuó un pago mínimo de 75 GTQ (quetzales guatemaltecos) por día para los trabajadores del sector formal a quienes se les suspendió temporalmente el contrato. Asimismo, se estableció un subsidio a la energía para ayudar a los hogares a lidiar con la contracción de los ingresos y se implementó "Bono Familiar" orientado al gasto de los hogares que consumen menos de $200 \mathrm{kWh}$ de energía. El nuevo programa social "Bono al Comercio Popular" se instituyó para ayudar a los trabajadores informales más vulnerables, permitiéndoles acceder a un bono único de 1000 GTQ. Asimismo, respecto a la mitigación de impactos en pobreza, se reforzó el Programa de "Aporte Económico al Adulto Mayor", un fondo creado en 2005, que en agosto del 2020, permitió a 100000 personas de 65 años o más que viven en la pobreza recibir un subsidio mensual de 400 GTQ. Siguiendo las nuevas disposiciones, los mayores tienen derecho a esta asistencia social de por vida. En términos más generales, como respuesta a la pandemia del COVID-19, las autoridades tributarias en Guatemala prorrogaron el plazo de presentación de determinadas declaraciones tributarias. Por ejemplo, la declaración del impuesto sobre la renta de 2019 y la correspondiente declaración del impuesto sobre el valor añadido mensual se aplazaron. Además, el proceso de inspección fiscal, las solicitudes de información y otros procedimientos se suspendieron hasta el 15 de abril de 2020. En el caso de las empresas, el gobierno instituyó el "Fondo de Crédito de Capital de Trabajo", que concede préstamos hasta un máximo de $250000 \mathrm{GTQ}$, especialmente a las pymes.

Los proyectos de cooperación internacional de Guatemala dentro y fuera de la región están armonizados para hacer frente a las dificultades a corto y largo plazo relacionadas con la crisis del COVID-19. El Consejo de Ministros de la Integración Social Centroamericana ordenó a la Secretaría de la Integración Social Centroamericana que desarrollase una respuesta articulada y preparase un Plan para la Recuperación, Reconstrucción Social y Resiliencia de Centroamérica y Guatemala. El plan contempla proyectos estratégicos organizados en tres ejes de intervención: i) protección social, ii) empleo y empleabilidad, y iii) asentamientos irregulares y desarrollo urbano sostenible. Estos proyectos pretenden generar las condiciones para una sociedad más resiliente, socialmente más justa y ambientalmente sostenible. El plan es también un ejemplo de que la cooperación internacional puede funcionar más allá de ALC, ya que se llevó a cabo con el apoyo de socios internacionales -el programa de cooperación EUROsociAL de la Unión Europea, en alianza con organismos especializados de las Naciones Unidas-. 


\section{Socioambientales}

Pobreza extrema ${ }^{4}$

Pobreza $^{5}$

Coeficiente de Gini ${ }^{6}$

Población total en hogares informales por quintil, $2018^{7}$

Gasto en salud ${ }^{8}$

Gasto en salud por cuenta propia ${ }^{9}$

Semanas de cierre total de las escuelas ${ }^{10}$

Aprendizaje en línea efectivo ${ }^{11}$

Aprendizaje en línea efectivo en escuelas de entornos desfavorecidos ${ }^{11}$

Proporción de usuarios de Internet ${ }^{12}$

Número de alumnos por ordenador ${ }^{13}$

Exposición a PM $2.5^{14}$

$\%$ de cambio en el paisaje forestal intacto $0^{15}$

\section{Competitividad e innovación}

Productividad laboral ${ }^{16}$

Exportaciones de productos de alta tecnología ${ }^{17}$

Gasto en $I+D^{18}$

Patentes TIC ${ }^{19}$

\section{Percepción de los ciudadanos e instituciones}

Percepción de la corrupción en el gobierno entre los ciudadanos ${ }^{20}$

Percepción entre los ciudadanos de que el país

está gobernado en interés de unos pocos ${ }^{2}$

Satisfacción con la atención sanitaria ${ }^{22}$

Satisfacción con la calidad del agua ${ }^{23}$

$\%$ de personas víctimas de delincuencia ${ }^{24}$

Puesto en la Clasificación Mundial de la Libertad de Prensa ${ }^{25}$

Cambio en la polarización política ${ }^{26}$

Índice de Instituciones Sociales y Género (SIGI) ${ }^{27}$

\section{Situación fiscal}

Total de ingresos tributarios ${ }^{28}$

Proporción del IVA en el total de ingresos ${ }^{29}$

Gasto social ${ }^{30}$

Las fuentes, las notas al pie y los detalles técnicos pueden consultarse al final de las notas por países.

\begin{tabular}{cccccc}
\multicolumn{6}{c}{ Indicadores clave - Guatemala } \\
\hline \multicolumn{2}{c}{ Guatemala } & \multicolumn{2}{c}{ ALC $^{2}$} & \multicolumn{2}{c}{ OCDE $^{3}$} \\
\hline 2019 & 2020 & 2019 & 2020 & 2019 & 2020 \\
\hline 15.4 & 18.7 & 8.1 & 10 & N. d. & N. d. \\
2019 & 2020 & 2019 & 2020 & 2019 & 2020 \\
\hline 50.5 & 50.9 & 26.8 & 30.9 & N. d. & N. d. \\
2009 & 2019 & 2009 & 2019 & 2009 & 2018 \\
\hline 0.56 & 0.53 & 0.5 & 0.46 & 0.31 & 0.31 \\
$20 \%$ & $20 \%$ & $20 \%$ & $20 \%$ & $20 \%$ & $20 \%$ \\
más bajo & más alto & más bajo & más alto & más bajo & más alto \\
\hline N. d. & N. d. & 78 & 19.1 & N. d. & N. d. \\
2010 & 2017 & 2010 & 2017 & 2010 & 2017 \\
\hline 6.1 & 5.8 & 6.5 & 6.8 & 8.1 & 8.8 \\
2010 & 2017 & 2010 & 2017 & 2010 & 2017 \\
\hline 59.6 & 54.1 & 35.6 & 34.1 & 20.2 & 20.6
\end{tabular}

\begin{tabular}{|c|c|c|c|c|c|}
\hline \multicolumn{2}{|c|}{33} & \multicolumn{2}{|c|}{26} & \multicolumn{2}{|c|}{15} \\
\hline \multicolumn{6}{|c|}{2018} \\
\hline \multicolumn{2}{|c|}{ N. d. } & \multicolumn{2}{|c|}{32.5} & \multicolumn{2}{|c|}{54.1} \\
\hline \multicolumn{6}{|c|}{2018} \\
\hline \multicolumn{2}{|c|}{ N. d. } & \multicolumn{2}{|c|}{21.5} & \multicolumn{2}{|c|}{48.8} \\
\hline 2009 & 2019 & 2009 & 2019 & 2009 & 2019 \\
\hline 9.3 & 44.4 & 29.3 & 67.8 & 68.3 & 85.8 \\
\hline 2015 & 2018 & 2015 & 2018 & 2015 & 2018 \\
\hline N. d. & N. d. & 2.4 & 1.6 & 1.8 & 1.1 \\
\hline 2010 & 2019 & 2010 & 2019 & 2010 & 2019 \\
\hline 29 & 27.8 & 18.1 & 18 & 15.7 & 13.9 \\
\hline \multicolumn{6}{|c|}{$2000-16$} \\
\hline & & & & & \\
\hline
\end{tabular}

\begin{tabular}{cccccc}
\multicolumn{2}{c}{ Guatemala } & \multicolumn{2}{c}{ ALC $^{2}$} & \multicolumn{2}{c}{ OCDE $^{3}$} \\
\hline 2009 & 2019 & 2009 & 2019 & 2009 & 2019 \\
\hline 21.8 & 22.2 & 29.3 & 26.7 & 72.2 & 70.7 \\
2009 & 2019 & 2009 & 2019 & 2009 & 2019 \\
\hline 4.8 & 4.9 & 8.7 & 8.3 & 19.5 & 17.9 \\
2009 & 2017 & 2009 & 2017 & 2009 & 2017 \\
\hline 0.1 & 0 & 0.4 & 0.4 & 2.4 & 2.5 \\
2009 & 2017 & 2009 & 2017 & 2009 & 2017 \\
\hline 1.3 & 2 & 726 & 521 & 173.44 & 141.358
\end{tabular}

\begin{tabular}{|c|c|c|c|c|c|}
\hline \multicolumn{2}{|c|}{ Guatemala } & \multicolumn{2}{|c|}{$\mathrm{ALC}^{2}$} & \multicolumn{2}{|c|}{$\mathrm{OCDE}^{3}$} \\
\hline 2009 & 2020 & 2009 & 2020 & 2009 & 2020 \\
\hline 88.1 & 77.9 & 72 & 72.4 & 67.5 & 58.8 \\
\hline 2009 & 2018 & 2009 & 2018 & 2009 & 2018 \\
\hline 75.3 & 76.6 & 64.8 & 82 & N. d. & N. d. \\
\hline 2009 & 2020 & 2009 & 2020 & 2009 & 2020 \\
\hline 66 & 56 & 56.9 & 48.2 & 69.2 & 70.7 \\
\hline 2009 & 2020 & 2009 & 2020 & 2009 & 2020 \\
\hline 78.8 & 84.6 & 74.8 & 76 & 77.9 & 79.4 \\
\hline 2010 & 2016 & 2010 & 2016 & 2010 & 2016 \\
\hline 23.3 & 23.8 & 19.6 & 23.8 & N. d. & N. d. \\
\hline \multicolumn{6}{|c|}{2021} \\
\hline \multirow{2}{*}{\multicolumn{2}{|c|}{116}} & \multicolumn{2}{|c|}{82} & \multicolumn{2}{|c|}{36} \\
\hline & & \multicolumn{2}{|c|}{ 2009-18 } & & \\
\hline & & & & \multicolumn{2}{|c|}{ N. d. } \\
\hline \multicolumn{6}{|c|}{2019} \\
\hline & & & & & \\
\hline
\end{tabular}

\begin{tabular}{cccccc}
\multicolumn{2}{c}{ Guatemala } & \multicolumn{2}{c}{ ALC $^{2}$} & \multicolumn{2}{c}{ OCDE $^{3}$} \\
\hline 2009 & 2019 & 2009 & 2019 & 2009 & 2019 \\
\hline 12.3 & 13.1 & 20.6 & 22.9 & 31.6 & 33.8 \\
2009 & 2019 & 2009 & 2019 & 2009 & 2019 \\
\hline 39.5 & 38.8 & 25.3 & 27.7 & 19.8 & 20.7 \\
2009 & 2018 & 2009 & 2018 & 2009 & 2018 \\
\hline 8.1 & 7 & 11.3 & 11.4 & 21 & 19.7 \\
\hline
\end{tabular}




\section{MÉXICO}

\section{Repercusiones socioeconómicas de la pandemia de coronavirus (COVID-19)}

México se ha visto muy afectado por la pandemia de COVID-19. En 2020, el producto interno bruto (PIB) se contrajo más de un $8 \%$ y empeoró las condiciones de ingresos de las poblaciones más desfavorecidas, aumentando la pobreza en nueve puntos porcentuales y la pobreza extrema en casi ocho puntos porcentuales, de acuerdo con las últimas estimaciones internaciones comparables. La desigualdad de ingresos ya era elevada antes de la pandemia, con alrededor del 0.48, al igual que el 0.46 de la región de América Latina y el Caribe (ALC), y se había mantenido estable en el último decenio. Entre marzo de 2020 y mayo de 2021, las escuelas han estado totalmente cerradas durante 53 semanas, frente a una media de 26 en la región de ALC y de 15 semanas en los países de la Organización para la Cooperación y el Desarrollo Económicos (OCDE). El aprendizaje en línea efectivo solo estuvo presente en el 33.8\% de las escuelas, una cifra que se acerca a la de la región de ALC (32.5\%), pero muy inferior a la de la OCDE (54.1\%).

El gasto público en salud se redujo 0.5 puntos porcentuales en el último decenio. Antes de la pandemia, en 2017, dicho gasto representaba el 5.5\% del PIB, un porcentaje inferior al de ALC (6.8\%) y la OCDE (8.8\%). De acuerdo con los datos de Gallup, el 50.5\% de las personas estaban satisfechas con la atención sanitaria pública en 2020, casi 12 puntos porcentuales menos que en 2009. Esta cifra supera ligeramente al promedio de ALC (48.2\%) pero es inferior al promedio de la OCDE, (70.7\%). En 2018, último año sobre el que se dispone de datos, más del $90 \%$ de los mexicanos creían que su país estaba gobernado en interés de unos pocos poderosos, uno de los porcentajes más elevados de ALC (82\%).

\section{Iniciativas nacionales e internacionales de cooperación destinadas a construir un futuro mejor.}

Previo a la crisis del COVID-19, México ya se centraba en políticas de bienestar destinadas a desarrollar un modelo universal de derechos sociales. Aunque se destacan los programas de transferencias monetarias condicionadas, muchas familias pobres siguen sin beneficiarse de asistencia social. El 1 de mayo de 2020, el gobierno emprendió una reforma constitucional que amplió los programas sociales para afrontar las consecuencias de la crisis. Estas medidas de alivio llegaron principalmente en forma de transferencias monetarias, incluyendo el pago de una pensión bimensual para las personas mayores (Programa Pensión para el Bienestar de las Personas Adultas Mayores) y las personas con discapacidad (Programa Pensión para el Bienestar de las Personas con Discapacidad Permanente). En cuanto al sector privado, se facilitaron préstamos de bajo costo y aplazamientos de pagos a las pequeñas y medianas empresas de los sectores formal e informal. De cara al futuro, México tiene como objetivo superar los obstáculos que inhiben actualmente la inclusión social, avanzando en la lucha contra la pobreza y la desigualdad. Las autoridades se han comprometido a ejecutar intervenciones integrales destinadas a garantizar los derechos sociales ya establecidos en la Constitución, una transformación estructural y creación de oportunidades para el desarrollo del capital humano y la productividad.

La pandemia de COVID-19 fue el elemento central de los proyectos de cooperación internacional de México tanto dentro como fuera de ALC. Se priorizaron las necesidades inmediatas, centrándose especialmente en la asistencia a países vecinos de la región, y a la medición del impacto socioeconómico de la crisis para aplicar mejores políticas a mediano y largo plazo. Dentro de ALC, los esfuerzos de cooperación se caracterizaron por el apoyo y la asistencia a los países vecinos mediante donaciones de respiradores a países de Centroamérica y el Caribe y, en colaboración con Argentina, la producción y distribución de la vacuna de AstraZeneca, así como cooperación para facilitar la administración y la aprobación de la vacuna Sputnik V. México también participó en una iniciativa para la adaptación y la resiliencia al cambio climático en el Caribe (México-Comunidad del Caribe-Organización para la Alimentación y la Agricultura), una iniciativa para el refuerzo de la seguridad alimentaria (Mesoamérica Sin Hambre) y la implantación de una plataforma para reforzar el sector turístico mediante formación virtual con los países de la Alianza del Pacífico. Fuera de la región, en el marco del programa de cooperación con la Unión Europea EUROsociAL+, se ha recibido apoyo para promover el empleo de las poblaciones vulnerables y políticas destinadas a proteger a los niños y adolescentes migrantes en el marco de la estrategia binacional de desarrollo territorial fronterizo México-Guatemala. 


\section{Socioambientales}

Pobreza extrema ${ }^{4}$

Pobreza $^{5}$

Coeficiente de Gini ${ }^{6}$

Población total en hogares informales por quintil. $2018^{7}$

Gasto en salud ${ }^{8}$

Gasto en salud por cuenta propia ${ }^{9}$

Semanas de cierre total de las escuelas ${ }^{10}$

Aprendizaje en línea efectivo ${ }^{11}$

Aprendizaje en línea efectivo en escuelas de entornos desfavorecidos ${ }^{11}$

Proporción de usuarios de Internet ${ }^{12}$

Número de alumnos por ordenador ${ }^{13}$

Exposición a PM $2.5^{14}$

$\%$ de cambio en el paisaje forestal intacto $0^{15}$

\section{Competitividad e innovación}

Productividad laboral ${ }^{16}$

Exportaciones de productos de alta tecnología ${ }^{17}$

Gasto en $I+D^{18}$

Patentes TIC $^{19}$

\section{Percepción de los ciudadanos e instituciones}

Percepción de la corrupción en el gobierno entre los ciudadanos ${ }^{20}$

Percepción entre los ciudadanos de que el país

está gobernado en interés de unos pocos ${ }^{2}$

Satisfacción con la atención sanitaria ${ }^{22}$

Satisfacción con la calidad del agua ${ }^{23}$

$\%$ de personas víctimas de delincuencia ${ }^{24}$

Puesto en la Clasificación Mundial de la Libertad de Prensa ${ }^{25}$

Cambio en la polarización política ${ }^{26}$

Índice de Instituciones Sociales y Género (SIGI) ${ }^{27}$

\section{Situación fiscal}

Total de ingresos tributarios ${ }^{28}$

Proporción del IVA en el total de ingresos ${ }^{29}$

Gasto social ${ }^{30}$

Las fuentes, las notas al pie y los detalles técnicos pueden consultarse al final de las notas por países.

\begin{tabular}{cccccc}
\multicolumn{7}{c}{ Indicadores clave - México $^{1}$} \\
\hline \multicolumn{2}{c}{ México } & \multicolumn{2}{c}{ ALC $^{2}$} & \multicolumn{2}{c}{ OCDE $^{3}$} \\
\hline 2019 & 2020 & 2019 & 2020 & 2019 & 2020 \\
\hline 10.6 & 18.3 & 8.1 & 10 & N. d. & N. d. \\
2019 & 2020 & 2019 & 2020 & 2019 & 2020 \\
\hline 41.5 & 50.6 & 26.8 & 30.9 & N. d. & N. d. \\
2009 & 2019 & 2009 & 2019 & 2009 & 2018 \\
\hline 0.51 & 0.47 & 0.5 & 0.46 & 0.31 & 0.31 \\
$20 \%$ & $20 \%$ & $20 \%$ & $20 \%$ & $20 \%$ & $20 \%$ \\
más bajo & más alto & más bajo & más alto & más bajo & más alto \\
\hline 70.9 & 17.4 & 78 & 19.1 & N. d. & N. d. \\
2010 & 2017 & 2010 & 2017 & 2010 & 2017 \\
\hline 6 & 5.5 & 6.5 & 6.8 & 8.1 & 8.8 \\
2010 & 2017 & 2010 & 2017 & 2010 & 2017 \\
\hline 45.7 & 41.3 & 35.6 & 34.1 & 20.2 & 20.6
\end{tabular}

\begin{tabular}{|c|c|c|c|c|c|}
\hline \multicolumn{2}{|c|}{53} & \multicolumn{2}{|c|}{26} & \multicolumn{2}{|c|}{15} \\
\hline \multicolumn{6}{|c|}{2018} \\
\hline \multicolumn{2}{|c|}{33.8} & \multicolumn{2}{|c|}{32.5} & \multicolumn{2}{|c|}{54.1} \\
\hline \multicolumn{6}{|c|}{2018} \\
\hline \multicolumn{2}{|c|}{12.7} & \multicolumn{2}{|c|}{21.5} & \multicolumn{2}{|c|}{48.8} \\
\hline 2009 & 2019 & 2009 & 2019 & 2009 & 2019 \\
\hline 26.3 & 70.1 & 29.3 & 67.8 & 68.3 & 85.8 \\
\hline 2015 & 2018 & 2015 & 2018 & 2015 & 2018 \\
\hline 2.2 & 2.4 & 2.4 & 1.6 & 1.8 & 1.1 \\
\hline 2010 & 2019 & 2010 & 2019 & 2010 & 2019 \\
\hline 21.5 & 20.1 & 18.1 & 18 & 15.7 & 13.9 \\
\hline \multicolumn{6}{|c|}{$2000-16$} \\
\hline \multicolumn{2}{|c|}{-4.6} & \multicolumn{2}{|c|}{-8.8} & \multicolumn{2}{|c|}{-6.3} \\
\hline
\end{tabular}

\begin{tabular}{cccccc}
\multicolumn{2}{c}{ México } & \multicolumn{2}{c}{ ALC $^{2}$} & \multicolumn{2}{c}{ OCDE $^{3}$} \\
\hline 2009 & 2019 & 2009 & 2019 & 2009 & 2019 \\
\hline 46.6 & 47.4 & 29.3 & 26.7 & 72.2 & 70.7 \\
2009 & 2019 & 2009 & 2019 & 2009 & 2019 \\
\hline 22.7 & 20.4 & 8.7 & 8.3 & 19.5 & 17.9 \\
2009 & 2017 & 2009 & 2017 & 2009 & 2017 \\
\hline 0.5 & 0.3 & 0.4 & 0.4 & 2.4 & 2.5 \\
2009 & 2017 & 2009 & 2017 & 2009 & 2017 \\
\hline 132 & 199 & 726 & 521 & 173.44 & 141.358
\end{tabular}

\begin{tabular}{cccccc}
\multicolumn{2}{c}{ México } & \multicolumn{2}{c}{ ALC $^{2}$} & OCDE $^{3}$ \\
\hline 2009 & 2020 & 2009 & 2020 & 2009 & 2020 \\
\hline 73.2 & 77.2 & 72 & 72.4 & 67.5 & 58.8 \\
2009 & 2018 & 2009 & 2018 & 2009 & 2018 \\
\hline 78.3 & 90.5 & 64.8 & 82 & N. d. & N. d. \\
2009 & 2020 & 2009 & 2020 & 2009 & 2020 \\
\hline 62.1 & 50.5 & 56.9 & 48.2 & 69.2 & 70.7 \\
2009 & 2020 & 2009 & 2020 & 2009 & 2020 \\
\hline 74.1 & 77.3 & 74.8 & 76 & 77.9 & 79.4 \\
2010 & 2016 & 2010 & 2016 & 2010 & 2016
\end{tabular}

25.9

30.7

19.6

23.8 N. d. N. d.

\begin{tabular}{ccc} 
& 2021 & 36 \\
\hline 143 & 82 & \\
\hline-1 & $2009-18$ & N. d. \\
\hline 29 & 2019 & 16.3
\end{tabular}

\begin{tabular}{cccccc}
\multicolumn{2}{c}{ México } & \multicolumn{2}{c}{ ALC $^{2}$} & \multicolumn{2}{c}{ OCDE $^{3}$} \\
\hline 2009 & 2019 & 2009 & 2019 & 2009 & 2019 \\
\hline 12.5 & 16.5 & 20.6 & 22.9 & 31.6 & 33.8 \\
2009 & 2019 & 2009 & 2019 & 2009 & 2019 \\
\hline 26.9 & 24.3 & 25.3 & 27.7 & 19.8 & 20.7 \\
2009 & 2018 & 2009 & 2018 & 2009 & 2018 \\
\hline 9.4 & 8.7 & 11.3 & 11.4 & 21 & 19.7
\end{tabular}

11.3 


\section{PANAMÁ}

\section{Repercusiones socioeconómicas de la pandemia de coronavirus (COVID-19)}

La crisis afectó fuertemente a la economía de Panamá. En 2020, el producto interno bruto (PIB) se contrajo casi un 18\% anual, debido especialmente a la interrupción del comercio mundial y el turismo. Tras años de mejora, en 2020 la tasa de pobreza alcanzó el 17.8\% de acuerdo con las últimas estimaciones internacionales comparables, un incremento de más de tres puntos porcentuales con respecto al año anterior. Esta cifra es inferior al 30.9\% correspondiente a América Latina y el Caribe (ALC). La pobreza extrema se mantuvo estable en 2020, en el 6.4\%, frente al promedio de ALC del 10.0\%. Previo a la crisis, el gasto público en salud de Panamá era del 7.3\% del PIB, un porcentaje ligeramente superior al promedio de ALC (6.8\%); gasto que supo mantenerse estable en el último decenio, frente a un incremento de 0.3 puntos porcentuales en la región. Sin embargo, la percepción de la calidad de los servicios de salud entre los ciudadanos se deterioró. En 2020, el 50.8\% de las personas se declararon satisfechas con la atención sanitaria, un porcentaje que si bien es superior a la media de la región de ALC (48.2\%) y considerablemente menor al promedio de la Organización para la Cooperación y el Desarrollo Económicos (OCDE) (70.7\%), es finalmente casi 18 puntos porcentuales más baja que hace diez años. La pandemia también generó un duro efecto en la educación, ya que, entre marzo de 2020 y mayo de 2021, las escuelas han estado totalmente cerradas durante 55 semanas, una de las cifras más altas de ALC (26 semanas) y mucho más elevada que en la OCDE (15 semanas). El aprendizaje en línea efectivo no ayudó demasiado a amortiguar los inconvenientes para los alumnos, puesto que solo estaba disponible en el $23.9 \%$ de las escuelas, frente al 32.5\% en ALC y el 54.1\% en la OCDE. En cuanto a la percepción de la transparencia del gobierno, el $86.6 \%$ de los panameños creían que el gobierno era corrupto en 2020, un porcentaje considerablemente superior al de la región de ALC (72.4\%) y la OCDE (58.8\%).

\section{Iniciativas nacionales e internacionales de cooperación destinadas a construir un futuro mejor}

Frente a la crisis del COVID-19, la prioridad de Panamá ha sido la protección de los hogares, los trabajadores y las empresas más vulnerables. En cuanto a los hogares, Panamá emprendió una iniciativa de transferencias de efectivo (Panamá Solidario) para distribuir fondos y recursos a los más afectados por la pandemia. En lo que respecta a los trabajadores y las empresas, Panamá estableció programas dedicados a nuevas líneas de crédito, préstamos y garantías para microempresas y pequeñas y medianas empresas y los sectores económicos más afectados, como la agricultura y la hostelería, incluido el turismo, para fomentar su actividad económica y la creación de empleo. Además, el país puso en marcha el Plan "Recuperando Mi Barrio" para generar empleo temporal mediante inversiones en proyectos de infraestructuras locales.

Panamá estableció un plan de recuperación económica que prioriza la conservación de empleos y la generación de nuevas oportunidades. A largo plazo, se pretende combatir la pobreza y la vulnerabilidad, problemas estructurales que se han visto exacerbados por la crisis. Utilizando un gasto público de calidad como catalizador de la recuperación económica, Panamá se propone atender las antiguas necesidades en materia de infraestructura pública. Algunos proyectos que destacan son los relativos a la educación, el transporte y las infraestructuras de servicio público. Estas inversiones de calidad tienen como objetivos adicionales, impulsar la productividad y reforzar las cadenas de suministro. Asimismo, la atracción de inversión extranjera directa y la implementación de reformas para mejorar la competitividad y la productividad siguen siendo los pilares centrales del plan de recuperación. Respecto a los proyectos de cooperación internacional derivados de la pandemia de COVID-19 dentro de la región, Panamá colaboró con la Organización Panamericana de la Salud en la distribución de más de 35 toneladas de suministros, medicamentos y equipos de protección para luchar contra la pandemia en 26 países de ALC a través del Centro Regional de Distribución de Ayuda Humanitaria en Salud. En cuanto a la cooperación fuera de la región, en el marco del programa de cooperación con la Unión Europea EUROsociAL+, se ha prestado asistencia para garantizar el bienestar biopsicosocial de la población de edad avanzada. Además, han cooperado con Naciones Unidas en proyectos relacionados con la educación post-COVID-19, la correcta eliminación de los riesgos biológicos relacionados con el COVID-19 y el desarrollo de un estudio que codifica las buenas prácticas en la gestión de los sistemas penitenciarios durante la pandemia. 


\section{Socioambientales}

Pobreza extrema ${ }^{4}$

Pobreza $^{5}$

Coeficiente de Gini ${ }^{6}$

Población total en hogares informales por quintil. $2018^{7}$

Gasto en salud ${ }^{8}$

Gasto en salud por cuenta propia ${ }^{9}$

Semanas de cierre total de las escuelas ${ }^{10}$

Aprendizaje en línea efectivo ${ }^{11}$

Aprendizaje en línea efectivo en escuelas de entornos desfavorecidos ${ }^{11}$

Proporción de usuarios de Internet ${ }^{12}$

Número de alumnos por ordenador ${ }^{13}$

Exposición a PM $2.5^{14}$

$\%$ de cambio en el paisaje forestal intacto $0^{15}$

\section{Competitividad e innovación}

Productividad laboral ${ }^{16}$

Exportaciones de productos de alta tecnología ${ }^{17}$

Gasto en $I+D^{18}$

Patentes TIC ${ }^{19}$

\section{Percepción de los ciudadanos e instituciones}

Percepción de la corrupción en el gobierno entre los ciudadanos ${ }^{20}$

Percepción entre los ciudadanos de que el país

está gobernado en interés de unos pocos ${ }^{2}$

Satisfacción con la atención sanitaria ${ }^{22}$

Satisfacción con la calidad del agua ${ }^{23}$

$\%$ de personas víctimas de delincuencia ${ }^{24}$

Puesto en la Clasificación Mundial de la Libertad de Prensa ${ }^{25}$

Cambio en la polarización política ${ }^{26}$

Índice de Instituciones Sociales y Género (SIGI) ${ }^{27}$

\section{Situación fiscal}

Total de ingresos tributarios ${ }^{28}$

Proporción del IVA en el total de ingresos ${ }^{29}$

Gasto social ${ }^{30}$

Las fuentes, las notas al pie y los detalles técnicos pueden consultarse al final de las notas por países.

\begin{tabular}{cccccc}
\multicolumn{7}{c}{ Indicadores clave - Panamá1 } \\
\hline \multicolumn{2}{c}{ Panamá } & \multicolumn{2}{c}{ ALC $^{2}$} & \multicolumn{2}{c}{ OCDE $^{3}$} \\
\hline 2019 & 2020 & 2019 & 2020 & 2019 & 2020 \\
\hline 6.6 & 6.4 & 8.1 & 10 & N. d. & N. d. \\
2019 & 2020 & 2019 & 2020 & 2019 & 2020 \\
\hline 14.6 & 17.8 & 26.8 & 30.9 & N. d. & N. d. \\
2009 & 2019 & 2009 & 2019 & 2009 & 2018 \\
\hline 0.5 & 0.47 & 0.5 & 0.46 & 0.31 & 0.31 \\
$20 \%$ & $20 \%$ & $20 \%$ & $20 \%$ & $20 \%$ & $20 \%$ \\
más bajo & más alto & más bajo & más alto & más bajo & más alto \\
\hline N. d. & N. d. & 78 & 19.1 & N. d. & N. d. \\
2010 & 2017 & 2010 & 2017 & 2010 & 2017 \\
\hline 7.2 & 7.3 & 6.5 & 6.8 & 8.1 & 8.8 \\
2010 & 2017 & 2010 & 2017 & 2010 & 2017 \\
\hline 28.4 & 33.3 & 35.6 & 34.1 & 20.2 & 20.6
\end{tabular}

\begin{tabular}{|c|c|c|c|c|c|}
\hline \multicolumn{2}{|c|}{55} & \multicolumn{2}{|c|}{26} & \multicolumn{2}{|c|}{15} \\
\hline \multicolumn{6}{|c|}{2018} \\
\hline \multicolumn{2}{|c|}{23.9} & \multicolumn{2}{|c|}{32.5} & \multicolumn{2}{|c|}{54.1} \\
\hline \multicolumn{6}{|c|}{2018} \\
\hline \multicolumn{2}{|c|}{11.2} & \multicolumn{2}{|c|}{21.5} & \multicolumn{2}{|c|}{48.8} \\
\hline 2009 & 2019 & 2009 & 2019 & 2009 & 2019 \\
\hline 39.1 & 63.6 & 29.3 & 67.8 & 68.3 & 85.8 \\
\hline- & 2018 & 2015 & 2018 & 2015 & 2018 \\
\hline- & 1.6 & 2.4 & 1.6 & 1.8 & 1.1 \\
\hline 2010 & 2019 & 2010 & 2019 & 2010 & 2019 \\
\hline 15.5 & 13.2 & 18.1 & 18 & 15.7 & 13.9 \\
\hline \multicolumn{6}{|c|}{$2000-16$} \\
\hline & & & & & \\
\hline
\end{tabular}

\begin{tabular}{cccccc}
\multicolumn{2}{c}{ Panamá } & \multicolumn{2}{c}{ ALC $^{2}$} & \multicolumn{2}{c}{ OCDE $^{3}$} \\
\hline 2009 & 2019 & 2009 & 2019 & 2009 & 2019 \\
\hline N. d. & N. d. & N. d. & N. d. & N. d. & N. d. \\
2009 & 2019 & 2009 & 2019 & 2009 & 2019 \\
\hline 1.4 & 13.7 & 8.7 & 8.3 & 19.5 & 17.9 \\
2009 & 2017 & 2009 & 2017 & 2009 & 2017 \\
\hline 0.1 & 0.1 & 0.4 & 0.4 & 2.4 & 2.5 \\
2009 & 2017 & 2009 & 2017 & 2009 & 2017 \\
\hline 1 & 2 & 726 & 521 & 173.44 & 141.358
\end{tabular}

\begin{tabular}{|c|c|c|c|c|c|}
\hline \multicolumn{2}{|c|}{ Panamá } & \multicolumn{2}{|c|}{$\mathrm{ALC}^{2}$} & \multicolumn{2}{|c|}{$\mathrm{OCDE}^{3}$} \\
\hline 2009 & 2020 & 2009 & 2020 & 2009 & 2020 \\
\hline 87.8 & 86.6 & 72 & 72.4 & 67.5 & 58.8 \\
\hline 2009 & 2018 & 2009 & 2018 & N. d. & N. d. \\
\hline 44.8 & 84.9 & 64.8 & 82 & N. d. & N. d. \\
\hline 2009 & 2020 & 2009 & 2020 & 2009 & 2020 \\
\hline 68.1 & 50.8 & 56.9 & 48.2 & 69.2 & 70.7 \\
\hline 2009 & 2020 & 2009 & 2020 & 2009 & 2020 \\
\hline 82.3 & 84.3 & 74.8 & 76 & 77.9 & 79.4 \\
\hline 2010 & 2016 & 2010 & 2016 & N. d. & N. d. \\
\hline 11.3 & 16 & 19.6 & 23.8 & N. d. & N. d. \\
\hline \multicolumn{6}{|c|}{2021} \\
\hline \multicolumn{2}{|c|}{77} & \multicolumn{2}{|c|}{82} & \multicolumn{2}{|c|}{36} \\
\hline \multicolumn{6}{|c|}{$2009-18$} \\
\hline \multirow{2}{*}{\multicolumn{2}{|c|}{10.1}} & \multicolumn{2}{|c|}{9.6} & \multicolumn{2}{|c|}{ N. d. } \\
\hline & & \multicolumn{2}{|c|}{2019} & & \\
\hline & & & & \multicolumn{2}{|c|}{ N. d. } \\
\hline
\end{tabular}

\begin{tabular}{cccccc}
\multicolumn{2}{c}{ Panamá } & \multicolumn{2}{c}{ ALC $^{2}$} & \multicolumn{2}{c}{ OCDE $^{3}$} \\
\hline 2009 & 2019 & 2009 & 2019 & 2009 & 2019 \\
\hline 16 & 14.1 & 20.6 & 22.9 & 31.6 & 33.8 \\
2009 & 2019 & 2009 & 2019 & 2009 & 2019 \\
\hline 12.8 & 15.5 & 25.3 & 27.7 & 19.8 & 20.7 \\
2009 & 2018 & 2009 & 2018 & 2009 & 2018 \\
\hline 9.2 & 8.8 & 11.3 & 11.4 & 21 & 19.7
\end{tabular}




\section{PARAGUAY}

\section{Repercusiones socioeconómicas de la pandemia de coronavirus (COVID-19)}

El impacto económico de la pandemia de COVID-19 en el crecimiento de Paraguay fue moderado y uno de los más bajos de la región de América Latina y el Caribe (ALC), pues el producto interno bruto (PIB) solo se contrajo un $0.6 \%$ anual y la pobreza se ha mantenido invariable. A su vez, las tasas de pobreza y pobreza extrema se han mantenido (del 19.7\% y el 6.2\%, respectivamente, en 2020, de acuerdo con las últimas estimaciones internacionales comparables), siendo más bajas que en la región de ALC (del 30.9\% y el 10.0\%, respectivamente). Previo a la crisis, el gasto público en salud de Paraguay era del 6.7\% del PIB, un porcentaje similar al de la región de ALC del 6.8\%, pero muy inferior al 8.8\% correspondiente a los países de la Organización para la Cooperación y el Desarrollo Económicos (OCDE). No obstante, en el último decenio el gasto público en salud creció dos puntos porcentuales del PIB y alcanzó el nivel de la región, que registró un ligero aumento de 0.3 puntos porcentuales. En 2020, el 38.4\% de las personas se declaraban satisfechas con la calidad de la atención sanitaria, un porcentaje más bajo que en la región de ALC (48.2\%) y considerablemente inferior al de la OCDE (70.7\%). La calidad percibida ha disminuido más de 15 puntos porcentuales en el último decenio, frente a una reducción de casi diez puntos porcentuales en la región de ALC y un aumento de más de un punto porcentual en la OCDE. Entre marzo de 2020 y mayo de 2021, las escuelas han estado cerradas durante 32 semanas, frente a 26 semanas en la región de ALC y 15 semanas en la OCDE. En 2020, el 87.2\% de los ciudadanos creían que el gobierno era corrupto, lo que supone un aumento de siete puntos porcentuales en un decenio. Los paraguayos comparten esta preocupación con otros latinoamericanos, dado que el $72.4 \%$ de las personas de la región tienen la misma percepción negativa, muchas más que en la OCDE (58.8\%).

\section{Iniciativas nacionales e internacionales de cooperación destinadas a construir un futuro mejor}

Paraguay adoptó medidas para mitigar el impacto de la crisis del COVID-19, destinadas a aliviar y contener el impacto regresivo en los hogares, los trabajadores y las empresas más vulnerables. A través de la Ley $\mathrm{N}$ $6524 / 2020$, se realizaron transferencias monetarias para la compra de alimentos y productos de higiene con el fin de ayudar a las familias no cubiertas por los programas tradicionales de protección social. También subvencionó exenciones y aplazamientos de pagos de servicios públicos. Con respecto a los trabajadores, se establecieron subsidios adicionales para aquellos que perdieron su empleo durante la pandemia, sobre todo los trabajadores del sector informal, y otorgó indemnizaciones por despido y suspensión de pagos a los empleados del sector formal. Para ayudar a las empresas, Paraguay realizó transferencias y concedió garantías para que las instituciones nacionales pudiesen proporcionar financiación a las pequeñas y medianas empresas. De cara al futuro, el Plan de Recuperación Económica Ñapúa Paraguay (financiando por el Banco de Desarrollo de América Latina) se centra en tres objetivos a corto plazo: i) aumento de la protección social; ii) inversión y empleo; y iii) financiación del crecimiento económico y objetivos a medio-largo plazo que consisten en reformas estructurales destinadas a la transformación del Estado. El plan reconoce que las instituciones actuales deben reforzarse y que el bienestar de los ciudadanos debe ser el eje del modelo de desarrollo económico. Las propuestas para la Transformación del Estado tienen como objetivo encauzar al país hacia un nuevo contrato social que reduzca las desigualdades existentes y busque un futuro sostenible.

Los proyectos de cooperación internacional dentro y fuera de la región han canalizado la colaboración con diversos países socios y organizaciones internacionales para superar las dificultades planteadas por el COVID-19. Dentro de ALC, en el marco del Fondo para la Convergencia Estructural del Mercado Común del Sur (MERCOSUR), se creó una red de trabajo para el apoyo a la salud y el desarrollo y la producción de pruebas de diagnóstico grave y serológicas. Además, Paraguay colaboró con los gobiernos de Chile, Colombia, México, Uruguay, Argentina y Brasil en el intercambio y fortalecimiento de personal médico. Fuera de la región, socios estratégicos de Paraguay como la Unión Europea, Estados Unidos, Taipéi chino, Qatar, los EAU e India, han reorientado sus proyectos para apoyar los sectores esenciales para la recuperación económica y social en el país. Se destacan las iniciativas de consolidación de la protección social, refuerzo de los sistemas de agua y saneamiento (Acción: suministro de agua a las ciudades del Chaco paraguayo), apoyo a las pequeñas y medianas empresas, educación de calidad para todos los niños, campañas contra la violencia de género y la mejora de las oportunidades de formación en el empleo para jóvenes. 


\section{Socioambientales}

Pobreza extrema ${ }^{4}$

Pobreza $^{5}$

Coeficiente de Gini ${ }^{6}$

Población total en hogares informales por quintil. $2018^{7}$

Gasto en salud ${ }^{8}$

Gasto en salud por cuenta propia ${ }^{9}$

Semanas de cierre total de las escuelas ${ }^{10}$

Aprendizaje en línea efectivo ${ }^{11}$

Aprendizaje en línea efectivo en escuelas de entornos desfavorecidos ${ }^{11}$

Proporción de usuarios de Internet ${ }^{12}$

Número de alumnos por ordenador ${ }^{13}$

Exposición a PM $2.5^{14}$

$\%$ de cambio en el paisaje forestal intacto $0^{15}$

\section{Competitividad e innovación}

Productividad laboral ${ }^{16}$

Exportaciones de productos de alta tecnología ${ }^{17}$

Gasto en $I+D^{18}$

Patentes TIC $^{19}$

\section{Percepción de los ciudadanos e instituciones}

Percepción de la corrupción en el gobierno entre los ciudadanos ${ }^{20}$

Percepción entre los ciudadanos de que el país

está gobernado en interés de unos pocos ${ }^{2}$

Satisfacción con la atención sanitaria ${ }^{22}$

Satisfacción con la calidad del agua ${ }^{23}$

$\%$ de personas víctimas de delincuencia ${ }^{24}$

Puesto en la Clasificación Mundial de la Libertad de Prensa ${ }^{25}$

Cambio en la polarización política ${ }^{26}$

Índice de Instituciones Sociales y Género (SIGI) ${ }^{27}$

\section{Situación fiscal}

Total de ingresos tributarios ${ }^{28}$

Proporción del IVA en el total de ingresos ${ }^{29}$

Gasto social ${ }^{30}$

Las fuentes, las notas al pie y los detalles técnicos pueden consultarse al final de las notas por países.

\begin{tabular}{|c|c|c|c|c|c|}
\hline \multicolumn{6}{|c|}{ Indicadores clave - Paraguay ${ }^{1}$} \\
\hline \multicolumn{2}{|c|}{ Paraguay } & \multicolumn{2}{|c|}{$\mathrm{ALC}^{2}$} & \multicolumn{2}{|c|}{$\mathrm{OCDE}^{3}$} \\
\hline 2019 & 2020 & 2019 & 2020 & 2019 & 2020 \\
\hline 6.2 & 6.2 & 8.1 & 10 & N. d. & N. d. \\
\hline 2019 & 2020 & 2019 & 2020 & 2019 & 2020 \\
\hline 19.4 & 19.7 & 26.8 & 30.9 & N. d. & N. d. \\
\hline 2009 & 2019 & 2009 & 2019 & 2009 & 2018 \\
\hline 0.5 & 0.47 & 0.5 & 0.46 & 0.31 & 0.31 \\
\hline $\begin{array}{c}20 \% \\
\text { más bajo }\end{array}$ & $\begin{array}{c}20 \% \\
\text { más alto }\end{array}$ & $\begin{array}{c}20 \% \\
\text { más bajo }\end{array}$ & $\begin{array}{c}20 \% \\
\text { más alto }\end{array}$ & $\begin{array}{c}20 \% \\
\text { más bajo }\end{array}$ & $\begin{array}{c}20 \% \\
\text { más alto }\end{array}$ \\
\hline 95.3 & 22.8 & 78 & 19.1 & N. d. & N. d. \\
\hline 2010 & 2017 & 2010 & 2017 & 2010 & 2017 \\
\hline 4.6 & 6.7 & 6.5 & 6.8 & 8.1 & 8.8 \\
\hline 2010 & 2017 & 2010 & 2017 & 2010 & 2017 \\
\hline 45.9 & 44.2 & 35.6 & 34.1 & 20.2 & 20.6 \\
\hline \multicolumn{6}{|c|}{$03 / 2020-05 / 2021$} \\
\hline \multicolumn{2}{|c|}{32} & \multicolumn{2}{|c|}{26} & \multicolumn{2}{|c|}{15} \\
\hline \multicolumn{6}{|c|}{2018} \\
\hline \multicolumn{2}{|c|}{ N. d. } & \multicolumn{2}{|c|}{32.5} & \multicolumn{2}{|c|}{54.1} \\
\hline \multirow{2}{*}{\multicolumn{2}{|c|}{ N.d. }} & \multirow{2}{*}{\multicolumn{2}{|c|}{21.5}} & & \\
\hline & & & & \multicolumn{2}{|c|}{48.8} \\
\hline 2009 & 2019 & \multicolumn{2}{|r|}{2019} & \multicolumn{2}{|l|}{2009} \\
\hline 18.9 & 68.5 & 29.3 & 67.8 & 68.3 & 85.8 \\
\hline 2015 & 2018 & 2015 & 2018 & 2015 & 2018 \\
\hline N. d. & N. d. & 2.4 & 1.6 & 1.8 & 1.1 \\
\hline 2010 & 2019 & 2010 & 2019 & 2010 & 2019 \\
\hline 15.3 & 12.8 & 18.1 & 18 & 15.7 & 13.9 \\
\hline \multicolumn{6}{|c|}{$2000-16$} \\
\hline & & & & & \\
\hline
\end{tabular}

\begin{tabular}{cccccc}
\multicolumn{2}{c}{ Paraguay } & \multicolumn{2}{c}{ ALC $^{2}$} & \multicolumn{2}{c}{ OCDE $^{3}$} \\
\hline 2009 & 2019 & 2009 & 2019 & 2009 & 2019 \\
\hline 22 & 27.2 & 29.3 & 26.7 & 72.2 & 70.7 \\
2009 & 2019 & 2009 & 2019 & 2009 & 2019 \\
\hline 12 & 7.2 & 8.7 & 8.3 & 19.5 & 17.9 \\
2009 & 2017 & 2009 & 2017 & 2009 & 2017 \\
\hline 0.1 & 0.1 & 0.4 & 0.4 & 2.4 & 2.5 \\
2009 & 2017 & 2009 & 2017 & 2009 & 2017 \\
\hline N. d. & N. d. & 726 & 521 & 173.44 & 141.358
\end{tabular}

\begin{tabular}{|c|c|c|c|c|c|}
\hline \multicolumn{2}{|c|}{ Paraguay } & \multicolumn{2}{|c|}{$\mathrm{ALC}^{2}$} & \multicolumn{2}{|c|}{$\mathrm{OCDE}^{3}$} \\
\hline 2009 & 2020 & 2009 & 2020 & 2009 & 2020 \\
\hline 79.7 & 87.2 & 72 & 72.4 & 67.5 & 58.8 \\
\hline 2009 & 2018 & 2009 & 2018 & N. d. & N. d. \\
\hline 67.7 & 90 & 64.8 & 82 & N. d. & N. d. \\
\hline 2009 & 2020 & 2009 & 2020 & 2009 & 2020 \\
\hline 54.1 & 38.4 & 56.9 & 48.2 & 69.2 & 70.7 \\
\hline 2009 & 2020 & 2009 & 2020 & 2009 & 2020 \\
\hline 88 & 79.6 & 74.8 & 76 & 77.9 & 79.4 \\
\hline 2010 & 2016 & 2010 & 2016 & N. d. & N. d. \\
\hline 18.3 & 23.7 & 19.6 & 23.8 & N. d. & N. d. \\
\hline \multicolumn{6}{|c|}{2021} \\
\hline \multirow{2}{*}{\multicolumn{2}{|c|}{100}} & \multicolumn{2}{|c|}{82} & \multicolumn{2}{|c|}{36} \\
\hline & & \multicolumn{2}{|c|}{ 2009-18 } & & \\
\hline & & & & \multicolumn{2}{|c|}{ N. d. } \\
\hline \multicolumn{6}{|c|}{2019} \\
\hline \multicolumn{2}{|c|}{32.8} & \multicolumn{2}{|c|}{25.6} & \multicolumn{2}{|c|}{16.3} \\
\hline
\end{tabular}

\begin{tabular}{cccccc}
\multicolumn{2}{c}{ Paraguay } & \multicolumn{2}{c}{ ALC $^{2}$} & \multicolumn{2}{c}{ OCDE $^{3}$} \\
\hline 2009 & 2019 & 2009 & 2019 & 2009 & 2019 \\
\hline 11.5 & 13.9 & 20.6 & 22.9 & 31.6 & 33.8 \\
2009 & 2019 & 2009 & 2019 & 2009 & 2019 \\
\hline 34.6 & 35.7 & 25.3 & 27.7 & 19.8 & 20.7 \\
2009 & 2018 & 2009 & 2018 & 2009 & 2018 \\
\hline 7 & 8.6 & 11.3 & 11.4 & 21 & 19.7 \\
\hline
\end{tabular}

11.3 11.4 


\section{PERÚ}

\section{Repercusiones socioeconómicas de la pandemia de coronavirus (COVID-19)}

La crisis ocasionada por la pandemia de COVID-19 en el 2020 tuvo un efecto devastador en la economía de Perú, generando una caída del producto interno bruto (PIB) del 11\% anual. De acuerdo con las últimas estimaciones internacionales comparables, la tasa de pobreza aumentó más de seis puntos porcentuales con respecto al año anterior, elevándose al 21.9\%, mientras que en la región de América Latina y el Caribe (ALC) el aumento fue de menos de cinco puntos porcentuales, alcanzando el 30.9\%. En los años anteriores a la pandemia, el gasto público en salud representaba el 4.9\% del PIB, 0.2 puntos porcentuales más que en 2010. Este porcentaje es inferior al correspondiente a los países de la región de ALC (6.8\%) y la Organización para la Cooperación y el Desarrollo Económicos (OCDE) (8.8\%), los cuales experimentaron un ligero aumento similar. En el 2020 el 41.3\% de los peruanos consideraban que la atención sanitaria era de buena calidad, un porcentaje inferior al de la región de ALC (48.2\%) y la OCDE (70.7\%). Entre marzo de 2020 y mayo de 2021, las escuelas han estado totalmente cerradas durante 26 semanas, el mismo tiempo que en la región de ALC y más que en la OCDE (15 semanas). La interrupción de la educación resultó especialmente dura para los niños debido a la ausencia de aprendizaje en línea efectivo, que solo estaba presente en el $24.0 \%$ de las escuelas, frente al $32.5 \%$ en la región de ALC y el 54.1\% en la OCDE.

\section{Iniciativas nacionales e internacionales de cooperación destinadas a construir un futuro mejor}

Perú ha aplicado una amplia variedad de medidas de mitigación. Con respecto a los hogares, se realizaron transferencias monetarias a personas que viven en situación de pobreza o pobreza extrema y a personas que se encuentran en zonas geográficas con mayores riesgos sanitarios (Bono Familiar Universal y Bono Yo Me Quedo En Casa). Asimismo, se aprobó un subsidio dirigido en particular a los hogares rurales que quedaron excluidos de los programas tradicionales de asistencia social durante la pandemia (Bono Rural). Además, pusieron en marcha en 2020 el programa Trabaja Perú, dirigido a las personas que viven en situación de pobreza o pobreza extrema, mediante la creación de empleos temporales para proyectos de inversión y actividades de intervención inmediata. A fin de proteger a los trabajadores, Perú fomentó la conservación del empleo y la contratación concediendo un subsidio a los empleadores privados que se vieron afectados durante la pandemia. Además, autorizó a los trabajadores a retirar fondos de pensión sin penalización y estableció un subsidio para los trabajadores por cuenta propia (Bono Independiente). En cuanto a la recuperación, los planes de Perú a mediano y largo plazo se basan en la preservación de la sostenibilidad productiva. Arranca Perú es un programa de resiliencia económica y creación de empleo que consiste en subsidios para crear nuevos empleos y apoyo a la financiación de empresas (por ejemplo, Reactiva Perú, Fondo de Apoyo Empresarial a las MYPE), que comprende programas de garantía de la cartera de préstamos, promoción de la contratación pública con respecto a las microempresas y pequeñas empresas, y diversas medidas tributarias (por ejemplo, promoción de la inversión y desgravación fiscal). Perú también llevará a cabo el Plan Estratégico de Desarrollo Nacional para cumplir los objetivos estructurales nacionales, proponiendo abordar los medios de vida, la productividad, la seguridad social integral y el diálogo para el desarrollo integral del país.

Los proyectos de cooperación internacional de Perú dentro y fuera de la región responden a las prioridades nacionales de desarrollo frente a los efectos adversos del COVID-19. Dentro de ALC, han participado en programas de cooperación en materia de migración rural (cooperando con el Banco Interamericano de Desarrollo), cooperación regional para la gestión climática de los ecosistemas agrícolas (con la Organización para la Alimentación y la Agricultura - regional), técnicas para la construcción de viviendas de adobe resistentes a terremotos (intercambio con Argentina). Fuera de la región, participaron en alianzas internacionales en respuesta a la pandemia (por ejemplo, el Acelerador del acceso a las herramientas contra el COVID-19, el Acceso Mundial a las Vacunas contra el COVID-19 [COVAX], el Acceso Mancomunado a las Tecnología contra el COVID-19, el Grupo de Apoyo para la Respuesta Global a Enfermedades Infecciosas y el Grupo de Coordinación Ministerial sobre el COVID-19). Además, Perú participó en programas para elaborar planes de mitigación de la pandemia en las comunidades indígenas y los centros rurales de la región del Amazonas con Alemania y Suiza. Por último, en el marco de la última fase (2020-2021) del programa EUROsociAL+, se ha reforzado la Red de Protección de Personas Mayores y Personas con Discapacidad. 


\section{Socioambientales}

Pobreza extrema ${ }^{4}$

Pobreza $^{5}$

Coeficiente de Gini ${ }^{6}$

Población total en hogares informales por quintil. $2018^{7}$

Gasto en salud ${ }^{8}$

Gasto en salud por cuenta propia ${ }^{9}$

Semanas de cierre total de las escuelas ${ }^{10}$

Aprendizaje en línea efectivo ${ }^{11}$

Aprendizaje en línea efectivo en escuelas de entornos desfavorecidos ${ }^{11}$

Proporción de usuarios de Internet ${ }^{12}$

Número de alumnos por ordenador ${ }^{13}$

Exposición a PM $2.5^{14}$

$\%$ de cambio en el paisaje forestal intacto $0^{15}$

\section{Competitividad e innovación}

Productividad laboral ${ }^{16}$

Exportaciones de productos de alta tecnología ${ }^{17}$

Gasto en $I+D^{18}$

Patentes TIC ${ }^{19}$

\section{Percepción de los ciudadanos e instituciones}

Percepción de la corrupción en el gobierno entre los ciudadanos ${ }^{20}$

Percepción entre los ciudadanos de que el país

está gobernado en interés de unos pocos ${ }^{2}$

Satisfacción con la atención sanitaria ${ }^{22}$

Satisfacción con la calidad del agua ${ }^{23}$

$\%$ de personas víctimas de delincuencia ${ }^{24}$

Puesto en la Clasificación Mundial de la Libertad de Prensa ${ }^{25}$

Cambio en la polarización política ${ }^{26}$

Índice de Instituciones Sociales y Género (SIGI) ${ }^{27}$

\section{Situación fiscal}

Total de ingresos tributarios ${ }^{28}$

Proporción del IVA en el total de ingresos 29

Gasto social ${ }^{30}$

Las fuentes, las notas al pie y los detalles técnicos pueden consultarse al final de las notas por países.

\begin{tabular}{cccccc}
\multicolumn{7}{c}{ Indicadores clave - Perú1 } \\
\hline \multicolumn{7}{c}{ Perú } & \multicolumn{2}{c}{ ALC $^{2}$} & \multicolumn{2}{c}{ OCDE $^{3}$} \\
\hline 2019 & 2020 & 2019 & 2020 & 2019 & 2020 \\
\hline 3 & 3.5 & 8.1 & 10 & N. d. & N. d. \\
2019 & 2020 & 2019 & 2020 & 2019 & 2020 \\
\hline 15.4 & 21.9 & 26.8 & 30.9 & N. d. & N. d. \\
2009 & 2019 & 2009 & 2019 & 2009 & 2018 \\
\hline 0.48 & 0.43 & 0.5 & 0.46 & 0.31 & 0.31 \\
$20 \%$ & $20 \%$ & $20 \%$ & $20 \%$ & $20 \%$ & $20 \%$ \\
más bajo & más alto & más bajo & más alto & más bajo & más alto \\
\hline 89.2 & 18.2 & 78 & 19.1 & N. d. & N. d. \\
2010 & 2017 & 2010 & 2017 & 2010 & 2017 \\
\hline 4.7 & 5 & 6.5 & 6.8 & 8.1 & 8.8 \\
2010 & 2017 & 2010 & 2017 & 2010 & 2017 \\
\hline 39.6 & 28.2 & 35.6 & 34.1 & 20.2 & 20.6
\end{tabular}

\begin{tabular}{|c|c|c|c|c|c|}
\hline \multicolumn{2}{|c|}{26} & \multicolumn{2}{|c|}{$\frac{20-05 / 2021}{26}$} & \multicolumn{2}{|c|}{15} \\
\hline \multirow{2}{*}{\multicolumn{2}{|c|}{24}} & \multicolumn{2}{|c|}{2018} & \\
\hline & & \multicolumn{2}{|c|}{32.5} & \multicolumn{2}{|c|}{54.1} \\
\hline \multicolumn{6}{|c|}{2018} \\
\hline \multicolumn{2}{|c|}{12.3} & \multicolumn{2}{|c|}{21.5} & \multicolumn{2}{|c|}{48.8} \\
\hline 2009 & 2019 & 2009 & 2019 & 2009 & 2019 \\
\hline 31.4 & 60 & 29.3 & 67.8 & 68.3 & 85.8 \\
\hline 2015 & 2018 & 2015 & 2018 & 2015 & 2018 \\
\hline 2.2 & 1.4 & 2.4 & 1.6 & 1.8 & 1.1 \\
\hline 2010 & 2019 & 2010 & 2019 & 2010 & 2019 \\
\hline 30.4 & 31.1 & 18.1 & 18 & 15.7 & 13.9 \\
\hline \multicolumn{6}{|c|}{$2000-16$} \\
\hline & & & & & \\
\hline
\end{tabular}

\begin{tabular}{cccccc}
\multicolumn{2}{c}{ Perú } & \multicolumn{2}{c}{ ALC $^{2}$} & \multicolumn{2}{c}{ OCDE $^{3}$} \\
\hline 2009 & 2019 & 2009 & 2019 & 2009 & 2019 \\
\hline 18.1 & 24.5 & 29.3 & 26.7 & 72.2 & 70.7 \\
2009 & 2019 & 2009 & 2019 & 2009 & 2019 \\
\hline 0.1 & 0.1 & 8.7 & 8.3 & 19.5 & 17.9 \\
2009 & 2017 & 2009 & 2017 & 2009 & 2017 \\
\hline 0.1 & 0.1 & 0.4 & 0.4 & 2.4 & 2.5 \\
2009 & 2017 & 2009 & 2017 & 2009 & 2017 \\
\hline 6 & 7 & 726 & 521 & 173.44 & 141.358
\end{tabular}

\begin{tabular}{cccccc}
\multicolumn{2}{c}{ Perú } & \multicolumn{2}{c}{ ALC $^{2}$} & \multicolumn{2}{c}{ OCDE $^{3}$} \\
\hline 2009 & 2020 & 2009 & 2020 & 2009 & 2020 \\
\hline 91.9 & 88.7 & 72 & 72.4 & 67.5 & 58.8 \\
2009 & 2018 & 2009 & 2018 & 2009 & 2018 \\
\hline 84.6 & 87.5 & 64.8 & 82 & N. d. & N. d. \\
2009 & 2020 & 2009 & 2020 & 2009 & 2020 \\
\hline 41.1 & 41.3 & 56.9 & 48.2 & 69.2 & 70.7 \\
2009 & 2020 & 2009 & 2020 & 2009 & 2020 \\
\hline 62.7 & 63.5 & 74.8 & 76 & 77.9 & 79.4 \\
2010 & 2016 & 2010 & 2016 & 2010 & 2016 \\
\hline 31.1 & 33 & 19.6 & 23.8 & N. & d.
\end{tabular}

\begin{tabular}{llllll}
31.1 & 33 & 19.6 & 23.8 & N.d. & N. d. \\
& & & 2021 & & \\
\hline
\end{tabular}

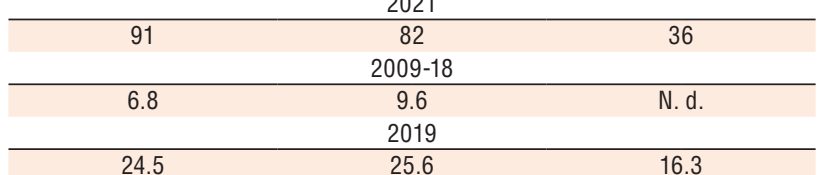

\begin{tabular}{cccccc}
\multicolumn{2}{c}{ Perú } & \multicolumn{2}{c}{ ALC $^{2}$} & \multicolumn{2}{c}{ OCDE $^{3}$} \\
\hline 2009 & 2019 & 2009 & 2019 & 2009 & 2019 \\
\hline 16.9 & 16.6 & 20.6 & 22.9 & 31.6 & 33.8 \\
2009 & 2019 & 2009 & 2019 & 2009 & 2019 \\
\hline 38.4 & 38.5 & 25.3 & 27.7 & 19.8 & 20.7 \\
2009 & 2018 & 2009 & 2018 & 2009 & 2018 \\
\hline 10.2 & 11.1 & 11.3 & 11.4 & 21 & 19.7
\end{tabular}

11.3 


\section{URUGUAY}

\section{Repercusiones socioeconómicas de la pandemia de coronavirus (COVID-19)}

La crisis provocada por la pandemia de COVID-19 ha impactado negativamente a la economía uruguaya. En 2020, el producto interno bruto (PIB) cayó un 5.9\% anual, afectando sobre todo a los grupos más vulnerables. En 2020, la tasa de pobreza, de acuerdo con las últimas estimaciones internacionales comparables, alcanzó el 5.1\%, aumentando en dos puntos porcentuales, aunque sigue siendo una de las más bajas de la región de América Latina y el Caribe (ALC) y considerablemente inferior al promedio regional, del 30.9\%. En 2020, el 75.1\% de los uruguayos se declararon satisfechos con la calidad de la atención sanitaria, una cifra solo dos puntos porcentuales más baja que diez años atrás. Este porcentaje es muy superior al 48.2\% registrado en la región de ALC e incluso más elevado que el promedio de la Organización para la Cooperación y el Desarrollo Económicos (OCDE), del 70.7\%. Uruguay destaca como el país con mayor gasto público en atención sanitaria en ALC: un 9.3\% del PIB, frente a un 6.8\% en la región de ALC y un 8.8\% en la OCDE. Aunque la pandemia afectó también al sistema educativo, Uruguay estuvo entre los países de ALC que lograron minimizar la interrupción de la educación de los alumnos. Entre marzo de 2020 y mayo de 2021, las escuelas cerraron durante 14 semanas, menor a la media de la región de ALC (26 semanas) y cercano al promedio de la OCDE (15 semanas). Durante las semanas de cierre, el aprendizaje en línea ayudó a mitigar el impacto negativo en los alumnos, ya que el 47.4\% de las escuelas tenían acceso a plataformas digitales, una cifra superior a la media de la región de ALC (32.5\%), aunque ligeramente inferior al promedio de la OCDE (54.1\%).

\section{Iniciativas nacionales e internacionales de cooperación destinadas a construir un futuro mejor}

Uruguay ha realizado amplios esfuerzos para afrontar la crisis sanitaria y reducir el impacto del COVID-19 en los hogares, los trabajadores y las empresas más vulnerables. El Fondo Solidario COVID-19 fue fundamental para aplicar estas medidas, reforzando y ampliando el programa ya existente de transferencias monetarias Asignación Familiar Plan de Equidad, para apoyar a los hogares más vulnerables. También implementó una aplicación de cartera electrónica (TuApp) permitiendo a los usuarios recibir cupones gubernamentales para el reembolso de alimentos y efectuar pagos diversos. Además, se estableció un régimen especial de prestaciones de desempleo para todos los trabajadores afectados y han prorrogado su duración. Uruguay concedió prórrogas y beneficios fiscales, en particular en relación con las contribuciones para pensiones, y añadió un incentivo monetario mensual para que las empresas reincorporen o contraten trabajadores. Además, se hicieron efectivas una serie de transferencias, posibilidades de crédito y otras prestaciones, en particular para microempresas y pequeñas y medianas empresas (mipymes). Con respecto a la recuperación, los planes de Uruguay a mediano y largo plazo se centran en la importancia de la resiliencia de las empresas y la creación de empleo y la sostenibilidad de las políticas sociales. Los principales motores son las inversiones para fomentar el empleo, nuevos marcos jurídicos para la inversión y la vivienda social, innovaciones fiscales para las mipymes y una reforma de la seguridad social. Por último, Uruguay está diseñando una política de comercio exterior para mejorar la presencia de productos nacionales en el extranjero.

Los proyectos de cooperación internacional de Uruguay dentro y fuera de la región se centran en las necesidades estructurales a largo plazo y en la respuesta a los apremiantes desafíos derivados de la crisis. Dentro de ALC, Uruguay participó en un proyecto de cooperación con México para reforzar la capacidad de los equipos sanitarios en la prevención y contención de la pandemia. También colaboró con Colombia en una iniciativa para compartir estrategias y buenas prácticas a fin de superar la pobreza durante la crisis y, junto al sector privado y el BID, se creó el "Fondo de Innovación de Energías Renovables", cuyo objetivo es descarbonizar los sectores de la industria y el transporte y garantizar el acceso universal a las fuentes renovables. Fuera de la región, Uruguay participó en proyectos junto a Naciones Unidas centrados en las perspectivas de género e intergeneracional en respuesta a los impactos socioeconómicos de COVID-19. En cuanto a la creación de empleo y la consolidación de un ecosistema empresarial, se promovió la cooperación triangular con Alemania y Paraguay. En cuanto a la alianza bilateral con la Unión Europea, buscan reforzar el diálogo estratégico, adaptando las iniciativas de cooperación triangular para responder a los efectos de la pandemia y promoviendo el enfoque de Desarrollo en Transición y la Agenda 2030 de las Naciones Unidas. 


\section{Socioambientales}

Pobreza extrema ${ }^{4}$

Pobreza $^{5}$

Coeficiente de Gini ${ }^{6}$

Población total en hogares informales por quintil. $2018^{7}$

Gasto en salud ${ }^{8}$

Gasto en salud por cuenta propia ${ }^{9}$

Semanas de cierre total de las escuelas ${ }^{10}$

Aprendizaje en línea efectivo ${ }^{11}$

Aprendizaje en línea efectivo en escuelas de entornos desfavorecidos ${ }^{11}$

Proporción de usuarios de Internet ${ }^{12}$

Número de alumnos por ordenador ${ }^{13}$

Exposición a PM $2.5^{14}$

$\%$ de cambio en el paisaje forestal intacto $0^{15}$

\section{Competitividad e innovación}

Productividad laboral ${ }^{16}$

Exportaciones de productos de alta tecnología ${ }^{17}$

Gasto en $I+D^{18}$

Patentes TIC ${ }^{19}$

\section{Percepción de los ciudadanos e instituciones}

Percepción de la corrupción en el gobierno entre los ciudadanos ${ }^{20}$

Percepción entre los ciudadanos de que el país

está gobernado en interés de unos pocos ${ }^{2}$

Satisfacción con la atención sanitaria22

Satisfacción con la calidad del agua ${ }^{23}$

$\%$ de personas víctimas de delincuencia ${ }^{24}$

Puesto en la Clasificación Mundial de la Libertad de Prensa ${ }^{25}$

Cambio en la polarización política ${ }^{26}$

Índice de Instituciones Sociales y Género (SIGI) ${ }^{27}$

\section{Situación fiscal}

Total de ingresos tributarios ${ }^{28}$

Proporción del IVA en el total de ingresos ${ }^{29}$

Gasto social ${ }^{30}$

Las fuentes, las notas al pie y los detalles técnicos pueden consultarse al final de las notas por países.

\begin{tabular}{|c|c|c|c|c|c|}
\hline \multicolumn{6}{|c|}{ Indicadores clave - Uruguay ${ }^{1}$} \\
\hline \multicolumn{2}{|c|}{ Uruguay } & \multicolumn{2}{|c|}{$\mathrm{ALC}^{2}$} & \multicolumn{2}{|c|}{$\mathrm{OCDE}^{3}$} \\
\hline 2019 & 2020 & 2019 & 2020 & 2019 & 2020 \\
\hline 0.1 & 0.3 & 8.1 & 10 & N. d. & N. d. \\
\hline 2019 & 2020 & 2019 & 2020 & 2019 & 2020 \\
\hline 3 & 5.1 & 26.8 & 30.9 & N. d. & N. d. \\
\hline 2009 & 2019 & 2009 & 2019 & 2009 & 2018 \\
\hline 0.45 & 0.39 & 0.5 & 0.46 & 0.31 & 0.31 \\
\hline $\begin{array}{c}20 \% \\
\text { más bajo }\end{array}$ & $\begin{array}{c}20 \% \\
\text { más alto }\end{array}$ & $\begin{array}{c}20 \% \\
\text { más bajo }\end{array}$ & $\begin{array}{c}20 \% \\
\text { más alto }\end{array}$ & $\begin{array}{c}20 \% \\
\text { más bajo }\end{array}$ & $\begin{array}{c}20 \% \\
\text { más alto }\end{array}$ \\
\hline $48.00 \%$ & $2.20 \%$ & 78 & 19.1 & N. d. & N.d. \\
\hline 2010 & 2017 & 2010 & 2017 & 2010 & 2017 \\
\hline 8.6 & 9.3 & 6.5 & 6.8 & 8.1 & 8.8 \\
\hline 2010 & 2017 & 2010 & 2017 & 2010 & 2017 \\
\hline 20.5 & 17.5 & 35.6 & 34.1 & 20.2 & 20.6 \\
\hline \multicolumn{6}{|c|}{$03 / 2020-05 / 2021$} \\
\hline \multicolumn{2}{|c|}{14} & \multicolumn{2}{|c|}{26} & \multicolumn{2}{|c|}{15} \\
\hline \multicolumn{6}{|c|}{2018} \\
\hline \multicolumn{2}{|c|}{47.4} & \multicolumn{2}{|c|}{32.5} & \multicolumn{2}{|c|}{54.1} \\
\hline \multicolumn{6}{|c|}{2018} \\
\hline \multicolumn{2}{|c|}{55.7} & \multicolumn{2}{|c|}{21.5} & \multicolumn{2}{|c|}{48.8} \\
\hline 2009 & 2019 & 2009 & 2019 & 2009 & 2019 \\
\hline 41.8 & 83.3 & 29.3 & 67.8 & 68.3 & 85.8 \\
\hline 2015 & 2018 & 2015 & 2018 & 2015 & 2018 \\
\hline 2.7 & 2.3 & 2.4 & 1.6 & 1.8 & 1.1 \\
\hline 2010 & 2019 & 2010 & 2019 & 2010 & 2019 \\
\hline 9.5 & 9.6 & 18.1 & 18 & 15.7 & 13.9 \\
\hline \multicolumn{6}{|c|}{$2000-16$} \\
\hline & & & & & \\
\hline
\end{tabular}

\begin{tabular}{cccccc}
\multicolumn{2}{c}{ Uruguay } & \multicolumn{2}{c}{ ALC $^{2}$} & \multicolumn{2}{c}{ OCDE $^{3}$} \\
\hline 2009 & 2019 & 2009 & 2019 & 2009 & 2019 \\
\hline 36.4 & 48.2 & 29.3 & 26.7 & 72.2 & 70.7 \\
2009 & 2019 & 2009 & 2019 & 2009 & 2019 \\
\hline 6.4 & 8.3 & 8.7 & 8.3 & 19.5 & 17.9 \\
2009 & 2017 & 2009 & 2017 & 2009 & 2017 \\
\hline 0.4 & 0.5 & 0.4 & 0.4 & 2.4 & 2.5 \\
2009 & 2017 & 2009 & 2017 & 2009 & 2017 \\
\hline 9 & 3 & 726 & 521 & 173.44 & 141.358
\end{tabular}

\begin{tabular}{|c|c|c|c|c|c|}
\hline \multicolumn{2}{|c|}{ Uruguay } & \multicolumn{2}{|c|}{$\mathrm{ALC}^{2}$} & \multicolumn{2}{|c|}{$\mathrm{OCDE}^{3}$} \\
\hline 2009 & 2020 & 2009 & 2020 & 2009 & 2020 \\
\hline 38.7 & 48.2 & 72 & 72.4 & 67.5 & 58.8 \\
\hline 2009 & 2018 & 2009 & 2018 & - & - \\
\hline 32.9 & 70.4 & 64.8 & 82 & - & - \\
\hline 2009 & 2020 & 2009 & 2020 & 2009 & 2020 \\
\hline 77.2 & 75.1 & 56.9 & 48.2 & 69.2 & 70.7 \\
\hline 2009 & 2020 & 2009 & 2020 & 2009 & 2020 \\
\hline 89.2 & 83.9 & 74.8 & 76 & 77.9 & 79.4 \\
\hline 2010 & 2016 & 2010 & 2016 & N. d. & N. d. \\
\hline 21 & 23.5 & 19.6 & 23.8 & N. d. & N. d. \\
\hline \multicolumn{6}{|c|}{2021} \\
\hline \multirow{2}{*}{\multicolumn{2}{|c|}{18}} & \multicolumn{2}{|c|}{82} & \multicolumn{2}{|c|}{36} \\
\hline & & \multicolumn{2}{|c|}{ 2009-18 } & \\
\hline \multirow{2}{*}{\multicolumn{2}{|c|}{2.3}} & \multicolumn{2}{|c|}{9.6} & \multicolumn{2}{|c|}{ N. d. } \\
\hline & & \multicolumn{2}{|c|}{2019} & & \\
\hline & & & & \multicolumn{2}{|c|}{16.3} \\
\hline
\end{tabular}

\begin{tabular}{cccccc}
\multicolumn{2}{c}{ Uruguay } & \multicolumn{2}{c}{ ALC $^{2}$} & \multicolumn{2}{c}{ OCDE $^{3}$} \\
\hline 2009 & 2019 & 2009 & 2019 & 2009 & 2019 \\
\hline 26 & 29 & 20.6 & 22.9 & 31.6 & 33.8 \\
2009 & 2019 & 2009 & 2019 & 2009 & 2019 \\
\hline 33.4 & 25.4 & 25.3 & 27.7 & 19.8 & 20.7 \\
2009 & 2018 & 2009 & 2018 & 2009 & 2018 \\
\hline 12.7 & 17.2 & 11.3 & 11.4 & 21 & 19.7
\end{tabular}

11.3 


\section{Notas técnicas}

1. En la mayor medida posible, el cuadro refleja los aspectos principales señalados en Perspectivas económicas de América Latina 2021: i) aspectos socioambientales; ii) competitividad económica e innovación; iii) percepción de los ciudadanos e instituciones; y iv) situación fiscal.

2. La media de América Latina y el Caribe (ALC) es una media simple del mayor conjunto de países de ALC para los que se dispone de datos sobre el último año.

3. La media de la Organización para la Cooperación y el Desarrollo Económicos (OCDE) es una media simple que incluye a todos los países miembros de la OCDE a fecha de mayo de 2021.

4. Los datos se refieren a la definición de pobreza extrema especificada por la Comisión Económica de las Naciones Unidas para América Latina y el Caribe (CEPAL, 2021), Panorama Social de América Latina 2020, https://repositorio.cepal.org/bitstream/handle/11362/46687/8/S2100150_es.pdf. Los datos para 2020 se refieren a una estimación basada en los datos de 2019, como se especifica en el Anexo I.A2 de (CEPAL, 2021). Las proyecciones se basan en datos de 2017 para Chile, 2014 para Guatemala y 2018 para México. Aplicando los mismos criterios que en las ediciones anteriores de LEO, la selección de datos prioriza la comparabilidad entre los países de ALC y muestra los últimos datos comparables disponibles en la fecha de publicación del informe.

5. Los datos se refieren a la definición de pobreza especificada por la CEPAL (2021), Panorama Social de América Latina 2020, https://repositorio.cepal.org/bitstream/handle/11362/46687/8/S2100150_es.pdf. Los datos para 2020 se refieren a una estimación basada en los datos de 2019, como se especifica en el Anexo I.A2 de la CEPAL (2021). Las proyecciones se basan en datos de 2017 para Chile, 2014 para Guatemala y 2018 para México. Aplicando los mismos criterios que en las ediciones anteriores de LEO, la selección de datos prioriza la comparabilidad entre los países de ALC y muestra los últimos datos comparables disponibles en la fecha de publicación del informe.

6. Los datos de la región de ALC se han extraído de la CEPAL, CEPALSTAT| Bases de datos y publicaciones estadísticas, https://cepalstat-prod.cepal.org/cepalstat/tabulador/ConsultaIntegrada.asp?IdAplicacion= 1\&idTema=363\&idIndicador=250\&idioma=e. Los datos de Chile se refieren a 2017, en lugar de 2019, los datos de Guatemala se refieren a 2014.

7. Datos de la OCDE procedentes de la base de datos de distribución de la renta de la OCDE, www.oecd.org/ social/income-distribution-database.htm.

8. El indicador proporciona la distribución de la población total que vive en hogares informales por quintiles. Un hogar informal tiene a todos sus trabajadores en el trabajo informal. Los quintiles se basan en el consumo o los ingresos totales mensuales del hogar. La fuente de este indicador es la base de datos de la OCDE de indicadores clave de informalidad basados en las personas y sus hogares, https://stats. oecd.org/Index.aspx?DataSetCode=KIIBIH_B5.

9. Gasto sanitario como porcentaje del producto interno bruto (PIB). Datos de la OCDE (2020), Panorama de la Salud: Latinoamérica y el Caribe.

10. Datos de la UNESCO, https://es.unesco.org/covid19/educationresponse\#schoolclosures.

11. Datos de OCDE et al. (2020), Perspectivas económicas de América Latina 2020, https://www.oecd.org/ publications/perspectivas-economicas-de-america-latina-20725183.htm.

12. Datos de la Unión Internacional de Telecomunicaciones (2020), www.itu.int/en/ITU-D/Statistics/Pages/ stat/default.aspx.

13. Datos de OCDE et al. (2020), Perspectivas económicas de América Latina 2020, https://www.oecd.org/ publications/perspectivas-economicas-de-america-latina-20725183.htm.

14. $\mu \mathrm{g} / \mathrm{m}^{3}$. Los datos se refieren a la exposición de la población a más de 10 microgramos/m $\mathrm{m}^{3}$ y se expresan como medias anuales. Datos de la OCDE, https://data.oecd.org/air/air-pollution-exposure.htm.

15. Datos de la OCDE, https://stats.oecd.org/Index.aspx?DataSetCode=INTACT FOREST LANDSCAPES.

16. Producción por persona empleada como porcentaje de la producción de 2019 de los Estados Unidos por persona empleada. Datos de Conference Board, www.conference-board.org//retrievefile.cfm?filename= FAQ-for-China-GDP_9nov1511.pdf\&type=subsite.

17. Exportaciones de productos de alta tecnología como porcentaje de las exportaciones de productos manufacturados. Datos del Banco Mundial, https://datos.bancomundial.org/indicador/TX.VAL.TECH.MF.ZS.

18. Gasto en investigación y desarrollo como porcentaje del PIB. Datos del Banco Mundial, https://datos. bancomundial.org/indicador/GB.XPD.RSDV.GD.ZS.

19. Familias de patentes IP5. Datos de la OCDE, https://stats.oecd.org/Index.aspx?DataSetCode=PATS IPC.

20. Porcentaje de personas que creen que el gobierno es corrupto. “¿Es generalizada la corrupción en el gobierno en (este país) o no?" Datos de Gallup 2021.

21. Porcentaje de personas que creen que el país está gobernado en interés de unos pocos. "En términos generales ¿diría usted que (país) está gobernado por unos cuantos grupos poderosos en su propio beneficio, o que está gobernado para el bien de todo el pueblo?" Datos del Latinobarómetro, 2020. 
22. Porcentaje de personas que creen que la atención sanitaria es de buena calidad. "En su ciudad o en la zona donde vive, ¿está satisfecho o insatisfecho con la disponibilidad de atención sanitaria de calidad?" Datos de Gallup 2021.

23. Porcentaje de personas que creen que el agua es de buena calidad. "En su ciudad o en la zona donde vive, ¿está satisfecho o insatisfecho con la calidad del agua?” Datos de Gallup 2021.

24. Porcentaje de personas que han sido víctimas de delincuencia, "¿ha sido víctima de algún tipo de delito en los últimos 12 meses?”. Datos del Proyecto de Opinión Pública de América Latina, https://www. vanderbilt.edu/lapop-espanol/acceso-a-datos.php.

25. Datos de RSF, Reporteros Sin Fronteras, https://rsf.org/es/datos-clasificacion.

26. Porcentaje de personas que se declaran de izquierdas o de derechas en una escala de 1 a 10 ( 1 =izquierda, 10 = derecha). "En política se habla normalmente de izquierda y derecha. En una escala donde 0 es la izquierda y 10 la derecha. ¿Dónde se ubicaría Ud.?” Datos del Latinobarómetro, 2020.

27. Datos de la OCDE, www.genderindex.org/ranking/.

28. Ingresos como porcentaje del PIB. Datos de OCDE et al. (2021), Estadísticas tributarias en América Latina y el Caribe (2021).

29. Impuestos sobre el valor añadido como \% del total de ingresos. Datos de OCDE et al. (2021), Estadísticas tributarias en América Latina y el Caribe (2021).

30. Gasto en protección social como porcentaje del PIB. Datos de la OCDE y la CEPAL.

\section{Referencias}

Conference Board (2015), The Conference Board's Alternative China GDP, http://www.conference-board.org// retrievefile.cfm?filename=FAQ-for-China-GDP 9nov1511.pdf\&type=subsite.

CEPAL (2020), Panorama Social de América Latina, publicación de las Naciones Unidas, https://repositorio.cepal. org/bitstream/handle/11362/46687/8/S2100150 es.pdf.

EUROsociAL (2021), La hoja de ruta para la cooperación UE-Colombia en materia de cohesión social, https://eurosocial.eu/.

Gallup (2021), Gallup World Poll (base de datos), www.gallup.com/analytics/232838/world-poll.aspx.

UIT (2020), World Telecommunication/ICT Indicators Database 2020, https:/www.itu.int/en/ITU-D/Statistics/ Pages/stat/default.aspx.

Latinobarómetro (2020), Vanderbilt (base de datos), Proyecto de Opinión Pública de América Latina, https://www.vanderbilt.edu/lapop-espanol/.

OCDE (2021), OECD.Stat (base de datos), Social and Economical Indicators, https://stats.oecd.org/Index.aspx

OCDE et al. (2020), Perspectivas económicas de América Latina 2020: Transformación digital para una mejor reconstrucción, Publicaciones de la OCDE, https://doi.org/10.1787/f2fdced2-es.

OCDE/Banco Mundial (2020), Panorama de la Salud: Latinoamérica y el Caribe 2020, Publicaciones de la OCDE, https://doi.org/10.1787/740f9640-es.

Reporteros Sin Fronteras (2021), Clasificación Mundial de la Libertad de Prensa (base de datos), https://rsf.org/es/ datos-clasificacion.

SIGI (2019), OECD.Stat (base de datos), Social Institutions \& Gender Index (SIGI), http://www.genderindex. org/ranking/.

UNESCO (2020), Impacto de la COVID-19 en la educación - Cierres de escuelas, https://es.unesco.org/covid19/ educationresponse\#schoolclosures.

Banco Mundial (2020), "Gasto en investigación y desarrollo (\% del PIB)", https://datos.bancomundial.org/ indicador/GB.XPD.RSDV.GD.ZS.

Banco Mundial (2019), “Exportaciones de productos de alta tecnología”, https://datos.bancomundial.org/ indicador/TX.VAL.TECH.MF.ZS. 


\section{Perspectivas económicas de América Latina 2021}

\section{AVANZANDO JUNTOS HACIA UNA MEJOR RECUPERACIÓN}

Esta decimocuarta edición de Perspectivas económicas de América Latina: Avanzando juntos hacia una mejor recuperación (LEO), analiza y ofrece recomendaciones de política pública para una recuperación fuerte, inclusiva y sostenible en la región. El informe explora las acciones necesarias para mejorar los mecanismos de protección social y promover la inclusión social, fomentar la integración regional y fortalecer las estrategias industriales, y repensar el contrato social para restaurar la confianza y empoderar a los ciudadanos en todas las etapas del proceso de elaboración de políticas públicas. Además, resalta la necesidad de promover marcos macroeconómicos sostenibles y adaptables para financiar la recuperación, y la importancia de renovar la cooperación internacional para apoyar estos esfuerzos. Por último, la publicación incluye tres temas transversales clave: el cambio climático y la recuperación verde, la transformación digital y la dimensión de género.

EI LEO es una publicación anual conjunta del Centro de Desarrollo de la OCDE, la Comisión Económica para América Latina y el Caribe de las Naciones Unidas (CEPAL), el Banco de Desarrollo de América Latina (CAF) y la Unión Europea (UE). Este informe constituye el Pilar 1 de la Facilidad Regional de la UE para el Desarrollo en Transición en América Latina y el Caribe.

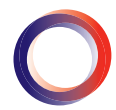

$A F D$ AGENCE FRANCAISE
DE DEVELOPPEMENT

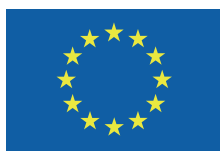

Cofinanciado por la Unión Europea

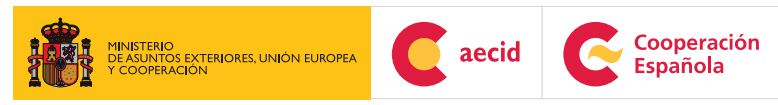
Española

G

Universidad del

Rosario 3chweizerische Eidgenossenschaft

Confédération suisse

Confederaziun svizzra Swiss Agency for Development
and Cooperation SDC

\section{El futuro}

es de todos

DNP

Departamento
Nacional de Planeación

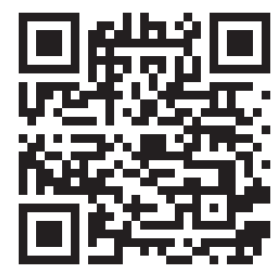

PRINT ISBN 978-92-64-82289-4 PDF ISBN 978-92-64-47036-1

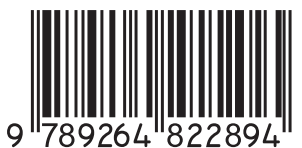

